Gectupospanol

\title{
Número 10
}

6ergonserva don

\section{conservaçäo / Conservation}

Año2016

[SSN: 1989-8568 


\section{Dirección Editorial:}

Consejo de Redacción:

Edición Suplemento

Secretaria de Edición:

Webmaster GEIIC:

Diseño página web:

Maquetación:

Traducción:

Imagen portada:

Imagen suplemento:
Rocío Bruquetas Galán

María Aguiar, Emilio Cano Díaz, Rafael Fort González, Emma García Alonso, Silvia García Fernández-Villa, Marisa Gómez González, Ana Laborde Marqueze

Elena García Gayo

Ma Concepción de Frutos Sanz

Ma Concepción de Frutos Sanz

Pepe Nieto PEZRED

Ma Concepción de Frutos Sanz

María José Pimentel (Agoralíngua - Centro Oficial de Lengua Portuguesa).

Placa del tórax donde se aprecian distintos tipos de huesos como vértebras cervicales y rótulas envueltos en un textil de hilo entorchado. Radiología José Luis Velázquez@

Mural: Tecnología by CNFSN+ y Malakkai para el 5*Asalto de Zaragoza. 2010. Observatorio de Arte Urbano $\odot$

\section{ISSN: 1989-8568}

Esta publicación utiliza una licencia Reconocimiento-NoComercial-SinObraDerivada 3.0 Creative Commons

Se permite compartir, copiar, distribuir y comunicar públicamente la obra con el reconocimiento expreso de su autoría y procedencia. No se permite un uso comercial de la obra original ni la generación de obras derivadas.

Esta revista utiliza Open Journal Systems, software libre de gestión y publicación de revistas desarrollando, soportado y libremente distribuido por el Public Knowledge Project bajo Licencia Pública General GNU.

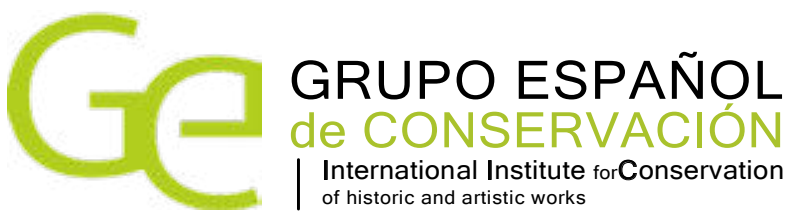

GE-conservación no se responsabiliza de la información contenida en los artículos ni se identifica necesariamente con ellas.

(c) La propiedad intelectual de los artículos pertenece a los autores, y los derechos de edición y publicación de este número son de Ge-conservación. Rogamos que en la difusión libre de los contenidos queden patentes los créditos de los autores y la procedencia.

El Grupo Español de Conservación es una asociación independiente afiliada a The International Institute for Conservation of Histtoric and Artistic Works, inscrita en el Registro Nacional de Asociaciones, Sección 1a, № 160.299. Sede: I.P.C.E. C/Greco, 4 28040 Madrid. Asociación Declarada de Utilidad Pública por Orden del Ministerio del Interior 3404/2009 (BOE 18-12-2009).

\section{Ge-conservación}




\section{Índice}

\section{Artículos}

Estudo para a caracterização espacial das lacunas no processo de reintegração cromática da pintura A Circuncisão do Menino Jesus

Ana Bailão, Frederico Henriques, Susana Mendes, Alexandre Gonçalves

Restauración de un daguerrotipo español de 1844

Raquel Esteban Vega

Ensayos de consolidación en los revestimientos murales del Conjunto Arqueológico de Castulo (Linares, Jaén)

Ana Isabel Calero-Castillo, Teresa López-Martínez, Ana García-Bueno, María Teresa GonzálezMuñoz, Victor J. Medina-Flórez

Survey of the state of conservation of the Mylodon listai (Xenarthra-Mylodontidae) skin fragment from the Pleistocene of Argentina kept at the Museum of La Plata (Argentina)

Raquel Esteban Vega

La radiología digital para relicarios de ceroplástica: estudio interdisciplinar para identificar el sistema constructivo y la ubicación de los restos óseos

Gabriela Sánchez Reyes, José Luis Velázquez Ramírez, Ana Lucía Montes Marrero

\section{Reseñas de publicaciones}

Historia de la historia del mueble en España. Teoría, historiografía y corrientes metodológicas (1872-2011)

Cristina Ordóñez y Leticia Ordóñez

Colecciones Educativas de la Universidad de Sevilla

María Dolores Ruiz de Lacanal Ruiz-Mateos

Revista Internacional de Conservación, Restauración y Museología, 7(14), julio-diciembre 2016 Brenda Judith Caro Cocotle

Hamilton Kerr Institute Bulletin Number 6, 2016

Rocío Bruquetas Galán 


\section{Suplemento:}

\section{Monográfico Arte Urbano. Conservación y Restauración de Intervenciones} Contemporáneas

Presentación

Prólogo

Estudio del arranque sobre pintura con aerosol vinculada al grafiti y arte urbano: posibilidades, incompatibilidades y alternativas

Rita Lucía Amor García

Etapas del Arte Urbano. Aportaciones para un Protocolo de conservación

Elena García Gayo

El papel del conservador-restaurador en el arte urbano comisionado: reflexiones a partir de los datos recogidos en la Open Walls Conference 2015 de Barcelona

Rosa Gasol Fargas y Rosa Senserrich Espuñes

Arte relacional en la calle. Casos de conservación colectiva

Laura Luque Rodrigo

Entre la Teoría de la Restauración y el Arte Urbano, una paradoja disciplinar

Ana Lizeth Mata Delgado

M.I.A.U. (Fanzara), una propuesta social. Historia, materiales y conservación

Ma Teresa Pastor Valls

Acercamiento a la evolución histórica y tecnológica de los materiales pictóricos empleados en el grafiti y arte urbano

Mercedes Sánchez Pons

La conservación del arte urbano. Dilemas éticos y profesionales

Carlota Santabarbara Morera

Propuesta de un modelo de registro para el análisis y documentación de obras de arte urbano

Recreación virtual del arte urbano

Ma del Mar Vázquez de la Fuente

Anexo I. Propuesta de código deontológico para la conservación y restauración de arte urbano

Anexo II. Encuestas. Diseño de la investigación 
Artículos 


\title{
Estudo para a caracterização espacial das lacunas no processo de reintegração cromática da pintura $A$ Circuncisão do Menino Jesus
}

\author{
Ana Bailão, Frederico Henriques, Susana Mendes, Alexandre Gonçalves
}

Resumo: O estudo que aqui se apresenta foi efetuado no âmbito do curso de doutoramento em Bens Culturais, na especialidade de Pintura, que decorreu na Universidade Católica Portuguesa, subordinado ao tema da qualidade em reintegração cromática. O objetivo do presente trabalho é propôr um sistema para a caracterização das lacunas da superficie pictórica, direccionado específicamente para o processo de reintegração cromática, de modo a que o conservador-restaurador possa ter acesso a uma informação qualitativa e quantitativa mais rigorosa, antes, durante e depois da intervenção. Para o efeito, utilizaram-se imagens fotográficas de uma pintura sobre madeira do século XVI e um sistema de informação geográfica (SIG). Trata-se de um programa informático utilizado no processamento de dados espaciais, o software open-source QGIS. O projeto tem a particularidade de ter sido efetuado em tempo-real, à medida que a intervenção foi decorrendo, como forma de apoio à tomada de decisão.

Palavras-chave: caracterização de lacunas, reintegração cromática, SIG, QGIS, tomada de decisão

\section{Estudio para la caracterización espacial de lagunas en el proceso de reintegración cromática en la pintura La circuncisión del Niño Jesus}

Resumen: El estudio que aquí se presenta ha sido realizado en el ámbito del programa de doctorado de Bienes Culturales, en la especialidad de Pintura, que tuvo lugar en la Universidad Católica Portuguesa, bajo el tema de la calidad en reintegración cromática. El objetivo de este estudio es proponer un sistema para la caracterización de las lagunas de la superficie pictórica, por lo que el conservador-restaurador puede tener acceso a la información cualitativa y cuantitativa más precisa antes, durante y después de la intervención. Con este fin, hemos utilizado imágenes fotográficas de una pintura sobre tabla (siglo XVI) y un programa informático, un sistema de información geográfica (SIG), que se utiliza en el procesamiento de datos espaciales, el programa QGIS, de código abierto. El proyecto tiene la particularidad de haber sido hecho en tiempo real, durante la intervención, con el fin de apoyar la tomada de decisiones.

Palabras-clave: caracterización de lagunas, reintegración cromática, SIG, QGIS, tomada de decision

\section{Study for spatial characterization of losses for the chromatic reintegration process of the painting The Circumcision of Jesus}

\begin{abstract}
The study presented here was conducted in the framework of the doctoral program in Cultural Heritage, specialization in easel paintings, which took place at the Catholic University of Portugal, upon the theme of quality in chromatic reintegration. The aim of this study is to propose a system for the characterization of the losses in the pictorial surface, so that conservator-restorer can have access to qualitative and quantitative accurate information before, during and after the intervention. We used photographic images of a panel painting from the XVI century and a geographical information system (GIS) software used for processing spatial data, the QGIS open source program. The project has the particularity of being done in real time, during the intervention, in order to support the decision-making process.
\end{abstract}

Keyword: characterization of losses, chromatic reintegration, GIS, QGIS, decision-making 


\section{Introdução}

Neste estudo, aplicado a uma pintura sobre madeira, designada por A Circuncisão do Menino Jesus em itálico pertencente à coleção privada do Seminário Maior de Nossa Senhora, no Porto, propõe-se demonstrar a aplicação e o uso de uma ferramenta de análise espacial para a caracterização de lacunas durante a fase de reintegração cromática, como forma de apoio à tomada de decisão. $O$ principal objetivo é a documentação e o registo das lacunas de forma qualitativa, quantitativa e rigorosa. Esta informação não é somente útil durante a intervenção, mas também na primeira fase de projeto e diagnóstico, constituindo um documento essencial de análise da obra após a conclusão da intervenção. $O$ sistema apresentado possibilita o registo individualizado de cada lacuna - por parte do conservador-restaurador responsável pela reintegração técnica e dos materiais utilizados. Em certa medida, poderá ser, no futuro, uma ferramenta nuclear para o processo de verificação e avaliação de qualidade, que deve ser efetuado sempre e após uma intervenção pelo conservador-restaurador.

A "reintegração cromática tradicional", corrente no século XIX, implicava a reinvenção e raramente se restringia aos limites da lacuna, convertendo-se facilmente em repinte. Todavia, a consciência histórica alcançada a partir do século XX recomenda que a autenticidade das obras do passado seja respeitada (Mora, Mora, Philippot, 1984: 301), assim como a criatividade do autor, não podendo por isso ser reproduzida, mas apenas interpretada de um modo crítico (Philippot, Philippot, 1959:5; IDEM, Ibidem em itálico). Isto significa que a operação de reintegração cromática deve parar quando a hipótese começa.

Sobre a especificidade e particularidades das intervenções de reintegração cromática, depois da análise espacial das lacunas, com o método apresentado e, no decurso da tomada de decisão, importa ressalvar que o conhecimento acerca da tipologia das lacunas pode implicar uma avaliação gestaltista (Bailão, 2010: 128-139). Um processo considerado essencial para o entendimento de cada uma das lacunas presentes na obra. Contudo, a correlação da apreciação gestalista, associada à análise métrica com parametrização de percentagens de área, podem, segundo os autores, revelar-se instrumentos de suporte essenciais ao planeamento da intervenção da reintegração cromática.

\section{Tipologia de Lacunas}

Em linhas gerais, para reconhecer a tipologia de lacunas é necessário reconhecer um método de análise passível de ser utilizado como referencial de interpretação. No presente trabalho, numa primeira fase de análise, optámos por recorrer ao trabalho que resultou das reflexões de Paolo Mora, Laura Mora e Paul Philippot sobre as tipologias de lacunas (Mora, Mora, Philippot, 1984: 305-315).
Se bem que tais reflexões tenham sido direcionadas para a problemática e especificidade da pintura mural, é possível, com as devidas ressalvas, observar o problema de acordo com o estrato pictórico (ou policromia) e tais lacunas podem ser divididas em cinco tipos diferentes. Para essa parametrização, sistematizada aqui como de tipo I, II, III, IV e V, devem-se ter em linha de conta a localização, a dimensão ou extensão e a profundidade com que as lacunas atravessam os estratos pictóricospictórico [ver Tabela 1]:

Para os autores acima referidos, nas lacunas Tipo $V$, exige-se uma intervenção onde se deve preservar o valor histórico, com eventual reconstrução, mas sempre discernível. Após a análise das cinco tipologias indicadas, é possível verificar que a caracterização das lacunas é feita, sobretudo, em função da perda verificada. Parâmetros como a localização, extensão em superfície e profundidade da lacuna são sumariamente referidos, embora sejam essenciais para a caracterização das lacunas, uma vez que podem comprometer ou favorecer (no caso das lacunas com suporte à vista) a interpretação da imagem pictórica. Na presença de lacunas Tipo V, para os autores Paolo Mora, Laura Mora e Paul Philippot, deve-se preservar o valor histórico, com eventual reconstrução, mas sempre discernível. Como contributo para o enquadramento teórico-prático, equacionam-se cinco situações [Figura 1]:

1. Lacunas pouco extensas que devido à sua localização, podem ser reconstruidas com técnicas miméticas ou diferenciadas;

2. Lacunas pouco extensas que devido à sua localização não devem ser reconstruídas (ausência de informação formal);

3. Lacunas que devido à sua localização não devem ser reconstruídas;

4. Lacunas que devido à sua extensão e localização não devem ser reconstruídas;

5. Lacunas que, embora extensas, podem ser reconstruídas, por se situarem em áreas de composição pictórica com padrões e valores cromáticos e formais evidentes, que não coloquem dúvidas na interpretação.

As tipologias de lacunas enunciadas são interpretadas de um modo diferente por Umberto Baldini (Baldini, 1998: 22). Para o historiador, existem dois tipos de lacunas: a "lacuna-perda" e a "lacuna-falta".

A primeira tipologia de lacuna, a"lacuna-perda", caracterizase pela separação total e permanente de uma determinada parte da obra associada ao destacamento, dano ou ruína. Na prática, numa superfície pintada, a"lacuna-perda" será a ausência total de cor, de imprimadura [2] e de preparação. Isto significa que o suporte (tela, madeira ou metal) está à vista do observador.

A"lacuna-falta"corresponde aos fenómenos de degradação na camada cromática como a rede de microfissuras, as abrasões ou desgastes, entre outros (IDEM, lbidem). Nesta 


\begin{tabular}{|c|c|c|}
\hline Tipologia & Característica da tipologia de lacuna & Soluções apresentadas pelos autores \\
\hline $\begin{array}{l}\text { Tipo I } \\
\text { (desgaste) }\end{array}$ & Desgaste da pátina. & $\begin{array}{l}\text { Poderá ser solucionado através de uma reintegração por } \\
\text { velatura a aguarela, que deverá ser no tom da pátina }\end{array}$ \\
\hline $\begin{array}{l}\text { Tipo II } \\
\text { (desgaste) }\end{array}$ & $\begin{array}{l}\text { Desgaste da camada pictórica (desgaste que resultou de } \\
\text { um fator externo, uma ação física, ou ausência diminuta } \\
\text { de perca de material ocasionada por alterabilidade do } \\
\text { tipo de pulverulência). }\end{array}$ & $\begin{array}{l}\text { Poderá ser solucionado com uma velatura mais clara e fria } \\
\text { que o tom original. }\end{array}$ \\
\hline $\begin{array}{l}\text { Tipo III } \\
\text { Lacuna (camada pictórica) }\end{array}$ & $\begin{array}{l}\text { Lacunas na camada pictórica, pouco extensas, bem } \\
\text { limitadas em área, passíveis de serem reconstruídas. }\end{array}$ & $\begin{array}{l}\text { Possibilidade de reconstrução com técnicas diferenciadas, } \\
\text { sugerindo os autores, Paolo e Laura Mora e Philippot, o } \\
\text { tratteggio [1]. }\end{array}$ \\
\hline $\begin{array}{l}\text { Tipo IV } \\
\text { Lacuna (camada pictórica) }\end{array}$ & $\begin{array}{l}\text { Lacunas extensas na camada pictórica com perca total da } \\
\text { matéria. }\end{array}$ & $\begin{array}{l}\text { Pela sua extensão e localização não devem ser } \\
\text { reconstruídas. }\end{array}$ \\
\hline $\begin{array}{l}\text { Tipo V } \\
\text { Lacuna (camada pictórica) }\end{array}$ & $\begin{array}{l}\text { Lacunas de considerável extensão que colocam em causa } \\
\text { o significado arquitetónico das cenas. }\end{array}$ & $\begin{array}{l}\text { Devido à importância que estas lacunas têm para a } \\
\text { totalidade da obra, independentemente da extensão, } \\
\text { podem ser reconstruídas. São exemplo os marmoreados, } \\
\text { o trompe l'oeil em itálico, as composições ilusionistas e } \\
\text { os elementos decorativos. Apesar de não existirem regras } \\
\text { universais de atuação, as reintegrações podem assumir } \\
\text { uma vertente conservativa, arqueológica, e, em alguns } \\
\text { casos, reconstrutiva. O processo poderá ser feito com } \\
\text { uma técnica próxima do original, em tom mais claro e } \\
\text { frio, sempre circunscrito à área da lacuna, mas discernível } \\
\text { quando observado de perto. }\end{array}$ \\
\hline
\end{tabular}

Tabela 1.- Interpretação da relação das tipologias de lacunas e soluções apresentadas por Paolo Mora, Laura Mora e Paul Philippot, no contexto das intervenções de reintegração cromática em pintura mural (Mora, Mora, Philippot, 1984: 305-315).

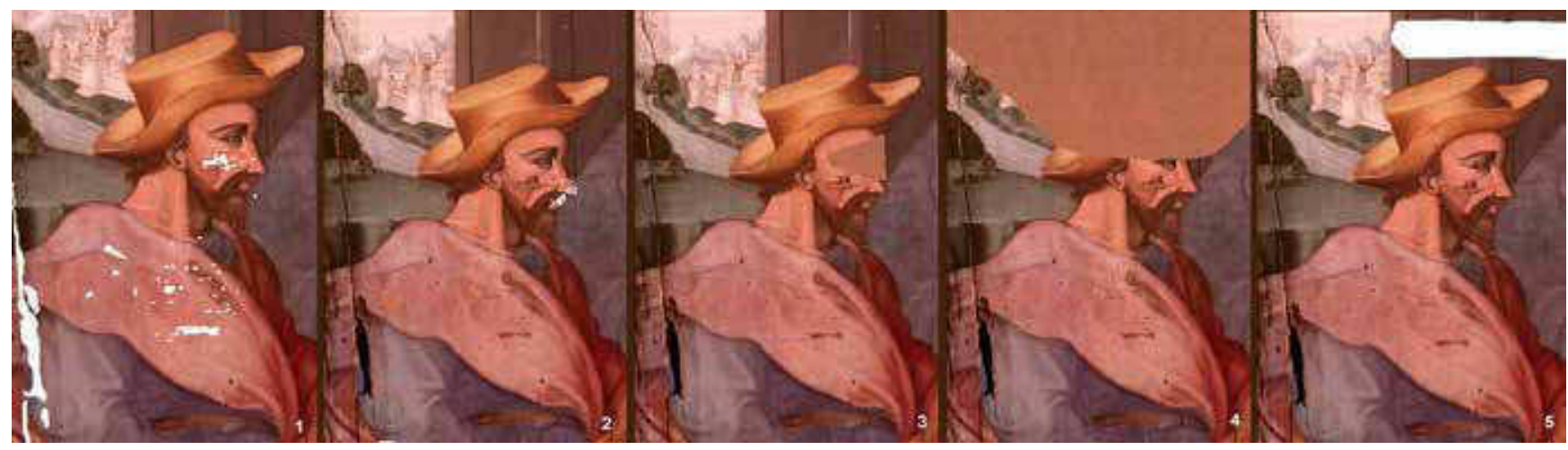

Figura 1.- No contexto do painel em análise, simulação das cinco tipologias de lacunas. Esquema gráfico de Ana Bailão.

situação, para Baldini, não é necessária nenhuma ação, uma vez que é preferível deixar a matéria original evidenciar o seu percurso na história (a sua degradação), designado por Baldini como "tempo de vida", em vez de efetuar uma reintegração que falsifique este percurso e diminua a originalidade do bem cultural.

A intervenção sucede quando a obra apresenta a "lacunaperda". Estando presente esta tipologia de lacuna, podem ocorrer, de acordo com Baldini, duas situações: quando existem referências formais e cromáticas, utiliza-se o método de seleção cromática [3]; quando não existem estes dados opta-se pelo método de abstração cromática [4] (Ciatti, 2009: 24) [Tabela 2]

No seguimento da análise de classificação de Mora, Mora e Philippot, e de Umberto Baldini, pode-se concluir que, quando estamos perante lacunas, podemos ter dois tipos de posições:

a) Uma posição mais pragmática de Paolo e Laura Mora e de Paul Philippot para a solução do problema, que se caracteriza por uma noção espacial da extensão das lacunas com aplicabilidade prática na perceção da imagem e na intervenção da obra. 
b) Uma posição de vertente epistemológica de Umberto Baldini, que consiste na análise da tipologia de lacuna em função da sua origem e aparecimento, existindo apenas duas soluções viáveis: seleção cromática ou abstração cromática. A aplicabilidade prática desta proposta é mais limitada, uma vez que a última técnica citada nem sempre resulta agradável do ponto de vista visual, pelo facto de realçar demasiado a intervenção realizada quando observada de longe ou de perto, e pelos diversos fenómenos de gestaltismo que condicionam a perceção do observador.

O fenómeno gestaltista foi primeiramente investigado pelo psicólogo dinamarquês Edgar Rubin e mais tarde correlacionado ao património por Cesare Brandi. Segundo o historiador, no contexto de uma imagem, a lacuna, perante a perceção espontânea do observador, é vista como uma "figura", enquanto a composição pictórica é visualizada como "fundo". E é essa relação entre "figura-fundo" que está na base da perceção sensorial associada à caraterização das lacunas, quando se observa um objeto.

Importa referir novamente que a interpretação das lacunas neste estudo teve como ponto de partida as tipologias de lacunas indicadas por Paolo Mora, Laura Mora e Paul Philippot, com a apreciação e a avaliação das lacunas de acordo com os seguintes parâmetros: a localização, a extensão e a profundidade da lacuna. A opção pela intervenção ou não intervenção, assim como a eleição da técnica de reintegração cromática dependeu,

\begin{tabular}{|l|l|}
\hline \multicolumn{1}{|c|}{ TIPOLOGIA } & \multicolumn{1}{c|}{ SOLUÇÃO } \\
\hline $\begin{array}{l}\text { Tipo I: } \\
\text { Lacuna perdida }\end{array}$ & $\begin{array}{l}\text { • Abstração cromática (sem referências) } \\
\text { • Seleção cromática (com referências }\end{array}$ \\
\hline $\begin{array}{l}\text { Tipo ll: } \\
\text { Falta (fissuras ou } \\
\text { abrasões) }\end{array}$ & • Não se faz nada \\
\hline
\end{tabular}

Tabela 2.- Relação das tipologias de lacunas e soluções apresentadas por Umberto Baldini (Baldini, 1998: 22). também, desta apreciação. De seguida, esquematizamse os fatores considerados em cada parâmetro [Tabela 3]:

Os pontos elencados na Tabela 3, associados aos três parâmetros (localização, extensão e profundidade) podem ser interpretados, em pinturas de caráter figurativo, em função das composições pictóricas, da existência de figuras, da presença de arquiteturas, dos fundos apresentarem um trabalhado simples ou de detalhe e da dimensão da pintura.

Se excluirmos as lacunas de desgaste (Tipo I e II), a área lacunar da pintura intitulada A em itálico Circuncisão do Menino Jesus não era significativa, existindo pequenas lacunas ao nível da camada cromática, do preparo e do suporte, localizadas em carnações, em panejamentos, na arquitetura e na paisagem de fundo. A presença destas lacunas não afetava a leitura da composição pictórica, nem tinha mais protagonismo do que a obra. Existiam ainda lacunas ao nível do suporte lenhoso, de maior dimensão, em extensão e profundidade, que, por se localizarem em zonas de panejamento castanho, integravam-se perfeitamente com a camada cromática original.

Para reforçar e ilustrar a descrição supra mencionada, recorreu-se a uma ferramenta informática de sistemas de informação geográfica (SIG). Esta plataforma permitiu a visualização e a análise qualitativa e quantitativa das lacunas presentes na pintura sobre madeira em estudo.

\section{Caracterização de lacunas através de análise métrica}

A caracterização de lacunas pode ser efetuada através da análise métrica utilizando ferramentas da georreferenciação, uma técnica utilizada em caracterização e ordenamento de território com sistemas de informação geográfica [5]. Para este ensaio académico recorreu-se a um programa informático open-source, denominado QGIS, na versão 2.6.0 (Brighton). Como estudo de caso, utilizou-se uma pintura a óleo sobre madeira, proto-maneirista, denominada A Circuncisão do Menino Jesus, com as seguintes dimensões: $204 \mathrm{~cm} \mathrm{x}$
- Medida em percentagem de área da - Carnação; lacuna em comparação com a área total - Panejamento; da obra.
- Desgaste da camada de pátine; - Desgaste na camada pictórica; - Lacunas da camada pictórica; - Lacunas que incluem tanto a camada pictórica como o preparo.

Tabela 3.- Caracterização de lacunas em função da localização, extensão e profundidade. 
149,2 cm. Trata-se de uma obra de oficina desconhecida, proveniente, presumivelmente, da Igreja de Rossas, em Arouca, e que incorpora na atualidade a coleção privada do Seminário Maior de Nossa Senhora da Conceição, no Porto [6].

Acerca do painel, sabe-se que, em 1600, existia na Igreja de Rossas uma obra com a representação da "Circuncisão", e que era da mesma autoria do retábulo principal, encomendado por Frei Duarte de Brito, em 1600. Numa transcrição contemporânea de parte do livro de Visitações sobre a igreja, realizada por António Brandão de Pinho (estudioso dedicado à história da paróquia e freguesia de Rossas), refere-se que:

[...] e no alto dele [retabolo] esta hua pintura da Virgem Snra Nossa que he Padroeira desta Comda, no meyo do dicto retabolo esta hum letreiro da qual consta que o Com.dor Fr. Duarte de Brito Pr.a mandou fazer esta obra no anno de 1600. Tem esta Igr.a do arco a fora dous Altares collecteraes com dous retabolos de obra de boa talha e dourados de ouro sobre azul; e no da parte do Evang.o esta hua Imagem de Vulto de Sam Sebastiam, e junto delle esta pregado na parede hum painel da circumcizam de Christo Snr Nosso, e que mostra ser feito p.lo mesmo Pintor, que fes os painéis do retabolo da Capp.a Mor [...] (Visitações Gerais da Ordem de Malta à Comenda de Rossas [Manuscrito], 1718-1719: 68).

Na fase de processamento digital do presente trabalho, através da utilização do programa informático de uso livre, QGIS 2.6.0. Brighton, foi realizado o mapeamento e a quantificação de lacunas [figura 2]. Neste exercício, a identificação de lacunas fez-se em modo de edição vetorial, de forma não automática, com base na fotointerpretação da imagem da obra. As lacunas analisadas foram especificamente as que, nas tipologias de Paolo Mora, Laura Mora e Paul Philippot, se enquadram no tipo III e IV. Importa referir que, pelo facto de a proposta de intervenção não contemplar a reintergração cromática sob a forma de velatura, as lacunas do tipo I e II não foram vetorizadas.

Quanto ao tipo de análise com o SIG, importa referir que, em vez do modelo de representação vetorial, também se pode usar o modelo de representação matricial, orientado ao píxel. E quanto a este último tipo de análise, são conhecidas algumas abordagens noutros estudos. Veja-se, por exemplo, os casos da pintura quinhentista $O$ Calvário, do Museu Nacional Machado de Castro, Coimbra (Henriques, Gonçalves, Calvo, Bailão, 2011: 234-236) e da pintura mural do arco triunfal da Charola, do Convento de Cristo, em Tomar (Henriques, Gonçalves, Calvo, Bailão, 2009: 13-15) [7]. No entanto, esta investigação foi estritamente direcionada para o modelo de representação de tipo vetorial (ponto, linha e polígono).

No decurso das operações, a análise espacial da composição pictórica da pintura seiscentista sobre madeira, $A$ Circuncisão do Menino Jesus, permitiu contabilizar 1091 lacunas de forma e extensão variadas, que representam $3 \%$ da área total da obra [figura 3 e 4].

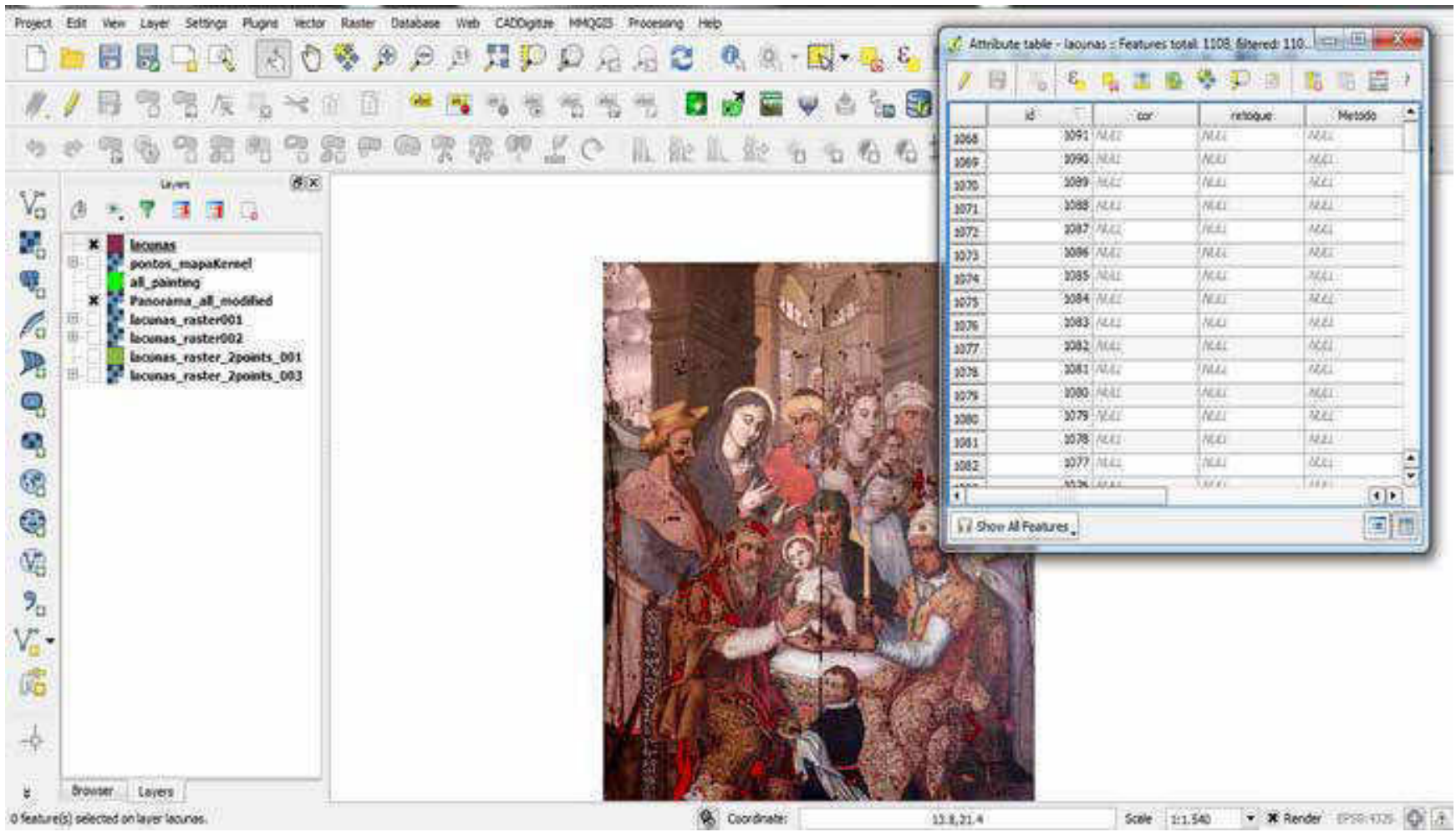

Figura 2- Visualização do interface gráfico e da pintura durante o processamento das lacunas no programa QGIS. Esquema gráfico de . 

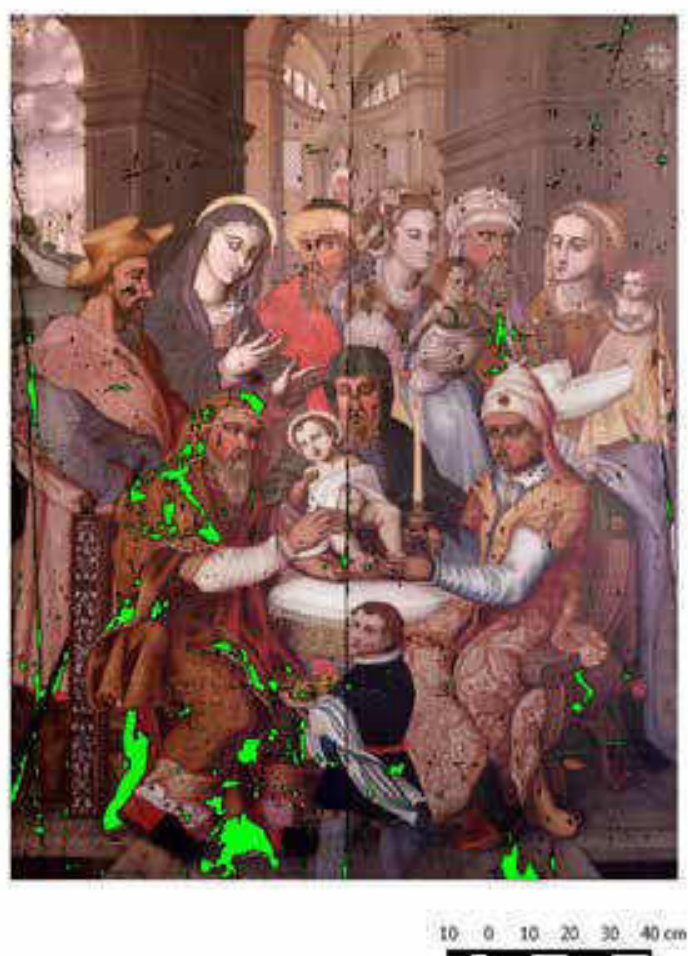

Figura 3- Visualização da imagem da pintura com indicação das lacunas a verde. $\mathrm{O}$ tom verde das lacunas resultou de um processamento digital com o programa informático QGIS

Numa apreciação do mapa temático produzido, a área lacunar é manifestamente de pouca extensão. A maioria das lacunas são muito pequenas e situam-se em zonas marginais à representação pictórica. Apenas 38 lacunas, que se estendem até ao suporte lenhoso, assumem maiores dimensões.

Com esta ferramenta foi possível projetar e obter a seguinte informação:

- Quantificação percentual da área que as lacunas ocupam na superfície pictórica;

- Quantificação precisa do número de lacunas;

- Classificação métrica e indicação espacial da localização das respetivas lacunas;

- Estimativa do número de horas afetas à reintegração cromática, calculada através dos valores de área;

- Criação de uma tabela de atributos com informação alfanumérica associada a cada lacuna, nas quais se pode especificar, por número de identificação da lacuna, a técnica de reintegração, as cores e os materiais utilizados na concretização da tarefa.

Neste ensaio, determinou-se que, na pintura $A$ Circuncisão do Menino Jesus, as lacunas estão distribuídas do seguinte modo:

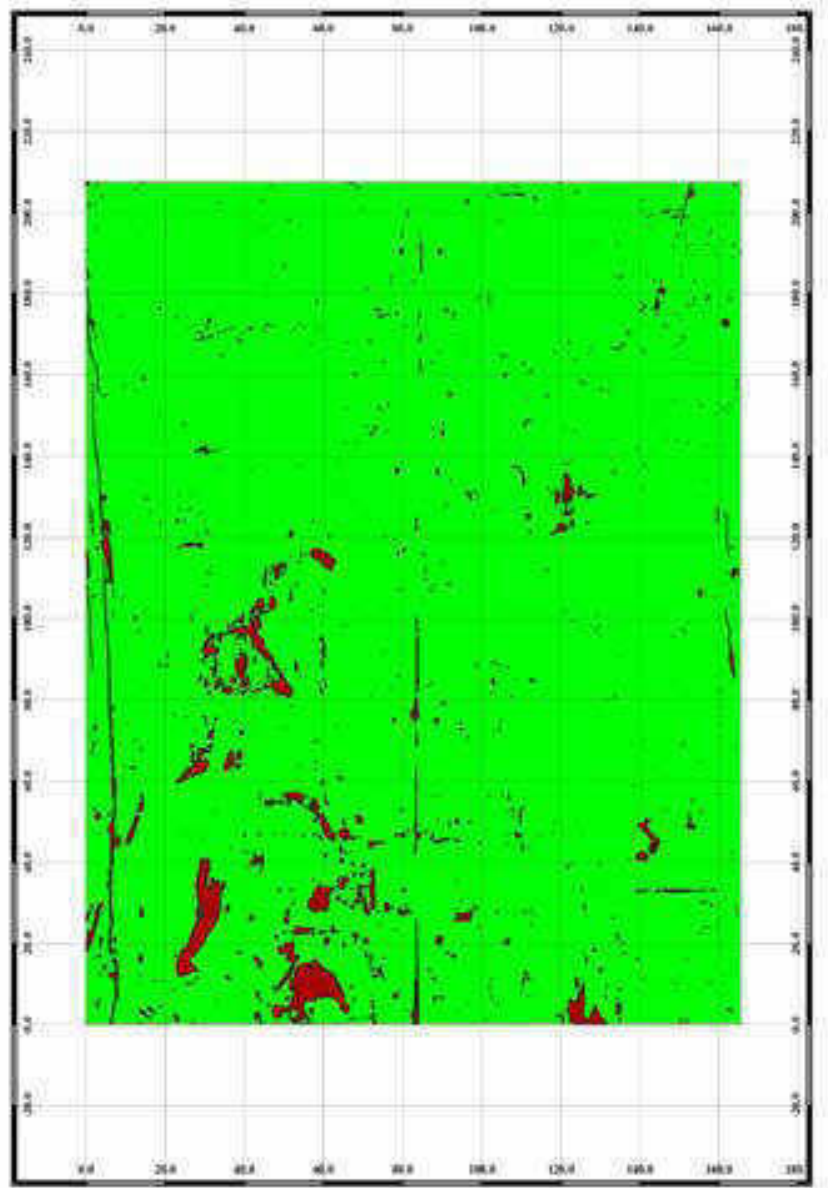

Figura 4- Mapa temático que indica a distribuição espacial das lacunas. Esquema gráfico de Ana Bailão.

\begin{tabular}{|l|l|}
\hline $0.4 \%$ & $\operatorname{RGB}(255,25,23)$ \\
$0.1 \%$ a $0.4 \%$ & $\operatorname{RGB}(255,127,0)$ \\
$0.01 \%$ a $0.1 \%$ & $\operatorname{RGB}(255,246,3)$ \\
$<0.01 \%$ & $\operatorname{RGB}(186,221,105)$
\end{tabular}

Tabela 4- Escalas de cor com intervalos para caracterização da área lacunar e informação específica de parâmetros RGB. Esquema gráfico de Ana Bailão.

-Existem 5 lacunas de maiores dimensões, que ocupam áreas de $0,1 \%$ a $0,4 \%$ e que correspondem a $1,2 \%$ da área total da pintura;

-Existem 33 lacunas de tamanho médio, que ocupam áreas entre 0,01\% a 0,08\% e que correspondem a $0,9 \%$ da área total;

—Existem 1053 lacunas pequenas, que ocupam individualmente áreas menores que 0,009\% e que em conjunto correspondem a $0,9 \%$ da área total da obra.

A seleção da tipologia de lacunas fez-se por intervalos de percentagem [8], que se ajusta em função da dimensão do objeto [tabela 4]. Para facilitar a interpretação dos 
dados, propõe-se uma escala de cores [9] com 4 classes: vermelho (área elevada), laranja (área grande), amarelo (área média) e verde (área pequena).

No caso da pintura A Circuncisão do Menino Jesus apenas se verificaram 3 classes, o intervalo laranja, o amarelo e o verde, não se verificando lacunas de tamanho elevado, acima de 0,4\% [figura 5].

Com base nos dados obtidos com o QGIS e refletindo nos parâmetros indicados ao longo do texto, pode-se concluir o seguinte:

1- Em relação à extensão, as lacunas da pintura $A$ Circuncisão do Menino podem ser classificadas em três classes:

- 1,2\% correspondem a 5 lacunas de maiores dimensões;

- 0,9\% correspondem a 33 lacunas de tamanho médio;

- 0,9\% correspondem a 1053 lacunas de pequeñas dimensões.

2- Em relação à localização e profundidade das lacunas pode dizer-se o seguinte [figura 6 e tabela 5]:
- 1044 lacunas são pouco extensas e poderiam ser reintegradas por se situarem em áreas de composição pictórica com padrões e valores cromáticos e formais evidentes, que não colocam dúvidas na interpretação.

- 9 lacunas, mais extensas, poderiam colocar problemas durante a reintegração, por se situarem em áreas de composição pictórica que colocariam dúvidas, nomeadamente associadas à extensão das sombras, das luzes e da gradação de cor entre o vermelho e o castanho. No entanto, são lacunas que se estendem ao nível do suporte lenhoso e se localizam numa zona de panejamento castanho, passando, por isso, despercebidas ao observador (a uma distância de 2 a 3 metros), em contexto museológico. $\mathrm{O}$ mesmo acontece com as 3 lacunas de maiores dimensões, com a identificação na tabela de atributos, de ID n.o 48, 118 e 501, não sendo necessária, na opinião dos autores, qualquer reintegração cromática para valorização da interpretação da obra.

Após a análise supra da distribuição e quantificação de perdas, depreende-se que, pelo facto de algumas zonas da pintura apresentarem uma tonalidade geral acastanhada, próximo da cor do suporte, a maioria das lacunas
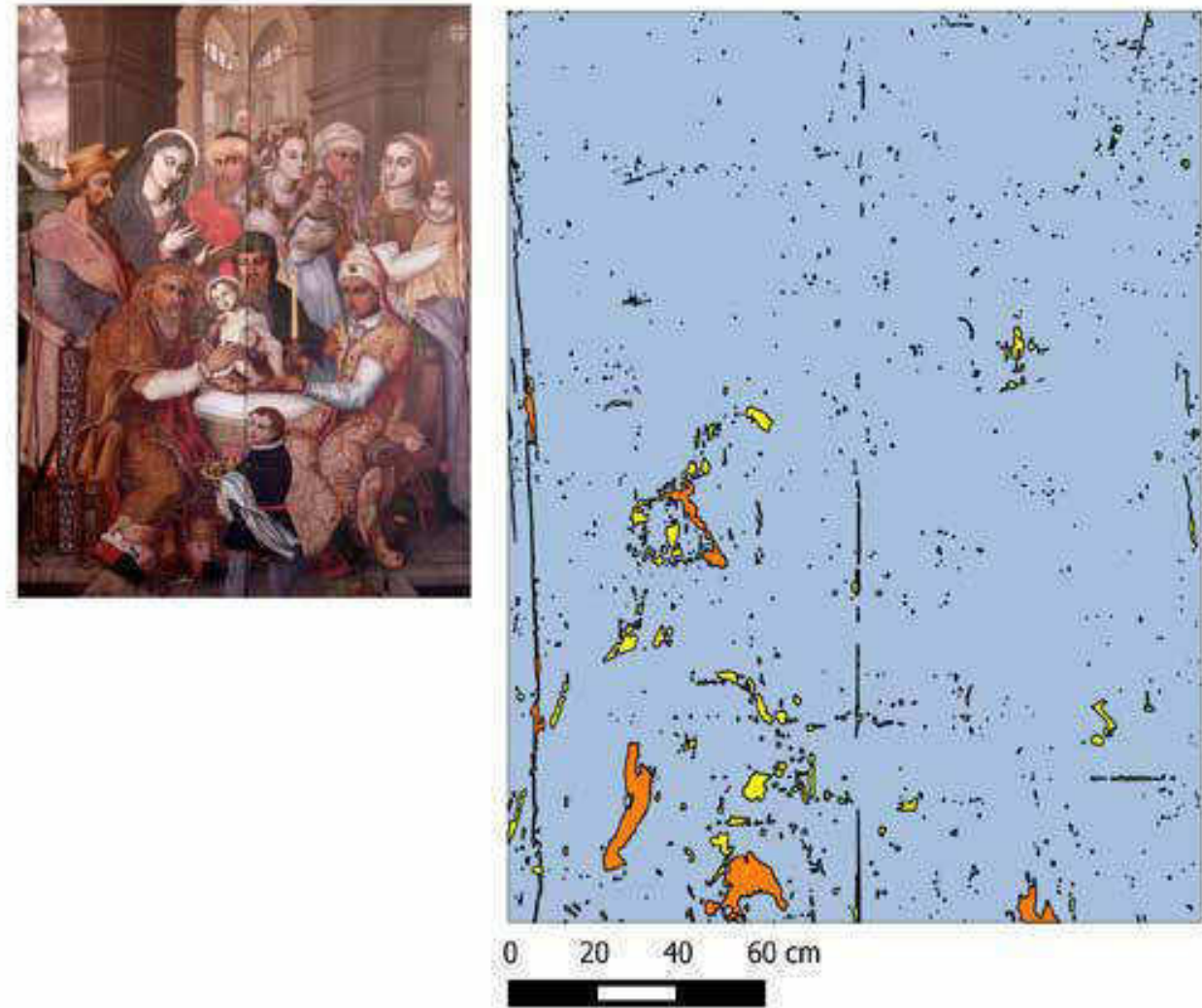

TABELA DE ATRIBUTOS

\begin{tabular}{|c|c|c|c|}
\hline id & AREA & AFEA TOTHL & AEES PE \\
\hline 2 & 1.434177 & 34346.404905 & 0.004176 \\
\hline 3 & 6.035407 & 34345.404905 & 0.017581 \\
\hline 2 & 0.059651 & $34346,40 * 905$ & 0.000251 \\
\hline 9 & $0.334: 24$ & 34345,404905 & 0.000973 \\
\hline 8 & 0,510512 & 34345.404905 & 0.001486 \\
\hline 17 & 0.114204 & 34346.404905 & 0.000334 \\
\hline 6 & 0.291385 & 34345.404905 & 0.008848 \\
\hline
\end{tabular}

\section{LEGENDA}

Classificacto de lacunas por percentagem de área

$10.358 \% \cdot 0.115 \%$

$(0.076 \%-0.010 \%)$ $[<0.009 \%)$

Número de lacunas: 1091

Percentagem total de lacunas: $3 \%$

Figura 5- Composição gráfica com imagem fotográfica da pintura, um mapa das lacunas e respetiva tabela de atributos. No que diz respeito à classificação de lacunas por percentagem de área, o valor estimado foi de $3 \%$ da área total, num total de 1091 lacunas. No mapa temático das lacunas podem-se observar a localização e a distinção cromática entre lacunas de pequena, média e maiores dimensões. A tabela de atributos dá como exemplo seis lacunas, a indicação da área específica de cada lacuna, da área total da obra e a respetiva percentagem. Esquema gráfico de Ana Bailão. 
confundia-se com o manto e não ganhava protagonismo. Neste caso, o fenómeno gestaltista de "figura-fundo" não foi tão evidente [10]. Através de uma análise detalhada da obra, chegou-se à conclusão que, para este ensaio, se podia prescindir da ação de reintegração na generalidade das lacunas [figura 7], tendo-se selecionado somente 40 lacunas para eventual intervenção. As lacunas que assumiam maior protagonismo eram as longitudinais e as de forma arredondada que, na sua maioria, se localizavam em rostos ou em zonas em que as cores, em torno da lacuna, realçavam a cor do suporte perante o observador

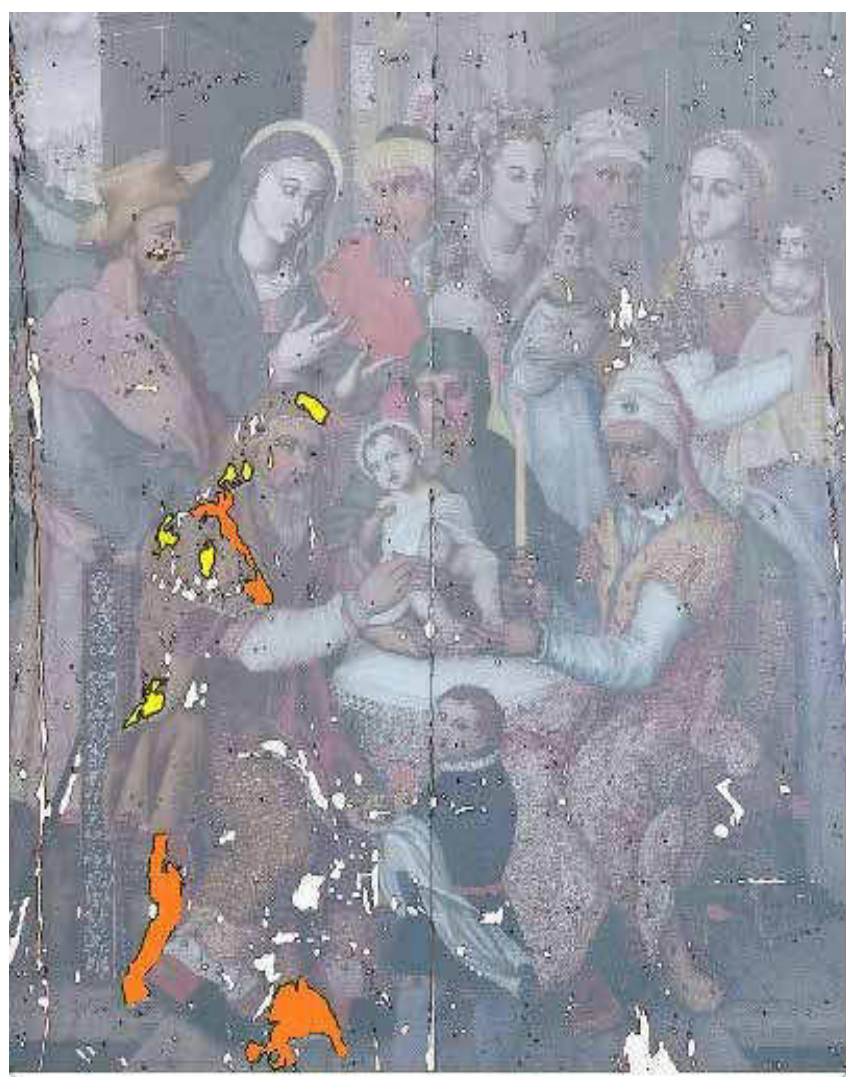

Figura 6- Localização das 9 lacunas que podem suscitar dúvidas no momento da intervenção comum. Eram lacunas de cores e formas homogéneas, minimizando, assim, as interpretações dúbias, quer em relação às gradações dos tons e reprodução das sombras e das luzes, quer na continuidade de linhas ou fisionomias.

Para além da classificação de lacunas, calculada por percentagem de área de ocupação na totalidade da obra, e calculada em $\mathrm{cm}^{2}$ de cada lacuna, fez-se também, no contexto da investigação e estudo da obra, uma estimativa de horas afetas à componente prática da reintegração cromática [11]. Esta estimativa foi efetuada após a reintegração a aguarela de uma lacuna. Se bem que o tempo que cada conservador-restaurador demora a fazer o acerto de uma cor seja sempre uma questão subjectiva, este teste permitiu avaliar o tempo necessário para a conclusão das bases cromáticas [12], mediante a reintegração de uma lacuna, por parte da responsável pela intervenção. Como técnica de reintegração optou-se pelas
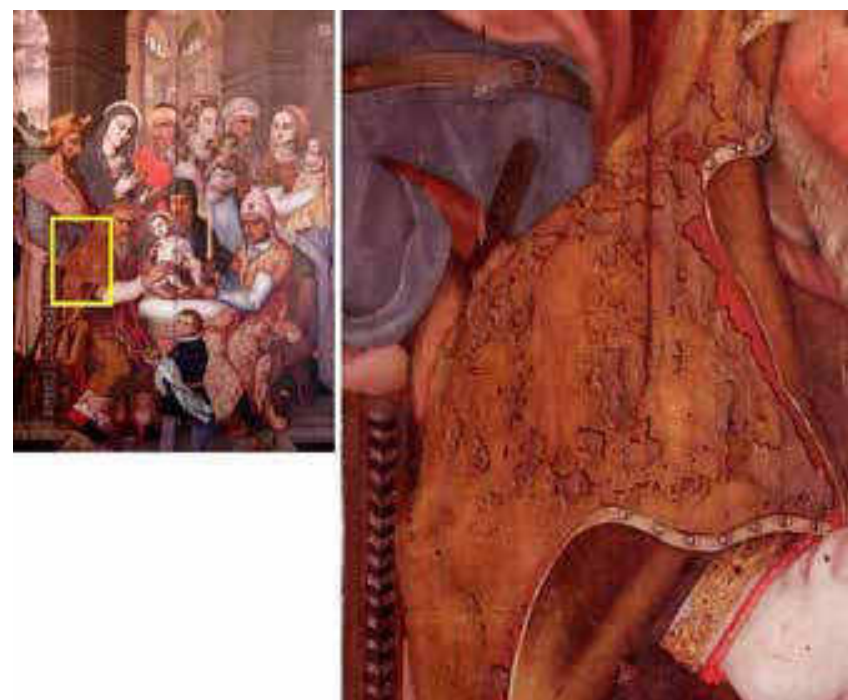

Figura 7- Vista geral da pintura A Circuncisão do Menino Jesus. Pormenor de um manto onde se pode verificar que, devido à proximidade tonal da cor da camada cromática e do suporte lenhoso, as lacunas, durante a observação, são remetidas para segundo plano. Fotografias e esquemas gráficos dos autores.

\begin{tabular}{|c|c|c|c|c|c|c|}
\hline id & $\Gamma$ & AREA & AREA_PERC & TEC_REINTG & Matizes & MATIZES \\
\hline & $48:$ & 123.070393 & 0.858321 & Sem Reintegragăo & sem indicagro & E \\
\hline & 149 & $118: 467280$ & 0.344919 & Sem Reintegragầ & sem indicagấo & $=$ \\
\hline & 421 & 22,584074 & 0.065754 & Sem Reintegraga & Sem indicasto & E \\
\hline & $474:$ & 12.745410 & 0.037108 & Sem Reintegragäo & sem indicagấo & $=$ \\
\hline & 5401 & 16.658862 & 0.043502 & Sem Reintegragá & sem indicaşo & $E$ \\
\hline & 521 & 4.971687 & 0.014475 & Sem Reintegrăgä̀ & sern inidicagắo & $=$ \\
\hline & 52 & 78829789 & 0.022797 & Sem Reintegraga & Sem indicasto & E \\
\hline & 512 & 11.710260 & 0.084095 & Sem Reintegragầ & serninidicagáo & $=$ \\
\hline & 501 & 53.395941 & 0.155461 & Sem Reintegragäo & Sem indicasao & $E$ \\
\hline
\end{tabular}

Tabela 5- Assinala-se a laranja as três lacunas com perda de material ao nível do suporte. Excerto da tabela de atributos com apresentação de apenas 9 lacunas. Na primeira coluna temos o n. ${ }^{\circ}$ de ID, na segunda coluna está a indicação da área específica e na terceira coluna está a área percentual de cada lacuna. 
bases planas, ao tom da madeira, tendo sido aplicadas duas camadas de cor.

Através do valor de tempo despendido numa determinada área foi possível calcular o tempo necessário para a restituição cromática da restante área lacunar. Foi escolhida a lacuna $n .^{\circ} 243$, previamente preenchida com massa de preenchimento, e com uma área de $39,5 \mathrm{~cm}^{2}$. A reintegração demorou 36 minutos a finalizar. Com estes dados foi possível calcular uma estimativa para a totalidade de lacunas $\left(913,1 \mathrm{~cm}^{2}\right)$ ou apenas para as 40 lacunas que se pretendia reintegrar na fase inicial do projeto $\left(139,4 \mathrm{~cm}^{2}\right)$ [figura 8]. É importante referir que a área total da obra é $30.436,8 \mathrm{~cm}^{2}$.

Para estimar o número de horas necessário para a realização da reintegração, recorreu-se a uma regra de

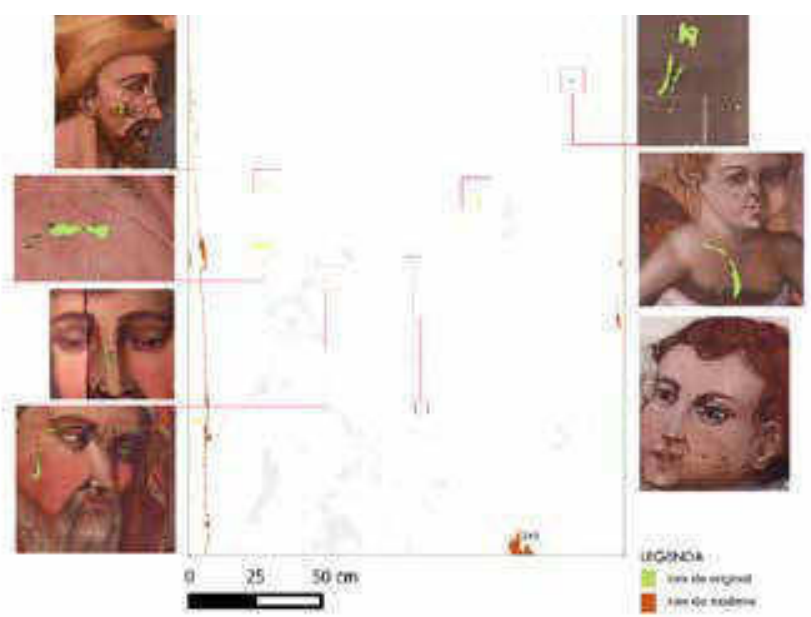

Figura 8- De modo esquemático apresentam-se as regiões selecionadas na fase de projeto para a reintegração cromática. Nas sete regiões indicadas do esquema, as lacunas encontram-se reintegradas virtualmente a verde. Nesta vista global do mapa de perdas, a lacuna $\mathrm{n}^{\circ} 243$ foi a escolhida para o teste cromático e está localizada na zona inferior direita da obra Esta lacuna serviu de base para a estimativa e cálculo das horas necessárias para a conclusão da aplicação de bases cromáticas. A área da lacuna a reintegrar corresponde a $0.04 \%$ da área total da pintura. Esquema gráfico de Ana Bailão. três simples. Para as 40 lacunas selecionadas estimaramse, aproximadamente, 2 horas e para a totalidade das lacunas, caso fosse esse o objetivo, estimaram-se 15 horas. Contudo, convém ter sempre presente, que esta previsão temporal varia em função da técnica de reintegração escolhida e da experiência do conservador-restaurador, responsável pela tarefa, sobretudo no que diz respeito à sua capacidade para misturar e diluir tintas, com vista ao acerto final da cor.

Uma das vantagens dos programas de sistemas de informação geográfica (SIG), em relação a outras ferramentas computacionais, é a possibilidade de se puder criar uma base de dados, que neste caso possibilita a descrição pormenorizada e personalizada de cada lacuna. Pode-se agregar informação do projeto numa tabela alfanumérica, designada em SIG de "tabela de atributos", que foi criada durante o processamento de dados em QGIS. À tabela de base adicionou-se ainda mais duas colunas, uma para o registo da técnica de reintegração, e outra para a anotação dos materiais e misturas que foram usados para obtenção dos matizes [tabela 6], podendo esta informação ser utilizada no relatório ou consultada no futuro.

A informação obtida com esta ferramenta revelou-se uma mais-valia porque ajuda a fundamentar algumas das tomadas de decisão pertinentes na fase de reintegração cromática, associadas ao rigor da descrição do método e ao tempo aproximado de intervenção. Obviamente que, em contexto de relatório técnico, toda a informação adquirida poderá ser também apreciável para a caracterização da área original da obra e da área não original (intervencionada pelo conservador-restaurador), assim como pode servir de apoio a posteriores intervenções e a consequentes tomadas de decisão.

Como último reparo, convém salientar que o ensaio aplicado na pintura não contemplou as lacunas de desgaste ou abrasão, do tipo I e II (Mora, Mora, Philippot, 1984: 305315). Não obstante o facto do processo de análise para esse tipo de lacunas poder vir a ser semelhante, como o que foi apresentado, por uma questão de simplificação
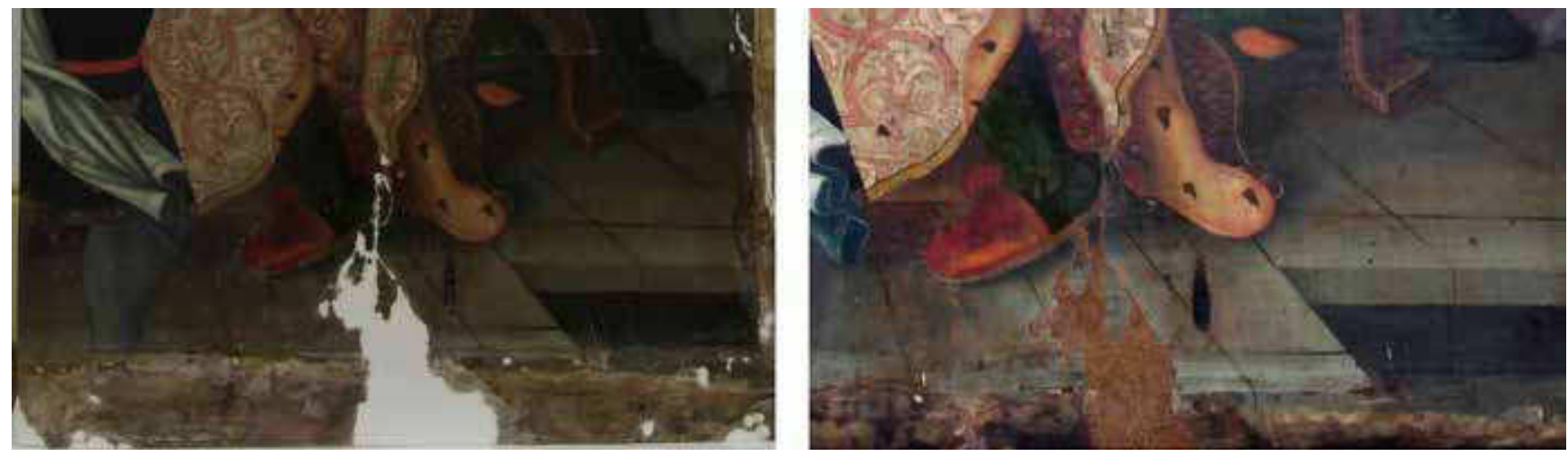

Figura 9- Visualização da lacuna n. ${ }^{\circ} 243$, a de maiores dimensões, antes (esquerda) e depois (direita) da aplicação de uma base ao tom da madeira. 


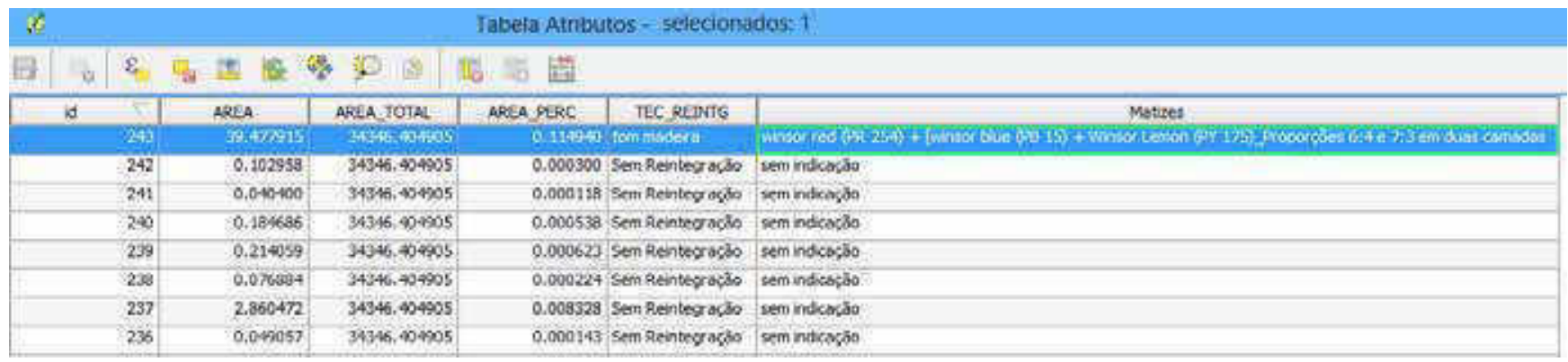

Tabela 6- Tabela de atributos que contém a informação associada às lacunas, em destaque, como exemplo, a n. ${ }^{\circ} 243$, a técnica de reintegração e os procedimentos e materiais utilizados. Tabela elaborada por Ana Bailão.

e clarificação do método sugerido, prevê-se fazer esse estudo noutra abordagem, em desenvolvimentos futuros.

\section{Conclusão}

O processo apresentado, dedicado à vertente da Documentação dos Bens Culturais aplicada às reintegrações cromáticas, poderá constituir uma estratégia para a análise quantitativa e qualitativa das obras. Isto significa que, para além de servir de método de registo, poderá influênciar a escolha da área a reintegrar, assim como contribuir para a organização do orçamento final de uma intervenção.

O método de documentação e análise exposto em modo de ensaio, poderá ser um sistema de apoio essencial para o conservador-restaurador, quer no diagnóstico, quer no planeamento da intervenção e durante o processo de reintegração. Embora possa contribuir decididamente para a tomada de decisão, a apreciação e avaliação do projeto deverá ser sempre multifatorial, e ter em linha de conta múltiplas vertentes, desde a opinião do proprietário da obra e o seu contexto sócio-cultural, assim como fatores bem conhecidos pelo conservador-restaurador: os atributos da cor, o formato da lacuna, os matizes a utilizar, a caracterização dos tons de sombra e de luz, o reconhecimento da anatomia das figuras, entre outros.

Contudo, após se superarem as dificuldades nas estratégias técnico-cientificas da operação de reintegração cromática, além da formação adequada do conservador-restaurador, talvez seja importante referir que a definição dos critérios éticos e deontológicos das intervenções constitui sempre o maior desafio dos projetos. $E$, além disso, não menos importante deverá ser o contínuo papel pedagógico das intervenções, junto dos fruidores de património, de modo a cultivar a importância do papel do conservadorrestaurador no enquadramento da lei, na sociedade e da sua participação direta no processo da tomada de decisão junto dos donos de obra.

\section{Agradecimentos}

Este estudo teve o apoio da Fundação para a Ciência e a Tecnologia (FCT) e QREN - POPH, co-financiado pelo Governo Português e União Europeia através do MCTES. Esta investigação foi financiada pelas bolsas de estudo da FCT: SFRH/BD/69783/2010 e SFRH/BPD/99163/2013.

\section{Notas}

[1] O tratteggio é um sistema de reintegração cromática elaborado com linhas verticais. Os primeiros traços verticais, que podem indicar o tom básico da reintegração, são sempre paralelos com intervalos regulares e equidistantes. Esses traços são muito importantes porque servem de linhas de referência para as cores que se seguem. Após essa primeira fase, sobre essas linhas fazem-se novos traços de cor pura ou com a mistura de cores. No intervalo dos traços aplicam-se as misturas de cores sobre a forma de velatura.

[2] Imprimadura: se bem que seja um vocábulo não muito comum em português, usamos a terminologia "imprimidura" como tradução da palavra italiana "imprimitura". Isto é, uma camada de cor que se aplica sobre o preparo, antes da aplicação da camada cromática (Cruz, 2006: 76). Acerca da utilização do vocábulo consultar a obra de Francisco Assis Rodrigues, Diccionario Technico e Historico de Pintura, Esculptura, Architectura e Gravura. Lisboa: Imprensa Nacional, 1875, p. 224.

[3] O princípio básico da seleção cromática é seguir as formas da composição através da aplicação de traços curtos e pequenos de cores puras (não misturadas na paleta) em camadas sucessivas, justapondo e sobrepondo de tal modo que, à distância, o efeito da cor reintegrada seja equivalente ao original. São usadas aguarelas ou pigmentos em pó aglutinados em verniz e, em teoria, apenas as cores primárias e secundárias, ocasionando o fenómeno da mistura ótica da cor (Casazza 1981: 30-32; Scarzanella e Cianfanelli 1992: 203). Na prática podem ser utilizadas todas as cores disponíveis, desde que sejam puras, à exceção do branco (este forçosamente presente na camada de nivelamento da lacuna, como fundo liso e refletor), por quebrar a transparência dos tons (Casazza 1981: 30, 34-63, Bailão, 2011: 54).

[4] A abstração cromática resulta da sobreposição sucessiva de camadas de cores puras sob a forma de curtos traços, 
ligeiramente encurvados e espontâneos. Todavia, a orientação dos traços varia da primeira à quarta camada (Casazza 1981:68). Os tons são combinados para criar uma opção quente e outra fria (Casazza 1981:67; Bailão, 2011: 57).

[5] O processo de georreferenciação inicia-se com a atribuição de coordenadas $\mathrm{X}$ e $\mathrm{Y}$ da imagem de referência. Estas correspondem a pontos de controlo a partir dos quais se consegue ter uma indicação métrica da área da imagem. Com a imagem georreferenciada é possível verificar a localização exata dos fenómenos presentes na superfície, as suas coordenadas e, em suma, caracterizar espacialmente a imagem.

[6] Esta obra foi objeto de dissertação de Susana Catarina Silva Mendes, para obtenção do grau académico de Mestre em Conservação e Restauro, na Escola das Artes, Universidade Católica Portuguesa. Acerca da pintura ver a seguinte obra: BRANDÃO, Domingos de Pinho (1984). Obra de Talha Dourada, Ensamblagem e Pintura na cidade e na Diocese do Porto. Documentação I - Séculos XV a XVII. Porto: Diocese do Porto, 168-169.

[7] As primeiras experiências documentadas de modo sistemático de análise métrica e espacial em património, recorrendo a ferramentas dos Sistemas de Informação Geográfica (SIG), remontam a 1999: SCHMID, W., ed. (2000). GRADOC: Graphic Documentation Systems in Mural Painting Conservation. Research Seminar Rome 16-20 November 1999. Roma: ICCROM. Outros estudos se seguiram, sobretudo em arqueologia e pintura mural. Mais recentemente, em contexto nacional, foram feitas aplicações de SIG e processamento digital sobre superfícies pictóricas: PIRES, H., MARQUES, P., HENRIQUES, F., OLIVEIRA, R. (2007). "Integrating laser scanning, multispectral imagery and GIS in C\&R documentation practices: A first approach using two XVIth century wood paintings from Convento de Cristo in Tomar". En XXI International CIPA Symposium, 01-06 October 2007, Athens, Greece; HENRIQUES, F. GONÇALVES, A. BAILÃO, A. (2009). "Tear feature extraction with spatial analysis: A thangka case study". Estudos de Conservação e Restauro, 1: 11-23; HENRIQUES, F., GONÇALVES, A. (2010). "Identificação de regiões de lacunas numa pintura retabular: análise comparativa de métodos de classificação em ambiente SIG". Estudos de Conservação e Restauro, 2: 72-81; HENRIQUES, F., GONÇALVES, A. (2010). "Analysis of Lacunae and Retouching Areas in Panel Paintings Using Landscape Metrics". En EuroMed 2010, Lecture Notes in Computer Science (LNCS), 6436: 99-109; HENRIQUES, F., GONÇALVES, A., CALVO, A. (2010). "Caracterização da densidade das lacunas em superfícies pictóricas com recurso a Sistemas de Informação Geográfica (SIG)". Conservar Património, 11: 3 - 11; FUENTES PORTO, A. (2010). Los Sistemas de Información Geográfica aplicados al estudio de las superficies pictóricas. Valência: Universidad Politécnica de Valencia. Dissertação de Mestrado; HENRIQUES, F., GONÇALVES, A., CALVO, A., BAILÃO, A. (2011). "Identificazione di lacune di un dipinto dopo la stuccature e prima del ritocco pittorico". En VCongresso Internazionale "Colore e Conservazione", Le fasi finali nel restauro delle opere policrome mobili. Cesmar7, Saonara: II Prato, 234-236; HENRIQUES, F.
(2012). Metodologias de Documentação e Análise Espacial em Conservação de Pintura. Porto: Escola das Artes, Universidade Católica Portuguesa. Doutoramento em Conservação de Pintura; ROQUE, D., MENDES, M., PEREIRA, S., FONSECA, A., MIMOSO, J. M. (2012)."Deteção de Anomalias em Azulejos através de Técnicas de Processamento Digital de Imagem". En Proceedings Congresso Internacional AZULEJAR 2012. Aveiro: Universidade de Aveiro; Departamento de Engenharia Civil; ROQUE, D., FONSECA, A., MIMOSO, J. M. (2013). "Mapeamento Digital e Classificação de Anomalias em Paramentos Murais: Processamento Digital de Imagem e Classificação Orientada por Objetos". En Proceedings Segundo Encontro Luso-Brasileiro de Conservação e Restauro. São João Del Rei; Brazil: Universidade Federal de São João Del Rey; FONSECA, A., ROQUE, D. PEREIRA, S., MENDES, M., MIMOSO, J. M. (2015). “Digital Image Processing: application to automatic classification of tile panel pathology". En International Conference Glazed Ceramics in Architectural Heritage (GlazeArch 2015). Lisboa: Laboratório Nacional de Engenharia Civil, 154-159.

[8] O programa informático QGIS 2.6. (QGIS), assim como todos os programas de SIG, têm a possibilidade de editar tabelas e de colocar as percentagens por ordem crescente, permitindo selecionar as regiões (lacunas) em função da ordem de grandeza dos valores, à qual pode ser atribuída uma escala de cor. Vd. QGIS, "A Free and Open Source Geographic Information System". http://www.qgis.org/en/site/. [09/07/2015]; QGIS, "Guia do utilizador do QGIS", em Documentação do QGIS 2.8. http://docs.qgis.org/2.8/pt_PT/docs/user_manual/. [09/07/2015].

[9] A escala de cores é disponibilizada pelo programa Quantum Gis 2.6. Existem várias escalas, motivo pelo qual, fica ao critério do operador a eleição de uma escala cromática especifica.

[10] Vd. BRANDI, C. (1961). "II Trattamento delle lacune della gestalt psychologie". En XX International Congress of History of Art. Nova lorque: [s.n.], pp. 149, 150; BAILÃO, A. (2010). “O gestaltismo aplicado à reintegração cromática de pintura de cavalete". Estudos de Conservação e Restauro. 1: 128-139.

[11] A tomada de decisão sobre a reintegração desta obra foi realizada em grupo. Foram tido em consideração vários fatores tais como o valor simbólico e a função da obra, a extensão e localização das lacunas, as referências cromáticas e formais em torno das lacunas, entre outros. Respostas a estas e outras questões podem ser consultadas na tese de doutoramento de BAILÃO, A. M. dos S. (2015). Critérios de intervenção e estratégias para a avaliação da qualidade da reintegração cromática em pintura. Porto: Universidade Católica Portuguesa, em Apêndice III.

[12] O termo "bases cromáticas" pode ser utilizado na conservação e restauro para caracterizar a primeira fase da reintegração cromática. Pode ser plana ou sob a forma de traços ou pontos. Sobre essa camada, efetuada num sistema aquoso, a aguarela ou gouache, segue-se a aplicação da camada de proteção (verniz), e a finalização, por exemplo, com pigmentos em pó e verniz. 


\section{Bibliografia}

BALDINI, U. (1998). Teoria de la restauración. Madrid: Editorial Nerea, Vol. 2.

BAILÃO, A. (2010). "O gestaltismo aplicado à reintegração cromática de pintura de cavalete", Estudos de conservação $e$ restauro, 1: 128-139.

BAILÃO, A. (2011). "As Técnicas de Reintegração Cromática na Pintura: revisão historiográfica", Ge-Conservación, 2: 45-63.

BAILÃO, A. (2015). Critérios de intervenção e estratégias para a avaliação da qualidade da reintegração cromática em pintura. Porto: Universidade Católica Portuguesa. Tese de doutoramento.

BRANDÃO, D. P. de (1984). Obra de Talha Dourada, Ensamblagem e Pintura na cidade e na Diocese do Porto. Documentação I Séculos XV a XVII. Porto: Diocese do Porto, 168-169.

BRANDI, C. (1961). "Il Trattamento delle lacune della gestalt psychologie". En XX International Congress of History of Art, Nova lorque: [s.n.], 149-150.

CASAZZA, O. (1981). Il restauro pittorico nell'unità di metodologia. Florença: Nardini Editore.

CRUZ, A. J. (2006). "Sobre o uso e o desuso de alguns termos relacionados com os materiais constituintes das obras de arte", Conservar Património, 3-4: 76.

CIATTI, M. (2009). "Appunti sulla storia del restauro pittorico in Italia". En Lacuna, Riflessioni sulle esperienze dell'Opificio delle Pietre Dure, Florença: Edifir - Edizioni Firenze.

FONSECA, A., ROQUE, D., PEREIRA, S., MENDES, M., MIMOSO, J. M. (2015). "Digital Image Processing: application to automatic classification of tile panel pathology". En International Conference Glazed Ceramics in Architectural Heritage (GlazeArch 2015). Lisboa: Laboratório Nacional de Engenharia Civil, 154159.

FUENTES PORTO, A. (2010). Los Sistemas de Información Geográfica aplicados al estudio de las superficies pictóricas. Valência: Universidad Politécnica de Valencia. Dissertação de Mestrado.

HENRIQUES, F., GONÇALVES, A., BAILÃO, A. (2009). “Tear feature extraction with spatial analysis: A thangka case study", Estudos de Conservação e Restauro, 1: 11-23.

HENRIQUES, F., GONÇALVES, A., BAILÃO, A., CALVO, A. (2009). "A lacuna pictórica: metodologias de interpretação e análise", Pedra e Cal. 11, 42: 13-15.

HENRIQUES, F., GONÇALVES, A. (2010). “Identificação de regiões de lacunas numa pintura retabular: análise comparativa de métodos de classificação em ambiente SIG", Estudos de Conservação e Restauro, 2: 72-81.
HENRIQUES, F., GONÇALVES, A. (2010). "Analysis of Lacunae and Retouching Areas in Panel Paintings Using Landscape Metrics", En EuroMed 2010, Lecture Notes in Computer Science (LNCS), 6436: 99-109.

HENRIQUES, F., GONÇALVES, A., CALVO, A., BAILÃO, A. (2011). "Identifcazione di lacune di un dipinto dopo la stuccature e prima del ritocco pittorico". En $V$ Congresso Internazionale "Colore e Conservazione", Le fasi finali nel restauro delle opere policrome mobili, Cesmar7, Saonara, II Prato, 234-236.

HENRIQUES, F. J. R. (2012). Metodologias de documentação e análise espacial em conservação de pintura. Porto: Universidade Católica Portuguesa. Doutoramento em Conservação de Pintura.

HENRIQUES, F., GONÇALVES, A., CALVO, A. (2010). “Caracterização da densidade das lacunas em superfícies pictóricas com recurso a Sistemas de Informação Geográfica (SIG)", Conservar Património, 11: 3-11.

MORA, P., MORA, L., PHILIPPOT, P. (1984). Conservation of wall paintings. Londres, Boston: Butterworths, 301-312.

PHILIPPOT, A., PHILIPPOT, P. (1959). “Le problème de l'intégration des lacunes dans la restauration des peintures", Bulletin de I'Institut Royal du Patrimoine Artistique. Bruxelas: IRPA. Vol. 2 (1959), p. 5.

PIRES, H., MARQUES, P., HENRIQUES, F., OLIVEIRA, R. (2007). "Integrating laser scanning, multispectral imagery and GIS in C\&R documentation practices: A first approach using two XVIth century wood paintings from Convento de Cristo in Tomar". En XXI International CIPA Symposium, 01-06 October 2007, Athens, Greece.

QGIS, "A Free and Open Source Geographic Information System", http://www.qgis.org/en/site/ [09/07/2015].

QGIS, "Guia do utilizador do QGIS", em Documentação do QGIS 2.8", http://docs.qgis.org/2.8/pt_PT/docs/user_manual/ [09/07/2015].

RODRIGUES, F. A. (1875), Diccionario Technico e Historico de Pintura, Esculptura, Architectura e Gravura, Lisboa: Imprensa Nacional, 224.

ROQUE, D., MENDES, M., PEREIRA, S., FONSECA, A., MIMOSO, J. M. (2012)."Deteção de Anomalias em Azulejos através de Técnicas de Processamento Digital de Imagem". En Proceedings Congresso Internacional AZULEJAR 2012. Aveiro: Universidade de Aveiro; Departamento de Engenharia Civil.

ROQUE, D., FONSECA, A., MIMOSO, J. M. (2013). “Mapeamento Digital e Classificação de Anomalias em Paramentos Murais: Processamento Digital de Imagem e Classificação Orientada por Objetos". En Proceedings Segundo Encontro Luso-Brasileiro de Conservação e Restauro. São João Del Rei; Brazil: Universidade Federal de São João Del Rey. 
SCARZANELLA, C. R.; CIANFANELLI, T. (1992). “La percezione visiva nel restauro dei dipinti. L'intervento pittorico". En Problemi di restauro. Riflessioni e ricerche, CIATTI, M. ed., Florença: EDIFIR, 185-211.

SCHMID, W. ed. (2000). GRADOC: Graphic Documentation Systems in Mural Painting Conservation. Research Seminar Rome 16-20 November 1999. Roma: ICCROM.

\section{Manuscrito:}

Lisboa, Arquivo Nacional da Torre do Tombo (Portugal), Registo das Visitações Gerais da Ordem de Malta à Comenda de Rossas, 1718-1719, livro 17, fl. 68 ss.

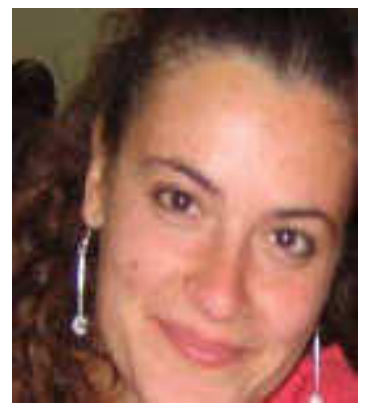

\section{Ana Bailão}

ana.bailao@gmail.com

Universidade Católica Portuguesa

Conservadora-restauradora em Pintura de cavalete. Doutoranda na Universidade Católica Portuguesa (UCP). Obtenção do grau de Mestre com o tema "Metodologia e técnicas da reintegração cromática em pintura de cavalete" pela mesma instituição. Licenciatura pré-Bolonha, pelo Instituto Politécnico de Tomar (IPT).

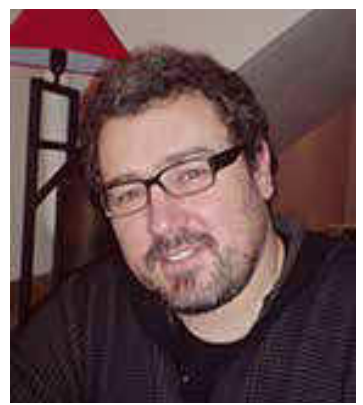

\section{Frederico Henriques}

frederico.painting.conservator@gmail.com Universidade Católica Portuguesa

Conservador-restaurador na especialidade de pintura, bacharel pela Escola Superior de Conservação e Restauro (1997), licenciatura pré-Bolonha no Instituto Politécnico de Tomar (2005), doutoramento em Conservação de Pintura pela Escola das Artes, da Universidade Católica Portuguesa (2013) e pós-doutorando no Centro de Investigação em Ciência e Tecnologia das Artes (CITAR), e no Laboratório HERCULES, da Universidade de Évora. Atualmente é bolseiro da Fundação para a Ciência e Tecnologia (FCT) e dedica-se exclusivamente à documentação digital de Bens Culturais. 


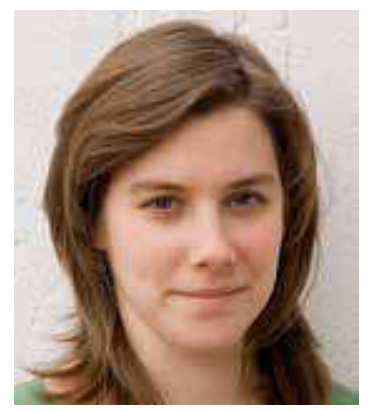

\section{Susana Mendes}

susmendes@gmail.com

Universidade Católica Portuguesa

Conservadora-restauradora. Licenciatura em Conservação e Restauro pela Escola das Artes, da Universidade Católica Portuguesa (2011) e Mestrado em Conservação e Restauro de Bens Culturais - Especialização em Pintura pela Escola das Artes, da Universidade Católica Portuguesa (2015). Principais interesses: Conservação e restauro de pintura sobre madeira, história da conservação e restauro, iconografia e iconologia.

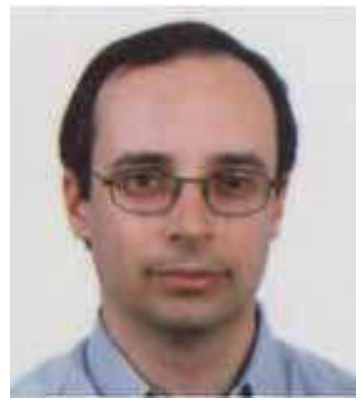

\section{Alexandre Gonçalves}

alexandre.goncalves@tecnico.ulisboa.pt

Instituto Superior Técnico, Universidade de Lisboa

Licenciado em Matemática Aplicada e Computação (1995, IST), mestre em Sistemas de Informação Geográfica (1998, IST) e doutorado em Engenaria do Território (2007, IST). É professor no Instituto Superior Técnico (IST). Os seus intereses científicos incluem Sistemas de Informação Geográfica, Análise Espacial, Otimização, Modelação Geográfica, Algoritmos para Dados Espaciais e aplicações genéricas de SIG, incluindo aplicações à arte e às reconstruções históricas. 



\section{Introducción}

Una de las fotografías de primera época de producción nacional que se conservan en España es el daguerrotipo objeto de este artículo, que forma parte de la Colección de Adquisiciones y Subastas del Instituto del Patrimonio Cultural de España. Con motivo de la reciente restauración de su sistema de montaje [figuras 1 y 2], se analizarán algunos aspectos de esta pieza que reúne condiciones como para considerarla estimable dentro del patrimonio fotográfico nacional.

Los daguerrotipos que, como este, se identifican como producción española, deben ser objeto de especial atención, tanto por su valor documental para la construcción de la crónica gráfica de personalidades y gentes del ámbito social, como por su aportación a la historia de nuestra fotografía desde un punto de vista técnico y estético.

La intervención restauradora de cualquier pieza requiere de un amplio conocimiento de la materia que integra el objeto para favorecer una toma de decisiones correcta y disminuir los riesgos durante su manipulación y tratamiento. Por ello, en este trabajo, se ha realizado un especial esfuerzo para comprender mejor la morfología y la química implicada en el proceso de creación de los daguerrotipos, acotando esta información a la cronología y ámbito geográfico de la obra a intervenir.
Debido a la imposibilidad de llegar a este conocimiento a partir de análisis directos sobre la obra, dada la protección de la misma y los riesgos potenciales derivados de su manipulación, se aborda el tema desde el estudio de fuentes primarias como los tratados de época y secundarias como las monografías de carácter científico, entre las que cabe destacar aquella que firman Susan Barger y William B. White (1991).

\section{Tecnología del daguerrotipo: proceso y materia.}

\section{Morfología}

El daguerrotipo es un proceso sin emulsión, es decir, la imagen no se encuentra embebida en un aglutinante como ocurre en la mayoría de los procedimientos fotográficos; en este caso, forma parte integrante del soporte. El aspecto más llamativo del daguerrotipo y clave para su identificación, es su capacidad para mostrarse positivo o negativo, en función de cómo incida la luz sobre su superficie especular.

Materialmente, esta tipología fotográfica está formada por una lámina de cobre plateada donde se forma la imagen, compuesta a su vez de plata metálica y amalgama de plata y mercurio con presencia de oro en muchos de los casos'.
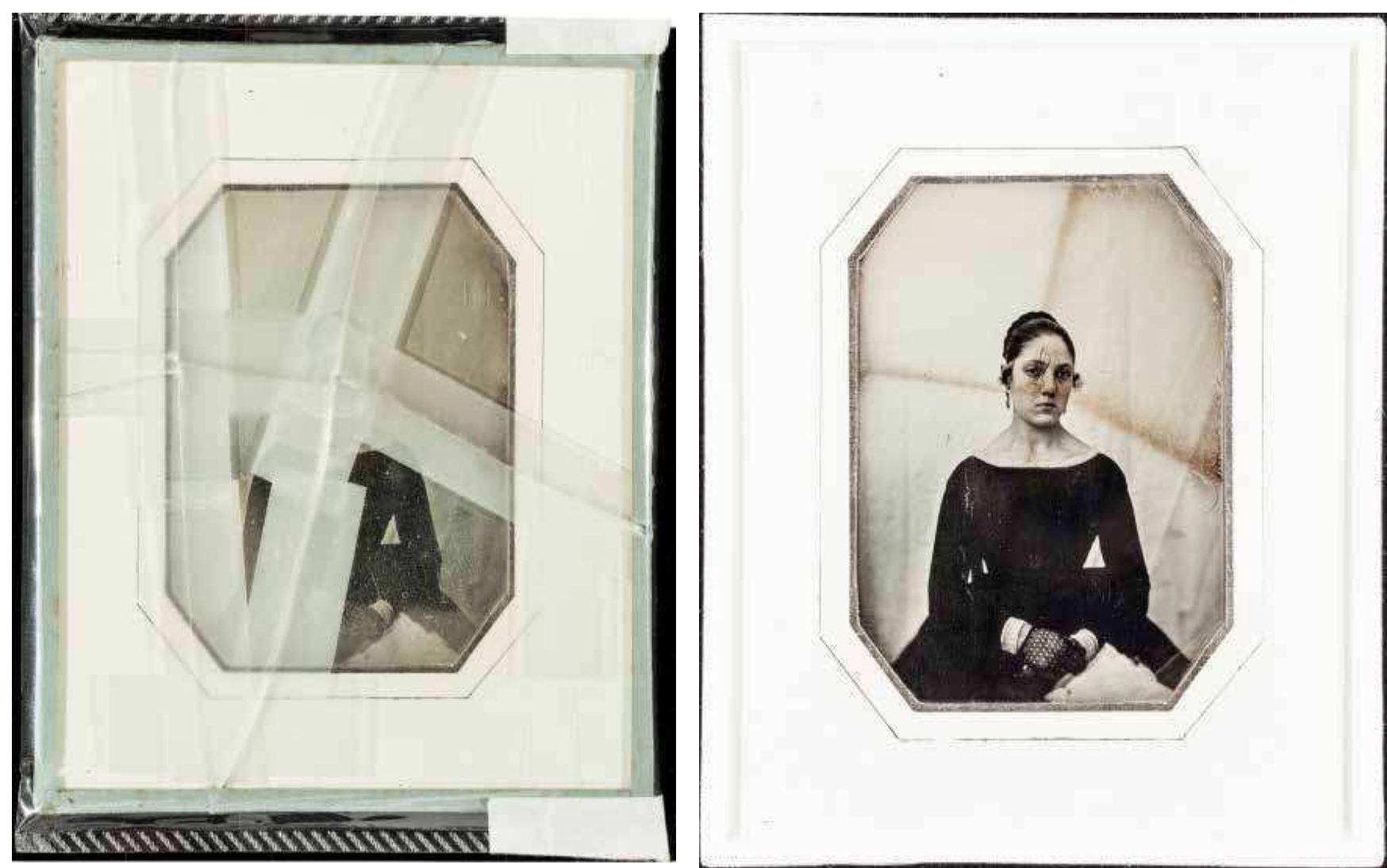

Figuras 1 y 2.- Daguerrotipo antes y después de la restauración. Foto: José Luis Municio 
El formato de esta lámina se estandarizó desde los inicios de la técnica, partiendo del primer tamaño utilizado que se denomina placa entera correspondiente a las medidas de $6,5 \times 8,5$ pulgadas $(162 \times 216 \mathrm{~mm})$. A partir de este formato se fueron reduciendo los tamaños y denominando en función del número de piezas en que se podía dividir una placa entera. Así surgieron los formatos más pequeños como $1 / 2$ placa, $1 /{ }_{4}$ de placa... Además, se debe tener en cuenta que, a veces, las piezas se cortaban después de procesarse, para adaptarlas al montaje o variar el encuadre de la toma.

Para comprender mejor el sistema de producción de un daguerrotipo, se realizará un análisis más detallado.

\section{Preparación de la placa}

El soporte de la imagen, como ya se ha mencionado, es de cobre plateado, al menos, por la cara en la que se va a formar la fotografía. El grosor de la placa de cobre (Lavedrine 2010: 37) solía ser de 0,4 $\mathrm{mm}$ y 0,01 $\mathrm{mm}$ el de la lámina de plata, pero esto también podía variar ya que algunas placas se vendían con mayor proporción de plata, lo que permitía rreutilizarlas puliéndolas de nuevo, en caso de producirse tomas fallidas.

\section{A este respecto el propio Daguerre (1839) escribe:}

$<<[\ldots]$ el cobre ha de tener el grueso que baste para mantener la planimetría de la plancha, a fin de que no se vicie la forma de las imágenes; pero es preciso irse con cuidado en darle más de lo que convenga, para obtener este resultado, por razón del peso que se produciría $>>$.

La lámina de plata podía aplicarse de varias formas: por plateado mecánico, mediante la superposición de una lámina de plata fina, o por medio de un procedimiento químico o electroquímico, que podía darse a su vez de dos formas ${ }^{2}$.

- Se puede considerar en primer lugar el plateado por baño, que se puede producir de forma espontánea al introducir la lámina en una solución acuosa de un compuesto de plata. En estos casos, el baño podía ser de nitrato de plata (soluble en agua) o sales no solubles como cloruro o cianuro de plata que se estabilizan en la disolución gracias a la adición de cianuro potásico (Pfanhauser 1926: 114), por formación de un complejo de coordinación soluble ${ }^{3}$.

- En el caso segundo, que parece el más probable, el plateado se haría por electrólisis, mediante el uso de una corriente eléctrica que se hacía pasar a través del baño (un electrolito) en el que se introduce la placa de cobre que se conecta al polo negativo para que funcione como cátodo captando electrones y un ánodo de otro metal que preferiblemente no se oxide en baño acuoso para evitar la contaminación del electrolito ${ }^{4}$. Este sistema se conoce como procedimiento americano (Barger y White 1991: 45)

En ambos casos se deposita plata metálica de forma más o menos uniforme sobre la placa de cobre hasta que la superficie queda cubierta del todo. Se produce un proceso de reducción por el que el catión de plata gana un electrón y se convierte en plata metálica.

El objetivo era obtener una fina capa de plata sobre el cobre de forma que no se viera comprometida la estabilidad física de la lámina pero tampoco añadiera excesivo peso al ya pesado equipo fotográfico, unos cincuenta kilogramos, según afirma Sougez (2001: 72).

- El plateado mecánico ${ }^{5}$ más frecuente se realizaba depositando sobre la lámina de cobre otra finísima de plata que se calentaba en un horno hasta alcanzar una temperatura mínimamente inferior a la de fusión de la plata $\left(962^{\circ} \mathrm{C}\right)$, momento en el que se aplicaba presión mediante el uso de una laminadora de rodillos ${ }^{6}$. La pieza resultante se cortaba en partes, a las medidas deseadas, y cada pieza se enderezaba con peso o a martillo para eliminar cualquier deformación (Barger y White 1991: 49). El resultado ofrecía una superficie algo más blanda que las de sistema electrolítico $y$, por tanto, las piezas así obtenidas pueden ser más sensibles a daños mecánicos por abrasión así como a delaminaciones por falta de adherencia entre las capas (Barger y White 1991: 161). En la superficie por plateado mecánico se forman cristales de mayor tamaño que en las placas plateadas por electrólisis, en las que se crea una estructura microcristalina.

También se podía dar un plateado mecánico inicial para luego proceder al plateado electroquímico mediante pila galvánica, llevado a cabo en ocasiones por los más exigentes operadores (Newhall 1961: 35)

Descrito el proceso de plateado no es difícil suponer que los fotógrafos encargaran esta tarea a la incipiente industria artesana surgida rápidamente para abastecer el novedoso y lucrativo mercado de la daguerrotipia que, en sus inicios, fue asumida por los talleres de orfebrería tradicionales, familiarizados con las técnicas.

Obtenida la placa, el proceso continuaba con un pulido de la superficie, lo que suponía una meticulosa labor cuyo objetivo era conseguir un exquisito reflejo especular en la plata con las mínimas líneas de abrasión visibles. La calidad del pulido revertía en un mayor contraste de la imagen, para lo que era más conveniente trabajar sobre una placa plateada por electrólisis que por aplicación mecánica (Barger y White 1991: 161). El pulido se realizaba minuciosamente con diferentes abrasivos como trípoli (sílice) y rojo de joyero o rojo inglés (óxido de hierro) (Gallego 1851: 6), ayudado de un alcohol ${ }^{7}$ y algodón en rama para su aplicación. La última fase de este proceso 
requería de un pulidor fabricado en madera, acolchado con paño o tela y cubierto con una piel de gamuza, lo que proporcionaba una superficie uniforme y perfecta. El uso exclusivo de rojo inglés para este paso final parecía dar los mejores resultados (León 1846: 11).

\section{Formación de la imagen latente}

Una vez preparado el soporte, las imágenes en origen se formaban a partir de yoduro de plata que se generaba en la superficie plateada exponiéndola a vapores de cristales de yodo ${ }^{8}$. La elección del yodo en primer lugar frente a otros halógenos se debió a su estado sólido a temperatura ambiente, lo que favorecía su manejo frente al bromo o el cloro, también conocidos por entonces (Barger y White 1991: 31-32).

La reacción del yodo con el metal noble generaba sales o haluros de plata que se caracterizan por su sensibilidad a la luz. Pese a obtenerse imágenes con el uso del yodo, su sensibilidad era lenta y las tomas requerían largos periodos de exposición, motivo por el cual, desde 1841 se combinaron con sales de cloro y bromo reduciendo así los tiempos de cada toma.

Estas sales argénteas al reaccionar con la luz que penetra dentro de la cámara, generan una imagen latente que no es perceptible a simple vista, por lo que requiere 'un proceso de revelado ${ }^{9}$ para su intensificación.

\section{Procesado}

Para hacer visible la imagen, en principio, se exponía la placa a vapores de mercurio mediante el uso de una llama que provocaba el cambio de estado del azogue. Al alcanzar la temperatura de ebullición el mercurio desprendía vapor que en contacto con la plata creaba una amalgama con esta. La función de los vapores de mercurio sería, por tanto, intensificar la acción de la luz actuando sobre los cationes de plata próximos a los que ya se han reducido en la toma, convirtiéndolos también en plata metálica y haciendo crecer los cúmulos metálicos.

Las partículas de amalgama de plata y mercurio adquieren un color blanquecino, color que correspondería a las zonas de luces, aquellas del sujeto fotografiado que han reflejado luz sobre la placa.

Posteriormente era necesario realizar el fijado de la imagen, ya que, de no hacerse, se mantendría la naturaleza fotosensible de los haluros de plata restantes y la imagen acabaría perdiéndose. Para ello se realizaba una inmersión de la placa en disoluciones acuosas de tiosulfato sódico o amónico para eliminar las sales de plata que no se habían reducido y eran aun fotosensibles.
Obtenida y fijada la imagen, que está invertida lateralmente ${ }^{10}$, presentaba una gran vulnerabilidad al más mínimo contacto directo, pudiendo llegar a borrarse con el dedo. Daguerre y otros tempranos operadores enseguida fueron conscientes de este problema, aportando soluciones de carácter físico, primero con el uso de barnices ${ }^{11}$, para acabar llegando a los sofisticados sistemas de protección que acompañaron a las piezas durante todos sus años de producción.

La solución de naturaleza química llegó en 1840 de la mano del estudiante de ciencias, Hippolyte-Louis Fizeau que, inducido por el propio Arago, descubrió que los daguerrotipos tratados con una solución de cloruro de oro con tiosulfato de sodio, calentada levemente, presentaban una mejora del contraste y mayor resistencia física frente a la manipulación (Barger y White 1991: 38). Tan pronto como se hace público el proceso conocido como virado al oro, se incluye en el procesado y pasa a formar parte del sistema de producción inmediatamente ${ }^{12}$.

La alternativa al sistema de revelado con vapores de mercurio surgió gracias al joven físico Edmond Becquerel ${ }^{13}$, el segundo de una saga familiar de físicos franceses, cuyas investigaciones se centraron durante años en los efectos de la radiación espectral sobre placas de daguerrotipos. En el transcurso de su concienzudo estudio descubrió que un daguerrotipo ya expuesto y sometido a la radiación de haces de luz amarillos o rojos, bajo un vidrio coloreado a modo de filtro, revelaba la imagen latente sin necesidad de usar el vapor de mercurio, tan solo gracias a la acción de los rayos continuos de luz amarilla (Barger y White 1991: 40). El proceso, conocido como sistema Becquerel requería además la inmersión en solución caliente de cloruro sódico ${ }^{14}$ a distintas concentraciones (Lavedrine 2010: 37). La toxicidad del mercurio motivó su sustitución entre los operadores.

En el sistema Becquerel se da una reacción fotoquímica donde las radiaciones del haz luminoso comprendidas entre los $550 \mathrm{~nm}$ y $700 \mathrm{~nm}$ aproximadamente, harían el efecto de revelado que provocaba el mercurio, reduciendo los cationes de plata a plata metálica.

Teniendo en cuenta la introducción y éxito del sistema Becquerel, publicado en 1840 pero extendido tiempo después, debemos esperar que las imágenes en daguerrotipos puedan estar formadas tanto por plata y mercurio, como por plata metálica fijada con sal común, posiblemente con presencia de oro ${ }^{15}$.

\section{El color en los daguerrotipos}

El tono de los daguerrotipos es monocromo para decepción de muchos de los asistentes a las demostraciones públicas que hacía Daguerre en su propia casa los jueves desde septiembre de 1839 (Sougez 2001: 59). Aun así es posible encontrar color en el daguerrotipo que puede tener orígenes y naturalezas bien distintas. 
Uno de los tonos más frecuentes en algunas imágenes es un azul tenue que se origina sobre la plata fruto de la sobreexposición, quedando visible solo en las zonas de altas luces. Esto podía ser un error de la exposición o tener una intencionalidad y, aunque caben ambas posibilidades, parece más razonable inclinarse por la primera ya que desde 1844 se introduce un método de sensibilización en tres pasos (yodo/bromo/yodo) para evitar el tono azul de las altas luces.

En algunos daguerrotipos puede además encontrarse una sutil coloración fruto de la iluminación manual, que se podía realizar principalmente de dos maneras distintas:

-Aplicando un barniz o adhesivo sobre la imagen y depositando los pigmentos molidos mientras el barniz se encuentra mordiente.

-Mediante el uso de una goma arábiga que permitía aglutinar el pigmento en medio acuoso para aplicarlo diluido.

Esta aportación de color era bastante corriente cuando se quería dotar al retrato de mayor naturalidad y, más aún, teniendo en cuenta que algunos de los daguerrotipistas venían del mundo de la pintura en miniatura y eran diestros en las artes de la iluminación y el uso del color.

Es frecuente, además, encontrar dorados y plateados para resaltar algunos detalles de la indumentaria de los sujetos como botones o joyas. Podían hacerse de forma sencilla, mediante la aplicación de pintura, o incluso haciendo pequeñas incisiones en forma de puntos que producían un efecto brillante al recibir luz.

También se usaron métodos más elaborados basados en sistemas electrolíticos que requerían el uso de metales, no solo el oro, sino también plata y cobre, según el color deseado, aplicados de forma local. Esto se podía hacer confiando en la habilidad y destreza del operador o mediante inmersión, para lo que previamente se protegían las reservas con goma arábiga y alguna sustancia grasa. Una vez concluido el tratamiento, el daguerrotipo se hervía en lejía. El proceso se podía repetir para aplicar varios colores. A pesar de los sistemas que se patentaron ${ }^{16}$ para este tipo de coloración electrolítica, fueron más corrientes las aplicaciones a pincel (Barger y White 1991: 39).

Una mención aparte merecen los 'daguerrotipos' a color bautizados como hillotipos que dieron notoriedad al ministro baptista neyorquino Levi L. Hill y de los cuales se conservan sesenta y dos ejemplos en el Museo de Historia de América. Fueron y son aun controvertidos, aunque llegaron a contar con los avales de personalidades de la comunidad fotográfica americana como Samuel F. B. Morse, entre otros. Pese a todo, al señor Hill se le consideró un farsante y hoy en día se desconoce su procedimiento para obtener color, aunque parece haber cierto consenso en que, a pesar de que se hicieron sobre placas de daguerrotipo, no son consideradas como tal.

Este recorrido por la tecnología de daguerrotipos pretende ser una aproximación a los procesos físico-químicos implicados en el procedimiento, prestando mayor atención a sus vertientes más populares y extendidas de los primeros años de producción. Cabe mencionar que, tras el descubrimiento de la daguerrotipia, fueron varios los experimentos y variantes que se introducen, así que, aunque en grandes líneas hemos mostrado el sistema mayoritario de producción, lo cierto es que como en todos los procesos artesanales, siempre hay que contar con unos amplios márgenes de desconocimiento e incertidumbre.

Los aspectos relativos a las cámaras fotográficas han sido omitidos ya que es, en sí mismo, un tema amplio y complejo y su estudio no queda claramente justificado en este trabajo.

\section{Montajes y sistemas de preservación de época}

La vulnerabilidad del daguerrotipo está vinculada especialmente a su exposición al ambiente, que cataliza procesos químicos en los metales que componen la placa y a daños mecánicos por manipulación directa. Ambos factores de deterioro eran ya conocidos por los fotógrafos desde sus inicios, ya que los daños asociados se hacen visibles con cierta facilidad. Por este motivo, las placas daguerrianas se desarrollan conjuntamente con eficientes sistemas de sellado y montajes de protección.

Estos sistemas responden a dos funciones principales: la ya mencionada preservación y la función estética.

Encontramos mayoritariamente dos tipologías: el estuchado, vinculado con el mundo americano y anglosajón, y el enmarcado, también conocido como montaje francés, más propio de la Europa continental. Además, se pueden encontrar, con una menor incidencia en las colecciones, un tipo de estuchado que podríamos considerar mixto ya que, pese a tener un formato de caja cerrada, su apertura frontal permite su exposición tipo atril. Este montaje es más propio de la Europa central y del este.

Esta distribución geográfica puede venir determinada por cuestiones socioculturales, ya que parece razonable vincular el modo de vida estable de la sociedad acomodada de la vieja Europa y sus sistemas de enmarcado para colgar, frente a la movilidad de la población de la emergente clase burguesa americana y sus sistemas de estuchado transportables.

Se analizan a continuación la morfología y estructura del montaje tipo europeo ya que es la tipología presente en el daguerrotipo objeto de este artículo. 
El montaje para enmarcado consta básicamente de un vidrio de protección y un passe-partout o espaciador, ambos de formato superior a la placa daguerriana, la propia placa con la imagen y un soporte de cartón que cierra el conjunto por el reverso. Todo ello se une por uno o varios papeles engomados. Las intervenciones restauradoras sobre obras de características similares consultadas muestran esta morfología, con pequeñas variantes en cuanto a la adhesión del daguerrotipo al espaciador que podía ser con tiras de papel adhesivas o mediante el uso de cera, como refiere la publicación de Caroline Barcella (2009). La misma publicación hace referencia a la presencia de una 'puerta' en el cartón del reverso para insertar la pieza.

La elección de los vidrios en este periodo responde principalmente a cuestiones de transparencia y coloración, obviando valores relativos a su estabilidad química. Los análisis sobre vidrios de principios y mediados del XIX han demostrado que su composición era muy variada. Algunos de estos vidrios presentan una intrínseca inestabilidad química en presencia de humedad.

El espaciador comenzó siendo de papel con alguna sencilla decoración que era visible a través del vidrio, para ir desarrollándose a lo largo de la década de 1840 con la introducción de vidrios lacados por la cara interna del montaje y combinados, frecuentemente, con espaciadores gruesos y biselados que aportaban profundidad al montaje.

A través de la ventana del espaciador queda visible el daguerrotipo que podía ir sujeto al passe-partout por tiras de papel engomado, material de adhesión similar al utilizado para realizar un sellado perimetral que incluía una trasera de cartón. Frecuentemente el anverso quedaba cubierto por un papel adherido. Los daguerrotipistas podían encontrar en los manuales de daguerrotipia los sistemas y recomendaciones para preparar este papel engomado que consistían, básicamente, en aplicar sobre el papel que iba a servir de sellado, cola de pescado, goma arábiga o de tragacanto junto con un conservante. Cuando se requería su uso, estaba ya preparado y tan solo era necesario cortar el papel en tiras o piezas a la medida deseada.

El marco completaba el conjunto con una amplia y variada morfología, con materiales como la madera que podía quedar vista o cubierto con piel o textil, decorarse con incrustaciones de madreperla u otros elementos decorativos, o, desde 1954 podían fabricarse por medio de moldes con un material termoplástico, sistema que dio lugar a marcos con profusa decoración en relieve.

\section{Caracterización de la obra}

Una vez descrita la morfología y procesos técnicos necesarios para la obtención de un daguerrotipo, se analizan los aspectos relativos a la pieza que no ocupa.
Se trata de un daguerrotipo de formato correspondiente a un cuarto de placa que, como se ha mencionado con anterioridad, se realiza en España en la década de 1840. Es un retrato en tres cuartos de una mujer identificada en el reverso del montaje como María Fernández de Juez Sarmiento. Dicha inscripción junto con la datación del retrato, 13 de agosto de 1844, está realizada en tinta negra y de forma manuscrita directamente sobre el papel que sella el conjunto por el verso.

La fotografía carece de un decorado pintado o atrezo de estudio, lo que podría indicar cierto arcaísmo en la construcción de la escena o, por el contrario, tratarse de una decisión de tipo estética o técnica, puesto que el fondo blanco favorece la obtención de un mayor contraste entre el sujeto retratado y el fondo. Se incluye a este respecto la publicación de un anuncio del daguerrotipista Manuel Herrero en fechas cercanas a la toma de esta fotografía, quien, como mencionaremos más adelante, podría ser el autor de la imagen. En este anuncio se demuestra la intencionalidad en el uso de un fondo blanco [figura 3].

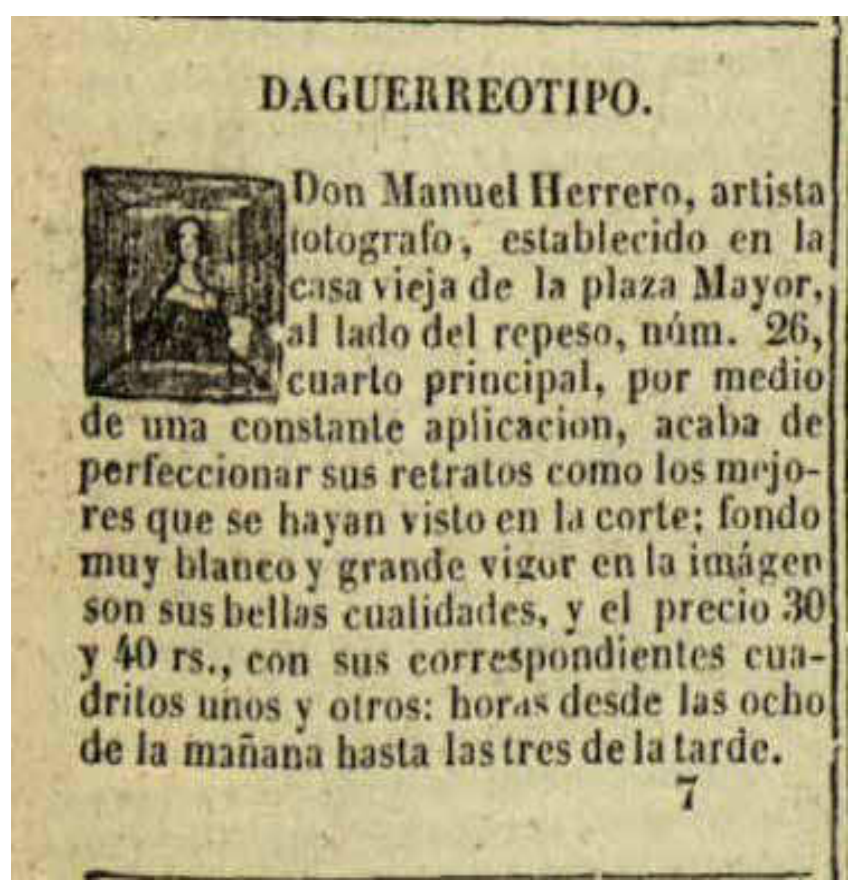

Figura 3.- El Nuevo avisador 19 de agosto de 1844. BNE

Morfológicamente la obra presenta una complejidad inherente a su naturaleza y rigores propios de su conservación ya conocidos desde los inicios de su descubrimiento y a los que eran claramente sensibles los propios daguerrotipistas, como demuestran los sistemas de preservación que acompañan a este tipo de objetos.

Como ya se ha mencionado en el apartado anterior, la vulnerabilidad de los daguerrotipos motivaba su montaje y, en concreto, la fotografía que nos ocupa está inserta en 
un sistema tipo europeo que, básicamente, se compone de un vidrio, un espaciador o passe-partout y una trasera de cartón, todo ello unido por dos papeles de sellado.

El vidrio de protección es de formato superior a la fotografía (125 x $148 \mathrm{~mm}$ ), con $2 \mathrm{~mm}$ de grosor, aunque un tanto irregular como corresponde a la fabricación artesanal de este periodo del siglo XIX. Su función es aislar la placa del contacto ambiental y físico, dos importantes factores externos de deterioro.

El espaciador es sencillo, de papel sin teñir, con ventana octogonal y una orla decorativa hecha a mano en tinta negra a unos $26 \mathrm{~mm}$ de cada borde (con variaciones de $3 \mathrm{~mm}$ de un lado a otro). La orla la forman dos líneas, una gruesa en el interior y otra más fina en el exterior, separadas entre sí por $6 \mathrm{~mm}$.

Cabe destacar que el diseño y factura de la orla es idéntico a otras dos presentes en daguerrotipos adquiridos por el IPCE en el mismo lote y que están identificados como obras realizadas por el fotógrafo conocido como C. Fischer. El hecho de que fueran comprados juntos y la similitud de los espaciadores nos hacen relacionar las piezas, aunque no hasta el punto de atribuir su autoría.

Los espaciadores de papel son propios de las primeras etapas de producción, ya que según avanza la década de 1840 se produce una sofisticación de estos elementos alcanzando gran desarrollo ornamental.

Esta parte del montaje cumple una doble función: la estética, como demuestra su tamaño cuyo fin es engrandecer el aspecto de la fotografía; y la de su conservación, ya que separa mínimamente la placa y el vidrio protector, evitando un contacto directo entre estos elementos y, con ello, las posibles reacciones que este pueda causar por deterioro del vidrio o por procesos de condensación.

El montaje se completa con una trasera de cartón cubierta por dos capas de papel engomado azul, la interior llega hasta el vidrio por el anverso del sistema y abraza todo el conjunto solapándose sobre el vidrio con una anchura de $15 \mathrm{~mm}$ aproximadamente. Una segunda capa refuerza el sellado por el reverso abarcando casi la totalidad del mismo. Sobre este papel se encuentra la anotación manuscrita mencionada anteriormente [figuras 4 y 5].

\section{Estado de conservación}

El deterioro más evidente se encuentra en el vidrio de protección que está fragmentado, por lo que el daguerrotipo ha permanecido relegado dentro de la colección del IPCE desde su adquisición en 1996, ya que ofrece una desafortunada apariencia que impide la lectura de la imagen. Huelga decir que la visión de un retrato que presenta interferencias en la apreciación del rostro del sujeto representado es fuertemente perturbadora, como ejemplifica perfectamente esta fotografía [figura 1].

Además de los fragmentos de vidrio de considerable tamaño hay numerosas lascas y esquirlas pequeñas que desgraciadamente quedaron en íntimo contacto con la superficie de la placa.

El sellado perimetral también está roto en algunos puntos debido al impacto sufrido, mientras que en el reverso el papel se encuentra en muy buen estado, con una tonalidad parda provocada por la migración del adhesivo, pero sin daños mecánicos.
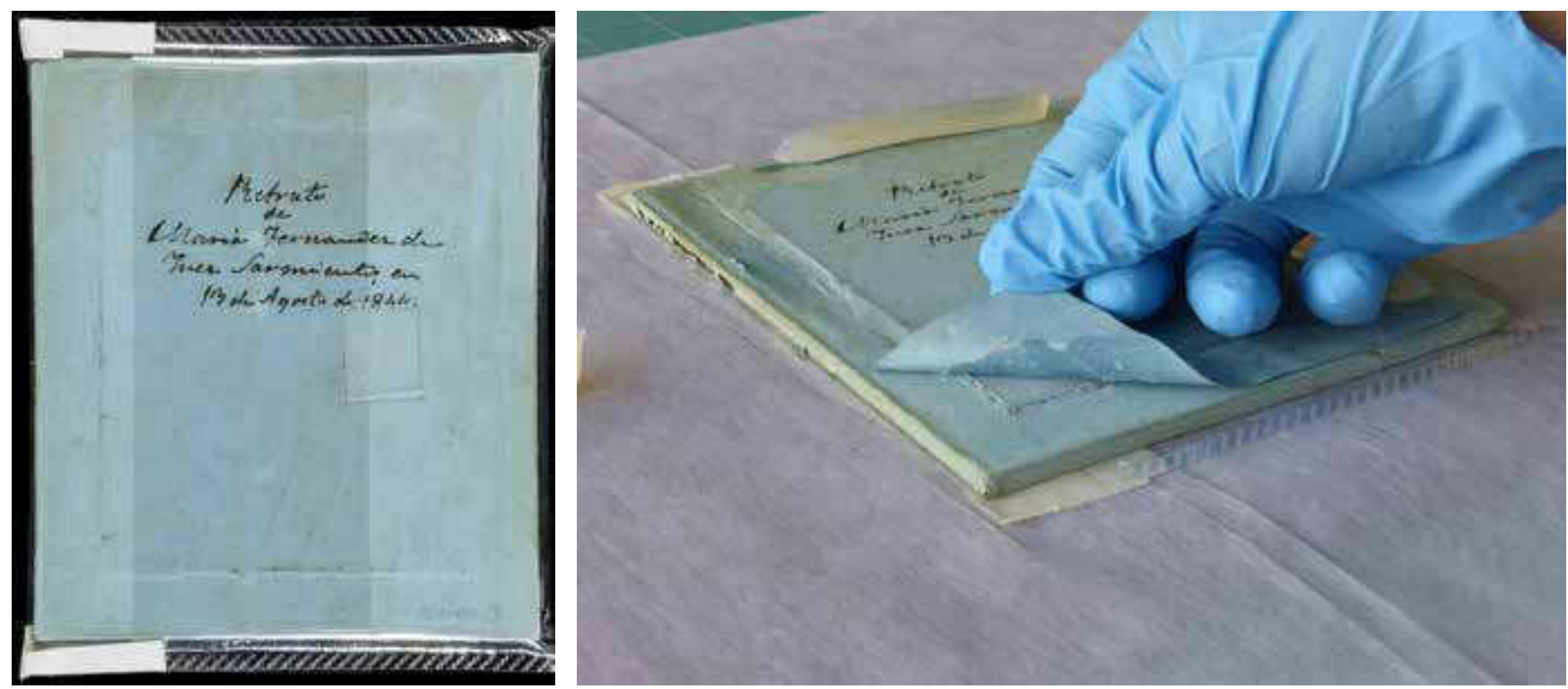

Figuras 4 y 5.- Reverso del daguerrotipo antes y durante la intervención. Foto: José Luis Municio 
Al margen del lamentable estado del vidrio que, afortunadamente, es una parte del montaje que carece de entidad estética, la evaluación de la superficie metálica se realiza tras el desmontaje, momento en el que se hace patente la existencia de un patrón de alteración química coincidente con las líneas de fractura del vidrio. La gravedad de estas alteraciones que dotan de una coloración parda a la placa no es alta y, en parte, es gracias al sistema de adhesión y protección temporal al que se dotó a la pieza en el momento de su desafortunado accidente [figura 1]. Retirado el vidrio se aprecian incisiones y arañazos en la placa metálica localizados, mayoritariamente, en el rostro de la mujer [figura 6] y que fueron provocados por el impacto sufrido, de consecuencias irreversibles. Pese a que algunos de los arañazos son de carácter superficial, en la parte central del rostro se pueden observar incisiones de mayor consideración que han alcanzado el cobre subyacente. Afortunadamente no hay evidencias de alteración química asociada a estos daños mecánicos.

El desmontaje permite observar los bordes de la plancha metálica donde se hace patente un patrón de coloración variada muy frecuente en la zona perimetral de otros daguerrotipos, vinculado al proceso de producción de los mismos y la mayor exposición de los bordes a potenciales factores de deterioro y alteración química [figuras 8 y 9 ].

\section{Proceso de intervención}

El objetivo principal de la intervención es la puesta en valor de este objeto fotográfico que en la actualidad está fuera de uso y disfrute por la inviabilidad de su apreciación física así como por el alto riesgo que conlleva su manipulación. Mediante este trabajo también se persigue frenar el deterioro de la imagen asociado al mal estado del sellado, que actualmente cumple su función de preservación y aislamiento de forma deficiente. La intervención permite, por tanto, mejorar el sistema, en términos de protección física y ambiental, que exige la naturaleza material de la obra, teniendo en cuenta el uso y función de la misma dentro de la Institución que la custodia.

El último objetivo, por orden de relevancia, es mejorar la potencialidad estética de la fotografía, considerando la placa y todos los elementos de su montaje como una unidad física que cuenta con relevantes valores estéticos, históricos y documentales.

En resumen, con esta restauración pretendemos poner de nuevo en valor la pieza, mejorando sus condiciones de preservación, así como su lectura y funcionalidad documental y estética reduciendo, además, los actuales riesgos por manipulación.

La restauración de este objeto se rige por los criterios que vienen determinados por su nivel de protección y recogidos en la Ley de Patrimonio Histórico Español 16/1985, concretamente en el artículo 39.3.

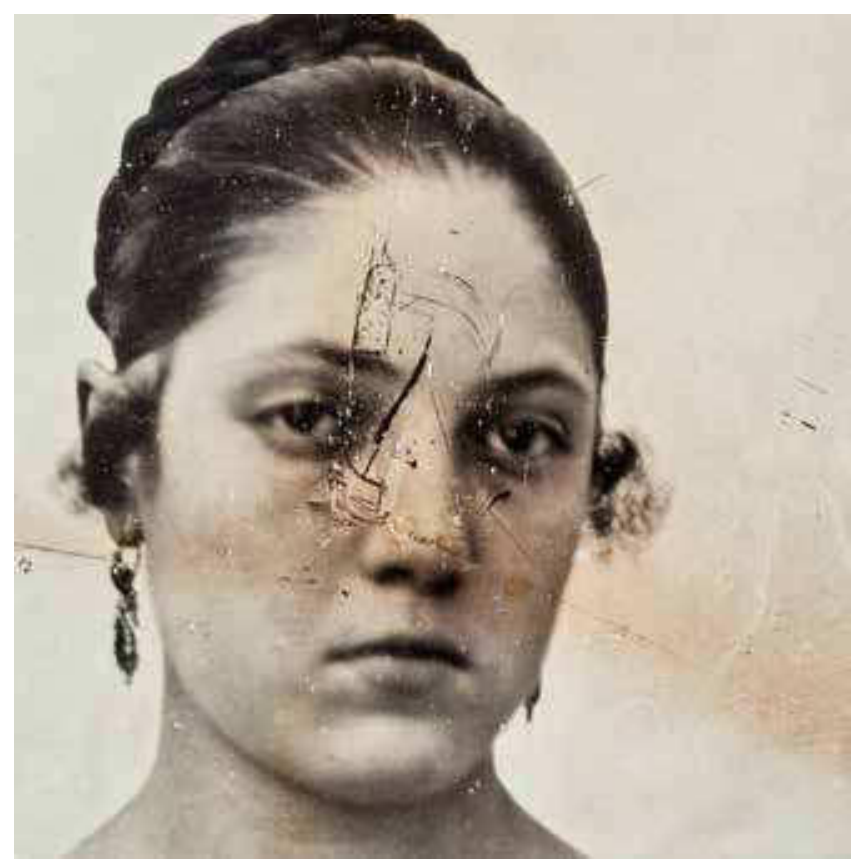

Figura 6.- Detalle de la placa desmontada. Foto: José Luis Municio

Como se ha mencionado al inicio de este artículo, el conjunto material de este objeto cuenta no solo con los valores estéticos propios de su naturaleza fotográfica, sino que además contribuye a conformar el mapa técnico de los inicios del daguerrotipo en España, mapa que comparte con un número limitado de piezas. Por este motivo, ponemos en consideración cada uno de los elementos que componen este bien.

Uno de los criterios sobre los que sustentamos el trabajo es la mínima intervención que asegure la reducción de los riesgos potenciales que presenta la obra.

Para alcanzar los objetivos propuestos se procede al desmontaje del sistema y montaje con un sellado nuevo, previa limpieza de la placa. La elección del vidrio de borosilicato ${ }^{17}$ para el nuevo montaje está motivada por su estabilidad química y mayor resistencia física, así como por sus excelentes cualidades ópticas. Las dimensiones del vidrio son idénticas a las del original (125 x $148 \mathrm{~mm})$ e idéntico grosor ( $2 \mathrm{~mm}$ ). La cinta de sellado elegida es Filmoplast ${ }^{\circledast}$ P90, apta para conservación y con buena reversibilidad.

Para el desmontaje se realizan pruebas de solubilidad que muestran que el adhesivo es acuoso y la coloración del papel no es soluble. Esto permitiría el tratamiento con humedad controlada para retirar el sellado pero, la presencia de una doble capa de papel continuo cubriendo todo el verso del montaje, plantea nuevos riesgos por manipulación y alta exposición a la humedad, motivo que determina la apertura perimetral del sellado.

Una vez separadas las distintas partes del montaje se descubre que la placa se encuentra fuertemente adherida 

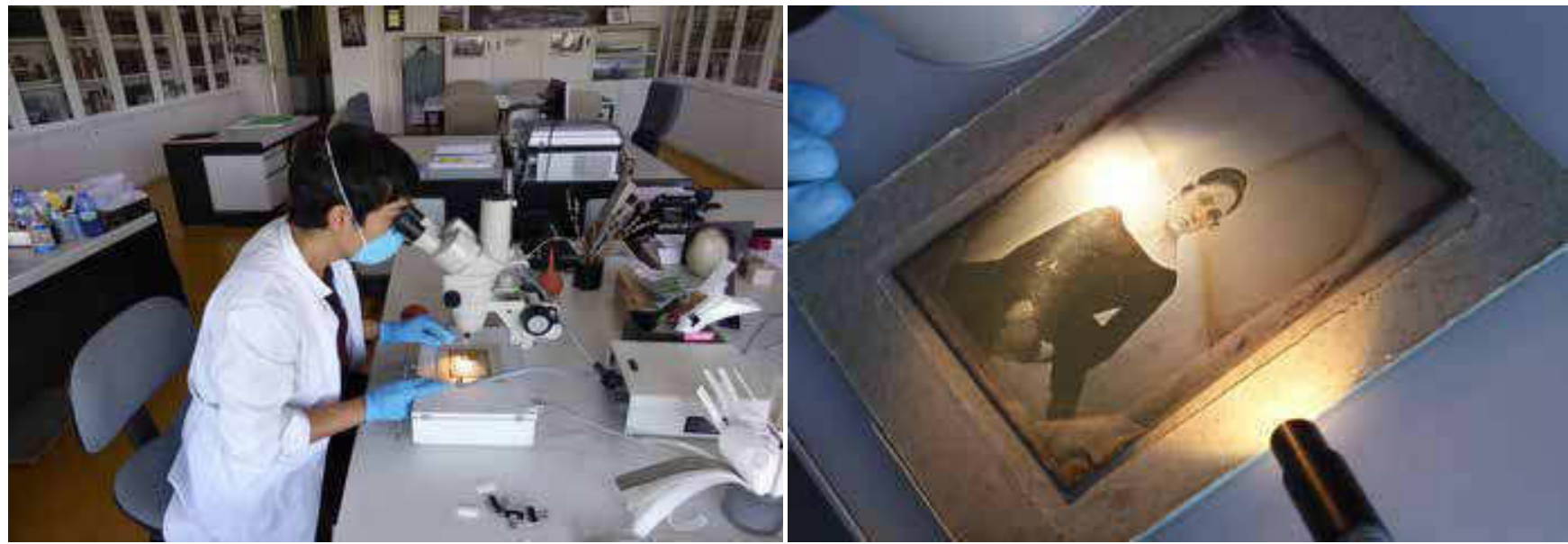

Figuras 7 y 8.- Proceso de limpieza de la superficie de la placa. Foto: Carlos Teixidor

al cartón de la trasera y el espaciador está suelto, pese a que se desconoce la sustancia adherente, podría ser cera, gelatina o alguna sustancia de naturaleza similar. El acceso y documentación del sistema de montaje de este daguerrotipo permite recabar la información que se recoge en este artículo sobre los métodos de protección de daguerrotipos.

En el proceso de limpieza con aire se comprueba su baja eficacia ya que no elimina la mayoría de lascas que están en íntimo contacto con la obra, por lo que se procede a una limpieza con pincel suave, con ayuda de una lupa binocular, previa evaluación de la resistencia de la imagen al contacto físico [figuras 7 y 8]. La respuesta al contacto, junto con la fecha de producción, sugiere la posibilidad del virado al oro de la imagen.

Tras una cuidada limpieza del nuevo vidrio, se unen todas las partes del conjunto realizando un doble sellado continuo (Murata 2003) que se sitúa sobre el vidrio unos 15 $\mathrm{mm}$, a imitación del sellado original, cerrando el conjunto. Este tipo de sellado favorece el aislamiento ambiental de la pieza, con respecto a sistemas de sellado en cuatro tiras, en los que las esquinas podrían ser potencialmente vulnerables. El sellado posterior original se mantiene intacto evitando una intervención de mayor magnitud por los riesgos asociados a una excesiva manipulación del daguerrotipo $y$, teniendo en cuenta el estado del vidrio y su íntimo contacto con la placa. El sellado efectuado asegura la reversibilidad del nuevo sistema tanto por la situación del mismo como por los materiales empleados.

Gracias a la intervención de la obra se ha podido documentar la marca de platero y la de contraste presentes en las esquinas superiores de la placa que estaban cubiertas por el passe partout. Ambas marcas se encuentran en excelente estado de conservación y aportan relevantes datos sobre la fabricación de la placa.

Las referencias ${ }^{18}$ halladas de la marca de la derecha la sitúan dentro de la producción francesa de la década de 1840 [figura 10]. Este marco de producción concuerda con la tipología de sello de orfebre en el siglo XIX en Francia, donde se repite con frecuencia la inicial inserta en un losange.

Por otro lado, debemos tener en cuenta que la producción de daguerrotipos en España en este primer periodo está en manos de un número reducido de fotógrafos que trabajan, en su mayoría, de forma itinerante con estancias algo más largas en las ciudades donde esperan tener mayor volumen de negocio. Es de suponer que la artesanía de placas en nuestras fronteras no fuera, aun en estas fechas, muy rentable por lo que dudamos de la existencia de un amplio mercado estable y nacional.

Un anuncio en el Diario de Madrid del daguerrotipista Manuel Herrero, con fecha del 26 de julio de 1845 demuestra el uso de placas francesas incluso un año después de la toma de esta fotografía:

$<<$ En el gabinete fotográfico de don Manuel Herrero, se acaba de recibir de París un abundante surtido de placas, marcos medallones, etc. $>>$

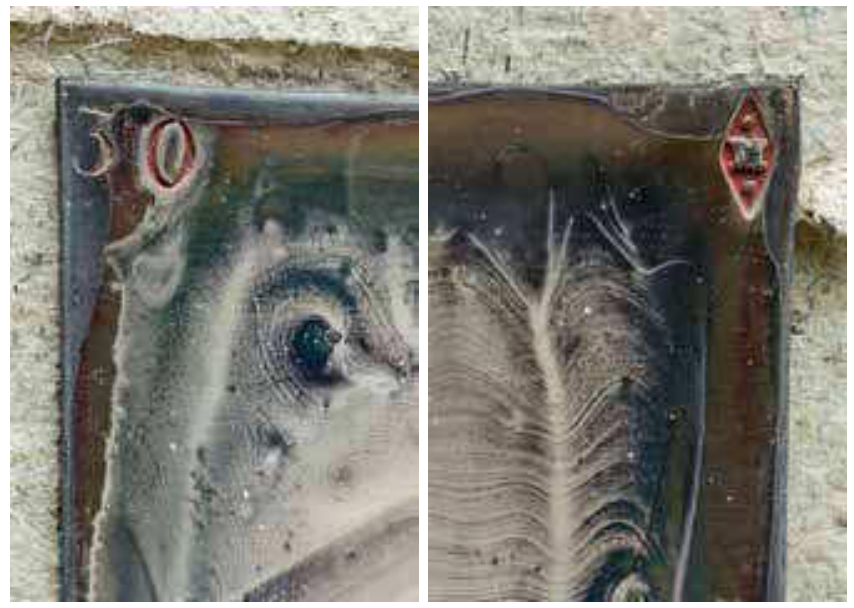

Figuras 7 y 8.- Detalle de las marcas de platero de la placa. Foto: José Luis Municio 
La marca que se puede apreciar en la esquina superior izquierda de la pieza desnuda [figura 9] muestra la relación de plata de la placa en el momento de su adquisición por el fotógrafo, una parte de plata por cada treinta de cobre. Se trata de una proporción generosa teniendo en cuenta que también era habitual la proporción de una parte por cuarenta, con el consiguiente abaratamiento del coste de la placa.

El color rojo presente en ambas marcas corresponde a los restos de pulimentador que, por el color, podría tratarse de óxido de hierro. No es muy corriente hallar marcas tan bien conservadas con restos que evidencian el proceso de pulido final.

\section{Conclusiones}

Este artículo recoge, en líneas generales, las características materiales del daguerrotipo para favorecer una aproximación a los valores específicos de la pieza. El objetivo principal ha sido la restauración del montaje y la consiguiente puesta en valor de la obra que ha estado durante veinte años relegada en las instalaciones del IPCE pero, además, se ha querido abordar con mayor profundidad el conocimiento material de estos objetos fotográficos para facilitar la comprensión del valor tecnológico y material de la fotografía, más allá de su reconocido e inestimable valor documental.

El privilegiado acercamiento a la pieza durante el proceso de restauración ha contribuido a trazar nuevas líneas de estudio muy estimables y reveladoras. Una de ellas, llevada a cabo por Carlos Teixidor, conservador de la Fototeca del Instituto del Patrimonio Cultural de España, ha permitido atribuir el retrato al ya mencionado daguerrotipista Manuel Herrero, lo que sitúa a esta pieza como la más antigua que se conserva de este reconocido autor.

\section{Notas}

[1] Como veremos más adelante, hay que considerar también la imagen de plata metálica sin mercurio, aspecto que no incluimos aquí para evitar confusión.

[2] Ya que no hemos encontrado datos que especifiquen claramente el proceso de plateado químico, recogemos los dos posibles sistemas que se podían realizar en la primera mitad del siglo XIX.

[3] Pese a que estos ejemplos nos dan una idea de las disoluciones que podrían usarse, las disoluciones del baño de plata pueden ser variadas y de cierta complejidad.

[4] La composición del electrolito podía ser similar a la descrita anteriormente, en el caso del plateado por baño.

[5] La producción de placas con este procedimiento en las ciudades inglesas de Birmingham y Sheffield es muy prestigiosa en Europa y América, hecho que provoca que las placas para daguerrotipos producidas con esta técnica se denominen de forma genérica Sheffield plates.

[6] Existen otros procesos pero no se contemplan en este trabajo por ser minoritarios y apenas representativos dada su escasa producción.

[7] También se usaba esencia de trementina, aceite de oliva o agua de lavanda entre otros.

[8] Susan Barger en su artículo Technological Practice of Daguerreotype afirma que la mayoría de tratamientos con halógenos en estado de vapor no se conocían en 1840 ya que, pese a que la fotosensibilidad de los compuestos de plata se conocía con mucha anterioridad, los halógenos habían sido descubiertos hacía relativamente poco. Niépce usó yodo en combinación con plata porque para entonces se sabía que a la luz formaba un compuesto oscuro, pero lo usó junto con betún de Judea. Daguerre eliminó el uso del betún. (Barger y White, 1991:31) El cloro recibió su nombre y se incluyó como elemento de la tabla periódica en 1811 . El bromo en 1826.

[9] La exposición a vapores de mercurio no siempre tiene esta consideración de revelado, pero nos parece apropiada ya que 'revela' la imagen latente no perceptible.

[10] También tiene inversión en sentido vertical, pero girando la placa se corrige.

[11] Como resina dammar, cera, copal, con las que llegan a eliminar la imagen.

[12] Susan Barger menciona además un proceso de dorado por electrólisis, pero su escaso uso y la aparición del sistema Fizeau provocan su temprana desaparición, sin apenas relevancia.

[13] Alexandre-Edmond Becquerel (1820 - 1891 ) fue un físico francés que desarrolló importantes estudios sobre el espectro solar, magnetismo, electricidad y óptica.

[14] Según Bertrand Lavedrine aun no se había extendido el uso de tiosulfato sódico.

[15] La espectrometría por fluorescencia de rayos $X$ podría determinar los componentes exactos del daguerrotipo y la proporción de cada elemento.

[16] Las dos patentes que recogen ambos sistemas mencionados son la de Daniel Davis y Warren Thompsons.

[17] Este tipo de vidrio se fabrica mediante la sustitución de grandes cantidades de álcali $y$, con frecuencia, de toda la cal, con $\mathrm{B}_{2} \mathrm{O}_{3}$ que reacciona también con el $\mathrm{SiO}_{2}$, casi de la misma forma que el sodio y la cal. El uso de $\mathrm{B}_{2} \mathrm{O}_{3}$ reduce el coeficiente de dilatación, por lo que la resistencia de estos vidrios a los choques térmicos es muy superior a la de los sodocálcicos. 
Además, la reducción de la cantidad de alcalinos presente reduce su reactividad. La pieza, adquirida a la empresa Vidrasa, cuenta con un $81 \%$ de sílice en composición.

[18] Ver estudios de Floyd y Marion Rinehart así como los más recientes de Gabriele Chiesa y Paolo Gosio.

\section{Bibliografía}

BAJAC, Q. (2011) La invención de la fotografía. La imagen revelada. Barcelona: Blume.

BARCELLA, C. (2009) Conservation Project of the Manila daguerreotypes en: http://notesonphotographs.org/ index.php?title=Barcella,_Caroline._\%22Conservation Project_of_the_Manila_Daguerreotypes.\%22 [consulta: 12/8/2015].

BARGER, S.; WHITE, W. B. (1991) The Daguerreotype: NineteenthCentury Technology and Modern Science. Washington: Smithsonian Institution Press.

CHIESA, G.; GOSIO, P. (2012) Dagherrotipia, ambrotipia, ferrotipia. Positivi, unici e processi antichi nel ritratto fotografico. Youcanprint.
DAGUERRE, L.J.M. (1839) Historia y descripción del los procederes del daguerrotipo y diorama, Barcelona: Francisco Piferrer.

GALLEGO PANIAGUA, A. (1851) Secretos del Daguerrotipo al alcance de todos. Madrid.

LAVÉDRINE, B. (2010) Reconocer y conservar las fotografías antiguas. París: CTHS.

LEÓN, E. (1846) El daguerrotipo. Manual para aprender por sí solo. Madrid.

MURATA, H. (2003) Investigation of historical and modern conservation daguerreotype housing. Nueva York. Proyecto desarrollado en George Eastman House, Rochester.

NEWHALL, B. (1961) The daguerreotype in America. Nueva York: Dover Publications.

PFANHAUSER, W. (1926) Tratado de Galvanotecnia. Barcelona: Gustavo Gili.

RINEHART, F. Y M. (1981) The American daguerreotype. Athens, Ga.: University of Georgia Press

SOUGEZ, M. L. (2001) Historia de la Fotografía. Madrid: Cátedra.

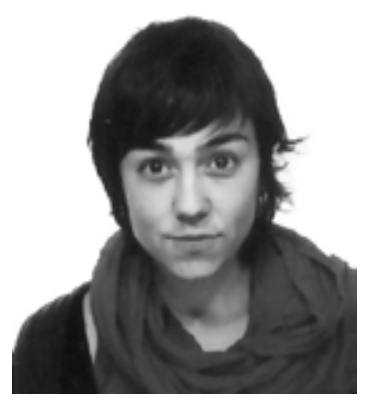

\section{Raquel Esteban Vega}

raquelestebanvega@gmail.com

Conservadora-restauradora de fotografía y obra gráfica graduada por la Escuela Superior de Conservación-Restauración de Bienes Culturales de Madrid en la especialidad de Documento Gráfico y Técnico Superior en Fotografía por el Stevenson College de Edimburgo. Trabaja actualmente en la elaboración del censo de patrimonio fotográfico de Castilla y León desarrollando paralelamente proyectos de investigación sobre fotografía y conservación. Con anterioridad y durante cinco años ha llevado a cabo trabajos de preservación y documentación de colecciones y fondos fotográficos en el Archivo del Territorio Histórico de Álava, así como varios proyectos de conservación preventiva, comisariado y restauración.

\section{Artículo enviado el 22/01/2016 \\ Artículo aceptado el 04/11/2016}




\title{
Ensayos de consolidación en los revestimientos murales del Conjunto Arqueológico de Castulo (Linares, Jaén)
}

\author{
Ana Isabel Calero-Castillo, Teresa López-Martínez, Ana García-Bueno, María Teresa González-Muñoz, \\ Victor J. Medina-Flórez
}

\begin{abstract}
Resumen: Los revestimientos murales de origen arqueológico presentan una problemática de conservación e intervención muy compleja, en los que la elección del consolidante a emplear ocupa un papel fundamental. Este trabajo pretende mostrar los ensayos de distintos tratamientos de consolidación que se han efectuado sobre fragmentos de pintura mural y de cornisa de cronología romana, procedentes del Conjunto Arqueológico de Castulo. El trabajo ha permitido desarrollar un análisis comparativo entre los distintos tratamientos basándonos, entre otros, en el estudio de micromuestras mediante microscopía electrónica de barrido de alta resolución (HRSEM), permitiendo comprobar las ventajas e inconvenientes del uso de cada uno de ellos.
\end{abstract}

Palabras clave: consolidación, revestimientos murales arqueológicos, Paraloid ${ }^{\circledR}$ B-72, silicato de etilo, carbonatogénesis bacteriana, HRSEM

\section{Consolidations test in the decorative surfaces of the archaeological site of Castulo (Linares, Jaén)}

Abstract: The architectural decorations of archaelogical origin pose a challenge for the conservation and intervention of restauration, in which the choise of the consolidant product plays a key role. This work aims to compare different treatments of consolidation that have been tested on fragments of wall painting and ledge roman from the archaelogical site of Castulo (Spain). This comparative analysis of the different treatments based on, among other techniques, the study of microsamples by scanning electron microscopy of high resolution (HRSEM) allowed to stand out the advantages and disadvantages of using each consolidant product.

Keyword: consolidation, archaeological decorative surfaces, Paraloid B-72, ethyl silicate, biomineralization, HRSEM.

\section{Ensaios de consolidação dos revestimentos murais do Conjunto Arqueológico de Castulo (Linares, Jaén )}

Resumo: Os revestimentos murais de origem arqueológica apresentam uma problemática de conservação e de intervenção muito complexa, onde a escolha do produto solidificador a usar ocupa um papel fundamental. Este trabalho pretende mostrar os ensaios de diferentes tratamentos de consolidação efectuados em fragmentos de pintura mural e de parapeitos romanos procedentes do Conjunto Arqueológico de Castulo. Este trabalho permitiu desenvolver uma análise comparativa entre os diferentes tratamentos, baseando-nos,entre outros, no estudo de micro amostras através da microscopia eletrónica de alta resolução (HRSEM), permitindo comprovar as vantagens e desvantagens da utilização de cada um destes tratamentos.

Palavras-chave: Consolidação, revestimentos de murais arqueológicos, Paraloid ${ }^{\circledR}$ B-72, silicato de etilo, biomineralização, HRSEM 


\section{Introducción}

La problemática de conservación e intervención del material arqueológico radica, principalmente, en dos aspectos.

En primer lugar, extraer la obra a la superficie supone la ruptura del equilibrio establecido entre ésta y el ambiente que la rodea. En el momento de la excavación, habitualmente la obra pasa de estar en unas condiciones de humedad y temperatura que se han mantenido estables durante cientos de años, a ser expuesta a unos valores completamente distintos, pudiendo desencadenar una serie de alteraciones que, unidas a las que ya presentaba antes de su descubrimiento, en ocasiones dificultan su legibilidad y comprensión.

En segundo lugar, la obra de procedencia arqueológica presenta otro problema derivado de las intervenciones que, a menudo, hay que llevar a cabo en el propio yacimiento. En estos casos, tanto las condiciones como los recursos de los que se disponen suelen ser limitados, ocasionando que no sean del todo adecuados e interfiriendo en su posterior intervención, ya sea in situ o en el taller de restauración. Todo ello no supone que no haya que hacerlos, al contrario, puesto que de ellos depende en gran medida la conservación de la obra y su posible manipulación, pero sí la preocupación por elegir el tratamiento más adecuado y compatible, tanto con la obra original como con futuros tratamientos.

En este aspecto, uno de los procedimientos que más inconvenientes presenta, tanto en las intervenciones de urgencia como en los tratamientos definitivos, es la consolidación. Los tratamientos empleados habitualmente generan considerables problemas que se deberían evitar en todo momento, sobre todo por la pérdida de permeabilidad de la capa polícroma, por el cambio que ocasionan en su apariencia y propiedades ópticas, variando parámetros como el brillo, el color, la opacidad o la textura de la capa pictórica, así como por su irreversibilidad con el paso del tiempo (AA.VV. 2003: 19). Todas estas cuestiones exigen tener en cuenta numerosos factores, no solo la elección del consolidante, sino también su método de aplicación e, incluso, las características del disolvente empleado. Del mismo modo, es imprescindible que cumpla uno de los requisitos indispensables para que un material pueda ser utilizado en restauración, su reversibilidad y la compatibilidad con otros posibles tratamientos de restauración como la limpieza, que posteriormente en la mayor parte de los casos deben llevarse a cabo en el taller de restauración.

Resulta por ello primordial la realización de este tipo de estudios, donde analizar con detenimiento las propiedades y el efecto de estos materiales sobre la obra. Además hay que señalar que uno de los problemas fundamentales al abordar este tipo de investigaciones es el gran número de productos de tratamiento que se comercializan para este tipo de superficies y sobre los que, en ciertos casos, hay una limitada experiencia en cuanto a los resultados que proporcionan sobre determinado tipo de obras. Teniendo en cuenta estas consideraciones, y después de hacer una revisión en profundidad de los posibles consolidantes a utilizar, para esta investigación se seleccionaron tres consolidantes entre los que se encuentran dos tratamientos que se han utilizado tradicionalmente para la intervención de este tipo de obras así como uno de nueva incorporación, menos estudiado. En el primer caso, se seleccionaron dos de los consolidantes más empleados en contextos arqueológicos (ya sea para tratar los revestimientos antes de su extracción, para su conservación in situ o en el museo) que son la resina acrílica de metacrilato-etilmetacrilato, más conocido como Paraloid ${ }^{\circledR}$ B72 y el silicato de etilo (Bioestel 1200-CTS) (Moreno Cifuentes 1998:66; Renzo dal Monte 1998:113). Por otra parte se ha seleccionado el tratamiento de bioconsolidación por carbonatogénesis bacteriana, un tratamiento de reciente incorporación cuya investigación se ha centrado básicamente en su empleo sobre piedra, pero sobre el que en los últimos años se está investigando para este tipo de revestimientos con acabados polícromos (Jroundi et al. 2014: 3844-3854).

De manera que, en este caso concreto se pretende, a partir del análisis comparativo de los distintos tratamientos aplicados sobre fragmentos de pintura mural y de cornisa procedentes de la Sala del Mosaico de los Amores del Conjunto Arqueológico de Castulo [figura 1], establecer las ventajas e inconvenientes del empleo de cada uno de ellos, estudiando en cada caso los cambios que se producen en la morfología original de la obra y la distribución del consolidante, valorando la respuesta del mismo tratamiento sobre dos materiales similares pero ejecutados siguiendo técnicas distintas ya que, si bien tanto la pintura mural como la cornisa están compuestas por morteros de cal, mientras que la primera de ellas se presenta espatulada y conserva la capa pictórica en su totalidad, en el caso de la cornisa, el mortero resulta mucho más poroso y solo conserva restos puntuales de policromía.

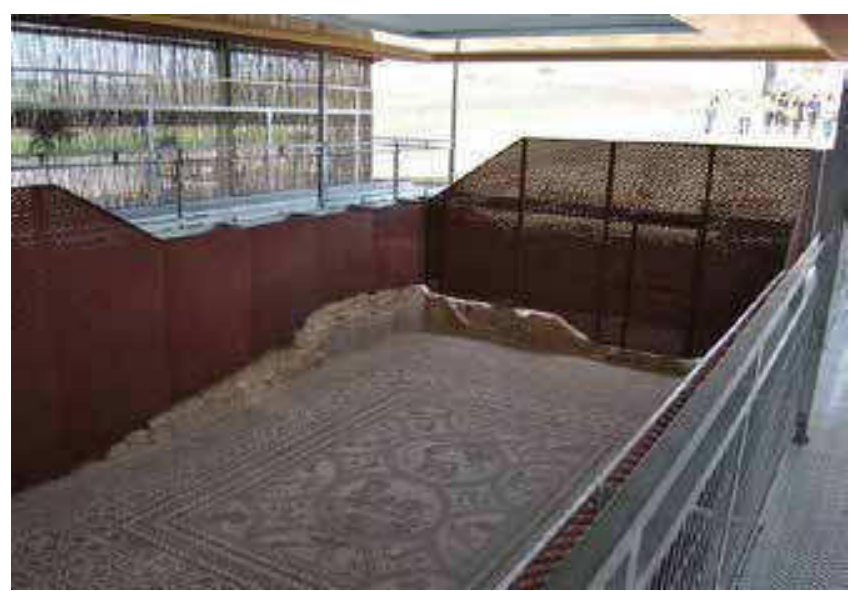

Figura 1.- Sala del Mosaico de los Amores del Conjunto Arqueológico de Castulo. 


\section{Objetivos}

El objetivo principal de esta investigación se centra en uno de los aspectos fundamentales a evaluar en los tratamientos de consolidación: valorar la compatibilidad entre los consolidantes y los materiales constitutivos de la obra. El concepto de compatibilidad se refiere a que el consolidante tenga una naturaleza y propiedades similares al material original de modo que no cambie sustancialmente las características de éste $y$, por tanto, actúe como un solo material, no dando lugar a tensiones internas ni a una velocidad de degradación diferente. En este último sentido no es necesario que sean iguales que el material original, pero deben resistir las modificaciones del sustrato y del ambiente. Además se debe tener en cuenta uno de los principios fundamentales de Cesare Brandi con el que se acepta que la intervención realizada no será, seguramente, la última, por lo que debe permitir tratamientos posteriores (López Ortega 1999). No hay que olvidar que cualquier material que se introduzca en la obra va a modificar su relación con el ambiente, de manera que su comportamiento en el futuro puede verse afectado. Cuando se interviene un revestimiento de estas características el objetivo es conseguir su conservación y que su comportamiento mejore, es decir, que disminuya su alterabilidad.

Teniendo en cuenta estas consideraciones, y la ya expuesta problemática de conservación e intervención que presentan los revestimientos arqueológicos, sobre todo en cuanto a tratamientos de consolidación se refiere, con este estudio se han perseguido fundamentalmente los siguientes objetivos:

- Realizar una revisión de los posibles tratamientos de consolidación a emplear en revestimientos murales de procedencia arqueológica y seleccionar aquellos que puedan considerarse más adecuados y compatibles.

- Hacer pruebas sobre fragmentos descontextualizados para analizar la penetración de cada tratamiento y el cambio que produce en la morfología original de la obra.

- Valorar la respuesta que ofrece cada tratamiento en función de la técnica de ejecución que presenta el revestimiento mural, manteniendo el mismo material.

- Desarrollar nuevas líneas de investigación encaminadas a la puesta a punto de nuevos materiales y procedimientos de restauración aplicables a obras de tipología similar.

\section{Metodología}

En un trabajo de este tipo resulta imprescindible la aplicación de una metodología rigurosa, de forma que se puedan establecer conclusiones seguras y fiables. En este caso, se ha buscado que el material sobre el que se ensayasen los distintos métodos de consolidación se asemejasen al máximo a las características originales, de manera que se pudiera comprobar la respuesta específica del tratamiento sobre la obra original. Es por ello que las pruebas se han realizado sobre pequeños fragmentos descontextualizados pertenecientes a los revestimientos murales de la Sala del Mosaico de los Amores, en el Conjunto Arqueológico de Castulo, concretamente proceden de los paneles intermedios de la composición de la decoración parietal y de la zona superior, correspondiente a una cornisa decorada con motivos vegetales. Para ello se ha seguido la siguiente metodología:

\section{-Elección de los fragmentos:}

Escoger fragmentos tanto de pintura mural como de cornisa permite estudiar el comportamiento de cada tratamiento sobre revestimientos que, presentando los mismos materiales constitutivos, difieren en la técnica de ejecución. Por un lado, la pintura mural está ejecutada al fresco sobre mortero de cal y siguiendo la técnica de las politiones, es decir, el pulido de la superficie por el que se facilita la salida del agua y el hidróxido cálcico que queda en el interior del mortero favoreciendo nuevas carbonataciones en la superficie y compactando en gran medida el mortero (Mora et al. 2002: 115-118). Los fragmentos escogidos son todos de color rojo, ya que éste es el color que se presenta en mayor proporción en la decoración de la estancia, además de ser el que mayores problemas de conservación posee, mostrándose muy pulverulento. Por otro lado, en la cornisa que está realizada con un mortero de cal con otros materiales en pequeña proporción, se percibe una base mucho más porosa. En este caso la policromía que conserva es muy escasa, también de color rojo y, en algunas zonas, amarillo.

En ambos casos se ha tomado la precaución de emplear fragmentos hallados en las cribas de tierra de forma que no hubiesen recibido ningún tratamiento previo en el momento de la extracción de los fragmentos, y fuese posible el análisis de cada consolidante sobre el material original, sin ningún tipo de interferencia [figura 2].

Los fragmentos seleccionados se trasladaron a uno de los laboratorios del Centro de Restauración de la Universidad de Granada donde se llevó a cabo la aplicación de los diferentes tratamientos.

\section{—Elección de los tratamientos consolidantes:}

Como ya se ha señalado, dentro de las intervenciones que se realizan en las excavaciones, la consolidación es una de las que más complejidad plantea, ya que debe de adecuarse a la problemática de su aplicación in situ, además de permitir la posterior intervención de la obra (limpiezas, consolidaciones posteriores). Como se ha expuesto en 


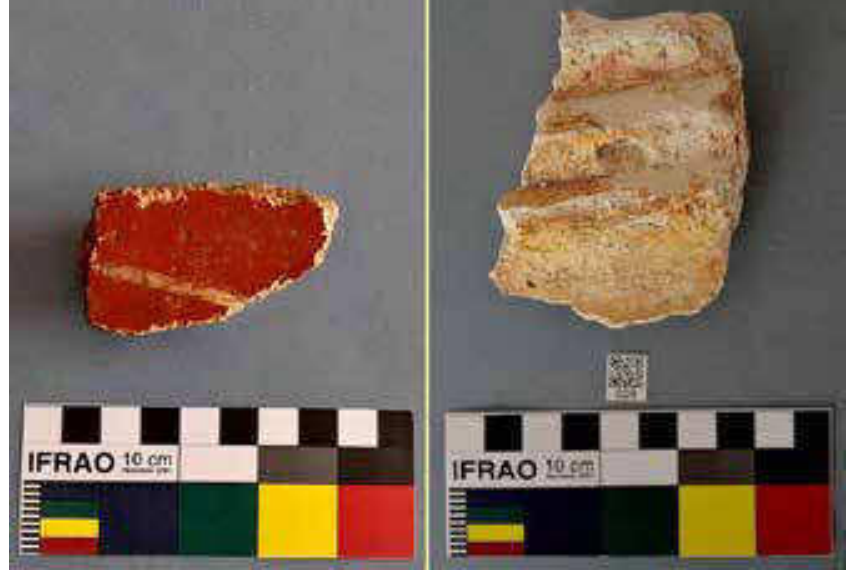

Figura 2.- Fragmento de pintura mural y de cornisa empleados para el estudio.

la introducción, se decidió escoger para estos ensayos dos de los tratamientos más empleados en arqueología, como son el Paraloid ${ }^{\circledR}$ B-72 y el Bioestel 1200. El Paraloid ${ }^{\oplus}$ B-72, es el consolidante orgánico más empleado en el campo de la restauración y está constituido por una resina acrílica al $100 \%$ cuya composición está formada por un copolímero de metilacrilato y etilmetacrilato. En el segundo caso, el Bioestel 1200 es un éster de silicio, cuya acción se basa en la precipitación de la sílice en el interior de los poros que incorpora además en este caso una "acción protectora de la degradación producida por la contaminación y el desarrollo de organismos vegetales biodeteriorantes" (Dal Monte 1998:113).

De forma general, la ventaja de la resina acrílica radica en su reversibilidad, aunque puede crear una barrera impermeable sobre la capa pictórica que, en ese caso, ocasionaría graves problemas; por otra parte, el cambio que ocasiona en la porosidad del material dificulta los procesos de secado del muro, pudiendo generar problemas de cristalización de sales. Por el contrario, la ventaja del silicato de etilo reside en la afinidad de su composición con los materiales constitutivos de la obra, aunque por el contrario, su reversibilidad es peor.

Dado que ambos materiales, en ocasiones, plantean problemas, el primero por crear una capa prácticamente impermeable y el segundo por su irreversibilidad, se optó por seleccionar un material experimental que hasta el momento ha demostrado resultados bastante satisfactorios en la consolidación de material pétreo, la carbonatogénesis bacteriana, y que a priori presenta ventajas como respetar la permeabilidad de los materiales sobre los que se aplica y no interferir en tratamientos posteriores (González-Muñoz et al. 2015; Jroundi et al. 2011). Su acción se basa fundamentalmente en la formación de minerales mediante un proceso biológico a partir de la aplicación de una solución nutritiva adecuada que activa las bacterias carbonatogénicas presentes en los revestimientos, induciendo a la precipitación de carbonato cálcico natural como consecuencia de su metabolismo, lo que produce la consolidación del substrato. Esto es debido al hecho de que la producción de carbonato cálcico por bacterias es un fenómeno bastante extendido (Boquet et al. 1974) y de que se ha encontrado que práctimante el $95 \%$ de las bacterias presentes en el patrimonio pétreo son carbonatogénicas (Jroundi et al. 2010; Rodríguez-Navarro et al., 2015:89-92); igualmente, su actividad se ha detectado en revocos de yeso (Jroundi et al. 2014), comprobándose la eficacia de este tratamiento en estudios anteriores sobre yesos de procedencia arqueológica (Jroundi et al. 2014; Jroundi et al. 2011) en los que se ha puesto de manifiesto "una adecuada activación de las bacterias carbonatogénicas y consiguientemente, un notable grado de consolidación" (González-Muñoz et al. 2015:97). Sin embargo, ya que los ensayos que hasta el momento se han realizado son sobre material pétreo o morteros de yeso con escasísimos restos de policromía, en este trabajo se pretende valorar el nivel de consolidación real que presenta sobre capas pictóricas.

En lo que respecta a los materiales utilizados mientras que los dos primeros fueron adquiridos de la casa comercial CTS, la solución nutritiva M3-P necesaria para la aplicación del tratamiento de la carbonatogénesis bacteriana nos fue facilitada por el Departamento de Microbiología de la Facultad de Ciencias de la Universidad de Granada, responsables de la patente de este producto (GonzálezMuñoz et al. 2008) que se encuentra comercializado por la compañía global biotecnológica KBYO Biological SL.

\section{- Aplicación de los tratamientos:}

Todos los fragmentos, tanto los de pintura mural como los de cornisa, han sido tratados en una primera fase de la misma manera: tras una documentación fotográfica del estado inicial, se ha realizado una limpieza mecánica eliminando restos de depósitos terrosos y concreciones y se ha procedido a la aplicación de los diferentes tratamientos de consolidación.

En el caso del silicato de etilo y de la resina acrílica, se ha seguido la misma metodología variando sólo su concentración; el primero de ellos se ha aplicado sin diluir mientras que la consolidación con Paraloid ${ }^{\circledR}$ B-72 se ha realizado en disolución al $5 \%$. Para ello, en vez de utilizar un disolvente orgánico como el tolueno o el disolvente nitrocelulósico, se ha realizado una mezcla de tres disolventes menos tóxicos bajo una fórmula ideada por los profesores del ISCR (Istituto Superiore per la Conservazione ed il Restauro) de Roma, Maurizio Coladonato y Fabio Talarico; en concreto, se ha empleado Taco 8, disolvente de volatilidad media compuesto por alcohol isopropílico, octano y acetona, a una concentración del $45 \%, 32 \%$ y $23 \%$ respectivamente. Además de la menor toxicidad, esta mezcla de disolventes tiene una velocidad de evaporación menor, lo que impide, en gran medida, que se cree una película superficial. 
En ambos casos, la aplicación del tratamiento se ha llevado a cabo mediante pincel de pelo suave, protegiendo la capa pictórica con papel japonés y se ha repetido el proceso una vez al día durante tres días consecutivos. Por el contrario, el tratamiento con carbonatogénesis bacteriana exige una metodología diversa que ha consistido en la aplicación mediante nebulización de la solución nutritiva acuosa M-3P sobre la superficie pictórica hasta saturación, realizando tres aplicaciones al día durante seis días consecutivos desde, aproximadamente, $20 \mathrm{~cm}$ de distancia, según la técnica descrita por Jroundi et al. (2014). En los tres casos se estableció un tiempo de curado de tres meses.

\section{-Métodos de análisis:}

Una vez realizados los tratamientos se han valorado sus resultados con métodos objetivos, estudiando tanto los cambios estructurales producidos en la materia, como los cambios estéticos de la capa pictórica. Para ello se ha realizado un análisis visual de la superficie, pruebas de solubilidad en el caso de los fragmentos de pintura mural y un análisis textural y elemental mediante microscopía electrónica de barrido de alta resolución (HRSEM).

Cabe señalar que previamente a estos ensayos se analizaron diversas muestras con el fin de caracterizar los materiales constitutivos de los revestimientos murales (López Martínez et al. 2016). Gracias a las diversas técnicas empleadas (microscopía estereoscópica, microscopía petrográfica, microscopía electrónica de barrido con EDX, difracción de rayos $\mathrm{X}$, cromatografía de gases y espectroscopía infrarroja por transformada de Fourier) ha sido posible reconocer, en el caso de la pintura mural, cuatro estratos de mortero de cal y árido a base de cuarzo, feldespato potásico y plagioclasas, en una proporción del $75 \%$ de árido en el estrato más superficial, y una capa pictórica constituida por hematites y minio [figura 3]. En el caso de la cornisa, se ha identificado un mortero de cal con porcentajes minoritarios de sulfato de calcio y de silicio y, en casos puntuales correspondientes a las zonas policromadas, hierro.

Para el análisis de los ensayos de consolidación, se han tomado, en primer lugar, micromuestras de todos los fragmentos y se han analizado mediante microscopio estereoscópico; se ha utilizado un microscopio Nikon SMZ 1000 del que se obtuvieron microfotografías tanto de la superficie como del corte estratigráfico gracias a la cámara que lleva incorporada el dispositivo (DS-U3 Digital Camera). Para ello, las micromuestras se prepararon dividiendo cada una de ellas en dos mitades y colocando ambos fragmentos en un mismo soporte, uno en posición horizontal y otro en posición vertical, de forma que se pudiese analizar tanto la capa pictórica como el perfil del corte [figura 4]; en todo momento las muestras se han manipulado con pinzas buscando la sección sobre la cual se obtiene mayor información. La realización de las microfotografías antes de ser metalizadas las muestras

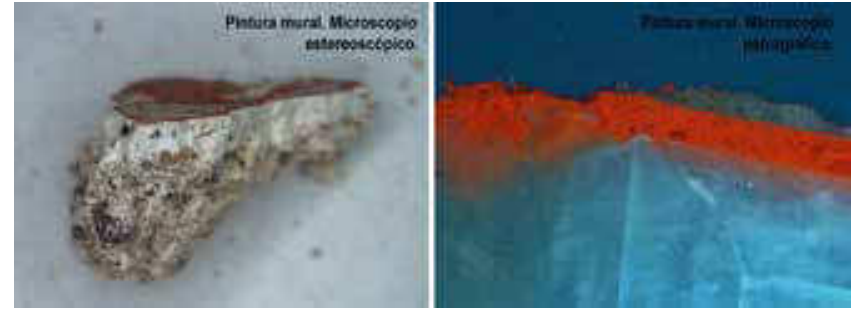

Figura 3.- Muestras estudiadas mediante microscopio estereoscópico y microscopio petrográfico.

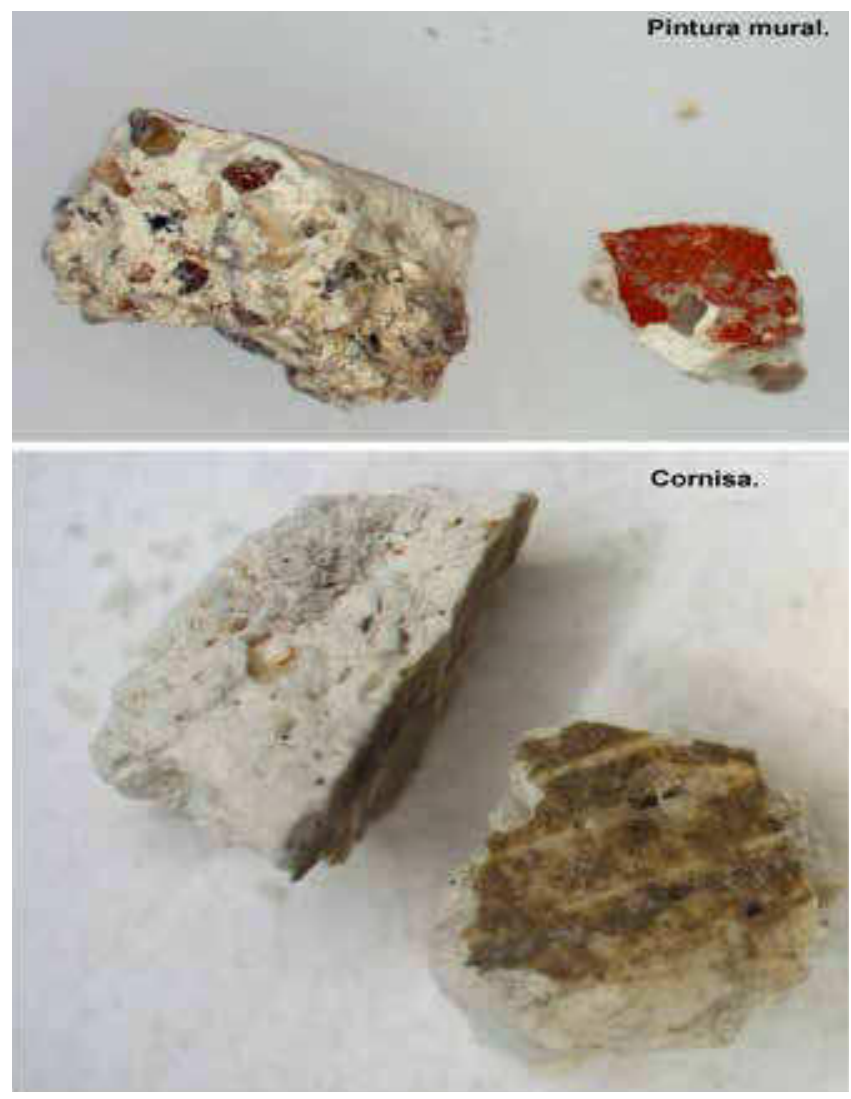

Figura 4.- Esta figura es identificativa de la metodología de estudio tanto de pintura mural como de cornisa. En ambos casos, como se especifica en el texto se seleccionó un fragmento para el estudio del perfil y otro para el estudio de la superficie como puede comprobarse en esta figura.

con carbono supone una gran ventaja ya que permite referenciar las características estéticas de cada muestra $y$, en caso de querer obtener información sobre algún aspecto en concreto o realizar alguna aclaración, poder recurrir a las imágenes. Con esta observación se ha podido examinar la estratigrafía, restos de policromía, morfología del mortero y cambios de apariencia entre los diferentes fragmentos tratados.

Tras el análisis con microscopio estereoscópico se han metalizado las muestras y se ha procedido a su estudio mediante microscopía electrónica de barrido de presión variable de alta resolución (HRSEM), para lo que se ha empleado un microscopio electrónico de barrido de presión variable de alta resolución Zeiss SUPRA 40VP 
equipado con sistema de microanálisis por Energía dispersiva de Rayos X (EDX) con detector de gran superficie X-Max 50mm. El objetivo fundamental de este método ha sido obtener datos precisos de la distribución de los consolidantes sobre las muestras tratadas, tanto en superficie como en profundidad, detectar diferencias entre las muestras consolidadas y sin consolidar (porosidad, cambios de composición, sistema de cristalización, grado de penetración del consolidante...), así como posibles alteraciones o particularidades de los tratamientos tales como la morfología de la película que forman y sus características. Para ello, se ha establecido una metodología de estudio que se ha seguido en todas las muestras analizadas. Esta sistemática ha consistido en la obtención de imágenes de diferentes resoluciones de la superficie de las muestras estudiadas (100x, 500x, 1500x, 5000x, 15000x), mapas de distribución de elementos de la superficie (bajo las siguientes condiciones: mapa de 510 pixeles, binning factor, imagen con resolución de 1024 pixeles, 34 frames, $20 \mathrm{kw}, 100$ microsegundos, 13,6 duel time) así como un análisis elemental de la distribución del consolidante en el perfil (line profile) que ha sido determinante para observar la penetración de los tratamientos y su composición.

Finalmente, las pruebas de solubilidad realizadas en los fragmentos de pintura mural se han llevado a cabo mediante la doble rotación de un hisopo impregnado de agua destilada sobre la capa pictórica.

\section{Resultados}

En primer lugar, el examen a visu no ha mostrado cambios evidentes entre la superficie sin tratar y la superficie una vez tratada. Tanto en el caso de los fragmentos de pintura mural como en los fragmentos de cornisa, el color de la policromía no se ha visto modificado con ningún tratamiento ni tampoco se aprecian cambios estructurales significativos en la superficie de los fragmentos.
En el caso de las pruebas de solubilidad realizadas a los fragmentos de pintura mural se ha comprobado que, mientras que antes de los tratamientos de consolidación la capa pictórica se mostraba pulverulenta y se dispersaba al menor contacto con el agua, tras la aplicación de los tratamientos la capa se muestra más cohesionada, no manchando de color el hisopo impregnado de agua destilada cuando éste se rotaba sobre la superficie.

Por el contrario, el análisis con HRSEM ha puesto en evidencia las diferencias entre los tratamientos que en el examen $a$ visu eran imposibles de apreciar. En lo que respecta al comportamiento de los tratamientos en ambos revestimientos (pintura mural y cornisa) los resultados han sido fundamentalmente los mismos con pequeñas diferencias que se detallarán en la exposición de los resultados.

En primer lugar se ha estudiado una muestra sin tratar tanto de pintura mural como de cornisa, de forma que sirviese de testigo comparativo para analizar las modificaciones que se pudieran producir tras la aplicación de los diversos consolidantes. En lo que respecta a la morfología del mortero, la observación realizada mediante HRSEM ha permitido constatar que la diferencia de ejecución entre ambos revestimientos ha dado lugar a cambios en el aspecto textural de ambos. Mientras que en los fragmentos de pintura mural observamos un mortero compacto, consecuencia del espatulado, en el caso de los fragmentos de cornisa se percibe un mortero mucho más poroso, lo que se debe tanto a la técnica de ejecución (molde o terraja de madera) como a la posible adición de material orgánico en la formulación del mortero (aunque no se haya podido detectar en los análisis) para aligerar el peso de estos revestimientos que se encontraban en la parte superior de los muros tal y como era habitual en la realización de este tipo de decoraciones (Guiral Pelegrin y Martín-Bueno 1996) [figura 5].

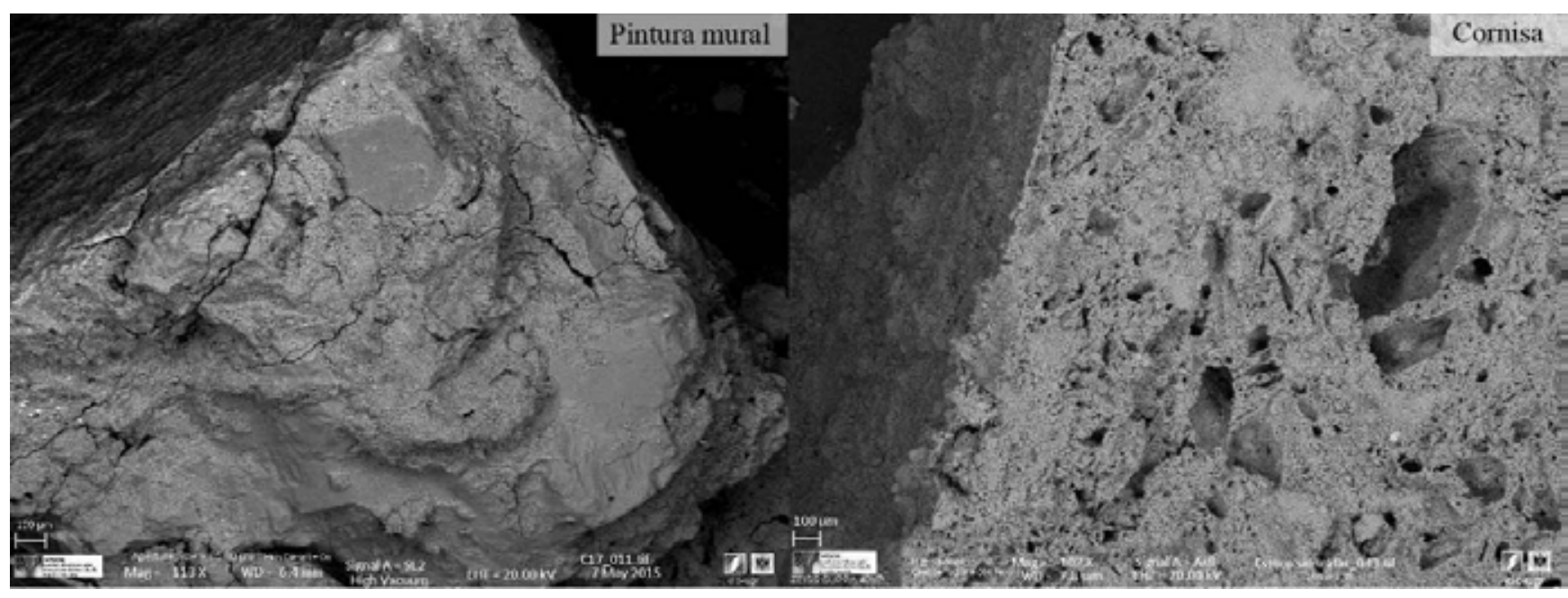

Figura 5.-Diferencias entre las texturas del mortero procedente de pintura mural y el de cornisa. Imagen obtenida mediante HRSEM. 
En lo que respecta a los resultados obtenidos en el análisis de los fragmentos tratados, la mayor información se ha conseguido a partir del estudio de la morfología de la muestra. En el caso de los tratamientos con resina acrílica y silicato de etilo, los datos obtenidos del análisis del line profile han corroborado la información recopilada al observar las imágenes; sin embargo, el tratamiento con carbonatogénesis bacteriana, dado que consolida con el mismo material que constituye el mortero, sólo se ha podido comprobar mediante el examen morfológico de la superficie, ya que resultaba imposible diferenciar el carbonato cálcico de nueva formación respecto al material constitutivo tanto de la superficie como del perfil, no dando resultados concluyentes.

El estudio de las muestras tratadas con silicato de etilo ha permitido observar con claridad tanto en el fragmento tratado de pintura mural como de cornisa, la existencia de una serie de grietas de similar morfología en la superficie [figura 6]. Se ha considerado que estas pequeñas fisuras pudieran deberse a la rigidez de la película que forma este tipo de consolidante en las que al evaporarse el disolvente hubiera provocado su fractura. Este tipo de alteración ya ha sido expuesta en otros trabajos de investigación sobre consolidantes como en el publicado por Jroundi et al. (2014) en el que se realizaron pruebas sobre fragmentos de yeso procedentes del Alcázar de Guadalajara. En lo que respecta a su penetración en el caso de la pintura mural se detecta material hasta aproximadamente $30 \mu \mathrm{m}$, mientras que en la cornisa éste llega hasta aproximadamente $100 \mu \mathrm{m}$, lo que se ha atribuido a su porosidad [figura 7]. Por otra parte, el mapa de distribución de elementos muestra un depósito homogéneo de silicio por toda la superficie tratada [figura 8].

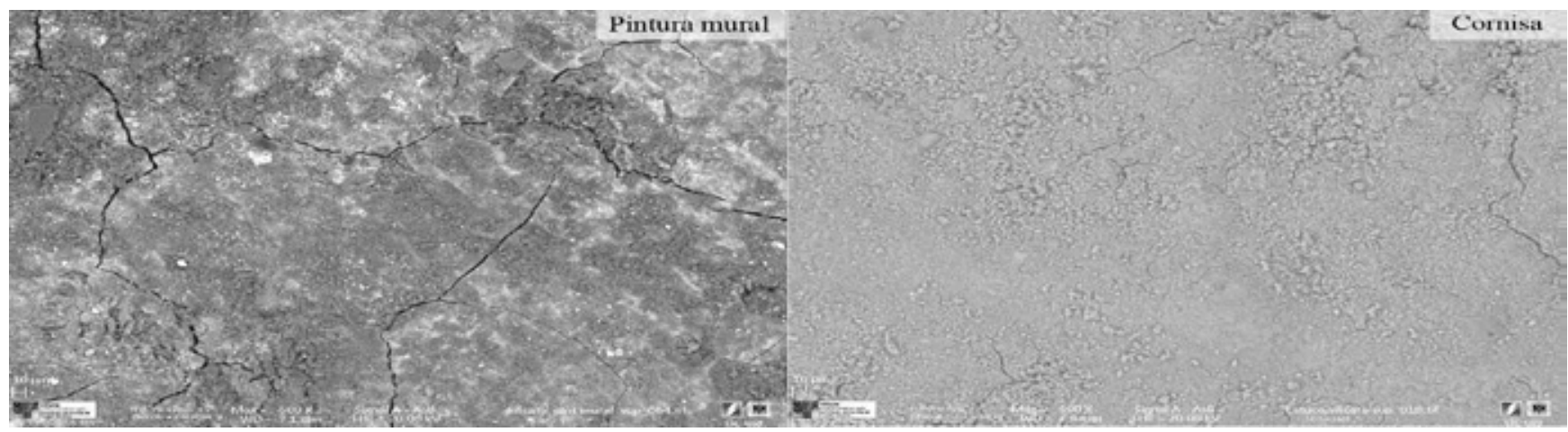

Figura 6.-Diferencias entre las texturas del mortero procedente de pintura mural y el de cornisa. Imagen obtenida mediante HRSEM.

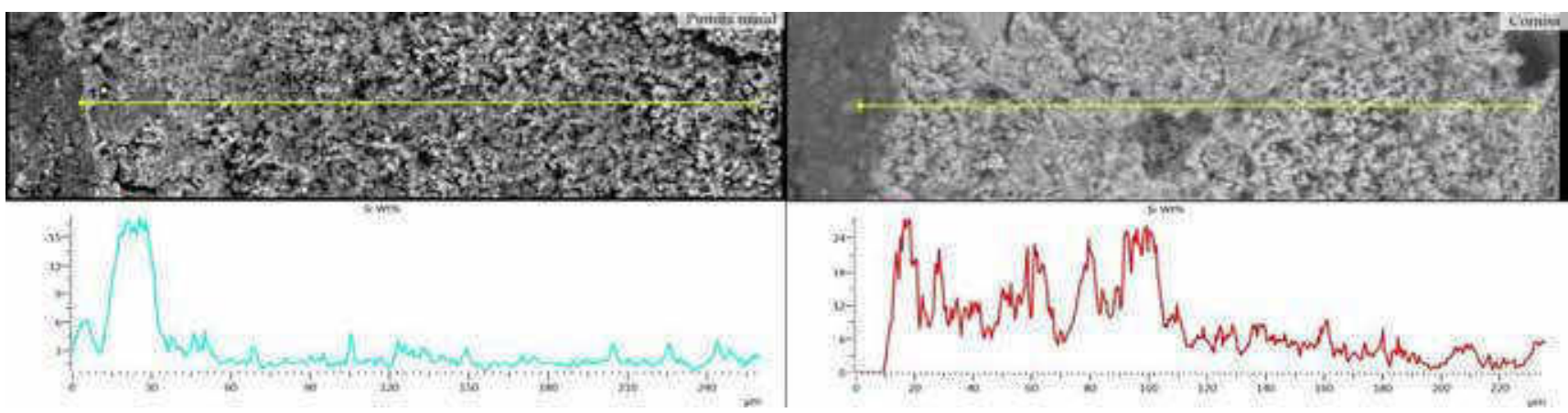

Figura 7-Grado de penetración de las muestras tratadas con silicato de etilo. Line profile del fragmento de pintura mural (izq.) y de la cornisa (derecha) en el que se muestra la cantidad de silicio identificado.

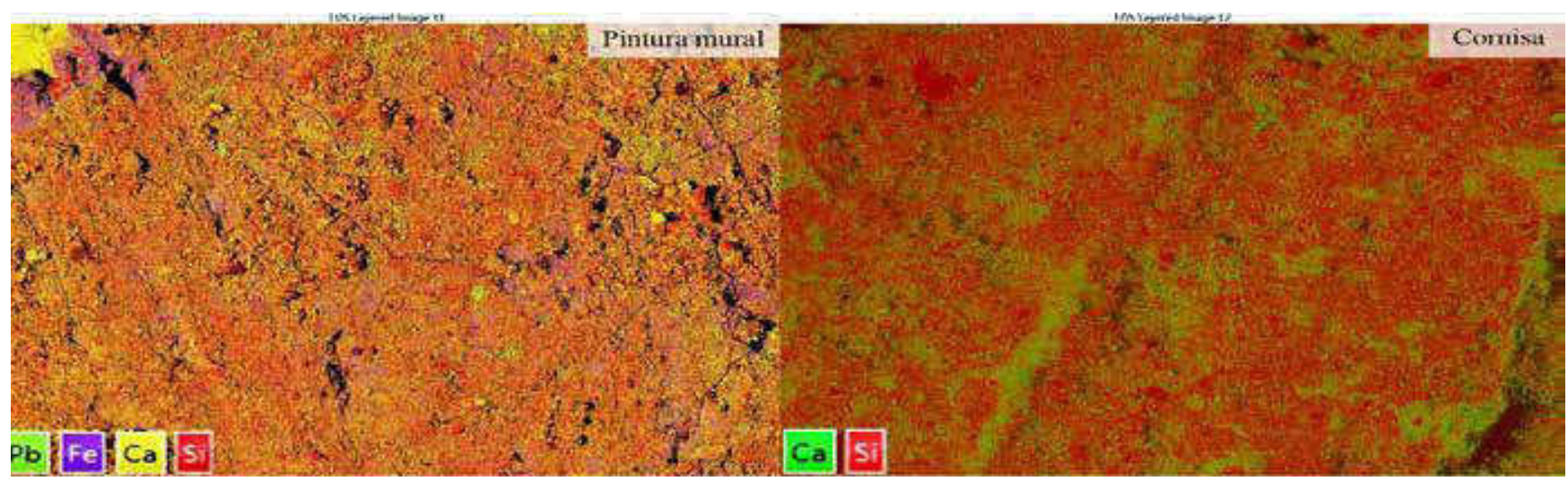

Figura 8-Mapa de distribución de elementos de las muestras tratadas con silicato de etilo. En ambos casos el silicio está representado con color rojo. 
Por otra parte, aparentemente, la consolidación con resina acrílica tanto en el fragmento de pintura mural como en el de cornisa no evidencia cambios significativos ni en el perfil ni en la superficie. Solamente en el caso de la moldura se observan restos en la imagen de perfil de lo que parece ser una película de aspecto plástico [figura 9]. Los resultados obtenidos se han comparado con una investigación que de forma paralela se está llevando a cabo, en la que se aplicó una capa de resina acrílica a mayor concentración a un fragmento de pintura mural tras su extracción para la fijación de su policromía en el mismo yacimiento, lo que ha permitido obtener observaciones bastante interesantes. Si se comparan ambos resultados se advierte que en el caso del fragmento tratado in situ, la capa pictórica evidencia la huella de burbujas creadas por la resina acrílica además de craquelados y desprendimientos, mientras que en el tratado a menor concentración esto no se observa [figura 10]. Por otro lado, atendiendo a la visión del corte en el fragmento tratado en la excavación con la resina acrílica en mayor proporción, se percibe claramente un estrato orgánico superpuesto a la capa pictórica. En todas las muestras tratadas en el yacimiento se observa cómo la resina ha cubierto con un film la superficie por completo, percibiéndose un claro contraste entre la superficie y el interior de la grieta, donde se mantiene la textura original, mientras que en las muestras tanto de pintura mural como de cornisa en las que se aplicó el producto al $5 \%$ en el laboratorio no se detecta la formación de esta película.

En cuanto a lo que respecta del análisis del line profile se observa una penetración relativamente superior a la del silicato de etilo; en el caso del fragmento de pintura mural se caracteriza material orgánico hasta $50 \mu \mathrm{m}$ aproximadamente de profundidad, mientras que en la cornisa la presencia de materia orgánica no muestra una variación significativa [figura 11].

Finalmente, el estudio de la muestra de pintura mural y de la cornisa consolidadas con carbonatogénesis bacteriana ha permitido comprobar que el tratamiento no presenta grietas o fracturas aparentes cuando se realiza un examen general de la muestra (100x). A dicha

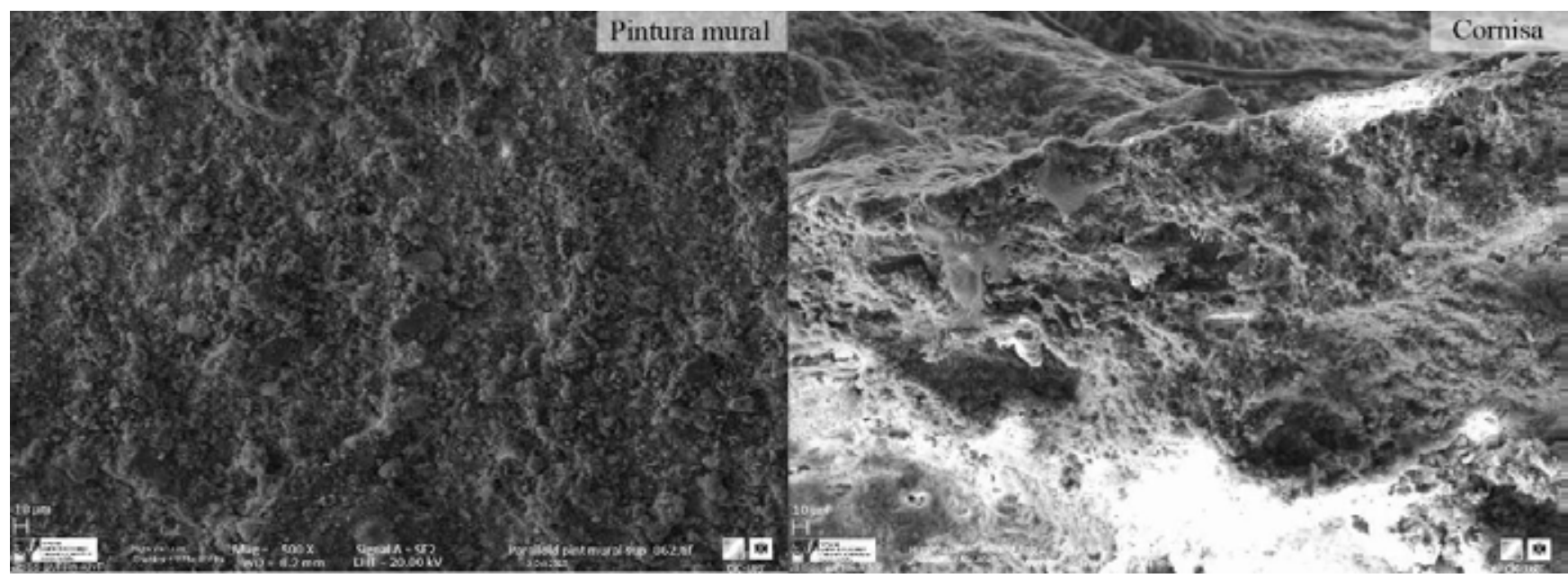

Figura 9- Muestras tratadas con Paraloid B-72 al 5\%. Imágenes obtenidas mediante HRSEM.

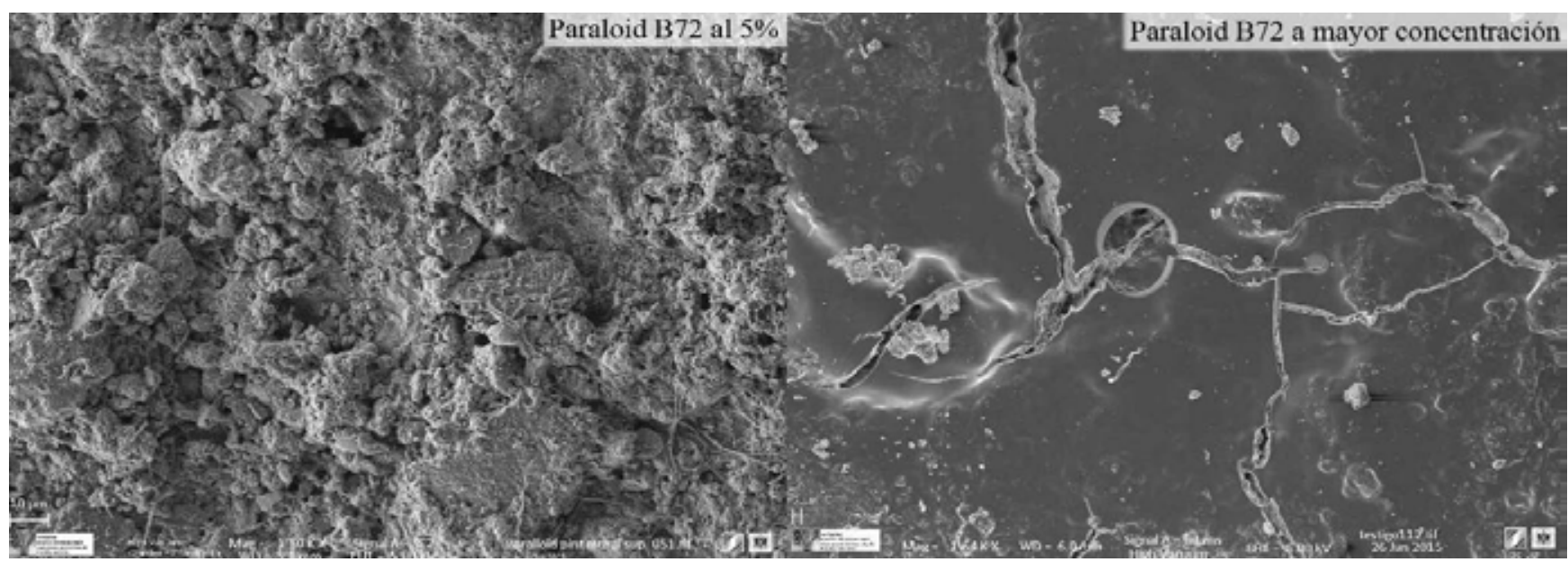

Figura 10- Diferencias entre la muestra tratada con Paraloid B-72 al 5\% (izq.) y la tratada con la misma resina en mayor concentración (derecha). Imágenes obtenidas mediante HRSEM. 

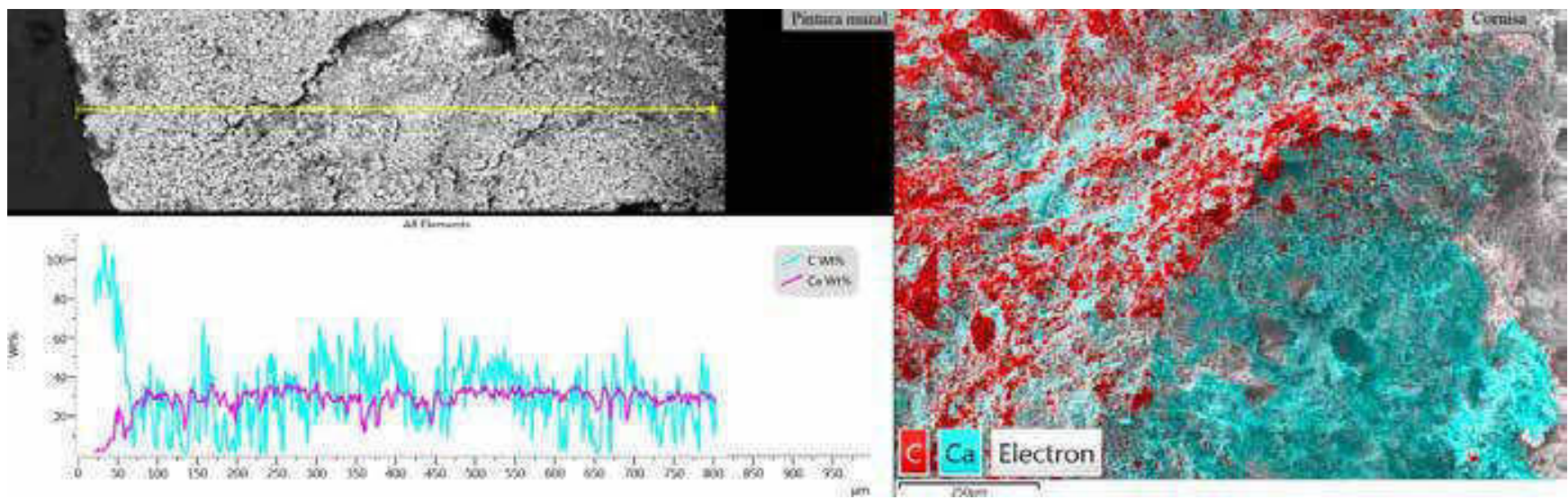

Figura 11-Grado de penetración de las muestras tratadas con Paraloid B-72. Line profile del fragmento de pintura mural (izq.) y mapa de distribución de elementos de la muestra colocada de perfil de cornisa donde puede comprobarse la escasa penetración del producto.

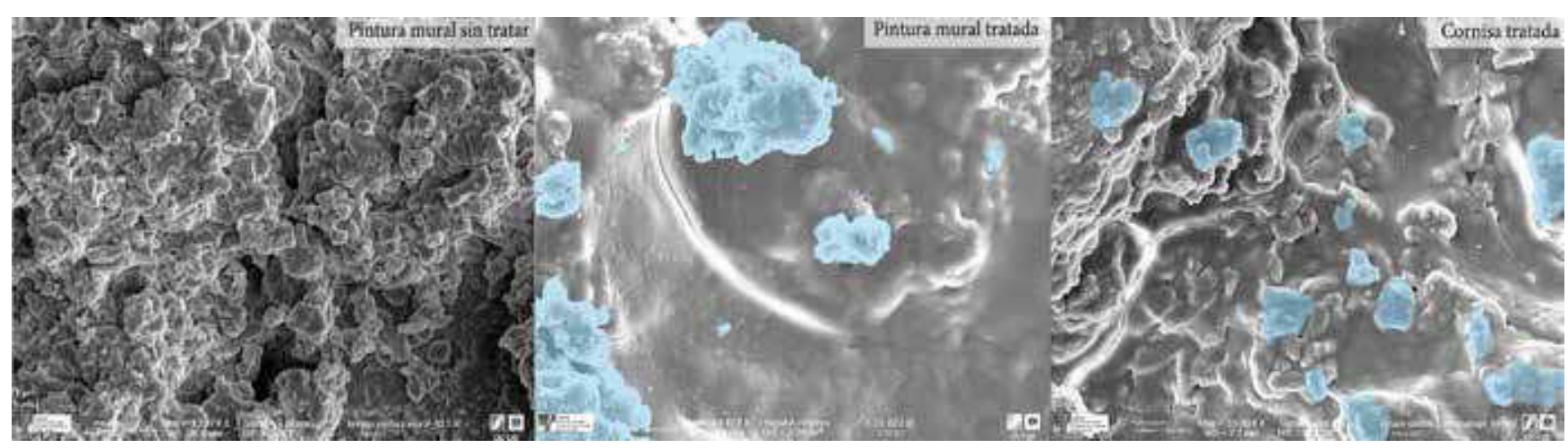

Figura 12- Muestra testigo de pintura mural y muestras tratadas mediante carbonatogénesis bacteriana donde se aprecian las sustancias expoliméricas y la calcita de nueva formación (señaladas en color azul). Imágenes obtenidas mediante HRSEM. Las barras corresponden a $1 \mu \mathrm{m}$ en la microfotografía correspondiente a pintura mural sin tratar, a $200 \mathrm{~nm}$ en la correspondiente a pintura mural tratada y a $1 \mu \mathrm{m}$ en la correspondiente a cornisa tratada.

magnificación puede parecer que el tratamiento ha creado una película sobre la superficie semejante a la que produce la resina acrílica; sin embargo, al elevar los aumentos se puede distinguir que lo que antes parecía una película impermeable es en realidad el tapizado de la superficie provocado por la precipitación de cristales de carbonato cálcico de nueva formación.

Asimismo se pueden apreciar la presencia de sustancias exopoliméricas (EPS), constituidas mayoritariamente por exopolisacáridos y proteínas (Branda et al. 2005) formadas como subproducto de la actividad microbiana y la existencia de fracturas derivadas de la formación del ya citado tapiz que respeta la morfología del fragmento tratado [figura 12]. El tratamiento aplicado conduce a la producción de carbonato cálcico al dar lugar a las condiciones físico-químicas necesarias para la actividad microbiana, además de que tanto las células bacterianas como el EPS que éstas producen actúan como núcleos heterogéneos de cristalización para la producción de carbonato cálcico, por lo que todo el proceso contribuye a la consolidación del material tratado (ver, por ejemplo, Jiménez-Lopez et al. 2008, Rodriguez-Navarro et al. 2015).
Aunque en este caso no se ha podido comprobar la penetración del producto, en investigaciones publicadas realizadas sobre yesos arqueológicos, en los que sí se puede comprobar el aumento de carbonato cálcico y su profundidad, se afirma que alcanza los $2 \mathrm{~cm}$ de profundidad (Jroundi et al. 2014); se puede considerar que en este caso fuera algo similar.

\section{Conclusiones}

Los resultados obtenidos han demostrado la efectividad de los productos ensayados, no obstante se deben tener en cuenta las particularidades que presentan cada uno de ellos con el objetivo de seleccionar el más adecuado atendiendo a las características de la obra tratada. Los datos recopilados de los fragmentos de pintura mural y cornisa son muy parecidos, demostrando que presentan un comportamiento similar, lo que es lógico debido a las coincidencias en su composicion material.

En el caso de la resina acrílica de metacrilato-etilacrilato Paraloid $^{\circledast}$ B-72, tanto el mapa de distribución de 
elementos como el análisis del perfil demuestran una presencia importante de producto y por tanto su efectividad. Sin embargo, se debe tener en consideración, sobre todo cuando la concentración es superior al 5\%, que se produce la formacion de una película densa en superficie, que aunque es indicativa de la efectividad, también lo es de una capa que afecta a la permeabilidad del soporte. Por este motivo, este producto sería recomendable en bajas concentraciones y siempre que la obra se encuentre en condiciones estables y controladas.

En lo que respecta al silicato de etilo, Bioestel 1200, se puede afirmar que presenta una ventaja fundamental que es la de la compatibilidad material. Sin embargo, su escasa penetración (en torno a las $100 \mu \mathrm{m}$ ) y la formación de una película que se microfractura deben tenerse en consideración cuando se aplica sobre este tipo de revestimientos, sobre todo en substratos poco porosos donde el producto tiende a quedar muy en superficie.

Por último, en el caso de la carbonatogénesis, aunque no se produce una capa uniforme como en el resto de los tratamientos, se ha podido constatar la formación de sustancias exopoliméricas, producto de la acción bacteriana que, junto con el carbonato cálcico de nueva formación, han consolidado la superficie. Este hecho se ha considerado muy importante pues es indicativo de que el tratamiento, además de ser efectivo, respeta la porosidad del soporte tratado y no impide tratamientos posteriores, ya que el material formado es el mismo del mortero y por lo tanto absolutamente compatible. No obstante, a pesar de estos resultados positivos consideramos la necesidad de realizar pruebas previas antes de abordar una intervencion general en este tipo de revestimientos, pues tanto el nivel de descohesión de la capa pictórica, así como su posición en vertical (revestimientos in situ), pueden influir en la respuesta al tratamiento. Además su reciente incorporación en el campo de los revestimientos polícromos hace que no se puedan conocer todavía los efectos que a largo plazo se pudieran producir.

En conclusión, esta investigación evidencia la necesidad de continuar realizando estudios sobre productos de consolidación, tanto aquellos utilizados de manera tradicional como de otros de reciente incorporación, con el objetivo de ofrecer a los restauradores las herramientas necesarias para seleccionar los tratamientos más adecuados para las obras a tratar. De esta manera, evitaremos comportamientos indeseados que provoquen daños en los materiales, contribuyendo a su conservación.

Además, la metodología aplicada ha demostrado ser efectiva por lo que ha permitido extraer resultados concluyentes y con garantías en esta primera fase de la investigación.

\section{Agradecimientos}

Queremos hacer constar nuestro más profundo agradecimiento al proyecto FORVM MMX, en especial a su director Marcelo Castro, por permitirnos el estudio de estos revestimientos murales, y a $\mathrm{M}^{\mathrm{a}}$ de la Paz López, restauradora, por la información que nos ha facilitado, así como al Departamento de Microbiología de la Universidad de Granada, concretamente a la doctora Fadwua Jroundi por proporcionarnos la solución nutritiva de la carbonatogénesis bacteriana. También agradecemos la colaboración de la doctora Isabel Guerra Tshchuschke, quien ha realizado los análisis mediante HRSEM en el Centro de Instrumentación Científica de la Universidad de Granada.

Asimismo, la realización de este trabajo ha sido posible gracias a la financiación por el Ministerio de Economía y Competitividad y por el Fondo Europeo de Desarrollo Regional(FEDER) en el marco del Proyecto de Investigación Estudio científico y tratamientos de conservación en revestimientos arquitectónicos de época romana a medieval, de referencia (HAR2015- 66139-P), al proyecto Decoración arquitectónica de tradición islámica. Materiales y técnicas de ejecución, de referencia (HAR 2011- 27598) $(01 / 01 / 2012$ - 31/12/2015) y al proyecto de excelencia de la Junta de Andalucía Tratamientos cromáticos en la arquitectura de tradición Hispanomusulmana. Técnica y Conservación (HUM 1941) (01/01/2014 - 31/12/2017). Ha sido posible gracias a la obtención de la beca de Formación del Profesorado Universitario (FPU) de Teresa López Martínez, y del programa de contratos puentes de la Universidad de Granada, del cual Ana Isabel Calero Castillo ha sido beneficiaria. Finalmente, este artículo se ha realizado dentro del programa de Doctorado de Historia y Artes de la Universidad de Granada

\section{Bibliografía}

AA.VV. (2003): Criterios de intervención en materiales pétreos. Revista Bienes Culturales del Instituto de Patrimonio Histórico Español, (2).

BRANDA, S., VIK A., FRIEDMAN, L., KOLTER, R. (2005). Biofilms: The matrix revisited. Trends Microbiol, 13, 20-26.

BOQUET, E., BORONAT, A., RAMOS-CORMENZA, A. (1973). Production of calcite (calcium carbonate) crystals by soil bacteria is a general phenomenon. Nature, 246, 527-529.

DAL MONTE, R. (1998). Morteros de consolidación para revestimientos pintados. La línea PLM. Un nuevo silicato de etilo para pintura mural: Bioestel. En J. Barberó Encinas, Técnicas de consolidación en pintura mural. Actas del Seminario Internacional sobre la Consolidación de pintura mural celebrado en Aguilar del Campoo (Palencia) (págs. 75-95). Aguilar del Campoo (Palencia): Fundación Santa María la Real. Centro de estudios del románico. 
GONZÁLEZ-MUÑOZ, M. T., JROUNDI, F., GARCÍA BUENO, A., MARTÍN PEINADO, B., \& RODRÍGUEZ-NAVARRO, C. (2015). Bioconsolidación de materiales pétreos y ornamentales mediante carbonatogénesis bacteriana. La ciencia y el arte $\mathrm{V}$. Ciencias experimentales y conservación del patrimonio, (págs. 71$80)$.

GONZÁLEZ-MUÑOZ, M. T., RODRÍGUEZ-NAVARRO, C.; JIMÉNEZLÓPEZ, C., RODRÍGUEZ-GALLEGO, M. (2008). Método y producto para la protección y consolidación de materiales de construcción y ornamentales. Patente WO 2008/009771 A1.

GUASCH FERRÉ, N. (2009). Caracterització dels materials constitutius de les bases de preparació de les pintures murals a les terres baixes maies del nord (Península de Yucatán, Méxic), Universitat Politècnica de València.

GUIRAL PELEGRíN, C., \& MARTíN-BUENO, M. (1996). Bílbilis I. Decoración pictórica y estucos ornamentales. . Zaragoza: Institución Fernando el Católico.

JROUNDI, F., FERNÁNDEZ-VIVAS, A., RODRIGUEZ-NAVARRO, C., J. BEDMAR, E., GONZÁLEZ-MUÑOZ, M.T. (2010). Bioconservation of deteriorated monumental calcarenite stone and identification of bacteria with carbonatogenic activity. Microbial Ecology, 60, 39-54.

JROUNDI, F., GONZÁLEZ-MUÑOZ, M. T., GARCIA BUENO, A., \& RODRÍGUEZ-NAVARRO, C. (2014). Consolidation of archeological gipsum plaster by bacterial biomineralization of calcium carbonate. Acta Biomaterialia, 10, 3844-3854.
JROUNDI, F., RODRÍGUEZ-NAVARRO, C., GARCÍA BUENO, A., MEDINA- FLÓREZ, V., \& GONZÁLEZ-MUÑOZ, M. T. (2011). Consolidación de materiales arqueológicos procedentes del Alcázar de Guadalajara, mediante carbonatogénesis bacteriana. XVIII Congreso Internacional Conservación y Restauración en Bienes Culturales (págs. 125-127). Granada: Universidad de Granada.

LÓPEZ MARTÍNEZ, T., LÓPEZ CRUZ, O., GARCÍA BUENO, A., CALERO-CASTILLO, A.I., \& MEDINA FLÓREZ, V. (2016). Las pinturas murales de Castulo. Primeras aportaciones a la caracterización de materiales y técnicas de ejecución. Lucentum, (35), en prensa.

LÓPEZ ORTEGA, T. (1999). Evaluación de los tratamientos de conservación efectuados en los mascarones de estuco de Kohunlich. Mexico. Distrito Federal: Quintana Roo.

MORA, P., MORA, L., \& PHILIPPOT, P. (2001). La conservazione delle pitture murali. (Segunda ed.). Bologna: Editrice compositori.

MORENO CIFUENTES, M.A. (1998). La consolidación de revestimientos murales en yacimientos arqueológicos. En J. Barberó Encinas, Técnicas de consolidación en pintura mural. Actas del Seminario Internacional sobre la Consolidación de pintura mural celebrado en Aguilar del Campoo (Palencia) (págs. 53-75). Aguilar del Campoo (Palencia): Fundación Santa María la Real. Centro de estudios del románico.

RODRIGUEZ NAVARRO, C., JROUNDI, F., GONZÁLEZ-MUÑOZ, M.T. (2015). Stone consolidation by bacterial carbonatogenesis: Evaluation of in situ applications. Restoration of Buildings and Monuments, 21 (1), 9-20.

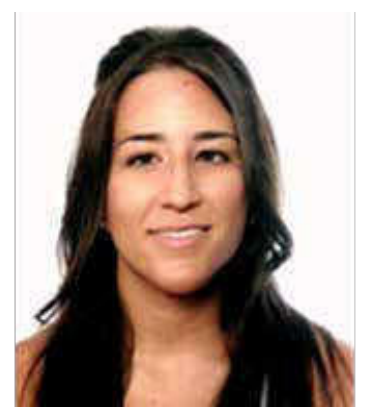

\author{
Ana Isabel Calero Castillo \\ anacalerocastillo@hotmail.com \\ Universidad de Granada
}

Doctora en Artes, especialidad Técnicas de Restauración y conservación de obras de arte con mención europea en el año 2016. Actualmente es miembro del Departamento de Pintura de la UGR con un contrato puente del plan propio de la misma universidad. Ha sido becaria FPU y miembro investigador en diversos proyectos competitivos de I+D orientados a la recuperación del color en la arquitectura y al estudio de los revestimientos cromáticos. Ha trabajado en diversos proyectos de restauración como el estudio de las yeserías del patio de las Doncellas del Real Alcázar de Sevilla y el de las pinturas murales de Castulo. Ha realizado además dos estancias formativas en Roma (Italia) en los laboratorios de restauración de pintura mural del ISCR, lo que le ha permitido trabajar en la restauración de revestimientos murales de Pompeya, el ciclo pictórico de Sant'Agata que se encuentra en Largo dei mutilati ed invalidi da guerra así como en las estancias de Piranesi de época romana situadas en Villa Massenzio en el Appia Antica entre otras. 


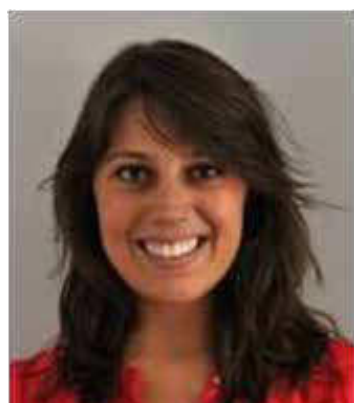

\title{
Teresa López Martínez
}

terelm@ono.com

Universidad de Granada

Graduada en Conservación y Restauración de Bienes Culturales por la Universidad de Granada en el año 2014. Es miembro del Departamento de Pintura de la Universidad de Granada gracias a la beca de Formación del Profesorado Universitario (FPU) de la que disfruta desde el año 2015 y gracias a la cual actualmente está realizando su tesis doctoral. Ha participado en diversos proyectos en Italia durante su beca Erasmus como los estudios previos de la sala II ridotto del Teatro Grande o del monumento a Arnaldo, ambos en Brescia, así como en diversas restauraciones, entre las que destacan la Madonna Nera de la iglesia de Santa Maria della Caritá o la escultura pétrea II Bigio. Además ha realizado prácticas de arqueología en el Alfar de Cartuja (Granada) así como en Castulo. Ha colaborado en el desarrollo de proyectos I+D orientados al estudio de revestimientos cromáticos. Fruto de ese trabajo se han realizado diversas aportaciones a congresos y publicaciones en revistas nacionales.

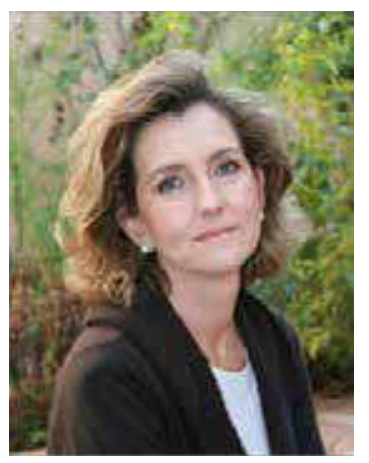

\author{
Ana García Bueno \\ anagar@ugr.es \\ Universidad de Granada
}

Profesora Titular del Departamento de Pintura, especialidad de Restauración, actualmente directora del Departamento de Pintura de la UGR. Ha sido miembro investigador en diversos proyectos competitivos de I+D orientados a la recuperación del color en la arquitectura y al estudio de los revestimientos cromáticos, sobre todo en la Arquitectura Islámica. En relación con su actividad profesional, ha participado en diversos proyectos de restauración de pintura mural, entre los que destacan los trabajos llevados a cabo en Qsayr 'Amra (Jordania), miembro integrante del asesoramiento facultativo durante la intervención en los elementos decorativos del Cuarto Real de Santo Domingo; los estudios previos de la Madraza y de varios espacios del Real Alcázar de Sevilla como la fachada del palacio de Pedro I o la decoración arquitectónica del patio de las Doncellas, así como los revestimientos romanos de Cástulo. Fruto de estas investigaciones se han publicado numerosos artículos s en revistas indexadas y ha dirigido varias tesis doctorales. 


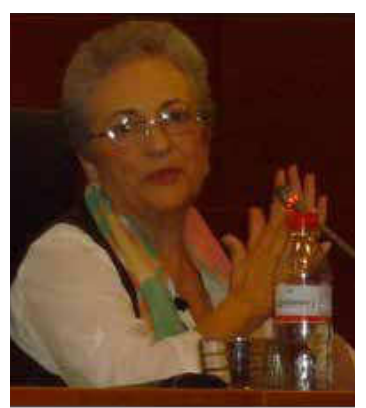

\title{
María Teresa González Muñoz
}

mgonzale@ugr.es

Universidad de Granada

Catedrática de Microbiología, actualmente es Profesora Emérita de la Universidad de Granada. Con dilatada labor docente (en Licenciatura, Grado, Doctorado y Máster) y amplia tarea investigadora en diferentes campos de la Microbiología. Ha desarrollado, en los últimos 25 años, una línea de investigación interdisciplinar con profesores e investigadores (de Universidad y del CSIC) del Área de Mineralogía y Cristalografía sobre diferentes aspectos de la Biomineralización bacteriana, con importantes aportaciones plasmadas en numerosas publicaciones de elevado índice de impacto, habiendo desarrollado una patente de un producto y método para consolidación de materiales de construcción y ornamentales, licitada ya por una empresa. Investigadora e I. P. de numerosos Proyectos de Investigación, destaca, además, su colaboración de los últimos años con profesores e investigadores de Belllas Artes y Arquitectura.

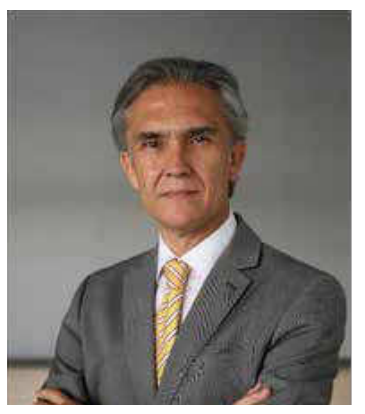

\section{Victor J. Medina Flórez}

vmedina@ugr.es

Universidad de Granada

Catedrático del Departamento de Pintura, de la Facultad de Bellas Artes desde el año 2008 y en la actualidad Vicerrector de Extensión Universitaria de la UGR. Desde su incorporación en la misma universidad en 1997, su docencia e investigación se han relacionado con temas de Conservación y Restauración, fundamentalmente restauración de pintura mural y conservación preventiva. Ha sido investigador en diversos proyectos competitivos de I+D orientados a la recuperación del color en la arquitectura y al estudio de los revestimientos cromáticos. Como resultado de este trabajo ha dirigido varias tesis doctorales y realizado más de 40 publicaciones especializadas. Ha participado en diversos proyectos de restauración como son el de los revestimientos murales de Luca Jordan, Carreño y Rizzi, Qsayr 'Amra (Jordania), la Casa de Zafra, el Corral del Carbón; los estudios previos de la Madraza, los Reales Alcázares de Sevilla, o las pinturas arqueológicas de época romana de Cástulo, además de otras obras.

\author{
Artículo enviado el 04/02/2016 \\ Artículo aceptado el 21/09/2016
}




\title{
Survey of the state of conservation of the Mylodon listai (Xenarthra-Mylodontidae) skin fragment from the Pleistocene of Argentina kept at the Museum of La Plata (Argentina)
}

\author{
Daniela Silvana Nitiu, Andrea Mallo, Mario Saparrat, Mauro Garcia Santa Cruz
}

\begin{abstract}
The aim of the present study was to assess the state of conservation of the fossilized skin fragment assigned to Mylodon listai preserved in a showcase of the Paleontology Hall of the Museum of La Plata. To this end, we conducted a volumetric aerobiological sampling both inside the showcase and in the hall to detect the presence of fungal load that could alter its preservation. We also determined the environmental parameters both inside and outside the showcase. The aerobiological sampling inside the showcase showed 3061.50 spores $/ \mathrm{m} 3$ corresponding to 22 fungal types, while in the hall, 2283.20 spores $/ \mathrm{m} 3$ corresponding to 14 fungal types where detected. Cladosporium was the most important type in all the sampling points. The temperatures recorded were lower than those recommended for the conservation of leather and the relative humidity values were acceptable in $70 \%$ of the record for this material
\end{abstract}

Keyword: environmental monitoring, fungal load, preventive conservation, Mylodon listai, Museum of La Plata

\section{Estudio del estado de conservación del fragmento de piel de Mylodon listai (Xenarthra- Mylodontidae) del Pleistoceno argentino conservado en el Museo de La Plata (Argentina)}

Resumen: El objetivo del presente trabajo fue evaluar el estado de conservación de un fragmento fósil de cuero de Mylodon lista conservado en una vitrina de la Sala de Paleontología del Museo de La Plata. Se realizó un muestreo aerobiológico volumétrico en el interior de la vitrina y en la Sala con el objeto de detectar la presencia de carga fúngica que pudiera alterar su preservación. Se relevaron parámetros ambientales en el interior y exterior de la vitrina. El muestreo aerobiológico reveló en el interior del expositor un total de 3061.50 esporas $/ \mathrm{m} 3$ y 22 tipos fúngicos mientras que en la sala se cuantificó un total de 2283.20 esporas $/ \mathrm{m} 3$ y 14 tipos fúngicos. Cladosporium sp. fue el máximo exponente identificándose en todos los puntos del muestreo. Las temperaturas registradas en la vitrina son menores a las recomendadas y la humedad relativa es aceptable en un $70 \%$ del registro para la conservación de cuero.

Palabras clave: monitoreo ambiental, carga fúngica, conservación preventiva, Milodon listai, Museo La Plata.

\section{Estudo do estado de conservação do fragmento de pele de Mylodon Listai (Xenarthra- Mylodontidae) do Pleistoceno argentino conservado no Museu da Plata (Argentina)}

Resumo: O objetivo deste estudo foi avaliar o estado de conservação de um fragmento fóssil de couro de Mylodon listai conservado numa vitrina na sala de Paleontologia do Museu da Plata. Levou -se a cabo uma recolha de amostras aerobiológicas volumétrico no interior da vitrina e na sala com o objetivo de detetar a presença de carga fúngica que pudesse ter alterado a sua conservação. Encontraram-se parâmetros ambientais no interior e no exterior da vitrina. A recolha de amostras revelou que no interior do expositor havia um total de 3061.20 esporos de fungos / m3 e 22 tipos de fungos enquanto que na sala quantificaram-se um total de 2283.20 esporos de fungos / $\mathrm{m} 3$ e 14 tipos de fungos. O Cladosporium sp. Foi o máximo expoente identificado em todos os pontos da recolha de amostras. As temperaturas registadas na vitrina são menores às recomendadas e a humidade relativa é aceitável em $70 \%$ do registo para a conservação do couro.

Palavras-chave: monitoramento ambiental, carga fúngica, Conservação preventiva, Mylodon listai, Museu de La Plata 


\section{Introducción}

The collections of the Division of Vertebrate Paleontology at the Museum of Natural Sciences of La Plata (La Plata, Buenos Aires, Argentina) host more than 120.000 specimens from cataloged fossil vertebrates. These scientific collections have more than 500 type specimens and 2300 figured specimens (www.museo.fcnym.unlp.edu.ar). These collections, many of which were obtained by reference naturalists as F.P. Moreno, F. and C. Ameghino, R. Hauthal, A. Mercerat and S. Roth, among others, in the second half of the nineteenth and early twentieth centuries, testify the past 250 million years of evolution in the extreme south of the American continent. In the last decades, other important collections due to their variety or number of specimens have been added to these collections.

The Museum of La Plata has on display a Mylodon listai skin fragment and remnants of fecal matter that were found by the German soldier Hermann Eberhardt in 1895 in the Cave "Última Esperanza"located in the Magallanes province in the Austral Patagonia of Chile. In 1897, such site was visited by Francisco P. Moreno, who took the skin fragment to London, England, for its study in 1898. A fragment of this skin was then taken to the Museum of La Plata in Argentina (Moreno \& Woodward, 1899; Martinic, 1996). The material found lacked the head and extremities. Its skin was very hard, about 10$15 \mathrm{~mm}$ thick, composed of bony plates called osteoderms and thick $3-5-\mathrm{cm}$-long blond hairs. Carbon-14 studies carried out in the Laboratory of Tritium and Radiocarbon of the Museum of La Plata allowed assigning the material an average age of 11-12 thousand years, which corresponds to the end of the Pleistocene (Tonni et al., 2003).

Mylodon listai (Xenarthra-Mylodontinae) was a large quadruped herbivorous belonging to the same group as current armadillos, anteaters and sloths, with the ability to stand in two legs. It was $1.50 \mathrm{~m}$ tall $\times 75 \mathrm{~cm}$ wide and it could weigh one ton. From the taxonomic point of view, researchers have not reached a consensus about the number of valid taxa for the genus Mylodon (Kraglievich, 1934; Esteban, 1996; Tonni et al., 2003). The following species have been included in it: Mylodon darwini Owen and Mylodon insigne Kraglievich, from the Pampean region, and Mylodon listai Ameghino, from the Argentine Patagonian region and similar regions in Chile (Brandoni et al., 2010).

The Museum of La Plata conserves objects and material which form part of the material memory of our ancestors, and plays a vital cultural and educational role for the whole country. Thus, a good state of conservation of both its building structure and the environmental context where the collections are hosted is vital to keep the material in good condition and minimize natural progressive ageing. Records of relative humidity, temperature, light intensity, light quality, and pest control, as well as of the conditions of exposure, storage, maintenance (cleaning, periodic controls), and handling of the material should be a priority.
Although there is no consensus on the range of temperature and relative humidity required to conserve collections, each specimen or part has specific requirements which are dependent on their composition and state of preservation. Also, intradiurnal fluctuations of temperature and relative humidity play a preponderant role in preservation. If these fluctuations are significant, they may constitute a major problem because they may promote stress that can damage the specimen, sometimes being irreversible (Michalski, 2007). The aim of the present study was to assess the state of conservation of the skin fragment assigned to Mylodon listai displayed in a showcase located in the Vertebrate Paleontology Hall of the Museum of La Plata, and monitor the fungal spore load and environmental conditions associated with this hall.

\section{Materials and methods}

\section{Study site}

The Exhibition Hall of Paleontology of Cenozoic Vertebrates of the Museum of Natural Sciences of La Plata that hosts the Mylodon listai skin fragment studied in the present work is located on the ground floor. This hall has an area of approximately $70 \mathrm{~m} 2$ and is connected to other immediate Paleontology Halls, which host fossils of other geological ages. The walls of this hall are covered by 20 closed showcases that host various fossils. The center of the room displays a reconstruction of the life in the past based on large mammal fossils ("megafauna"), remains which have been preserved from the organisms, and signs of their activity [figure 1.1]. Room lighting in the hall is natural through windows, whereas that inside the showcases is artificial.

The showcase of the genus Mylodon is $1.30 \mathrm{~m}$ high, $1.50 \mathrm{~m}$ wide and $0.55 \mathrm{~m}$ deep, is built in wood and glass, and has a constant warm fluorescent lighting during the opening hours of the Museum. In addition to the biological remains, there are two explanatory posters of the site of discovery, characterization of Mylodon and the geographic location of the cave "Última Esperanza" in the Austral Patagonia of Chile [figure 1.2].

\section{Sampling}

\section{Collection of aerobiological samples}

Air samples from both the Exhibition Hall and the inside of the showcase were collected through a volumetric system, which consists in taking air samples with a Z-LitelAQ vacuum pump calibrated at $15 \mathrm{l} / \mathrm{m}$, connected to a disposable Air or Cell ${ }^{\Phi}$ cassette. Each sample was the result of the air particles captured during the passage of air through the cassette for 5 minutes. We followed a diagonal sampling design, taking three reference points (upper, middle and lower sectors), both within the hall and inside the showcase, according to the FEDECAI-01 standards (2007). 

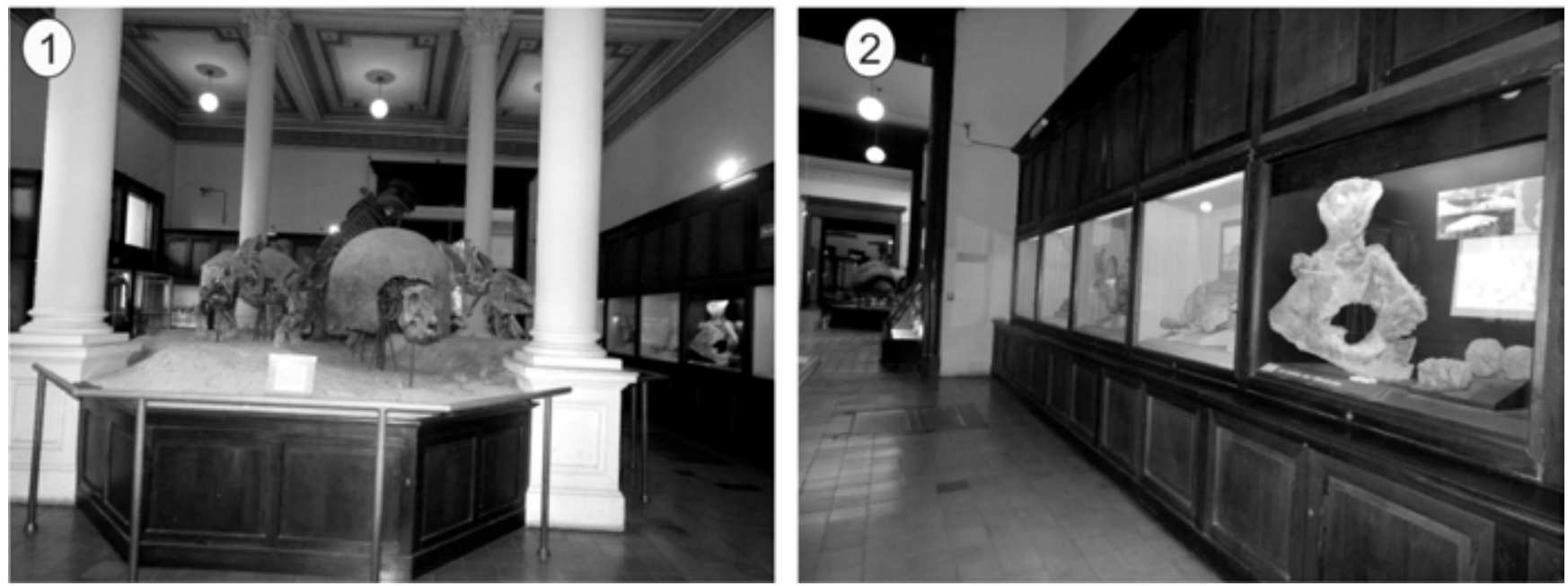

Figure 1.- Hall of Paleontology of Pleistocene Vertebrates of the Museum of La Plata, La Plata. 2, Showcase where the skin fragment of Mylodon listai is kept.

Each cassette sample obtained was processed using the Air or Cell ${ }^{\circledR}$ protocol, mounted, and stained with lactophenol cotton blue for its analysis. Samples were observed with an optical magnification of $400 \mathrm{X}$, covering $100 \%$ of the sampled surface. Bioaerosols, particularly fungal spores, were identified using reference atlases (Käärik et al., 1983; Barnet and Hunter, 1987; Grant Smith 1990; Lacey and West, 2006; Nitiu et al., 2010) and specialized databases. The concentration of each air particle/m3 was estimated following Baxter's procedure (2006).

Characterization of the skin, isolated fossil hairs and coprolite

The skin was macroscopically observed with binocular lenses $4.8 \mathrm{X}$ to characterize it and distinguish possible fungal structures on its surface. The isolated fossil hairs available at the base of the showcase were processed according to the technique of Arita and Aranda (1987) and characterized with an optical microscope. On the other hand, the material destined for scanning electron microscope was processed following the protocol of Bozzola and Russel (1991). Photomicrographs were obtained from both techniques. With respect to the coprolite, we followed the direct contact technique, according to the protocol previously described (Nitiu et al., 2015).

\section{Analysis of temperature and relative humidity}

The HOBO Temp/RH data logger records temperature and relative humidity (within $2.5 \%$ accuracy) in indoor environments with its integrated sensors. The device was placed inside the showcase and two similar data loggers were placed in the Paleontology Hall to record the values of temperature and relative humidity in both sectors. These values were then analyzed by means of graphs and tables.

\section{Results}

To obtain an atmosphere as stable as possible in terms of microorganisms and physical variables, the sampling was carried out on September 30th, 2015, between 8 and 10 o'clock a.m., a lapse in which the Museum is still closed to the public. The relative humidity and temperature of the hall during the sampling period were $59 \%$ and $15^{\circ} \mathrm{C}$ respectively, whereas those inside the showcase were $57 \%$ and $16^{\circ} \mathrm{C}$ respectively.

\section{Aerobiological study}

The aerobiological analysis inside the showcase allowed quantifying a total of 3061.50 spores $/ \mathrm{m} 3$, corresponding in the three sampling points to a mycobiota represented by 22 fungal types. In the lower and middle sectors of the showcase, the fungal load did not exceed 800 propagules/ $\mathrm{m} 3$, with only 10 morphological types in each sector, whereas the upper sector revealed greater concentration and richness of fungal taxa [table 1].

Fungal taxa such as Cladosporium cladosporioides, Agrocybe sp., Coprinus sp. and Agaricus sp. were represented in the three sectors, with $C$. cladosporioides being the most abundant, with $76.09 \%, 39.29 \%$ and $39.81 \%$ in the upper, middle and lower sectors respectively.

The area outside the showcase (the hall) revealed a total of 2283.20 spores/m3 corresponding to 14 fungal types, with 639.98 spores/m3, 518.91 spores/m3 and 1107 spores/m3 contributed by 7,10 , and 11 morphological types in the upper, middle and lower sectors respectively. Spores of $C$. cladosporioides, Agrocybe sp., Agaricus sp., Coprinus sp., Leptosphaeria type, and Didimospora type were common to all sites. The lower sector was characterized by the Leptosphaeria type, with $23.68 \%$, whereas the middle and upper sectors were characterized by the presence of $C$. cladosporioides, with $40 \%$ and $42.19 \%$ respectively [table 2]. 


\begin{tabular}{lll}
\hline \multicolumn{2}{l}{ Fungal spore identified in the inside the showcase } & \\
\hline Lower sector & Middle sector & Upper sector \\
\hline Cladosporium cladosporioides & Cladosporium cladosporioides & Cladosporium cladosporioides \\
Coprinus & Agrocybe & Myxomycota \\
Agaricus & Agaricus & Aspergillus/Penicillium \\
Agrocybe & Myxomycota & Chaetomium \\
Chaetomium & Tipo Lepthosphaeria & Boletus \\
Tipo Lepthosphaeria & Coprinus & Tipo Arthrinium \\
Ganoderma & Botrytis & Agrocybe \\
Tipo Didimosphaeria & Tipo Arthrinium & Politrincium \\
Alternaria & Tipo Caloplaca & Tipo Sporidesmium \\
Parapheosphaeria & Ganoderma & Parapheosphaeria \\
& & Coprinus \\
& & Agaricus \\
& Curvularia \\
& Cercospora \\
& & Tipo Didimosphaeria \\
& & Diatrypaceae \\
& & Bipolaris
\end{tabular}

Table 1.- Spores types identified at the three sampling heights (sectors) inside the showcase where the skin of Mylodon listai is kept

\begin{tabular}{|c|c|c|}
\hline \multicolumn{3}{|c|}{ Fungal spore identified in the Sala of Paleontologv } \\
\hline Lower sector & Middle sector & Upper sector \\
\hline $\begin{array}{l}\text { Tipo Lepthosphaeria } \\
\text { Tipo Didimella } \\
\text { Agaricus } \\
\text { Aspergillus/Penicillium } \\
\text { Cladosporium cladosporioides } \\
\text { Coprinus } \\
\text { Agrocybe }\end{array}$ & $\begin{array}{l}\text { Cladosporium cladosporioides } \\
\text { Agaricus } \\
\text { Tipo Lepthosphaeria } \\
\text { Tipo Didimella } \\
\text { Agrocybe } \\
\text { Myxomycota } \\
\text { Cercospora } \\
\text { Coprinus } \\
\text { Trichotecium } \\
\text { Ganoderma }\end{array}$ & $\begin{array}{l}\text { Cladosporium cladosporioides } \\
\text { Agaricus } \\
\text { Tipo Lepthosphaeria } \\
\text { Caloplaca } \\
\text { Tipo Didimella } \\
\text { Coprimus } \\
\text { Cladosporium herbarum } \\
\text { Agrocybe } \\
\text { Tipo Botritis } \\
\text { Tipo Cercospora } \\
\text { Tipo Didimosphaeria }\end{array}$ \\
\hline
\end{tabular}

Table 2.- Spores types identified at the three sampling heights (sectors) of the Paleontology Hall.

The air of the hall also presented skin flake-like organic fragments and other opaque particles associated with environmental dust (data not recorded).

Macroscopic naked-eye observations of the skin allowed recognizing an extremely hard skin, with light-yellow 3-5-cm-long hairs ending in a narrower blunt tip [figure $2.1,4]$ Although the diameter of the hair was uniform, the basal area was slightly narrower. The electron microscope showed a compact surface with waxy depositions vulnerable to treatment with xylol [figures 2.2, 5]. In addition, we observed cracks along the hair structure, which were possible signs of dehydration. We identified no fungal colonies, hyphae or propagules associated with the fur. Optical microscopy also revealed the absence of bone marrow [figures 2.3, 6]. Direct observation of the contact samples of the coprolite allowed identifying no fungal hyphae or structures on the surface. 


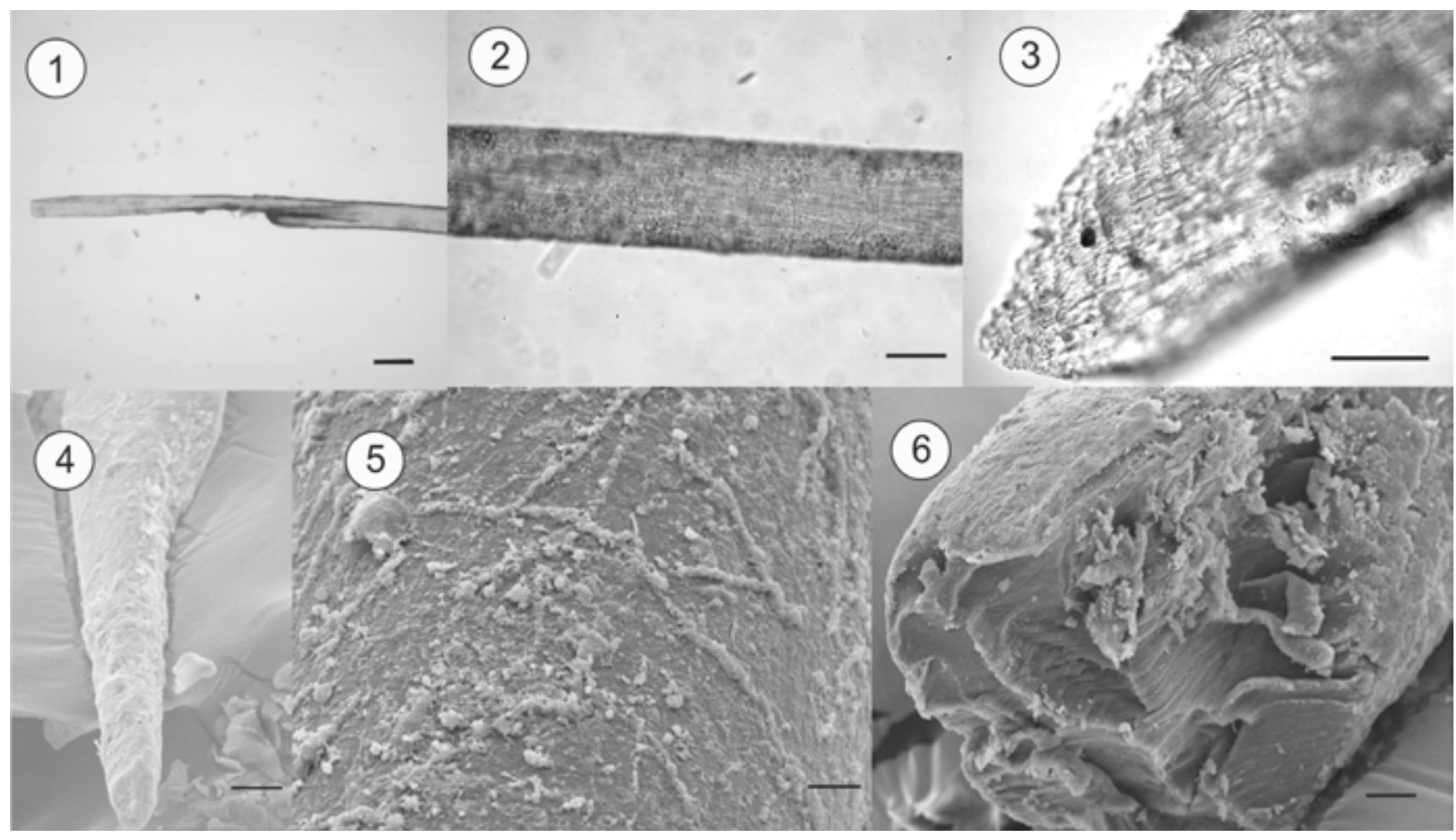

Figure 2.- Photomicrograph of fossil hair obtained by optical microscope (1-3) and by scanning electron microscope (4-6). 1, Detail of the blunt tip of the hair (Scaling $=20 \mu \mathrm{m}) .2$, Detail of the hair surface. (Scaling $=10 \mu \mathrm{m}) .3$, Detail of the inner section of the hair where the absence of bone marrow is observed. (Scaling $=20 \mu \mathrm{m}) .4$, Detail of the blunt tip of the hair (Scaling $=200 \mu \mathrm{m}) .5$, Detail of the hair surface (Scaling $=100 \mu \mathrm{m}) .6$, Detail of the inner section of the hair where the absence of bone marrow is observed (Scaling $=200 \mu \mathrm{m})$.

\section{Discussion and conclusions}

The Vertebrate Paleontology Halls of the Museum of La Plata are home to important paleobiological collections that provide support to the historical information about the natural environment and evidence of primitive life (Brook et al. 2015). The Mylodon is a reference fossil of the late Pleistocene and early Holocene of the south of Argentina, of which scarce fractions are kept in the world. Thus, the skin fragment kept at this Museum is of great heritage value for the institution, and actions aimed at its preservation and long-term conservation are essential.

It is well known that the air inside each museum is characterized by the building materials, furniture and types of showcases used, but also by microclimatic parameters, ventilation systems and lighting of each hall or showcase, which, together with the different materials and textures that make up the cultural/patrimonial property, may contribute to the presence and growth of bioaerosols (Shelton et al., 2002). In addition, the anthropogenic activity can play a very important role either due to its involuntary action as a means of transport of particles or for being a potential substrate for the development of different fungal structures (Van Duin, 2014).

In the present study, the analysis of the mycological load of the environment of the Paleontology Hall and the inside of the showcase where the Mylodon skin fragment is displayed showed the presence of 22 morphological types, which contributed to a total of 1020.50 spores $/ \mathrm{m} 3$. On the other hand, the microbiology of the atmosphere of the hall was represented by 14 spore types, which contributed an average of $761.06 \mathrm{spores} / \mathrm{m}^{3}$. These differential values of richness and concentration between both sites could be due to the fact that the hall has wide connections with other adjacent areas where the atmosphere may be a key element as a means of transportation for particles, generating a cleaning effect and decreasing the concentration of particles, whereas the showcase is an enclosed space with low air current and possibility of removal (Borrego \& Perdomo 2014).

The analysis of spore richness and total concentration at the different heights of the hall and the showcase showed larger values in the upper sectors in both sites. This may indicate that the atmosphere in the upper sector is more stable or less disturbed by anthropogenic activity or by the environmental flow than that in the lower sector. These results are similar to those of Khattab and Levetin (2008) but different from those of Atluri et al., (1988) and RantioLethimaki et al., (1999), who reported lower concentrations of this spore type as the sampling height increases.

With respect to the other three spore types that were common to both sites, Agrocybe presented slightly greater concentrations in the upper sector of the showcase, Agaricus had a similar behavior in the hall, and Coprinus showed similar concentrations at the different sampling heights. 
Although we must consider each spore type in particular, several authors agree that small spores are commonly found at higher heights and large spores at lower heights (Khattab \& Levetin, 2008).

The fact that 11 of the spore types found were common to both sampling sites would indicate the existence of some kind of connection between sites, mainly by the lower sector of the showcase, where you have access to it. The spore types involved were mostly representatives of the Phyla Ascomycota, with the anamorphs AspergillusPenicillium sp., Botrytis sp., Cladosporium cladosporioides and Cercospora sp., and teleomorphs such as Leptosphaeria sp. and Caloplaca sp. We also identified Basidiomycota spores: Agaricus sp., Agrocybe sp., Coprinus sp. and Ganoderma sp., as well as representatives morphologically related to Myxomycota (Phylum Mycetozoa). Cladosporium sp. was the most important spore type in the three sampling sectors of both sampling sites. Singh (2003), Florian (2004), Valentin (2010) and Solís (2011) reported Cladosporium sp. as one of the main pollutant genera of interior rooms at global level and as a spore type commonly isolated in homes, archives, libraries and museums (Walter, 2003; Gutarowska, 2010).

Our macroscopic and microscopic observations confirm the absence of bone marrow of the hair of the skin fragment of Mylodon listai, described by Ridewood in 1901 and mentioned by Arzani et al., (2014).

The development of microorganisms, including that of environmental fungi, stops when the activity of the support water is lower than that needed to remain in a resistance phase for a variable period of time (García Miniet \& Sánchez Espinosa, 2012). In the case of spores, the resistance phase can be extended for years, thus not being alarming for the development of biodeterioration (Florian, 2004).

Despite the presence of suspended spores, the absence of signs of deterioration both in the skin and hair is a clear sign of the good state of conservation of the Mylodon specimen hosted at the Museum of La Plata. However, the fall of the hairs from the skin continues to be a concern that needs to be clarified and controlled. In this sense, photochemical and hydrothermal stability processes (González Álvarez, 2005) or molecular strategies to obtain nucleic acids from fossilized dehydrated biological material may help determine the need to maximize the preservation of materials of biological collections.

The vegetative state of fungi, either as unicellular fungi or in the form of mycelia, is a key physiological state in the process of degradation of various media used as growing substrates (Guiamet et al., 2006; Cappitelli \& Sorlini, 2010; Rodriguez García 2016). Under appropriate temperature and relative humidity conditions, the mycobiota can latently coexist with museum specimens in the state of spores. However, an increase in temperature and relative humidity can lead to the activation of the propagules as well as to their germination and mycelial development, generating serious problems in the biodeterioration of specimens (Pinzari et al., 2004).

Considering that the specimen studied was a skin fragment, we determined the reference values recommended for the conservation of the category "skin" (UNI10829:1999 Norm), which considers optimal values of relative humidity those between $45 \%$ and $60 \%$ and optimal values of temperature those between $19^{\circ} \mathrm{C}$ and $24^{\circ} \mathrm{C}$. In our study, the temperatures recorded by the data loggers at both sites were lower than the recommended ones. However, we must consider that the sampling was carried out in winter and that these values are thus acceptable. Analysis of the histogram of temperature and relative humidity showed that the temperature in the hall behaved similarly to that inside the showcase and that the values of relative humidity showed greater dispersion [figure 3].

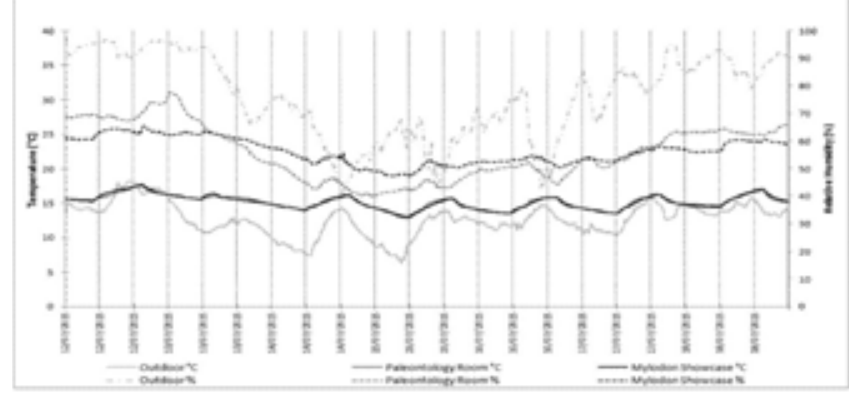

Figure 3.- Histogram of the temperature and relative humidity of the Paleontology Hall and of the inside of the Mylodon showcase, obtained between July $12^{\text {th }} 2015$ and July $18^{\text {th }} 2015$.

On the other hand, the daily variation of temperature recorded by the data loggers was higher than the recommended one and the daily variation of relative humidity in the showcase was optimal in six of the seven days analyzed, although that in the hall was higher than the recommended one in half of the days [figure 4]. In addition, $42 \%$ of the relative humidity values recorded in the hall and $70 \%$ of the values recorded inside the showcase were within those recommended for the conservation of skin.

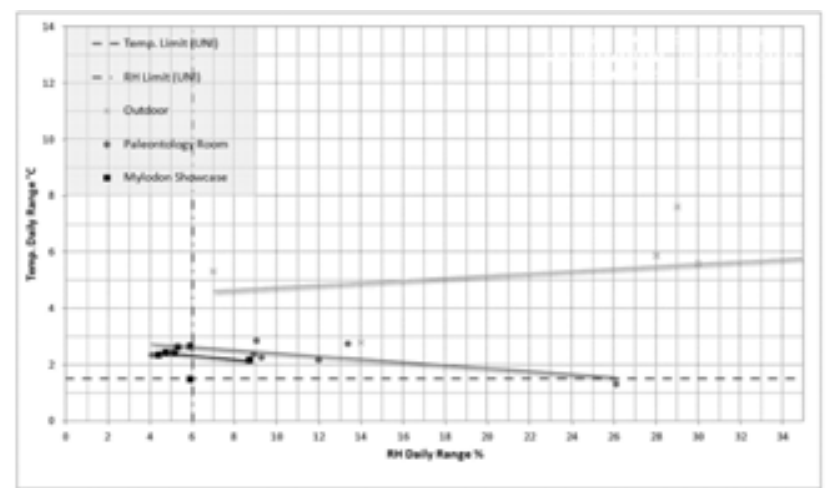

Figure 4.- Variation in the daily temperature and relative humidity of the Paleontology Hall and the Mylodon showcase. Relative humidity and temperature limits for the preservation of skin. 
Although most of the fungal types identified are representatives of ubiquitous indoor genera, the presence of Aspergillus/Penicillium and Cladosporium alerts on the need to carry out a continuous scrutiny given their significance as environmental contaminants (Hyvärinen, 2001; Xu \& Yao, 2011).

Given the historical importance of the skin fragment of Mylodon as well as that of other related specimens for the Paleontology of the South American region, the early detection of biological or physical agents with possible negative action is essential to minimize the natural progressive ageing and avoid potential problems and losses by biodeterioration that may impact on the patrimonial history of such region.

\section{Acknowledgments}

The present study was financially supported by the Consejo Nacional de Investigaciones Científicas y Técnicas (CONICET) PIP 112-201101-00087, PIP 112-20110100391; Agencia Foncyt PICT 2013-0418, and Proyecto de Incentivos a la Investigación (N11/781) of the Facultad de Ciencias Naturales y Museo (FCNyM), Argentina. We thank the Paleontology Unit of the FCNyM and the Conservation and Exhibition Unit of the Museum of La Plata. We also thank Dr. Lorena Elíades for her collaboration and Dr. Marta Morbelli for her support.

\section{References}

ARITA, H. \& ARANDA, M. (1987). Técnicas para el estudio y clasificación de los pelos. Cuadernos de Divulgación, Instituto Nacional de Investigaciones sobre Recursos Bióticos; 32:1-21.

ARZANI, H., LANZELOTTI, S.L., ACUÑA SUÁREZ, G.E. \& NOVO, N.M. (2014). Primer registro de pelos fósiles en Glossotherium robustum (Xenarthra, Mylodontidae), Pleistoceno Tardío, Mercedes, Provincia de Buenos Aires. Ameghiniana; 51 (6): 585-590.

ATLURI, J., VERMA, K.V. \& REDDI, C.S. (1988). Distribution of fungal spore within and above a crop of rice. Proc. Indian Acad. Sci.; 98:25-30.

BARNET, H.L. \& HUNTER, B.B. (1987). Illustrated Genera of Imperfect Fungi, MacMillan Publ. Co. New York.

BAXTER, A. (2006). "Air O Cell Interpretation guide." Environmental Analysis Association. http://eaabaxter.com/ [last update 12/7/2016.].

BORREGO, S. \& PERDOMO, I. (2014). Caracterización de la micobiota aérea en dos depósitos del Archivo Nacional de la República de Cuba. Rev Iberoam Micol.; 31:182-187.

BOZZOLA, J.J. \& RUSSELL, L.D. (1991). Electron microscopy: principles and techniques for biologists. Jones and Barlett publishers. USA.
BRANDONI, D., FERRERO, B. \& BRUNETTO, E. (2010). Mylodon darwini Owen (Xenarthra, Mylodontinae) from the late Pleistocene of Mesopotamia, Argentina, with remarks on individual variability, paleobiology, paleobiogeography and paleoenvironment. Journal of Vertebrate Paleontology; 30:1547155.

BROOK, G.A, FRANCO, N.V., AMBRÚSTOLO, P., MANCINI, M.V., WANG, L. \& FERNANDEZ, P.M.(2015). Evidence of the earliest humans in the Southern Deseado Massif (Patagonia, Argentina), Mylodontidae, and changes in water availability. Quaternary International; 379:107-123.

CAPPITELLI, F. \& SORLINI, C. (2010). Paper and manuscripts. En Mitchell R. McNamara Cl. Editores. Cultural Heritage microbiology: Studies in conservation science. Washington. DC: ASM Press. 45-58.

ESTEBAN, G.I. (1996). Revisión de los Mylodontinae cuaternarios (Edentata-Tardigrada) de Argentina, Bolivia y Uruguay. Sistemática, filogenia, paleobiología, paleozoogeografía y paleoecología.Ph.D. dissertation, Universidad Nacional de Tucumán, Facultad de Ciencias Naturales e Instituto Miguel Lillo, Tucumán, 314 pp.

FEDECAI-01 2007 Programa de certificación de calidad ambiental en interiores. Calidad ambiental en interiores: Criterios de muestreo: 4-6. Federación Española de Empresas de Calidad Ambiental Interior (FEDECAI).

FLORIAN, M.L.E. (2004). Fungal facts. Solving fungal problem in heritage collections. London UK.

GARCÍA MINIET, M. \& SÁNCHEZ ESPINOSA, R. (2012). Estudio de la concentración fúngica aérea de los depósitos del Archivo Municipal de Cárdenas, Cuba. Revista de la Sociedad Venezolana de Microbiología; 32:37-43.

GUIAMET, P.S., GOMEZ DE SARAVIA, S.G., ARENAS, P., PEREZ, M.L., DE LA PAZ, J. \& BORREGO, S.F. (2006). Natural products isolated from plant used in biodeterioration control. Pharmacologyonline; 3:537-544.

GONZALEZ ALVAREZ, G. (2005). Recientes avances en conservación de objetos de cuero. [IsBasedOn] Museos.es: Revista de la Subdirección General de Museos Estatales; 1:8087.

GRANT SMITH, E. (1990). Sampling and identifying allergenic pollens and molds. Blewstone Press, San Antonio, Texas.

GUTAROWSKA, B. (2010). Metabolic activity of moulds as a factor of building materials biodegradation. Polish J. Microbiol.; 59:119-124.

HYVÄRINEN, A., VAHTERISTO, M., MEKLIN, T., JANTUNEN, M., NEVALAINEN, A. \& MOSCHANDREAS, D. (2001). Temporal and spatial variation of fungal concentrations. Indoor Air, Aerosol Science Technology; 35:688-695. 
KÄÄRIK, A., KELLER, J., KIFFER, E., PERREAU, J. \& REISINGER, O. (1983). In Nilsson, S. Ed. Atlas of airborne fungal spores in Europe. Springer -Verlag, Berlin.

KHATTAB, A. \& LEVETIN, E. (2008). Efect of sampling height on the concentration of airborne fungal spore. Annals of Allergy, Asthma \& Immunology 101:529-534.

KRAGLIEVICH, L. (1934). Contribución al conocimiento de Mylodon darwini Owen y especies afines. Revista del Museo de La Plata; 34:255-292.

LACEY, M.E. \& WEST, J.S. (2006).The Air Spore, Springer, Dordrecht, Netherlands.

MARTINIC, M. (1996). La cueva del Mylodon: Historia de los hallazgos y otros sucesos. Relación de los estudios realizados a lo largo de un siglo (1895-1995). Anales del Instituto de la Patagonia. Serie Ciencias Humanas:24.

MICHALSKI, S. (2007). Preservación de las colecciones. In Como administrar un Museo: Manual Práctico. UNESCO. 5190.

MORENO, F. \& WOODWARD, S.A. (1899). On a portion of mammalian skin, named Neomylodon listai, from a Cavern near Consuelo Cove, Patagonia. Proceedengs of the Zoological Society of London; 144-156.

NITIU D.S., MALLO A.C., ELÍADES L.A., SAPARRAT M.E. \& VAZQUEZ, H.R. (2015). Monitoreo de la carga fúngica ambiental y de otros bioaerosoles en un depósito de restos momificados del NOA del Museo de La Plata (Argentina). Boletín de la Sociedad Argentina de Botánica; 50(4):427-436.

NITIU, D.S., MALLO, A.C., GARDELLA SAMBETH, M.C. \& MORBELLI, M.A. (2010). Contribución a la identificación de esporas del Reino Fungi en la atmósfera de La Plata (Argentina). Boletín de la Sociedad Argentina de Botánica; 45:301-308.

NORMA UNI 10829:1999. Beni di interesse storico e artistico: Condizioni ambientali di conservazione mizurazione ed analisi. Ente Nazionale di Unificazione, Milano.

PINZARI, F., FANELLI, C., CANHOTO, O. \& MAGAN, N. (2004). Electronic nose for the early detection of moulds in libraries and archives. Indoor Built Environment; 13:387395.

RANTIO-LEHTIMAKI A., KOIVIKKO A., KUPIAS R., MAKINEN Y. \& POHJOLA A. (1991). Significance of sampling height of airborne particles for aerobiological information. Allergy; 46:68-76.

RIDEWOOD, W.G. (1901). On the structure of the hair of Mylodon listai and other South American edentate. Quarterly Journal of Microscopical Science; 2:393-411.
RODRIGUEZ GARCÍA, J.C. (2016). Evaluación aeromicrobiológica del depósito del Centro de Documentación del Museo Nacional de la Música de Cuba. Ge-conservacion 9; 117-126

SHELTON, B.G., KIRLAND, K.H., FLANDER W.D. \& MORRIS, G.K. (2002). Profiles of airborne fungi in building and outdoor environments in the United States. Applied an Environmental Microbiology; 68(4):1743-1753.

SINGH, J. (2003). European Heritage conservation and environmental monitoring-making informed decisions. European Heritage conservation environmentally sustainable Solutions. Dublin, Ireland, Trinity College.

SOLIS, E. (2011). Estudio micológico del aire en áreas ocupacionales y exteriores del laboratorio de investigación en productos naturales ubicado en el edificio T-10 en la ciudad universitaria en zona 12 y el laboratorio ubicado en la zona 1 del centro de información y asesoría toxicológica del departamento de toxicología de la facultad de ciencias químicas farmacia de la universidad de San Carlos de Guatemala.Web page: biblioteca.usac.edu.gt/ tesis/06/06_3102.pdf. [Last update 12/7/2016].

TONNI, E.P., CARLINI, A.A., SCILLATO YANÉ, G.J. \& FIGINI, A.J. (2003). Cronología radiocarbónica y condiciones climáticas en la "Cueva del Milodón" (sur de Chile) durante el Pleistoceno Tardío. Ameghiniana 40(4):609-615.

VALENTÍN, N. (2010). Microorganism in museum collections. Coalition; 19:2-5.

VAN DUIN, P. (2014). Climate effects on Museum objets. The Need for Monitoring and Analysis. In Conservation Perspective. The GCl Newsletter. Collection Environments; 29(2):13-16.

WALTER, A. (2003). Basic preservation guidelines for library and archive collections. London: Natural Preservation Office, NPO Preservation Guidance. British Library.

XU Z. \& YAO M. (2011). Analysis of culturable bacterial and fungal aerosol diversity obtained using different samplers and culturing methods. Aerosol Science Technology; 45:11431153. 


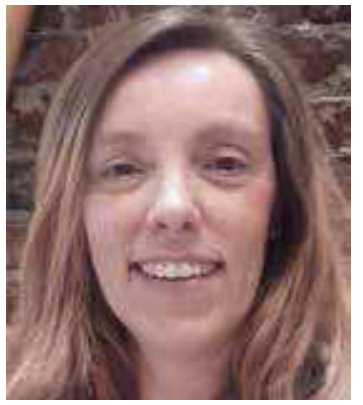

\title{
Dra. Daniela Silvana Nitiu
}

danielanitiu@yahoo.com.ar

Universidad Nacional de La Plata. Buenos Aires, Argentina

La Dra. Daniela S. Nitiu es docente en la Facultad de Ciencias Naturales y Museo desde 1996, fue becaria de CIC y CONICET. Obtuvo su título de Doctora en Ciencias Naturales con el tema "Estudio aeropalinológico de la ciudad de La Plata" en el año 2006, otorgado por la Facultad de Ciencias Naturales y Museo UNLP. Investigadora Asistente del CONICET desde 2009. Es Investigador Responsable de: un Proyecto PIP CONICET, un PICT y de un Proyecto de Incentivos a la Investigación de la UNLP. Categoría de Docente Investigador III. Evaluador de Proyectos de Investigación para CONICET, AGENCIA y UNLP y ha realizado arbitrajes en revistas internacionales. Es Directora de Tesis Doctoral de la Lic. Anabel Calderón (CONICET) desde 2015 y Directora de la pasante Lic Cintia San Martín en el Programa de Entrenamiento y Apoyo a la Investigación para estudiantes de la FCNYM (UNLP). Posee numerosos antecedentes en Reuniones y Publicaciones en distintos ámbitos científicos nacionales e internacionales. Ha recibido premios a trabajos científicos en diversos eventos científicos. Ha dictado un curso de Postgrado dentro del Programa INTER-U como Miembro Responsable en la Facultad de Química, Bioquímica y Farmacia. Universidad Nacional de San Luis (2012). Es miembro editor de la Revista Timisoara (Polonia). Trabaja en estudios aeromicológicos en ambientes de interior desde el año 2010.

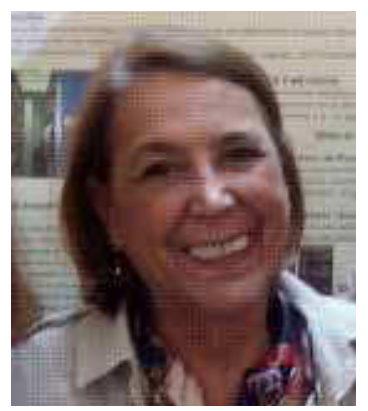

\author{
Lic. Andrea Cecilia Mallo \\ malloa2001@yahoo.com.ar \\ Universidad Nacional de La Plata. Buenos Aires, Argentina
}

La Lic. Andrea C. Mallo, se desempeña como Personal de Apoyo a la investigación, categoría Principal CIC -PBA en la temática de Aerobiología y Aeromicología desde el año 2006 en la Cátedra de Palinología de la Facultad de Ciencias Naturales y Museo. Docente en la Cátedra de Introducción a la Botánica en la Facultad de Cs Naturales y Museo, Categoría de Docente Investigador IV. Ha participado en 9 Proyectos de Investigación de la Universidad Nacional de la Plata y CONICET y en la actualidad es integrante de 2 Proyectos PIP CONICET y ANPCyT bajo la dirección de la Dra. Daniela Nitiu. Ha sido Miembro de Comisiones Asesoras, Consejo Consultivo Departamental de Botánica, evaluador de Proyectos de Investigación para la Agencia Nacional de Promoción Científica y Tecnológica (ANPCyT) y ha realizado arbitrajes en revistas internacionales. Actualmente posee 16 trabajos publicados en revistas científicas indexadas, 1 capítulo de libro, 5 trabajos completos en Actas de Congreso y 50 presentaciones en congresos en modalidad oral y paneles. Ha realizado informes técnicos de distintas Salas del Museo de La Plata y del Archivo y Biblioteca Ataúlfo Perez Aznar del Senado de la Provincia de Buenos Aires, Legislatura de la Provincia de Buenos Aires. Es Codirectora de una Pasantía en la Facultad de Ciencias Naturales y Museo. 


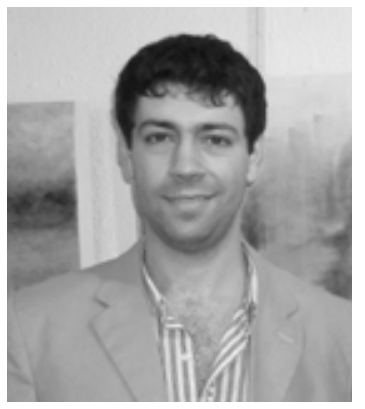

\author{
Arq. Mauro García Santa Cruz \\ mggarciasc@gmail.com \\ Universidad Nacional de La Plata. Buenos Aires, Argentina
}

El Arq. Mauro García Santa Cruz es Arquitecto FAU UNLP, 2014. Secretario Técnico del Laboratorio de Arquitectura y Hábitat Sustentable FAU UNLP desde 2010. Censista en el Censo Nacional de Infraestructura Escolar, relevamientos de campo y procesamiento de datos (CeNIE09 - FAU UNLP). Asesor en la consultora grgarcía\&asoc en temas de arquitectura sustentable y conservación preventiva. Participó de la Puesta en valor de la capilla de la Estancia Los Álamos, que recibió el Premio a la mejor Intervención 2003 SCA CICOP, del Mapeo de desajustes para la intervención de las capillas de los Hospitales Borda y Moyano y del proyecto para el Museo Histórico del Partido de Pinamar. Participa en proyectos de investigación con financiamiento de ANPCyT, CONICET y UNLP sobre arquitectura sustentable y condiciones ambientales en edificios para la cultura desde 2007. Becario Doctoral CONICET desde 2014, siendo el tema de investigación el “Desarrollo de un protocolo para evaluación y certificación de la sustentabilidad en edificios para la cultura". Alumno del Doctorado en Arquitectura y Urbanismo, Facultad de Arquitectura y Urbanismo, UNLP. Participó en más de 35 congresos, encuentros y jornadas sobre temas de arquitectura sustentable, conservación del patrimonio y conservación preventiva. Autor y coautor de artículos publicados en revistas científicas con referato, capítulos de libros y trabajos publicados en las actas de eventos científicos. Editor Técnico y co-autor del libro "Cuadernos de Arquitectura Sustentable, Artículos Seleccionados, 2011", compilado por Jorge D. Czajkowski y Analía F. Gómez ISBN 978-950-34-0800-1.Miembro del Comité Organizador del “I Encuentro Nacional sobre Ciudad, Arquitectura y Construcción Sustentable"del "Seminario Técnico ASHRAE y el LAyHS FAU UNLP y del Seminario"Reflexiones sobre las transiciones energéticas metropolitanas" organizado por el LAyHS FAU UNLP y el Centro de Estudios Urbanos y Regionales CEUR CONICET.

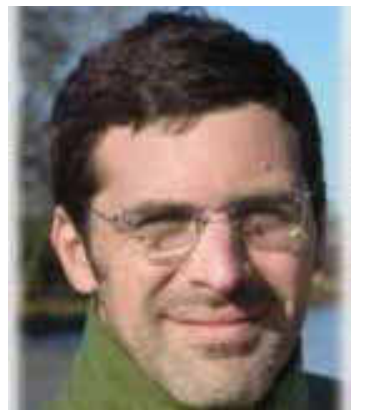

\title{
Dr. Mario Nazareno Saparrat
}

masaparrat@yahoo.com.ar

Instituto de Fisiología Vegetal. CONICET-UNLP de La Plata. Buenos Aires, Argentina

EI Dr. Mario Saparrat, Investigador Adjunto CONICET en el INFIVE, Profesor Adjunto UNLP en la Cátedras: Microbiología agrícola (Facultad de Ciencias Agrarias y Forestales, UNLP) y Botánica Sistemática I (Facultad de Ciencias Naturales y Museo, UNLP), Vicepresidente de la Asociación Micológica Carlos Spegazzini. Desarrolla investigación en el campo de la fisiología de hongos y su rol en la transformación de materiales orgánicos y los pigmentos de los hongos, específicamente melaninas. Participa del Programa de Incentivos a los Docentes-Investigadores, Secretaría de Política Universitaria del Ministerio de Educación de la Nación en la Categoría III. Posee financiamiento para su investigación PICT como Investigador responsable (grupo en formación). Ha realizado diversas estancias y pasantías posdoctorales en el exterior. Ha recibido 4 distinciones. Ha sido docente expositor en numerosos cursos de postgrado. Ha sido coordinador y expositor en numerosos y diversos eventos científicos. Es director de varios becarios y tesistas en diferentes centros del país. Evaluador de Comisiones Científicas, Tesis y concursos docentes. Tiene en su haber numerosos arbitrajes de publicaciones científicas nacionales e internacionales y es Editor de sección sobre Plantas avasculares en la Revista Nacional "Darwiniana Nueva Serie". Ha participado en numerosos congresos y eventos científicos y presenta un alto número de publicaciones como primer autor, autor responsable (último) y en coautoría.

Artículo enviado el 14/07/2016

Artículo aceptado el 16/11/2016 


\title{
La radiología digital para relicarios de ceroplástica: estudio interdisciplinar para identificar el sistema constructivo y la ubicación de los restos óseos
}

\author{
Gabriela Sánchez Reyes, José Luis Velázquez Ramírez, Ana Lucía Montes Marrero
}

\begin{abstract}
Poco se han estudiado los relicarios en ceroplástica de origen romano, simulacros de cera y otros materiales que representan el cuerpo de santos catacumbales, denominados corpi santi. En su interior resguardan restos óseos variados, expuestos ya fuera en la cabeza o en las extremidades a través de ventanas, y su técnica de factura es poco conocida. A partir de la radiología digital directa, técnica no invasiva, se propone analizarlos para conocer el sistema constructivo que muestra variantes en cada ejemplar, identificar la cantidad y ubicación exacta de las reliquias, y su estado de conservación general.
\end{abstract}

Keyword: Radiología digital, ceroplástica, relicario, reliquia, cuerpo santo, santo catacumbal, sistema constructivo, técnica de factura, conservación, corpi santi.

\section{The digital radiology for ceroplastic reliquaries: interdisciplinary study to identify the constructive system and the location of the skeletal remains}

Resumen: There are few studies about Roman ceroplastic reliquaries. These sculptures are a kind of wax simulacrum, representing the body of Catacomb saints or "corpi santi". Inside them, some bones are to be found in head, arms or legs, visible through windows. However, their manufacture in unknown. From direct digital radiology, a non-invasive technique, we proposed, to analyze them to know, not only the constructive system. But also, to identify the exact amount and location of the relics inside, and their general state of preservation, since each piece, is different to another.

Palabras clave: direct digital radiology, ceroplastic, reliquary, relic, catacomb saints, construction system, manufacture, conservation, corpi santi.

\section{A radiografia digital para relicários ceroplásticos: estudo interdisciplinar para identificar o sistema construtivo e a localização de restos ósseos}

Resumo: Pouco se tem estudado os relicários ceroplásticos de origem romana, simulacros de cera e outros materiais que representam o corpo de santos catacumbais, denominados corpi santi. No seu interior, protegem-se variados restos ósseos expostos na cabeça ou nas extremidades através de aberturas, sendo pouco conhecidas as suas técnicas de execução. A partir da radiografia digital direta, técnica não-invasiva, propõe-se analizá-los para conhecer o sistema construtivo que mostra variantes em cada exemplar; identificar a quantidade e a localização exata das reliquias e o seu estado geral de conservação.

Palavras-chave: Radiografia digital, ceroplástico, relicario, corpo santo, santo catacumbal, sistema construtivo, técnica de execução, conservação, corpi santi. 


\section{Introducción}

La investigación sobre el origen de las reliquias remite a distintos periodos históricos, el más importante de ellos fue el hallazgo fortuito ocurrido el 31 de mayo de 1578 en la vía Salaria, en un viñedo que pertenecía a Bartolomé Sánchez de Alda, que revelaría un mundo de vestigios de los primeros mártires de la Iglesia Católica, que denominó corpi santi o "cuerpo santo", que define únicamente a un tipo de reliquias mártires extraídas de las catacumbas romanas. Este hecho dio origen a la idea de una nueva Roma subterránea, recinto donde serían buscados con tesón las osamentas sagradas, para ser repartidos por la cristiandad. Este inventio o descubrimiento de reliquias fue duramente criticado por los protestantes, pero para la Iglesia Romana esto no fue sino la confirmación divina del culto a las reliquias y a los santos, por lo que su presencia fue una herramienta para iniciar un proceso de cristianización, no sólo en Europa sino también en América. Los restos óseos de los mártires romanos fueron tan apreciados que surgió un tráfico y venta de falsas reliquias, por lo que en 1667, se creó la Congregación de Indulgencias y de Santas Reliquias, entre cuyas funciones estaba vigilar la extracción y autenticación de cuerpos santos a través del Vicario de Roma. El origen de la arqueología cristiana también fue un fruto de este descubrimiento, que tenía como meta la extracción de mártires para poblar los templos con estos vestigios y testimonios de santidad. Uno de los grandes estudiosos fue Antonio Bosio (1575-1629) que exploró sistemáticamente las catacumbas desde 1593, y sus observaciones serían publicadas, de manera póstuma, en la obra Roma subterránea (Roma sotterranea). En el caso de México, por ejemplo, las reliquias llegaron como resultado del intenso proceso de circulación y traslado de reliquias por el mundo católico; apenas establecidas las órdenes religiosas, comenzaron a formarse colecciones de reliquias que se ostentaban ya fuera en las sacristías, retablos, capillas o en altares domésticos. (Sánchez, en proceso).

El estudio de la reliquia está en relación con el relicario, por ello es necesario estar familiarizado con las tipologías, terreno que aún debe explorarse debido a la gran variedad formal que existe, y del que falta aún profundizar. Su identificación es de gran utilidad para su catalogación, no sólo en museos sino para ingresarlos en bases de datos de registro patrimonial. El relicario debe entenderse como un receptáculo en cuyo interior se resguardan, los restos de los santos. En general puede decirse que tiene dos funciones básicas: proteger su contenido sagrado y a la vez, exponer y dejar visible una parte o la totalidad de la reliquia. Una de las tipologías que han sido analizadas es el relicario de ceroplástica, que no cuenta con una terminología aceptada de manera generalizada. En unos casos lo llaman "imagenrelicario" (Bouza 1990), en otros como "relicarios-estatuas de cera" (Ballestriero 2013), o bien como corpisanti en cerolástica (corpisanti in ceroplástica) (Ghilardi 2015); mientras que la historiografía francesa los designa como corp-reliquiare o cuerpo-relicario (Laurence 1999), es esta última designación la que se ha adoptado porque nos parece es inequívoca, ${ }^{1}$ para designar un cuerpo completo elaborado en cera en cuyo interior se resguardan restos óseos de un mártir catacumbal romano. Estas obras se caracterizan por estar generalmente en posición yacente, tener vestimentas elaboradas con textiles lustrosos, aplicaciones de postizos, accesorios y en ocasiones con una palma del martirio, una tablilla con su nombre y el vas sanguinis o vaso de sangre. Todo lo anterior se encuentra dentro de urnas realizadas especialmente para cada ejemplar. Para su exposición, algunos huesos son visibles gracias a pequeñas ventanas localizadas en los brazos, pecho, piernas, plantas de los pies y palmas de las manos, y en ocasiones en la parte posterior del cráneo, por lo que es importante señalar, que la cantidad de ventanas varía en cada ejemplar. A pesar de haber sido incorporado este tipo de relicario a estudios sobre santos catacumbales (Bouza 1990) o en fechas más recientes como una tipología de obras de ceroplástica (Ballestriero 2013), se desconocen detalles sobre su elaboración, cantidad y ubicación exacta de las reliquias, puesto que sólo se podía realizar una observación superficial de la imagen, sembrando de alguna forma, la incertidumbre respecto al contenido. ${ }^{2}$ (Ghilardi 2015)

En la historiografía de la historia del arte virreinal en México, pocos acercamientos se habían realizado sobre este tipo de obras. En 2004 una investigación hizo una propuesta tipológica para identificarlos en los acervos de los recintos religiosos y museísticos, además de proponer pautas para comprenderlos como objetos de devoción a partir de sus características materiales y formales, con apoyo de documentación histórica. (Sánchez 2004). En dicho estudio se incorporó el término de cuerpo-relicario, y se proponía la observación como único medio para identificar la osamenta, para lo cual sólo quedaba rodear la imagen para encontrarla e identificar la teca donde se depositaban las reliquias. A partir de la inspección visual realizada en varios ejemplares, quedó claro que cada relicario expone las reliquias en diferentes lugares, por lo que cada ejemplar era singular. [figura 1]

Entre los estudiosos de relicarios en ceroplástica se pensaba que cada imagen contenía únicamente las reliquias que eran visibles (Sánchez 2004), aunque se ha planteado la posibilidad de que hubiera restos óseos en el interior, pero no se tenía manera de constatarlo (Ghilardi 2012) Esta interrogante hoy día se puede resolver gracias a una propuesta resultado de una preocupación sobre la conservación y restauración de este tipo de relicario, que consiste en aplicar técnicas radiográficas para el estudio de este tipo de bienes culturales. (Montes en proceso) Si bien la radiología se ha aplicado previamente en esculturas de ceroplástica, especialmente en ceras anatómicas, no se había hecho así para esta tipología de relicario. Por primera ocasión se aplicó esta técnica en un par de relicarios 


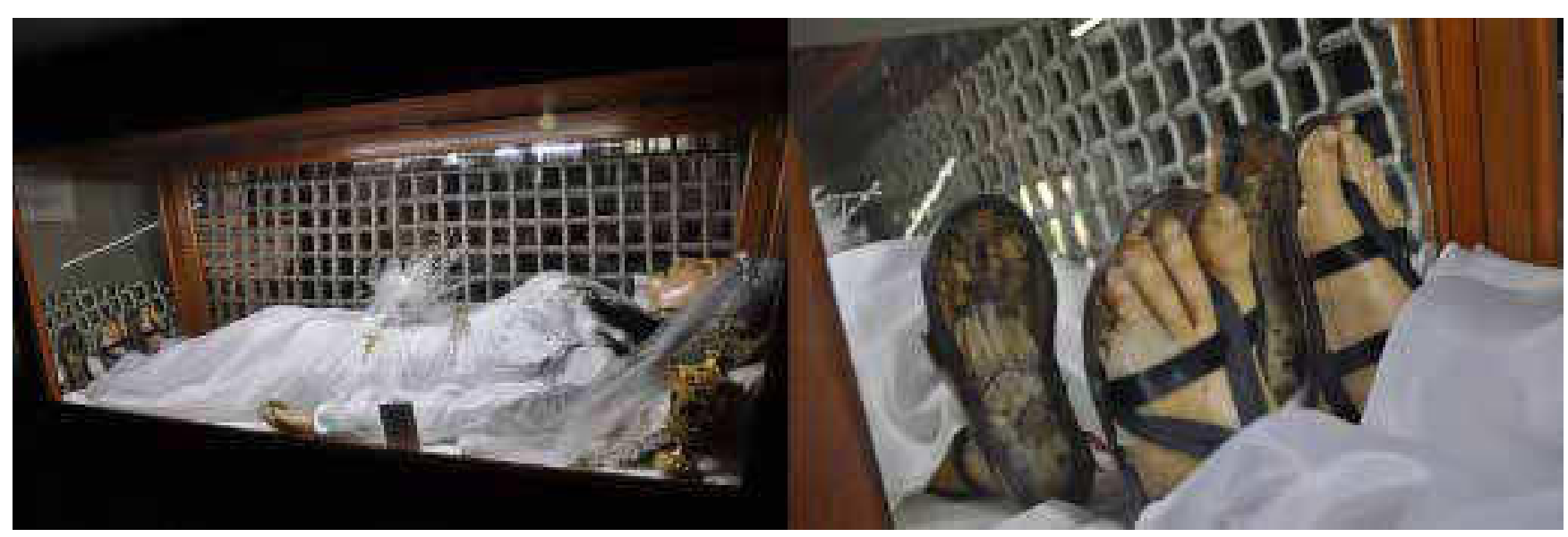

Figure 1.- La inspección visual era la única opción que se tenía para saber dónde se encontraban los restos óseos de los relicarios en ceroplástica, así que debían buscarse en los pies, brazos o cabeza. Cuerpo-relicario de santa Celeste. Templo de santa Teresa la Nueva. Ciudad de México. Fotografía Gabriela Sánchez Reyes

localizados en la Catedral de Durango, México: un cuerpo-relicario de san Plácido mártir y la cabezarelicario de ceroplástica de santa Faustina. Las placas obtenidas mostraron no sólo la estructura interna de las piezas, sino que reveló que contenía más huesos de los que se veían a simple vista (Montes, en proceso). A partir de este estudio y debido a los exitosos resultados obtenidos, se replicó esta técnica radiológica en tres obras de la Catedral Metropolitana de la Ciudad de México $^{3}$ y una más en el templo del Carmen de San Ángel, para observar la técnica de factura y los restos óseos del interior. El objetivo de este texto entonces, es mostrar los resultados de este primer muestreo donde se confirma la hipótesis planteada, siendo ésta, que cada ejemplar de cera presenta variantes en su técnica de factura y no sólo resguarda reliquias, sino que están distribuidas de forma distinta y la cantidad también varía. Lo que ha enriquecido el conocimiento sobre este tipo de obra y ha sido posible identificar vertientes en su factura así como analizar y ubicar las reliquias óseas en su interior.

\section{Aplicación de la radiología digital directa (RRD) en bienes muebles culturales}

En 1895 cuando Wilhelm Conrad Roentgen descubrió los rayos $X$, nunca imaginó el alcance que tendría su descubrimiento a través de los años, extendiéndose su uso en la comunidad médica y posteriormente entre veterinarios, odontólogos, antropólogos, de la historia del arte y como herramienta de evaluación en procesos de restauración del patrimonio. Por más de 100 años se ha utilizado la película radiográfica, chasis, reveladores y fijadores para obtener imágenes radiográficas de calidad diagnóstica. Sin embargo, en la forma tradicional se requería de un cuarto oscuro para realizar el reemplazo de película radiográfica de los chasis, múltiples tamaños de éstos dependiendo de las dimensiones la obra o paciente, y luego proseguía el revelado, fijado y secado, todo ello de forma manual. Estos métodos, aunque fueron muy eficientes por muchos años, en la actualidad resultan poco prácticos y lentos desde el punto de vista logístico, sobre todo cuando se requieren realizar trabajos en campo, o cuando las obras son frágiles, y no puede trasladarse ni la obra a un laboratorio o el equipo al recinto religioso. Si bien existen equipos análogos portátiles, se requiere armar un cuarto oscuro para procesar con líquidos reveladores y fijadores. Afortunadamente, la radiología en los últimos 40 años ha dado un salto exponencial en su evolución, tanto en la forma de tomar las placas como en su revelado, y se ha automatizado este proceso haciéndolo más fácil y práctico. En la actualidad se cuentan con equipos de radiología digital directa (RDD) que recibe la radiación electromagnética, la digitaliza y convierte en imágenes radiográficas en tan sólo 4 a 8 segundos. Un equipo de estas características es sin duda una opción alterna a los equipos análogos y de radiología computarizada (RC), teniendo como ventajas su capacidad de conocer los resultados al instante, y hace posible realizar trabajos in situ, especialmente en casos en los que los custodios del patrimonio religioso, no autorizan la salida de los bienes muebles históricos. En el caso de los equipos de radiología digital directa totalmente inalámbricos, se cuenta con dos principales tamaños de chasis digitales: $8 \times 10$ y 14 x 17 pulgadas, que optimizan los rayos $X$ que reciben y permiten obtener imágenes de extraordinaria calidad radiográfica y diagnóstica. Otra ventaja es que debido a su tamaño se pueden colocar detrás de espacios de difícil acceso como podrían ser retablos, altares, urnas, entre otros y poder obtener imágenes sin la limitante de la longitud del cable. En equipos inalámbricos esta limitante no existe ya que el chasis se puede colocar a diferentes distancias sin tener ninguna variación en la calidad de radiografía obtenida. Por otro lado existen disponibles en el mercado generadores de rayos $X$ de baterías, lo cual vuelve al sistema completamente 
inalámbrico e independiente de corriente eléctrica, lo que permite trabajar en lugares remotos, en andamios a diferente altura, en campo con antropólogos, etcétera. El software para analizar las radiografías permite realizar varias funciones de gran utilidad, como mediciones de elementos de la obra, manejar una escala de grises para ir encontrando diferentes detalles, evaluar la placa radiográfica en positivo o negativo, magnificar áreas, etc., procedimiento que en el pasado se hacía después de escanear la película radiográfica, y que en muchos casos, perdía calidad durante el proceso. En cuanto al número de radiografías que se requieren de cada obra, dependerá de las necesidades de la investigación y de la pieza a evaluar.

El formato de las imágenes radiográficas ya sea en el ámbito médico como para bienes patrimoniales, se obtiene en el sistema de comunicación de imágenes digitales DICOM por sus siglas en inglés, y entran en un almacenamiento de imágenes PACS, para ser vistas y analizadas en cualquier parte del mundo. Por otro lado, el manejo, evaluación y movilización rápida de las radiografías también es en formato JPG, por lo que pueden almacenarse en medios ópticos o magnéticos (CD, DVD, USB) o en la nube virtual. En la actualidad incluso se habla ya de radiología de alta definición (HDR), lo que pone de manifiesto la evolución que ha tenido desde sus orígenes, hace más de 120 años. El estudio radiográfico in situ aplicado a bienes culturales aporta gran cantidad de información útil sobre sus sistemas constructivos, el estado de conservación y deterioros que de otra forma pueden ser imperceptibles a simple vista. Tiene la ventaja de proporcionar un análisis global, sin duda una cualidad es la portabilidad del equipo con resultados no invasivos ni destructivos. [figura 2]

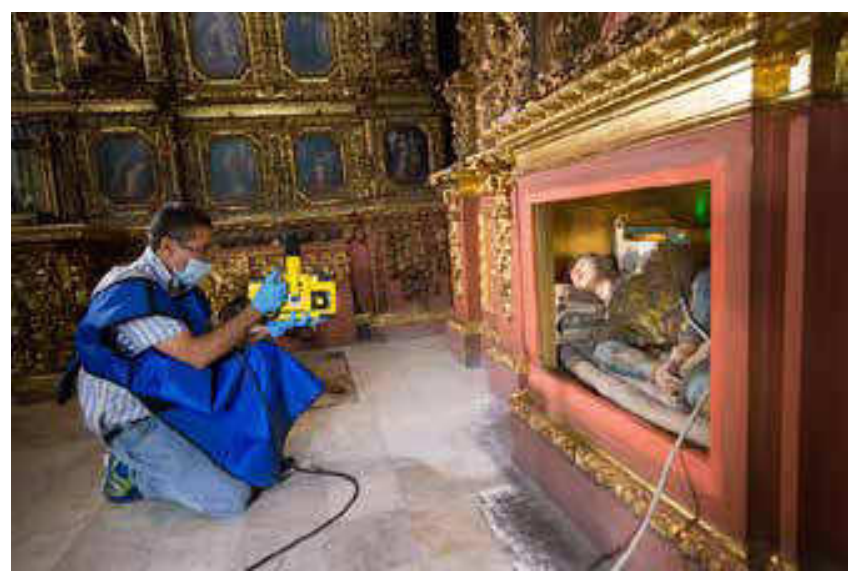

Figure 2.- Toma radiográfica in situ de un relicario donde se observa al radiólogo, el generador de rayos $\mathrm{X}$ y uso del mandil de plomo para protección de radiación; el chasis digital se aprecia por detrás del cuerpo-relicario. Es importante ver que la pieza no fue sustraída de la urna para su evaluación radiográfica. Técnica radiográfica $60 \mathrm{kv}$. mAs 0.12 . Distancia $1 \mathrm{~m}$. Generador marca mini $X$ ray. 80kv 20 mAs. Chasis digital marca cuattro de cesio. Fotografía de Javier Otaola. Radiología José Luis Velázquez.
Quizá la aplicación más conocida de la radiología en bienes muebles sea en pinturas de caballete $y$ escultura policromada, aunque también se ha utilizado prácticamente en cualquier material, como cerámica, metales, textiles y papel, por mencionar algunos. En el ámbito del estudio de los relicarios de otras tipologías, se han realizado algunos estudios de esculturas policromadas, como bustos-relicario (Valverde 2012) y brazos-relicario, ${ }^{4}$ o bien, en ejemplares de orfebrería. Una institución como el Royal Institute for Cultural Heritage (KIK-IRPA) fundado por Paul Coremans, al tener como vocación analizar científicamente las obras de arte, comenzó a utilizar la radiología en objetos tan variados como cerámica, vidrio, papel o urnas (châsses) con reliquias, sin embargo aún no han incluido en su muestreo obras en ceroplástica como esta tipología de relicario. ${ }^{5}$ Esta técnica ha demostrado su utilidad para el estudio de obras ceroplástica a nivel internacional, sobre todo para modelos anatómicos de cera y obras artísticas, por lo que es un campo abierto a la investigación (Gramtrop 2015).

Para el caso de México el estudio de la radiología de bienes culturales inició en 1957 cuando Abelardo Carrillo y Gariel analizó la escultura del Cristo de Mexicalzingo, pero fue hacia el año 2000 que se difundieron trabajos de escultura ligera (Amador 2002) en muchos casos con aparatos analógicos, lo que significaba el traslado de la pieza hasta las instalaciones donde se encuentra el generador de Ratos $X$. Mucho se ha avanzado en este sentido y sin duda se trata de una técnica que ya forma parte de los equipos de trabajo en universidades. Por ejemplo desde 2005 es parte de la currícula de los alumnos de restauración de la Escuela de Conservación y Restauración de Occidente (ECRO) en Guadalajara, Jalisco, por lo que incluso publicó un Manual de Radiología aplicada al estudio de bienes muebles, el primero en su género (Bautista e Insaurralde 2012). En el caso de proyectos museográficos, también se empieza a incluir como parte sustancial de la curaduría, como es el caso de la exposición Santiago un caballero con alma de maíz en el Museo Nacional del Virreinato. (Santiago 2016).

Hace apenas unos años se tomaron placas a algunas ceras anatómicas pertenecientes al Museo del Palacio de la Escuela de Medicina en la ciudad de México; con ello se descubrió que contenían huesos humanos, madera y relleno y piezas unidas con clavos y alambres, gracias a lo cual pudieron restaurarse adecuadamente (Perpetua Restauración 2012). Sin embargo, a pesar de la relevancia del estudio, los resultados no fueron publicados. [figura 3 ].

En el caso específico de los relicarios en ceroplástica, no se habían realizado nunca antes rayos $X$ con fines académicos. De ahí que el análisis radiológico puesto en práctica primero en los casos de Durango, y que se presenta a continuación, podrá ser de gran utilidad al diagnosticar estas esculturas de cera, para analizar su estructura y determinar estado de conservación. Los resultados son de gran interés para una amplia gama de especialistas que comparten el mismo objeto de estudio. 


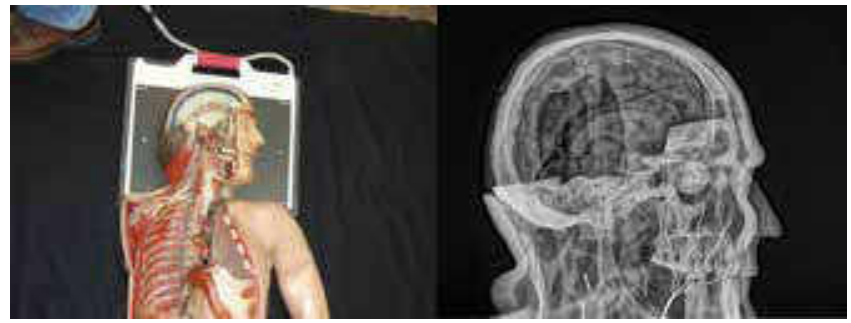

Figure 3.- Estudio radiográfico de una cera anatómica donde se encontraron restos óseos, procedimiento muy similar al de los cuerpos-relicario. Técnica radiográfica $60 \mathrm{kv}$. mAs 0.12 . Distancia $1 \mathrm{~m}$. Generador marca mini X ray. 80kv 20 mAs. Chasis digital marca cuattro de cesio. Fotografía y radiología José Luis Velázquez.

\section{La imagen radiográfica de relicarios en ceroplástica: los casos de santa Faustina y san Clemente}

Para mostrar la aplicación de la radiología para el estudio de los sistemas constructivos, se presentan dos casos de relicarios de ceroplástica, el primero es el de santa Faustina mártir, cabeza-relicario que forma parte de la colección expuesta en la Galería Episcopal de la Catedral de Durango, Dgo., (Montes en proceso); el segundo caso es San Clemente Flavio, ubicado en el templo del Carmen de San Ángel, en la Ciudad de México. Los rayos X en este tipo de obras permiten conocer si los elementos de cera son ahuecados o sólidos, si tienen armazones al interior, o identificar la presencia de distintos materiales como elementos metálicos y textiles; también es posible apreciar intervenciones anteriores, su estado de conservación general, el tipo de ensambles, así como la ubicación de las decoraciones -encajes, botones, hilos entorchados, cinturones, etcétera. El análisis se enriquece al colaborar en conjunto con especialistas de la antropología física, ya que se puede obtener información específica sobre los restos óseos del individuo, como la identificación del sexo, la edad aproximada de su muerte, el estado de conservación, la presencia de enfermedades, constatar si toda la osamenta pertenece a un mismo individuo, en caso de haber fracturas si fueron o no en vida y si los huesos se han colocado en una posición anatómica (Montes en proceso)

\section{Santa Faustina}

La actual Catedral de Durango debe su origen a la creación del obispado en 1620. El edificio actual inició su construcción en 1695 y se concluyó parcialmente en 1713, pero no fue sino hasta 1844 que la decoración interior y los altares fueron concluidos. Entre los bienes muebles que se han conservado se encuentran pinturas, mobiliario, escultura, textiles, platería y desde luego, algunos relicarios. Tal es el caso de un par de cabezas-relicario: la de santa Faustina y san Benedicto mártires [figura 4], realizados con la misma técnica de factura, aunque no se cuenta aún con información sobre su traslado y ubicación original, antes de ser parte de la Galería Episcopal. Las dos obras son una variante tipológica del cuerpo-relicario ya que presentan básicamente la misma factura: elementos de ceroplástica, restos óseos al interiory otros diversos materiales, pero sólo se representó la cabeza el mártir, cercenada, incluso sin evidenciar heridas; llevan también elementos iconográficos propios de los mártires catacumbales como el gesto in somni pacis del rostro, una corona de flores, una tablilla con su nombre en latín y se muestran dentro de urna protectora que a la vez permite admirarlas.

Esta variante al parecer no fue común, o al menos son muy pocos los ejemplares de los que se tiene noticia hasta ahora, pues apenas se conocen otros cuatro: en la localidad de

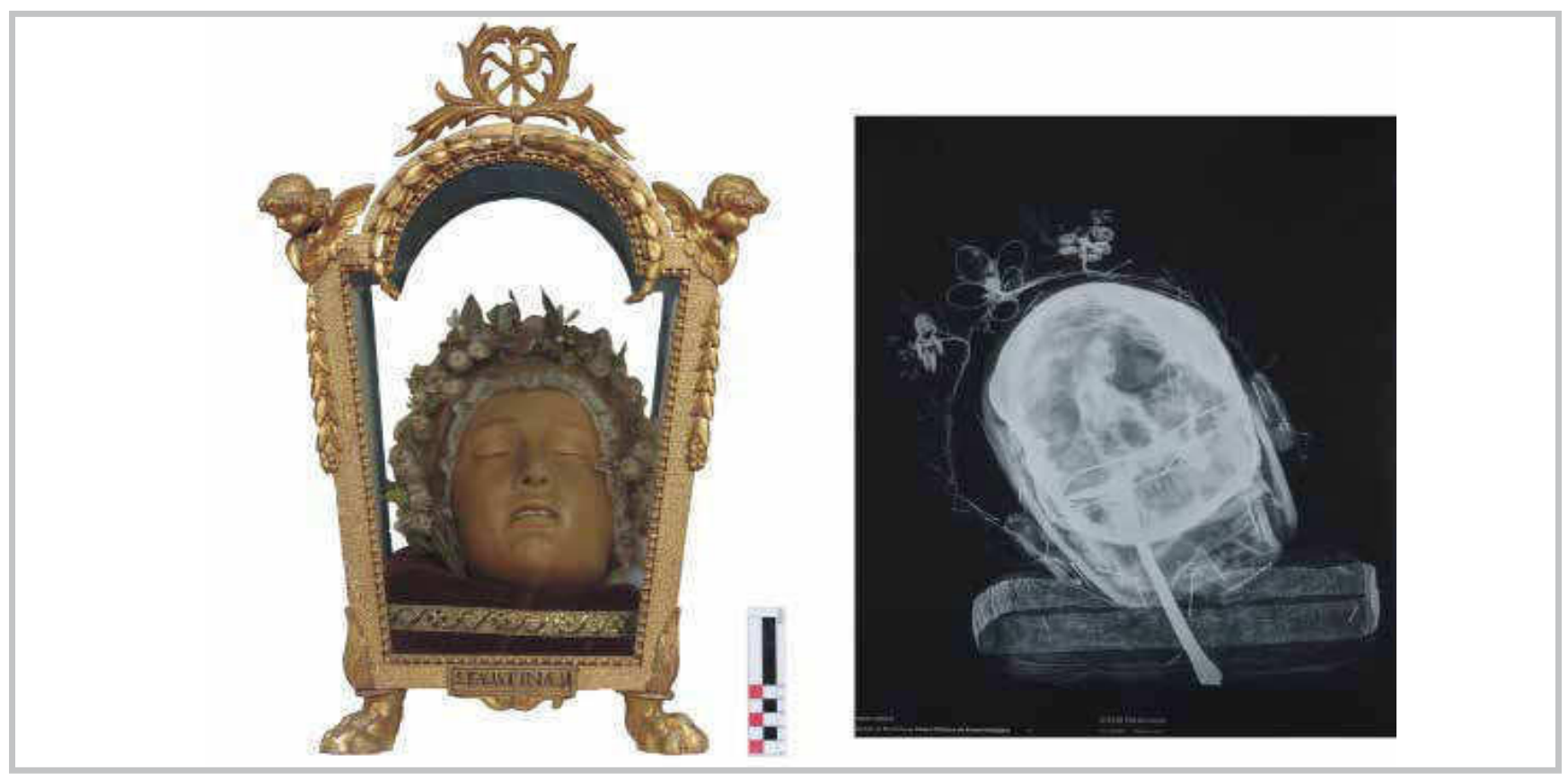

Figure 4.- (izq.) Cabeza-relicario de santa Faustina mártir en la Galería Episcopal de la Catedral de Durango, Dgo; (der.) placa radiográfica, vista frontal, donde se observa cráneo completo, elementos de cera, varilla metálica, corona de alambre e hilos metálicos del cojín. Técnica radiográfica 80 kv, 20 mAs. 1 metro distancia. Fotografía y radiología Ana Lucía Montes Marrero. 
Montalto di Castro, Italia, se encuentran los santos patronos, san Quirino y san Cándido que son sacados en procesión; en México, sólo se tenía noticia gracias a la historiadora Alicia Bazarte Martínez, de las cabezas-relicario de santa Cristina y santa Emérita del acervo de los franciscanos de Guadalupe, Zacatecas, datadas en el siglo XIX. (Bazarte) En ambos casos llama la atención que las cabezas se exponen en pares.

El estudio inicial para santa Faustina mártir, consistió en una inspección visual, para luego pasar a emplear la radiología computarizada con equipo médico portátil, por lo que la toma de placas se realizó in situ con una mínima manipulación. Debido a que sólo mide $24 \mathrm{~cm}$ x $19 \mathrm{~cm}$ x $21 \mathrm{~cm}$, fue posible sacarla de la urna para facilitar la toma de tres placas: frontal, lateral y cenital. A partir del estudio tanto visual como radiográfico se concluyó que el cráneo-reliquia es el soporte de la estructura de ceroplástica, sobre el cual se colocaron los demás elementos. Además cuenta con otros restos óseos como la mandíbula, que no está en posición anatómica, posiblemente de forma intencional, para proporcionar más soporte a la mascarilla de cera; cuenta con todas sus piezas dentales que muestran erupción del tercer molar por lo que se determinó que pertenecen a un individuo adulto mayor de 18 años [figura 5] El cráneo fue revestido con un textil embebido en cera que cubre toda la parte frontal pero deja expuesta la parte posterior del cráneo, posiblemente su función fue unir la mandíbula con el cráneo, hacer coincidir los dientes con la abertura de los labios de cera, y mejorar la adhesión de la mascarilla.

Dos hileras de dientes pueden observarse en la boca entreabierta del relicario: los inferiores corresponden a los de la mandíbula adelantada, pero los superiores están acomodados artificialmente por el interior, sujetados con una banda de textil embebido en cera, aunque no puede descartarse la posibilidad de que se trate de los propios dientes del cráneo, sacados y reacomodados según los requerimientos de la mascarilla. ${ }^{6}$

Los elementos de ceroplástica son dos, el rostro y el cuello, ambos de cera coloreada en tono encarnación. El primer elemento está hecho por molde, posiblemente tomado de un modelo vivo. El cuello se unió a la mascarilla mediante calor, luego de lo cual debió detallarse manualmente para borrar rastros de dicha unión, alisar y pulimentar la superficie mediante frotado con telas. El único toque de color se encuentra en los labios, una veladura rosada, quizá con óleo. Los postizos que posee el relicario son de cabello humano color claro. Para las cejas se hicieron incisiones verticales en las que se introdujeron los cabellos, mientras que para las pestañas se aprovecharon las ranuras de los párpados cerrados.

Una varilla de hierro proporciona estabilidad y fija la obra al fondo de la urna, aunque no se trata de un armazón interno, pues contornea al cráneo por fuera, siguiendo su curvatura. Para colocarla, se hicieron dos perforaciones al cráneo por la parte posterior. La corona está elaborada con alambre recubierto y flores de tela. La cabeza se apoya en un cojín con relleno, aparentemente de crin de caballo, que está forrado de terciopelo rojo, con un galón perimetral de hilo entorchado. Finalmente, la urna es de madera tallada y dorada, con tres vidrios que permiten observar la obra, a la vez que la protegen. La parte trasera se encuentra actualmente sin tapa o vidriera alguna, dejando expuesta la cabeza, aunque algunos restos de lacre rojo permiten sugerir que originalmente la urna estuvo sellada y en algún momento se abrió. En cuanto a estado de conservación, las radiografías mostraron que el cuello de cera, que colapsó en algún momento, se encuentra ahora dentro de la cabeza, además de la presencia de algunas fisuras en la parte posterior del cráneo, donde se hicieron los orificios para la varilla metálica.

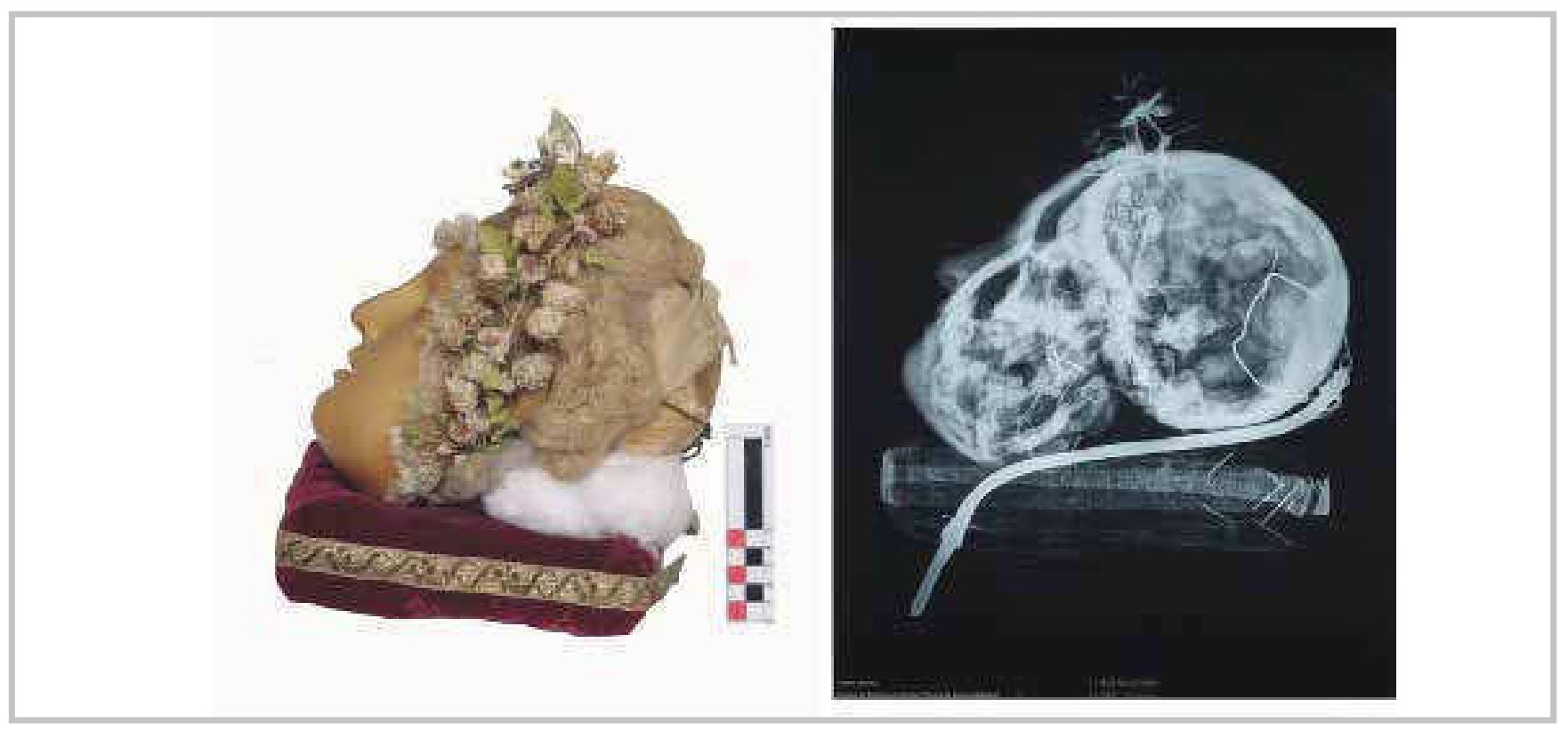

Figure 5.- Vista lateral izquierda de la cabeza-relicario, y placa radiográfica donde se observa desfase de mandíbula, cantidad de piezas dentales, y radiodensidad de la mascarilla de cera. Técnica radiográfica 80 kv, 20 mAs. 1 metro distancia. Fotografía y radiología Ana Lucía Montes Marrero. 


\section{San Clemente Flavio}

El cuerpo-relicario de san Clemente Flavio es de tamaño natural y se encuentra en el templo de el Carmen de San Ángel, en la Ciudad de México ${ }^{7}$ dentro de una urna ubicada en una mesa de altar del retablo lateral dedicado al Sagrado Corazón y realizado en el siglo XX. La Orden de los Carmelitas Descalzos llegó a la Nueva España en el año de 1585, y se fundaría la Provincia Mexicana de san Alberto, dando así inició su labor evangelizadora. Esta fundación de san Ángel es obra del fraile constructor fray Andrés de San Miguel, y la fábrica material del conjunto conventual se inició al colocarse la primera piedra en el año de 1615 y se concluyó en 1616; mientras que la iglesia se terminó en

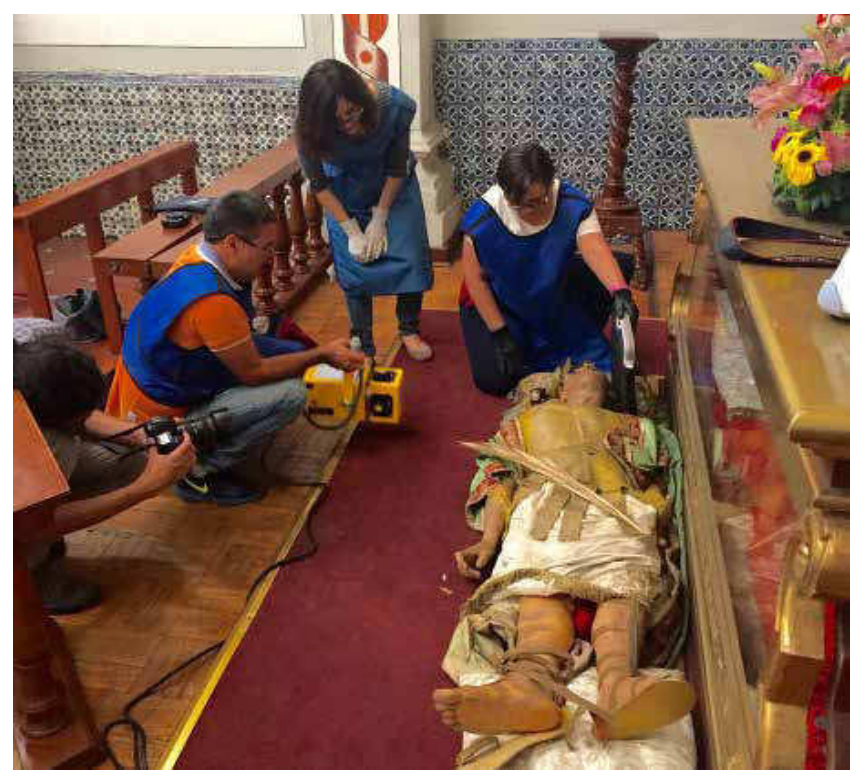

Figure 6.- Aplicación de radiología digital directa con el generador de Rayos $\mathrm{X}$ portátil en una toma de cráneo lateral. El personal porta mandiles de plomo como medida de seguridad radiológica. Fotografía José Luis Velázquez.
1626. La orden del Carmen se empeñó en tener grandes colecciones de reliquias y relicarios en sus conventos, al grado de edificar capillas-relicario en el ábside del templo, una creación totalmente novohispana, como es el caso de san Ángel, Atlixco o san Joaquín, entre otros. De igual forma se distinguieron por la creación de retablos-relicario para ostentar colecciones de reliquias de numerosos mártires y santos de la Orden como santa Teresa de Jesús y san Juan de la Cruz. (Sánchez 2004: 117-136, 153-168.) Por ello, es natural encontrar la donación de este tipo de relicarios en ceroplástica, actualmente la orden cuenta, además del cuerpo de san Clemente Flavio, con el de san Plácido en el templo del Carmen en la ciudad de Celaya, Guanajuato. Por tratarse de un mártir cuyos restos fueron extraídos de una catacumba romana, no se cuenta con una hagiografía que dé cuenta de su vida, y no ha sido posible localizar su Auténtica, es decir, el documento que especifica de qué catacumba procede, ni fecha de donación que pudiera dar razón de su origen.

Para la toma de placas del cuerpo-relicario, se empleó un equipo portátil de radiología de alta frecuencia (HF) con colimador de luz y láser para reducir la radiación secundaria. En este caso se contó con la autorización correspondiente para abrir la urna y extraer la figura para hacer un barrido completo cenital, colocando el chasis debajo de éste. [figura 6].

Un aspecto que es importante recordar es que al realizar una inspección visual del relicario, es imposible saber la cantidad y ubicación exacta de restos óseos que se encuentran al interior, y en este caso, el cuerpo de san Clemente no dejaba a la vista ninguna reliquia. [figura 7] Quedó claro entonces, que el cuerpo -tórax, muslos y brazos- están compuestos por un cuerpo de tela relleno con algodón, mientras que sólo las extremidades y la cabeza ,son de cera. Es así que, la radiología se vuelve una técnica fundamental para conocer la estructura interior de

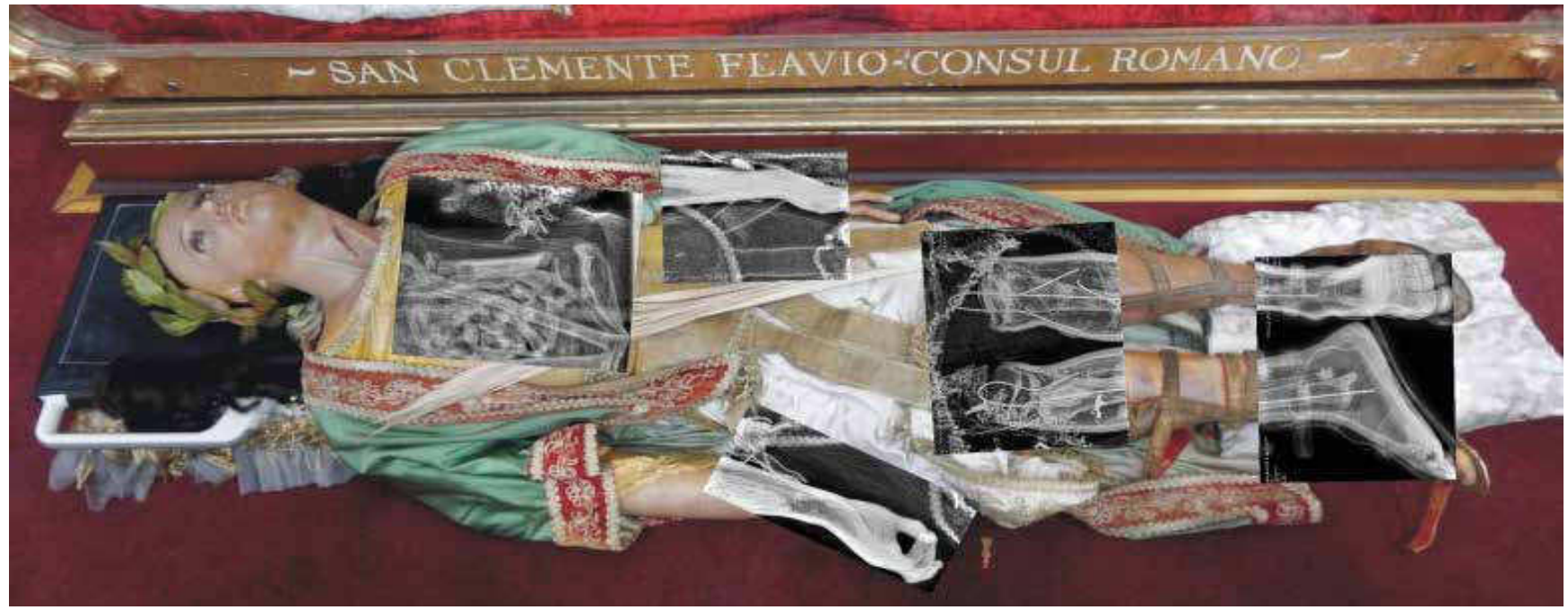

Figure 7.- Vista general del cuerpo-relicario de san Clemente Flavio, con placas radiográficas superpuestas. Técnica radiográfica 60kv. $\mathrm{mAs}$ 0.12. Distancia $80 \mathrm{~cm}$. Generador marca mini X ray. 80kv $20 \mathrm{mAs}$. Chasis digital marca cuattro de cesio. Fotografía Gabriela Sánchez Reyes y composición digital Ana Lucía Montes Marrero. Radiología José Luis Velázquez. 
la obra y su diversidad material, ya que la imagen reveló que en el área del tórax, se guardaron un conjunto de vértebras y costillas que fueron envueltas con un textil de hilo entorchado metálico, identificadas por una alta radiodensidad. En la parte central superior hay una vértebra dorsal, una rótula, una parte de vértebra cervical; al centro del lado izquierdo unos fragmentos de huesos largos, un húmero izquierdo que está roto en la parte

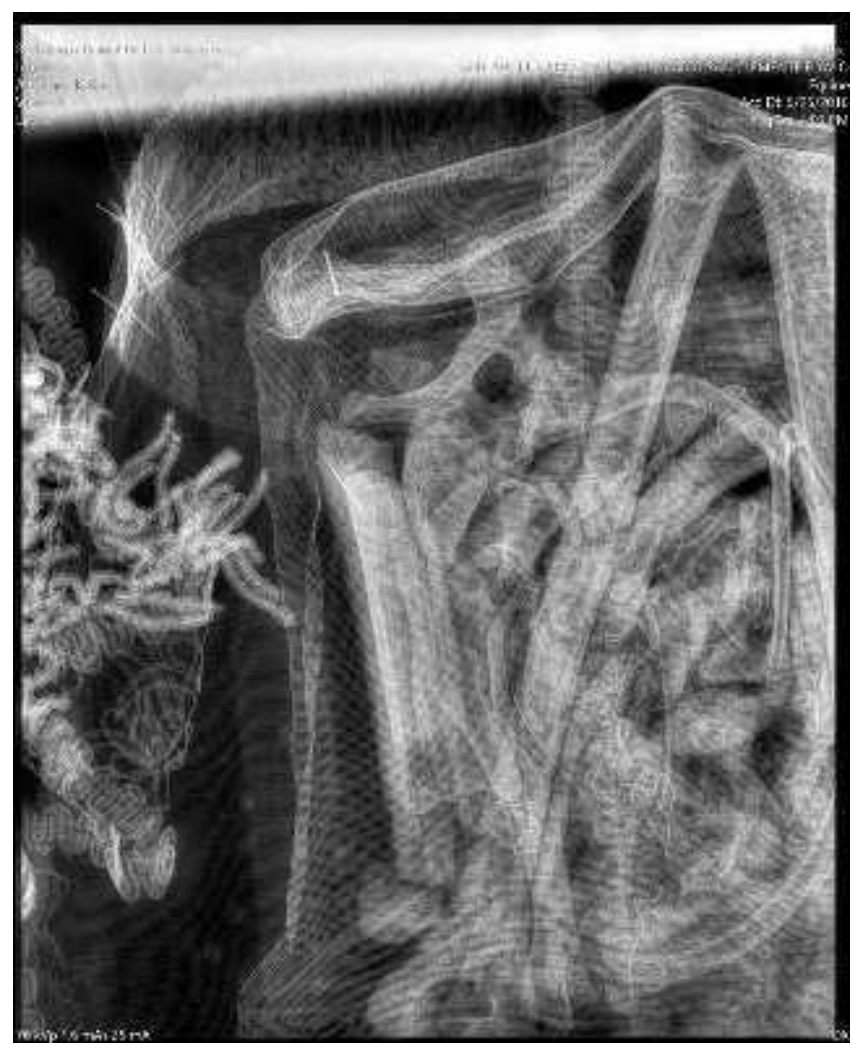

Figure 8.- Placa del tórax donde se aprecian distintos tipos de huesos como vértebras cervicales y rótulas envueltos en un textil de hilo entorchado. Técnica radiográfica 60kv. mAs 0.12 . Distancia $1 \mathrm{~m}$. Generador marca mini X ray. $80 \mathrm{kv} 20 \mathrm{mAs}$. Chasis digital marca cuattro de cesio. Radiología José Luis Velázquez.

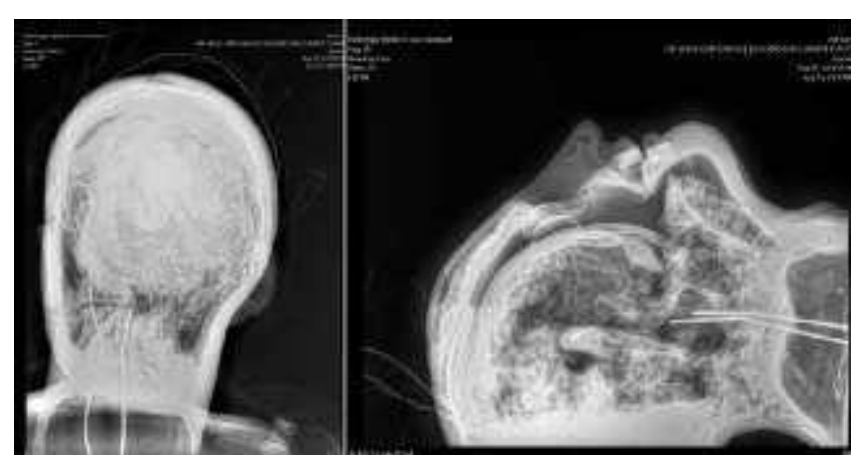

Figure 9.- (Izq) Vistas frontal que parecía indicar que no tenía restos óseos en el interior. (Der). Toma lateral donde quedó registrada la radiodensidad del cráneo, molares y alambres. Por ello se recomienda realizar tomas desde diferentes ángulos para obtener mayor información. Técnica radiográfica 60kv. mAs 0.12 . Distancia $1 \mathrm{~m}$. Generador marca mini X ray. 80kv 20 mAs. Chasis digital marca cuattro de cesio. Radiología José Luis Velázquez. superior (epífisis proximal) y en la parte inferior se aprecia la epífisis distal de radio lado no determinable. [figura 8] También se observa en la parte derecha de la placa, al menos tres costillas (una de ellas es una costilla flotante) así como un cuerpo de vértebra lumbar. La radiología también mostró que en las extremidades de cera se colocaron algunos huesos: en la cabeza, gracias a la toma lateral apareció un cráneo en posición no anatómica; [figura 9] en el caso de las piernas se registraron tibias y peroné, y en ambos antebrazos parecen contener otros huesos, aunque fragmentados. Tras la colocación de los restos óseos se añadieron los elementos de ceroplástica, realizados por vaciado en moldes -muestra de lo cual son algunas pequeñas burbujas-, y el método de unión fue a través de alambres, que por dentro recorren las piernas y antebrazos de cera. A simple vista se observan venas resaltadas en las manos, y las imágenes radiográficas mostraron lo que parecen ser alambres delgados cumpliendo esta función, lo que recuerda a los métodos de elaboración de modelos anatómicos, donde se usaban cuerdas, telas embebidas y alambre. (Montes, en proceso).

Como postizos, la cabeza lleva ojos de vidrio de media esfera, dientes superiores e inferiores realizados posiblemente con alguna pasta de carbonato de calcio a juzgar por la alta radiodensidad registrada que fueron colocados por dentro; pestañas y dos mechones gruesos de cabello que no son los originales, pues en la cabeza se aprecian manchas de adhesivo que indican que tenía otra peluca. Otro elemento importante para analizar, es la indumentaria que se compone de una túnica corta blanca con aplicaciones de hilo entorchado dorado en el borde, una coraza de textil amarillo moiré o muaré, 8 y una toga o pallium verde con un borde de terciopelo rojo. Como accesorios se le colocaron una corona de alambre y una palma, símbolo de martirio.

\section{Conclusiones}

Este tipo de relicarios son obras frágiles cuya manipulación excesiva, podría derivar en deterioros debido a su complejidad estructural y material. La inspección visual como única fuente de análisis para la identificación de la técnica de factura, resulta insuficiente, pues implicaría retirar las vestimentas, los accesorios y cambiar la posición del cuerpo para acceder al interior, lo que posiblemente provocaría desensamble de elementos, quiebre de la cera, roturas en textiles, eliminación de costuras, entre otros. Debido a tal fragilidad deben estudiarse in situ, habiendo obtenido previamente el permiso correspondiente para abrir las urnas y tener acceso a la obra. La inspección visual, aunque importante, tiene sus limitantes puesto que permite únicamente tener una idea general de la estructura del cuerpo. La radiología, en cambio, permite una inspección no invasiva del interior, puesto que requiere de una mínima manipulación, por ello se recomienda contar con un equipo de rayos $X$ portátil para evitar el traslado del cuerpo-relicario. 
A partir de este primer muestreo de relicarios de ceroplástica en el que se aplicó radiología digital directa, se propone como metodología para el estudio de cada ejemplar, realizarle placas de cuerpo completo para realizar posteriormente la reconstrucción digital de la obra. Antes de iniciar la sesión de radiología es necesario contar con las medidas de las urnas así como del relicario, ya que de ello depende el tipo de chasis que se introducirá, ya sea de $8 \times 10$ pulgadas $(20.32 \times 25.4 \mathrm{~cm})$ o bien de $14 \times 17$ pulgadas $(35.56 \times 43.18 \mathrm{~cm})$. Para tener el registro completo del relicario, se propone emplear las siguientes vistas: latero laterales y ventrodorsales para tórax y cadera; dorso palmares y latero mediales para extremidades torácicas; dorso plantares y latero mediales para extremidades pélvicas a una distancia ideal de un metro entre la fuente de rayos $X$.

Una parte fundamental del estudio, es la interpretación de las placas radiográficas para analizar los materiales de tan variadas radiodensidades que se encuentran dentro de una misma obra, lo que permitirá dilucidar cómo fueron creadas por parte de los artistas. Para ello, se recomienda la formación de equipos de especialistas en diversas disciplinas, así como en este caso se conjuntaron los conocimientos de la restauración de bienes muebles, antropología física, radiología e historia del arte.

Debe hacerse énfasis en que cada relicario en ceroplástica a estudiar, presentará sus propias características y por consiguiente sus propios retos, por lo que la metodología de aplicación de los rayos $X$ deberá modificarse según los requerimientos. Por ejemplo, el diseño de las urnas varía mucho de un ejemplar a otro, lo que implica solucionar en primer lugar su apertura para introducir los chasis, o incluso proceder al estudio con la urna cerrada, colocando los chasis por fuera. En cada caso es importante registrar en los resultados, la técnica radiográfica utilizada, precisando los valores empleados de kilovoltaje, miliamperaje, la distancia, así como las características técnicas del equipo y del chasis. En cuanto a seguridad, al momento de realizar el estudio radiológico es necesario aislar la zona en un perímetro de 3 a $5 \mathrm{~m}$ del área de trabajo, ya sea con cinta delimitadora, o bien, colocando las bancas del templo como barrera, para evitar el contacto de los visitantes con la radiación, mientras que los involucrados en el estudio deben portar mandil de plomo y dosímetros.

Existen muchos más detalles de los que el ojo puede llegar a percibir de un cuerpo-relicario, y es importante ir registrando particularidades y constantes. Ejemplos claros de lo primero los encontramos en san Clemente Flavio, donde el textil fino de hilos metálicos que protege y rodea los huesos del tórax, no hubiera sido nunca identificado de no ser por las placas radiográficas, y resulta algo distinto de la mayoría de los ejemplares en los que sólo se han encontrado textiles interiores simples e incluso burdos, como mantas de algodón. De igual forma, el hecho de encontrar el cráneo invertido, habla de las soluciones técnicas de cada artista o taller, pues es posible que haya sido una decisión consciente que facilita la factura del cuello de cera, o que brinda más soporte a la mascarilla, pero también habla de que no siempre los huesos se colocaron en posición correcta anatómicamente, y no por ello debe considerarse un desconocimiento de esta ciencia.

Conscientes de que queda un largo camino por recorrer, esta propuesta queda abierta para ampliar el muestreo y descubrir la técnica de factura de otros ejemplares mediante la radiología, una herramienta que ha probado ser tan útil en otros bienes patrimoniales. Esto permitirá formar una base de datos de los materiales comúnmente empleados, para realizar comparaciones, hallar similitudes e incluso identificar talleres o autorías. Una conclusión clara es que cada figura de cera resguarda diferente cantidad, ubicación y disposición de restos óseos, lo que bien justifica el análisis de otras obras.

La aplicación de radiología para analizar el cuerpo-relicario en ceroplástica, cambia la idea de que la función del relicario es permitir la visibilidad total de la reliquia. En este caso, la efigie que ostentaba de manera parcial su contenido, muestra a través de los rayos $x$, las reliquias antes ocultas. De igual forma, la estructura interior así como la cantidad y ubicación de los restos óseos parece que sólo era conocida por el artista que cuidadosamente las envolvió, colocó y recubrió de cera, textiles y rellenos. Frente a los fieles, y los estudiosos del arte, sólo era evidente la recreación, el simulacro del cuerpo del santo catacumbal, que yace apenas con una discreta herida. Estos relicarios comienzan ya a ser apreciados y leídos adecuadamente no como contenedores de reliquias, sino como objetos artísticos e históricos, gracias a que se está estudiando su técnica particular de factura. En la actualidad, la tecnología y en específico la radiología, permite comprender el proceso de factura de este tipo de relicario, permitiendo visualizar el interior, con toda su complejidad estructural así como la visibilidad total de los restos sagrados de los mártires catacumbales.

\section{Notas}

[1] Este término es la adaptación castellana del que se utiliza en la historiografía francesa: corps-reliquaire. Laurence Rey, "L'invencion d'une vierge martyr. les reliquiaires de sainte Philomene au XIXe siécle" en Reliques d'Europe et d'Océanie. "la mort n'en saura rien", pp. 105, 108.

[2] Agradecemos a Massimiliano Ghilardi que compartiera una copia de su ponencia inédita.

[3] Los cuerpo-relicario analizados son los de san Deodato, san Víctor Niño y santa Felícitas, que forman parte del proyecto de catalogación de la colección de relicarios de la Catedral Metropolitana de México. 
[4] Treasures of Heaven saints, relics and devotion in medieval Europe, 23 June - 9 October 2011. Exhibition, 2001. http:// www.learn.columbia.edu/treasuresofheaven/relics/ArmReliquary-of-the-Apostles.php. [consulta: 23/6/2016].

[5] http://www.kikirpa.be/EN/141/0/doc++imagerie+scient+-+Une+longue+tradition.htm.

http://www.kikirpa.be/EN/120/342/Radiographie.htm. [consulta: 23/6/2016].

[6] Agradecemos a la antropóloga física Adriana Alfaro Vega por el análisis de la osamenta.

[7] Agradecemos al padre José de Jesús Orozco OCD, responsable del Archivo Histórico de la Provincia de los Carmelitas Descalzos en México por las facilidades que dio para realizar este estudio.

[8] Término francés aplicado a textiles de seda con un patrón que forma ondulaciones.

\section{Bibliografía}

AMADOR MARRERO PABLO F., (2002). Traza española, ropaje indiano. El Cristo de Telde y la imaginería en caña de maíz. Telde: Ayuntamiento de Telde.

BALLESTRIERO ROBERTA (2013). Efigie, cadáver y cuerpo enfermo en la ceroplástica, Tesis para obtener el grado de Doctorado. Madrid: Universidad Complutense de Madrid.

BAUTISTA MARTÍNEZ JOSEFINA, MIRTA INSAURRALDE CABALLERO (coordinadoras) (2012). Manual de Radiología aplicada al estudio de bienes culturales. México: El Colegio de Michoacán- Escuela de Conservación y Restauración de Occidente.

BAZARTE MARTÍNEZ, ALICIA, "Veneración de reliquias y cuerpos de cera en los días de los fieles difuntos y todos santos", en Patrimonio cultura y turismo 16, Cuadernos, pp. 57- 68. http://www.cultura.gob.mx/turismocultural/ cuadernos/pdf16/articulo4.pdf. [ consulta: 23/6/2016].

BOUZA ÁLVAREZ JOSÉ LUIS, (1990). Religiosidad contrarreformista y cultura simbólica del barroco. Madrid: Consejo Superior de Investigaciones Científicas.

GHILARDI MASSIMILAINO (2013) "Paolino e gli altri martiri. II culto de "corpi santi" nella prima età moderna" en Il cardonal Montelpare, Atti del Convegno. Montelparo 17 giugno 2012, Archivo Diocedano San Benedetto del Trento, Quaderno perla Ricerca, 17.

GHILARDI MASSIMILAINO (2015), "Le commerce des objets de dévotion chrétiens: approches croisées (XVleXIXe siècle)" en Journée d'étude, Calenda. Ponencia inédita.
GRAMTORP DORTE, KNUD BOTFELDT, JENS GLASTRUP \& KIM PILKJ/ER SIMONSEN (2015).“Investigation and conservation of Anne Marie Carl-Nielsen's wax models" en Studies in Conservation, 60:2, 97-106, http://dx.doi.org/10 $.1179 / 2047058413$ Y.0000000111. [ consulta: 23/6/2016].

REY LAURENCE. (1999). "L'invention d'une vierge martyr. Les reliquaires de sainte Philomène au XIXe siècle" en Reliques d'Europe et d'Océanie. "la mort n'en saura rien". Paris : Musée national des Arts d'Afrique et d'Océanie.

MONTES MARRERO, ANA LUCÍA (en proceso). Radiología aplicada al estudio de relicarios en ceroplástica: técnica de factura de factura de Santa Faustina y San Plácido mártires, Catedral de Durango, México. Tesis para obtener el grado de Licenciatura en Restauración de Bienes Muebles, Escuela de Conservación y Restauración de Occidente.

PERPETUA RESTAURACIÓN (2012). "Informe de restauración". Inédito.

SÁNCHEZ REYES GABRIELA (en proceso). Reliquias $y$ relicarios en México.

SÁNCHEZ REYES GABRIELA (2004). Relicarios novohispanos a través de una muestra de los siglos XVI al XVIII. México: Tesis para obtener el grado de Maestra en Historia del Arte, Universidad Nacional Autónoma de MéxicoFacultad de Filosofía y Letras, División de Estudios de Posgrado.

Santiago un caballero con alma de maíz (2016). México: Instituto Nacional de Antropología e HistoriaCoordinación Nacional de Difusión.

VALVERDE LARROSA CONSUELO, CRISTINA GÓMEZ GONZÁLEZ, JUAN CARLOS MARTÍN GARCÍA, PILAR VIDAL MELER, MILAGROS BURÓN ÁLVAREZ (2012). “Estudios radiográficos determinantes para el conocimiento constructivo de tres esculturas policromadas realizados por el CCRBC de Castilla y León", Ge-conservación / conservação, No. 3: 152-168.

VELÁZQUEZ RAMÍREZ JOSÉ LUIS (2012). en Memoria $5^{\circ}$ Foro Académico 2012. México:, Instituto Nacional de Antropología e Historia, CONACULTA, Escuela de Conservación, Restauración y Museografía, Núm. 5, abril. https://www.revistas.inah.gob.mx/index.php/foro/ article/view/246. [ consulta: 17/5/2016]. 


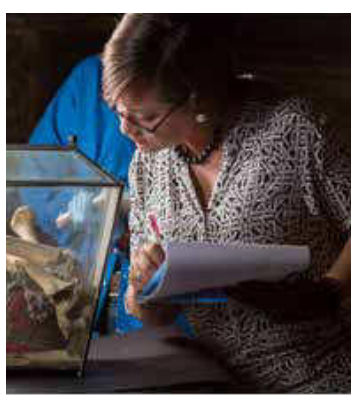

\section{Gabriela Sánchez Reyes}

gabysare@gmail.com

Instituto Nacional de Antropología e Historia

La Licenciada en Ciencias Humanas por la Universidad del Claustro de Sor Juana (1997) y Maestra en Historia del Arte con la especialidad de Arte Colonial Mexicano por la Universidad Nacional Autónoma de México (2004). Desde 2004 es investigadora de tiempo completo (Titular C) de la Coordinación Nacional de Monumentos Históricos del Instituto Nacional de Antropología e Historia. Sus líneas de investigación son la historia la urbanización y bienes inmuebles históricos en el Centro Histórico de la Ciudad de México y la cultura material de las devociones, en particular los relicarios, la medalla devocional y las medidas de imágenes. Actualmente es coordinadora del proyecto interdisciplinario para la catalogación de los relicarios de la Catedral Metropolitana de México y a la par concluye libro sobre relicarios en la Nueva España. Ha sido co-curadora de exposiciones temporales en el Museo Soumaya, Museo Franz Mayer, Museo Nacional del Virreinato y Museo del Templo Mayor.

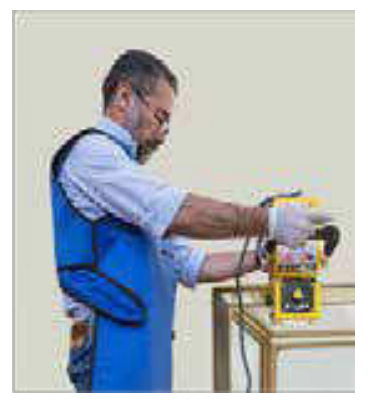

José Luis Velázquez Ramírez

jlvr@unam.mx

Universidad Nacional Autónoma de México

Obtiene el grado de Licenciado en medicina veterinaria y zootecnia en la Facultad de Medicina Veterinaria y Zootecnia por la Universidad Nacional Autónoma de México en 1990. El grado de maestro en Ciencias de la Salud y la Producción Animal por la División de Estudios de Posgrado por la misma institución en el año 2002. Es profesor de tiempo completo "Asociado C" definitivo, PRIDE "C" en la Facultad de Medicina Veterinaria y Zootecnia, imparte las cátedras de cirugía, Radiología y Clínica en equinos. Es socio de la American Assotiation of Equine Practitioners y de la Asociación Mexicana de Médicos Veterinarios Especialistas en Equinos. A partir del año 2011 ha apoyado con radiología digital directa a restauradores, historiadores del arte, escuelas de restauración y museos en bienes culturales como escultura ligera, pintura de caballete, retablos, esculturas de madera y levantamientos antropológicos. En fechas recientes es el responsable de la radiología del proyecto de catalogación de los relicarios de ceroplástica de la Catedral Metropolitana de México. 


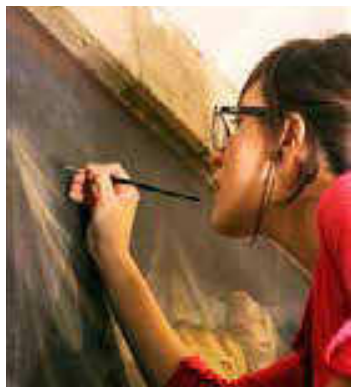

\section{Ana Lucía Montes Marrero}

lucia.m.marrero@gmail.com

Escuela de Conservación y Restauración de Occidente

Pasante de la Licenciatura en Restauración de Bienes Muebles por la Escuela de Conservación y Restauración de Occidente, Guadalajara, Jal. Participó en 2014 en el registro de bienes muebles de iglesias del Estado de Durango, proyecto del Centro Regional del Instituto Nacional de Antropología e Historia. En 2016 intervino una obra textil del Museo Nacional del Virreinato, para la exposición temporal “Santiago. Un caballero con alma de maíz". Forma parte del equipo interdisciplinario para la catalogación de los relicarios de la Catedral Metropolitana de México apoyando con el análisis del sistema constructivo de los relicarios en ceroplástica. Actualmente realiza su tesis de licenciatura titulada "Radiología aplicada en relicarios con ceroplástica: Estudio de la técnica de factura de Santa Faustina y San Plácido mártires, Catedral de Durango, México". Tiene interés particular en la conservación y restauración de textiles y de relicarios en ceroplástica y su técnica de manufactura.

\section{Artículo enviado el 15/07/2016 \\ Artículo aceptado el 07/12/2016}


Reseñas 


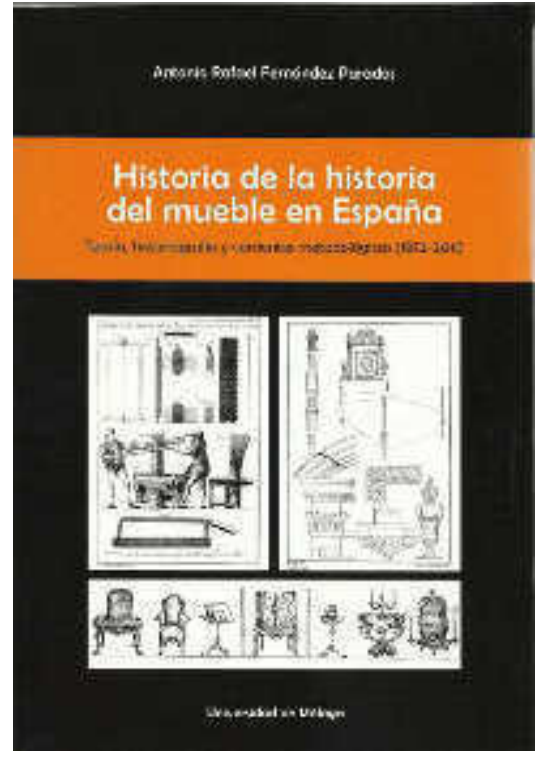

Historia de la historia del mueble en España. Teoría, historiografía y corrientes metodológicas (18722011)

\author{
Fernández Paradas, Antonio Rafael
}

Publicaciones y Divulgación científica. Universidad de Málaga, 2016

Páginas: 322

Idioma: Español

ISBN: 978-84-9747-474-0
Este libro, fruto de la investigación llevada a cabo por Antonio Paradas para su doctorado en la Universidad de Málaga presenta un profundo y meticuloso análisis de la historiografía del mueble español con el singular título Historia de la historia del mueble en España.

La primera parte del libro se abre con un capítulo ("Una historia que comenzó a escribirse tarde. Los inicios de la historia del mueble en España, 1872-1969") que traza una trayectoria de la historiografía del mueble en España desde sus orígenes en el año 1872 --con la publicación de Juan Facundo Riaño y Montero para el South Kensington Museum, hoy Museo Victoria \& Albert-- hasta la edición del El mueble español de Luis Feduchi (1969). El análisis pormenorizado de textos, tanto españoles como extranjeros, del lapso de tiempo mencionado, revela que el interés por los muebles que se produjeron en nuestro país en épocas pasadas fue en aumento a partir del volumen de Riaño, a excepción del paréntesis de la Guerra Civil española en el que decayó el número de publicaciones.

El segundo capítulo ("El mueble popular. De la antropología cultural a los historiadores del arte") se centra en el análisis de los textos referidos a esta tipología de mobiliario de nuestro país. En él se definen y establecen, en primer lugar, las diferencias entre las expresiones "mueble popular", "mueble tradicional", "mueble provincial" y "mueble noble o culto". Después se clasifica la bibliografía existente sobre mueble popular español por áreas geográficas.

Por su parte, los capítulos tres y cuatro ofrecen una información detallada sobre los historiadores más relevantes del mueble español y sobre las exposiciones específicas de mobiliario. El gran valor documental del contenido de los catálogos de estas muestras es refrendado por el análisis de Paradas, quien de este modo ofrece una herramienta útil para futuros investigadores. Es acertada la importancia que otorga el autor al volumen ("Mueble, español, estrado y dormitorio") de la mítica exposición celebrada en Madrid en 1990, resultado del pionero interés por la exhibición y catalogación de las artes decorativas desde la Administración. Afortunadamente, este libro, en la actualidad descatalogado, puede consultarse en la red.

Bajo el título "Sistemas de construcción y visión técnica del mueble español en la historiografía" se extiende el siguiente capítulo en el que se recogen las publicaciones referidas a los materiales y a la tecnología de elaboración del mobiliario, un aspecto fundamental para el conocimiento en profundidad de las obras. En concreto, este apartado se centra en los sistemas constructivos, en los textiles, en la marquetería, en los acabados, en los mármoles y en la madera.

El sexto capítulo estudia, desde una óptica comparativa, la bibliografía sobre muebles españoles generada desde el siglo XIX por las distintas regiones geográficas de nuestro país. Al análisis de estos textos se adjuntan ilustrativas tablas cronológicas que ponen de manifiesto las acusadas diferencias entre las comunidades autónomas, no solo en lo que se refiere al número de publicaciones, sino también al grado de iniciativas públicas y privadas registradas en torno al mobiliario. Además de las diferencias cuantitativas se observa, en ciertos territorios, una tendencia hacia el estudio exclusivo de su propia producción, de manera que ya es posible hablar de una historia del mueble catalán, balear, etc.

En el séptimo capitulo se exponen las distintas tipologías de 
mobiliario --mesas, contenedores, escaparates, asientos o mueble litúrgico-- que han sido objeto de estudio por parte de los investigadores. El apartado sucesivo recoge la bibliografía internacional sobre historia del mueble español, desde su nacimiento en Londres en el año de 1872 con el mencionado texto de Riaño titulado Classified and descriptive catalogue of the Art objects of Spanish production in the South Kensington Museum with an introducction and notes.

La sección siguiente examina las publicaciones ubicadas entre los años 1970 y 2011, fechas que, según Paradas, delimitan el período moderno de la historiografía del mueble español. El autor ofrece una clasificación de las asociaciones, revistas, monografías y autores más destacados de dicha época.

Los capítulos diez y once se refieren, respectivamente, a la aportación de la mujer a la historiografía del mueble español —cuyo origen se remonta a los años cincuenta del siglo XX-y a la presencia de la historia del mueble en los nuevos soportes de edición, tanto en lo que se refiere a textos como a bases de datos de imágenes. Destaca en este sentido, por su utilidad, el banco de datos Domus, creado en los años noventa por el Ministerio de Cultura, en el que se recogen imágenes de los fondos catalogados en diversos museos españoles.

Los dos capítulos de la segunda parte del volumen titulada "Muebles, comercio y bibliografía", versan sobre el mercado del mueble en el pasado y en el presente y hacen mención a su eco en artículos y revistas especializadas. Compartimos la convicción de Paradas sobre la necesidad de considerar los catálogos de subastas como fuentes para la historia del mueble. Finalmente se mencionan las frecuentes "restauraciones" poco afortunadas que se producen en el mercado de las antigüedades que alteran y desvirtúan considerablemente los objetos. En este sentido Paradas revela su preocupación por una lamentable realidad de cuyo perjuicio para el patrimonio no existe suficiente conciencia.

Bajo el epígrafe "Corrientes metodológicas de la historia del mueble en España" se estructura el tercer bloque del libro. En él el argumento tratado se ejemplifica mediante cuatro monografías representativas: Hispanic furniture, from fifteenth century through the eigtheenth century (1964), de Grace Hardendoff Burr, El mueble español (1969), de Luis Feduchi El Mueble en España, siglos XVI- XVIII (1993) de María Paz Aguiló y la monografía Audacia i delicadesa. El Moble de toerra de montgrí i l' ampordá de Mónica Piera (2008).

El libro concluye con un repertorio bibliográfico que da buena cuenta del rigor documental que define la investigación doctoral. Este se coloca intencionadamente antes de las conclusiones para, tal y como el propio Paradas indica, otorgar protagonismo a la bibliografía aportada y de enfatizar su importancia como fuente de acceso y divulgación del conocimiento.

El libro que reseñamos contribuye al conocimiento de la historiografía del mueble español entre 1872 y 2011. La información relativa a artículos, monografías y catálogos de exposiciones se ordena temporal y geográficamente en ilustrativas tablas cronológicas que facilitan la rápida visualización y el cotejo de los datos aportados.

A la sistematización de estos datos le acompaña un análisis minucioso del contenido de las publicaciones recogidas, una valoración crítica de gran utilidad para futuras labores de investigación.

Estas dos dimensiones de la obra, que estructuran e interpretan la información, la convierten en una referencia fundamental para todas aquellas personas -profesionales o amateurs- que deseen aproximarse a la Historia del Mueble español. De hecho se trata de un libro de consulta, tanto para aquellos que quieran obtener una visión panorámica del argumento como para los que pretendan abordar un tema concreto de estudio.

Otro aspecto destacable del volumen es la novedosa metodología de estudio empleada al adoptar un enfoque transversal que relaciona la historiografía del mueble español con otros ámbitos disciplinares como el coleccionismo, el mercado de antigüedades, las exposiciones o las asociaciones destinadas al estudio del mueble, dentro de un contexto histórico y cultural determinados.

A menudo el autor excede lo puramente historiográfico y ofrece una estimulante visión poliédrica del asunto, al realizar incursiones en otros aspectos de índole social, histórica o económica que han repercutido en la investigación sobre el mobiliario. Así, la obra puede constituir un punto de partida para futuras indagaciones sobre aspectos sociológicos, antropológicos o culturales relacionados con el estudio del mueble antiguo español como actividad humana.

En definitiva, la visión panorámica que se extrae de la publicación de Paradas permite detectar, desde finales del siglo XIX, un incremento de los estudios sobre mobiliario español que auguramos continúe en un futuro próximo, con la incorporación, aún insuficiente, de análisis científicos, con el aprovechamiento máximo de las posibilidades que abren las nuevas tecnologías y con la difusión de los resultados obtenidos del examen directo de los muebles.

Concluimos este breve apunte recomendando la lectura de esta sugerente publicación, no solo por la inédita y enriquecedora visión que ofrece de la historiografía del mueble español, sino también por la transversalidad del enfoque adoptado, por la exploración de las conexiones entre el argumento tratado y las ciencias sociales.

Cristina Ordóñez y Leticia Ordóñez Grupo de Artes Decorativas del GEIIC 


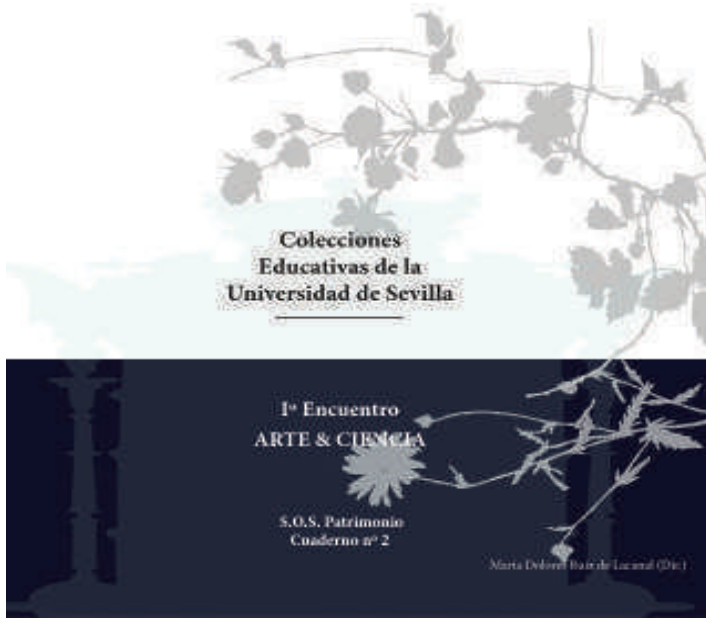

Se presenta el libro Colecciones Educativas de la Universidad de Sevilla, publicado por la Real Academia Santa Isabel de Hungría en 2015. Realizado por el Grupo de Investigación S.O.S. Patrimonio, el libro contiene en parte los textos realizados por los profesores universitarios en el 10 Encuentro Arte $y$ Ciencia organizado por la Facultad de Bellas Artes a lo que se añade otros trabajos realizados por investigadores y alumnos.

Academia y universidad muestran de este modo la estrecha relación que existe entre ambas instituciones, particularmente interesadas en la conservación del patrimonio.

En el libro confluyen muchas aportaciones. De hecho cada capítulo es una mirada diferente a las colecciones de la Universidad de Sevilla. Eso lo convierte en un trabajo singular, rico y abierto a muchas lecturas.

Atento a los bienes culturales (patrimonio documental y bibliográfico, monumental, arqueológico, patrimonio histórico-artístico y patrimonio científico y técnico), abarca los diferentes eslabones de la cadena de la protección del patrimonio: desde la identificación a la catalogación, pasando por el diagnóstico y la exposición, desde la difusión a la educación.

Señalar que el mismo se recogen las aportaciones de un nutrido grupo de profesores e investigadores que trabajan para hacer realidad el proceso de su mantenimiento, disfrute y conservación.
Colecciones Educativas de la Universidad de Sevilla María Dolores Ruiz de Lacanal Ruiz-Mateos

Real Academia de Bellas Artes Santa Isabel de Hungría. Sevilla, 2015

Páginas: 206

dioma: Español

SBN: 978-84-608-3934-7
Algunos capítulos son:

-Encuentro con los bienes culturales de la Universidad de Sevilla escrito por la doctora $\mathrm{M}^{\mathrm{a}}$ Dolores Ruiz de Lacanal Ruiz-Mateos, profesora del Departamento de Escultura e Historia de las Artes Plásticas, Universidad de Sevilla y Directora del Grupo de Investigación S.O.S. Patrimonio.

- Colecciones arqueológicas de la Universidad de Sevilla. Apuntes históricos, escrito por el catedrático José Beltrán Fortes, del Departamento de Prehistoria y Arqueología de la Universidad de Sevilla y Director del Grupo de Investigación: Historiografía y Patrimonio Andaluz.

- Herbarios históricos de la Universidad de Sevilla, escrito por los doctores Monserrat Aristas y Francisco Javier Salgueiro, del Departamento de Biología Vegetal y Ecología del Vicerrectorado de Investigación de la Universidad de Sevilla y miembros del Grupo de Investigación: Ecología y Reproducción de Plantas.

-El Museo Pedagógico de la Facultad de Ciencias de la Educación de la Universidad de Sevilla: El Patrimonio Escolar como recurso científico y didáctico por los doctores Pablo Álvarez Domínguez, Marina Núñez Gil y María José Rebollo Espinosa, del Departamento Teoría e Historia de la Educación y Pedagogía Social de la Universidad de Sevilla y miembros del Grupo de Investigación Historia de las Enseñanzas no Obligatorias en el Distrito Universitario de Sevilla (1845-1990). 
-Patrimonio, difusión, docencia e investigación: El Museo de Historia de la Farmacia de Sevilla por el doctor Antonio Ramos Carrillo, del Departamento de Farmacia y Tecnología Farmacéutica de la Universidad de Sevilla y Director del Museo de Historia de la Farmacia de Sevilla, miembro del Grupo de Investigación: Andalucía y América Latina: Marco Historiográfico y Desarrollo Económico y Cultural.

- La conservación del patrimonio artístico universitario: Memoria de cuatro años de gestión en la Universidad de Sevilla, escrito por la Doctora María Fernanda Morón de Castro del Departamento de Escultura e Historia de las Artes Plásticas. Facultad de Bellas Artes de la Universidad de Sevilla, Directora del Grupo de Investigación: Museum.

-El Museo Virtual de la Vida. ¿Embrión de un futuro Museo de Historia Natural en Sevilla? escrito por el Doctor Juan Francisco Beltrán Gala, del Departamento de Zoología, Facultad de Biología, de la Universidad de Sevilla y Director del Grupo de Investigación: Estudio de Vertebrados.

A este significativo número de profesores hay que unir otros autores, como son los jóvenes investigadores del Grupos SOS. Patrimonio (HUM 673), que aportan los siguientes capítulos:

- Conservación estratégica de colecciones históricas educativas y científicas, escrito por la doctora Ana Galán Pérez.

-Una aproximación al patrimonio bibliográfico universitario: el fondo antiguo de la Facultad de Bellas Artes, escrito por la doctora Alejandra Herrera Picazo Espinar.

-El chozno del Gabinete de Ciencias Naturales y el actual museo virtual de la vida escrito por Francisco José Medina Pérez.

-Una visita al Museo de Geología. Meteoritos, huesos de elefante, minerales y gemas en la Universidad de Sevilla, por Álvaro Vera Barrera.

_Una visita a la Fototeca de la Universidad de Sevilla por Carmen María Vélez Escofet.

-Propuesta de ruta por el patrimonio cultural de la Universidad de Sevilla por Andrés Trevilla García.

Señalar finalmente que varias ideas cruzan transversalmente el libro, una idea es que la conservación del legado universitario sevillano solo puede ser conservado a partir de su estudio, su valoración y su estima y otra idea, aquella que revela que su conservación es el resultado del compromiso generacional en su investigación y su difusión. El libro es valioso también por encontrar la confluencia y el encuentro de muchas disciplinas en torno a la conservación del patrimonio cultural universitario sevillano.

sevillano. \\ María Dolores Ruiz de Lacanal Ruiz-Mateos Profesora Titular Universidad de Sevilla.}




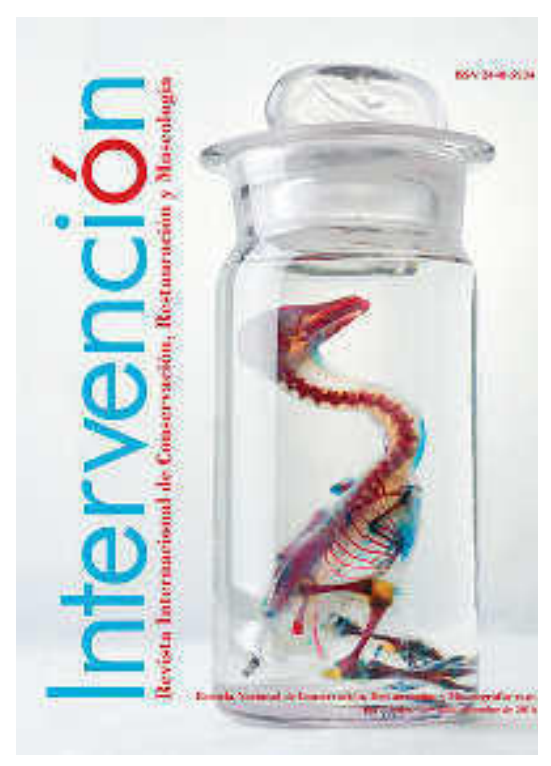

\section{Revista Internacional de Conservación, Restauración y Museología, 7(14), julio-diciembre 2016}

\author{
Isabel Medina-González (Editora) \\ Escuela Nacional de Conservación, Restauración y \\ Museografía, México. 2016
}

Páginas: 322

Idioma: Español/Inglés

ISSN 2448-5934
Reseña del último número de la revista Intervención, publicada por la Escuela Nacional de Conservación, Restauración y Museografía, adscrita al Instituto Nacional de Antropología e Historia, México. Se presenta una valoración crítica del contenido y se enfatiza la pertinencia de la publicación como una vía abierta de diálogo entre profesionales.

Ocho años se dicen fácil, pero sin duda no lo es si dicha cantidad se piensa con relación a los espacios de producción y difusión académica que en el transcurso de ese periodo han surgido y cesado de publicarse, entre glorias y penas. Este nuevo número de Intervención, el 14, es también el primero en el que la revista posee el rango de publicación arbitrada con competencia internacional.

Bajo la edición de Isabel Medina y coordinado en esta ocasión por Dafne Juliana Díaz de la Vega Núñez, el volumen tiene como hilo conductor la transdisciplina. Los seis artículos incluidos abordan este aspecto: desde la importancia de la colaboración interdisciplinar en términos de metodología, investigación experimental e interpretación de datos, hasta en la necesidad de ampliar el sentido mismo del término, con la finalidad de consolidar cuerpos conceptuales, criterios, marcos de operación y estructuras de gestión.

El artículo de Astrid Esquivel y Laura Filloy Nadal, "Evaluación del proceso de carbonatación de nanocales aplicadas a pinturas murales prehispánicas de origen maya", y el de Claudia García Solís, Demetrio Mendoza Anaya y Patricia Quintana Owen, "La escultura arquitectónica modelada en estuco de Calakmul, Campeche, México: la transformación material en el proceso tecnológico", presentan los resultados de la investigación aplicada. Si bien ambos documentos poseen un marcado perfil técnico, el primero se detiene en el nivel experimental, mientras que el segundo hace énfasis en la selección del enfoque de análisis para la interpretación de datos. Los reportes revisten interés no sólo por la utilidad que la información técnica sobre los nanocales pueda tener para conservadores y restauradores, o por la descripción puntual respecto a cómo el análisis matérico puede resultar una fuente de información sobre el contexto histórico, arquitectónico y cultural maya; sino porque tanto en uno y otro, la descripción de cómo fue planteado el muestreo, la prueba y el modelo de interpretación de resultados, deja ver al lector lo necesario de que la colaboración disciplinar sea parte fundamental en el trabajo institucional.

Lamentablemente, esto último es una tarea pendiente. Tal cual puede leerse entre líneas en la semblanza sobre la Red de Ciencias Aplicadas a la Investigación y Conservación del Patrimonio Cultural (Red-caicpc), dichas sinergias han sido resultado del esfuerzo conjunto de individuos particulares, quienes desde sus oficinas, museos, aulas y centros de investigación en México, han buscado tender lazos profesionales y establecer mecanismos de investigación. La existencia de la red demanda el despliegue de una política institucional en concreto, no sujeta a caprichos administrativos y a programas de contentillo, que permitiera estructurar acciones integrales para la conservación, investigación y difusión del patrimonio, la producción académica y avance metodológico.

El número también presenta tres textos que ponen en 
entredicho la idea misma de lo "disciplinar", la construcción de conocimiento, su sistematización y las categorías epistemológicas que sirven de marcos de referencia e interpretación.

El primero de ellos "Perspectivas y reflexiones sobre la conservación preventiva: la instrumentación del enfoque de sistemas", escrito por María de Lourdes Graciela Gallardo Parrodi y Ana Laura Peniche Montfort, propone que la conservación no debe ser enfocada como un proceso aislado sino como parte de un conjunto mayor de acciones técnicas, de intervención y de gestión. Con claras referencias a la metodología utilizada en la elaboración y evaluación de proyectos culturales (sobre todo, del contexto español y británico), el artículo resalta por su claridad expositiva, aunque, a juicio personal, no resulta novedoso. En todo caso, la novedad estriba en el no muy grato hecho de caer en cuenta de que lo que debería ser protocolo en la práctica profesional, en la realidad no lo es.

Por su parte, el recuento que presenta Miguel Ángel Mesinas en su reporte titulado "El derecho del patrimonio cultural. Análisis desde la perspectiva de los derechos humanos y su aplicación por el Instituto Nacional de Antropología e Historia (inah), México" es de gran pertinencia en un momento en el cual se discute la conformación de la Ley General de Cultura. Pese a su brevedad, ofrece un buen marco para observar la dificultades para hacer operativos conceptos legales internacionales en contextos particulares, así como para reflexionar desde dónde se construyen los criterios normativos, las discrepancias en la interpretación de los mismos y la falta de vinculación existente entre el discurso legal como cuerpo jurídico y su realidad institucional.

Un acercamiento a la idea de interdisciplina como "diálogo de saberes" en constante flujo es el que brinda María Guillermina Fressoli en su informe sobre el Museo Móvil. Éste es una iniciativa del Museo de los Asentamientos, localizado en Federación, Entre Ríos, Argentina. Si bien la autora analiza una propuesta museal y museográfica particular -la manera en cómo el museo ha buscado construir una relación con los habitantes, quienes asumen su pasado reciente como un evento "traumático", en tanto se viven como desplazados y desterritorializados-, el estudio de caso pone sobre la mesa puntos críticos por encima del contexto local al que se haya referido. Dos de ellos son capitales. Uno es el atributo dado al museo como dispositivo de la memoria: en qué medida la institución está dispuesta a cuestionar la narrativa que de la misma construye, y si es capaz de ver su papel dentro de los procesos de gentrificación y resistencia cotidiana. Si bien otros investigadores han trabajado el tema de la memoria y el museo, lo interesante del artículo es el elemento de incertidumbre que introduce con respecto a si e "la conciliación" con el pasad es un elemento de cohesión colectiva o de contención social. Lo segundo es el aparente repliego de la voz de autoridad del museo para dar espacio a los otros como sujetos con igual rango. La pregunta, por supuesto, es qué sucederá una vez que esa construcción de conocimiento conjunto entre dentro de las estructuras institucionalizadas del museo. Pese a que la lectura del texto puede resultar un tanto pesada por el exceso de notas a pie, es uno de los más sugerentes de la revista.

La calidad de este número 14 pierde piso con el texto de Naudy Trujillo, "Los museos veterinarios: puntos de encuentro entre la historia y la ciencia". La premisa inicial promete, pero el desarrollo es pobre y se reduce a referir una serie de datos e información sobre la historia de los museos en general. Es una lástima pues si bien en Latinoamérica hay investigación sobre museos de ciencia, son pocos los buenos textos en las que se atienda a su especificidad discursiva, tanto conceptual como museográfica.

La revista incluye también una reseña del libro de Jéssica Ramírez Puente, Los carmelitas descalzos en la Nueva España. Del activismo, a cargo de Leticia Pérez, que cumple con su objetivo de presentar y poner en contexto el libro en cuestión.

Sin duda, Intervención es uno de los proyectos editoriales más consistentes. Este número de nueva cuenta refrenda los que son sus mejores rasgos en tanto proyecto: rigor en la selección de textos, articulación de los contenidos, amplitud disciplinar -no es la "revista de los conservadores" o "la revista de los museólogos"-, cuidado de la edición y el manejo de un lenguaje claro que la hace accesible a una audiencia de lectores más amplia de lo que podría pensarse. Pero, considero que la revista sigue debiendo el que arriesgue a ser un foro de debate mucho más activo. Estoy segura que conforme el proyecto continúe, habrá de conseguirlo. 


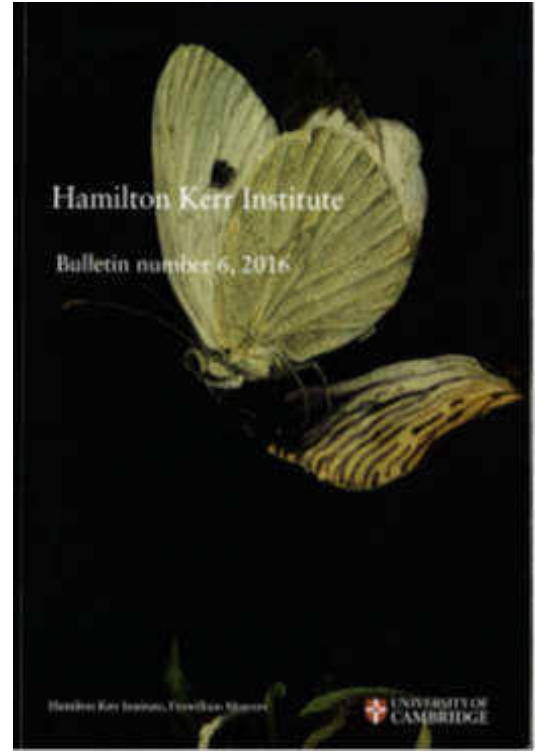

\section{Hamilton Kerr Institute Bulletin Number 6, 2016}

Lucy Wrapson y Christine Braybrook, eds.

\author{
Londres, Archetype Publications Ltd. / Hamilton Kerr \\ Institute, University of Cambridge. 2016
}

Páginas: 138

Idioma: Inglés

ISBN: 978-1-909492-45-5
El Instituto Hamilton Kerr fue creado en el año 1976 como departamento del Museo Fitzwilliam, perteneciente a la Universidad de Cambridge, con el fin de dar servicio al museo y a otras colecciones públicas de Gran Bretaña en conservación y restauración de pintura de caballete. El Instituto, fundado con el apoyo de la Fundación Gulbenkian y de otras fundaciones y consorcios británicos, tiene también como misión fundamental la formación de restauradores de alto nivel en esta especialidad y la investigación científica, técnica e histórica de obras de arte. Esta función fue establecida en el mismo momento de su creación como respuesta a las recomendaciones publicadas unos años antes por la Fundación Calouste Gulbenkian en su informe Training in the Conservation of Painting. Para ello el Instituto imparte estudios de postgrado en Conservación de Pintura de gran reconocimiento internacional y desarrolla programas de investigación interdisciplinar en estrecha relación con la prestigiosa Universidad británica.

Desde el año 1988 el Instituto Hamilton Kerr viene editando una publicación periódica dedicada a la difusión de investigaciones recientes sobre conservación, historia, técnicas y materiales de la pintura. La mayor parte de sus artículos son producto de los programas de investigación desarrollados en el Instituto y proceden de contribuciones de investigadores y estudiantes que, ahora o en el pasado, han estado vinculados al él.

La publicación no ha tenido hasta ahora una periodicidad continuada, pues desde el primer boletín, aparecido en el año 1988, sólo han salido a la luz otros cinco en los años de 1994, 2000, 2013, 2014 y 2016. Afortunadamente, a partir de este último número, el boletín del Instituto Hamilton Kerr se convertirá en una publicación periódica bienal a la que se podrá acceder mediante suscripción o compra.

Las editoras del boletín número 6, cuya salida coincide con el doble aniversario de la fundación de ambas instituciones -hace 200 años el Museo Fitzwilliam y 40 el Hamilton Kerr- son Lucy Wrapson, doctora en Historia del Arte por la Universidad de Cambridge y diplomada en Conservación de Pintura de Caballete por el Courtland Institute, actualmente Asistente del Director del HKI, y Christine Braybook, Conservadora de Pintura de Caballete por la Universidad de Northumbria y restauradora del HKI desde 2011. En este volumen han reunido una serie de artículos que tratan sobre distintos estudios multidisciplinares dirigidos a la comprensión de la pintura de caballete desde variados puntos de vistas: técnicos y materiales, iconográficos, históricos o estilísticos. Lo más señalado es que todos ellos armonizan diferentes metodologías de estudio científico, desde las aportadas por las técnicas instrumentales de carácter físico-químico y las de tipo humanístico, cada vez más estrechamente vinculadas en la exploración de nuevos cauces para la historia del arte.

Los dos primeros artículos tratan sobre el pintor inglés Thomas Gainsborough (1727-1788). El de Kristina Mandy analiza su faceta de copista (Thomas Gainsborough as a copyist), y el segundo, de la misma autora y de Spike 
Bucklow, da a conocer un uso técnico particular del artista, los mordientes a base de estaño en su pintura al óleo, a partir del estudio de unas vejigas contenedoras de pigmentos molidos en aceite (The Gainsborough's House paint bladders: tin-based mordants and the attribution of artists' materials). El siguiente artículo (Daniël Seghers, phoenix of flower-painters - Sven Van Dorst), de Sven van Dorst, compara dos pinturas de flores del artista flamenco Danïel Seghers (1590-1661), una perteneciente al Museo Fitzwilliam y otra la Royal Collection Trust, aportando nuevos conocimientos sobre su proceso de trabajo. Christhine Braybrook, una de las editoras del volumen, participa con las investigaciones realizadas durante la restauración de una obra anónima de artista angloflamenco, perteneciente a la Honourable Society of the Midle Temple londinense (Judgement and speculation: an appraisal of the Middle Temple's Judgement of Solomon), que revelaron unas supuestas iniciales del autor y otros interesantes detalles de su técnica.

Mary Kempski contribuye con un estudio de carácter más técnico sobre un pigmento rojo encontrado en la obra de un pintor anónimo alemán, El Hombre de Rojo (C. 1535), perteneciente a la Royal Collection Trust ( $A$ note on the use of the purple pigment fluorite on The Man in Red). Una investigación muy completa sobre un panel decorativo de una chimenea del siglo XVII en la Charterhouse de Londres nos la ofrece el historiador y restaurador español Carlos González Juste (All that is gold does not glitter: a technical, historical and iconographical study of the central panel of the Great Chamber fireplace, Charterhouse, London, and the figure of Rowland Buckett).

Sarah Bayliss, Alice Tate-Harte y Paul Joannides participan con un estudio sobre la figura subyacente revelada en la radiografía de un retrato femenino de Tiziano guardado en la Colección Wellinton de la Apsley House ('Titian's Mistress' at Apsley House and the painting beneath). Otro estudio técnico de un retrato femenino, esta vez del pintor inglés Joshua Reynolds (1723-1792) (A technical study of Sir John Reynolds' Portrait of Anne Liddell, Duchess of Grafton 1757-59), es analizado por Pia Dowse. A partir de los tratamientos de conservación, el examen técnico y las reconstrucciones efectuadas, Christine Slottved Kimbriel y Paul Joannides demuestran en su artículo ("On the unorthodox origin and Byzantine journey of the Lavenham Madonna") cómo las alteraciones sufridas en una pintura medieval del siglo XV, supuestamente bizantina, pueden enmascarar una obra veneciana con posibles atribuciones a Gentile da Fabriano (c. 13701427) o su discípulo Jacopo Bellini (c. 1396-1470).

Por último, cierra el volumen un artículo de Sally Woodcock en el que repasa los proyectos de investigación realizados por alumnos del HKI durante los 40 años de su existencia (Forty years of student projects as waymarks on the professional path). Estos proyectos, de los que se incluye un resumen, reflejan los ámbitos de interés de la institución, desde aspectos del desarrollo profesional de los restauradores al impacto de las nuevas tecnologías, y hace un Ilamamiento a avanzar hacia nuevos retos en la investigación en conservación de pintura.
Rocío Bruquetas Galán

Directora de Ge-conservación 


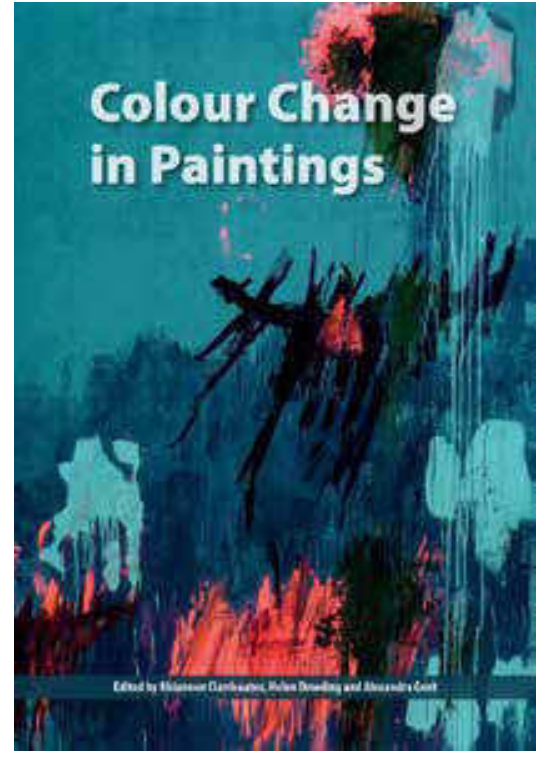

Los artículos compilados en esta publicación incluyen los trabajos presentados en la conferencia Appearance and Reality: Examining Colour Change in Paintings, celebrado en la Tate Gallery (Londres) en Octubre de 2015 y publicados por la editorial Archetype en colaboración con el Grupo de Pintura ICON (The Institute of Conservation), organizador de la misma. En él se recogen un interesante grupo de artículos de autores de ámbito internacional en torno a la temática de los cambios cromáticos que afectan a las pinturas en su más amplio sentido, incluyendo desde obras tradicionales a contemporáneas. Dentro de la problemática abordada se ofrecen diferentes puntos de vista como las intervenciones de restauración que afrontan los cambios cromáticos afectan a ciertas pinturas, los métodos de iluminación, los sistemas de monitorización de los cambios cromáticos o cómo estos influyen en los métodos de presentación y exposición.

Abordando sus contenidos en mayor detalle, resulta de gran interés el artículo firmado por Marika Spring sobre las decoloraciones, oscurecimientos y blanqueamientos sufridos por algunas de las pinturas más emblemáticas de la National Gallery de Londres, los cuales se estudian a la luz de diferentes técnicas analíticas. En este trabajo se hace patente el importante número de obras afectadas por tales cambios, como el oscurecimiento del bermellón cuyo proceso de cambio cromático se detalla en profundidad, haciendo un interesante recorrido bibliográfico sobre los trabajos precedentes publicados por diferentes investigadores. Otras modificaciones, como las sufridas por el minio, las lacas rojas, las pinturas al óleo con verdigris, el
Colour Change in Paintings

Rhiannon Clarricoates, Helen Dowding, Alexandra Gent (eds)

Archetype Publications Ltd.London, 2015

Páginas: 138

dioma: Inglés

ISBN: 9781909492431 blanqueamiento de la laca amarilla y el azul ultramar o el deterioro de los esmaltes, se evidencian e ilustran con imágenes de relevantes obras de la colección y sus correspondientes estratigrafías.

La monografía también contiene trabajos con enfoques más generalistas, como el texto de Larry Keith, en el que se detallan ciertos cambios cromáticos apreciados en diversas obras de Velázquez, algunos de los cuales se evidenciaron con motivo de la organización de la exposición monográfica celebrada en la National Gallery de Londres, y otras derivadas del estudio de las obras del genio sevillano presentes en dicha colección. En el caso de este trabajo, y a partir de dichos datos y observaciones, se justifica la toma de decisiones relativas a ciertas reintegraciones cromáticas realizadas con el fin de neutralizar los desequilibrios originados por dichos cambios.

De gran relevancia resulta el trabajo de Ormsby y Lee sobre los cambios cromáticos en el ámbito de la pintura contemporánea, los cuales pueden originarse por la luz o la acción de determinados químicos (especialmente en el caso de formulaciones en gel o las primeras formulaciones de acrílico), por la formación de productos de degradación, por la migración de materiales del interior de la capa pictórica, los depósitos de suciedad o el amarilleamiento de materiales orgánicos tales como aditivos, aceites o resinas sintéticas. Estos cambios, producidos de modo similar en pinturas tradicionales, se agravan ante el hecho de que las pinturas contemporáneas frecuentemente carecen de capa de barniz, razón por la cual éstos se 
hacen aún más evidentes. Cabe destacar en este trabajo la presencia de una notable bibliografía en cuanto a su calidad y cantidad, lo que sin duda será de gran interés para el lector que desee ampliar su conocimiento en torno al tema.

El lector tendrá también la oportunidad de acercarse brevemente a la polémica presentación y exhibición de los Ilamados murales de Harvard (1962) de Mark Rothko, gracias a la cual se compensa su cambio de color original mediante la proyección de luz a partir de un proyector digital; este interesante trabajo de Stenger y colaboradores sin duda puede constituir un innovador punto de partida para abordar otras presentaciones y sistemas expositivos de obras de similar problemática.

Otros artículos reseñables contenidos en la monografía recogen investigaciones de cambios cromáticos sufridos por el azul de Prusia en pinturas del siglo de oro danés (partiendo de los resultados obtenidos mediante fluorescencia de rayos $X$ y espectroscopía Raman) o el uso del MFT (Microfader Tester) y su contribución al estudio de los cambios cromáticos de diferentes tipos de obras (texto de Joyce H. Townsend).

Finalmente, en conveniente destacar que en diversos trabajos presentados en la publicación, resultan de gran utilidad las reconstrucciones hipotéticas digitales que muestran el posible aspecto original de las pinturas antes de haber sufrido modificaciones cromáticas, tal y como sucede el trabajo sobre Vincent Van Gogh (texto de Ella Hendriks), en el de los pigmentos púrpuras empleados en los retratos de los Tudor y Estuardo (texto de Rae y Sheldon), en el estudio una obra de Powel Weyts (texto de Vehave y Speleers) y, finalmente, en un trabajo que aborda la reconstrucción cromática de lo que fue en origen la Sala Dorada de la Galería Mauritshuis de La Haya (Pottasch et al.). 


\section{Suplemento:}

Monográfico ARTE URBANO. Conservación y Restauración de Intervenciones Contemporáneas 


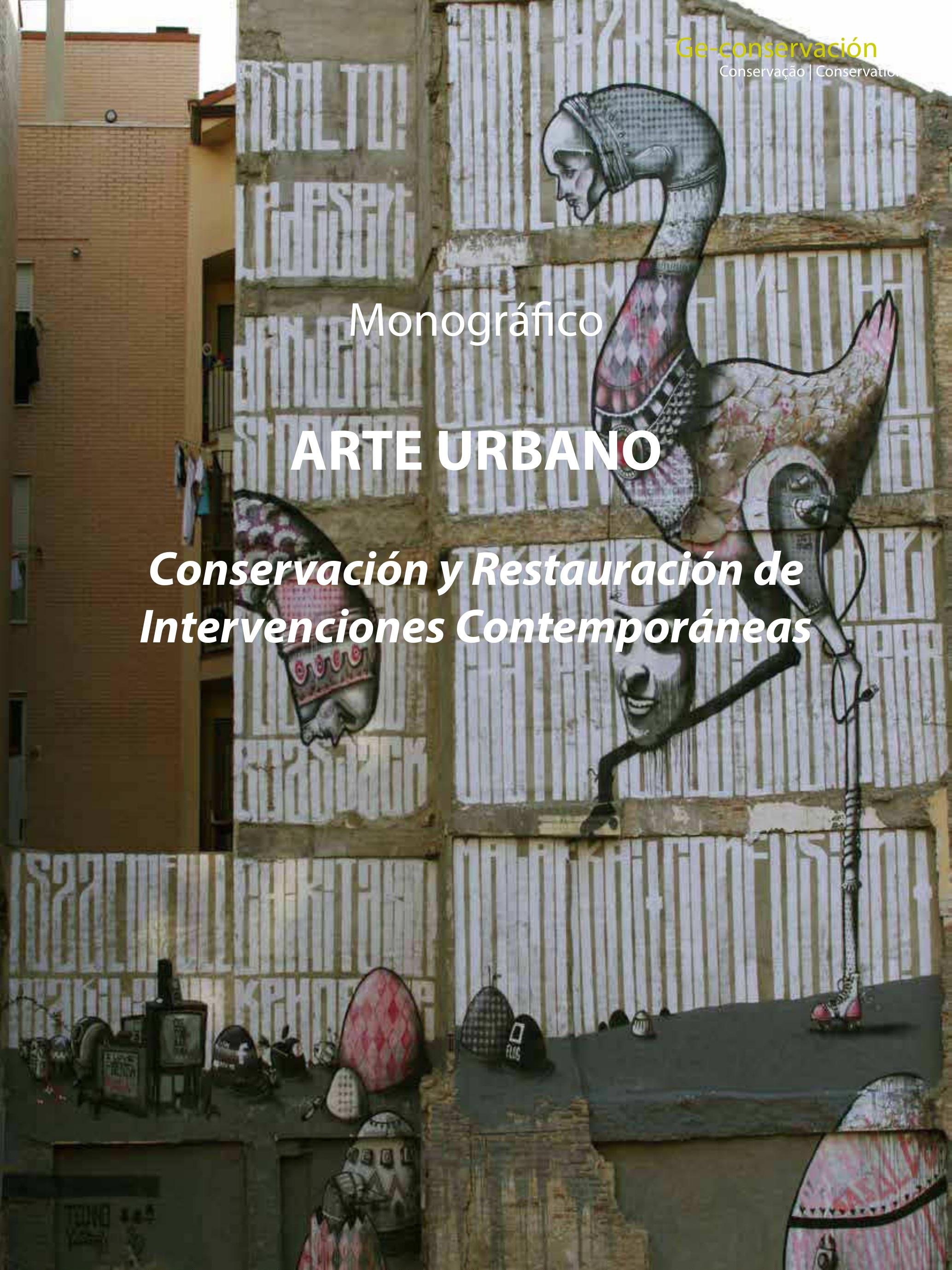

Imagen del mural: Tecnología by CNFSN+ y Malakkai para el 5*Asalto de Zaragoza. 2010. @Observatorio de Arte Urbano 


\section{Índice}

Páginas

\section{Suplemento:}

\section{Monográfico Arte Urbano. Conservación y Restauración de Intervenciones Contemporáneas}

Estudio del arranque sobre pintura con aerosol vinculada al grafiti y arte urbano: posibilidades, incompatibilidades y alternativas

Rita Lucía Amor García

Etapas del Arte Urbano. Aportaciones para un Protocolo de conservación

Elena García Gayo

El papel del conservador-restaurador en el arte urbano comisionado: reflexiones a partir de los datos recogidos en la Open Walls Conference 2015 de Barcelona

Rosa Gasol Fargas y Rosa Senserrich Espuñes

Arte relacional en la calle. Casos de conservación colectiva

Laura Luque Rodrigo

Entre la Teoría de la Restauración y el Arte Urbano, una paradoja disciplinar

Ana Lizeth Mata Delgado

M.I.A.U. (Fanzara), una propuesta social. Historia, materiales y conservación $M^{a}$ Teresa Pastor Valls

Acercamiento a la evolución histórica y tecnológica de los materiales pictóricos empleados en el grafiti y arte urbano

Mercedes Sánchez Pons

La conservación del arte urbano. Dilemas éticos y profesionales

Carlota Santabarbara Morera

Propuesta de un modelo de registro para el análisis y documentación de obras de arte urbano Ma Isabel úbeda García

Recreación virtual del arte urbano

Ma del Mar Vázquez de la Fuente

Anexo I. Propuesta de código deontológico para la conservación y restauración de arte urbano Grupo de Arte Urbano

Anexo II. Encuestas. Diseño de la investigación 


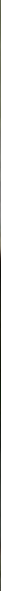

\section{Presentación}

El presente monográfico Arte Urbano. Conservación y Restauración de Intervenciones Contemporáneas es el resultado del trabajo del grupo de Arte Urbano del Grupo Español del International Institute for Conservation que se creó en la convocatoria de la 16 Jornada de Conservación de Arte Contemporáneo celebrada en febrero de 2015 en el Museo Nacional Centro de Arte Reina Sofía de Madrid. Inicialmente, empezó su andadura con más de sesenta voluntarios que desarrollan su trabajo en las universidades de Barcelona, Complutense de Madrid, País Vasco, Politécnica de Valencia, Jaén y Sevilla; Escuelas Superiores de Restauración de Suiza y México D. F. Diputaciones de Barcelona, Castellón, Ciudad Real y el Gobierno de Navarra. Además de un nutridísimo grupo de estudiantes de Grado en Conservación Restauración de diferentes universidades de toda España. Esto indica, no sólo, la expectación que el tema despierta en el ámbito de la conservación de patrimonio, sino también la necesidad de formación que se reclama desde el alumnado universitario para un campo tan desigualmente abordado académicamente.

El numeroso grupo original aportó en su primera tormenta de ideas muchos puntos de vista diferentes que supusieron un valioso material de trabajo con el cual iniciar la descripción de los aspectos que definen las posibilidades de conservación del Arte Urbano.

Ante el convencimiento de que unificar algunos términos restaría matices al trabajo que se proponía, se optó por unas normas flexibles y por este motivo en los artículos presentados aparece la misma palabra con una grafía diferente; así, se puede leer grafiti, que es el término aceptado por la Real Academia de la Lengua y que algunos autores relacionan sólo con el grafiti histórico, y otros simplemente aceptan la norma aprobada. Graffiti, en su grafía internacional en la que, además, es reconocido como una tendencia artística, si es con mayúscula; graffiti si se refiere de una forma general a las firmas callejeras. Arte Urbano, referido a un movimiento artístico y arte urbano cuando se refiere al arte de la calle y de forma general.

Ahora, una pequeña parte del grupo ha asumido ser portavoz del trabajo realizado durante año y medio a través de la investigación individual y la contribución colectiva; esta suma de esfuerzos ha dado lugar a un código deontológico adaptado a las necesidades del Arte Urbano y un sistema de encuestas para artistas y público, publicado en los anexos I y II, respectivamente, al final.

El presente trabajo aspira a ser el impulso necesario que marque el inicio para la investigación sobre materiales artísticos modernos en condiciones extremas, no sólo desde el ámbito académico sino comercial, y que justifique la misma actividad investigadora en nuevos sistemas y materiales de protección. Pretende difundir los argumentos necesarios que inicien una completa base de datos de obras de Arte Independiente y Murales Contemporáneos con la posibilidad de realizar una consulta pública que con el tiempo podría contemplar su proceso de degradación, y cuyo objetivo debe ser el registro de obras artísticas en el que prime la descripción de técnicas y el seguimiento de la evolución de materiales y productos. A su vez, sería necesario ampliar esta información con el análisis de la motivación y el proceso creativo, dentro de un contexto determinado, donde la experiencia vital sea la materia que inspire a las obras artísticas de la calle.

Por otra parte, este número monográfico es el inicio de una forma de trabajo voluntario en el que es fundamental la participación activa en el propio ámbito de estudio. Así, el grupo ha asistido a las convocatorias 
del Asalto de Zaragoza y Open Walls de Barcelona. Ha convocado la primera edición de Vincularte, encuentro abierto sobre Arte Urbano, en La Casa Encendida de Madrid, en el que sus miembros actuaron de nexo de comunicación entre los artistas y el público.

Paralelamente, ha surgido la necesidad latente de comunicar, ya que esta es una parte muy importante de visibilidad de la que siempre ha carecido el ámbito de la Conservación Restauración, y se espera que en el futuro los miembros del nuevo equipo (2017-2019) puedan aportar nuevas formulas de difusión. En esta etapa que finaliza, se han publicado artículos cortos trimestrales en la revista del Observatorio de Arte Urbano, Mural Street Art Conservation, cuya colaboración también ha favorecido la difusión en redes sociales: Instagram, Twitter y Facebook.

El trabajo en red ha sido fundamental, con un grupo tan disperso entre España, Suiza y México, contando, además, con alguna colaboración desde Portugal. Hasta el momento, el grupo nunca ha conseguido estar completo en ninguna de las reuniones físicas, ni siquiera por streaming, excepto el día de su creación. Esperemos que este aspecto humano se pueda mejorar en un futuro.

\section{Elena García Gayo}

Coordinadora del grupo de trabajo de

Arte Urbano del GEIIC 


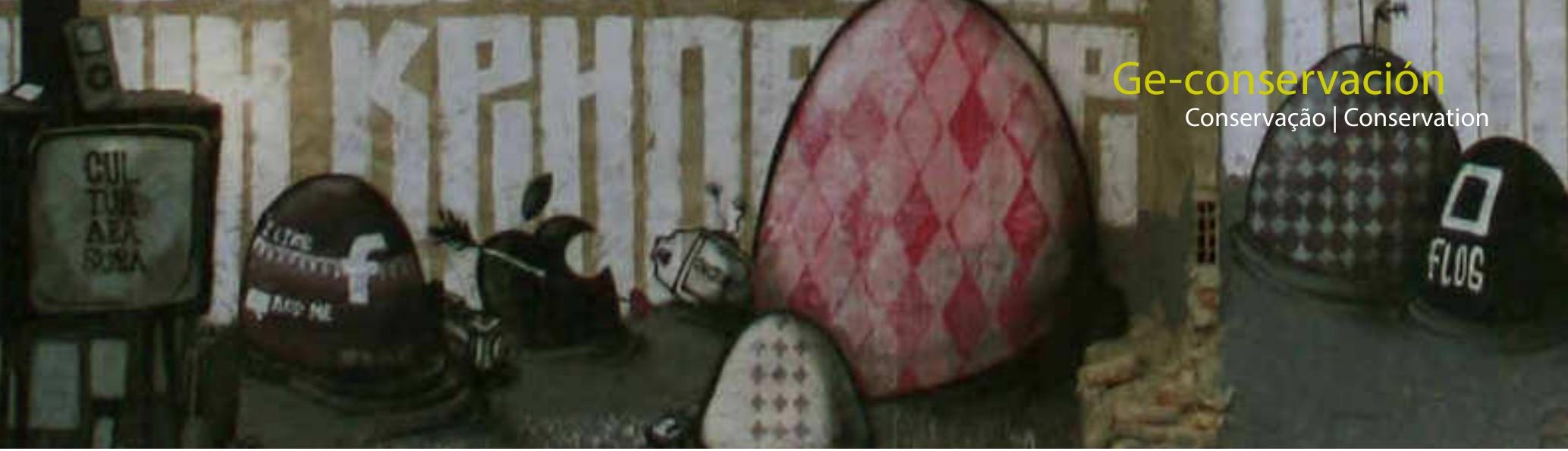

\section{Prólogo}

El monográfico Arte Urbano. Conservación y Restauración de Intervenciones Contemporáneas, que nos ofrece GeConservation y que coordina Elena García Gayo, reúne algunas de las más destacadas contribuciones por parte de diez investigadoras, miembros del Grupo de Trabajo de Arte Urbano del GEIIC, respecto a cómo abordar este nuevo horizonte profesional surgido en la transición del siglo XX al XXI. Se trata, por supuesto, de una publicación muy oportuna, en un momento muy significativo del debate y puesta al día de la conservación y restauración del patrimonio urbano.

La labor en común de este grupo no se limita al presente texto colectivo, sino que se ha ido visualizando a lo largo de algo más de un año, por medio de diversos artículos en la revista digital Mural Street Art Conservation del Observatorio de Arte Urbano (desde agosto de 2015), o eventos como el encuentro abierto Vincularte, celebrado en la Casa Encendida de Madrid ( 8 y 9 de marzo de 2016). Toda esta actividad se ha encaminado a asentar unas bases sólidas, fundadas en un concienzudo plan de trabajo, sobre las que edificar con garantías profesionales la conservación-restauración del Arte Urbano, además de velar por la divulgación y la pluralidad en su análisis.

Durante el siglo XX la legislación sobre patrimonio histórico-artístico fue aumentando sus horizontes, conforme a la relajación y ampliación de la consideración alto cultural y social de lo que podía ser representativo de la cultura pretérita y coetánea, al tiempo que se buscaban soluciones cada vez más óptimas para mejorar la consecución de la conservación material y velar por su contextualización comprensiva. Del mismo modo, ha previsto de una manera más o menos formal qué es relevante de nuestro presente para formar parte de ese legado destinado a las generaciones futuras o del lícito comercio de antigüedades, en un mundo saturado de productos culturales gracias a la maquinaria industrial, pero aún preso por viejos esquemas de pensamiento en lo que concierne al patrimonio. Esta tarea ocasiona la revisión y redefinición de lo considerable como patrimonio cultural, abriéndose más y más a la cultura popular.

La efervescencia creativa y social posterior a la Segunda Guerra Mundial y, sobre todo, desde los años setenta nos ha permitido observar una alta aceleración de los procesos de renovación de los elementos que constituyen y conforman el paisaje urbano. Es tan notable la alteración y la realidad de la pérdida del patrimonio popular bajo el peso de la vorágine inmobiliaria y de negocio desde la posguerra, que la desaparición de los testigos físicos de la memoria histórica cotidiana, los hitos vivenciales que han formado parte del paisaje emocional de generaciones enteras, se han ido expoliando, esquilmando o sustituyendo sin reparo ni remisión bajo la pulsión de la perpetua búsqueda de estímulos de consumo o ruptura. Qué decir, pues, de aquellas producciones de menor calibre, libres o espontáneas, vulgares o singulares de las que han surgido fenómenos tan espectaculares como el Graffiti o el Arte Urbano, menospreciadas como subproductos, si acaso, sofisticados o pintorescos, y a menudo confundidos con los culpables del expolio cultural antes que contemplarse como parte de las propuestas que configuran el nuevo patrimonio castizo de las ciudades vivas surgidas con la era postmoderna.

Es tan sustancial la alteración del paisaje urbano, por tan diferentes agentes y factores, que ha obligado a replantearse la necesidad de proteger un patrimonio urbano y cultural que navega entre la fragilidad paliada por los medios de registro visual, la precariedad de una labor apresurada o amateur y un clima social que impide su desarrollo con una perspectiva más sólida, pero tan maravilloso que, pese a que se nos escurre por entre los dedos de nuestras miradas, reclama su pervivencia como un fenómeno físico, sensorial y emocional, un proceso en comunidad. 
El conservador-restaurador ha sido sensible a esta corriente cultural polifacética, que ha tenido al espacio público como vertebrador, y a sus distintas capas. ¿Por qué no conservar lo que ciertos individuos o grupos han donado con objeto de ser compartido, de revivirse en unos y otros, y ha adquirido una singularidad notable, traspasando lo que sería una expresión estética a la categoría de producto artístico? ¿Por qué las mismas cualidades que legitiman la protección de un mural institucional no lo hacen frente a una intervención mural realizada por libre, manteniendo una calidad reconocible y no ocasionando su presencia un conflicto serio con la propiedad? ¿Qué salvaguarda remedia el desamparo de una producción artística pública que no asume la entidad de mercancía o cuenta con el aval institucional? ¿Qué es lo que enriquece la cultura: la monetización o el uso suntuoso del arte, o la simple presencia del arte? No voy a contestar a esas cuestiones aquí, pero seguramente el lector halle en las aportaciones de este monográfico algunas claves para responderse a sí mismo con mayores fundamentos. Lo cierto es que hay una creatividad tan desperdigada como desperdiciada y que, en ocasiones, habiendo recibido el aprecio popular y hasta de los expertos, no recibe ninguna consideración por una administración que ni siquiera ha sido capaz de diseñar los medios o los mejores cauces para evaluar esa clase de demandas sin que tenga que entrar en juego la pacatería esnobista, el oportunismo mediático, en suma, la imagen política o el rédito electoral.

Este ensanchamiento de horizontes no está exento de debate ni polémica, ni dejan de concurrir en él junto a los juicios los más diversos prejuicios, pero lo importante es aceptar la evidencia de que no estamos ante un fenómeno ocasional o caprichoso, sino persistente y dilatado en el tiempo. Entre la demanda de una forma diferente de construir la ciudad como una comunidad humana y la capacidad de discernir entre el maremágnum consumista y espectacular, nos situamos en el brete de evitar la desnaturalización de una producción artística, hija de su tiempo y que no se puede limitar a menudo a lo meramente objetual, punto crucial en el tema que nos ocupa. Como sucede con otro tipo de producciones culturales sin un carácter monumental, el aprecio de ciertas producciones de carácter temporal, efímero o fugaz radica fundamentalmente en su valor como testimonios de un proceso cultural y un contexto histórico, de un modo de entender y sentir la cultura que nos permite un más completo retrato del cuerpo de pensamiento y acción de tal o cual sociedad. La visión elitista del relato cultural se empezó a resquebrajar en el siglo XIX y, aunque exista también una selección de los materiales, se obra en nuestros días con un vivo compromiso por la memoria histórica general y la perspectiva clarividente de la importancia de entregar un legado lo más completo, plural y democrático posible que nos represente en los siglos venideros.

El desarrollo del Graffiti y el Arte Urbano a lo largo de estas décadas y el palpable peso cultural que han adquirido ambos ponen sobre la mesa una perspectiva diferente acerca de lo que en sus inicios se consideraba un subproducto cultural, a causa de su ubicación en un territorio menospreciado por su vulgaridad: la calle. Si bien el Graffiti ofrece una propuesta homogénea, extensiva y accesible, fácil de entender a nivel popular en sus motores y objetivos y en su vocación como una comunidad de iguales; el Arte Urbano presenta una complejidad discursiva mayor, capaz de invocar el viejo fantasma del desapego social que aún adolece el arte contemporáneo frente al ciudadano de a pie, a pesar de su vocación de proximidad y disolución en la vida cotidiana. El Arte Urbano se concentra en barrios-escaparate, que garantizan un seleccionado o selecto público y distinguida entidad, se presta a integración en programas de desarrollo comunitarios en espacios periféricos o colabora en procesos de gentrificación, en un ambiguo juego de intereses sociales o consciencia del tablero y las reglas de juego marcadas desde el poder. No cabe duda de que su configuración como una comunidad más difusa y libre en criterios creativos se presta a un variopinto ramillete de planteamientos y actitudes. Su irrupción no fue en vacío, sucedió a otras experiencias precedentes, gráficas, plásticas o escénicas, más o menos informales.

Por esa razón, los artistas urbanos van a verse situados en las mismas encrucijadas vividas en los años setenta y ochenta por muralistas sociales, activistas culturales o escritores de graffiti, pero en un marco propio de la era digital y neoliberal que colocará al Arte Urbano en una posición mucho más apurada respecto al discurso de su identidad. Ahí surge el dilema del experto que afronta su conservación: la permanencia a pie de calle, una calle inestable, desgajada y acartonada, cada vez más transitoria en cuerpo y alma, o su inmersión en los entornos subyugantes de exhibición y comercio del arte o en los insulsos contenedores de la simulación y la virtualidad, plegándose a un sistema enajenante.

Es un punto central que el reconocimiento de su importancia cultural choque no sólo con las cualidades materiales del Arte Urbano y su exposición a la intemperie y a la acción humana, sino incluso con el desamparo de la administración e, incluso, su persecución. Esa es la razón fundamental de que algunos conservadoresrestauradores hayan sentido la necesidad de aventurarse seriamente en la misión de velar por este tesoro y asumir la tarea de cuestionar, desde la teoría y la práctica, inercias e inadecuadas praxis. Dentro de la cultura popular encontramos claros ejemplos que muestran producciones relacionadas con lo transitorio: las que son de carácter inmaterial, las realizadas de modo temporal, las elaboradas sin pretensión de perduración o las que tienen implícita en su concepción su destrucción final, pasiva o activa, y hasta su reconstrucción o emulación. Sin embargo, aunque el artista urbano amalgama múltiples propósitos y perspectivas de cómo ha de desarrollarse su proyecto, los vecindarios o los expertos tienen su potestad legítima para reclamar el derecho a la trascendencia física, el poder solicitar la conservación y la salvaguarda de aquellas obras que estimen oportuno, abriendo con ello 
lo que sería un nuevo episodio de su existencia pública, cuya viva consciencia puede abrir nuevos horizontes a los creadores e, incluso, reconsiderar las razones por las que nos plegamos o no a una cosmovisión de la existencia basada en lo efímero o en lo inmortal.

Es posible que las personas especialmente sensibles, por su oficio o su formación, a la consciencia del valor histórico de los productos de su cultura sean vistas, en estos tiempos de superficialidad cultural, memoria enlatada, consumismo, materiales fungibles y obsolescencia programada, como obsesos subversivos que deambulan entre la traba al progreso de la maquinaria económica y la pasión maníaca por guardar artefactos de todo tipo en museos. Poco se entiende que no hay pretensión alguna de almacenar nada, de encerrar lo que nació para estar vivo hasta deshacerse en el tiempo y el espacio, porque entre lo lúdico, lo lírico o lo crítico, el Arte Urbano no es un producto que salga beneficiado del envasado, si no se respetan ciertas claves que pasan por el respeto a la capacidad creativa y la libertad de expresión de lo que es la huella de un pensamiento activo o un acto de comunicación. Precisamente, la comprensión profunda que expresa la labor de estos profesionales entiende la complejidad que entraña lo que es un fenómeno muy rico y diverso, que plantea muy diferentes retos en su campo y que reúne suficientes méritos para ser considerado un bien cultural, tal y como se nos irá desgranando. El conocimiento y su divulgación no pueden plegarse a un simulacro de cultura, reproductivo y evocador, porque entraña un distanciamiento y un margen de perversión de la percepción de la dinámica histórica y del valor del esfuerzo humano y sus frutos bastante preocupante, y en eso el papel de los conservadores-restauradores es crucial, puesto que subraya el aprecio a lo que no tiene precio.

Los mecanismos de absorción de la periferia cultural son siempre los mismos. Combinan su reconversión a modo de actividad laboral, aderezada con presiones coercitivas o disuasorias y con ofertas seductoras, focalizadas en una hipotética promoción social. El traspaso pasa por el pertinente tributo, las oportunas censuras, el medido aligeramiento o la inevitable mistificación que comporta mantener una etiqueta llamativa que simbolice el simulacro ritual de renovación y confirme el éxito del proceso. A menudo el filtraje de su absorción como arte público (arte urbano comisionado) o promoción comercial (mecenazgo empresarial-publicitario) lo convierten en una especie de 'decorado', de 'ilustración' monumental, de prisión aurática, tan útil a los propósitos del poder como alejada del individuo común. Como digo, el Arte Urbano no se enfrenta en lo básico a nada nuevo desde tiempos de Ulises. Pasó con la institucionalización del movimiento muralista surgido en 1965, de carácter social, reivindicativo y participativo, cuyo eco llegó en los setenta y ochenta a España, para padecer un destino similar. Pero la especulación-espectacularización del Arte Urbano no debe distorsionar nuestra mirada frente a un tipo de propuestas creativas que ha aspirado a romper con la brecha del artista contemporáneo con el pueblopúblico y que entiende la ciudad como un laboratorio libre de experiencias y plataforma de comunicación en sí misma.

El conservador-restaurador debe ser consciente de esta mecánica y, tome la opción que tome, no obrar jamás desde la ignorancia de todos los factores que concurren en este escenario. Su actuación le ofrece la posibilidad de participar en el proceso de absorción o de velar por la integridad de la naturaleza no sólo de cada proyecto creativo, sino de la experiencia estética, sensorial-intelectiva-emocional que contenga a priori o se genere a posteriori. La conciliación entre ambos extremos es posible, porque la absorción que implica la conservación abre la puerta a la recuperación, si se conjuga con la tolerancia.

Qué y cómo debe conservarse es otra cuestión imprescindible de tratar, que clama en nuestro marco actual por reunir en un foro de diálogo a las comunidades vecinales, los autores, la administración y los especialistas encargados de velar por el legado cultural, todos con voz y voto, quizás un voto ponderado, quizás un dictamen generoso y, por tanto, quizás una ejecución revisable. La ciudad es de todos y de nadie, por esa razón las instancias públicas, si se exceden, debe ser siempre en positivo, no en la senda de lo restrictivo o el mal ejemplo de lo destructivo. La administración debe ser consciente de su papel delegado, de que está al servicio de una ciudadanía en la que la cultura ha de ser su bien más importante, una cultura integradora, una cultura viva, una cultura compartida, participativa y tolerante, expresada en ese crisol que es el espacio público. Posiblemente la deriva espectacularizadora y especulativa que amenaza al Arte Urbano constituya un aval envenenado de las pretensiones de su conservación-restauración, pero precisamente la comprensión consciente de las profesionales que comparten sus aportes en este libro nos haga ver que aspiran a no dejarse embrollar en la absorbente maraña que se cierne sobre la creatividad artística de calle, tal y como se expresa en su código deontológico. El patrimonio cultural común está por encima de oscuras maniobras, responde al principio de la filantropía desde la perspectiva histórica.

Como sucede con el Graffiti, el Arte Urbano se convierte en algo imprescindible, porque satisface con éxito unas necesidades vitales sin pedir una titulación de ingreso, en esa extraña tensión que se establece en un espacio hiperregulado y densificado, y en ese tirante, asfixiante y emocionante pulso con los poderes oficiales y otros agentes sociales. Sin embargo, si tras sus primeras décadas el Graffiti se acabó atrincherando en la periferia física y cultural, para construir su propia dinámica de promoción al margen de la calle; la política institucional o las nuevas perspectivas de negocio del mercado caen ahora con contundencia sobre el Arte Urbano, ofreciendo unas posibilidades de desarrollo menos problemáticas para el orden público que lo que supusieron las maniobras de absorción del Graffiti. Su carácter menos 'analfabeto', menos 'salvaje', más recogido 
en el espacio, menos estigmatizado, menos subcultural, menos 'criminal', más fácilmente domesticable y útil a la representación del poder o a la configuración de una mercancía renovable, ha dado a luz entre otras fórmulas a una especie de gigantismo o colosalismo festivo-triunfal, a una promoción cultural snob-modernista, a una exaltación del arte de bajo coste y de fácil lectura o al turismo cultural de fachada y simulacro como motor económico, en el que se invita a los artistas a aplicarse y portarse bien en los límites y condiciones que se les marca, como sucede en otras esferas convencionales de la cultura. La demanda o ausencia de interés por la conservación de estas producciones nos hablan de los intereses que hay detrás de estas maniobras, nos permiten también atender que, tanto en la opción de conservar como en la de no hacerlo, se amalgaman diferentes sensibilidades y criterios éticos, paradójicamente, a favor o en contra. Da igual. Por eso es importante que el profesional, opte por lo que opte, sepa cuál es el espíritu que alienta su labor, para qué lo hace, y así labrar con ello un mundo sin conflicto interior.

Recogiendo estas cuestiones y otras, el contenido de esta monografía se dispone en cuatro bloques temáticos. El primero se centra en registrar y analizar el nuevo panorama de técnicas y materiales empleados por el Arte Urbano, y que exige el diseño de estrategias específicas e innovadoras de conservación-restauración. En esa línea, Mercedes Sánchez Pons nos advierte de la importancia para los conservadores de conocer la evolución histórica en el uso de materiales y en las técnicas pictóricas empleadas por los escritores de graffiti o los artistas urbanos, resaltando su dinamismo y variabilidad. No sólo se cuenta con los cambios en las ofertas de productos industriales, pensados o no para la pintura, sino con el uso casero o heterodoxo de estos, lo que exige un estudio concienzudo de los elementos presentes en cada obra en particular. $M^{a}$ Teresa Pastor Valls realiza otro retrato similar desde el análisis de las producciones que forman parte del Museo Inacabado de Arte Urbano (MIAU) y se ocupa del proceso de realización y del surgimiento, en la pequeña comunidad rural de Fanzara, de una sensibilidad social proclive a la conservación de productos inicialmente destinados a una existencia efímera. El peso de la adopción comunitaria de algunas piezas desemboca en una demanda de su conservación física más allá de la mera y usual documentación gráfica. Esta conversión en hitos simbólicos comunitarios es una posibilidad que debe tenerse en cuenta en las políticas municipales y cuyo reconocimiento público debe articularse administrativamente.

Un segundo bloque, planteada la cuestión de reconocer la existencia de un nuevo campo de desarrollo para la conservación y restauración patrimonial, se ocupa del modo en que debe de abordarse las intervenciones de conservación-restauración. El aspecto ético no sólo debe afrontar el pulso que se establece entre el criterio variopinto de los autores, de los vecindarios, de las administraciones públicas o del ámbito académico, sino que debe bregar con la comercialización expoliadora de estas producciones o la hegemonía del argumento del interés turístico (capitalización del patrimonio) como aval de conservación, además de la subsiguiente especulación económica que genera el fenómeno con su conversión en arte público. Por esa razón, contestarse el para qué, resulta crucial y determina la cualidad añadida a los conservadores-restauradores como protectores de las obras frente a abusos particulares o públicos que distorsionen o mistifiquen la naturaleza del objeto y su experiencia estética.

Ana Lizeth Mata Delgado aborda de modo directo esta cuestión, mediante el testimonio de artistas y el estudio de casos concretos, evaluando lo pertinente de sistematizar la conservación del producto de unas expresiones eminentemente procesuales. La protección, conservación y restauración es ya un hecho, no una posibilidad y eso hace que se plantee cuáles han de ser sus directrices y sus límites en el hoy y cara al futuro, exigiendo la adaptación de sus criterios y formas de actuación respecto a este nuevo fenómeno patrimonial. Por su parte, Carlota Santabárbara Morera se enfrasca en resolver los dilemas éticos y profesionales en un terreno muy variable y que pone a prueba la capacidad de resolución de la conservación, y subraya la importancia de lo ambiental, del contexto, y de plantear para el Arte Urbano un enfoque de restauración dinámica, ajustado a la naturaleza propia de su proceso estético. Ambas inciden en sensibilizarnos acerca de que el objeto artístico del Arte Urbano no se limita a un producto físico o a una imagen, sino a un proceso en un contexto dinámico y social.

El tercer bloque se ocupa de una problemática muy patente en el marco del Arte Urbano: la urgencia de las intervenciones de conservación. Un aspecto que exige un rico intercambio de experiencias entre profesionales que mejore los protocolos y técnicas de actuación, en beneficio de un objetivo asaltado pormúltiples obstáculos eintereses. Rita L. Amor García analiza los inconvenientes y abusos de una técnica que ha proliferado en los últimos años: el strappo, por medio de ilustrativos ejemplos. Pone sobre la mesa los motivos que la hacen pertinente o impertinente en el marco del Graffiti o el Arte Urbano. Los propietarios de los soportes donde se ubican estas producciones son los principales interesados en esta clase de preservación extractiva por motivos eminentemente económicos y que socialmente se justifica por el carácter invasivo de esas producciones. Sin embargo, más allá de su legitimidad - legalidad, no siempre se realiza con las garantías adecuadas. Amor García da en el quid de la cuestión cuando revisa el objetivo de este tipo de actuaciones: si se realiza en beneficio de la obra o por intereses derivados, como la explotación comercial del objeto o su imagen, o las exposiciones-espectáculo 'decimonónicas', en este caso de trofeos callejeros; para establecer un juicio ético y el grado de coherencia del discurso que argumente su conservación. En estos casos, el profesional se enfrenta a un conflicto añadido que sobrevuela la intervención y que podría plantear la misma traición del espíritu de la conservación patrimonial, patente en la gratuidad 
depredadora de ese tipo extremo de medidas sobre unos bienes que, en principio, carecen de entidad como mercancías y se han ofrecido libremente a la ciudadanía. Sin duda, es una cuestión por sí misma urgente de tratar y zanjar dentro del debate de la conservación y restauración del siglo XXI.

El cuarto bloque se concentra en las actuaciones preliminares que deben realizarse para determinar la pertinencia de la conservación de una pieza: marco legal, marco físico, decisión u opinión de los autores, encuestas vecinales, etc. Así, Elena García Gayo emprende la redacción de un protocolo específico para la conservación del Arte Urbano, entendido como un bien cultural, desde una nueva sensibilidad que abre la puerta a la colaboración entre los conservadores-restauradores y los creadores. Su perspectiva preventiva nos hace sensibles al valor de este tipo de producciones como memoria vivencial, como arqueología barrial y urbana. No se trata de entregar materiales para reconstruir el pasado, sino de entregar a la posteridad, de forma íntegra, las pruebas de un presente que se ha de recrear más allá de lo intelectivo, hacia lo emocional, y con una perspectiva generacional y comunitaria. Rosa Senserrich Espuñes y Rosa Gasol Fargas parten de la experiencia de Openwalls Conference 2015 y un plan de recopilación de encuestas orientativas y conversaciones con las partes implicadas, para tratar de forma concreta la conservación de las piezas realizadas en el marco de los festivales de Arte Urbano, dentro de sus entornos, y proponer la actuación conjunta de profesionales de la conservación-restauración con los organizadores de este tipo de eventos. En todos los textos se hace patente la reivindicación de la profesionalidad y en éste especialmente, junto a la consulta de las comunidades que conviven con tal o cual obra en la toma de decisión de una conservación. Laura Luque Rodrigo plantea la conservación desde la relación entre la obra y el espectador, yla concepción del Arte Urbano como experiencia colectiva. Su discurso se elabora a partir del análisis de varios casos y se enfoca en discernir qué potencial manifiesta para la transformación social cada tipo de estas experiencias, libres, participativas, comisariadas, etc. María Isabel Úbeda propone una metodología de registro, análisis objetual y conceptual, frente a la ímproba tarea que asoma ante un fenómeno con una alta productividad, carácter temporal y polifacético. Y plantea esa peliaguda pregunta que asalta al sentido crítico: ¿qué obra merece pasar a la historia y conservarse por ello dentro del patrimonio de interés cultural? Finalmente, María del Mar Vázquez de la Fuente, con un enfoque original, profundiza en la vinculación de la experiencia del videojuego o los simuladores virtuales con el Graffiti y el Arte Urbano; y muestra la utilidad de las herramientas digitales para la geolocalización del Arte Urbano y la recreación virtual de la experiencia graffitera o artístico-callejera.

Tras estos bloques, se nos ofrece en un anexo un código deontológico para conservadores-restauradores y otros especialistas ligados al Arte Urbano (historiadores del arte, artistas, gestores patrimoniales, arquitectos, sociólogos, antropólogos, críticos, filósofos, etc.) Por supuesto, el diseño de un código deontológico o unos criterios unificados que acoten los márgenes de intervención sobre las producciones del Arte Urbano es una tarea esencial, con todo el debate y los pormenores que pueda generar todavía. Ésa es la gran contribución en común del Grupo de Trabajo de Arte Urbano del GEIIC y que sirve de colofón a esta primera singladura, a partir de un borrador elaborado por Ester Giner Cordero y Carlota Santabárbara Morera. Expresa en conjunto la necesidad de poner sobre el tapete un asunto prioritario para que la relación del Arte Urbano y el Patrimonio Cultural no entre en una deriva crónica de frivolidad, irresponsable, inconsciente y de desamparo frente a un tesoro histórico, estético y social tan vulnerable al vandalismo institucional o a la corsaria y furtiva explotación comercial.

Como podrá comprobar el lector, este monográfico plantea muchas de las preocupaciones que revolotean sobre un sector profesional que busca situarse en un campo todavía por trillar en toda su amplitud. Algunas urgentes, pues en este nuevo horizonte de la conservación-restauración se hacen imperiosas, de querer evitar la pérdida de un patrimonio cultural tan importante en su práctica como en sus productos. Por ejemplo, el resalte de los firmantes de la figura del BIComún se vislumbra como una clarividente solución que permite rellenar, desde profundos valores democráticos y una sensibilidad cultural aguda, una laguna escandalosa en la construcción de nuestro patrimonio cultural contemporáneo.

Las conclusiones de todos estos artículos no aspiran sólo a ofrecer una guía fundamentada de actuación para cualquiera que se aproxime, con espíritu profesional, a la conservación del Arte Urbano, sino también que se reflexione con lucidez sobre la necesidad inaplazable de un criterio ético a la hora de abordar un plan de trabajo. La intervención cegada por el interés lucrativo, precarizada frente al aprecio mediático, presa de un materialismo desalmado, tiene el gran peligro de convertir al conservador-restaurador no ya en un cazador a sueldo o a destajo, sino en un taxidermista de la cultura o en un invitado de piedra, profesional-florero, transformado a su vez en objeto de exhibición y suntuosidad para las administraciones públicas y la industria de arte.

\section{Fernando Figueroa Saavedra}

Dr. en Historia del Arte 


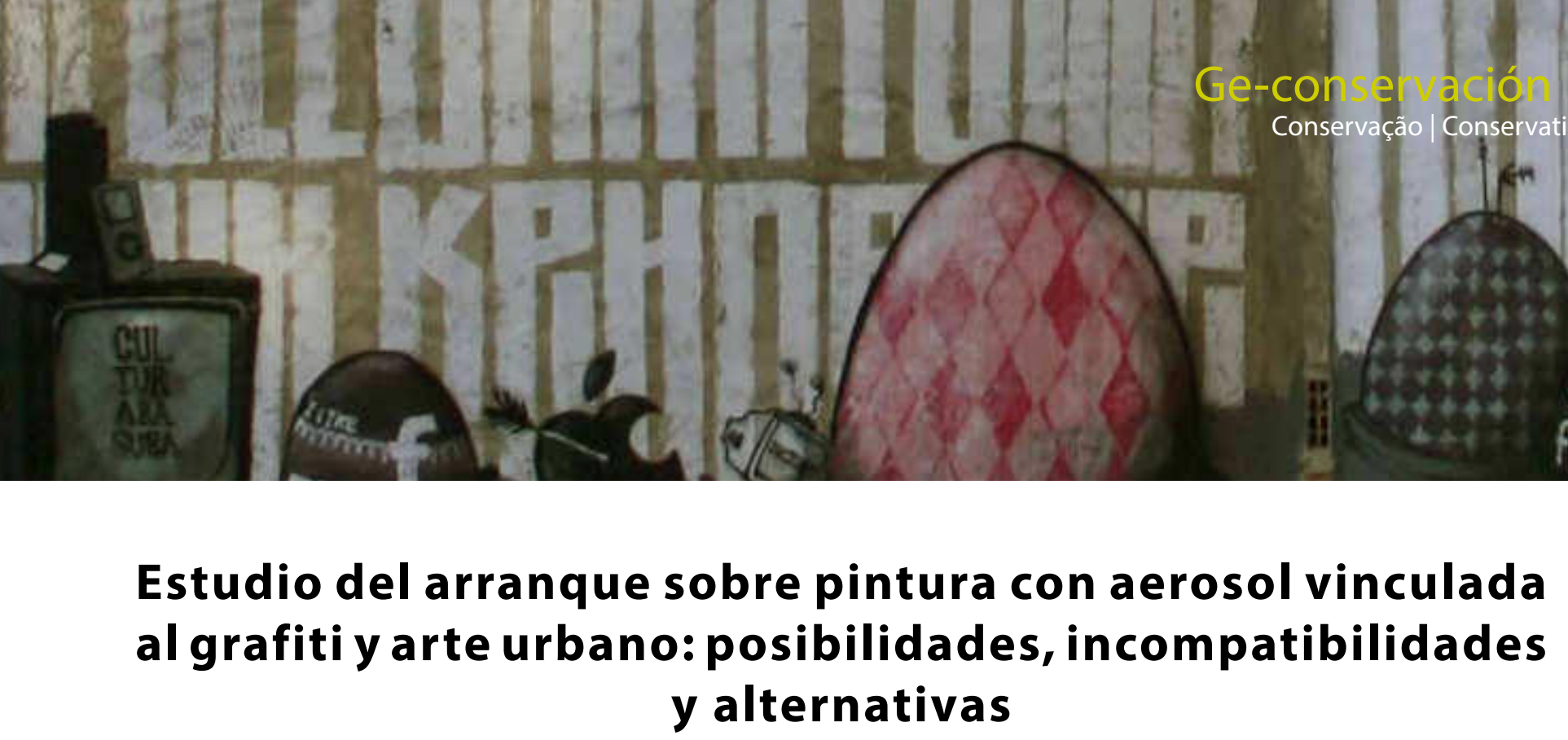

\title{
Rita Lucía Amor García
}

\begin{abstract}
Resumen: El conocimiento de la técnica del arranque a strappo surge en el siglo XVIII como una evolución de los sistemas de arranque para el traslado de obras murales. Su aplicación supuso una posibilidad para conservar obras ex situ pero, también, una problemática debido a su mala praxis y, más importante, por su abuso. La teoría de conservación establece que cualquier tipología de arranque se deberá aplicar en limitadas ocasiones, ya que se trata de una de las actuaciones de emergencia para la conservación de pintura mural. Desafortunadamente, esta situación no siempre se cumple. En la conservación de grafiti y arte urbano mural, el strappo supone ser una técnica factible, en la que se considera necesario, al igual que en arte convencional, establecer unas bases de actuación para que su uso se justifique únicamente como estrategia de conservación de la obra, respetando los deseos del artista y atendiendo al concepto de arte de la misma.
\end{abstract}

Palabras clave: arranque, strappo, pintura en aerosol, arte urbano, grafiti, pintura mural, actuaciones de emergencia

\section{Study on aerosol art transfers related to graffiti and street art: possibilities, incompatibilities and alternatives}

Abstract: Strappo detachment method appeared in 18th century as an evolution of detachment methods, for the transfer and relocation of wall paintings. Despite that this method allowed the ex-situ conservation, it could produce a great damage in the painting either because a wrong application or because an overuse. The conservation-restoration theories establish that any detachment method can be used in restricted situations, as the detachment is considered as an emergency action for conservation - it would be used only when other systems are impossible to apply. Unfortunately, this idea is not always contemplated. In order to conserve graffiti and street art, strappo method could be a possibility, but firstly, it is our duty as restorers to arrange the bases which must be follow to practice this method. Respect to artist's concept and artwork itself will be the main ideas to apply any emergency action for the conservation of those practices

Key words: detachment, strappo, aerosol art, street art, graffiti, wall-painting, emergency measures

\section{Introducción: arte urbano y conservación}

El arte urbano supone un reto en la conservación de sus formas, generalmente por la variedad de materiales y el uso de técnicas poco cercanas al arte tradicional, de la misma manera que ocurre en el arte contemporáneo. Lo anterior también sucede porque este tipo de manifestaciones artísticas que nacen en el espacio urbano de forma independiente deben, en su mayoría, evolucionary morir en el mismo; por lo que su salvaguarda contradice su concepto primordial. Sin profundizar en estos parámetros de estudio, y entendiendo que hay una actual necesidad y presencia de factores que apoyan la conservación de estas obras, el propósito que se plantea en este artículo se basa en las medidas críticas de intervención sobre arte urbano; consecuencia de esa dificultad de trabajo en el espacio público -por la materialidad y concepto de las obras-centrando el tema en aquellas actuaciones de emergencias posibles, que serán aplicadas con el objetivo de mantener y prolongar la vida de la obra.

Por otro lado, a pesar de que el arte urbano se muestra de diferentes maneras en las ciudades, es su forma mural la 
que hasta la fecha ha obtenido un mayor reclamo respecto a la idea de salvaguarda. Los factores que han posibilitado la conservación de murales relacionados con el mismo arte urbano o incluso con el grafiti ${ }^{1}$, están cercanamente conectados con las decisiones del público, aunque la realidad es que son los propietarios del soporte donde se presentan estas obras, los que pueden legalmente decidir sobre su futuro, lo que ha producido un enfrentamiento de preferencias en la preservación de las piezas como consecuencia a un reclamo externo por su posesión. Esto deviene en el arranque de las piezas murales de su ubicación original, su venta y traslado. Por ello, a pesar de que hasta el momento los factores que han posibilitado la aplicación de mecanismos de salvaguarda al arte urbano han cumplido con el objetivo de preservación de las obras, se establece una necesidad de revisar si su utilización ha sido en beneficio de la obra como objetivo primordial y no anteponiendo otros deseos, como la explotación de su imagen.

\section{Objetivos}

Este artículo tiene como objetivo principal identificar los criterios que han sido establecidos a la hora de preservar obras de carácter mural relacionadas con el arte urbano y el grafiti -manifestaciones artísticas independientesfuera de su entorno original, para poder establecer unos criterios precisos en el uso de medidas de emergencia en la salvaguarda de estas expresiones.

Secundariamente, se tomó como punto de atención también estudiar y entender los problemas más habituales que pueden surgir, y consecuentemente, comprender las posibilidades, incompatibilidades y alternativas al uso del arranque como medida de emergencia para la conservación de obras de carácter mural. Por esta razón se consideró necesario exponer los fundamentos teóricos sobre su uso, aportar ejemplos de situaciones que cumplan con unos criterios de conservación correctos y respetuosos, así como hacer comprensibles, a nivel práctico, las técnicas y uso del arranque sobre pintura en aerosol con imprimación de pintura plástica; técnica fundamental utilizada por gran parte de los artistas urbanos.

Por último, se establece también como objetivo revisar los casos y evaluar los criterios seguidos, lo cual servirá de guía para obtener un modelo de actuación en situaciones de emergencia, como propuesta para determinar la viabilidad del planteamiento y ejecución de estrategias de conservación sobre una obra de arte urbano, sea cual sea su naturaleza.

\section{Realidad y presente del arte urbano}

Cualquier manifestación artística independiente en el espacio urbano tiene la característica innata de que su duración dependerá de la calidad de los materiales constitutivos y su relación con los factores externos a la misma, así como una generalizada falta de interés en su mantenimiento o conservación. Es por ello que el arte urbano y el grafiti se identifican como obras de carácter efímero. Esto forma parte de su belleza y concepto, ya que su desaparición física se establece como una evolución del propio movimiento, siendo la fotografía el medio de preservación y difusión de la imagen.

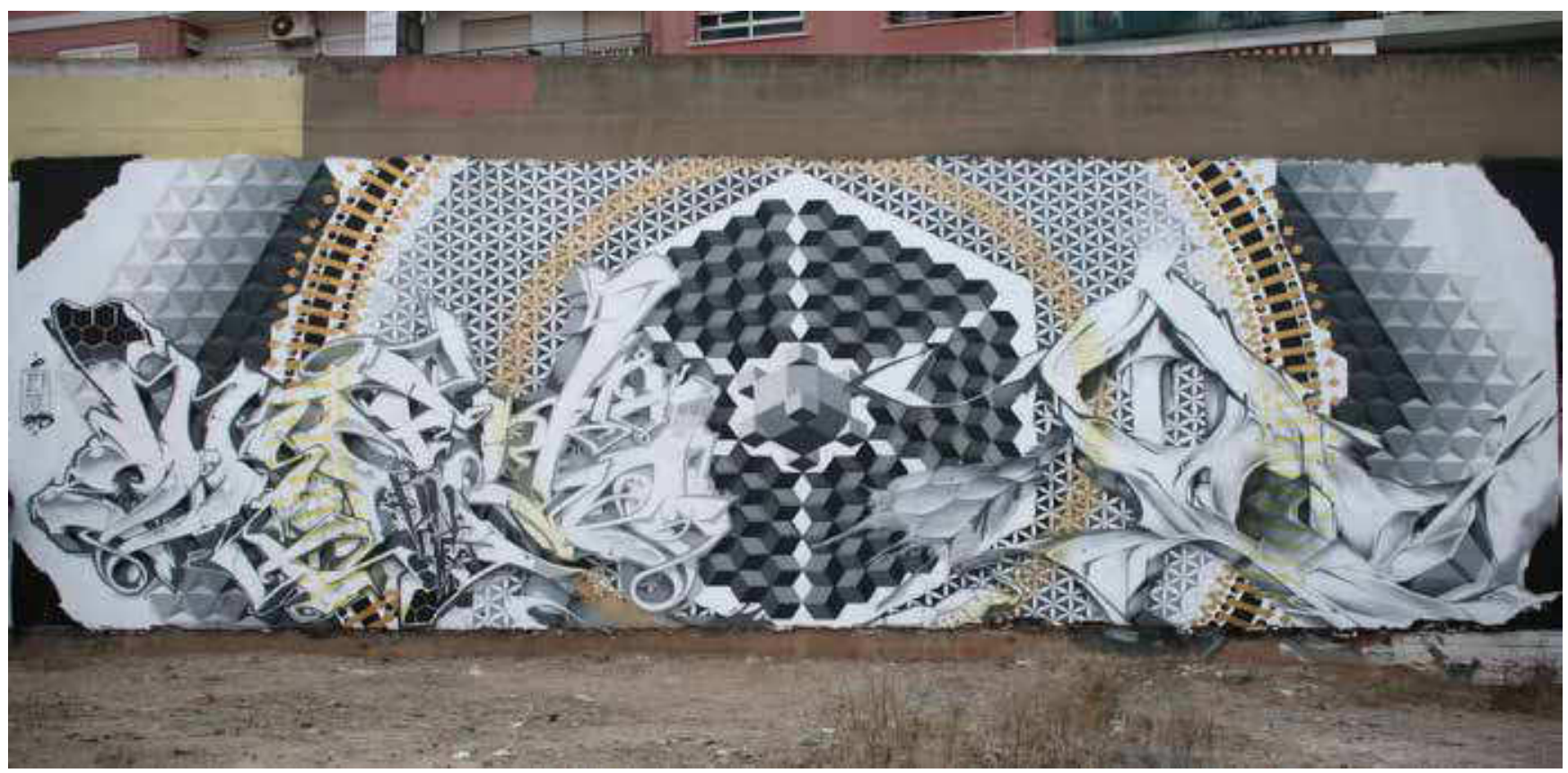

Figura 1. Ejemplo de mural con pintura en aerosol en Valencia. Obra de Miedo12 y Juan2. 
En contraposición, durante los últimos años, estas manifestaciones independientes que se concibieron sin una propuesta o intención conservativa, se han visto envueltas en situaciones que han hecho plantear la posibilidad de su mantenimiento. Este tipo de posibilidades se acercan a la conservación material de las obras, más allá del registro fotográfico, su difusión en plataformas online y publicaciones sobre intervenciones murales en todo el mundo.

Las circunstancias que actualmente apoyan la conservación de obras urbanas se vinculan a un interés del público por mantener ciertas imágenes en el lugar donde se plasmaron. Estos tipos de prácticas son aceptadas por un mayor número de personas - en comparación con los inicios del grafiti en los años setenta y su definición fija como vandalismo (Waclawek 2011: 41-54). Y ese carácter efímero, que se plantea de forma generalizada a todas las obras independientes del espacio urbano, contrasta con la idea de mantenimiento, tanto por el público como por algunos artistas de forma específica. Esto ocurre cuando ciertas obras adquieren valores y se transforman en iconos de una comunidad.

Los valores a los que se hace referencia pueden ir desde el valor social, el más relacionado con la sociedad al representar un cambio en el espacio; y/o al valor histórico-artístico, por ser un emblema representativo de la colectividad por diferentes circunstancias -históricas, culturales, artísticas-, similares al reconocimiento oficial de otros objetos del patrimonio tangible. Otros valores que juegan un papel importante en la conservación de las obras pueden ser el valor antropológico, ya que el arte urbano y el grafiti son movimientos o subculturas que se mueven, adaptan, imponen y/o exponen dentro de la ciudad; o el valor monetario, directamente relacionado con el mercado del arte.

Para ilustrar cómo dichos valores pueden alterar esa idea de lo efímero, a continuación, se resumen varios casos de obras murales ligadas al arte urbano que han sido conservadas.

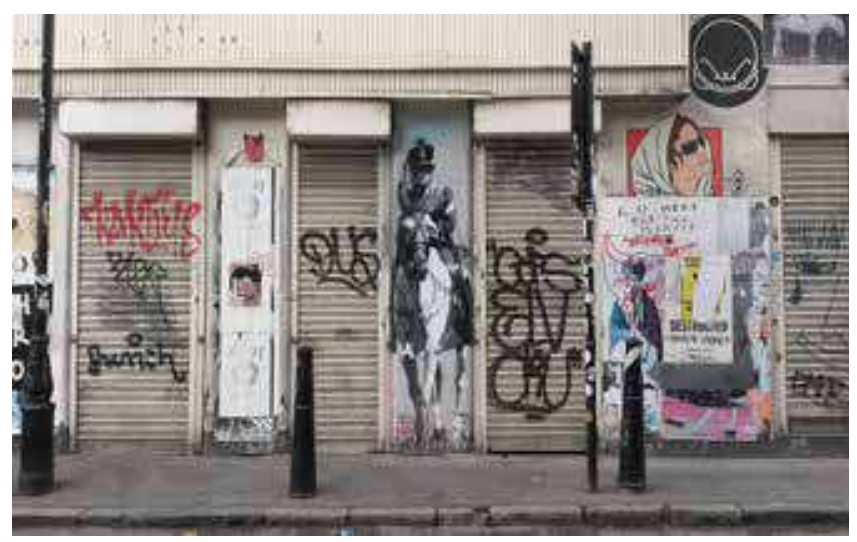

Figura 2. Ejemplo de manifestaciones independientes en el espacio público -tagging, mural, pósteres- en Shoreditch, Londres. Obra central de Conor Harrington.

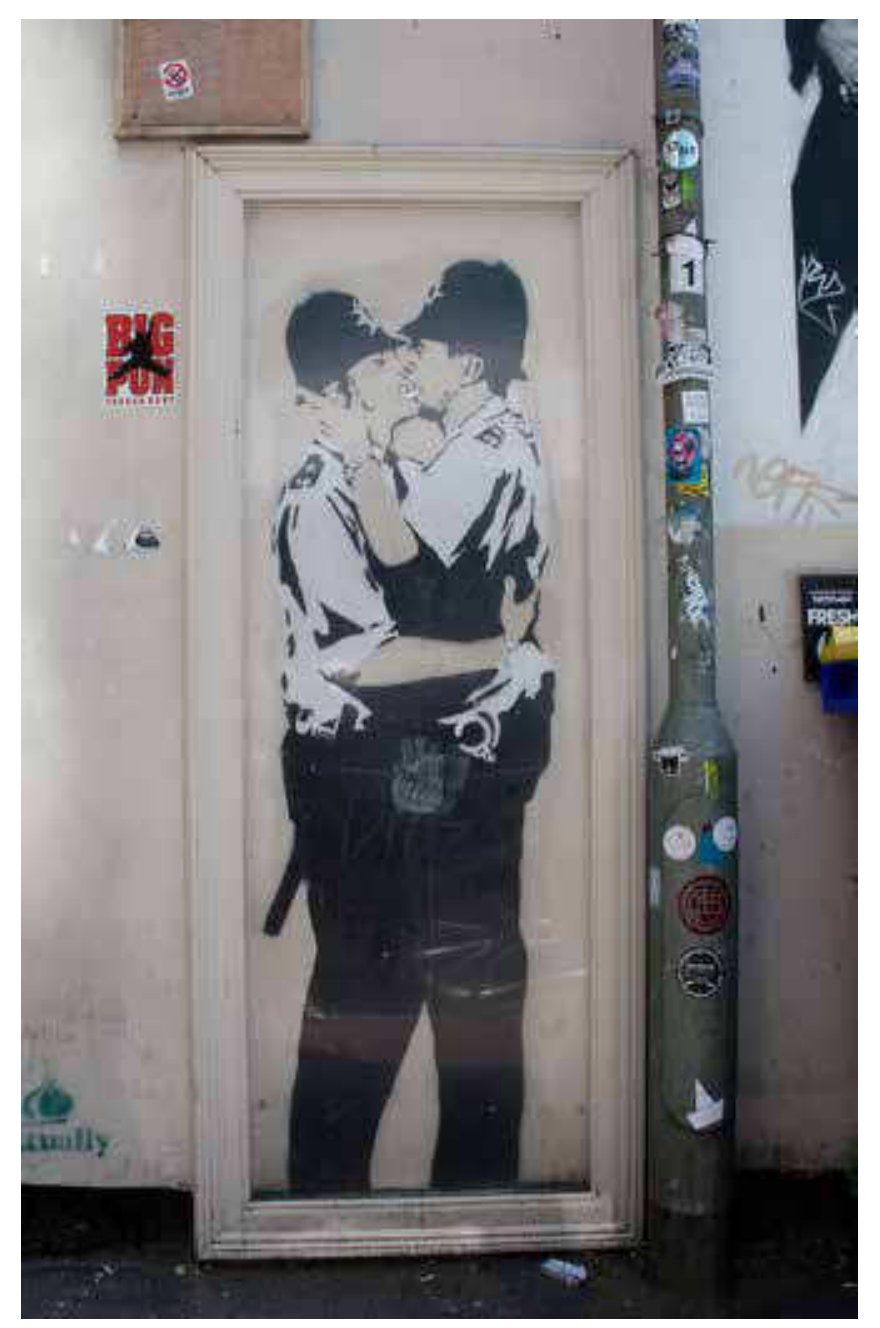

Figura 3. Reproducción de la plantilla Kissing Cops de Banksy en Brighton, posterior al arranque, traslado y venta de la obra original.

En primer lugar, el artista Banksy constituye un ejemplo por excelencia. El incremento de ventas de sus obras de galería en el mercado del arte, supuso que, casi paralelamente, sus obras en el espacio urbano también fueran objetivo de coleccionistas. Muchos de sus murales o plantillas fueron arrancados, trasladados y vendidos por los propietarios de las fachadas donde éstos se encontraban; en contra de las opiniones de los vecinos de los alrededores que reclamaban la obra como símbolo de la comunidad y parte del patrimonio público (Batty, 2013). Las ordenanzas municipales actuales y una falta de regularización acerca de este tipo de manifestaciones apoyan la decisión del propietario del lugar por encima de la petición del público. La conclusión obtenida de este caso se apoya en que el valor económico fue utilizado para posibilitar la conservación, pero por encima de todo, en beneficio de un colectivo reducido, la casa de subastas y el propietario.

El segundo caso, se trata de la conservación de obras relacionadas con el arte urbano y grafiti en Bolonia, con motivo de la exposición "Street Art - Banksy \& Co. L'arte allo stato urbano" (Arte Urbano - Banksy y compañía. El arte en el espacio urbano). Un grupo de especialistas en 
conservación y comisarios de exposiciones realizaron el arranque, traslado y exposición de obras que se encontraban en el espacio público, para exponerlas dentro del museo de la ciudad de Bolonia. Su objetivo, aunque se planteaba como medio de conservación y acercamiento de estas manifestaciones alternativas al público en general, suponía un beneficio económico para la organización. Además de restringir el libre acceso a las piezas por medio del pago de una entrada, no contaron con la opinión explícita de los autores de las obras arrancadas en la mayoría de los casos (Wu Ming, 2016). Como conclusión, a pesar de que con la exposición se intentaba atender a los valores histórico-artístico y antropológico, el valor monetario tenía un gran peso en toda la intervención.

El tercer caso, se trata del artista urbano $R O A$. Tras realizar un mural sobre la fachada de una cafetería en Hackney (Londres) en 2010, el ayuntamiento instó al propietario del lugar a eliminarlo en un plazo de tiempo establecido (Gabbat, 2010). La ordenanza municipal de la localidad prohibía la muestra de cualquier tipo de manifestación independiente sobre las fachadas externas de los edificios ${ }^{2}$. Finalmente, el propietario, con el apoyo de la comunidad de vecinos, consiguió acordar con el ayuntamiento la permanencia del mural. Como conclusión de este caso, se muestra cómo los valores social e histórico-artístico se antepusieron a las normas establecidas, para reconocer la importancia que pueden tener las manifestaciones artísticas independientes en el espacio público.

Similarmente se aplicaron los valores social e históricoartístico en la conservación de una obra de Blek le Rat en Leipzig. En este cuarto caso, la propuesta de recuperación de una obra casi perdida partió de la comunidad y el ayuntamiento la apoyó, pudiendo llevarse a cabo gracias a especialistas en conservación-restauración y el propio artista (I love Graffiti, 2013). Y, de igual manera, se pretende hacer con el quinto caso sujeto a estudio, Muelle, en una de las últimas piezas aún visibles del escritor de grafiti en Madrid (García Gayo, 2011:168-169).

La importancia de conservación en estos tres últimos casos, es establecer su interés al ser la comunidad la que solicita este tipo de intervenciones en el espacio, lo que incita a suponer que estas prácticas adquieren también un valor antropológico, por considerarse muestras de arte independiente procedentes de movimientos alternativos a la institución pública. De este modo, son estos casos puntuales de obras que se conservan, los que representan, por un lado, al arte urbano y grafiti en un cambio de cara a su inclusión en la sociedad, y, por otro, a su paulatina aceptación en el espacio urbano por parte del público, como si de cualquier otro tipo de expresión artística se tratara.

Al profundizar en el estudio de los dos primeros ejemplos, donde la obra ha sido separada de su lugar original, se visualiza claramente que, en la actualidad, la preservación de la obra fuera de su entorno se debe, a grandes rasgos, a una cuestión económica. De esta manera, se considera que se plantean una serie de deficiencias en el cumplimento de los criterios establecidos por la teoría de conservación y restauración de piezas artísticas y bienes culturales, por lo que, consecuentemente, la aplicación del arranque se queda sin argumento y deja de ser considerada como una opción válida.

\section{Criterios históricos para el uso del arranque}

Como se han visto en algunos de los casos expuestos en el punto anterior, el sistema del arranque es el medio utilizado para un rápido traslado de obras de arte urbano. Las intenciones de conservación expuestas en los casos primero y segundo, aunque sean correctas en el fin conservativo, parecen aplicarse de forma errónea o moralmente poco ética en cuestión de criterios, como se expone más adelante. Desgraciadamente, este no es un hecho nuevo a nivel histórico, ya que arranques de este tipo se llevan haciendo desde el siglo XIX sobre pintura mural tradicional (Brajer, 2002: 64-65).

Se debe entender que los criterios propuestos para la conservación de arte urbano se deberán regir de forma similar a las obras de arte contemporáneo convencional. La preservación de cualquier elemento que forma parte del patrimonio urbano es, por tanto, la idea que conduce a la aplicación de medidas de preservación en este tipo de obras y se debe supeditar no sólo al hecho de aplicar mecanismos de conservación mediante una praxis correcta, sino que también debe existir un criterio que defienda tal intervención.

El arranque es, en restauración, una intervención de alta dificultad técnica y de difícil justificación. Su uso -y abuso- ha sido tema de controversia desde las primeras teorías de restauración de la era moderna, ya que es una operación de carácter irreversible (Mora et al. 2003: 315) que implica la descontextualización de la obra respecto al espacio que la rodea, ya sea de interior o exterior. A nivel histórico, el uso del arranque ha sido planteado como una opción "fácil" de traslado de conjuntos murales, mecanismo ya utilizado en época romana para trasladar obras de otras civilizaciones. En sus inicios, los traslados de pinturas murales se realizaban en conjunto con su soporte, sistema denominado actualmente como stacco a massello. La evolución de este sistema de arranque dio paso al stacco, al reducirse el grosor y espesor de las piezas arrancadas, dando como resultado la separación de la pintura y los estratos de preparación del propio muro. La última opción de arranque, más contemporánea, se denomina strappo (descubierta por Antonio Contri en siglo XVIII). Es la opción más delicada de aplicar, ya que el adhesivo de arranque es el que produce la separación solamente del estrato pictórico del muro, lo que aumenta el riesgo de pérdidas de pintura si la tensión del encolado varía en algún punto. Es la que menos carga aporta a la pieza al reducirse -aún más- el 


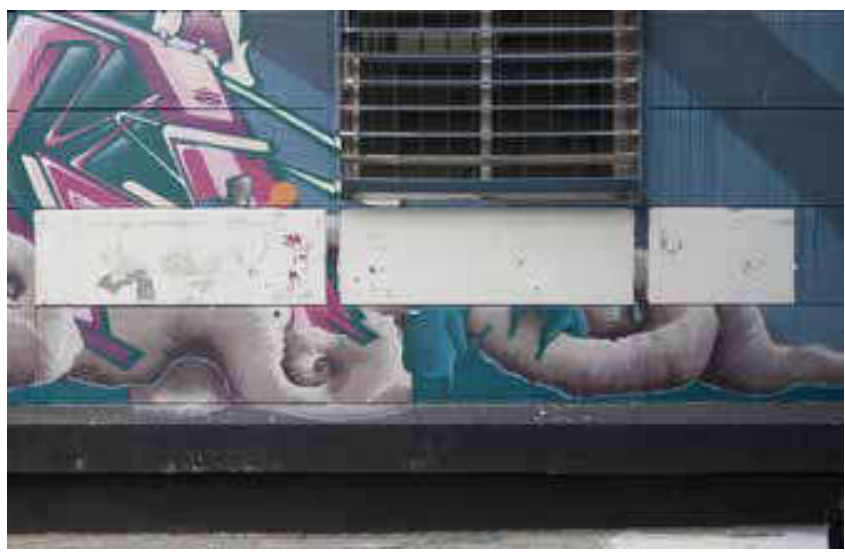

Figura 4. Superficie mural tras tres arranques parciales a strappo.

grosor del estrato arrancado y, por lo tanto, disminuye la complejidad del traslado debido a su menor volumen y peso (Soriano Sancho 2005:20; Brajer 2002:40).

Respecto a su uso como mecanismo de conservación, el arranque es una de las dos medidas de emergencia ratificadas en el Artículo 6 de la 14 a Asamblea General del ICOMOS en 2003, en el que se establece que el arranque y traslado "sólo resultan justificables en casos extremos, cuando todas las opciones de aplicación de otro tratamiento in situ carecen de viabilidad", confirmando lo establecido por los Artículos 7 y 8 de la Carta de Venecia (1964) respecto a la separación de cualquier tipo de decoración en el patrimonio, donde se afirma que "Los elementos de escultura, pintura o decoración que son parte integrante de un monumento sólo pueden ser separados cuando esta medida sea la única viable para asegurar su conservación." (Carta de Venecia 1964: Artículo 8).

Como medida de emergencia, el arranque de murales de arte urbano y grafiti es una posibilidad, pero, al igual que ocurre en pintura mural tradicional, su uso deberá limitarse a los criterios establecidos en la conservación-restauración de bienes culturales. Por ello, antes de proceder a marcar los estamentos de su aplicación, se debe plantear qué se entiende como medidas o actuaciones de emergencia en el patrimonio histórico-artístico.

\section{Actuaciones de prevención y emergencia}

Toda actuación conservativa que se realice sobre una obra que no haya sido puesta bajo control o mantenimiento previo, y/o se encuentre en una situación cercana a sufrir un daño irreparable en su condición por causas diversas, se considerará como una actuación de emergencia. La descripción de este hecho se basa en que cualquier proceso o sistema de conservación-restauración aplicado en primera instancia para contrarrestar los riesgos inmediatos a los que se enfrentan las obras en el espacio público, tal y como ocurre en las manifestaciones artísticas independientes, será considerado como una actuación de emergencia de este tipo.
Las obras de arte urbano y grafiti no se conciben con una duración determinada, y se plantean en el espacio público habiendo asumido su condición efímera, pero la adición de valores, tal y como se ha visto anteriormente, ofrece posibilidades en la aplicación de sistemas de conservación. Si se retoma la cuestión de los riesgos a los que estas obras están expuestas, se encontrará que son similares a los que se enfrenta cualquier bien del patrimonio histórico-artístico (ICOMS, 2010). Según lo expuesto, los riesgos más probables, y a los que ya se enfrentan estas obras, están directamente relacionados con la acción del hombre, y son: el vandalismo, por cuestiones de rechazo, diversión, ignorancia, falta de respeto, enfrentamientos fundamentados por diferentes cuestiones, etc. y donde también se podría incluir los vertidos químicos vandalismo con ácido-; el robo, para su posterior venta; y la remodelación de edificios. Por otra parte, existen otras tipologías de riesgos, menos probables, como serían las catástrofes relacionadas con desastres naturales terremotos, inundaciones- u otros tipos de carácter antrópico -incendios, atentados terroristas y guerras(Ministerio de Educación, Cultura y Deporte, 2014: 5).

En resumen, se entenderá que las actuaciones de emergencia podrán tratarse de cualquier acción aplicada sobre obras bajo tales circunstancias, pero su aplicación deberá ser siempre estudiada en profundidad a fin de encontrar la mejor alternativa en la conservación futura de la misma. Los procedimientos considerados como medidas de emergencia podrían ser cualquiera de los procesos y sistemas conocidos en el campo de la conservación-restauración -dependiendo de cada caso-, los cuales se adaptarán según las necesidades de la obra, y serán establecidos tras la realización de un diagnóstico de conservación, caracterización de técnicas y materiales, y establecimiento del contacto con el artista. Por el contrario, dentro de la conservación-restauración existen ciertas acciones consideradas como actuaciones de emergencia y que, al mismo tiempo, se consideran como "delicadas" ya que su aplicación será irreversible sobre la obra. Dentro de los tratamientos de conservación-restauración, la técnica del arranque es un sistema aplicado en casos de emergencia que implica una elevada complejidad técnica en su ejecución, junto a la irreversibilidad de la actuación.

\section{Las posibilidades y alternativas del arranque}

De ninguna manera la dificultad de aplicación del arranque como medida de salvaguarda o su limitado campo de actuación, implica su descarte como sistema de conservación. En este artículo se intenta defender el arranque como opción, y se insta a su estudio en profundidad para que, en caso de que sea necesario su uso, no existan deficiencias de ningún tipo.

Cualquiera de las tres formas de arranque conocidas ofrece, de diferentes maneras, garantías para la conservación de la obra, pero es siempre necesario conocer sus posibilidades 


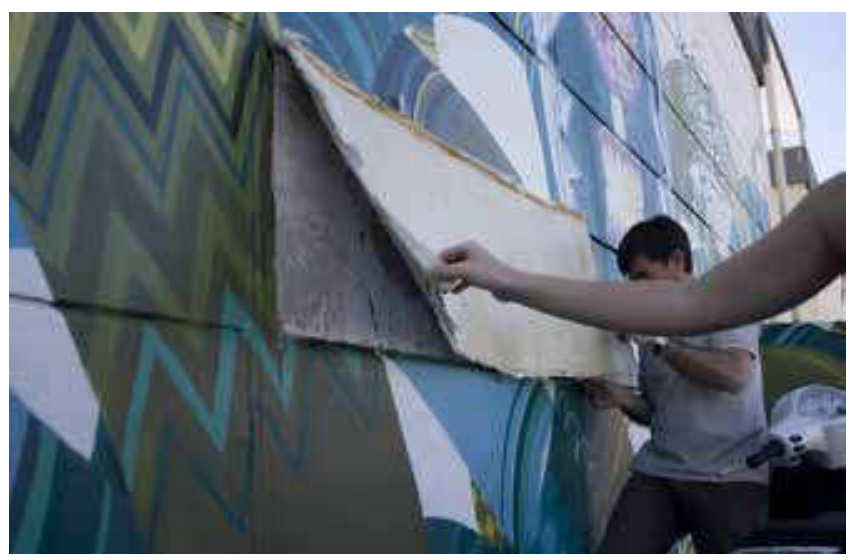

Figura 5. Ejemplo de arranque a strappo sobre pintura en aerosol.

y limitaciones para adaptar los medios a las características del soporte sobre al que se aplica. Una vez descritos los supuestos teóricos en los que se permite su uso, se pasará en la aplicación práctica y las posibilidades del arranque de pinturas murales realizadas con pintura en aerosol.

La pintura en aerosol (pintura procedente de resinas alquídicas, acrílicas o mezclas de otras resinas sintéticas) es la base casi fundamental en las intervenciones murales del arte urbano y, sobre todo, del grafiti (Waclawek, 2011: 32). Su aplicación puede ser independiente de la preparación, con imprimación de pintura plástica como recubrimiento previo (se trata de pinturas basadas en resinas acrílicas o vinílicas, que se utilizan a modo doméstico para recubrir paredes o fachadas); o bien, de carácter mixto, con la combinación de la pintura en aerosol y pinturas plásticas o acrílicos en el estrato pictórico. Paralelamente, los sistemas de arranque, necesitan un conocimiento y adaptación de sus materiales, para que éstos sean compatibles con la pintura que se pretende arrancar y evitar con ello alteraciones en las primeras etapas del proceso. A nivel general, el stacco a masello y el stacco, sólo necesitan tener en cuenta esta premisa en su primera fase -es decir, en el encolado/protección-ya que los materiales aplicados como protección de la superficie son casi los únicos que interactuarán de forma directa con el estrato pictórico.

En el caso del strappo esto será diferente. Pese a que se ha comprobado la efectividad del sistema tradicional con cola animal sobre la pintura en aerosol (Amor García, 2015: 386-391), algunos condicionantes externos pueden producir variaciones y pérdidas durante el arranque, por lo que su uso implicará el empleo de otros materiales con propiedades tensioactivas sobre la pintura -aplicación previa al encolado- al igual que ocurrirá en aquellos materiales que tienen por objeto completar la fase de refuerzo por el reverso. Esto sucede porque el limitado grosor de este tipo de arranques conlleva que cualquier material utilizado durante el proceso puede influir en la naturaleza de las pinturas en aerosol, produciendo su alteración.
Otro punto a tener en cuenta será la infraestructura necesaria para aplicar estos sistemas, ya que el stacco a massello y el stacco son arranques de grosor considerable, al separarse la pintura junto a los estratos de preparación y muro, lo cual aporta peso a la pieza arrancada. En cambio, el strappo, ofrece una separación de estratos con un grosor inferior (ver Figura 5), ya que al producirse la separación sólo de la capa pictórica se obtienen piezas fáciles de transportar, aunque sean de grandes dimensiones.

En consecuencia, la aplicación de unos criterios correctos junto a una buena praxis y preparación de cualquiera de los arranques, ofrece la posibilidad de emplear los tres sistemas de arranque con diferentes características, según la necesidad de cada caso.

De forma paralela a dichos sistemas de separación y traslado, se encuentran alternativas a la conservación de las piezas in situ, aplicando medidas de emergencia para evitar daños inminentes. Estas alternativas se basarán en el uso de barreras físicas o químicas sobre los murales, las cuales deberán ser compatibles con la pintura. Tal y como se establece para las actuaciones de emergencia en el Artículo 6 de la 14ª Asamblea General del ICOMOS de 2003, se tendrá en cuenta que "La aplicación de una capa de protección sobre la decoración existente, con el propósito de evitar el daño o destrucción que puede provocar su exposición a un ambiente inhóspito, habrá de realizarse con materiales compatibles con las pinturas murales, y de tal forma que permita que en el futuro puedan volver a destaparse". Por ello, en el caso de aplicación de barnices, aparte de ser compatibles con la pintura, las obras deberán estar bajo un control de mantenimiento activo hasta la aplicación de nuevas medidas. Similarmente a los barnices, las barreras físicas pueden ser una alternativa a los arranques, en este caso se tratarán de capas de protección externas que eviten una degradación directa sobre la obra, y de la misma manera deberán de evitar la producción de "ambientes inhóspitos" y requerirán de un control y mantenimiento.

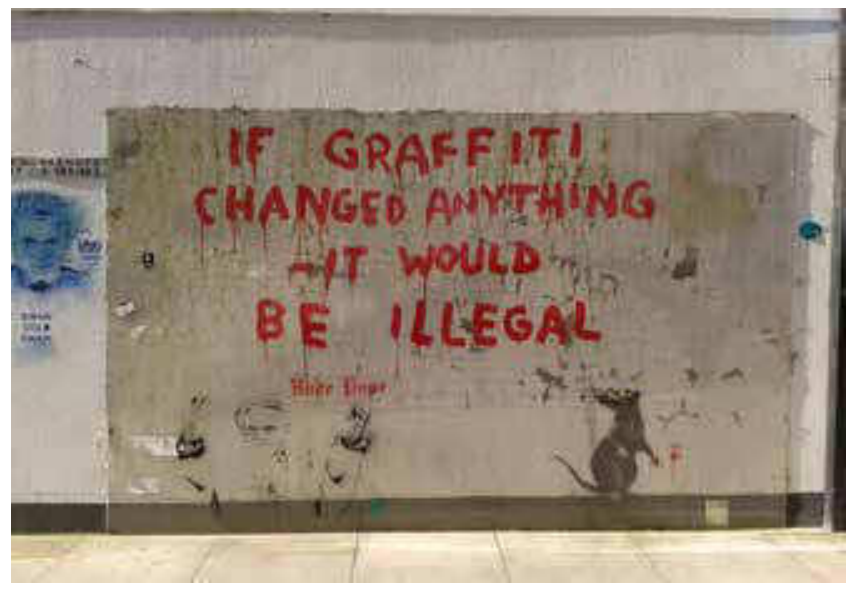

Figura 6. Barrera física de protección (Perspex ${ }^{\circledast}$ ) en un mural de Banksy, y las alteraciones sufridas a causa de su incorrecta colocación y falta de control. 


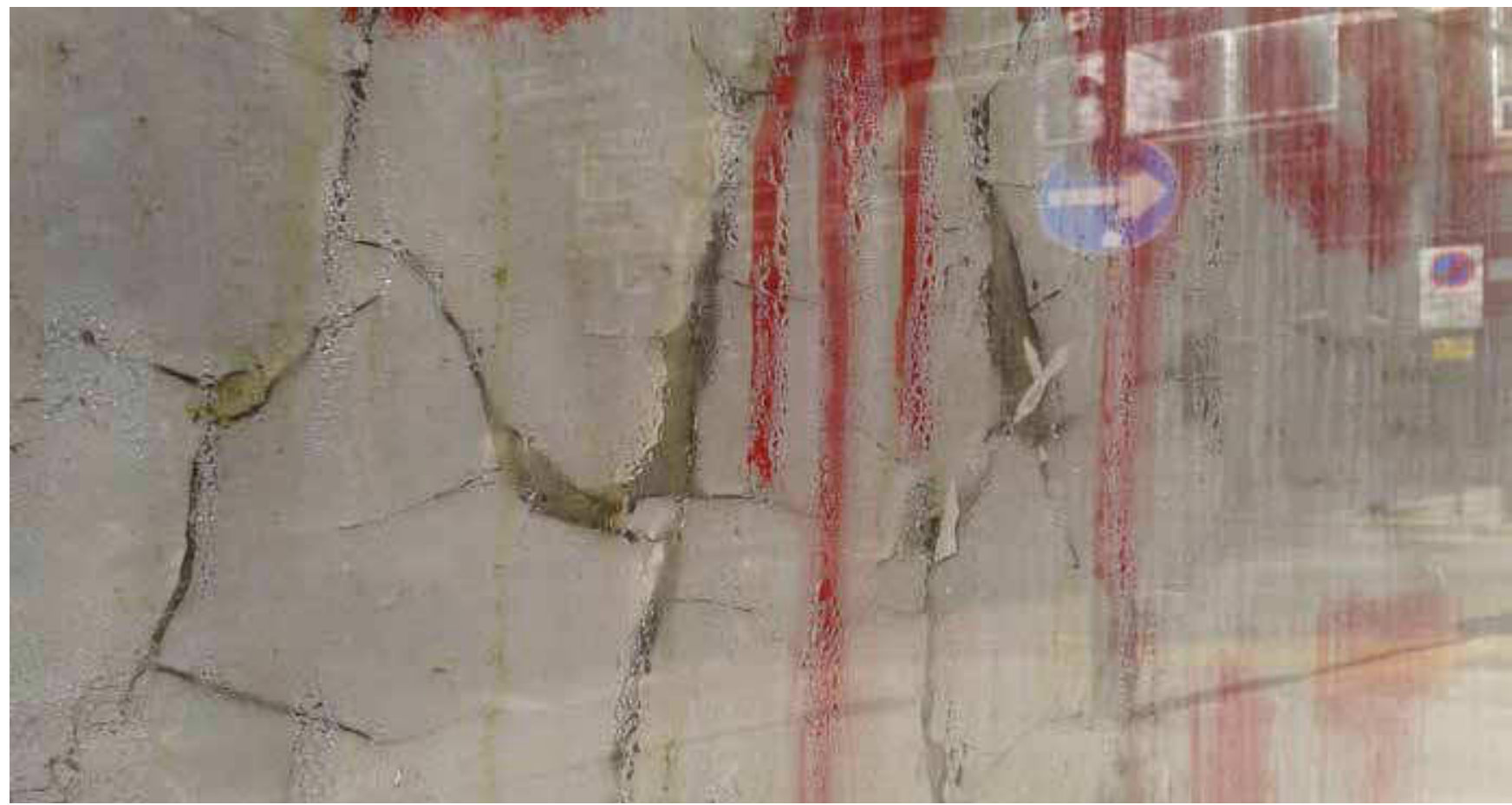

Figura 7. Detalle de las alteraciones sufridas en el mural -falta de transpiración, condensación, suciedad- a causa de la inadecuada colocación de la barrera física.

\section{Discusión y resultados}

La conservación de manifestaciones artísticas independientes es un tema nuevo y difícil de plantear, pero como resultado a las carencias encontradas en casos presentados hasta el momento, y teniendo en cuenta los criterios contemporáneos de conservación de las obras de arte, se ha considerado necesario plantear la realización de un estudio que refleje, por un lado, unos criterios de intervención lo más correctos y respetuosos con este tipo de manifestaciones independientes; $y$, por otro lado, un modelo de seguimiento para la conservación de estas obras.

Los criterios y el plan de actuación descritos a continuación podrán ser aplicables a cualquier intervención, aunque se tendrá que tener en cuenta que, debido a su naturaleza y localización, y al no existir un control sobre ellas, cualquier operación realizada en primera instancia podría ser considerada como una actuación de emergencia.

A partir del análisis de los casos hasta ahora conocidos $y$ en base a las premisas que garantizan su viabilidad y justifican la ejecución de arranques, los criterios necesarios para plantear la conservación de manifestaciones artísticas independientes son:

-En primer lugar, según los factores intrínsecos de la obra, ésta debería poseer unas características formales, conceptuales, estéticas y/o temática que la hagan poseedora de unos valores que destaquen sobre otras manifestaciones independientes. Igualmente, la obra habrá adquirido el reconocimiento del público, lo cual podrá ocurrir en consonancia con el primer enunciado o singularmente. Es necesario apuntar que la calidad de las obras, aunque puede influir en su consideración a la hora de ser conservadas, no debe ser una prioridad. Esta cuestión se tendrá en cuenta a la hora de conservar cualquier tipo de obra, aunque no se trate de actuaciones de emergencia.

—En segundo lugar, según los factores externos, la aplicación de cualquier actuación de emergencia sólo será viable cuando sea la última posibilidad de salvaguarda material de la obra-su conservación física- por lo que será necesario siempre hacer un estudio exhaustivo de la misma y de sus posibilidades de conservación desde otras perspectivas.

-En tercer lugar, la conservación de cualquier obra de arte urbano y grafiti no debería realizarse bajo un condicionamiento económico o beneficio individual. Se reconoce que el valor económico podría influir en la toma de decisión a la hora de conservar una obra, pero deben mediar otros factores a tener en cuenta, y éste nunca se puede anteponer a ninguno de ellos. Por esta razón, cualquier beneficio económico que atente contra la decisión del artista, la singularidad de la obra y/o el público, será considerado un hecho insuficiente para que se justifique la conservación material de la misma.

-En penúltimo lugar, la toma de decisiones no deberá ser realizada por un individuo o colectivo minoritario, sino que, en cualquier caso, deberá efectuarse en consonancia con especialistas de conservación-restauración y otras disciplinas afines, la comunidad, el artista, el propietario del emplazamiento donde se localiza la obra (si se da el 
caso) y el organismo público responsable, como requisitos necesarios que garanticen el éxito de las actuaciones.

-En último lugar, cualquier tratamiento de conservación aplicado sobre una obra, incluyendo las actuaciones de emergencia, deberá realizarse utilizando materiales compatibles, a la vez que garantice la retratabilidad. Así mismo se planteará un control y plan de mantenimiento en todos los casos. En las situaciones de traslado, las obras que no puedan ser devueltas a su emplazamiento original, deberán ser accesibles al público de similar manera a como lo eran en el espacio urbano, sin que pueda justificarse una remuneración económica impuesta en ningún caso.

De esa manera, la gratuidad y el libre acceso marcaran dos de los criterios fundamentales sobre los que se establecerá un plan de actuación en la conservación de este tipo de manifestaciones. Por la falta de estudios al respecto $-y$ una mala praxis encontrada en algunos casos- se plantea un plan de actuación a partir de premisas básicas en la conservación y restauración de arte convencional actual, aunque adaptado a las necesidades que las manifestaciones artísticas independientes requieren. Este plan de actuación, se dividirá por fases y poseerá un carácter multidisciplinar, además de participativo entre todos los intervinientes e interesados en el mantenimiento de la obra -comunidad, artista, especialistas, propietarios e instituciones públicas.

La primera fase del plan de actuación, forma parte del trabajo previo, en el que entrará la evaluación inicial de la obra, exposición de criterios para la conservación y la propuesta. Esta fase de trabajo preliminar envuelve cualquier actividad realizada antes de la proposición por cualquier colectivo con la intención de conservar una obra3. Para que esta fase esté completa y antes de proceder a las siguientes, se organizará un grupo de profesionales y conocedores del mundo del arte - historiadores, artistas, restauradores y otros agentes implicados. Juntos tomarán decisiones, aportarán conocimientos y plantearán los criterios durante todas las fases.

La segunda fase, se corresponderá a la fase de investigación, y en la que se estudiará de forma preliminar la obra y su entorno. En dicha fase se tratará de completar un estudio exhaustivo de su situación -física, matérica, estética y conceptual-tal y como propone el Artículo 2 de los Principios para la Preservación, Conservación y Restauración de Pinturas Murales (ICOMOS, 2003). También, se tendrán en cuenta los valores que influyen en la comunidad y que justifiquen su conservación. Esta fase se completará con la realización de encuestas sobre la obra al público y vecindario, así como la creación de plataformas online, si fuera necesario.

La tercera fase se focalizará en los mecanismos de intervención posibles y se evaluarán tanto sus limitaciones como sus posibilidades. En esta fase se tendrán en cuenta también alternativas a los mecanismos de emergencia, de cara a evaluar la posibilidad de aplicar sistemas de preservación de carácter menos arriesgado. Cualquier mecanismo planteado deberá ser expuesto de forma exhaustiva, desde las intervenciones más simples y seguras a las más arriesgadas, como podría ser el arranque.

La cuarta fase corresponderá a una fase de diálogo, en la que se contactará con el artista, y se realizará un cuestionario/entrevista sobre la obra u obras, siguiendo los modelos adaptados de entrevista a artistas contemporáneos. Aunque es necesario hacer partícipe al artista desde el inicio en que se promueve, por parte de cualquier grupo, la conservación de su obra, será en este momento cuando los especialistas le plantearán las posibilidades de conservación de la misma, la diversidad de propuestas de intervención y se le mostrarán los resultados obtenidos del estudio preliminar sobre la comunidad.

A partir de este momento, será decisión del artista dar su opinión sobre la propuesta de intervención, siendo posible la revisión de algunos puntos, si esa fuera su decisión. Tras ello, se llegaría a un consenso en la toma de decisiones sobre la intervención que debería aplicarse a la obra en concreto, haciendo partícipes también a los demás intervinientes comunidad, ayuntamiento y propietario.

La quinta y última fase de trabajo puede llevar a dos situaciones opuestas y dependerá de si la obra se interviene o no. Por un lado, en el caso de que la obra no se intervenga, se buscarán soluciones alternativas para la preservación no-material de la misma, tales como la recogida de documentación visual y de información relativa a la imagen de la obra desde su creación hasta su desaparición. De esta manera, aunque no se mantenga de forma física, habrá documentación suficiente para su estudio y difusión para las futuras generaciones. Por otro lado, en el caso de que la obra se intervenga, existirán diferentes medios de actuación dependiendo de si se mantiene in situ o se traslada. Para la conservación in situ, se procurará la aplicación de mecanismos de conservación respetuosos, con el único objetivo de mantenerla en el mejor estado de conservación, el mayor tiempo posible, sin producir daños o situaciones contraproducentes que aceleren su envejecimiento.

Cuando la conservación sólo sea posible mediante la aplicación de sistemas de conservación que impliquen el traslado definitivo o una separación provisional de la obra de su emplazamiento original -tales como el arranque en obras de carácter mural- se procurará, por todos los medios, que la obra se devuelva a tal emplazamiento. En el caso de que existan razones de peso que impidan su retorno, el traslado debe ser la opción única y más viable, y se plantearía una medida que garantizara la difusión libre de la imagen en su emplazamiento original (proyecciones, reproducciones, carteles informativos, etc.), para que siga siendo cercana y esté disponible al público. Esta situación tendrá en cuenta la consideración del artista, del grupo de profesionales y de la comunidad.

Aunque la naturaleza de estas obras y las situaciones en las que se han visto envueltas hasta el momento, de cara a su conservación, se acercan más a la puesta en marcha 
de actuaciones de emergencia, este plan de actuación será aplicable en cualquier situación. Las fases propuestas se determinan con el objetivo de establecer un modelo de trabajo seguro y respetuoso con la obra y el artista, pero partiendo de un consenso entre comunidad, especialistas y artista que será la base de trabajo para cualquier intervención conservativa. Por tanto, será ineludible que los especialistas tengan conocimiento de las posibilidades de trabajo establecidas, dependiendo de las diferentes condiciones y situaciones.

\section{Conclusiones}

Las intervenciones de emergencia, como el arranque, son actuaciones difíciles de abordar, por lo que respecta a la elevada complejidad técnica y de descontextualización espacial que aporta a las obras a conservar; no obstante, no aporta diferencias especiales a la conservación de ninguna manifestación concreta, incluyendo el arte urbano o grafiti. La aplicación de cualquier proceso o sistema de conservación sobre esta tipología de obras, generalmente consideradas efímeras, supone un reto. La adquisición de valores devenidos de un reconocimiento del público será la base para el planteamiento de medidas de conservación, ya que este tipo de expresiones, aunque sean independientes, se presentan cercanas al público, utilizando recursos plásticos estrechamente relacionados con las prácticas artísticas reconocidas en el arte contemporáneo.

Por tanto, será innegable afirmar que el reconocimiento que cualquier manifestación artística adquiera -sin depender de su origen-y que justifique la conservación de la misma, deberá regirse por los principios aceptados en el campo de la conservación-restauración de bienes culturales, estando dentro de unos principios éticos, consensuados con el artista y con el público, que finalmente es quien da sentido a este tipo de manifestaciones artísticas.

Respecto a las conclusiones establecidas, en cuanto a los criterios y valores que favorecen la conservación, cabe señalar que a la hora de llevar a cabo cualquier intervención de conservación-restauración sobre una obra, el valor económico de la misma debe considerarse en última instancia. Será la comunidad, el propietario, el artista y los especialistas en ese campo, los que deberán llegar a un consenso sobre el futuro de la obra. De esta manera, aunque esta se haya concebido con un carácter efímero, si el artista cree conveniente que su preservación es necesaria, se podrán aplicar mecanismos de conservación directamente. Si no se diera el caso, se buscarían alternativas a la conservación y difusión de la imagen más allá de la conservación matérica.

De forma más específica, atendiendo a las medidas de emergencia, la ejecución de un tratamiento de separación y traslado por arranque -en cualquiera de sus técnicasdebe entenderse como una opción drástica, que implica la descontextualización de la obra en un espacio que constituye un elemento importante de su propia creación, concepción y existencia. Ésta medida será únicamente utilizada en la conservación de cualquier expresión mural, cuando otros mecanismos de salvaguarda sean insuficientes. Alternativas propuestas al arranque y como medidas de emergencia, se tendrán en cuenta, como las capas de protección físicas o químicas, y en cualquier caso se considerará la aplicación de medidas de conservación preventiva e intervenciones puntuales de mantenimiento y/o acondicionamiento de la obra.

Se considera importante concluir que, como parte fundamental del discurso de cualquier especialista de arte urbano, se entenderá que la conservación material de las obras relacionadas con el arte urbano, en cualquiera de sus formas, se debe plantear de forma puntual, siempre que la obra en sí presente unos valores concretos y su conservación sea posible, sin dañar la imagen del artista ni de ningún colectivo vinculado a la propia obra.

\section{Notas}

[1] Existe una diferenciación entre las prácticas del arte urbano y grafiti, debido a la intención de cada una. Ambas trabajan en el entorno urbano paralelamente a las instituciones, pero el grafiti basa su práctica en la escritura, el uso de la firma y la abstracción de las letras dentro de un sector y público cerrado, en comparación de la diversidad técnica, material y expresión abierta al público general del arte urbano.

[2] En 2010 no se establecía todavía una diferencia "oficial" entre prácticas urbanas de carácter artístico y de carácter vandálico. Actualmente, el ayuntamiento de Hackney (en el este de Londres) diferencia ambas prácticas y facilita su expresión, aunque bajo el continuo control de las autoridades (Hackney Graffiti Policy).

[3] Como se establece en el primer borrador del Código Deontológico del Grupo de Arte Urbano del GE IIC, las propuestas de conservación podrán ser realizadas por cualquier individuo o colectivo, aunque se apreciarán aquellas que surjan de la comunidad.

\section{Bibliografía}

AMOR GARCÍA, R.L. et al. (2015). "Aproximación a la Viabilidad del uso de Strappo en la Conservación de Grafitis". En Conservation Issues in Modern and Contemporary Murals. Newcastle upon Tyne: Cambridge Scholars, 331-392.

BATTY, D. (2013). "Banksy Slave Labour mural row re-erupts over new sale in London". En The Guardian, Culture: Art and Design, 11 May 2013. https://www.theguardian.com/artanddesign/2013/ may/11/banksy-slave-labour-mural-row-sale [Consulta: 9/9/2016]

BRAJER, I. (2002). The Transfer of Wall paintings. Based on Danish Experience. Londres: Archetype Publications. 
GABBAT, A. (2010). "ROA's graffiti rabbit faces removal by Hackney council". En The Guardian, Culture: Art and Desing, 25 October 2010. https://www.theguardian.com/artanddesign/2010/oct/25/ roa-graffiti-rabbit-hackney-council [Consulta 9/9/2016]

GARCÍA GAYO, E. (2011). ¿¿Se debe conservar el arte urbano basado en la premisa de: piensa, crea, actúa y olvida?" En Conservación de Arte Contemporáneo 12a Jornada. Madrid: Museo Nacional Centro de Arte Reina Sofía, 159-178.

HACKNEY COUNCIL. (2012-2013). “Local Environmental Quality Enforcement Strategy". En Hackney, Environmental Problems: Environmental Enforcement: Graffiti Report. http://www.hackney. gov.uk/Assets/Documents/Hackney-graffiti-policy.pdf [Consulta 9/9/2016]

I LOVE GRAFFITI. (2013). “Leipzig - Restauriertes Stencil Von Blek Le Rat In Leipzig Enthüllt". En I Love Graffiti.de. http://ilovegraffiti.de/ blog/2013/04/12/leipzig-restauriertes-stencil-von-blek-le-rat-inleipzig-enthullt/ [Consulta: 15/10/2016]

International Commitee on Museum Security (ICOMS); HEKMAN, W. (Ed) (2010). Manual de Procedimientos de Emergencia. Países Bajos.

International Council of Monuments and Sites (ICOMOS) (2003). “Principios para la preservación, conservación y restauración de pinturas murales". En $14^{a}$ Asamblea General del ICOMOS. Victoria Falls.
International Council of Monuments and Sites (ICOMOS) (1964). "Carta Internacional sobre la Conservación y la Restauración de Monumentos y Sitios (Carta de Venecia 1964)". En II Congreso Internacional de Arquitectos y Técnicos de Monumentos Históricos. Venecia.

Ministerio de Educación, Cultura y Deporte (2014). “Plan Nacional de Emergencias y Gestión de Riesgos en el Patrimonio Cultural" En Textos de los Planes Nacionales del Ministerio de Educación, Cultura y Deporte. http://www.mecd.gob.es/planes-nacionales/ $\mathrm{dms} / \mathrm{microsites/cultura/patrimonio/planes-nacionales/textos-}$ planes-nacionales/13-emergencias-y-gestion-de-riesgos.pdf [Consulta: 9/9/2016]

MORA, P; MORA, L; PHILIPPOT, P. (2003). La conservación de las pinturas murales. Bogotá: Universidad Externado de Colombia e ICCROM.

SORIANO SANCHO, M. P. (2005). Los frescos de Palomino en la bóveda de la iglesia de los Santos Juanes de Valencia: estudio y aplicación de un nuevo soporte. Tesis Doctoral. Valencia: UPV.

WACLAWEK, A. (2011). Graffiti and Street Art. Londres: Thames and Hudson.

WU MING (2016). "Street Artist \#Blu Is Erasing All The Murals He Painted in \#Bologna" En Wu Ming Foundation, 12.03.2016. http://www.wumingfoundation.com/giap/?p=24357 [Consulta $12 / 9 / 2016]$

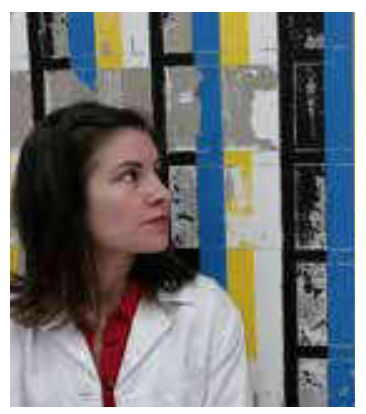

\author{
Rita Lucía Amor García \\ Conservadora-Restauradora \\ rita@cons-graf.com
}

Licenciada en Bellas Artes y posgraduada en Conservación y Restauración de Bienes Culturales por la Universitat Politècnica de València (UPV). Actualmente está finalizando su tesis doctoral en el programa de doctorado Ciencia y Restauración del Patrimonio HistóricoArtístico del Instituto Universitario de Restauración del Patrimonio (UPV), con su investigación en conservación de pintura mural contemporánea realizada con aerosol y la adaptación de la técnica de arranque por strappo. Ha participado en diferentes proyectos de investigación en conservación de pintura mural, cuenta con publicaciones relativas a su estudio de la conservación de grafitis y arte urbano mural y, desde 2014, colabora activamente con las artistas Patricia Gómez y Ma Jesús González. Por otro lado, es miembro del grupo de trabajo de arte urbano del GEIIC por la defensa en el uso de las buenas prácticas en la conservación de arte urbano. Desde 2012 reside en Londres, donde colabora activamente en programas educativos y de difusión del patrimonio británico dentro de la Royal Academy of Arts y los Royal Museums Greenwich, en estos últimos también realiza tareas de conservación en las colecciones de carácter permanente. 


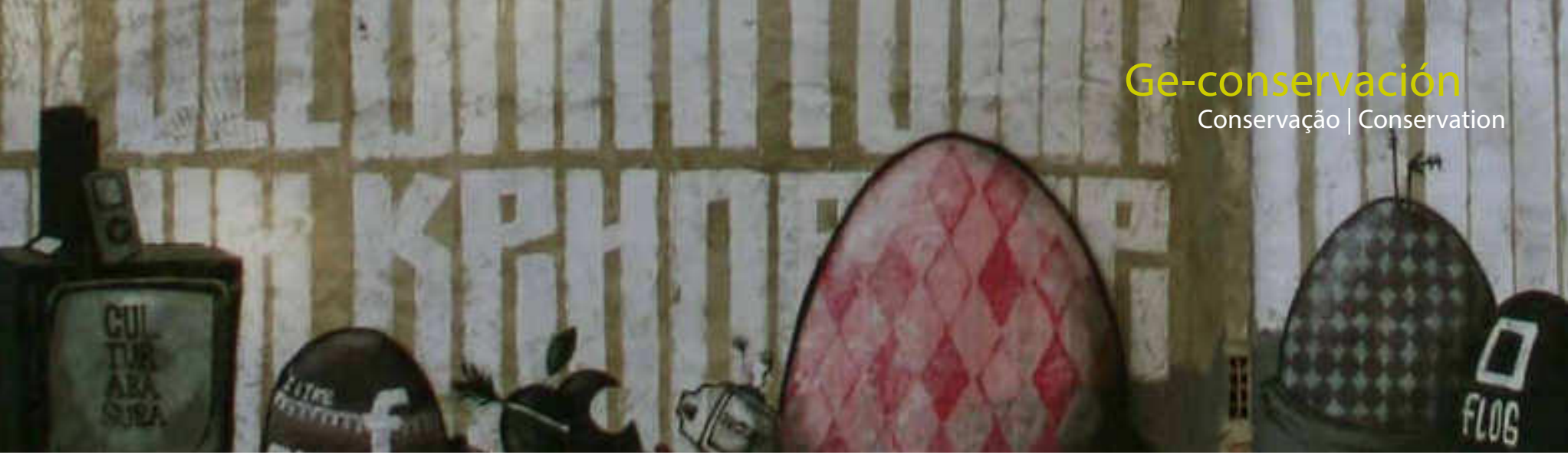

\title{
Etapas del Arte Urbano. Aportaciones para un Protocolo de conservación
}

\author{
Elena García Gayo
}

\begin{abstract}
Resumen: Los protocolos de conservación garantizan el adecuado tratamiento de los bienes culturales. Así como un reglamento de conservación preventiva puede sistematizar acciones que garanticen la correcta exhibición o manipulación de obras en un museo, un protocolo para la conservación de Arte Urbano adaptado a sus características y particularidades, ayudaría a deducir las posibilidades para conservar una obra desde la documentación técnica previa. La detección de los puntos claves que dan valor material a la obra, entre ellos, las condiciones espaciales que le son inherentes y el significado que adquieren para una comunidad de personas, daría pie a una base argumental que justificaría la decisión de conservarla. Para conseguir este objetivo es necesario describir unas etapas de Arte Urbano que faciliten la catalogación de obras.
\end{abstract}

Palabras clave: street art, expresión independiente, arte urbano, murales contemporáneos, protocolo, proto street art, intermural art, conservación

\section{Street art stages, contributions for a preserving protocol}

Abstract: The protocols guarantee the proper treatment of the cultural goods. As a preventive rules may systematize the actions so as to guarantee the suitable exhibition or of masterpieces in a museum, a particular protocol for the maintenance of Street Art, specifically adapted to its personal features and characteristics, would certainly provide with the possibilities to preserve a work of art from its very and previous technical literature. The early detection of the key points that substantiate its material value, among them, the spatial conditions inherent to those as well as the acquaired meaning to a community of individuals would provide with an argumental foundation that would justify the preservation choice. Nonetheless, it is almost mandatory to outline the stages of Street Art to facilitate the categorization of the pieces in particular.

Key words: street art, independent expressions, street/urban art, contemporary murals, protocol, proto street, intramural art, conservation. contemporary interventions.

\section{Introducción}

En los últimos años se tiende a usar el término"arqueología" para definir la recuperación de la memoria de obras desaparecidas y aunque es un término muy visual no es correcto; si la recuperación de piezas arqueológicas abre un camino al conocimiento de civilizaciones pasadas a partir de los artefactos que producen, en el caso del Arte Urbano es más coherente recuperar la memoria mural sentimental, de una generación, con los hechos que provocaron su existencia, el contexto en el que sucedieron y su relación con el entorno o, más concretamente, la de la memoria de un barrio en un punto concreto de su historia. Si se insiste en utilizar el término, lo más correcto sería hablar de "arqueología de la arquitectura" y más concretamente dentro de ella la disciplina encargada, entre otras cosas, de la "lectura de muros y paramentos".

Las acciones que tienen por objeto preservar la memoria están siendo llevadas a cabo por la facilidad de adquirir y divulgar imágenes digitales, pero la conservación de la materia reclama la creación de pautas preventivas que puedan conseguir un proceso de degradación muy lento, hasta la pérdida total. La naturaleza inestable, 
degradada y envejecida, así como las técnicas de ejecución rápidas utilizadas en el Arte Urbano, produce obras que se mantienen un periodo de tiempo demasiado corto; alargarlo, o no, dependerá del examen de sus particularidades. El análisis de sus contradicciones, los aspectos jurídicos o sociales que las protegen, la importancia o levedad de su resistencia material, la motivación que le dio origen y la importancia del contexto, son aspectos que ayudarán a clasificarlas dentro de una tendencia artística que tras cuarenta años de existencia ya no tiene nada de efímera.

\section{Objetivos y metodología}

Describir los parámetros que sirvan como referencia para ayudar al estudio y clasificación de obras de Arte Urbano a través de referencias; esto debe esclarecer si debe ser estudiado desde la Historia del Arte o desde la historia de movimientos urbanos contraculturales; si es susceptible de serlo desde el punto de vista de la conservación de obras efímeras, y si, además, estas herramientas pueden facilitar el análisis pormenorizado de cada caso en particular.

La metodología aplicada se basa en el análisis de entrevistas a artistas cuya ficha técnica fue publicada en la 12a Jornada de Conservación de Arte Contemporáneo del Grupo Español del IIC y que empezó a ser utilizada en 2011 en el V Asalto de Zaragoza, ampliada con entrevistas también a expertos en Arte Urbano desde 2014 (a partir de la base de datos del Grupo Español de Trabajo sobre Conservación y Restauración de Arte Contemporáneo GETCRAC que se puso en marcha en la Diputación Foral de Álava en 1988).

Se ha recurrido al examen de entrevistas publicadas en periódicos digitales y, además, los artículos del grupo de trabajo del GEIIC durante el año y medio de existencia. (Ver gráficos, encuestas y Código Deontológico propuesto por el grupo en el Anexo) y los artículos publicados por los miembros del grupo por el Observatorio de Arte Urbano en la revista digital especializada Mural Street Art Conservation $\mathrm{n}^{\text {os }} 1,2$ y 3. (2015- 2016).

\section{Paradojas y paradigmas del Arte Urbano}

Las intervenciones urbanas no se entienden de la misma manera a lo largo de la historia y varía su percepción según desde la disciplina que se aborde. Por ejemplo, desde la arquitectura; según C. Sitte (1889) el arte sirve al embellecimiento de las ciudades, y siguiendo los preceptos de R. Unwin el arte urbano debe ser la expresión de la vida de la comunidad. Con sus choques conceptuales, ambos autores lo definen desde el punto de vista de arquitectos urbanistas que cuentan con la síntesis de todas las áreas del diseño: la arquitectura, la jardinería, la pintura, entre otras, expresan la percepción intelectual de las intervenciones en la calle y cuáles deben ser sus reglas.
Si se tiene en cuenta la evolución de criterios de las disciplinas involucradas y que las obras son objetos jurídicos que forman parte de estructuras urbanas complejas ordenadas, se crean una serie de paradojas y paradigmas a su alrededor que hay que describir para poder examinar.

Entre las múltiples acepciones que definen las intervenciones artísticas producidas en la calle, la más controvertida es la de ilegalidad que, unida al valor artístico que la identifica como arte actual, constituyen la posible contradicción que enfrenta y anima la relación de los artistas con el público. "¿No será el arte verdadero una cosa clandestina?" se preguntaba su autor al analizar el movimiento internacional del Graffiti (Ramírez, J.A: 1992: 206).

De esta manera, el Arte Urbano se ha ido instalando en la sociedad que lo absorbe y transforma. Esta cercanía hace que desde las intervenciones ilegales hasta las más sociales el público se convierta en principio y fin de las propuestas y en dos agentes condenados a entenderse porque están emplazados a un futuro diálogo artístico por la conservación.

Por otra parte, si el arte debe tener un valor económico, que es la eterna cruz de todo lo artístico, al Arte Urbano reconocido como ilegal le viene bien la gratuidad; no se puede ser un alma más pura ni estar mejor condenado, a la indigencia, que cuando se es artista, urbano e ilegal. Pero como el reconocimiento social viene dado por la valoración económica y en los artistas no hay excepciones, se puede estar en la calle y en la galería con la consiguiente ambivalencia: la ilegalidad da respeto y mantiene la vigencia dentro del colectivo, mientras que la legalidad facilita su pervivencia y el reconocimiento social. Las obras de la calle transforman la regla stop, think, go, do en "piensa, crea, actúa y olvida", mientras que las obras de galería se rigen, como es habitual, por el mercado del arte que intentará crear marca comercial de cada artista y aprovechará la fama que le viene dada de la parte urbana. Así, aunque exponer en la calle y en una galería sean cosas diferentes, y a pesar de que los artistas alimenten esta bipolaridad, se trata de dos ámbitos de expresión con posibilidades diferentes. Uniendo esa información es cuando se debe valorar una carrera artística en la que no se podría entender una trayectoria sin la otra.

No todas las variables que interactúan en una performance urbana pueden ser registradas y conservadas. "Una obra de arte urbano no es pintura ni dibujo: es, ante todo, trabajo con un contexto. El material es la propia ciudad. El resultado tiene que ver con el dónde, el cómo y el cuándo, tanto o más que con el qué" (Abarca, J. 2016:4). Aun así, no se cree arriesgado afirmar que casi todos los estudiosos del Graffiti y el Arte Urbano conservarían algunas obras, si hubiera garantías. "Aunque la única forma de conservación del Graffiti que conozco es la fotografía, echo de menos el que no se haya podido conservar alguno de los vagones 
de metro de Nueva York de los 70". (Entrevista a Martha Cooper. Honolulu. Oahu, Hawaii. Febrero de 2014).

\section{Etapas del Arte Urbano}

Gracias a la era tecnológica estamos viviendo en un espacio digital al que nos hemos incorporado como un complemento más de nuestras posibilidades de observación del mundo, conocemos muchas obras de arte a través de este medio y sabemos exactamente dónde se encuentran aunque no salgamos a la calle. Incluso navegando por la red se puede entrar en el interior de muchos museos y tener la sensación de andar por las calles con google earth. Esta experiencia no sustituye a la realidad de pasear $y$, aunque ayuda a planificar exactamente dónde se quiere ir, evita en gran medida la sorpresa, uno de los fundamentos de esta manifestación. Si la red ha facilitado las posibilidades de difusión de obras de la calle, también ha modificado la percepción del mundo y nuestra participación en él. De hecho, en la actualidad, experimentar el Arte Urbano ha dejado de ser un hallazgo casual para convertirse en la búsqueda de un rastro virtual.

Bajo la mirada del observador, todo aquello que se sale de las fórmulas de diseño de la señalética urbana oficial y está en la calle puede ser considerado Arte Urbano, y es así porque según Beuys: "cada hombre es un artista", pero con una mirada analítica no se podría llamar Arte Urbano a todo sin "establecer un diálogo entre la micro y la macrohistoria, que conecta presente y pasado, prestando atención a precedentes, analogías con otros marcos culturales, lo particular y lo universal, lo heredado y lo legado, y dando luz a aspectos como la influencia cosmovisional, política o económica" (Figueroa 2016:12) para lo cual es necesario crear una metodología que sirva de estructura para su descripción. Tal y como sugiere Rafael Schacter (2016) recientemente si el Arte Urbano es finalmente reconocido como un periodo más del arte, éste, tiene unas etapas dentro de las cuales se pueden describir diferentes tipos de obras que se producen en la calle. Las diferencias no sólo deberían afectar a su tipología sino a su motivación y situación jurídica, porque estos aspectos dan pie a muchas diferencias de concepto y ejecución. Este autor propone el análisis de divisiones tales como"Proto Arte Urbano" o"Arte Intermural" que en el caso de la conservación, ayudaría a determinar diferencias en las producciones ejecutadas en el espacio público desde finales de los años sesenta hasta hoy y aportar claridad, también, para comparar las intervenciones entre sí y catalogar las obras producidas. Así pues, se propone la división en las siguientes etapas: Proto Arte Urbano, Arte Urbano, Muralismo Contemporáneo e Intervenciones Contemporáneas.

-Proto Arte Urbano, quedaría definido por las primeras actuaciones, las pioneras, aquellas que no imaginaban dar lugar a un movimiento internacional como las de Ernest Pignon de 1966, cuando probablemente ya se hacían oír las primeras voces que desencadenaron en las revueltas de Mayo del 68. Las obras del mismo autor, de 1971, cuando publicita y explica su exposición en galería. Aquellas, en las que después relaciona espacios y hechos históricos clave en la historia, situándolos en su espacio original ya descontextualizado por el paso del tiempo, y persigue la conservación de la memoria de hechos históricos sangrientos de Francia. Estas intervenciones, constituyen un tipo de expresión comprometida, como la anti celebración de los "contra-monumentos" que fue una propuesta expositiva producida por Hans Haacke.

Se pueden considerar así las primeras obras de Blek Le Rat o las acciones relacionadas con La Internacional Situacionista, que tienen que ver con la exploración del territorio y en las que hoy en día Eltono desarrolla algunas de sus experiencias urbanas, o las de Matthias Wermke y Misha Leinkauf en las líneas de metro fuera de servicio en Alemania y las de Les Frères Ripoulain en Francia.

Las incursiones de artistas muy conocidos en el Arte Urbano ofrecen claridad sobre cómo se produjeron las primeras intervenciones en la calle a partir de los años ochenta. Además de Keith Haring o Michel Basquiat, las sombras inquietantes de Richard Hamilton en el East Village de Nueva York aparecen en 1982 y las de Dennis Adams, que actuó a mediados de los ochenta en las paradas de autobús con un discurso artivista (contracción gramatical de arte y activismo).

Todos ellos intentaban romper la monotonía de las calles, esconderse para ser encontrados y con ello provocar al aburrido transeúnte saturado de información. La esencia que une a todas estas actuaciones, lo que se desprende de ellas, es que los artistas buscaban una manera personal de relacionarse con el entorno y son esas particularidades espacio-temporales en las que se producen obras artísticas únicas y de existencia efímera e irrepetible.

-Arte Urbano es el término con el que no queda más remedio que identificar, como referencia, las obras de Banksy y su entorno porque, se quiera o no, guste más o menos, es el artista que ha hecho posible el salto mediático de esta tendencia a nivel mundial y ha conseguido que se hable del arte de la calle en todos los foros posibles. Su aparición marca un punto de inflexión y ruptura con la influencia situacionista, para entrar en el mundo del espectáculo, en las salas de subastas, forzando su reconocimiento como artista contemporáneo y ser aceptado como artista conceptual. Banksy y Shepard Fairey, encabezan una lista de artistas que van de la calle a la galería y sus obras de la calle a las casas de subasta; con ellos se inicia un cambio en el concepto de intervención urbana independiente y aunque conservan algunas características que los identifican con el Proto Arte Urbano (como la ejecución en lugares de paso y el uso del pequeño y mediano formato, el juego por negar la autoría de algunas de 
sus obras y confirmar otras, a través de una oficina de autentificación de obras como hace Banksy con la web Pest Control) también les relaciona con una pérdida de criterio en favor de las ganancias obtenidas por la comercialización de sus obra.

-Muralismo Contemporáneo es la etapa que servirá para diferenciar las obras que se producen de forma legal, que surgen de la necesidad de expresión en el medio urbano y se convierten en novedad por la apropiación de las instituciones, las marcas y un sin fin de causas sociales. Son obras subvencionadas, en las que la organización actúa ejerciendo el comisariado y aparece una tímida pero clara intención de hacer exposiciones públicas y colección. En estos casos, normalmente no se interfiere en la libertad del artista, y las obras, además de ser encargos, pasan por una selección previa en la que se eligen los participantes o, a la inversa, se aceptan sus propuestas. Esta etapa, en España, puede tener una de sus muchas referencias en las primeras obras murales de un grupo de artistas canarios entre los que se encontraba el artista Manuel Padorno, [Figura 1] ejecutadas en el Paseo de Las Canteras en 1994, cuyas obras estaban basadas en su obra literaria y fueron un reclamo para atraer turismo a la isla. En ese año coincide la creación de la empresa de botes de pintura Montana Colors y posteriormente las convocatorias e intervenciones del Asalto de Zaragoza, Open Walls de Barcelona y una larga lista de festivales y convocatorias públicas y privadas.
Muralismo Contemporáneo o Intervenciones Contemporáneas, ambos son términos para definir una misma época, porque no todas las obras que se generan en la calle son murales, pero se le dé el nombre que se le dé al arte que tiene la calle como contexto, es imprescindible aclarar su situación jurídica y social, porque ambas van a influir en las posibilidades de conservación, como veremos.

\section{De lo jurídico y lo social}

Si algo es constante entre los siglos XX y XXI es la búsqueda de nuevos espacios para la expresión artística y ese es el motivo por el que cada vez más artistas salen de los museos y buscan nuevas formas y fórmulas de exposición. La calle es el ámbito social donde existe una clara necesidad por significar espacios que son cada vez más impersonales y parece el entorno idóneo para crear obstáculos visuales con propuestas artísticas atractivas ${ }^{2}$. El Arte Urbano es un medio útil para vincular socialmente a las personas con el territorio, porque lo interiorizan y"se hacen a sí mismas mediante las propias acciones en un contexto sociocultural e histórico" (Vidal Ty Pol U, 2005:283).

Las actuaciones artísticas murales son susceptibles de tener dos apariencias jurídicas diferentes (ilegal y legal) que son las que deciden su titularidad y protección en el código civil español (Art. 353) ${ }^{3}$ donde se regula el derecho de accesión. Así pues, la propiedad de los bienes

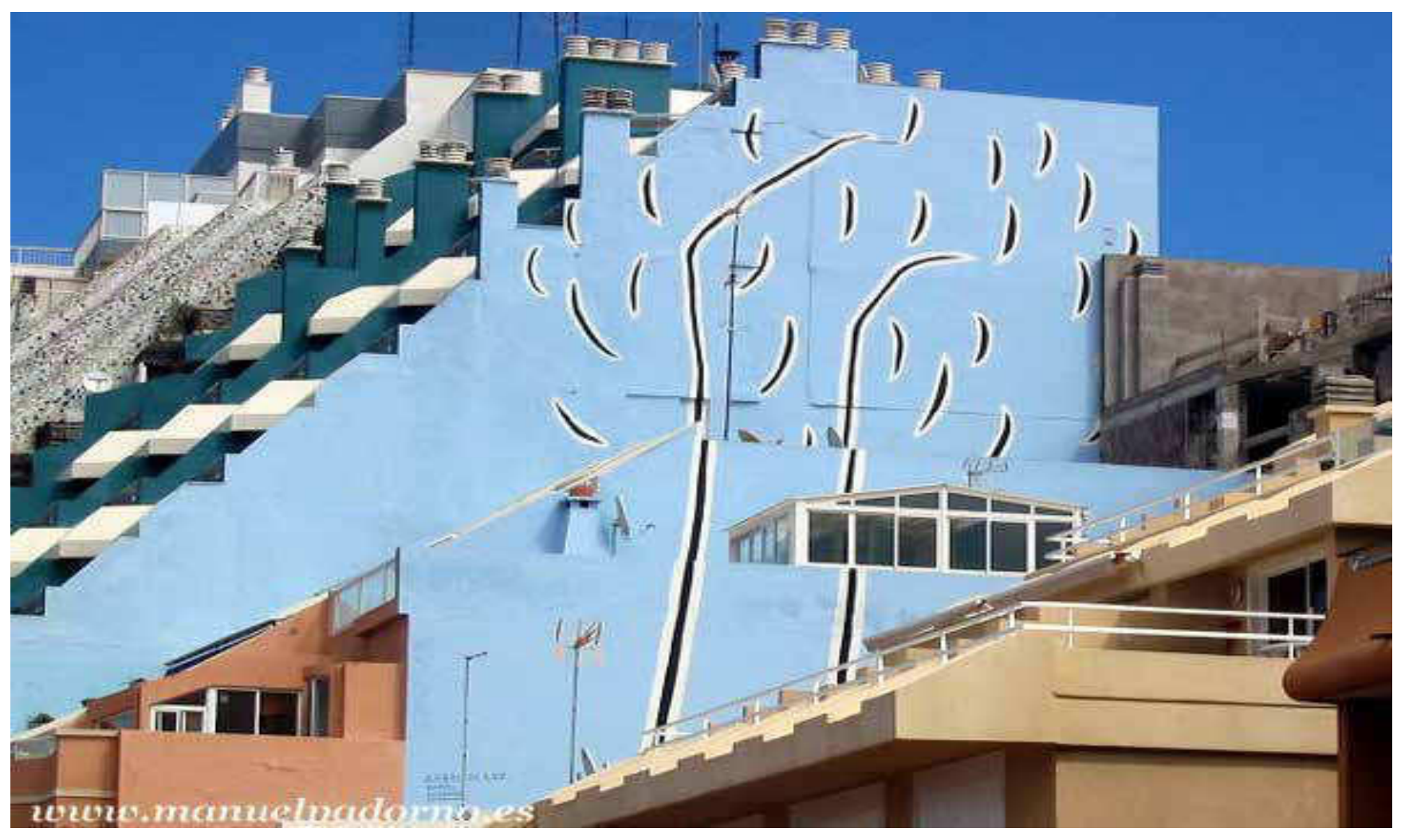

Figura 1. Mural de Manuel Padorno en Las Palmas de Gran Canaria. Árbol de luz. Anamorfosis, 1994. Foto de Patricia Padorno Asociación Cultural Manuel Padorno http://www.manuelpadorno.es/ (15-10-2016). 
da derecho por accesión a todo lo que ellos producen, o se les une o incorpora, natural o artificialmente; es decir, que el propietario del soporte, el muro, puede hacer suya cualquier producción artística que se realice en él. Como contrapartida, por el "derecho moral" mencionado en la Ley de Propiedad Intelectual ${ }^{4}$ por el que un artista puede elegir la forma de divulgación de su obra (art. 14.1) se crea una ambivalencia, por un lado el muro, como soporte, y por otro la capa pictórica, la obra. Estas dos individualidades constituyen una "dimensión dinámica que bajo determinadas circunstancias, cualquiera de las dos, soporte y obra pictórica, es capaz de atraer hacia su órbita la titularidad del objeto". (Sánchez Aristi, R.:2015:33).

Siempre que se habla de la ausencia de derechos de una obra de Arte Urbano se expresa un menosprecio de su valor en favor del valor inmobiliario del muro. Esto, en la obra de Banksy, que es un ejemplo muy conocido, es al revés porque la obra revaloriza, al alza, el valor de mercado del inmueble, tal y como hemos visto en múltiples ejemplo, uno de los últimos el del mural de los espías, The spy booh .

Las obras ilegales son independientes y espontáneas, normalmente de pequeño tamaño, ejecución rápida y una localización cercana a la línea de transeúntes donde, por un lado, son más vulnerables y muy efímeras y por otro, invitan a la participación, opinión o expresión sobre ellas.

Además de estos dos tipos jurídicos mencionados, se habla de obras alegales aunque llamarlas así es una licencia poética, pues se refiere a las que están en espacios muy degradados y pasan desapercibidas; su titular no llega nunca a ejercer el derecho de reclamación y muchas veces el propietario es el Estado, ya que la ley no deja vacía esta posibilidad de titularidad de bienes inmuebles. Son espacios en los que se generan obras ilegales pero no existe un conflicto de intereses al estar ejecutadas en muros abandonados, edificios esperando ser demolidos, fábricas sin actividad o muros provisionales.

Por el contrario, aquellas intervenciones realizadas en soportes muebles y abandonadas sí que son susceptibles de ser adquiridas por "ocupación" y conseguir así el derecho de exposición pública, según el artículo 56.2 de la Ley de Propiedad Intelectual.

Aparte de estas acepciones jurídicas se debe contar con la intervención del público, que tiene derecho de opinión y opina que no todas las propuestas son bien recibidas. Tal y como planteó Laura Luque Rodrigo con su intervención ¿El público decide? dentro de la convocatoria Vincularte. Encuentro abierto sobre Arte Urbano, organizado por el grupo de trabajo del GE-IIC y celebrado en La Casa Encendida de Madrid en Marzo de 2016. (Ver resumen de las encuestas realizadas por el grupo en el ANEXO). Eso no significa que una obra no deba llevarse a cabo; pero el artista va a estar siempre en desventaja de cara a la conservación si el tema elegido no gusta, por mostrar aspectos menos amables del ser humano o simplemente porque no entra dentro de unos cánones estéticos particulares. Cuando lo que se quiere expresar en un muro (que es el punto de vista del artista) y lo que se quiere ver a diario pintado en él (que es el punto de vista de la gente que vive frente a esa pared) son intereses enfrentados, la decisión que tiene respaldo legal es la decisión del propietario del muro. [Figura 2]

El arte no siempre es agradable o decorativo y la libertad de no ser agredido en las vistas cotidianas depende de la sensibilidad, es una causa subjetiva. Esta es una de las paradojas insalvables y el problema no es baladí porque hace que las representaciones no puedan ser todo lo independientes que debieran. Si la acción publicitaria no se puede evitar y no existe defensa legal que respalde el derecho a las propias vistas desde una vivienda, consecuentemente tampoco estará legislada la temática en un mural artístico.

La diferencia entre estos dos casos es que los murales sí que son eliminados mientras que las vallas de propaganda
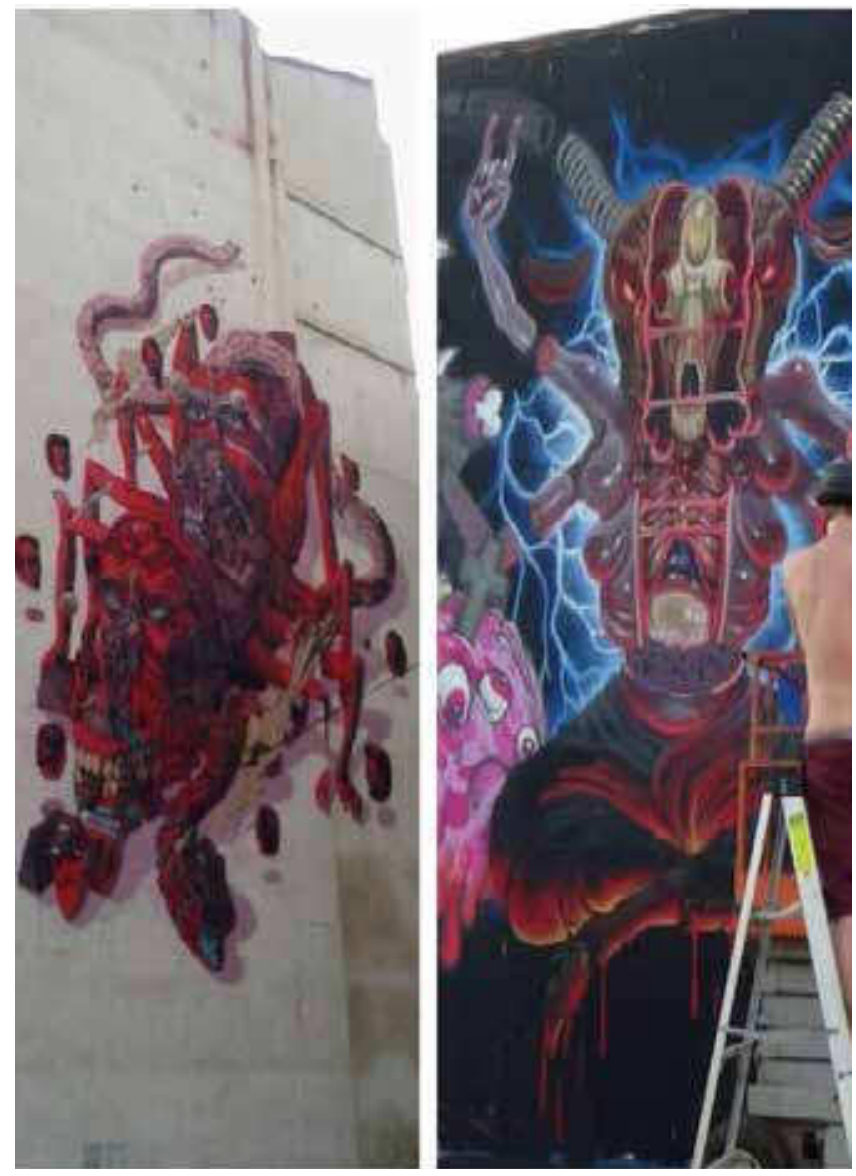

Figura 2. Obras borradas por decisión de los vecinos o el dueño del muro. Izquierda, de Smithe en el Asalto de Zaragoza y derecha, de Nychos en Pow! Wow! Hawaii. Honolulu. Fotos de la autora. 
no, al haber adquirido unos derechos comerciales. Quizá se debería hablar, también, de las razones del que ostenta el poder, decisivas, como bien se ha visto a lo largo de la historia. (Brihuega, J. 1996: 109-126).

En el hipotético caso de que las Intervenciones Contemporáneas sean a la carta, si se ponen límites a la expresión artística, la calle se convertirá en una mera piel amable y decorativa, invisible y superflua de la arquitectura del siglo XXI, al servicio de intereses espurios, a la que por economía de materiales se pedirá cada vez más durabilidad, resistencia y neutralidad, sobre todo neutralidad, para poder soportar el paso de los años y los gustos amables de la sociedad. [Figura 3]

Esa piel efímera, marcada por el ritmo vertiginoso de los acontecimientos, se resiste en muchas ocasiones a ser neutra y salta a la vista aún por encima de la arquitectura, a veces anodina, y reivindica contra todo pronóstico la posibilidad de trascendencia material. Las obras que lo consiguen se convierten en hitos generacionales y documentos de extraordinario valor.

Como ya es sobradamente conocido el caso de la documentadísima obra "Todos juntos podemos parar el sida" de Keith Haring en el histórico barrio del Raval de Barcelona (1989) fué una obra autogestionada pero realizada con permiso del Ayuntamiento de Barcelona y cuya memoria se decidió preservar haciendo, en 1992, un calco que se guarda en el Museo de Arte Contemporáneo de Barcelona (MACBA). La obra tenía un importante trasfondo social, el sida azotaba a la sociedad y este barrio estaba muy degradado. El edificio se tiró, la obra dejó de existir pero el calco garantiza que puede ser reproducida y se ha convertido en un objeto musealizado como registro de la memoria colectiva de una generación [Figura 4]

Todo este recorrido histórico quiere ser un ejemplo de cómo una protección afectará siempre a todos los aspectos contenidos en una obra artística. En la de Haring los derechos de reproducción deben ser de la Fundación Keith Haring que custodia su legado, puesto que se menciona en la reproducción de 2014, coincidiendo con el 25 aniversario de la realización del mural. Es la tercera vez que se reproduce.

Durante la ejecución (en 1989) Haring llevaba un cuaderno de anotaciones en el que describe lo que podría considerarse como una performance que merece la pena mencionarse: «He tardado cinco horas en pintarlo, como había previsto. La pared tenía una inclinación extraña en la que era difícil pintar, pero una de las cosas que más me gustan de este trabajo es la adaptabilidad (física) que requiere. He encontrado una postura que me permitía pintar de una forma homogénea y equilibrada. Algunas de las mejores fotos de este mural reflejan el lenguaje del cuerpo y las posturas que adopto para pintar.» (Web del MACBA).

En este caso, si el contenido social no fuera tan importante, cabría hacerse una pregunta: ¿podría existir infidelidad con el original en la simplificación de un calco que puede ser

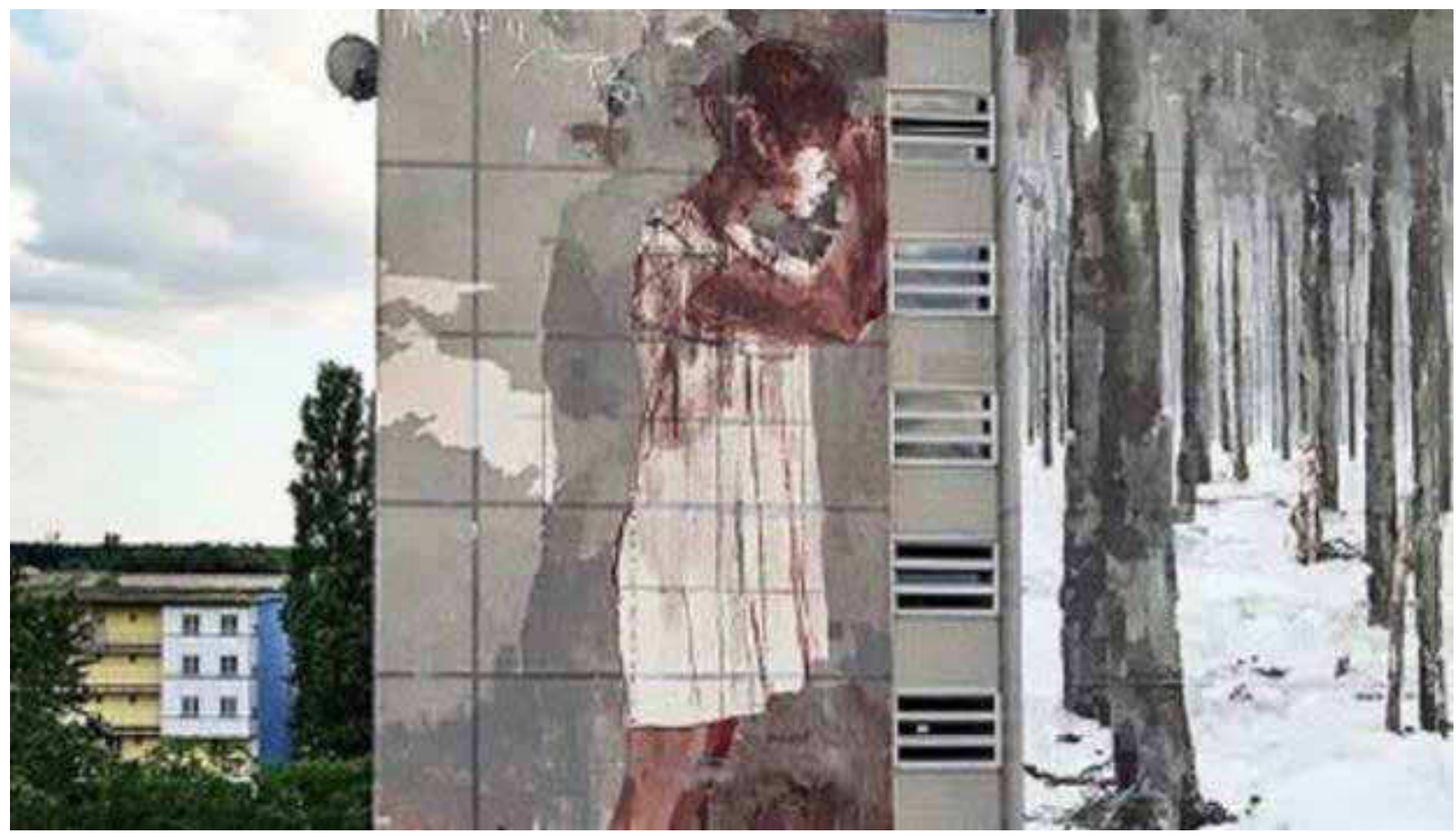

Figura 3. Gonzalo Borondo. Un mural de un artista español causa polémica en Berlín. ABC. 22-06-2016. Foto EFE. ABC Cultura https://goo. gl/MEhacB (15-10-2016). 


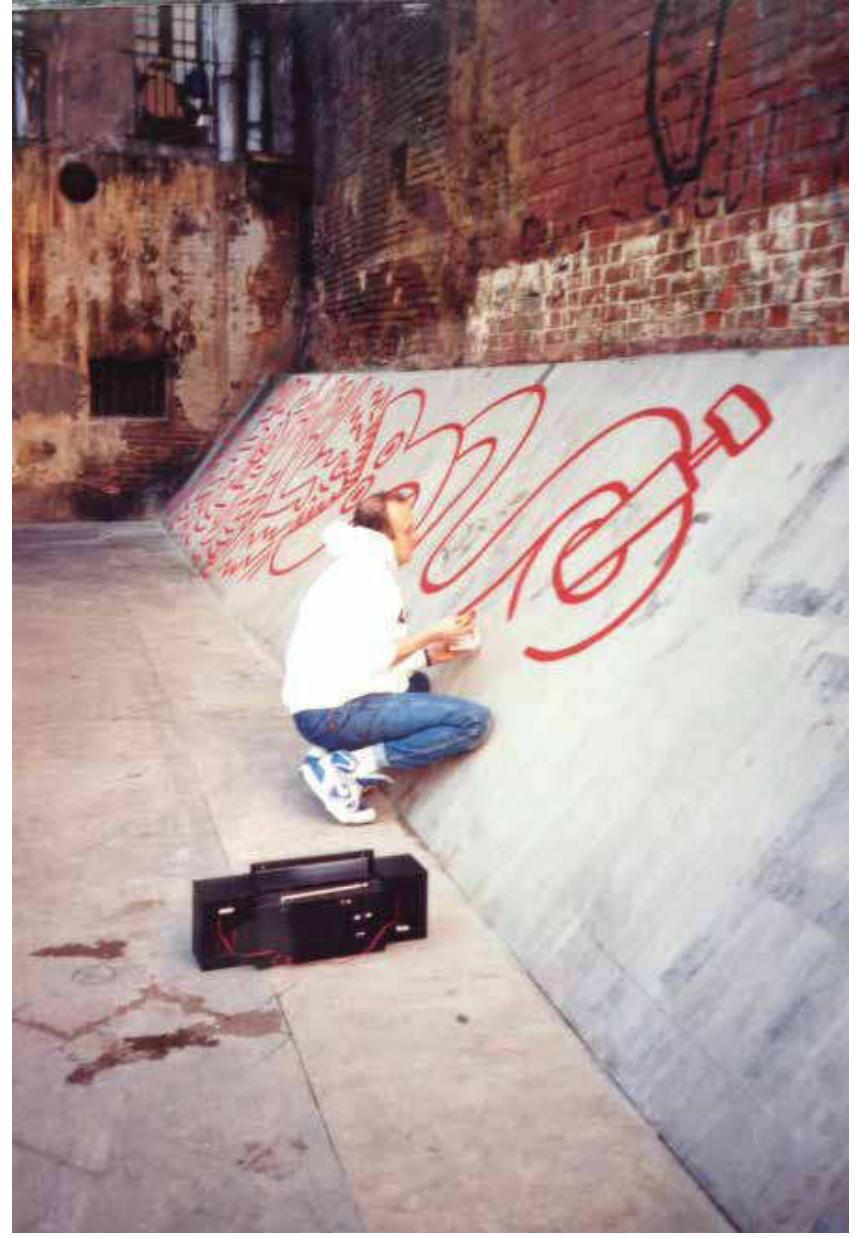

Figura 4. Keith Haring haciendo el mural 'Todos juntos podemos parar el sida', 27 de febrero de 1989, Barcelona. Foto: Montse Guillem. Viene de la página web del MACBA https://goo.gl/ I5PNkA.

reproducido en lugares diferentes y tantas veces como se quiera? Por el contrario, teniendo en cuenta la repercusión del hecho, la enorme difusión mediática de la idea ¿no es el propio acto de reproducción parte importante de la obra?

\section{Obsolescencia programada y levedad de lo efímero}

El espacio público es un palimpsesto en el que las distintas generaciones de artistas van modulando sus intervenciones entre eternos volúmenes arquitectónicos y expresiones plásticas que se complementan e incluso refuerzan; pero al contrario que en la arquitectura, en el soporte de las obras de Arte Urbano se renuncia a la búsqueda de la eternidad, y las producciones parecen tener los días contados desde el mismo momento de su aparición. Conceptualmente y después de dos décadas de existencia artística mediática, sobrevive el juego por vulnerar los límites sociales establecidos y comprobar el grado de represión de cada momento. Lo efímero tiene su sentido porque las obras son abandonadas a su suerte en espacios bien ordenados y neutros, cuya limpieza tiene su ayuda en un plan cultural bien trazado para "crear espacios absolutos para sociedades pluralistas, móviles, agnósticas y desideologizadas"
(Ramírez, J.A.1992:153-172) Quizá esta es la razón de la existencia del Arte Urbano y el Graffiti, que aparecen como respuesta artística a la cultura oficial de los siglos XX y XXI y ha conseguido afianzarse en la memoria colectiva de varias generaciones como una forma de expresión independiente, abierta y no impuesta.

El Arte Urbano es una manifestación cultural actual que no renuncia a formar parte de la historia, pero teme formar parte del eterno dilema de conservación que implicaría introducir cambios permanentes en la evolución urbana; para evitarlo, se hace el harakiri programando la desaparición de sus obras mediante el abandono a su suerte. Antes de morir, muchas de ellas consiguen dejar rastro digital de su esencia sentimental, pero a duras penas se pueden examinar en un monitor las superficies desgastadas, viejas y degradadas o el empaste y naturaleza de la pintura, de unos soportes a los que se ofrece una nueva oportunidad de supervivencia en forma de soporte artístico al que se le atribuye un papel fundamental.

No se puede decir que esta debilidad material facilite la tarea a la hora de decidir un plan de conservación, pero la elección contraria sí que puede llegar a comunicar un deseo de supervivencia. Ahí encuentran su sentido las obras expuestas en la calle y que tienen un acceso complicado en altura, al resguardo de la luz solar directa, la elección de orientación y superficies bien conservadas, ejecutadas con pinturas de calidad; estas obras son rastreadas por los seguidores de tesoros urbanos y sus particularidades pueden ser consideradas como una declaración de intenciones en cuanto a los deseos de conservación. Ningún artista en estas circunstancias negaría haber estudiado esa posibilidad alguna vez.

\section{Motivación, el Big Bang}

Los artistas que se expresan en la calle o en galería no son una unidad indisoluble; muchos no forman parte de ningún colectivo artístico y no hay nexos comunes entre ellos. Aun así, y por una necesidad de simplificación, se ha identificado al artista con el contexto en el que transcurre esta especie de performance urbana, llamándolos a todos artistas urbanos o street artist, cuando la motivación tiene tanto o más peso y, como hemos visto, la forma de usar el espacio público es fundamental. (Vermibus. 2016. Encuentro abierto sobre Arte Urbano. Organizado por el grupo de trabajo del GE-IIC y celebrado en La Casa Encendida de Madrid. Marzo de 2016) Así pues, si la motivación y el proceso creativo son dos piedras angulares para cualquier obra artística en la calle, el contexto tiene un papel decisivo porque añade la posibilidad de improvisación y es imposible generalizar tanto y etiquetar a los artistas por el entorno en el que actúan.

Así pues, si "cualquier actividad realizada sin autorización que, sin embargo, exija su difusión pública debe entenderse primordialmente como una modalidad de discurso" 
(McCormick, C. 2010:16) esto implica el análisis de todo el proceso de la obra incluida su difusión y registrar qué implicación conceptual ha podido tener en el discurso del artista. Según Duchamp, el "coeficiente de arte personal es una relación aritmética entre lo inexpresado pero intentado y lo expresado no intencionadamente" (Duchamp, M: Conferencia en la Federación Americana de Artes en 1957). Esta descripción cobra un especial valor cuando se interactúa en un medio tan rico en propuestas y variables que pueden llegar a influir en el artista a lo largo del proceso de ejecución.

Esta evolución creativa es el primer análisis a realizar sobre una obra artística susceptible de ser conservada, se tenga o no contacto con los artistas, porque siempre hay medios para desencriptar su esencia y conseguir la clave que aporte la información necesaria sobre la razón de su existencia, para situarla en un momento y lugar concretos. El artista o su entorno cercano, el barrio que vivió su aparición y las circunstancias que la envolvieron, pueden ser recogidas de formas diferentes y son imprescindibles para averiguar qué obras son susceptibles de preservarse y cuáles no.

"Los artistas urbanos pueden querer embellecer la ciudad, expresar sentimientos, crear juegos irónicos, lanzar mensajes encriptados o reflexiones críticas" (Prieto, Diana. 2016, pag Web) y se entiende que sus intervenciones deben permanecer el mayor tiempo posible siempre que su contexto no se desvirtúe: caminar por la ciudad e interactuar con el entorno, interpretar el espacio, artivismo, la conquista en tres dimensiones, reivindicar el derecho de expresión, relacionarse, mejorar la vida de barrios socialmente degradados, participar en convocatorias públicas; son algunas de las infinitas posibilidades que pueden llegar a motivar la intervención urbana actual.

\section{Contexto e historia del espacio}

Los artistas participan en muchos proyectos con la conciencia de realizar un trabajo público, donde los murales son la piedra angular que ofrece la visibilidad necesaria, están muy expuestos a la opinión pública y sus obras pueden llegar a ser manipuladas si después cambia el sentido del contexto5." La ubicación lo es todo; el contexto y el contenido son, a fin de cuentas, la diferencia más palpable entre las pintadas en la puerta de un lavabo y (...) el puente de Brooklyn" (McCormick C. 2010:51).

Cuando un barrio muy degradado socialmente es objeto de una reforma para desplazar a la población con menos recursos y convertirlo en un barrio de moda, el primer paso es ofrecer espacios baratos a jóvenes con profesiones liberales y pintar grandes murales. Automáticamente se produce una elitización residencial y un cambio del precio de la vivienda. Aunque los artistas que participan son generadores de ese cambio social cuyo contexto es transformado, hay que tener en cuenta, por un lado, que los artistas se han profesionalizado, ahora son muralistas y las obras son de encargo y, por otro lado, existe un intercambio económico en el que el que paga establece unas condiciones; una de ellas es la cesión de los derechos de imagen y propiedad intelectual de la obra. (Entrevista a Teresa LatuszewskaSyrda gestora de la Fundación Galeria Urban Forms. Łódz. Polonia. Diciembre de 2015).

Sirva como ejemplo los encargos murales del Soho de Málaga; para unos es una oportunidad única de expresión artística al aire libre y para otros un potente aparato al servicio de la gentrificación, tal y como reflexiona Rogelio López Cuenca: “¿Nadie le explicó a Fairey por qué "the art community here in Málaga" supuestamente había decidido poner el huevo precisamente allí? ¿No le hablaron de la transustanciación del "Ensanche" en "Soho"? ¿No le sonaría a otras experiencias de instrumentalización del arte y la cultura como coartada legitimadora de obscenas operaciones de especulación inmobiliaria?" (Web Cuenca Alternativa 2014).

El contexto condiciona el trabajo y la selección de artistas se hace a través de Internet, haciendo un seguimiento de los más populares del momento, no hay que saber demasiado sobre Arte Urbano, porque se trata de encontrar las ofertas más atractivas del mercado internacional. Así es como se llevan a cabo obras de ejecución muy rápida, cuyo encargo no permite que exista demasiada documentación previa por parte de los artistas invitados y así es como los espacios que podrían tener una especial significación local son modificados para crear nuevos contextos. Por primera vez y a través de obras murales de grandes dimensiones se busca que las obras contextualicen de forma atractiva un proyecto futuro, que muchas veces tiene un trasfondo de especulación inmobiliaria.

\section{Conservar es una decisión con implicaciones}

Es evidente que la posibilidad de conservación de Arte Urbano es un planteamiento que debe ir dirigido a unas cuantas obras elegidas y que plantear la conservación o restauración de forma masiva, musealizando la calle, no sería posible ni siquiera aconsejable; pensar esto sólo puede ser considerado una ingenuidad o desconocimiento del proceso de degradación de los materiales que se usan en un medio tan agresivo para ellos, además de una defectuosa valoración del contexto dinámico en el que se desarrolla el Arte Urbano.

La conservación material sólo puede aspirar a alargar la vida a las obras que ya de por sí estén más protegidas de las inclemencias del tiempo. Una vez decidido llevar a cabo un proceso de conservación, es el estudio de los materiales que la constituyen el que va a decidir las posibilidades reales de supervivencia y cómo se puede intervenir para mantenerla durante más tiempo; esto implicaría conseguir una estabilidad que permitiera una degradación muy lenta del color y no por desprendimientos de la materia del soporte, que implicaría una pérdida brusca y por tanto más traumática. 
Tener en cuenta las cuestiones propuestas hace que la catalogación de obras y el análisis de las posibilidades de protección sean complementarios. Así pues, parece lógico pensar que una vez reconocido el Arte Urbano como un período del arte actual algunas obras podrían ver alterada su situación jurídica, ya que el reconocimiento que lleva implícito todo proyecto de conservación las afectaría directamente, al ser aceptadas por los propietarios de los soportes. A partir de ahí se establecería el seguimiento de su degradación dentro de un plan de conservación preventiva.

Quizá no todas las obras en las que se pone el foco puedan soportar sobre sí la idea de este cambio tan radical; por eso, y para no interferir en los derechos morales que se reconocen a todas las obras artísticas, la decisión de alargarles la vida debe contar con el permiso del artista, que debe estar involucrado en el proyecto. Lo contrario, puede dejar a su suerte obras arrancadas de la calle, que son expuestas fuera de contexto, como es el caso de las obras de $B L U$, trasladadas de las calles de Bolonia al museo, aun cuando se ha llevado a cabo con una enorme respuesta popular en contra. ${ }^{6}$

En este caso, tal y como menciona Young, A. (2014:155) "el Arte Urbano que accede a la galería adquiere en su núcleo tres valores culturales: el sentido de la herencia, el carácter igualitario y la rentabilidad". Estos nuevos valores son los que resignificarán la obra y la convertirán en un producto del comisariado, diferente y tutelado.

Por otro lado, la restauración de una obra de Arte Urbano atrae sobre ella la creencia de que puede tener un valor artístico superior al que realmente tiene, porque lo artístico lo es no por razones intrínsecas al objeto, sino porque los usuarios lo reconocen como tal. Lo que tiene interés es que la obra ostenta unos valores de identificación grupal que permite que los individuos se identifiquen con ella" (Formaggio 1976 en Muñoz Viñas, S. 2010:56-57). [Figura 5]

La decisión de conservar depende de los comisarios de exposiciones, la de encargar depende de los gestores de las distintas convocatorias, y borrar, ahora mismo, es competencia municipal; cuyo criterio técnico es el de la "limpieza y eliminación de residuos" dentro del cual las obras se identifican con la suciedad. Este aseo diario de muros se deja a criterio de la empresa y/o la persona que la ejecuta y ni siquiera se utilizan los mismos colores del muro cuando se decide tacharlas, por lo que esa censura no hace más que contribuir a la recreación de un subjetivo arte abstracto que empeora la particular selección. Las normas a seguir se publican en las Ordenanzas Municipales.

En el hipotético caso de la protección de la imagen de obras murales urbanas, la diferencia que se plantea con respecto a otro tipo de obras estaría en la manera en la que debe serlo, cómo y quién las documenta o si se debe compartir públicamente esta documentación que se genera, puesto que son obras de dominio público. ¿Debe

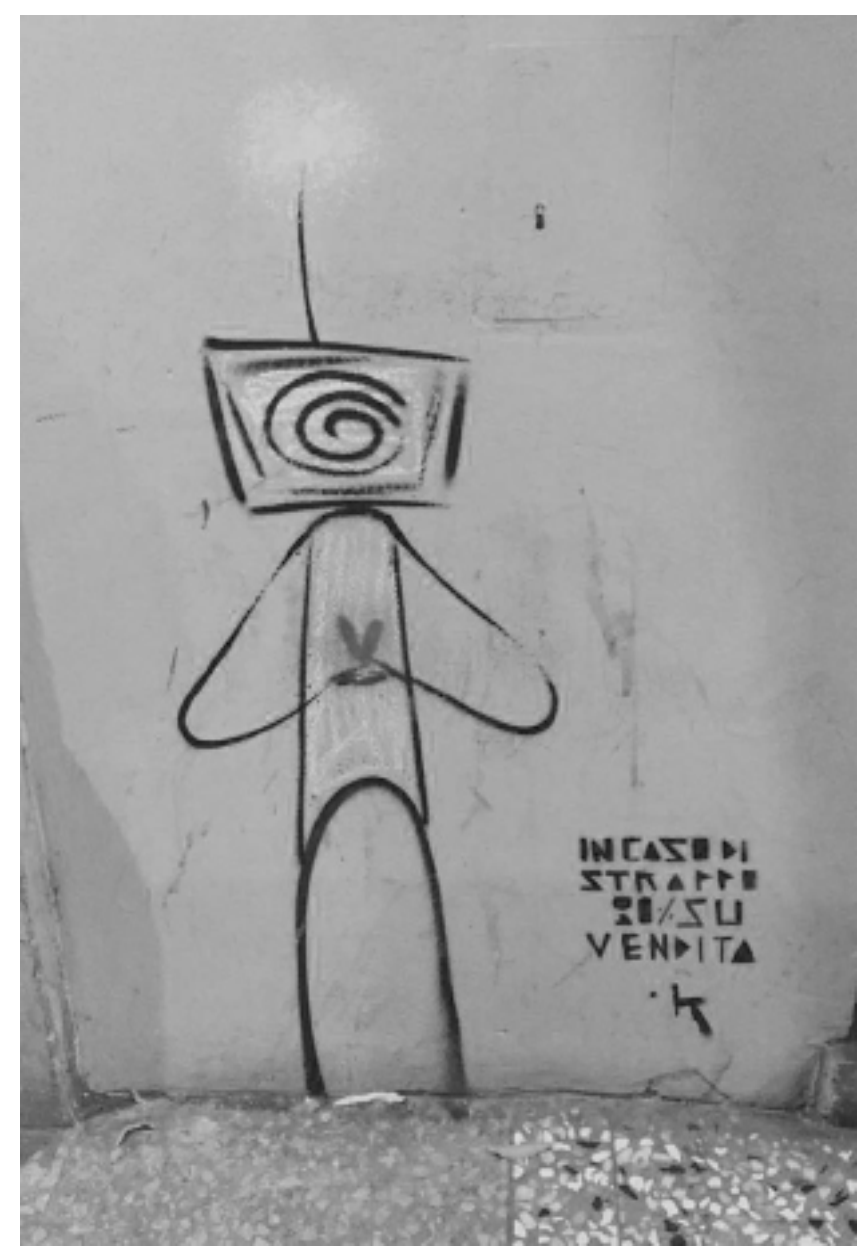

Figura 5. Obra de Exit Enter. Bolonia. "In caso di strappo 80\% su vendita". En referencia al arranque mural de obras de Blu para su exposición en el Palacio Pepoli: Street Art Banksy \& Co. L'arte allo stato urbano. Foto de la autora.

existir un registro municipal de obras que permita la información y seguimiento de las causas de conservación, del proceso de envejecimiento o de las causas que deciden su eliminación?. Llegado a este punto, el mismo trabajo que se realiza en obras de patrimonio histórico artístico sería realizado de cara al público.

Hay algunas consideraciones especiales de los procesos de conservación de Arte Urbano que deben ser tenidas en cuenta; la fundamental es que cualquier obra que haya sido colocada en la calle de forma desinteresada y con la única intención de relacionarse con su entorno, nunca debería ser arrancada para su venta o subasta. No existe ninguna posibilidad de argumentar esta afirmación con respaldo legal, sólo existen los limitados derechos recogidos en la Ley de Propiedad Intelectual, ya mencionados, y un código no escrito de respeto; parece lógico pensar que una obra arrancada de su lugar, que no cuenta con el beneplácito del artista ni de la opinión pública, se va a transformar en un objeto vacío por esas mismas causas. De ahí que el procedimiento a seguir sea tan importante.[Figura 6]

Como norma general, las obras que se han convertido en hitos generacionales y representan a un colectivo o a una 
ciudad, deben ser conservadas in situ el mayor tiempo posible. Para decidir si deben conservarse materialmente y cuáles son los límites en las acciones de preservación deben ser identificadas mediante marcadores objetivos, definiendo una metodología de trabajo a través de la que se genere una completa documentación previa que describa los siguientes aspectos:

- Trayectoria del artista

- La obra en el contexto productivo de su autor

- La relación con la producción de galería

-Motivación y contexto

-El entorno

- Los actores implicados en la conservación (teniendo en cuenta al artista y el propietario del soporte)

- La documentación aportada por el artista y como ha sido recibida la obra en su entorno

- Los intereses en conflicto y valoración de los mismos

-El proyecto de conservación. Valoración de: motivación, contexto y el entorno implicado en la propuesta de conservación

-Opciones de exposición

—La responsabilidad futura sobre los murales. El Comisariado

— La tutela después de la restauración

\section{Conclusión}

La conservación de Arte Urbano requiere de una ética y planteamientos previos que van a definir y garantizar el estudio en su contexto y la correcta valoración de las posibilidades de conservación.

Por otra parte, y debido a la enorme visibilidad de los grandes murales y las posibilidades de Internet, es necesario considerar que la conservación, aunque sea in situ, puede provocar un desequilibrio entre el valor sentimental y el artístico, por lo tanto, se deben contemplar opciones de difusión que permitan explicar las causas que llevan a su conservación.

Teniendo en cuenta que la decisión de arranque y traslado de una obra mural urbana puede provocar su descontextualización es necesario calibrar si con esta decisión de protección radical se puede llegar a provocar la pérdida de su esencia conceptual. Esta actuación debe estar plenamente justificada por la importancia de la obra en la memoria colectiva de un barrio o una ciudad, del que debe de tener su apoyo, y justificarse a través de una protección en la que el fin didáctico tenga un valor esencial. Por esto, el cambio de estatus jurídico y social, musealización, sólo estaría justificado por unas circunstancias extremas cuyo resultado incluyera su pérdida material inminente.

\section{Referencias:}

[1] La tipografía tiene mucho que ver en las obras de la calle y el título del libro de Heller e llic es muy gráfico de cómo es la actitud para actuar en la calle. Heller, S. Llic', M. Stop, think, go, do. How typography and graphic design influence behavior. Rockport Publisher. 2012

[2] "El arte debe ser libre como libre debe ser el espíritu humano, y recae sobre nosotros, los abogados entrometidos en estas cuestiones, recordar ese principio a nuestros semejantes, a los jueces, a los legisladores y a los formadores de opinión. El derecho es una respuesta, pero también un llamado". Discurso de agradecimiento pronunciado por D. Juan Javier Negri en el acto de entrega en Lisboa, el 7 de junio de 2016 del premio Rodrigo Uría de Derecho del Arte. https://goo.gl/JOeTSQ

[3] R.D. de 24 de julio de 1889, texto de la edición del Código Civil. Ley de 26 de mayo de 2015, vigente hasta el 30 de Junio de 2017.

[4] R.D. 1/1996, de 12 de abril, por el que se aprueba el texto refundido de la Ley de Propiedad Intelectual, regularizando, aclarando y armonizando las disposiciones legales vigentes sobre la materia".

[5] Entrevista a Gonzalo Borondo en la que se ve la manipulación que se hace del trabajo de los muralistas. Synamatix, A. (21-22015) Interview: Borondo on his "animal" exhibition, Street Art and gentrificacion. The Daily Street. "Porque el Consejo ha decidido que esta área debe ser cool y así todo el mundo puede pintar 
en las calles y luego los precios serán altos... ¡Boom! Destruido. Gentrificación."Vamos a poner grandes edificios allí, ahora y todo es más caro. Así que, al final, la gente que empezó a hacer estas cosas para hacer los espacios más públicos para la gente, nos estamos convirtiendo en mercenarios de la gentrificación. Es jodidamente raro, cómo cambian las cosas y cómo el sistema nos utiliza como una herramienta para hacer lo que no queremos". Traducción de la autora. https://goo.gl/Vi6VeD

[6] Entrevistas a los comisarios y restaurador de las obras de BLU arrancadas de la calle para ser expuestas, por Boris. The grifters Journal. Street Art. Banksy \& Co. L'arte allo stato urbano. Palazzo Pepoli. Bolonia Junio 2016. http://thegrifters.org/ inflvencers-interview-christian-omodeo-street-art-banksy-andco-exhibition/ Exposición que ha provocado una respuesta contundente por parte del autor, borrando todos sus murales de la ciudad: Abarca, J. Urbanario: http://urbanario.es/blu-estaborrando-todos-sus-murales-de-bolonia/

\section{Bibliografía}

ABARCA, J. (2016): Conservar o no conservar el arte urbano. Mural Street Art Conservation. Revista especializada digital del Observatorio de Arte Urbano n². (pp12-13) https://issuu.com/ observatoriodearteurbano/docs/mural__2

AZNAR ALMAZÁN, Y.(2009) Martinez Pino, J. Últimas tendencias del arte. Centro de Estudios Ramón Areces. Madrid.

BERTI, G. (2016) Arte efímero para una ciudad con memoria, también efímera...El caso Werens. Mural Street Art Conservation. $\mathrm{n}^{\circ}$ 3. Revista especializada digital. Observatorio de Arte Urbano. Madrid

BEUYS, J. BODENMANN-RITTER, C. Joseph Beuys: cada hombre, un artista: conversaciones en Documenta 5-1972, Editorial Visor, Madrid, 1995.

BRIHUEGA, J. (1996) Arte y Sociedad. Historia de las ideas estéticas y de las teorías estéticas contemporáneas. Vol. II, Madrid, Visor

CLARAMONTE ARRUFAT, J. (2011) Arte de contexto. Nerea

CIANCABILLA, L (2015) The Sight Gallery. Salvaguardia $e$ conservazione della pittura murale urbana contemporanea a Bologna. Bononia University Press.

CIANCABILLA, L. OMODEO, C, (2016) C. Street Art. Banksy \& Co. $L$ 'arte allo stato urbano. Bononia University.

DUCHAMP, M. Conferencia en la Federación Americana de Artes. Duchamp Art News, vol. 56 № 4, 1957. También en: https://goo.gl/ ga1Eec. Universidad de Texas

DUQUE, F. Arte público y espacio político. Arte y estética. Akal, 2001

FIGUEROA SAAVEDRA, F. (2014). El Graffiti de firma. Un recorrido histórico-social por el graffiti de ayer y hoy. Minobitia
FIGUEROA SAAVEDRA, F. (2015) El Historiador del Arte frente al Arte Urbano. Revista especializada digital. Mural Street Art Conservation. Observatorio de Arte Urbano n². (pp12-13) https:// issuu.com/observatoriodearteurbano/docs/mural__2

GARCIA GAYO, E. (2011) ¿Se debe conservar el arte urbano basado en la premisa de: "piensa, crea, actúa y olvida?. Conservación de Arte Contemporáneo. 12a Jornada. Museo Nacional Centro de Arte Reina Sofía y Grupo Español de Conservación. GEIIC.

HELLER, S. LLIC', M. (2012) Stop, think, go, do. How typography and graphic design influence behavior. Rockport Publisher.

LUQUE RODRIGO, L. (2016) ¿El público decide? Revista especializada digital. Mural Street Art Conservation. Observatorio de Arte Urbano n² (pp 32-35) https://issuu.com/observatoriodearteurbano/docs/ mural_3

MCCORMICK, C. (2010) Trespass. Historia del arte urbano no oficial. Taschen

MUÑOZ VIÑAS, S. (2010) Teoría contemporánea de la Restauración. Síntesis.

RAMIREZ, J. A. (1992) Arte y arquitectura en la época del capitalismo triunfante. Editorial Visor. Madrid

RENFREW,C. y BAHN P. 2008. Arqueología. Conceptos clave. Madrid: Ed. Akal S. A.

RUIZ DE ARCAUTE, E. (1993) Bases de datos sobre las técnicas de los artistas contemporáneos y sus criterios de conservación y restauración Boletín Informativo del Instituto Andaluz del Patrimonio Histórico. no 3. Junta de Andalucía. Consejería de Cultura y Medio Ambiente. Dirección General de Bienes Culturales. Sevilla, junio (pags 6 - 7)

SÁNCHEZ ARISTI, R. (2015) La propiedad trenzada: El juego de lo material y lo inmaterial en las obras de arte. Premio Rodrigo de Uría Meruéndano de Derecho del Arte. Anuario Iberoamericano. Cizur Menor, Navarra. Thomson Reuters Aranzadi

SITTE (1889) Construcción de la ciudad según principios artísticos. Fondo antiguo digitalizado. Universidad de Sevilla https://goo. gl/1R1xyR

UNWIN, R. (1909) La práctica del urbanismo. Una introducción al arte de proyectar las ciudades y barrios. G. Gili. Madrid

VVAA.2014. La escena del graffiti en Granada. Pérez Sendra, R (de) Ciengramos. Granada

VIDAL, T y POL URRUTIA,E.(2005) La apropiación del espacio: una propuesta teórica para comprender la vinculación entre las personas y los lugares. Anuario de Psicología, vol. 36, n 3, 281-297. Facultat de Psicologia Universitat de Barcelona. Disponible en https://goo. gl/wfuoaz

WARCLAWEK A.(2008) Graffiti and Street Art. Thames \& Hudson world of art. NY. 
YOUNG, A. (2014) Street art, public city. Law, crime and the urban imagination. Routledge. UK

\section{Vinculos web:}

ABARCA SANCHÍS, J. http://urbanario.es (15-10-2016)

ALDAZ,M. (Coord.). (9-1-2014) Cuenca Alternativa Obey en Málaga. Un análisis de Rogelio López Cuenca (9-1-2014) https://goo.gl/ fHqxjV (15-10-2016)

AYUSO, M. ¿Quienes deciden el valor real de las obras de arte? El Confidencial. 18-2-2012 https://goo.gl/HHscXc (15-10-2016)

BORONDO: http://gonzaloborondo.com/ (15-10-2016)

ELTONO: https://www.eltono.com/es/ (15-10-2016)

GARCIA GAYO, E.. Mural Street Art Conservation. Revista del Observatorio de Arte Urbano. http://observatoriodearteurbano. org/Todos los números disponibles en issuu. (15-10-2016)

GARCIA GAYO, E. Observatorio de Arte Urbano. Ficha técnica y entrevista a artistas (descargable) https://goo.gl/giODsi (15-10-2016)
HIPERALLERGYC. Enttrevista a Rafael Schacter: http://hyperallergic. com/author/rafael-schacter/ (15-10-2016)

MACBA: Haring. Todos juntos podemos parar el sida https://goo.gl/ fGZnne (15-10-2016)

PIGNON ESNST: http://pignon-ernest.com/ (15-10-2016)

PRIETO, DIANA: Preguntas abiertas respuestas cerradas. Input. https://goo.gl/m6UDys (15-10-2016)

MONSERRAT, D. (19-2-2014) Los vecinos obligan a borrar un mural espectacular de la calle Santiago. El periódico de Aragón https:// goo.gl/zyFhSN (15-10-2016)

MONTILLA, C. (13-11-2013) Obey aporta su esperanza a la creación de un Soho malagueño. elmundo https://goo.gl/LSauH6 (15-102016)

PLATIA, N. Athenas, un lienzo en blanco para el arte de la calle. Gounesco. https://goo.gl/leCrqF (15-10-2016)

VERMIBUS http://vermibus.com (15-10-2016)

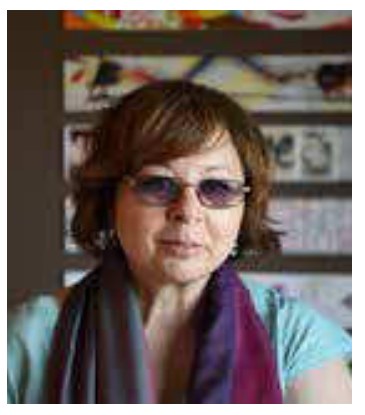

\section{Elena García Gayo}

Conservadora-Restauradora

observatoriodearteurbano@gmail.com

Titulada en Conservación Restauración de Bienes Culturales. ESCRBC de Madrid. Especialidad pintura. 1989. Titular de la plaza de Conservadora-Restauradora en el Servicio de Patrimonio Cultural de la Diputación Provincial de Ciudad Real, dónde desarrolla su labor profesional y de asesoramiento a corporaciones locales en el ámbito de la conservación restauración de patrimonio histórico artístico desde 1990. Paralelamente es coordinadora del grupo de trabajo de Arte Urbano del grupo español del International Institute for Conservation of historic and artistic works, GEIIC. 2015-2016. Asociación internacional sin ánimo de lucro y declarada de utilidad pública.

Principal impulsora de la Plataforma Muelle creada para la conservación de la firma en grosor situada en la c/ Montera de Madrid. Crea y administra el Observatorio de Arte Urbano, con presencia en redes sociales (http://observatoriodearteurbano.org/) y los distintos recursos generados desde el Observatorio: convocatoria participativa Objetivo Muelle, la revista especializada y digital para el análisis de las posibilidades de conservación del Arte Urbano, Mural Street Art Conservation, la cual edita y dirige. Co-Comisariado de la Exposición documental Registros de Arte Urbano 8 en el Centro de Exposiciones de la Diputación de Ciudad Real. 2010. Organiza, con el grupo de Arte Urbano del GE-IIC, el 1er VINCULARTE. Encuentro abierto sobre Arte Urbano, en La Casa Encendida de Madrid. 2016 


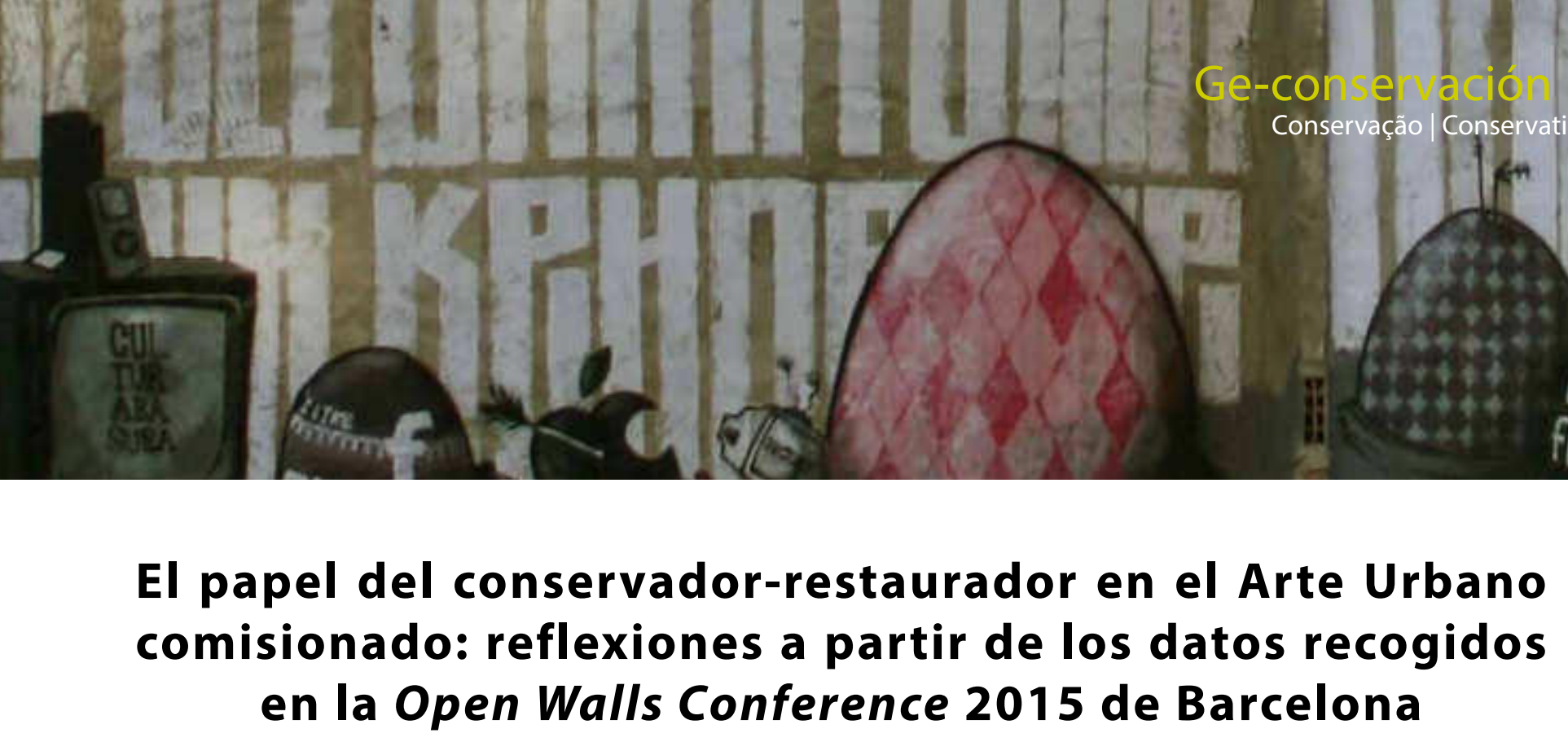

\author{
Rosa M. Gasol Fargas y Rosa Senserrich Espuñes
}

\begin{abstract}
Resumen: La participación del grupo de Arte Urbano del GEIIC en la Open Walls Conference (OWC), celebrada en octubre del 2015 en Barcelona, con una serie de actividades abiertas al público asistente dirigidas a obtener material para valorar la posibilidad de conservación de algunas obras de arte urbano comisionado, ha ampliado nuestras expectativas iniciales al analizar los datos recabados. Se abren nuevas posibilidades en el rol a desarrollar por el profesional de la conservación-restauración en relación al arte urbano, sobre todo en lo que se refiere a la actuación sobre el entorno. En este artículo se analizarán los resultados obtenidos en la OWC, se propondrán herramientas para completar estos datos en el contexto donde se encuentran los murales y, finalmente, se presentará una propuesta de actuación con los organizadores de festivales antes de que los artistas realicen sus obras.
\end{abstract}

Palabras clave: open walls conference, arte urbano, muralismo, conservación, restauración, público

\title{
The role of the conservator in comissioned street art: reflections on the collected data from the Open Walls Conference 2015 in Barcelona
}

\begin{abstract}
The involvement of the group Arte Urbano del GEIIC in the Open Walls Conference (OWC), held in October 2015 in Barcelona, with a series of activities open to the public and intended to obtain material to assess the possibility of conserving some works of commissioned street art, has widened our initial expectations when we looked at the information. New possibilities opened in the developing role of conservation-restoration professionals in relation to street art, especially in the context of the surroundings of the paintings. In this article, the results obtained from the OWC will be analyzed, tools will be proposed to complete this information in the context of where the murals are located, and finally an intervention proposal will be presented to the festival organizers before the artists create their work.
\end{abstract}

Key words: open walls conference, street art, muralism, preservation, conservation, public

\section{Introducción}

A partir de la edición de 2015 de la Open Walls Conference de Barcelona, en la que el Grupo de Arte Urbano del GEIIC fue invitado a efectuar una actividad relacionada con la conservación de los murales en la calle, las autoras han analizado los resultados de las encuestas dirigidas al público asistente, las votaciones llevadas a cabo en los pósteres expuestos y los temas surgidos durante el debate que se efectuó en el Centre de Cultura Contemporània de Barcelona (CCCB).

Ésta fue la segunda ocasión en la que el grupo llevó a cabo una acción de este tipo en el marco de festivales relacionados con el arte urbano (Openwalls Conference: Recasens y Ballaz 2015), tras la efectuada en el Asalto de Zaragoza en septiembre de 2015 (Festival Asalto).

\section{Objetivos y metodología}

Nuestro objetivo no es tanto exponer el marco teórico, como ya se hace en otros artículos en este mismo número', sino explicar una metodología de estudio de los diversos ejemplos de arte urbano para poder extraer y analizar los resultados. Siempre a partir de 
la experiencia de la Open Walls Conference, en una primera fase del trabajo se recogieron las valoraciones de artistas, expertos y gestores del arte mural, que en cierta medida son grupos coincidentes en cuanto a sus opiniones y percepciones, pero nos faltó valorar el punto de vista del público o de los usuarios.

Como ya indicamos en las conclusiones de nuestro artículo anterior (Gasol y Senserrich 2016: 26), esta parte nos permitirá poder completar el estudio y hacer un análisis más riguroso del impacto que el mural tiene dentro de su contexto inmediato, es decir, la forma en la que la obra es recibida por los usuarios del lugar en el que se encuentra ubicada. Para ello hemos creído necesario diseñar un modelo de encuestas que recojan sus opiniones y que nos darán el contrapunto respecto a los datos anteriormente recabados. El modelo que presentamos es una versión reducida de la encuesta al público especialista, con la característica de que es muy visual, directa y rápida de rellenar, para facilitar así su utilización.

Finalmente, nos planteamos también resaltar el papel del conservador-restaurador dentro de las manifestaciones de arte urbano comisionado, tanto por lo que respecta a la función de asesoramiento a los artistas y organizadores de festivales en cuanto a técnicas pictóricas y materiales, antes de la realización del mural, como a las posibles intervenciones de conservación y restauración que se decidan ejecutar $a$ posteriori.

La metodología utilizada para la recogida de datos durante las diferentes actividades destinadas al heterogéneo público reunido en la OWC, formado por gestores, programadores, artistas y seguidores del arte urbano, consistió en la elaboración de un cuestionario en relación al fenómeno del arte urbano, la realización de una votación a partir de diez pósteres con imágenes de murales realizados en ediciones anteriores y la invitación a un debate abierto con la audiencia (Gasol y Senserrich 2016: 24-26).

\section{Desarrollo y Resultados de la Open Walls Conference 2015}

\section{El análisis de las encuestas}

Al público asistente al acto se le proporcionó una encuesta con once preguntas, con el objeto de conocer su valoración sobre el arte urbano ${ }^{2}$. Al final de la sesión, se recogieron un total de 69 formularios contestados, cuyas respuestas fueron clasificadas en función del perfil del encuestado, analizadas e interpretadas. [Tabla 1]

A partir de los resultados obtenidos, se constató que la participación más elevada fue la de los artistas, así como de los profesionales relacionados con el patrimonio, seguida por la de los simpatizantes del Street $\mathrm{Art}^{3}$. El arte urbano suscita cada vez más el interés entre la gente y en los foros relacionados con el patrimonio.

Si se analizan estos tres sectores más activos, las respuestas más numerosas coinciden, en muchas ocasiones, con las mismas opciones, es decir, hubo bastante unanimidad entre el público asistente. Los pequeños matices y variaciones los aportan los artistas: así como la mayoría de los encuestados miran el entorno de la obra buscando explicaciones al motivo representado, la mitad de los autores no lo hace. Se supone que muchos están interesados solamente en el mero hecho plástico. Asimismo, una minoría de artistas opina que no defendería una obra de arte urbano que corriera el riesgo de ser eliminada, al contrario que los otros dos sectores, que no dudan en ponerse en marcha para que esto no suceda. Resulta también curioso ver cómo algunos artistas consideran el arte urbano como una cosa diferente al arte. En lo que hay unanimidad total es en que es necesario destinar más espacios para la expresión libre.

\section{El análisis de las votaciones}

Las imágenes de los murales recogidas en los pósteres fueron valoradas y votadas por los asistentes mediante

\begin{tabular}{l|l|l}
\hline COLOR & PERFIL DEL PÚBLICO & RESPUESTAS \\
\hline & Profesionales relacionados con el patrimonio & 21 \\
\hline & Seguidores del arte urbano & 20 \\
\hline & Escépticos & 2 \\
\hline & Artistas & 23 \\
\hline & No clasificados & 3 \\
\hline & TOTAL & 69 \\
\hline
\end{tabular}

Tabla1. Distribución de las respuestas recabadas en la OWC 2015, según el perfil del encuestado. 

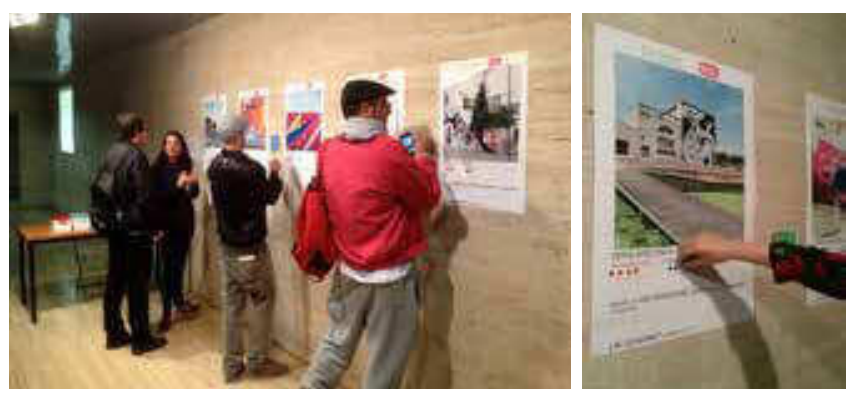

Figuras 1 y 2. Actividad de las votaciones con pegatinas de colores por parte del público asistente al evento (Fotos: R. Senserrich).

pegatinas de colores en función de unos códigos preestablecidos, con la posibilidad de escribir, en el mismo póster, un tag emocional o palabra que describiera la sensación que les transmitía la obra, así como si la conocían o no.

Las obras seleccionadas pertenecían a los artistas Blu (Barcelona, Influencers 2009), Jorge Rodríguez-Gerada (Badalona, Identitats 2010), SatOne (Barcelona, OWC 2011), Sam3 (Amposta, Openwalls Showcase-Fahr.01 2012), Sixe (Barcelona, Ciutat Bella-Ciutat Nova 2014), Escif (Barcelona, Open Walls Conference, 2014), Mcity (EI Prat de Llobregat, OWC 2014), Spogo (Badalona, OWC 2014), Kenor (Barcelona, OWC 2014) y Alexis Díaz + Pastel (Barcelona, OWC 2014)4. [Figuras 1 y 2]

Esta actividad tuvo una buena acogida y la participación fue muy alta, abriéndose pequeños debates, junto a los pósteres, entre el público y los miembros del grupo.

Por lo que se deduce de las respuestas recogidas en los tag, la gente emitía su valoración con independencia de si conocía o no el mural, especialmente en obras con una temática relacionada con la crítica social o con un carácter transgresor, que fueron las que suscitaron un mayor número de respuestas emocionales, las más acordes, seguramente, con el punto de vista del artista o que ofrecían una lectura más clara del tema representado. Algunos Tag cómo \#NOS VIGILAN o \#INSEGURIDAD en el mural de Mcity, o cómo \#MUERTE y \#SENTIMIENTO en el mural de Sam3, son un ejemplo de ello.

Por otro lado, los murales más conocidos por los asistentes coincidieron con los realizados por artistas de mayor popularidad y resonancia mediática, según los resultados de las votaciones en los pósteres. (Grupo de Arte Urbano del GEIIC). [Figuras 3 y 4 ]

\section{El debate con el público asistente}

Como culminación de la actividad organizada por el grupo del GEIIC, se llevó a cabo un debate con el público, previa presentación de una charla para centrar el tema. Se introdujeron cuestiones como: ¿Debe el arte urbano ser
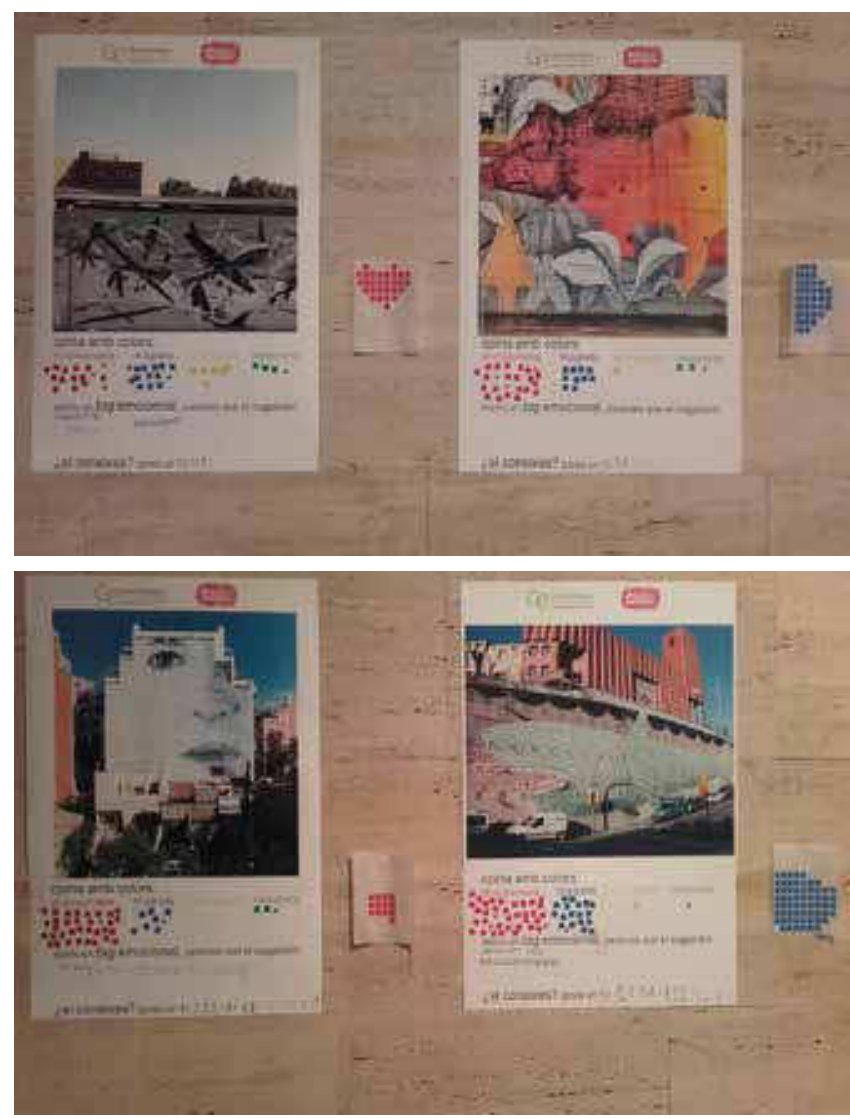

Figuras 3 y 4. Pósteres con los murales escogidos y con las valoraciones del público (Fotos: R. M. Ruiz). De izquierda a derecha: Mcity (Foto Mcity); Alexis Díaz + Pastel (Foto F. Alcalá); Jorge Rodríguez Gerada (Foto A. Poch) y Blu (Foto E. Balsera).

considerado un arte efímero?, ¿Debe ser conservado?, ¿Por qué, cuándo, por quiénes?. Las respuestas fueron conservadas en registros permanentes de audio-video y posteriormente transcritas y analizadas.

Las opiniones de los artistas giraron alrededor del carácter efímero de sus obras, manifestando unos su voluntad de conservarlas y sosteniendo otros que la obra es cambiante y hay que dejar que evolucione, como ente orgánico que es. Asimismo, destacaron la conveniencia de diferenciar entre los artistas que hacen graffiti, que les gusta la obra ilegal y tan solo les interesa su presencia puntual en un momento y espacio determinado, de aquellos que desean que su obra perdure.

A la pregunta de si hay que conservar el arte urbano, se apuntó que, en función del interés generado por una obra en cuestión y del nivel de integración que tenga en su contexto, ésta tendrá más posibilidades de ser apreciada y valorada, hasta el extremo de que la población pida su conservación por el valor simbólico y social adquirido. De esta manera, aunque en origen se trate de una obra efímera, si existe una voluntad social de que se conserve, el artista debería estar de acuerdo. [Figura 5] 


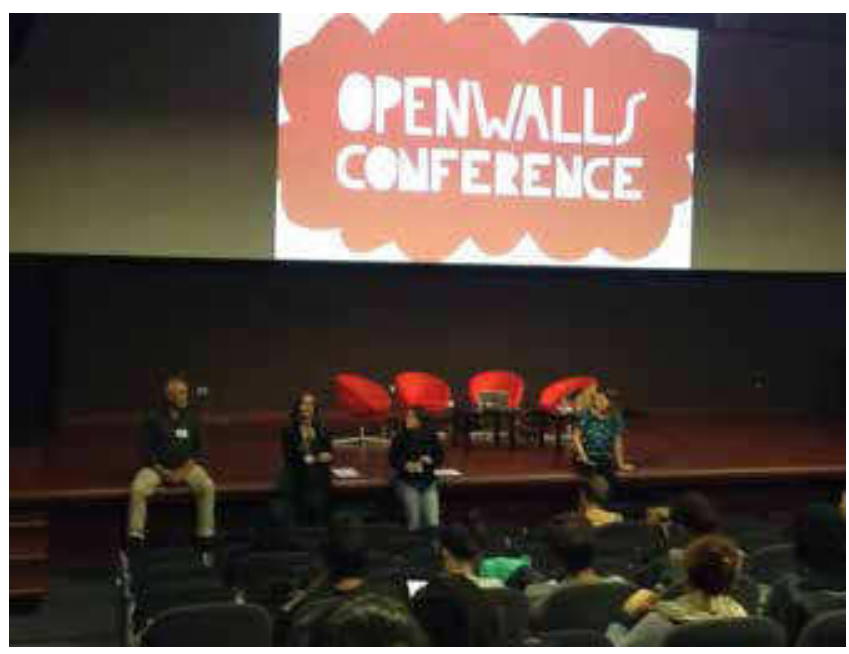

Figura 5. Momento del transcurso del debate con el público (Foto: R. M. Ruiz).

Sobre el tema de la técnica y de si los artistas son conscientes de la estabilidad de los materiales que utilizan, éstos respondieron afirmativamente, pero señalando el condicionante económico que les lleva a trabajar habitualmente con materiales menos costosos. Cabe destacar, además, que algunos artistas opinan que hoy día se pinta demasiado rápido, con el objetivo de tener un gran número de fotografías para la difusión y poder llegar, de este modo, a ser más visibles y realizar más obras. Ello a expensas de una calidad media-baja, no comparable con la alcanzada en otras épocas históricas, como por ejemplo durante el muralismo mejicano, cuando había una preocupación real por la técnica.

Por parte de los seguidores del arte urbano, se planteó también la dicotomía entre la persistencia del mural y el respeto a la voluntad del artista, cuando éste no desea que su obra perdure. El razonamiento consistía en que, por delante del valor de mercado y del posible reconocimiento que algunos artistas puedan llegar a tener en el futuro, ha de primar el respeto a una forma de arte que se considera libre, que no debe institucionalizarse y que, por lo tanto, hay que aceptar que pueda ser efímera.

Son de destacar también algunas opiniones de artistas recogidas en conversaciones una vez concluido el debate, como el hecho de considerar que la única forma de conservar el arte urbano, dado su carácter efímero, es a través de la fotografía, o bien la opinión de que "conservar es hipotecar", es decir, una vez se conservan las obras, se pierden espacios disponibles en los muros para pintar nuevos murales.

\section{Nuevas posibilidades de análisis y colaboración}

\section{La opinión de la comunidad}

Con el objetivo de completar el círculo del estudio y el impacto que genera la obra, creemos que es importante también, además de la opinión de artistas y del público especializado, tener en cuenta a una serie de actores o usuarios dentro de la comunidad en la que se encuentra ubicado el mural.

Para ello presentamos una propuesta metodológica que recoge la percepción y la opinión de la comunidad, de cara a poder efectuar este análisis de datos. Se trataría de hacer llegar un formato reducido de encuesta, sintética, muy visual y fácil de rellenar, a usuarios de lugares públicos del barrio o zona en la que se encuentra la obra: centros cívicos, centros de atención médica primaria (CAP), bibliotecas, escuelas, así como a los vecinos inmediatos que pueden contemplar la obra desde sus casas.

Se ha elaborado un modelo en el que se recoge el tipo de grupo o usuario a través de un código de color, para garantizar el anonimato, de igual manera que se hizo en las encuestas de artistas y especialistas y animar así al público a opinar. Por lo que respecta a la identificación de la obra, se establece una ficha mínima con la fotografía de la misma, un número de registro, el nombre o título si lo tiene, su autor, año de realización, técnica empleada, dimensiones, localización, quién ha hecho el encargo al artista y si existen entidades o grupos que han colaborado.

Las preguntas que se hacen se han extraído de la encuesta efectuada a los artistas y especialistas, para mantener cierta coherencia en los resultados, pero se han reducido a las cinco más representativas para facilitar las respuestas, teniendo en cuenta que en principio no se trata de un público especializado.

La valoración emocional que el público hace con respecto a la obra se traduce en un elemento adhesivo de color, una pegatina adherida debajo de la fotografía del mural, que plasma el grado de empatía con respecto a la obra y la opinión sobre su conservación o eliminación. La experiencia en este tipo de acciones nos demuestra que se trata de un elemento muy lúdico que atrae la atención del público, facilitando así la participación. Finalmente, se reserva un espacio a la libre expresión, por si el encuestado desea manifestar su opinión en relación a las preguntas que se le han formulado o acerca de cualquier otra cuestión relacionada con el tema. [Fig. 6]

Aunque por el momento todavía no disponemos de los resultados definitivos, creemos que la forma en cómo se percibe el mural en su contexto inmediato es de vital importancia para obtener unos datos cualitativos fiables. En un futuro ha de servir de guía a los profesionales, conjuntamente con la información recabada a través de las encuestas y entrevistas a los artistas y especialistas en arte urbano, de cara a las posibles iniciativas de conservación y/o restauración que puedan surgir entorno a una determinada obra. 


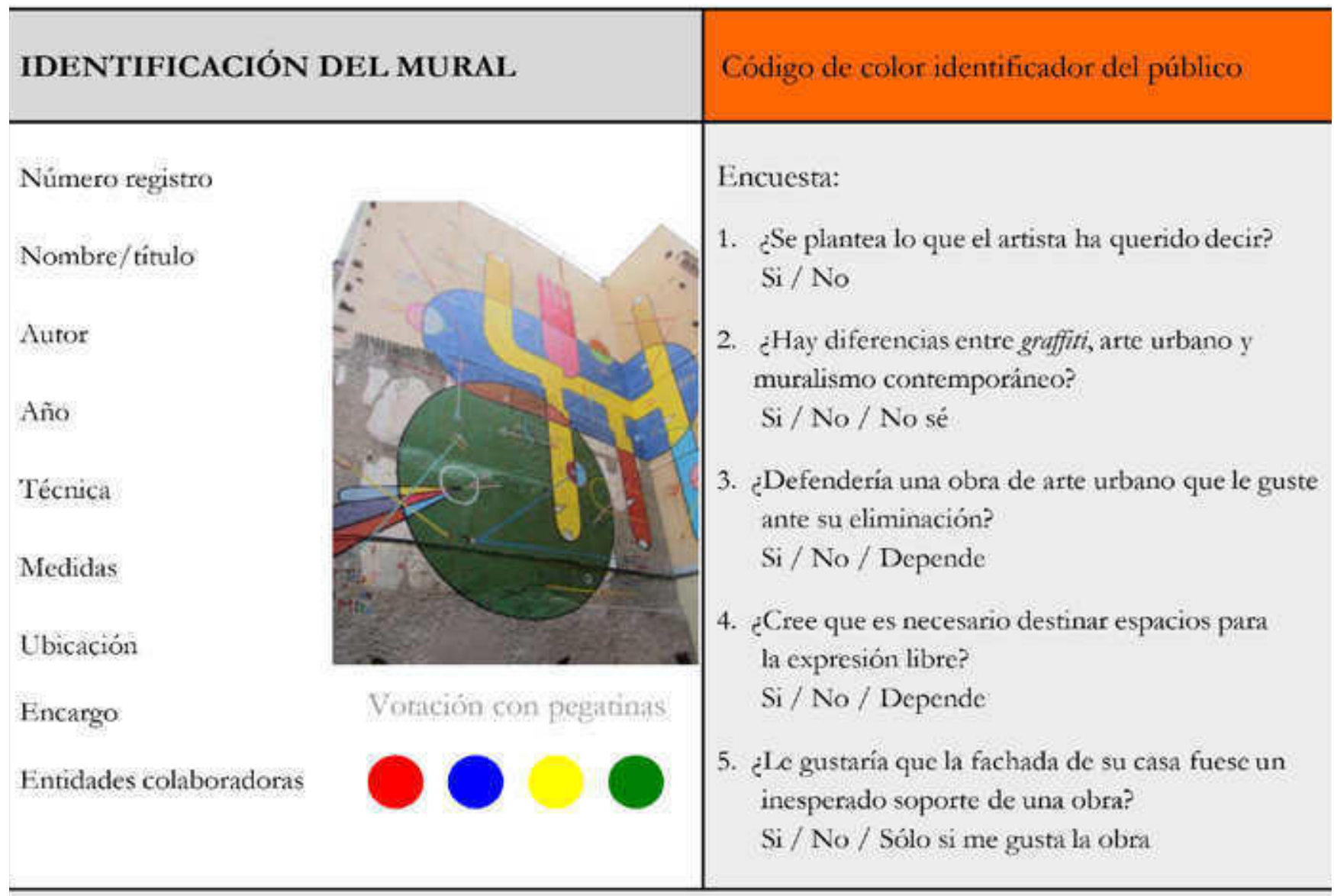

Espacio libre para escribir opiniones/rag emocional/observaciones:

Figura 6. Modelo de ficha reducida para recoger la opinión de público y usuarios. La imagen del mural corresponde a la obra de Sixe y pertenece al proyecto Ciutat Bella-Ciutat Nova, promovido por Kognitiv en 2014, en El Raval de Barcelona (Foto: R. Gasol).

\section{El papel del conservador-restaurador}

La participación en la OWC ha creado algunos vínculos de nuestro grupo con la organización y asistentes al festival, como consecuencia de las entrevistas realizadas (Senserrich 2015: 32-33) y de varias invitaciones a eventos de arte urbano que han desembocado en un par de proyectos de colaboración dirigidos a casos en que se pretendía realizar un mural de larga duración, poniendo el énfasis en su conservación.

Al margen de algunas opiniones que consideran que la única forma de preservar la obra es documentarla a través de la fotografía, es obvio que los registros e inventarios del arte urbano son del todo necesarios, tanto para el arte efímero como para obras permanentes. Se trata de un primer estadio para conocer y ubicar una obra determinada, y en caso que se llegue a realizar una intervención sobre ella, recoge la historia material, sus vicisitudes, los criterios y el proceso que se pueda llevar a término.
El papel del conservador-restaurador puede y debe incidir en esta primera fase de documentación, al lado de otros especialistas, pero sin duda debe estar presente en los casos de asesoramiento técnico previo a la realización de la obra y en la intervención posterior de conservación-restauración.

Esta necesidad se ha visto acrecentada después de la experiencia obtenida en algunos murales de gran formato comisionados que se han degradado con rapidez y en los que se han invertido recursos o depositado numerosas expectativas por parte de la organización o la comunidad. Un claro ejemplo de ello es el mural El rostro de Badalona /Identidad Compuesta, de Jorge Rodríguez-Gerada, promovido por la plataforma internacional de artistas Kognitiv y situado en la medianera de un edificio que da a la autovía de Badalona. Esta obra, de carácter efímero, fue creada en julio de 2010 utilizando el carboncillo, un material con poca estabilidad a la intemperie, elegido expresamente por el autor hablar del concepto de memoria, pues al 
igual que ella, va desvaneciéndose con el paso del tiempo, quedando solamente un leve vestigio sobre el muro. Para el artista, "la memoria de lo que fue siempre nos acompaña y nos reconforta, igual que el sentido de identidad que podamos tener". Aunque durante la ejecución del mural se optó por aplicar una ligera capa de fijativo en superficie, para alargar mínimamente su permanencia, el proceso de degradación continúa.

La obra, símbolo de convivencia, ha sido muy apreciada y valorada por la comunidad, identificándose desde el primer momento con ese retrato único formado por la composición de 34 rostros escaneados en 3D -uno por cada barrio de Badalona-, hasta el extremo de pedir su conservación, por reflejar la realidad social de la ciudad.

En casos como éste, en los que la población demanda la conservación de una creación efímera, tanto artistas como organizadores deberían estar preparados para replantear la vida otorgada al proyecto, afrontar el reto que supone este cambio y asumir que algunas obras, entregadas a la sociedad y que la sociedad, por diferentes mecanismos, ha hecho suyas, se han transformado y enriquecido con nuevos valores, que se tendrían que contemplar a partir de aquel momento.

Otro de los actores que puede jugar un papel determinante en la relación con el conservador-restaurador es el promotor. Algunas instituciones y ayuntamientos ceden muros o hacen encargos de arte urbano a cambio de que el mural cumpla una determinada función en el espacio público, exigiendo, habitualmente, una garantía de cierta durabilidad. El asesoramiento que el profesional de la conservación-restauración puede ofrecer, colaborando en la elección del tipo de preparación del soporte, pinturas y estratos de protección más adecuados, es muy útil y evita,

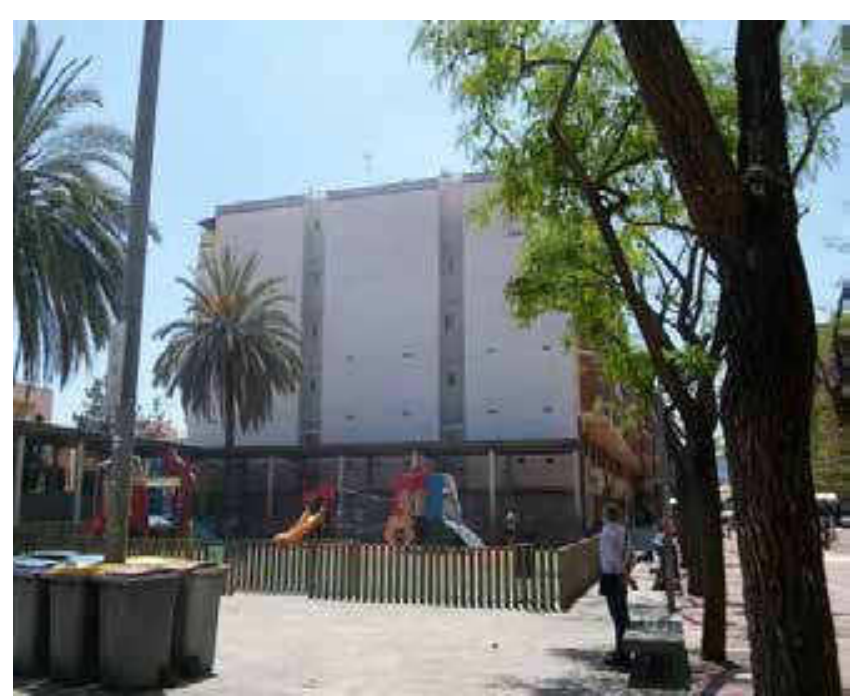

Figura 7. Medianera en la plaza de La Salut (Sant Feliu de Llobregat, Barcelona) para la que se ha pedido asesoramiento a un conservador-restaurador con el fin de preparar correctamente su superficie para pintar un mural (foto: R. Senserrich). en numerosas ocasiones, sorpresas derivadas del uso de materiales no compatibles con el substrato. En junio del año 2016, el director de Open Walls, Xavier Ballaz (Ballaz 2014: 13-14), pidió asesoramiento a un conservadorrestaurador para valorar el estado de conservación y realizar una propuesta de tratamiento y materiales necesarios para preparar correctamente una pared de 20 x 20 m. situada en el barrio de La Salut, en la localidad de Sant Feliu de Llobregat (Barcelona), cuyo ayuntamiento tiene previsto realizar un mural durable en la medianera de un edificio de viviendas que da a la plaza. Lo más interesante de este tipo de asesoramiento es hacer notar que cada muro es diferente en función de su naturaleza, situación, historia constructiva, recubrimientos aplicados a lo largo del tiempo y sus degradaciones. Todas estas variantes, a veces complejas, se deben poder identificar, así como conocer las compatibilidades entre los materiales existentes y el entorno, para llegar a proponer, con garantías de estabilidad, el mejor tratamiento para una determinada superficie [Figura 7]

Finalmente, se puede citar, como un ejemplo más de colaboración, la obra Panorama, de Jorge RodríguezGerada (Jassé y Molina 2015), realizada en el marco de la OWC 2015, donde también se requirió la opinión del conservador-restaurador para la elección de una técnica pictórica de carácter durable (pintura al silicato libre de resinas) que ofreciera garantías a favor del planteamiento del artista. Al igual que el resto de obras de la serie Identidad, los $280 \mathrm{~m} 2$ de pared del centro cívico del distrito sirven para plasmar una cara gigante, resultado de la fusión de los rostros de diez vecinas del barrio barcelonés de Sant Martí, elegidas concienzudamente por el artista por su sentido de pertenencia al territorio. El artista no utilizó en esta ocasión la técnica del carboncillo, porque lo efímero no formaba parte de su discurso; quería que la obra soportara la mirada sosegada de la gente que acudiera a contemplarla, y que, de esta forma, pudieran reflexionar sobre su contenido, su significado y, además, sobre el enorme esfuerzo que hay detrás de la realización de un mural de ese tamaño, donde diversas empresas y organizaciones que creen en el proyecto se ven abocadas a confluir y colaborar.

\section{Conclusiones}

Los resultados proporcionados por las encuestas y los pósteres presentados en la Open Walls Conference 2015 nos aportan detalles relevantes de la manera de actuar de algunos artistas minoritarios que difieren, en algunas ocasiones, del resto de opiniones, centrándose más en el resultado inmediato de la obra y haciendo pasar, a un segundo término, la preocupación por el contexto que los organizadores suelen perseguir, o la necesidad de su conservación, aunque también hay algunos artistas preocupados por la misma, como se pudo ver durante el debate. 
Cada vez está más claro que es necesario tener en cuenta el papel de la comunidad, que comparte el espacio con los murales diariamente, como un agente más en la opinión de la conservación o no de las obras de arte urbano. El diseño de una metodología de recogida de datos en los lugares públicos donde se encuentran ubicadas las obras es de fundamental importancia para la evaluación de la voluntad social en este sentido. Una vez consensuada su opinión con el resto de los agentes implicados (artistas, organizadores, propietarios, ayuntamientos), el conservador-restaurador puede ofrecer sus servicios en el caso de obras que requieran una intervención. Numerosos son los ejemplos de intervenciones realizadas en los últimos años en murales de grandes formatos, pero pocos los ejemplos en que se haya llegado a la intervención después de valorar a todos los agentes implicados.

El tipo de asesoramiento que el conservadorrestaurador puede ofrecer a los organizadores de eventos de arte urbano, artistas y promotores, es decir, al muralismo comisionado, actuando en el entorno y en la materia de manera preventiva, antes de la realización de los murales, es el más efectivo y con el que se lograrían unas garantías de mayor durabilidad de las obras a medio y largo plazo, sin la necesidad de invertir grandes recursos para su conservación posterior.

\section{Notas}

[1] Vean artículos de Laura Luque y Elena García Gayo en esta misma publicación.

[2] Vean Modelo de Encuesta al público - Grupo de Arte Urbano GEIIC, en el Anexo de esta publicación.

[3] Vean Resultados de la Encuesta al público OWC en el Anexo de esta publicación.

[4] Siete de los murales expuestos para la votación fueron obras creadas durante las pasadas ediciones de Openwalls Conference/Openwalls Showcase-Fahr.01 entre los años 2011 y 2014, organizadas por Difusor. Dos de los murales pertenecen a los proyectos Identidad(es) y Ciutat BellaCiutat Nova, promovidos por Kognitiv en los años 2010 y 2014, respectivamente. La obra más veterana, del año 2009, pertenece al proyecto The Influencers del CCCB.

\section{Referencias bibliográficas}

BALLAZ, X. (2014). “Barcelona. Donde el arte urbano siempre ha sido un movimiento valiente". En Urban Creativity Experience, Poch, A., Poch, D. (comp.). Madrid: Lemo, 1415. http://www.difusor.org/wp-content/gallery/urbancreativity/libro2.jpg y http://www.difusor.org/wp-content/ gallery/urban-creativity/libro3.jpg [consulta: 15.10.2016]
DIFUSOR. (2012). "Intervenciones artísticas en paisajes de periferia", en Franges. Els paisatges de la perifèria, de Joan Nogué, J., Puigbert, L., Bretcha, G., Losantos, A. (eds.). Olot: Observatorio del Paisaje de Cataluña (Plecs de Paisatge, Reflexions, 3), 278-296. http://www.catpaisatge.net/fitxers/ publicacions/franges/f_3_6.pdf [consulta: 15.10.2016]

DIFUSOR. An Open Walls movement?. http://www.difusor. org/2014/12/30/an-open-walls-movement/ [consulta: 15.10.2016]

FESTIVAL ASALTO. Décimo Asalto (2015). http://www. festivalasalto.com/ y http://www.festivalasalto.com/decimoasalto/ [consulta: 13/10/2016]

GASOL, R., SENSERRICH, R. (2016). "La interacción con el público: actividad del grupo de arte urbano del GEIIC en la Openwalls Conference 2015 de Barcelona", Mural Street Art Conservation, 3: 24-27. https://issuu.com/ observatoriodearteurbano/docs/mural_3 [consulta: $13 / 10 / 2016]$

GRUPO DE ARTE URBANO DEL GEIIC. Resultados de las Votaciones en los pósteres. Open Walls Conference 2015. https://db.tt/2ajF4Dub [consulta: 15.10.2016]

IDENTIDAD(ES), El Rostro de Badalona / Identidad Compuesta / Jorge Rodríguez-Gerada. https://www.youtube.com/ watch?v=ECfrdh9OLLo [consulta: 14/10/2016]

JASSÉ, A., MOLINA, A., Un mural gegant a la façana lateral del Centre Cívic Sant Martí, en BTV Notícies. http://www.btv. cat/btvnoticies/2015/12/23/un-mural-gegant-a-la-facanalateral-del-centre-civic-sant-marti/ [consulta: 15.10.2016]

OPENWALLS CONFERENCE. Open Walls 2015. http:// www.conference2015.openwalls.info/about/ [consulta: $14 / 10 / 2016]$

POCH, A., POCH, D. (2014). Urban Creativity Experience. Madrid: Lemo.

RECASENS CIRERA, M., BALLAZ BOGUNYÀ, X., Memoria Open Walls Conference 2015. https://db.tt/13m79MEx [consulta: 13/10/2016]

SENSERRICH， R. (2015). "Open Walls Conference 2015 en Barcelona: Entrevista a Xavier Ballaz, organizador", Mural Street Art Conservation, 2: 32-33. https://issuu.com/ observatoriodearteurbano/docs/mural__2 [consulta: $13 / 10 / 2016]$ 


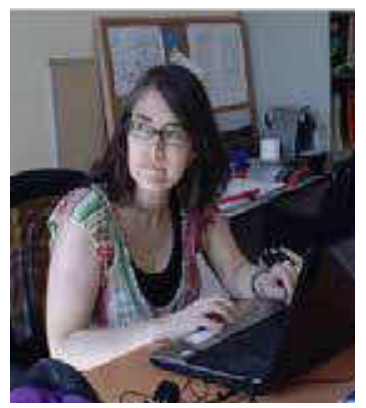

\section{Rosa Senserrich Espuñes}

Facultad de Bellas Artes, Universidad de Barcelona

rosa.senserrich@ub.edu

Licenciada en Bellas Artes por la Universidad de Barcelona (UB) con la especialidad de Restauración (1987). Desde entonces ejerce como técnico superior en conservación-restauración de pintura mural y decoraciones arquitectónicas, actividad que combina, desde hace años, con la docencia. En 2010 es contratada como profesora asociada del Departamento de Artes y Conservación-Restauración de la UB, siendo responsable de la asignatura de Grado Tratamientos aplicados a la pintura mural, y de Máster Pintura mural: entre el contexto arquitectónico y el museístico. Desde 2012 es miembro del grupo de investigación consolidado Conservación-Restauración del Patrimonio, formando parte del equipo que se dedica al estudio del arte mural en la calle. Con los alumnos de la universidad ha impulsado diferentes proyectos de examen, catalogación y evaluación del estado de conservación de murales en el espacio público, tutorizando algunas de sus tesis. En 2014-15 organizó unas jornadas de máster dedicadas al muralismo contemporáneo, con la participación de la asociación Difusor y de la plataforma Kognitif. En su faceta de free-lance, ha participado en numerosas intervenciones de conservación de pintura mural de ámbito nacional y ha sido co-comisaria de la exposición Murales bajo la Lupa (2012). También colabora con museos de arte contemporáneo en la restauración de sus colecciones. Cuenta con publicaciones sobre la técnica pictórica de los bienes examinados y sus efectos sobre la conservación. Desde 2013 forma parte de la junta directiva de la asociación CRAC (Conservadores-Restauradores Asociados de Cataluña) y es miembro del grupo de trabajo de Arte Urbano perteneciente al grupo español del International Institute for Conservation of historic and artistic Works (GEIIC), creado en 2015.

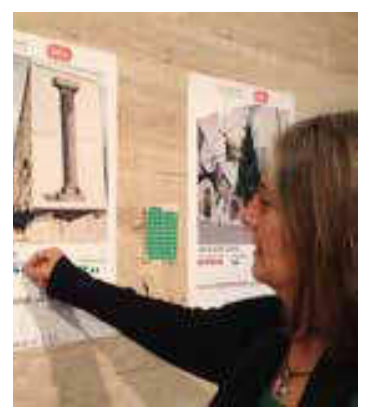

\section{Rosa M. Gasol Fargas}

Laboratorio de Conservación-restauración de la OPC . Diputación de Barcelona rmgasolf@gmail.com

Doctora en Bellas Artes por la Universitat de Barcelona, con una tesis sobre la técnica y la conservación de la pintura mural (2006). Máster en conservación de pintura mural en el Wall Painting Department del Courtauld Institute of Art de la Universidad de Londres (1995-96) y curso Mural Painting Conservation en el ICCROM, Roma (1993). Licenciada en Bellas Artes, Especialidad de Restauración por la Universidad de Barcelona (1984). Ha llevado a cabo docencia en conservación y restauración de pintura en l'Escola d'Arts i Oficis de la Diputació de Barcelona e impartido diversos cursos y colaborado en másters en la Universitat Autónoma de Barcelona (UAB), la Universitat Internacional de Catalunya (UIC) y en la Universitat de Barcelona (UB), donde inició el proyecto de documentación del Arte Mural en la calle como docente del Grado de Conservación-restauración de la Facultad de Bellas Artes. Ha sido además miembro colaborador del Grupo de Investigación consolidado Conservación-restauración del Patrimonio en esta universidad. Es autora de numerosas publicaciones en torno a la técnica pictórica y la conservación de la pintura mural. Actualmente trabaja como Técnica de Patrimonio Cultural en el Laboratorio de Conservación-restauración de la OPC, Diputación de Barcelona. Es miembro de la Junta Directiva de la Asociación de conservadores-restauradores de Catalunya (CRAC) y miembro del Grupo de trabajo de Arte Urbano del GE-IIC. 


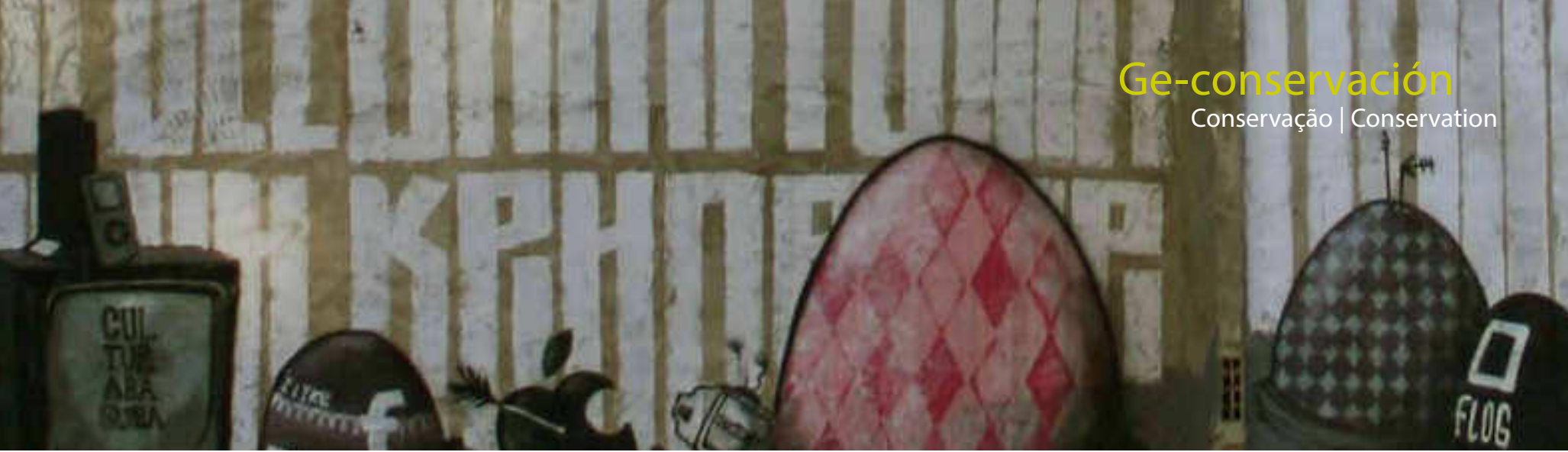

\title{
Arte relacional en la calle. Casos de conservación colectiva
}

\author{
Laura Luque Rodrigo
}

Resumen: Bourriaud formuló en la década de los '90 su estética de lo relacional, donde describía la relación entre la obra y el espectador, determinando como el significado es elaborado colectivamente, pero adscribiéndose a obras que específicamente están construidas mediante la participación del espectador. En el siglo XXI este tipo de manifestaciones se han multiplicado en número exponencialmente, sin embargo algunos autores resaltan que los resultados no dejan de ser individuales y contemplativos e incluso que la participación puede producir jerarquías entre las personas. Ante esto, en la actualidad, existen artistas y colectivos dedicados al arte urbano que buscan precisamente crear espacios donde las comunidades sí puedan ser igualitarias, pero ¿cómo se produce la conservación de las obras cuando son colectivas? En este trabajo se analizarán distintos casos mediante entrevistas a artistas y comunidades y documentación.

Palabras clave: Arte relacional, arte urbano, conservación, participación

\section{Relational art in the street. Cases of collective conservation}

Abstract: Bourriaud formulated in the decade of ' 90 his aesthetics of the relational art, where he was describing the relation between the artwork and the spectator, determining as the meaning it is elaborated collectively, but being assigned to works that specifically are constructed by means of the participation of the spectator. In the 21 st century this type of manifestations have multiplied, nevertheless some authors highlight that the results do not stop being individual and contemplative and even that the participation can produce hierarchies between the persons. Before this, at present, there exist artists and groups dedicated to the urban art that seek to create precisely spaces where the communities could be egalitarian, but how does the conservation of the works art take place when they are collective? In this work different cases will be analyzed by interviews to artists and communities and documentation.

Key words: Relational art, urban art, conservation, participation

\section{Introducción}

Desde hace algunos años se han incrementado propuestas artísticas en el ámbito urbano que tienen que ver con lo participativo o colaborativo, confirmando así una tendencia que décadas atrás ya empezaba a perfilarse. Estas propuestas no siempre se desarrollan de la misma forma, en ocasiones parten de los propios artistas, en otras de los vecinos de un barrio o un colectivo concreto y en otras tienen relación con lo institucional. Lo cierto es que no existe una opinión común entre todos, aunque sí se entrevén algunas coincidencias con respecto a la forma de trabajar y de considerar este tipo de arte. Igual sucede con su conservación, la diversidad de opiniones al respecto, a las que hay que sumar también las de los profesionales del sector del patrimonio -historiadores del arte, conservadoresrestauradores, antropólogos, juristas, etc.-, y la falta de consenso y protocolos claros de intervención, provoca la desigualdad en cuanto a las decisiones que se adoptan a la hora de conservar una obra. En este trabajo se presentan algunos casos concretos, sin pretender ser un catálogo completo, en el que se recoge la opinión de algunas de las partes implicadas, con el objetivo de comenzar a establecer criterios comunes, aunque siempre flexibles. 


\section{Arte urbano y participación: breve introducción al arte relacional.}

El situacionismo propuso como eje central la creación de situaciones, es decir, "la construcción concreta de ambientes momentáneos de la vida y su transformación en una calidad pasional superior" (Debord, 1957), con un objetivo político, que cristalizaron en diversas propuestas artísticas durante las décadas de los '70 y ' 80 . Cuando Bourriaud (2008) formuló su estética de lo relacional, en la década de los '90, describió la relación entre la obra y el espectador, determinando cómo el significado es elaborado colectivamente (en consonancia con los planteamientos de Eco para la música y la literatura, pero sobre artes plásticas). El teórico se adscribió en su estudio a obras que específicamente estaban construidas mediante la participación del espectador, conviniendo que "el arte es un estado de encuentro". Así, algunos artistas crean obras donde el objetivo no es la pieza en sí, sino la interrelación con el espectador. Laddaga (2006) destacó la proliferación de obras de carácter participativo o relacionales a partir de 2001, una participación que se define de forma diferente a la que existió en el arte de vanguardia o dentro del arte comprometido, en cuanto se remite a la invención de nuevos modelos de relación y socialización, en contraposición a la producción de masas y la mercantilización del arte, tal y como defendía Bishop (2012: 6-7). Kester (2011), sin embargo, resalta en sus estudios sobre arte colaborativo como, aunque los procesos sean participativos, los resultados no dejan de ser individuales y contemplativos (vídeos, fotografías, etc.). Pero iqué quiere decir participación? Sansi (2014: 24) considera que la participación puede producir jerarquías entre las personas y no sólo comunidades igualitarias. Ante esto, en la actualidad, existen artistas y colectivos que buscan precisamente crear espacios donde las comunidades sí que puedan ser igualitarias, artistas que piden la absoluta participación ciudadana, pues serán los habitantes de los barrios quienes queden como usufructuarios de estas obras de arte público y urbano.

Isidoro Valcárcel (VVAA 2014: 16-17) pone la atención sobre un espectador que no necesariamente tiene que situarse enfrente de la obra, con un cordón en medio: "Ten en cuenta que los receptores no lo son forzosamente como condición y, por otro lado, el emisor (el autor) tiene su obligación a satisfacer, en primera instancia, a su propio criterio y solo en ese segundo lugar al gusto o parecer de los demás". Además de asumir en su definición del arte que es inexorablemente un acto comunicativo y defender la preponderancia del criterio del artista por encima de gustos o modas de mercado, Valcárcel hace algo más. Sobre la afirmación "los receptores no lo son forzosamente", podríamos hacer múltiples interpretaciones, pero si la llevamos al campo que nos ocupa, ¿por qué no entender que el receptor pueda participar también del acto de comunicación? Estrella de Diego (2015) considera que frente a otro tipo de propuestas "frías", el arte relacional en un contexto de crisis social como el actual, adquiere una especial importancia. Paul Ardenne indica que el hecho de implicarse en una acción común, modifica la noción de público y revoca el principio de pasividad (Doctor 2013: 161).

Pero, ¿qué abarca el término público? La concepción de público, 'implica 'accesibilidad', 'participación', 'inclusión', tener en cuenta a la gente como usuaria del espacio público" (Parcesirsas 2008: 24). Lo que importa es el proceso de creación de la obra y las sinergias que genera en las personas que conforman ese entorno. La obra no nace con la idea de perdurar eternamente y en cualquier caso su trascendencia no depende sino de la propia comunidad que se convierte en usufructuaria.

Sin embargo, existen voces discordantes con respecto al arte urbano, como la de Mario Perniola (2016) que considera que "artificar" el graffiti es dar respuesta a un problema político sobre qué hacer con los jóvenes desempleados de las periferias. Perniola opina que las instituciones crean estructuras que hacen a los jóvenes creerse artistas, esperando que no se amotinen ni caigan en la delincuencia o vandalismo, no obstante, el propio autor afirma que "no existe un mundo del arte sino muchos mundos del arte, que se superponen y se influyen mutuamente".

Muchos artistas, que creen en las posibilidades del trabajo participativo y en la importancia del contexto urbano, consideran que es desde lo local cuando se puede trabajar de forma más directa con las personas y producir esos pequeños micro-cambios en barrios concretos. Es esencial en este punto entender el proceso creativo y formativo para las personas que van a participar y la gestión de la conservación de las obras.

\section{Artistas y proyectos}

"Una obra, sin embargo, es algo que el autor (el auctor: "el que hace") le brinda a los demás para que puedan olvidarse de ella y salgan de esa inmersión con un sentimiento de plenitud y una comprensión distinta a la que el entendimiento procura"

(VVAA 2014: 24).

La ciudad es el espacio en el que se desarrolla la vida pública, especialmente en la plaza, que históricamente ha servido de espacio de reunión y de celebración. Es además ahí, en la plaza, donde con frecuencia se concentran los edificios que representan los poderes, porque adquiere una especial significación. "Por definición el espacio público es aquel que el habitante de la ciudad -habitual o esporádico- puede utilizar sin más limitaciones que ciertas ordenanzas legales $y$ ateniéndose a unas normas de decoro aceptadas 
por el conjunto social" (Fernández 1988: 17-39); tradicionalmente ha estado ligado además a lo masculino, así como la casa a lo femenino, sin embargo, en la actualidad el espacio urbano es tanto del hombre como de la mujer, aunque sigue estando asociado al poder, a la fiesta, al trabajo e incluso, a las reivindicaciones, pues en ellas se desarrollan las manifestación y protestas ciudadanas. En materia artística, la arquitectura ha sido la que tradicionalmente ha estado presente en el espacio público, así como las fuentes y a partir del siglo XIX también el monumento conmemorativo, por ello "la estética urbana ha detectado siempre cada cambio en el medio cultural y lo ha expresado transformando su fisonomía, sustituyendo parte de sus elementos, poblándose de nuevas obras"(Fernández 1988: 17-39). Con la irrupción del graffiti y posteriormente de otros tipos de manifestaciones artísticas urbanas, los artistas comienzan a apropiarse del espacio urbano, con un claro objetivo de realizar obras fuera del mercado y de las instituciones y ligarlas a lo social.

Las manifestaciones artísticas en el espacio urbano convierten "en algo emocionante, excitante y seductor lo que por sí solo no logra manifestarse como tal" (Perniola 2016: 41), aunque con frecuencia estas manifestaciones han sido incluso fuente de conflicto, parece que la integración social del graffiti y la aceptación ciudadana se ha incrementado notablemente en los últimos tiempos, pero esto ha supuesto una institucionalización del arte urbano mediante la creación de concursos, festivales y distinto tipo de convocatorias de las que, al final, el ciudadano queda al margen. La arquitectura, sin duda, es una de las formas más evidentes de construir espacios que generen comunidad, pero también otro tipo de manifestaciones artísticas pueden promover la relación entre las personas, especialmente las prácticas colaborativas, "no siempre desarrolladas en contextos artísticos, cuyos resultados, abiertos e intangibles, pertenecen a los individuos que han formado parte de ella" (Doctor 2013: 202). Pero, ¿participan los ciudadanos verdaderamente de esta situación?

En España existen casos de regeneración de barrios a través del arte urbano y de artistas o colectivos que trabajan sobre la solución de problemas que plantea la ciudad, como el colectivo Truth Behind 404 que busca visualizar de forma crítica y mediante el juego cuestiones sobre la vida en el contexto urbano. Bajo la premisa de que "el arte cambiará el mundo cuando sea parte de la vida cotidiana"1, idean piezas como Make a Sity, con la que pretenden resolver la problemática de la falta de espacios públicos libres en ciudades como Madrid, por lo que crearon un banco que puede ser impreso mediante una impresora 3D y colocado en cualquier punto de la ciudad. El espectador ya no es tal, como indicaba Isidoro Valcárcel, pues debe convertir la idea artística en objeto artístico y ser quien escoja dónde debe estar situado, por lo que habrá tantas piezas como quieran los "espectadores".
El estudio de arquitectura 100 Architects, con sede en Shangai y dirigido por Marcial Jesús (Chile), Madalena de la Venta (Portugal) y Javier González (Chile), realiza intervenciones urbanas con objetos arquitectónicos, tanto efímeros como permanentes, que buscan la interacción y la estimulación de la dinámica social. Aunque no se consideran artistas, sus piezas van más allá de la utilidad, no sólo por la esteticidad o la innovación, sino por lo que generan en las personas. El cambio social por su parte viene de la mano de la sostenibilidad, pues "la escasez de áreas de recreación, el aumento de población mundial habitando en centros urbanos, la falta de tiempo para recreación urbana y la manera en que la revolución tecnológica ha influido e impactado en la forma en que las nuevas generaciones se relacionan con el espacio público", hacen necesaria la irrupción en el contexto urbano de espacios públicos que inviten a interactuar, motiven a crear y generar arte. Sus proyectos de arte urbano son de dos tipos, unos por encargo con vocación de permanencia (que les permita la libertad de emplear materiales holísticos) y otros de carácter efímero autogestionados o relacionados con eventos concretos, que consideran debieran ser rotativos "inyectando vida y dinámicas de cambio a los espacios urbanos"2. 100 Architects, a través de sus proyectos arquitectónicos-artísticos, logran crear espacios relacionales que inciden en las ciudades cambiando sus dinámicas, aunque sea de forma temporal. Los 'espectadores' no participan de la idea ni de la creación en sí de las piezas, pero construyen su significado cuando las usan y las viven, cambiando el concepto de lo arquitectónico, lo urbanístico y promoviendo las relaciones entre los habitantes de las ciudades. Consideramos estas obras como ejemplo de arte relacional aunque no tanto participativo en cuanto a que este término se empleará para definir aquellas propuestas en las que los espectadores participan de forma activa en el proceso de creación.

Existen colectivos que en los últimos tiempos han alcanzado notoriedad como Basurama, quienes con sus autoparques creados a partir de elementos de desecho en zonas deprimidas, implican tanto en su creación como en la posterior conservación a todo un barrio. Formado en 2001 en el seno de la Escuela de Arquitectura de Madrid, sus proyectos tienen un carácter internacional y una gran repercusión social, haciendo reflexionar sobre la enorme acumulación de basura que produce la sociedad de consumo y empleando los desechos como recurso artístico, consiguen generar un beneficio social ${ }^{3}$. Para la creación de los autoparques, espacios de ocio infantil en lugares en desuso, forman a voluntarios que participan en el proceso de creación, generando además un contexto de convivencia y unión colectiva. Uno de estos proyectos, realizado junto a Boa Mistura, en el que han apostado por un arte creado no sólo para los ciudadanos, sino ejecutado por ellos mismos, es el Barrio de San Cristóbal de Madrid. Ambos colectivos artísticos plantearon una serie de intervenciones que pretendían 
cambiar el aspecto de un paso a nivel que resultaba intransitable para los vecinos, mediante la participación de los propios vecinos que convivieron durante unos días entorno a un objetivo común. Lo interesante es no sólo la regeneración del espacio, sino lo que se provoca en las personas, conciencia de barrio y de pertenencia, por otro lado si ponemos la vista en lo meramente artístico, los vecinos realmente tampoco participan de la creación en cuanto a toma de decisiones, simplemente se limitan a hacer tareas del tipo rellenar con color las figuras ya proyectadas.

En el caso de Boa Mistura, colectivo creado también en 2001 en Madrid, buscan en sus proyectos la participación colectiva y se integran en los espacios en los que intervienen de tal forma que alteran su propia concepción artística. Por ejemplo, en Icalupe (Nicaragua, 2015) vieron que las mujeres del pueblo ya pintaban sus paredes recogiendo pigmentos de la tierra que mezclaban con agua por lo que decidieron organizar un taller de temple al huevo para que con los recursos de los que disponen pudieran seguir haciendo sus pinturas, pero de forma más duradera. Es decir, les dieron las herramientas para que ellas pudieran desarrollarse, la experiencia artística en este caso pasa por la formación y la creación juntos de algo identitario y no superpuesto. El arte urbano es la forma para conectar con las personas, el arte tiene capacidad de "estremecer, de inspirar, de emocionar... por eso es tan importante" ${ }^{\prime 4}$ y tiene capacidad para cambiar el mundo.

En algunos casos, sin embargo, como el Soho de Málaga, se pueden dar procesos de gentrificación, pues parten de iniciativas institucionales y no vecinales, sin entrar en aspectos morales, casos como este tienen consecuencias positivas para la ciudad, pero quizá no tanto para los vecinos originarios del barrio que al final terminan marchándose. No es así el caso del Barrio del Oeste de Salamanca, donde la regeneración del espacio a través del arte urbano promovida por la Asociación de Vecinos "Zoes", ha contribuido notablemente a la regeneración del barrio y al aumento del bienestar de sus habitantes. La iniciativa surgió en 2012 con la idea de mejorar el aspecto degradado de un barrio que contaba con el mayor índice de construcción de la ciudad y que contaba con más de quinientas puertas de garaje donde poder intervenir. Desde la Asociación creen que el arte puede contribuir a efectuar cambios sociales, culturales e incluso urbanísticos al generar "sentimiento de permanencia y autoestima colectiva, satisfacción de ser y sentir el Barrio del Oeste, genera adhesión y promoción" ${ }^{\prime \prime}$. Los vecinos participan de la creación y de momentos con los artistas que llegan al barrio de distintas formas (siempre por elección de los propios artistas y cuentan con libertad plena), aportan materiales como escaleras y charlan sobre las obras, además se hacen presentaciones a las que también acuden. En la actualidad, el barrio ha sido incorporado en los itinerarios turísticos de Salamanca.
Dos de los artistas que han participado en el Barrio del Oeste son Pablo S. Herrero y David de la Mano. Éste último considera que los vecinos deben participar de la creación de las obras, "pueden y deberían hacer sus propias propuestas, pero no 'participar' en la creación de piezas realizadas por los artistas", pues aunque puedan ayudar a rellenar, no parece apropiado que actúen como creadores, algo que parece obvio si imaginamos "qué sería de las grandes obras del arte: el Guernica, El Carro de Heno, la Gioconda, Los Girasoles... si se hubieran completado por los niños de un colegio o por los vecinos de un barrio". De la Mano considera que este tipo de obras no pueden considerarse como piezas artísticas, sino otra cosa. Está además convencido de que el arte urbano (y emplea el término con convicción), ayuda a los vecinos a reivindicar la calle, aunque también cree que las ciudades están necesitadas de "curadores y expertos que seleccionen artistas y que ellos lleven a cabo su obra sin condicionantes y con libertad plena"6.

Por su parte, Herrero, que comenzó a pintar en la calle en 2008 después de finalizar la licenciatura en Bellas Artes, cree que el arte puede generar cambios en cuanto a que puede cambiar a las personas y generar conciencia común. Se considera a sí mismo como un 'agente' de un movimiento que cree positivo en su etapa inicial, antes de que se desvirtúe con factores como lo monetario. Desde lo local, en zonas que el propio artista conoce bien, trabaja para mostrar "la ficción de un ecosistema, de un sistema sostenible y dinámico"7. Lo que le mueve a trabajar de forma colaborativa es la comunicación. En relación al Barrio del Oeste, su trabajo consiste en llevar a artistas al barrio, y en cuanto a su creación personal, trata de equilibrar el trabajo por encargo con el trabajo por iniciativa propia.

En una línea similar, Sabotaje al Montaje lleva trabajando desde 1990, especialmente en Las Palmas de Gran Canaria y Barcelona. Considera que "el arte tiene que acompañar a la sociedad" y entiende "la calle como un periódico que a diario manifiesta lo que la sociedad actual contempla, por lo tanto puede ayudar a cambiarlo desde su territorio", pues con "el simple hecho de apropiarse de un espacio público ya estamos reivindicando una libertad (y con) el hecho de poner color ya estamos cambiando la sociedad". En los proyectos colaborativos, el artista se convierte en una simple herramienta para el barrio, que les ayuda a crear sus propios "gritos de colores" y a expresar sus propias inquietudes. Sus inicios se enmarcan en el barrio de la Añaza de Tenerife, en los jardines prefabricados, creando murales que los vecinos rellenaban con el color, pero posteriormente decidió que el propio barrio fuera quien tomase sus decisiones artísticas, pues de otra manera las instituciones decidían por ellos sin conocerlos. Lo que buscaba en estos proyectos no era lo pictórico, sino la unión para hacer algo, "no tiene que haber un resultado, solo el proceso, acciones efímeras como la vida, el hecho de que gente tome decisiones en sus espacios ya es un gran paso"8. 
En España, existen precedentes en los que el cambio afecta o a un barrio sino a una localidad completa. Uno de estos casos es el de El Carpio, que a través de Scarpia y de la mano de Miguel Ángel Moreno Carretero, ha conseguido generar no sólo una importantísima colección de arte público situada tanto en el espacio público como natural, sino generar un cambio en la población de la localidad, patente por ejemplo en el incremento de jóvenes que deciden estudiar carreras de ramas artísticas. Otro ejemplo es el de Fanzara, que a través del proyecto M.I.A.U (Museo Inacabado de Arte Urbano), han incidido notablemente en la realidad de una localidad con una población envejecida, convirtiendo cada casa en un lienzo donde crear una obra de arte, lo que ha proporcionado al municipio un atractivo turístico del que carecían, desde hace un par de años.

Aunque el estudio se ha centrado en España, existen experiencias de este tipo reseñables en otros países. Un ejemplo de ello es el distrito de arte en el Windwood de Miami, fundado en 2003 por Mark Coetzee y Nina Arias, generando la aparición de galerías de arte, estudios y espacios alternativos y desde 2007 albergando ferias internacionales, como el ArtBasel. No obstante, este ejemplo parece similar al del Soho de Málaga, un proyecto que ha producido un proceso de regeneración de un barrio histórico, que supone un revulsivo económico, pero que probablemente provoque un proceso de gentrificación si los habitantes originarios no participan de ello. Más integrador parece el proyecto de la Galería de Arte Urbana de Lisboa, que si bien también es una iniciativa institucional, ha propiciado la interrelación entre artistas y ciudadanos con distintos proyectos desde 2008, que no sólo ha servido para situar Lisboa dentro del panorama internacional en cuanto a arte urbano y para incrementar la oferta turística, sino que ha permitido mejorar la imagen de los barrios y lo que nos interesa en este estudio, generar convivencia vecinal a través de algunos proyectos que implican a los vecinos de un barrio, a colegios o particulares en general, como el proyecto BIP-ZIP o Reciclar o Olhar, entre otros. Otro ejemplo interesante tiene lugar en París, en concreto el Distrito 13, pues aquí un especialista escoge varias ideas entre distintos artistas y son los vecinos quienes deciden cuál se lleva a cabo.

El colectivo Wochenklausur, nacido en Viena en 1993, desarrolla propuestas orientadas a reducir las diferencias sociales, siempre desde encargos institucionales. El significado de su nombre "semanas de encierro", indica su método de trabajo, que parte del conocimiento de la realidad en la que van a intervenir. El colectivo realiza obras con el objetivo de impactar en la sociedad, si bien creen que el arte no puede cambiar el mundo, opinan que sí pueden crear mejoras en ciertas realidades sociales. Al no formar parte de los sistemas institucionales o de autoridad, pueden acercarse a los problemas sociales de forma inesperada y sin generar sospechas, lo que facilita el contacto con las comunidades. Sus soluciones deben servir de modelo para solucionar ciertos problemas, inspirándose en modelos del pasado como el Constructivismo Ruso, Joseph Beuys o Artist Placemente Group. Sus obras nacen de conversaciones previas con las comunidades o las organizaciones que trabajan sobre el terreno concreto en que van a intervenir, así identifican cuales son los asuntos que les preocupan y sus deseos, también realizan una investigación sobre la localidad empleando los periódicos locales, internet, etc. No conciben este trabajo como su medio de vida, los miembros del colectivo tienen otros empleos, realizando un par de acciones al año, lo que les permite mayor libertad creativa, a pesar de que siempre trabajan por invitación?.

\section{La conservación del arte urbano participativo. Análi- sis de experiencias.}

¿QQué sentido tiene restaurar una obra que se autodestruye? -Heinz Althöfer- (...) El acto artístico ya no consiste en fabricar un artefacto que se pueda designar como obra, sino una acción a veces ínfima (...) el papel de la conservación deberá limitarse a documentarlo" (Perniola 2016: 84-85).

La conservación del arte urbano, debe contar en todos los casos con la opinión de sus creadores, pero aún más cuando se trata de arte participativo realizado por y para una comunidad concreta. En un artículo publicado en El País, se preguntó a uno de los vecinos de Fanzara si no temían quedarse sin paredes, a lo que contestó: "pues borramos y comenzamos de nuevo" (Ortega, L. 07/04/2015). Esta afirmación deja claro que en este caso se entiende que las obras no serán perennes en los muros de la localidad, se pretende precisamente el movimiento, que acuda el mayor número de artistas posibles, se busca lo nuevo. ¿Debemos por tanto los profesionales imponer nuestro criterio y conservar algunas de esas obras?

En muchas ocasiones tanto los artistas como los vecinos consideran que las obras deben tener una duración determinada, bien porque la degradación se considera parte de la pieza, bien porque detrás deban venir otras. Pero, en los casos en los que se considere que sí deben tener un mantenimiento que haga la obra más duradera ¿quiénes son los encargados? Sin duda deberían estar en manos de los profesionales, pero es evidente que por cuestiones económicas esto no siempre es posible, en estos casos ¿son los artistas o la comunidad quienes 'reparan' las obras?

En la Asociación de vecino Zoes del Barrio del Oeste de Salamanca, consideran tanto que el arte urbano puede conservarse como que debe ser efímero, pues aunque consideran que detrás de una obra debe venir otra, los 
vecinos "cogen cariño" a lo que llaman los 'lienzos' y pasan a formar parte de este 'museo al aire libre' de forma 'permanente'. En este caso, cuando alguno de los 'lienzos' necesita ser reparado, se recurre al propio artista o si éste está alejado geográficamente, es el propietario del muro o puerta quien lo hace, pero nunca han recibido indicaciones o formación por parte de los creadores para hacerlo.

El objetivo de las intervenciones de Basurama, es "la adquisición de autonomía y el poder de cambio"10 del propio entorno, por ello cuando intervienen en la rehabilitación de un solar o un espacio de la ciudad, es la propia comunidad la que se implica en el mantenimiento, aunque en muchas ocasiones las autoconstrucciones no disponen de los certificados exigidos, por lo que tienen una duración breve.

Boa Mistura se complace al ver como sus trabajos van mutando, creen que son obras vivas que van envejeciendo, como todo en la naturaleza. Consideran que una vez terminan su trabajo la obra es de la comunidad, por lo que deben ser ellos mismos quienes la cuiden y respeten ${ }^{11}$, por ello dejan algunas indicaciones en las comunidades en las que intervienen. Por ejemplo, en el proyecto Bacatá (Bogotá), dejaron un dossier en el que no sólo se explica y justifica el proyecto, sino que además se incluyen esquemas con el diseño, los colores, significación, proceso de trabajo, materiales, descripción técnica, y unas recomendaciones de mantenimiento. Éstas, no obstante, son muy nimias, se limitan a indicar que no se laven con agua y jabón durante los primeros treinta días después de su aplicación y que en caso de restauración cuentan con la información necesaria en el informe, pero obviamente esta restauración para ser tal debería realizarla un profesional, pues los ciudadanos sólo podrían limitarse a rellenar con color las zonas afectadas, de forma más o menos acertada, por lo que deberían considerarse repintes. Ellos mismos participaron en la restauración del mural "Somos Luz" en São Paolo, gracias a la colaboración de Odebrecht y Luz Botero y con la participación de los propios vecinos. Es decir, Boa Mistura diferencia entre las obras que hacen por iniciativa propia, las que prefieren ver evolucionar hasta morir; las que realizan para una comunidad, que deben conservar los propios vecinos y las encargadas por una institución. En cuanto a su técnica, difiere en cada proyecto, en el caso de Bacatá, se empleó pintura fabricada a partir de copolímeros diluibles en agua (pintura vinilacrílica).

David de la Mano, en cambio, no está de acuerdo con la conservación del arte urbano, de hecho considera que "una de las grandes virtudes del arte urbano" es precisamente el envejecimiento, el paso del tiempo que debe vivirse con naturalidad, aunque sí considera apropiado el registro fotográfico. También Sabotaje al Montaje cree que el arte urbano debe ser 'efímero', pues nuestra sociedad cambia muy rápidamente y el arte debe ir en paralelo, solo la memoria debe ser la conservación. Por ello, no hace seguimiento de las obras, aunque sí suele dar unas pequeñas clases formativas a las personas que van a colaborar en sus trabajos colaborativos, pero cree que cuando realmente aprenden es trabajando de la mano con el artista. Los productos empleados por Sabotaje al Montaje también difieren en cada proyecto, pero generalmente usa spray, pintura plástica y materiales reciclados.

Pablo S. Herrero, tampoco está de acuerdo con la conservación, especialmente si son obras espontáneas y en todo caso piensa que el artista debe ser consultado previamente y que la restauración "no debe responder a intereses relacionados con la especulación con bienes raíces, debe atender a lo que la comunidad demande". Por ello, aunque al inicio sí hacía seguimiento de las obras, dejó de hacerlo, a pesar de que en ocasiones le llegan fotografías de algunos de sus murales en los que puede comprobar su evolución, pues realmente lo que al artista le gustaría es que la naturaleza cubriera la 'ficción' que pintó. También Herrero emplea generalmente pintura plástica, y si el soporte está muy degradado los prepara previamente. Cuando el trabajo es remunerado además emplea un fijativo.

El colectivo Wochenklausur tampoco hace un seguimiento de las obras, sólo al inicio de haberlas creado y opinan que la intención con la que se crea la obra es la que debe determinar si la pieza debe perdurar en el tiempo o ser efímera. El colectivo, en concreto apunta a proyectos sostenibles que perduren a largo plazo. En ocasiones dejan obras terminadas, pero en otras lo que crean son estructuras que deben ser continuadas por la comunidad, siempre y cuando hayan podido asegurar previamente apoyo financiero e implicar no sólo a la comunidad sino a profesionales o personas con formación. Aun así, piensan que la auténtica conservación parte de la documentación, que reconocen no siempre realizan de forma completa.

Parece evidente que los artistas consideran esencial el proceso de documentación de las obras como parte, en muchas ocasiones única, de la conservación de las obras. David de la Mano incluso indica que "las ciudades están más necesitadas que nunca de curadores y expertos que seleccionen artistas y que ellos lleven a cabo su obra sin condicionantes y con una libertad plena". Reproducimos el término 'curador' empleado por el propio artista, aunque no estamos de acuerdo con la españolización del término inglés por ser impreciso y poco correcto, se recomienda el uso de 'gestor cultural' o 'comisario de exposición'. Las palabras del artista hacen patente la falta de un sistema que permita tanto a los artistas como a los expertos y comunidades, llevar un registro completo de las creaciones que se están llevando a cabo en la calle. 


\section{Conclusiones}

Son varias las reflexiones que podemos extraer a raíz de conocer estos ejemplos de creación y conservación participativa, especialmente a partir de las opiniones de los propios artistas. En primer lugar, nos planteamos si en el caso de aquellas comunidades que se encargan de la propia rehabilitación del barrio, en este caso mediante iniciativas artísticas, no están ejerciendo una función que realmente debería corresponder a las instituciones pertinentes. No quiere decir esto que los vecinos pierdan el contacto con sus barrios, al contrario, las instituciones tienen una tarea pendiente al respecto, pues el trabajo en las ciudades debería ser mucho más cercano a sus habitantes y por lo tanto las actuaciones que se acometiese estarían vinculadas a los deseos y a las decisiones que tomasen las mismas comunidades. Es evidente que las propuestas más interesantes parten de los propios vecinos en muchos casos, no se trata pues de terminar con esa iniciativa, sino de que las instituciones no deleguen sus funciones. Por otra parte, cuando se trata de un movimiento vecinal, nos planteamos hasta qué punto la libertad de los artistas es plena a la hora de crear. En los casos analizados es obvio que existe tal autonomía creativa, aunque por ejemplo en el Distrito 13 de París, son los vecinos quienes eligen la propuesta que más les interesa. ¿Tienen los ciudadanos conocimientos y criterio para tomar decisiones de tal calibre? Lo cierto es que son ellos quienes van a convivir con las obras y en ocasiones se producen enfrentamientos innecesarios, como en el caso del graffiti de la rata en el Soho de Málaga, que tanto horrorizó a los vecinos de la zona. Pero, ¿no son necesarios en ciertos casos estos choques para remover algo en las personas, generar una reflexión o incluso una crítica? Podría ser el reciente caso del mural de Borondo en Berlín en el que se representa a una niña refugiada ensangrentada. Evidentemente a los vecinos no les agrada una visión tan real y de actualidad, pero probablemente sea necesario para despertar conciencias.

En este punto es donde entra el importantísimo papel del experto en la materia y es que tal y como apuntaba David de la Mano, las ciudades están necesitadas de la presencia de más profesionales de la cultura trabajando para ella. Debemos pensar que el criterio de un grupo de personas que se dedican al arte debe ser no sólo tenido en cuenta, sino que ha de ser el instrumento de trabajo que genere ciudad y establezca los criterios artísticos, aunque tampoco podemos presuponer que este criterio sea siempre acertado e infalible, por ello no proponemos que su opinión prevalezca como única e indiscutible, sino que sea el nexo de unión entre instituciones, artistas y comunidades, para llegar así a un equilibrio perfecto. Probablemente un buen ejemplo de ello sea el caso de Lisboa, donde el Ayuntamiento genera este diálogo y potencia la creación de forma que todos los sectores estén conformes.
Nos referimos siempre en este punto a obras realizadas por encargo en la ciudad, ya sea por iniciativa pública o privada, en ningún caso nos referimos a obras espontáneas de los artistas. Además ellos mismos diferencian muy bien entre los distintos tipos de obras que realizan. Cuando son encargos entienden, en el aspecto de la conservación, que al ser remuneradas los materiales empleados deben ser lo más duraderos posible; cuando son colectivas consideran que las comunidades tienen mucho que decir al respecto y que la obra deja de ser del propio artista para ser de la comunidad en cuanto está terminada; en cambio, cuando son obras espontáneas, generalmente gustan de ver su evolución que conlleva la degradación y desaparición al cabo del tiempo.

En resumen, es evidente que artistas y comunidades van por delante de las instituciones e incluso de los profesionales, que estos últimos deberían tener mucha más presencia en las ciudades, que existe una enorme necesidad de consenso entre las partes y que es necesario aportar un protocolo que permita a todas las partes implicadas documentar los procesos artísticos que se están dando en la calle de forma que la memoria no se pierda, que se promuevan los estudios académicos al respecto y el conocimiento por parte de cualquier persona interesada. Un trabajo desarrollado al respecto fue presentado en el 5th INTERNATIONAL CONFERENCE YOuth in COnservation of CUltural Heritage, 2016 por Carmen Moral Ruiz y quien escribe este trabajo, el 21 de septiembre de 2016.

\section{Notas}

[1]TRUTHBEHIND 404 (Correo electrónico, 19 de enero de 2015).

[2] 100 Architects (Correo electrónico, 15 de junio de 2016)

[3] BASURAMA (Correo electrónico, 3 de noviembre de 2014).

[4] BOA MISTURA (Correo electrónico, 30 de junio de 2014 y 16 de octubre de 2014). Grupo artístico.

[5] Asociación de Vecinos Zoes (Correo electrónico, 7 de junio de 2016)

[6] David de la Mano (Facebook, 7 de junio de 2016)

[7] Pablo S. Herrero (Correo electrónico, 8 de junio de 2016)

[8] Sabotaje al Montaje (Correo electrónico, 21 de junio de 2016)

[9] Wochenklausur (Correo electrónico, 8 de junio de 2016)

[10] BASURAMA (Correo electrónico, 3 de noviembre de 2014).

[11] BOA MISTURA (Correo electrónico 16 de octubre de 2014). 


\section{Bibliografía}

BISHOP, C. (2004). "Antagonism and relational aesthetics", October magazine, 110: 51-80.

BOA MISTURA. Tedx Madrid. 9 de octubre de 2012. Consultado el 10 de febrero de 2015. https://www.youtube.com/

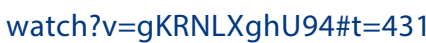

BOURRIAUD, N (2008). Estética relacional. Córdoba (Argentina): Adriana Hidalgo Editora.

DE DIEGO, E (2015). Artes visuales en occidente desde la segunda mitad del siglo XX. Madrid: Cátedra.

DEBORD, G. (1957). Informe sobre la construcción de situaciones y sobre las condiciones de la organización y la acción de la tendencia situacionista internacional. Documento Fundacional.

DOCTOR RONCERO, Rafael (coord.) (2013). Arte español contemporáneo, 1992-2013. Madrid: La Fábrica.

FERNÁNDEZ ARENAS, J. (1988). Arte efímero y espacio estético. Barcelona: Anthropos.

GRANT, K. (2011). The one contemporany art and the many in a global context. Durham: Duke University Press.

LADDAGA, R. (2006). Estética de la emergencia. Buenos Aires: Adriana Hidalgo Editora.

ORTEGA, L. "Fanzara, capital del grafiti”, El País [7 de abril de 2015], s.p.

PARCERISAS, P. (2008). “Arte y contexto. Hacia una redefinición del espacio público y el arte político", Arte, experiencias y territorios en proceso. A. de Calaf, A. de Manresa, Generalitat de Catalunya, Diputació Barcelona: 24-36.

PERNIOLA, M. (2016). El arte expandido. Madrid: Casimiro.

QUIROSA GARCÍA, V.; LUQUE RODRIGO, L. (2015). "Arte útil para la sociedad. Consideraciones entorno a seis artistas del siglo XXI en España", De arte: revista de historia del arte, 14. León: 249-261.

SANSI, R. (2014). "Arte, don y participación", Ankulegi, 18. Asociación Vasca de Antropología: 13-28.

VALERO, C. "Polémica en Berlín por un mural de una niña refugiada ensangrentada", El Mundo [22-06-2016], s.p.

VVAA. (2014). Cartas a Jóvenes artistas. Madrid: Continta me tienes.

"Los vecinos opinan sobre el grafiti de ratas del plan del Soho", El Observador [18/07/2013], s.p. (https://goo.gl/ teMqnX)

\section{Referencias Web}

Web oficial de Scarpia, http://scarpia.es/2015/ [consulta: 22/07/2016].

Web oficial de FAR (Foro de Arte Relacional), http://www. foroarterelacional.com/ [consulta: 22/07/2016].

Web oficial de 100 Architects, http://100architects.com/ [consulta: 22/07/2016].

Web oficial de Sabotaje al Montaje, http://www. sabotajealmontaje.com/ [consulta: 22/07/2016].

Blog oficial de David de la Mano, http://daviddelamano. blogspot.com.es/ [consulta: 22/07/2016].

Blog oficial de Pablo Herrero http://lasogaalcielo.blogspot. com.es/ [consulta: 22/07/2016].

Web oficial del Distrito del Arte de Miamia, http://espanol. miamiandbeaches.com/places-to-see/design-district [consulta: 22/07/2016].

Web oficial de Wochenklausur, http://www.wochenklausur.at/ [consulta: 22/07/2016].

Web oficial de la Asociación de Vecinos ZOES, Barrio del Oeste de Salamanca, https://zoes.es/ [consulta: 22/07/2016].

Web oficial de de Miau, http://miau32.wixsite.com/ miaufanzara [consulta: 22/07/2016].

Web oficial de Basurama, http://basurama.org/ [consulta: 22/07/2016].

Web oficial de Truth Behind 404, http://www.truthbehind404 com/ [consulta: 22/07/2016].

Web oficial de de Boa Mistura, http://www.boamistura.com [consulta: 22/07/2016].

Blog oficial de Miguel Ángel Moreno Carretero, http:// miguelangelmorenocarretero.blogspot.com.es/ [consulta: 22/07/2016].

Perfil en ISSU de la Galería de Arte Urbana de Lisboa, https:// issuu.com/galeriadearteurbana [consulta: 22/07/2016]. 


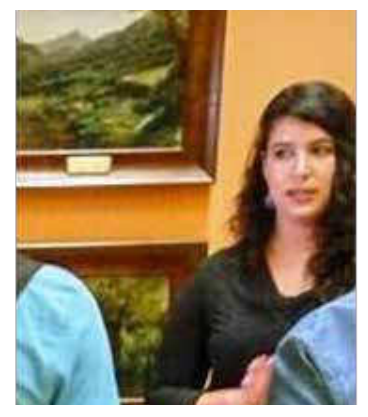

\section{Laura Luque Rodrigo}

Universidad de Jaén

lluque@ujaen.es

Doctora en Historia del Arte por la Universidad de Jaén, trabaja como profesora sustituta interina en el Área de Historia del Arte de la misma universidad. Sus investigaciones siguen dos líneas, por un lado en relación a su tesis Doctoral “Los Palacios Episcopales en Andalucía Oriental. Lecturas de Significación", sobre arquitectura de la Edad Moderna y Contemporánea y por otro, ha desarrollado otra línea vinculada al arte contemporáneo y últimamente al arte urbano. Ha trabajado en los inventarios de bienes muebles de la Catedral de Jaén, la Diputación Provincial y la Universidad de la misma ciudad. Ha participado en casi una treintena de congresos nacionales e internacionales, publicado numerosos artículos, capítulos de libro y libros. Ha participado en diversos proyectos de investigación relacionados con el arte contemporáneo y en un proyecto de innovación docente. Además ha coordinado más de veinte actividades de difusión, la mayoría relacionadas con el arte contemporáneo, entre las que se encuentra la Noche en Blanco de Jaén en sus primeras dos ediciones, Scarpia 365 y FAR. Pertenece al grupo de investigación Arquitecto Vandelvira (HUM 573) y es miembro del comité científico de la revista Galería Abierta. 
se encuentra, el uso y función que tiene dentro de éste y los alcances e impacto que tendrá nuestra intervención sobre la piezas. En este caso, el impacto de nuestra acción no solo ser verá en el objeto como tal desde el punto de vista material, sino en la manera en como lo percibirá la comunidad que convive con este tipo de obras, dado que al momento en que se considera una intervención hay una implicación de reconocimiento de valores y resignificación de la obra que le otorga nuevas características e implicaciones para su conservación y comprensión por parte del espectador.

Como lo explica Philipot: "Lo que distingue a la restauración de cualquier reparación es que se dirige a una obra de arte. Sin embargo ese reconocimiento de la obra de arte, que funda a la restauración, es claramente un momento actual, que pertenece al presente histórico del espectador-receptor. La obra de arte no deja por ello de ser reconocida como producto de una actividad humana en un tiempo dado y en un lugar dado, y por lo tanto, como un documento histórico, como un momento de pasado. Al estar presente en la experiencia actual que la reconoce como tal, la obra no puede por lo tanto ser únicamente el objeto de un conocimiento científico histórico: forma parte integrante de nuestro presente vivido, dentro de una tradición artística que nos une a ella, y permite sentirla como una interpelación del pasado dentro de nuestro presente: una voz actual en la cual resuena ese pasado." (Philipot 2015:20)

En este caso si bien el autor hace referencia a la obra de arte, es importante rescatar el enunciado que hace habla sobre el momento actual, el cual pertenece al presente histórico de quien genera y percibe la obra en cuestión por tanto, si bien el Arte Urbano no se ha considerado como tal una obra de arte en estricto sentido, sí tiene un reconocimiento social que da paso en ciertos casos a ser sujeto de una intervención, pues ya no solo es la visión del artista la que se tiene que considerar, sino también a ese espectador que vive, convive y de cierta manera consume la obra; más adelante se analizarán una serie de casos en donde se plantea la intervención y con qué objeto.

\section{Conservar Arte Urbano, ¿es posible?}

De cierta manera, la presencia de la Teoría de la Restauración, estructura la norma y ésta a su vez condiciona y establece el rigor que deberá seguirse para acercarnos al sujeto de estudio desde cualquiera de nuestras perspectivas disciplinares. Sin embargo, cuando se plantea aplicar esta teoría a las producciones del siglo $X X$ y $X X I$ se comienza a analizar de manera distinta su devenir y alcance, pues si bien, existe claridad de qué manera se establecen estas normas aún en arte moderno, cuando empezamos a hablar de arte contemporáneo el planteamiento teórico se tambalea dado que existen una serie de producciones que ponderan la experimentación, la creatividad, la innovación, la mezcla de materiales incompatibles entre sí, no necesariamente buscan la trascendencia e incluso en algunos casos, estas producciones ni siquiera contemplan la perdurabilidad ni la permanencia para futuras generaciones, sino que se centran principalmente en el momento presente. Si evaluar estas producciones artísticas en algunos casos resulta complejo, cuando se habla de Arte Urbano se vuelve prácticamente imposible encontrar un punto de comunión, un análisis siquiera posible de cómo y para qué conservarlo, pero sobre todo surge como primer cuestionamiento el por qué.

Si bien la aplicación de la Teoría de la Restauración en obras como éstas resulta contradictorio pues se trata de un tipo de producción efímera, procesual y contestataria que en muchos casos es ilegal (espontánea) o que no tiene por intención ser conservada ni restaurada (o no en la mayoría de los casos), aunado a que no considera el trascender y/o perdurar como lo haría una pintura mural por ejemplo. Estaríamos atentando de cierta manera contra sus características primarias ya por el simple hecho de considerar conservarla y hacerla trascender.

Es importante analizar cuáles son las principales características del Arte Urbano, para comprender la importancia y el impacto que tendrá nuestra intervención, por ello podemos enunciar varias: este tipo de arte plantea un reclamo del espacio público, una reapropiación de las calles, generar un vínculo hacia afuera de los espacios expositivos y hacerse presente en un contexto alternativo. Por tanto este tipo de obras son transgresoras, su producción está muy ligada al activismo y no consideran en inicio la permanencia pues al ser generalmente de producción ilegal su tiempo de vida es limitado. Además es justo ese carácter sorpresivo y de apropiación del espacio. "En ocasiones se trata de trabajos planeados y materializados con elementos que están ligados a la localización, historia o caracterización social de sitios específicos, o desde luego, a las fantasías propias de los autores" (Arroyo 2015:276).

Por su parte, el Arte Urbano es considerado como una derivación del Street Art pues generalmente se refiere a aquellas producciones artísticas ubicadas en el espacio público producto de comisiones y/o festivales patrocinados, aunque hay casos en donde se integran también producciones ilegales y/o espontáneas. En muchos casos buscan transmitir mensajes directos que no solo se queden en el contexto callejero sino que trascienden hacia otros foros. "Muchos de estos mensajes quedan referidos como una denuncia, que en el momento en que fue realizada tal vez hubiese querido ser un fuerte grito de inconformidad" (Marcial 2012:310)

Partiendo de estas prerrogativas, quizá hablar de arte urbano y conservación-restauración dentro de un mismo enunciado resulta paradójico y cuestionable, ¿quién decide qué y cómo debe de conservarse? ¿Se hace una acción directa o solo se documenta? ¿Quién lo hace, un 
restaurador o el artista? Estas y otras tantas preguntas nos surgen al momento de siquiera considerar conservarlas.

\section{Principales factores de deterioro que determinan una posible conservación}

Antes de dar paso a la revisión de casos en donde las obras de Arte Urbano han sido intervenidas, vale la pena revisar cuáles son los factores de deterioro más comunes a los que están expuestas este tipo de manifestaciones artísticas y que por ende dan paso a la consideración de conservarlas y/o restaurarlas, aunado a la relevancia que tienen los artistas que la crearon. Se dará un panorama general de los deterioros vinculados al arte urbano para contextualizar la motivación que da paso una intervención, pues si bien estos dependen también del contexto y la técnica de manufactura con la que fueron realizados, existen una serie de deterioros comunes.

Uno de los deterioros más frecuentes es el vandalismo. Es curioso cómo dentro de la misma dinámica procesual y de creación, algunos artistas consideran que el trabajo de sus colegas no es digno de apreciarse al punto de que se "pisan" entre sí como una manera de demostrar su desacuerdo con la obra en cuestión. De acuerdo con la RAE, el vandalismo es cuando emerge el "Espíritu de destrucción que no respeta cosa alguna, sagrada ni profana." $Y$ es que estas acciones de cierta manera destruyen la obra materia y visualmente.

Estos actos no se limitan a la invasión con pintura o algún otro material (pinturas, aerosol, stickers, incisiones, manchas de pintura, entre otros) a fin de destruir o alterar la imagen, a veces llevan a cabo incisiones, rayones e incluso desprendimientos de la obra a fin de que desaparezca. [Figuras 1 y 2]

La intemperización de los materiales constitutivos. Este es un factor de deterioro inminente en el contexto callejero pues el impacto que tienen los agentes medioambientales sobre este

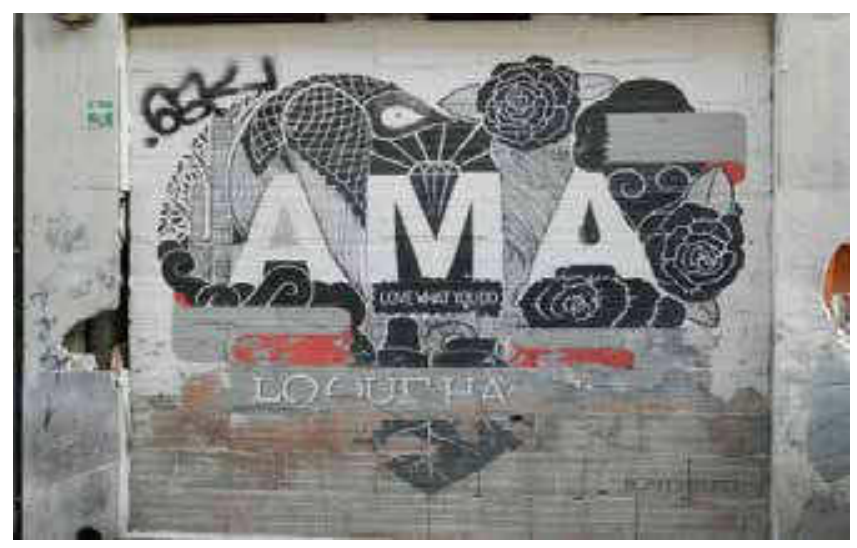

Figura 1. Graffiti sobre la obra de BoaMistura, (Madrid). Fotografía Ana Lizeth Mata Delgado.

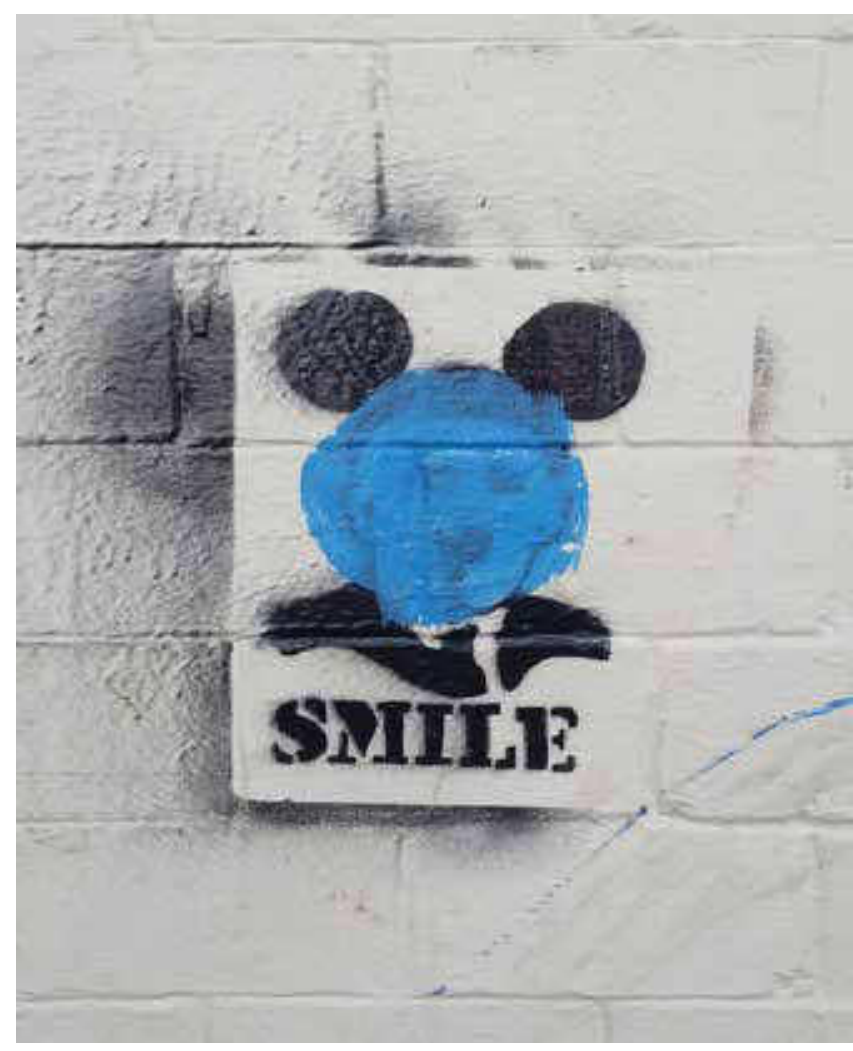

Figura 2. Colocación de pintura sobre stencil, artista desconocido, (CDMX). Fotografía Ana Lizeth Mata Delgado.

tipo de obras es constante, agresivo y genera daños que en otro tipo de contexto (espacios cerrados, museos, galerías, etc.) no se consideran. Deterioros como decoloración, escamación de capas pictóricas, abrasión, grietas, craqueladuras, pulverulencia, pérdida de adhesividad (en el caso de los stickers), manchas y desprendimientos son algunos de los deterioros que encontraremos en este tipo de obras y que en cualquier otro tipo de creación artística (a menos que lo consideren como un factor estético) sería factible de tratar por un profesional en el campo de la conservación. [Figuras 3 y 4 ]

Los desprendimientos y/o arranques de las obras de su contexto original; cada vez más se convierten en un método recurrente en los cuales se expolia la pieza para ser vendida o llevada a un contexto de galería o museo para el cual no fue creada. Es importante aclarar que si bien no aplica en todos los casos, cada vez más se observa esta acción como una manera de "conservar" la obra, descontextualizándola para ser insertada en un ambiente ajeno que termina por musealizar el objeto. Lo más grave es que en la mayoría de los casos el autor no está enterado y/o no ha dado su consentimiento.

Ejemplo de esto, fue el escándalo que se desató en 2013 por el arranque de la obra de Bansky ubicado en la calle principal de Wood Green, en el noroeste de Londres, el 14 de mayo de 2012, la obra titulada Slave Labour la cual hacía una crítica de la esclavitud infantil. Esta obra generó tal expectativa y apropiación por parte de la comunidad que incluso a la salida del metro se pusieron indicadores 


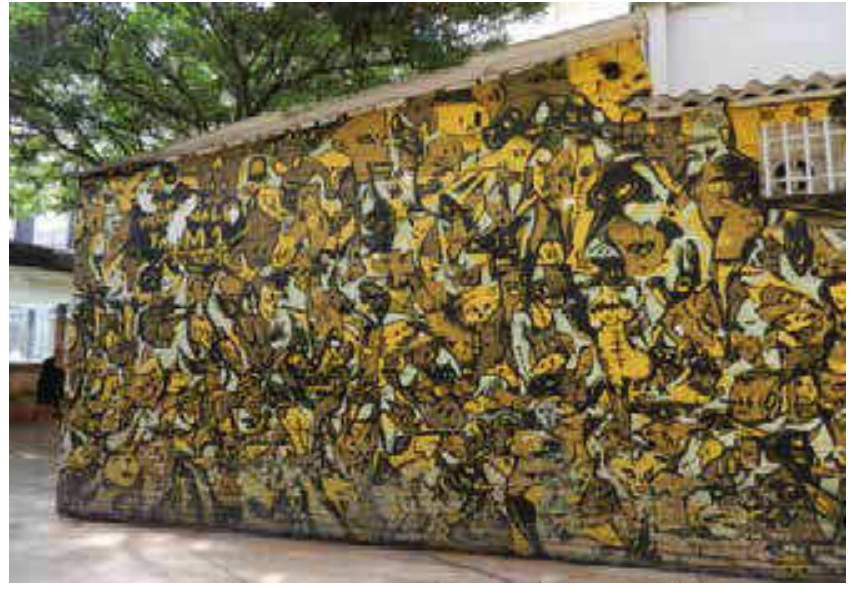

Figura 3. Abrasión y pérdida de capa pictórica. FASIM 1 (Valencia, España). Fotografía Ana Lizeth Mata Delgado.

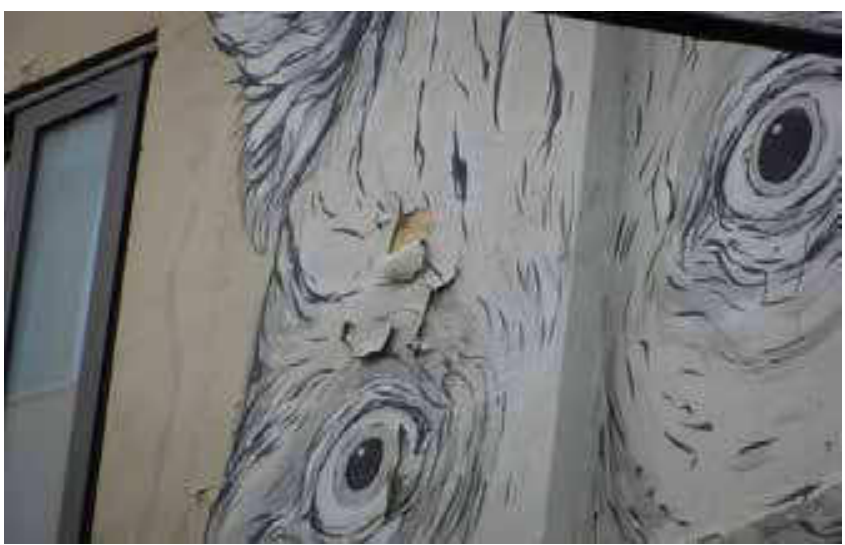

Figura 4. Detalle de escamación de capa pictórica, (Valencia, España). Fotografía Ana Lizeth Mata Delgado.

para que la gente supiera hacia dónde se encontraba y el transeúnte pudiera visitarla. Sin embargo, en 2013 esta obra fue arrancada sin ningún tipo de permiso, dando paso a un fuerte controversia pues horas después fue localizada en el catálogo de la casa de subastas Miami Fine Art Auctions para ser vendida. Este caso refleja claramente el interés no solo en la propuesta artística y el discurso planteado por el artista, también refiere al provecho que buscan extraer algunas personas con la venta de este tipo de obras, generalmente sin la autorización del artista. [Fig. 5]

Lo cuestionable en estos casos en sin duda la manera de eliminar y/o desaparecer una obra del contexto público, pues si bien está al alcance de todos, no significa que alguien tenga el derecho de sustraerla para beneficio personal y sin consultar ni considerar al creador.

\section{Alternativas de conservación}

A continuación se presentarán una serie de casos que ejemplifican las distintas alternativas con las que han sido intervenidos, lo interesante aquí es por quién, para qué y cómo han sido conservados. Partamos de una categorización previa de los alcances de estas intervenciones equiparando de cierta manera los principios de la Teoría de la Restauración y los alcances que ésta puede tener sobre el arte urbano.

Se pueden considerar tres momentos: documentación, conservación preventiva que podría equipararse a la mínima intervención necesaria y restauración. Finalmente en algunos casos se ha considerado también la reproducción de las obras cuando se tiene la documentación e información necesaria para llevarlo a cabo.

Una de las acciones de conservación más recurrentes desde los inicios de este movimiento artístico es la documentación, la cual se mantiene hasta ahora, cabe señalar que ésta no necesariamente la llevan a cabo profesionales en el campo de la conservación, sino desde sus inicios el graffiti neoyorquino comienza realizando fotografía de la imagen casi sin ningún tipo de texto explicativo. Actualmente existen textos especializados
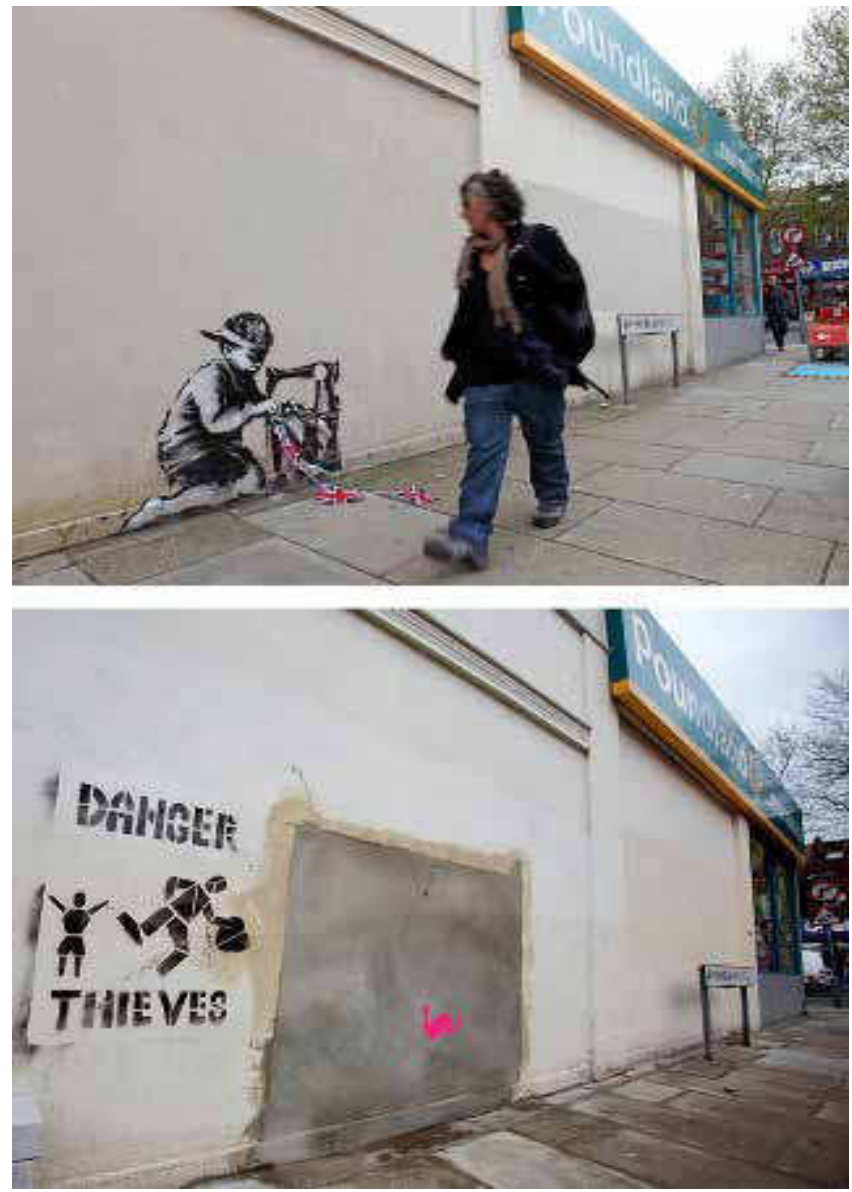

Figura 5. Banksy, Slave Labour. Wood Green, Haringey, Londres. Mayo de 2012 y su desaparición en 2013. Fotografía tomada de: http://www.elconfidencial.com/cultura/2013-06-01/londres-selevanta-en-armas-contra-la-venta-de-su-banksy_735833/ 
que no solo se basan en la imagen capturada sino que se trata de publicaciones especializadas en su investigación, sin embargo, desde la aparición de los teléfonos móviles inteligentes y otros dispositivos digitales como son las tablets, ipads, las cámaras de fotografía digital, por mencionar algunos, no solo es el artista o estudiosos del tema los que llevan a cabo el registro, sino el espectador, el ciudadano de a pie que se encuentra por casualidad y al que le resulta interesante, atractiva, curiosa, etc. una obra, acto seguido lleva a cabo un registro que compare en las redes sociales, nutriendo las páginas web de los creadores, compartiendo y difundiendo una obra de arte urbano, tenga o no la intención de ser conservada y/o restaurada materialmente. Esta manera de trascender es más sencilla, fácil y sobre todo masiva, actualmente existe millones de plataformas en la red que abordan a este tipo de producciones artísticas (Street Art, Graffiti, Arte Urbano, entre otros) las cuales siguen creciendo cada minuto.

La documentación se centra primordialmente en el registro fotográfico, pero también se puede considerar aquellas iniciativas que plantean cartografías de localización en donde se pueda ubicar la obra, su ubicación y una fotografía, tal es el caso de iniciativas como Street Art Chilango en la Ciudad de México o Madrid Street Art Project, por mencionar algunos. "Muchos de esos sitios no se limitan al hecho de documentar, sino además ofrecen recorridos virtuales o de forma presencial, usando los geolocalizadores para compartir la ubicación de las obras. En esos mapas suele mostrarse información sobre el artista y la ubicación, además de una imagen general de referencia." (Mata 2016:s/p)

Cabe mencionar que a pesar de que este fenómeno mediático que ha cobrado fuerza estos últimos años, la documentación de Graffitti como tal comenzó desde los años ochenta, pues fotógrafos como Martha Cooper y Henry Chalfant elaboraron un libro fundamental para el conocimiento y comprensión de éste titulado Subway Art, de 1984, considerado uno de los mayores exponentes publicados sobre este tema, con este texto se da inicio a una serie de documentos escritos y digitales enfocados al estudio de estas manifestaciones. A la fecha se han publicado un sinfín de textos especializados en el tema, lo que habla de un interés no solo por su difusión sino por su investigación, que a su vez ha servido para que sea asumido y comprendido como un fenómeno artístico actual que se desarrolla de manera paralela y del cual aún existen cuestionamientos sobre si debe o no conservarse, cómo y para qué o para quién.

La segunda categorización en la cual podemos hablar de una conservación preventiva en muchos casos está enfocada solo a la mera remoción de material ajeno a la obra para evitar su deterioro y promover su permanencia, en algunos caso se usan brochas, esponjas, o algún otro tipo de materiales de limpieza sin llevar a cabo una limpieza y/o intervención más profunda. Cabe señalar que ese tipo de intervenciones no solo se han registrado por parte de

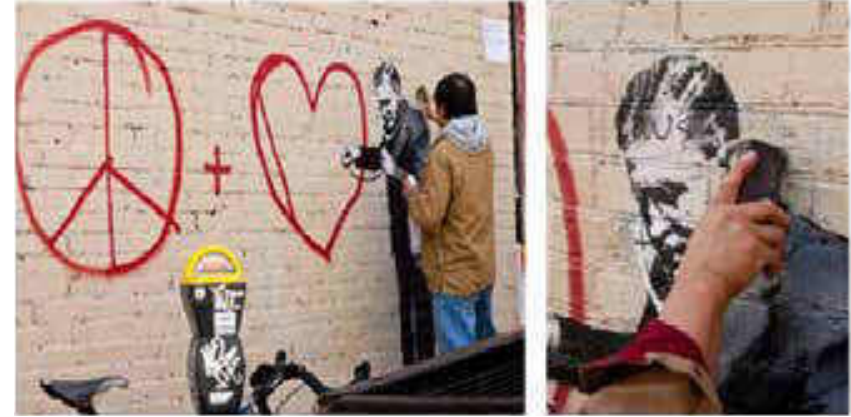

Figura 6. Limpieza de graffitis sobre la obra Peaceful Hearts de Banksy (Chinatown, San Francisco, CA). Fotografía D_Serna aka Tweak SF, tomada de http://warholian.com/2010/04/banksy-defaced-in-chinatown-warholian-san-francisco/

los conservadores sino en algunos casos son realizados por la comunidad, quien a fin de mantener estable la obra lleva a cabo estas labores. Esto nos habla ya de un reconocimiento y apropiación, sin embargo, la conciencia de aplicar un proceso basado en la mínima intervención necesaria, no está presente en sentido estricto. [Fig. 6]

Otra de las estrategias de conservación preventiva más recurrentes de conservación es la colocación de una placa de plexiglás o policarbonato al frente de la obra, atornillada al muro que contiene la obra.

Esto con la intención de que no la "pisen" otros artistas, la borren o sea dañada por los agentes medioambientales. Algunos de los artistas cuyas obras se han buscado conservar son primordialmente aquellos que representan un interés económico y de relevancia por su propuesta artística, como Blek le Rat y Banksy por mencionar algunos, pues más allá de la opinión de los creadores, son las personas cercanas y vinculadas a sus obras las que por conocimiento de su trabajo, el valor económico de las mismas o simplemente por un gusto, buscan protegerlas a fin de que se mantengan en las mejores condiciones posibles. [Fig. 7]

Esta acción de conservación se ha puesto sobre la mesa para ser cuestionada, dado que al momento de agregar un material ajeno a la obra e incluso al contexto, se hace referencia a dos cosas primordialmente: en primer lugar, al posible daño que pueda generarse por el microclima del entre el muro y el material plástico, además del daño a la estructura del muro que contiene a la obra como consecuencia de taladrar para sujetar el acrílico, y en segundo lugar, a la nueva visibilidad que se le da a la obra en cuestión, pues no sólo será percibida de forma distinta por el espectador, sino que se convierte en un punto focal para determinar que esa obra es valiosa y por tanto puede ser factible de robo o arranque en el peor de los casos. Esta tipo de actividad debe ser analizada si es necesaria antes de ser aplicada.

En el caso de obras que han sido restauradas podemos considerar un caso representativo en la obra de Black Le Rat, 


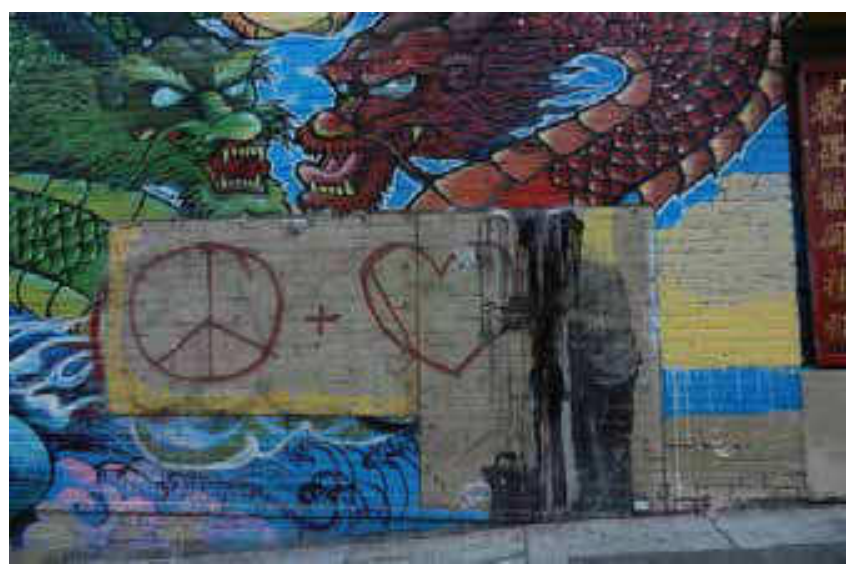

Figura 7. Peaceful Hearts de Banksy (Chinatown, San Francisco, CA). Protección con plexiglás, deterioro directo sobre la placa (2013), Fotografía Ana Lizeth Mata Delgado

Madona con niño creada en Alemania en la década de los años noventa. Esa obra fue descubierta en 2012 debajo de una serie de posters. Sin embargo, fue Maxi Kretzschmar, fue quien identificó y promovió que la obra fuese restaurada por un equipo de restauradores profesionales, incluso contaron con la participación del artista para ello. Curiosamente la obra no solo fue restaurada sino protegida de igual manera que los casos anteriores por un plexiglás para evitar que sea dañada de nuevo. Cabe señalar que le fue colocada una cédula informativa. (Schilling, 2012). [Fig. 8] Lo interesante en este caso, no es solo que la obra se haya considerado restaurar, sino que además fue realizada por profesionales en el campo con experiencia y por consecuencia quizá su intervención fue más apegada a los criterios usados en la pintura mural tradicional. Aunado a que el artista estuvo de acuerdo en la conservación de la misma. Este caso es relevante no solo por la intervención y los involucrados, sino porque además pasó a formar parte de la lista de obras relevantes de la ciudad, dando paso a la resignificación de la obra.

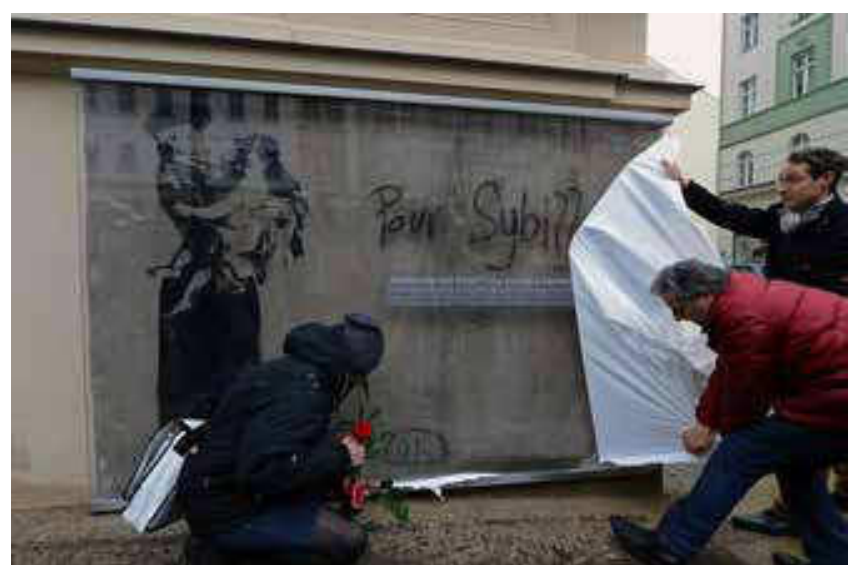

Figura 8. Blek Le Rat's «Madonna and Child» is back. photo: Hendrik Schmidt. Fotografía tomada de https://artsation.com/en/journal/ editorial/blek-le-rat-in-leipzig
Finalmente para dar cabida a las diversas alternativas de intervención, se considera la reposición como una opción si la obra se ha perdido por completo. Esta decisión debe de analizarse desde varias perspectivas pues es a partir de la relevancia de la obra, el productor, el contexto y el impacto que esta tiene en el entorno que la contiene e incluso la trascendencia como producción artística, es que se puede considerar como una alternativa viable.

Para ejemplificar esta alternativa se abordará el caso del mural Keith Haring pintó en Barcelona en el año de 1989 Todos juntos podemos parar el sida el cual realizó en el barrio del Raval, conocido entonces como el "Barrio Chino". Pese a la relevancia del artista para ese momento, la obra no tuvo un mantenimiento adecuado que promoviera su conservación y además el muro en donde fue creado sería demolido por la puesta en marcha Plan Especial de Reforma Interior del barrio del Raval. Debido a esta circunstancia a esta circunstancia, los responsables de obra de Haring y el Museo de Arte Contemporáneo de Barcelona (MACBA), en colaboración con el Ayuntamiento de Barcelona iniciaron el 1992 la calca de la obra y la toma de muestras del tipo de pintura con la que fue realizada para dar paso en un futuro a la reproducción de la misma.

Esta obra se ha reproducido en tres ocasiones (1996, 1998, 2014) en un muro de hormigón al exterior del MACBA, quedando a la vista de todos y si bien cambió de contexto, sigue cumpliendo con la función de transmitir un mensaje por demás relevante para la comunidad, pues esta obra no solo habla de su trabajo sino de la situación sanitaria que aquejaba al mundo en la década de los años ochenta, el impacto y relevancia que tuvo la presencia del artista y de la obra dentro de la ciudad y la trascendencia de la misma. (http://www.macba.cat/es/todos-juntos-podemos-pararel-sida-1465 [consultado 11/10/2016])

Es interesante analizar una opción como esta, pues si bien es una ganancia que la obra perdure y mantenga el diseño intacto e incluso se haya podido utilizar el mismo tipo de pintura para dar continuidad y autenticidad a la misma, el contexto en el que ahora se encuentra tiene un impacto diferente quizá en la significación de la obra. Para Haring la elección del sitio para pintarla no fue fortuito, eligió un sitio en donde diariamente aparecían jeringuillas y que le recordaban a los barrios de Nueva York, en donde además el muro donde fue realizado presentaba una inclinación importante que implicaba una adaptación anatómica por parte del artista para poder llevarla a cabo.

Ahora el espacio abierto en el que se encuentra la obra no tiene ninguna estas dos circunstancias, sin embargo lo importante aquí es la permanencia del mensaje a través de la reproducción del mural. [Fig. 9]

Es interesante cómo a pesar de que no se considera que este tipo de obras trasciendan o se conserven desde inicio, si hay una conciencia por parte de algunos artistas $y / o$ profesionales del campo de la restauración y afines, para que 


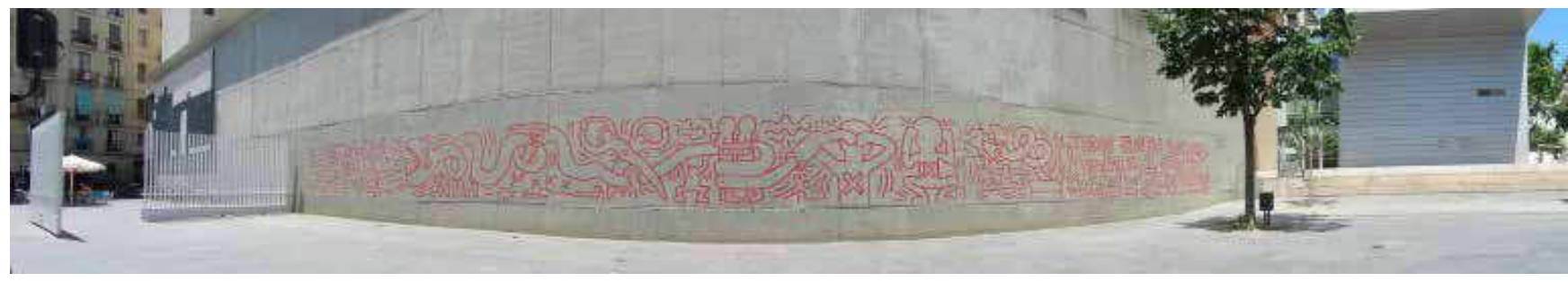

Figura 9. Todos juntos podemos para el sida, Keith Haring, 1989. Reproducción del mural explanada del MACBA (Barcelona, España). Fotografías Ana Lizeth Mata Delgado

la obra se mantenga en buen estado el mayor tiempo posible. En el caso de algunos artistas tienen contemplado desde el sitio donde la elaborarán hasta el material que usarán, cabe mencionar que actualmente existe una gama importante de materiales realizados exprofeso para la elaboración de arte urbano. "En lo que se refiere al Street Art y al Graffitti, la elección de materiales y el contexto donde se desarrollan juegan un papel fundamental para complementar su significado y el concepto que el artista proporcionó en un inicio, además de que en muchos casos no es una obra concluida sino que puede complementarse con diversas intervenciones de distintas temporalidades sino que pueden ser realizadas por otros artistas." (Mata 2013:3)

Incluso algunos consideran que esto puede ser necesario y fomentan su trascendencia, como lo comenta Abarca "alargar la vida de sus obras dentro de lo que las circunstancias lo permiten" (Abarca 2010: 90).

No obstante, es normal y derivativo que sea el entorno urbano el que plantee una serie de cambios y alteraciones sobre las obras, como bien comenta Anna Waclawek, esta interacción plantea una constante transformación que modifica y en algunos casos resignifica la obra.

"El proceso de nacimiento y muerte de una obra callejera en el contexto de la ciudad, atrae a muchos artistas por razones conceptuales y estructurales. [...] La experiencia [del Street Art] como un proceso transitorio está inextricablemente ligado al significado de la obra como un elemento de la composición cambiante de la ciudad. [...] La temporalidad del Street Art por lo tanto, traduce visualmente la experiencia de ser parte de la materia constitutiva de la ciudad." (Waclawek 2011: 91).

\section{Conclusiones}

Los posibles cruces entre la Teoría de la Restauración y el Arte Urbano aún no son del todo claros, pues dependerá del caso a tratar y de la manera en cómo sea abordado y por quién lo que determinará esta intersección. Sin embargo, es interesante como durante el análisis de las posibles alternativas y alcances que se tienen para conservar el arte urbano, podemos observar que no es una tarea ajena al campo disciplinar, por el contrario, cada vez los conservadores-restauradores se están involucrando a participar en la intervención de este tipo de manifestaciones artísticas e incluso a proponer alternativas para su conservación y/o restauración. Además de las intervenciones directas, cada vez más se desarrollan grupos de trabajo e investigación en torno al tema constituyéndose no solo por artistas y/o restauradores, sino en conjunto con otras disciplinas como la antropología, la sociología, la gestión o la curaduría por mencionar algunas, dando paso a nutridas discusiones en torno al tema.

En los casos mostrados para las cuatro alternativas de conservación propuestas, se plantea que en al menos dos de ellas ya sean restauradores profesionales los que se están involucrando en la ejecución de los procesos, incluso en algunos casos con la ayuda del artista como Blak le Rat en el caso de la Madona con el niño o en la reproducción de la obra de Keith Haring Todos juntos podemos parar el sida.

Es importante, tomar en cuenta que el arte urbano ha tenido que adaptarse a las nuevas tendencias no solo de su propio quehacer sino de aquellas disciplinas alrededor de ella en donde la perspectiva sobre su existencia ha cambiado, ya no solo se plantean la desaparición de inicio, sino que su proyección, aceptación, comprensión e incluso el interés que se tiene en ellas ha dado paso para tener una nueva perspectiva. Si bien, conservarlas y/o restaurarlas pareciera una afrenta directa a su propia naturaleza, también es cierto que no han tenido el suficiente espacio temporal para que se puedan visualizar de otra manera, no solo desde la perspectiva y relevancia del artista, sino desde la manufactura involucrada, la mezcla de materiales, el contexto, la importancia del tema o el impacto en la trasmisión del mensaje; sino como un documento que aportará información relevante al futuro sobre el tipo de manifestaciones artísticas desarrolladas en un periodo específico.

Una de las principales problemáticas a las que se enfrenta el conservador-restaurador es la diversidad material en la producción de arte urbano es por ello que resulta fundamental conocer y comprender los alcances y limitaciones de la disciplina ante este tipo de obras. De ahí también deriva el análisis sobre cuáles serían los criterios de intervención que tendrían que aplicarse para la conservación-restauración de estas obras.

Una alternativa que permite conservar la obra sin alterar su naturaleza efímera, procesual y transgresora como se 
mencionó antes, es quizá la documentación; puede ser una alternativa intermedia entre que desaparezcan y no quede ninguna referencia de la obra más que apelar a la memoria de quienes la conocieron versus la restauración de la misma, interviniendo cabalmente la materia que la conforma e inmortalizando aquello que fue creado para tener una existencia breve pero trascendental. Como lo comenta De la Rubia "A veces el punto medio ante discrepancias de este tipo se basará en tomar medidas plenamente preventivas, que ayuden a frenar el deterioro natural, pero sin intención de acabar con éste y asumiendo que la obra debe desaparecer" (De la Rubia 2013: 44).

En unos años podremos mirar al pasado y evaluar qué alternativa funcionó mejor, pero por lo pronto aprovechemos los nuevos recursos tecnológicos para documentar las obras, complementando idealmente con la opinión del artista a partir de realizar una entrevista con él (ella) para comprender adecuadamente cada una de las producciones artísticas vinculadas al arte urbano y hacer que nuestro proceder cualquiera que este sea, esté sustentado adecuadamente.

Una vez analizadas las diversas alternativas de conservación para el arte urbano, es pertinente e importante analizar de qué manera estamos asumiendo y comprendiendo la producción de arte urbano, ¿es la intervención directa, la manera correcta de conservarla? ¿Debemos dejar que la obra siga su curso, a pesar de que resulte relevante e importante para un público o una comunidad específicos? Quizá si buscáramos poner en balanza a la disciplina profesional de la restauración con el arte urbano, se podría pensar que el criterio usado más adecuado considerando sus características primarias es la "mínima intervención necesaria" no obstante, ¿qué tan válido es contener el proceso de degradación natural de la obra? ¿Es factible limitar su interacción con el contexto circundante e incluso el diálogo que establece de forma directa con las obras de otros artistas cercanos a fin de que se mantenga en las mejores condiciones posibles? Estos y otros cuestionamientos surgirán mientras no se determine claramente hasta donde es factible conservar y/o restaurar de esta naturaleza sin contrarrestar su origen e intención.

Para finalizar me parece importante plantear que la aplicación de criterios, se enfocará más en el planteamiento teórico y ético del hecho en sí mismo de restaurar o no, que en la manera de llevarlo a cabo, pues quizá los procesos técnicos no cambien radicalmente en la ejecución, sino más bien es la toma de decisión, la metodología planteada y los alcances de nuestra interacción con la obra desde el punto de vista de la disciplina.

\section{Bibliografia:}

ABARCA S. F. J. (2010). El postgraffiti, su escenario y sus raíces: graffiti, punk, skate y contrapublicidad, Tesis de Doctorado. Madrid: Facultad de Bellas Artes de la Universidad Complutense de Madrid.
ARROYO, S. R. (2015). CODEX Una aproximación al grafiti de la Ciudad de México. México: CONACULTA, TURNER.

MARCIAL, R. (2012)“El graffiti como discurso gráfico en la disidencia juvenil" en Pura imagen. Sarah Corona Berkin (coord.). México: CONACULTA

WACLAWEK, A. (2011). Graffiti and Street Art. Londres: Thames \& Hudson.

\section{Vinculos web}

DE LA RUBIA LÓPEZ, E. (2013). Arte urbano: graffiti y postgraffiti. Acercamiento a la problemática legal y patrimonial en torno a su conservación.TesisFinaldeMásterenConservacióny Restauraciónde Bienes Culturales, Universidad Politécnica de Valencia. Dirigida por Rosario Llamas Pacheco y Mercedes Sánchez Pons. PDF disponible en: http://riunet.upv.es/bitstream/handle/10251/39193/TESIS\%20 FINAL.pdf?sequence=1\&isAllowed $=y$ [consulta: 20/08/2016].

MATA DELGADO A. L., (2013) “Conservando el Street Art \& Graffiti, la pertinencia de su conservación y la problemática material derivada de su técnica de manufactura" en Memorias del X Foro Académico ECRO. Documento electrónico disponible en http://www.ecro.edu. mx/memorias_x_foro.html [consulta: 20/08/2016]

MATA DELGADO A. L. (2016). "Cartografías del arte urbano: su localización como medio de difusión, registro y conservación" en Archivo Churubusco. México: ENCRyM-INAH http:// archivochurubusco.encrym.edu.mx/cartografia.html [consultado 25/09/2016]

PHILIPOT, P. (2015). "La obra de arte, el tiempo y la restauración" en Conversaciones con Paul Phillipot. Revista de Conservación. México: CNCPC-INAH http://conservacion.inah.gob.mx/ publicaciones/?cat=350 [consultada 26/09/2016]

SCHILLING, J. (2012). "Preserving art that was never meant to last", Deutsche Welle, 7 de mayo de 2012. Disponible en: http://www. dw.de/preserving-art-that-was-never-meant-to-last/a-15933463 [consulta 10]/09/2016].

http://cultura.elpais.com/cultura/2013/06/03/ actualidad/1370285346_249416.html [consultado 9/09/2016]

http://scottreither.com/blogwp/2012/10/18/dear-banksy/ [consultado 25/09/2016]

http://warholian.com/2010/04/banksy-defaced-in-chinatownwarholian-san-francisco/ [consultado 25/09/2016]

https://artsation.com/en/journal/editorial/blek-le-rat-in-leipzig [consultado 20/09/2016]

https://www.youtube.com/watch?v=T-sEg_b3Fic [consultado 23/09/2017]

http://www.macba.cat/es/todos-juntos-podemos-parar-elsida-1465 [consultado 23/09/2016] 
http://ccaa.elpais.com/ccaa/2014/02/27/

catalunya/1393535246_601176.html [consultado 11/10/2016]

h t t p: / / c caa.elpais.com/ccaa/2014/02/2 7 /

catalunya/1393535246_601176.html [consultada el 12/10/2016]

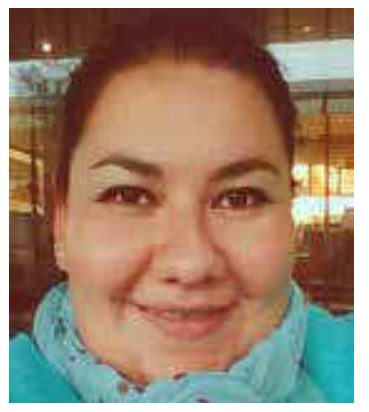

\author{
Ana Lizeth Mata Delgado \\ ENCRyM-INAH \\ lizeth_matadelgado@yahoo.com.mx
}

Licenciada en Restauración de Bienes Muebles por la Escuela Nacional de Conservación, Restauración y Museografía-INAH. Profesora titular del Seminario Taller de Restauración de Obra Moderna y Contemporánea en la ENCRyM-INAH. Maestrante de Historia del Arte por la Universidad Nacional Autónoma de México con especialidad en Arte Contemporáneo. Ponente en diversos foros de especialidad nacionales e internacionales (EUA, Argentina, Chile, España) en conservación-restauración de arte contemporáneo y arte urbano. Organizadora de los Cursos de Restauración de Arte Moderno y Contemporáneo llevados a cabo en la ENCRyM en colaboración con el MoMA de Nueva York en 2008 y 2010, respectivamente. En 2011 y 2013 impartió y coordinó el Curso Introductorio a la Restauración de Arte Moderno y Contemporáneo para el personal del CENCROPAM-INBA. Co-coordinó el 1er. Encuentro de INCCA (International Network for Conservation of Contemporary Art) en México, la conformación de la Red lberoamericana. El Encuentro de Conservación de Street Art y Graffiti en 2013 y el Encuentro Estrategias de Conservación en Arte Contemporáneo en colaboración con el MUAC-UNAM y Fundación Jumex Arte Contemporáneo en 2014. En 2015 coordinó e impartió el curso “Una década conservando el arte contemporáneo" en colaboración con el Museo de Arte Contemporáneo de Barcelona y las conferencias "Entre restauradores te veas. Charlando con artistas contemporáneos sobre restauración". En ese mismo año llevó a cabo una estancia de investigación en torno a la conservación de arte contemporáneo en el Museo Nacional Centro de Arte Reina Sofía en Madrid, España.

Es miembro del International Network for Conservation of Contemporary Art, del Grupo de Arte Urbano del Grupo Español del IIC y de la Red Iberoamericana de Restauración de Arte Contemporáneo. 


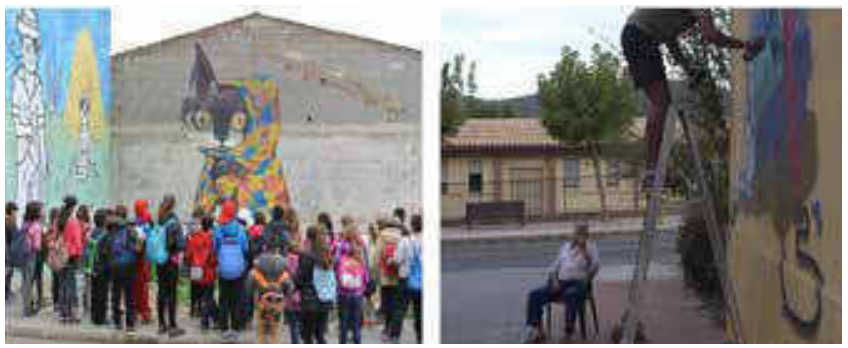

Figura 1. Grupo de alumnos/as del CEIP Pinar Grao de Castellón frente al mural de Bibbito y Thiago Goms. Vecino y perro a la fresca mientras se pinta mural. Fotos: M.I.A.U (1a) y Rafa Gascó.

Se trata de un museo situado en las calles del pueblo, gratuito y de libre acceso, organizado por amor al arte y sin contraprestaciones. La asociación M.I.A.U. y el Colectivo G.U.A.U. (Gestores Universales de Arte Urbano) son fundamentales en este sentido, así como la difusión online a través de su web, Facebook o Twitter, en la que se comparten noticias, imágenes, y en la que es posible adquirir productos través de la tienda online o la descarga del plano y programación. Materializado gracias al esfuerzo y a la ilusión, y bajo el lema Tomar y hacer, en lugar de pedir y esperar, cuenta con recursos económicos muy limitados, así como con la participación de diversas instituciones y empresas ${ }^{1}$.

Abiertos a la colaboración e implicados en diversas iniciativas socioculturales, se mantienen en contacto con artistas, críticos, así como con otros certámenes, siendo numerosos los medios nacionales e internacionales de prestigio que se han hecho eco de este proyecto. Pues, la repercusión que dicha iniciativa está teniendo para este pequeño pueblo del Alto Mijares ha superado todas las expectativas planteadas inicialmente. En reconocimiento de su labor, acaban de recibir los Premios Arte Blanco Pilares de la Cultura Provincia de Castellón 2016 IV edición (M.I.A.U. 2016).

Si nos centramos en las diferentes manifestaciones artísticas, cabe señalar que fueron concebidas a priori como efímeras, en las que su pervivencia o contemplación se encuentra relacionada con la necesidad de nuevos espacios sobre los que crear o en función de su propio estado de
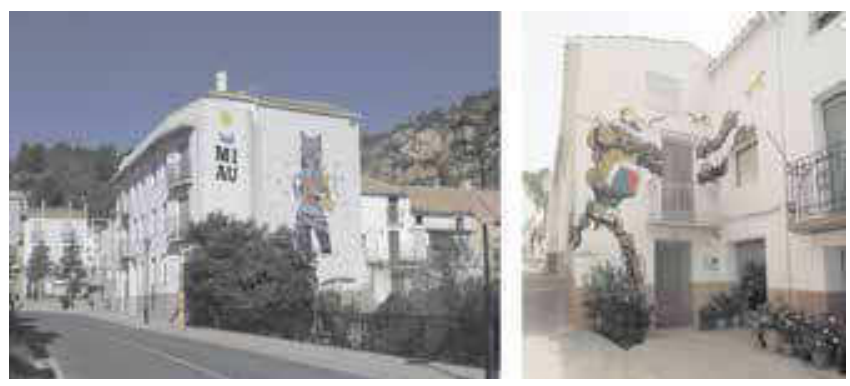

Figura 2. Logo del M.I.A.U y mural de DEIH a la entrada de Fanzara. Foto: Rafa Gascó. Obra de Xèlön adaptándose a la estructura de una vivienda. Foto: Mayte Pastor. conservación. No obstante, el carácter social del M.I.A.U. está provocando que la propia comunidad interiorice algunas obras dotándolas de unos valores propios que las convierten en representativas, lo cual está llegando a plantear la necesidad de su conservación futura. En este sentido, creemos necesario recabar la mayor información posible sobre las técnicas y materiales empleados.

\section{Selección de artistas y obras}

Tras tres años de búsqueda, espera y esfuerzo, aquel sueño del M.I.A.U. se hizo realidad en el verano de 2014 gracias al ayuntamiento y al inestimable apoyo del artista Miguel Abellán "Pincho", quien pronto implicó a otros artistas urbanos en este proyecto social. Su visita, junto a la de Sabek y Ruina, junto al contacto con la asociación Murmurs fueron decisivas en este sentido. $Y$ por supuesto, la implicación de vecinos y artistas, que hoy forman una gran familia. Así, sin casi creerlo, en aquella primera edición del M.I.A.U. se contó con la participación de veintiún artistas que realizaron cuarenta y cuatro intervenciones ${ }^{2}$. El logo de Pincho y la gata de DEIH, hijo predilecto de Fanzara, nos reciben a la entrada del pueblo [Figura 2a].

En la segunda edición, se pidió a los 21 artistas participantes del año anterior que propusieran a otros artistas que encajaran en el proyecto, realizando una selección. En la edición del corriente año 2016, la participación ha venido dada por un sistema de selección doble. Por una parte se ha contado con las propuestas de los artistas participantes en años anteriores y por otro, se ha realizado una convocatoria de participación abierta a nuevos creadores. Tal y como nos indican desde la organización, al tratarse de un museo, se busca la calidad y variedad, incluyendo nuevas propuestas que completen la colección artística urbana del M.I.A.U. Además de la ejecución de murales se ha contado con diversas intervenciones artísticas realizadas con materiales de reciclaje y basura, etc.

La siguiente tabla corresponde a los requisitos que se solicitaron a todos los artistas interesados en participar en el proyecto del M.I.A.U. 2016 y que transcribimos literalmente en el presente artículo (M.I.A.U. 2016). Como podemos observar, los valores de convivencia e intercambio a través del uso social del espacio quedan plasmados en esta propuesta [Tabla 1].

Al tomar como fuente los mapas y programas difundidos por la organización, se constata un crecimiento exponencial de las propuestas en solo tres años. En la actualidad el M.I.A.U. cuenta con la representación de artistas de talla nacional e internacional: Acció Poètica La Plana, Ana Pez, Animalito Land, Bibbito, Borondo, BTOY, Cere, Chylo, Col.lectiu Paral.lel, Collettivo FX, Costi, DEIH, Dingoperromundo, Escif, Emilio Cerezo, Gael, GR170, Hombre López, Hyuro, H101, llia Mayer, Isaac Mahow, Joan Tarragó, Joaquín Jara, Julieta XLF, Julián Arranz, Kenor, Laguna, Lolo, Luis Montolio, Martin Firrell, Natxuta, 
Que se adapten al medio, que sean majos y que sepan dibujar (por este orden). Los artistas del Festival 2015 proponen dos nombres.

Todos los demás que queráis participar podéis enviar vuestro proyecto, ideas,... a miau.fanzara2014@gmail.com Entre todas las propuestas recibidas la Asociación MIAU y el colectivo GUAU seleccionarán los artistas que participaran en el festival 2016.

(Si no sois seleccionados no desesperéis, el presupuesto es corto, pero habrá más ediciones) Asociación MIAU.

Tabla 1. Requisitos de los participantes M.I.A.U. edición 2016 (M.I.A.U. 2016).

NemO's, PichiAvo, Pincho, Pol Marban, Rodrigo Branco, Rosh Trestrestres, Ruina, Sabek, Srger, Susie Hammer, Taltos, Thiago Goms, Xavier XTRM, Xèlön y Yes.

Aparte se ha contado con otras propuestas tales como talleres y exposiciones de la mano de artistas como Aïda Gómez, Arquicostura, Artinwreck, Basurama, Bubble, Juan Plasencia (Fila 7), Luis Montolio (Fotografia XXL), Maya Jankovic (La Fontana della Fortuna), Trashformaciones, Secret Boards, etc., así como proyecciones de cine o actuaciones musicales: Lydia López, Daniel Chiva, The Small Street Band, DJ Gabho, DJ Casius Tonen, Rondalla Santa Cecilia de Fanzara (ronda a los artistas).

¿Pero cómo se eligen los lugares para ejecutar las distintas manifestaciones artísticas? Según Javier López, uno de los organizadores del M.I.A.U., son los propios vecinos los que ceden las paredes para pintar, animándose unos a otros ${ }^{3}$. Una vez tienen localizadas las superficies disponibles, realizan una fotografía con alguien sujetando un metro abierto delante de la pared. De este modo, pueden remitirlas a los artistas para que elijan el mejor lugar para ejecutar sus respectivos proyectos. Señala también que son muy pocos los que realizan un boceto, pues son conscientes de que los diseños pueden cambiar al llegar al pueblo, convivir e impregnarse de la esencia de sus calles y del carácter de sus gentes. Pues, es esa precisamente la filosofía del M.I.A.U., y para ponerla en práctica los artistas comienzan la ejecución de las obras tres días después de su llegada al pueblo, sin que los propietarios sepan qué van a pintar sobre sus viviendas.

Así lo pone de manifiesto en su blog la crítica Irene Gras Cruz tras su llegada a Fanzara:

“...NemO's estaba meditando frente la pared que iba a intervenir. Es como si mantuviese un diálogo con ella. Los tres artistas se debaten sobre qué plasmar en Fanzara y tras estudiar y escuchar a la gente del pueblo, Bibbito se decanta por representar 'La era' puesto que la pared que escoge está en la calle de 'Las Eras' mientras que Collettivo FX decide pintar la mano del hombre que le deja el muro, la mano de un hombre trabajador, labrador y que representa la dureza y el esfuerzo de toda una vida al servicio del campo. Del mismo modo, NemO's escoge un tema más comprometido y controvertido con la zona" (Gras 2015)
No hay censura ni prohibiciones, pero sí se pide que se tenga en cuenta que en el pueblo hay gente muy mayor. Debe prevalecer el espíritu de convivencia, las ganas de compartir y disfrutar, como las de escuchar a los vecinos y vecinas cada vez que interrumpen a los artistas para preguntar, curiosear o aprender. "No es solamente ir a pintar..., es algo social" -señala López -"No puede venir cualquiera..., ha de ser un buen/a tío/a, que se adapte al medio y que pinte perfecto". Y así, es como salen las ideas, las propuestas, incluso las colaboraciones entre artistas. No olvidemos que son los vecinos y vecinas los que acogen a gastos pagados a los artistas durante cuatro días, en un ambiente lleno de cultura y fiesta, en el que se fraguan amistades y emergen ideas ${ }^{4}$.

\section{Técnicas y materiales}

Llegados a este punto, nos centraremos en las técnicas y materiales empleados por los artistas participantes en el M.I.A.U., un tema de gran importancia y de gran implicación tanto para comprender este tipo de manifestación artística como para su posible conservación. De este modo, podemos agruparlos en soportes, fondos y capas de color (materiales pictóricos y no pictóricos).

Las paredes que sirven de soporte a los murales u otro tipo de intervenciones son de todo tipo y presentan distinto estado de conservación. De las de piedra tradicional con restos de mortero de cal y capas de pintura (a la cal y/o sintéticas), pasamos a las de ladrillo o a los bloques de cemento, así como a los muros cubiertos de cemento Portland $^{\circledR}$, los cuales pueden estar o no recubiertos con pintura de exteriores y presentar toda clase de acabados con superficies lisas a rugosas.

Según lo expuesto, fachadas de viviendas, garajes, corrales, edificios públicos, muros o el asfaltado de un aparcamiento, pueden albergar obras de gran calidad. Y no solamente los muros, las puertas (de madera o metálicas), las tapas de los registros de los contadores del agua (acero o aluminio), las señales de tráfico o los contenedores de plástico verde del vidrio reciclado son elegidos como soportes 5 .

Al respecto, la artista Ana Pez afirma que en la ejecución de su bosque en una de las estrechas calles del pueblo, empleó la gama cromática del entorno. “...e integré una 

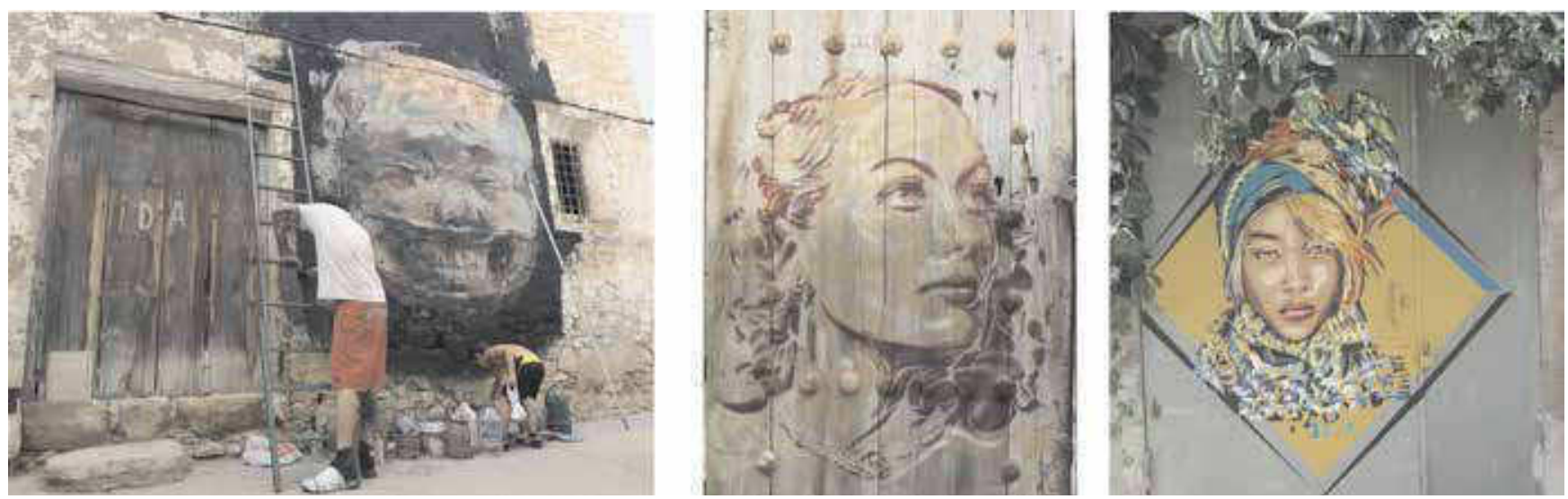

Figura3. Cerezo pintando sobre una casa de piedra y detalles pinturas de BTOY sobre puerta de madera y metal. Fotos: Rafa Gascó (3a y $3 c)$ y Mayte Pastor (3b).

puerta para construir el árbol principal, cuyas ramas (con la ayuda de Julián Arranz, quien cortó, pintó y colocó las maderas) crecieron hasta salirse de la pared...." (Pez 2014).

Dichos soportes tienen una trascendencia directa en las obras tanto a nivel creativo como por lo que respecta a una posible futura conservación. Ya que estos transmiten ciertas cualidades y características al acabado, inspirando el diseño o incluso formando parte de él, aportando texturas, tonalidades y formas. Así encontramos pinturas que cubren total o parcialmente los paramentos, junto a otras obras que se sirven de los desconchados de la pared o de los remiendos de cemento de los muros, incorporándolos como elementos creativos. [Figura 3]

En la calle Purísima, BTOY plasmó un retrato femenino sobre una puerta de madera, material que aporta calidez y una influencia directa sobre la obra dándole el aire vintage de las divas del cine clásico. La misma artista pinta sobre una puerta metálica con esmalte y el resultado es diferente, quizá más pop [Figura 3b y $3 c$ ]. Por supuesto, son cuestiones que definirán correctamente los historiadores y críticos del arte, si bien, desde nuestro punto de vista sí podemos observar la influencia de la selección de los materiales sobre las obras. Otro caso similar es el de Emilio Cerezo, quién trabaja de forma consciente sobre paredes viejas con distintos niveles de degradación [Figura 3a].

Al igual que el anterior, otros autores como Susie Hamer, Hyuro, Lolo, Sabek e Isaac Mahow pintan sobre las grises fachadas, dejando partes a vistas y sirviéndose de esta tonalidad para resaltar la composición. Estos pueden ser bloques de hormigón o enlucidos de origen. Thiago Goms, aprovecha este recurso en la parte superior del muro al pintar a sus gatos, combinando con restos de pintura en la primera mitad. Así mismo, NemO's pinta la balanza sobre el gris cemento, encajando el diseño entre el revestimiento y los bloques de la mediana.

La historia oral, los dichos y canciones, también tienen su representación en este museo a cielo abierto. En las tapas de los registros del agua, encontramos los "Registros del habla" de Hombre López, al que se sumó la participación vecinal. Dejando a vistas parte de la superficie metálica, unos personajes esquemáticos muestran en esmalte color turquesa oscuro, negro y blanco, las frases típicas del hablar de esta zona de transición lingüística entre valenciano y el castellano de Teruel [Figura 5].

Según el estado de las superficies, en ocasiones es necesario aplicar alguna capa de imprimación, pero suele recurrirse a bases de pintura de color blanco o negro, dando paso a los materiales del estrato de color propiamente dicho. Alejados de las preparaciones tradicionales, estos materiales o fondos, acostumbran a ser pictóricos, incluyendo los recubrimientos, esmaltes y barnices de fachadas, a los que se suman superficies como puertas y otros elementos. Ya hemos comentado que los paramentos suelen prepararse con bases blancas, pero esto no siempre es así, pues el artista puede encontrar en los propios muros materiales con características y desiguales estados de conservación que inspiran o sustentan las propias creaciones, pasando a formar parte de ellas ${ }^{6}$.

Por ejemplo, DEIH pinta The Visitor sobre un fondo blanco, al igual que Animalito Land o PichiAvo. Escif, Xèlön o Cere aprovechan en la composición el color con el que están ya pintadas las fachadas (ocre, blanco). El Colectivo FX emplea un fondo de color blanco para su diseño, pero este está enmarcado por el gris del muro.

Los materiales pictóricos son adquiridos por la organización del M.I.A.U., según demandan los artistas en base a la idea o el boceto presentando, tal y como relata con gran detalle Javier López. De forma habitual se utilizan pinturas en spray específicas para grafiti de la marca catalana Montana Colors S.L. (MTN ${ }^{\circledR}$ ) y pintura plástica de la empresa castellonense Pinturas Colom ${ }^{\circledast}$ (Hijo de Guillermo Colom S.A.), ambas colaboradoras del M.I.A.U. No obstante se atienden de forma expresa las peticiones y preferencias de los artistas, que pueden solicitar tintas, rotuladores, fijadores $u$ otros materiales ${ }^{7}$. Rodillos, brochas, aerosoles, tampones de estampar o plantillas son algunos de los sistemas de aplicación de estas pinturas [Figura 4]. 

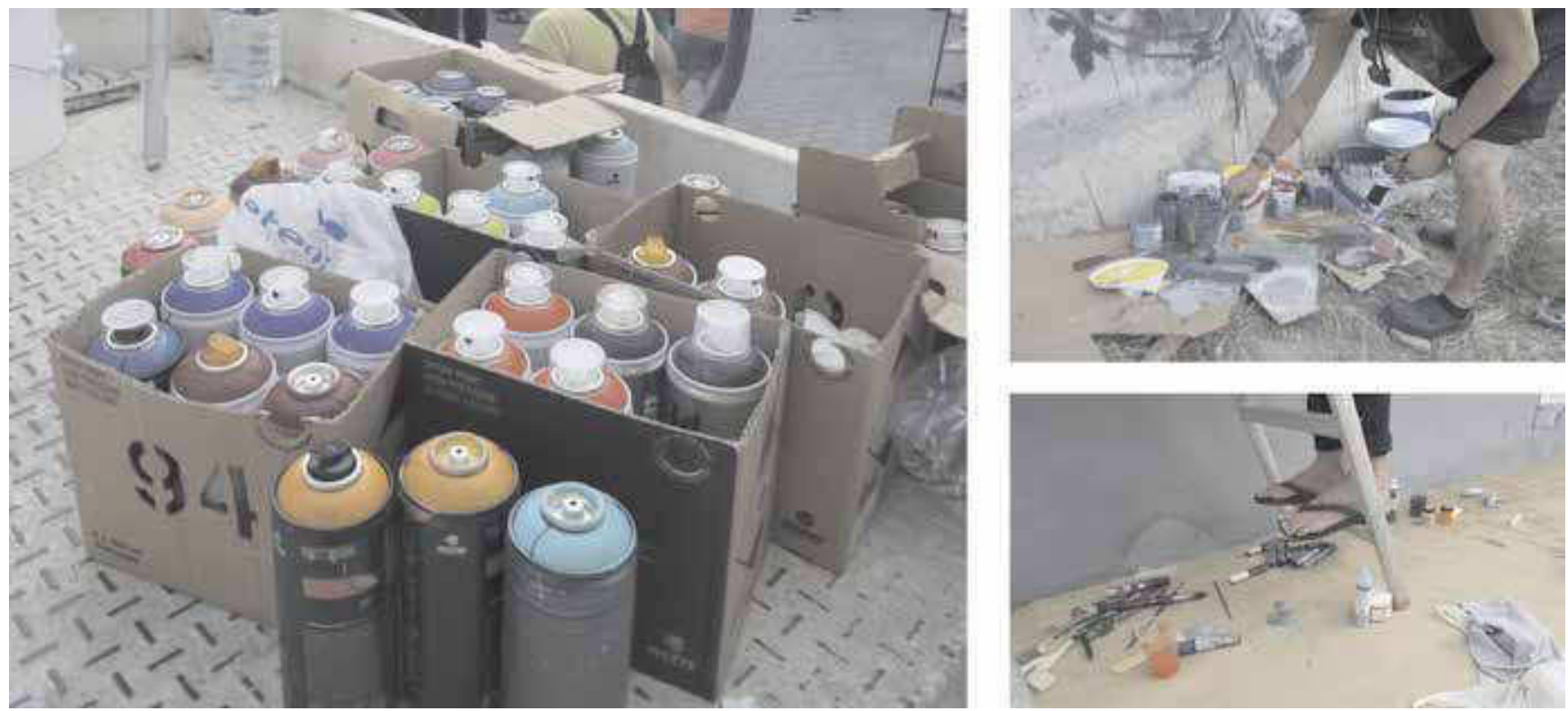

Figura4. Materiales pictóricos. Fotos: Rafa Gascó.

En las tablas siguientes se muestra la línea de pinturas seleccionadas, tal y como nos especifica López. Pinturas Colom ${ }^{\circledR}$ suministra la pintura plástica en los tonos básicos blanco y negro, junto a diversos colores (magenta, amarillo, bermellón, azul ultramar) para su posterior mezcla por los artistas [Tabla 2]. La línea Mayen Color ${ }^{\circledR}$ se fabrica para el revestimiento de interiores y exteriores con resinas acrílicas de alta calidad y pigmentos de gran estabilidad, ofreciendo un alto grado de lavabilidad, rendimiento y cubrición. Producidas con emulsiones acuosas de resinas estireno-acrílicas son las pinturas de interior Tinmate ${ }^{\circledR}$, que combinadas con los Tintes Lys ${ }^{\circledR}$ (bases pigmentarias de alta calidad) son mezcladas para obtener las distintas tonalidades necesarias (Pinturas Colom 2016).

A su vez, se emplean pinturas en spray fabricadas de forma específica para el mundo del grafiti por la marca $\mathrm{MTN}^{\circledR}$, con resinas alquídicas modificadas en mezclas aromáticas de solventes (ligante cetónico en colores metalizados). La línea MTN $94^{\circledR}$ proporciona acabados mates y la Hardcore ${ }^{\circledR}$ brillantes. Ambas ofrecen una altísima calidad con colores sólidos y gran resistencia tras la polimerización [Tabla 3] e información sobre su opacidad y resistencia a los rayos ultravioletas (Montana Colors 2016).

Otro tipo de medios pictóricos son las acuarelas de las marcas Winsor \& Newton ${ }^{\circledR}$ y Schmincke $^{\circledR}$ que Ilia Mayer combina con rotuladores $\mathrm{UNI}^{\circledR}$ o Pentel ${ }^{\circledR}$ de tinta china como medio de obtener un personal acabado con líneas de dibujo, colores diluidos y transparencias [Figura $4 \mathrm{C}]^{8}$.

Tras la visita a este museo descubrimos obras en blanco y negro (Collectivo FX, Joaquín Jara), con predominio del blanco y línea negra combinadas con color (Pincho), de colores vivos (Juan Tarragó, Bibbito, Animalito Land,
Julieta XLF, Kenor, H101, Srger, Taltos, Thiago Goms, los robots de Xèlön, Rosh 333, etc.), o más apagados, difuminados y sutiles (NemO's), pasteles (rosa, gris y azul en el Family Portrait de GR170), junto a acabados mates, satinados y brillantes, lisos o rugosos. Obras que cubren todo el paramento (Laguna y Xavier XTREM, Bibbito, Srger), o dejan partes al aire. Obras que precisan de la perspectiva para ser contempladas, o de lo contrario, siendo necesaria la proximidad en un espacio de zonas abiertas y callejuelas. Hay murales bajo puentes que hay que atravesar o intervenciones envolventes como la "capilla" de Jara, en la que utiliza tonos de blanco, negro y gris sobre ladrillo rojizo y puerta metálica.

Pero, no todo es pintura. En este sentido, y comprobando una vez más lo importante que es la población felina para este museo, destaca la cara de gato de losetas cerámicas hexagonales de tonos grises de Julián Arranz.

Cualquier material es válido: alimentos, piedras, sillas, cordeles, listones, tornillos, cemento blanco o escayola coloreada (salvavidas para el "Capitalismo" o "dentaduradonuts"), las tapas de los contadores, etc. Pues, en esta categorización de "estratos de color" se incluyen también aquellos materiales que aportan características en este sentido, como las ya citadas tapas metálicas de los registros del agua o la obra sobre madera de BTOY. Material empleado por Artinwreck o en las sillas con o sin asiento obradas en la fachada de una casa (Compañía de Mario). Del mismo modo, las obras "Flor de nocturna" y "Piedra Angular" de Xavier XTREM añaden listones y piezas de madera, junto a cordeles blancos atornillados para dibujar la geometría, dando volumen y profundidad [Figura 5].

Son muchos los ejemplos y la variedad matérica... La planta carnívora de Cerezo que cubre una tubería que la atraviesa, los cables de la luz incorporados a 


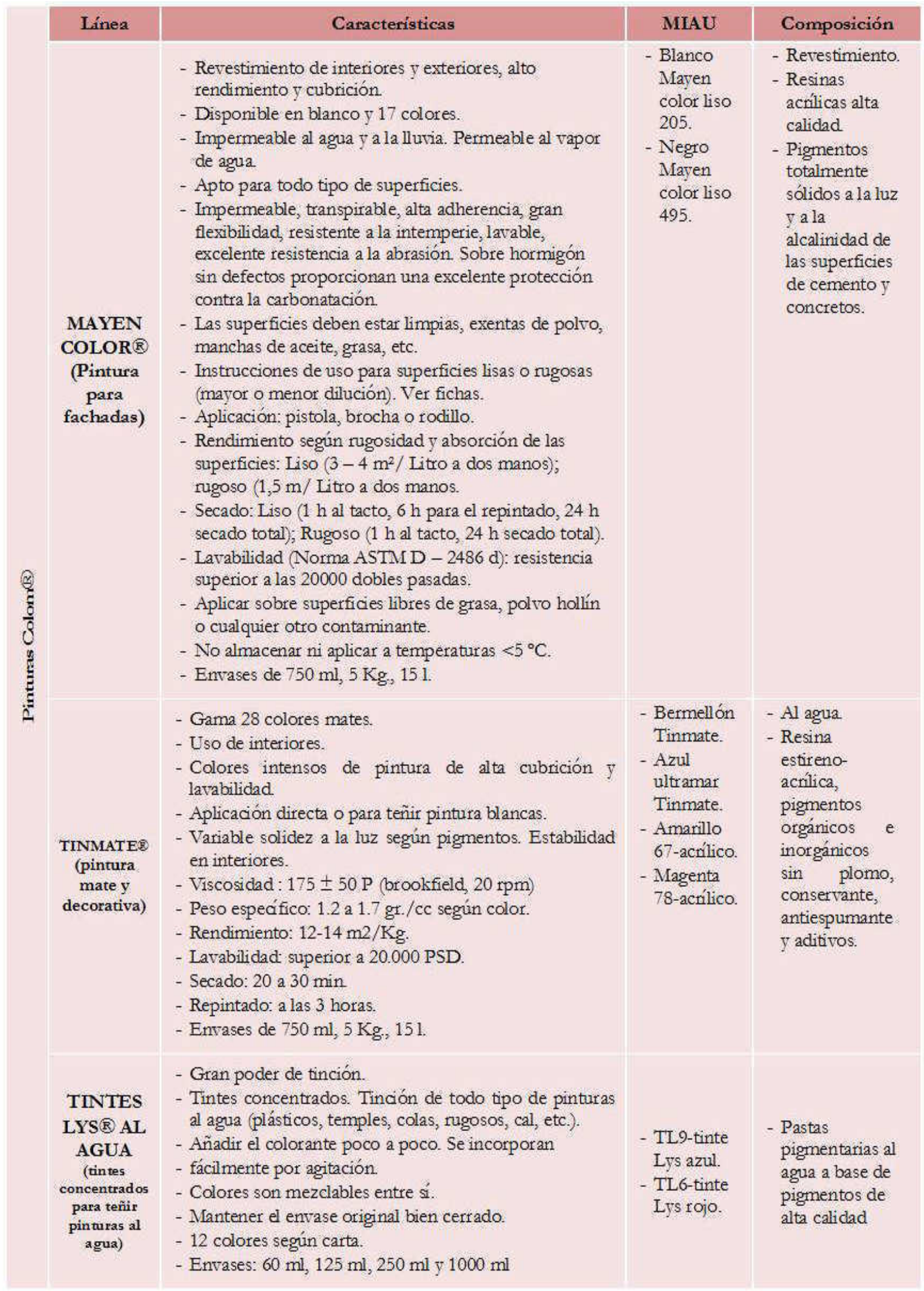

Tabla 2. Productos Pinturas Colom ${ }^{\circledast}$ (Pinturas Colom 2016). 


\begin{tabular}{|c|c|c|c|c|c|}
\hline Marca & Línea & Tipo & Características & $\begin{array}{l}\text { Aglutinante } \\
\text { /pigmentos }\end{array}$ & Solventes \\
\hline \multirow{2}{*}{ 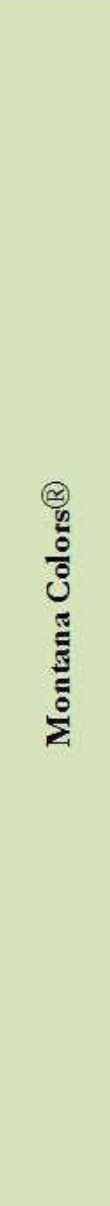 } & $\frac{\text { f) }}{\mathrm{g}}$ & के & $\begin{array}{l}\text { - Baja presión. } \\
\text { - Mate. } \\
\text { - } 400 \text { ml. } \\
\text { - Colores sólidos: } 174 \text { tonos. } \\
\text { - Buen poder de cubrición. } \\
\text { - Secado rápido. } \\
\text { - Buen endurecimiento. } \\
\text { - Flexibilidad excelente. } \\
\text { - Gran resistencia al rayado tras polimerización. } \\
\text { - No contiene plomo ni metales pesados. } \\
\text { - Durabilidad del color. } \\
\text { - Facilidad de aplicación y repintado. } \\
\text { - Buen comportamiento en la intemperie. } \\
\text { - Muy buena resistencia a los rayos U.V. }\end{array}$ & $\begin{array}{l}\text { Resina } \\
\text { alquídica } \\
\text { modificada }\end{array}$ & $\begin{array}{l}\text { Mezcla aromática: } \\
\text { acetato de etilo, } \\
\text { butano, xileno } \\
\text { (mezcla de } \\
\text { isómeros), } \\
\text { propano, } \\
\text { isobutano, acetato } \\
\text { de } 1 \text {-metil-2- } \\
\text { metoxietilo, } \\
\text { etilbenceno, } \\
\text { hidrocarburos } \\
\text { C10-C13 alifáticos } \\
\text { (aromáticos <2\%), } \\
\text { 2-butanona-oxima }\end{array}$ \\
\hline & $\begin{array}{l}\text { धृ } \\
\frac{8}{0} \\
\frac{0}{\text { है }} \\
\text { I }\end{array}$ & तै & $\begin{array}{l}\text { - Alta presión. } \\
\text { - Brillo. } \\
\text { - Secado muy rápido. } \\
\text { - Buen endurecimiento. } \\
\text { - Flexibilidad excelente. } \\
\text { - Gran resistencia al rayado tras polimerización. } \\
\text { - No contiene plomo ni metales pesados. } \\
\text { - Buen poder de cubrición. } \\
\text { - Durabilidad del color. } \\
\text { - Facilidad de aplicación y repintado. } \\
\text { - Muy buen comportamiento en la intemperie. } \\
\text { - Muy buena resistencia a los rayos U.V. } \\
\text { (consultar carta) }\end{array}$ & $\begin{array}{c}\text { Resina } \\
\text { alquídicas y } \\
\text { pigmentos de } \\
\text { alta calidad } \\
\text { *Ligante } \\
\text { cetónico: } \\
\text { gama } \\
\text { metalizada }\end{array}$ & $\begin{array}{l}\text { Acetato de etilo, } \\
\text { butano, xilenos, } \\
\text { propano, } \\
\text { isobutano, } \\
\text { etilbenceno, } \\
\text { acetato de } 1 \text {-metil- } \\
2 \text {-metoxietilo, } \\
\text { hidrocarburos } \\
\text { C10-C13, } \\
\text { isoalcanos, cíclicos } \\
\text { (aromáticos <2\%), } \\
\text { 2-butanona- } \\
\text { oxima. }\end{array}$ \\
\hline
\end{tabular}

Tabla 3. Productos Montana Colors ${ }^{\circledR}$ (Montana Colors 2016).

la composición de rostros de Borondo [Figura 6a], las carrocerías prensadas aparcadas en vertical sobre un muro de Trashformaciones o los bordados a punto de cruz con hilos gruesos de colores sobre rejilla metálica de Arquicostura. [Figura 6]

La técnica de la transferencia fotográfica sobre cantos rodados puede apreciarse en "Redes Sociales" de Hombre López y Rafa Gascó, creando una red de rostros de personas que vivieron y viven en Fanzara [Figura 5b]. A su vez, Bibbito interviene el reverso de una señal de tráfico de la Calle Santo Sepulcro utilizando la técnica del Stickerart.

Mención aparte son aquellas obras que cuentan con materiales orgánicos más o menos perecederos, tales como la guirnalda floral de Borondo en la que combina pintura con cañas [Figura 6b], las formas circulares que encontramos colgadas en las calles o interior del lavadero realizadas con este material y hojas de pino (pintadas o no) por Col.lectiu Paral.lel y vecinas, o los limones y rollos de pan de la intervención artística de Jara (balcón de la Plaza de la Virgen).

\section{Plazos de lo efímero}

El M.I.A.U. es un proyecto social, inacabado, que tiene la vocación de ampliarse y renovarse edición tras edición. Es por ello, que a priori, y en relación a la filosofía del arte urbano, las obras han de entenderse como obras efímeras. Por tanto, los muros se cubrirían con una nueva obra si no hay espacio suficiente o si la degradación de las obras sustenta esta decisión.

En cuanto esta última variable, ¿es posible establecer unos plazos a lo efímero? Cada obra tendrá una evolución particular a nivel de conservación dependiendo de una serie de factores interrelacionados. Esto es, del estado de conservación de los soportes, de la calidad de los materiales y la técnica empleada o de lo resguardadas que estén del impacto de los agentes ambientales (rayos ultravioleta, oscilaciones termohigrométricas, exposición al viento o Iluvia, contaminación, etc.) y demás agentes externos.

La aplicación de pinturas sobre bases pictóricas o recubrimientos ya de por sí deteriorados podrá comprometer su estabilidad a corto plazo provocando 

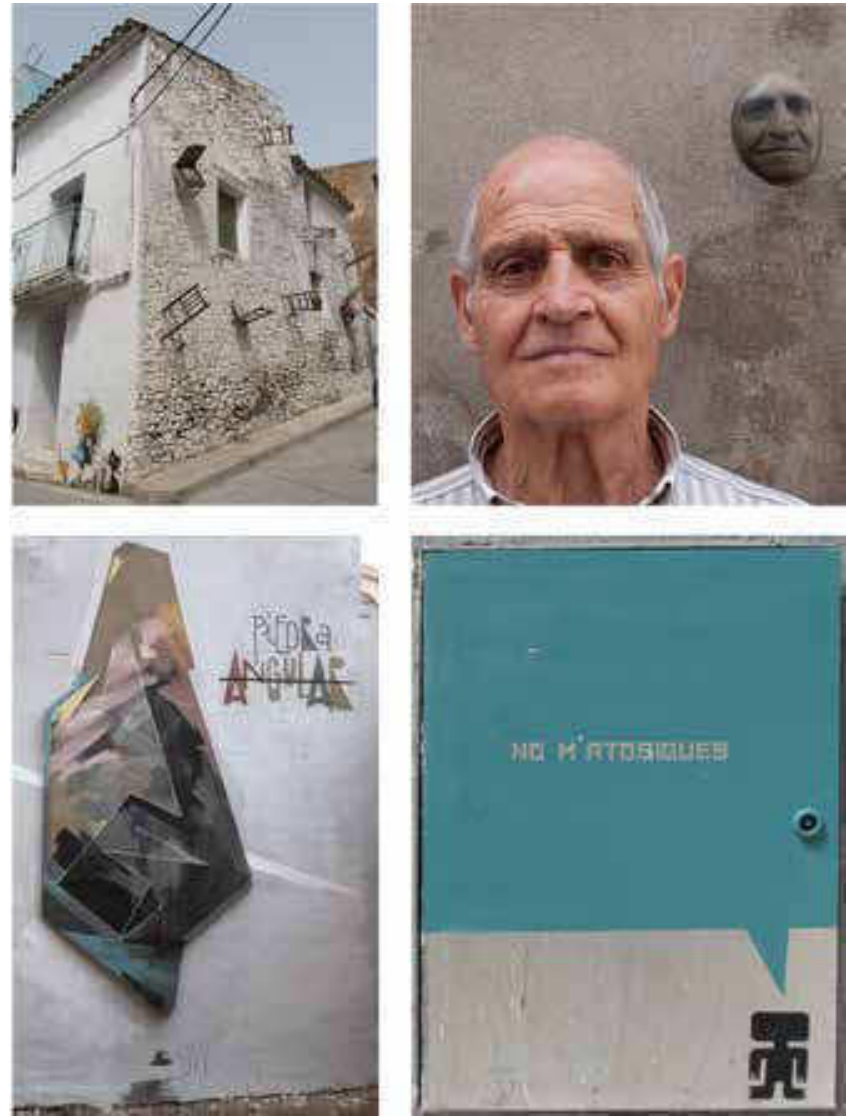

Figura5. Materiales en las obras de la Compañía de Mario, Hombre López, Xavier XTREM y Hombre López/Rafa Gascó. Fotos: Rafa Gascó (5b) y Mayte Pastor (5a, 5c y 5d).

su delaminación y pérdida, bien sea por fallos adhesivos y/o cohesivos e incluso por la migración sales en función de los distintos revocos (cal, cemento). Por tanto la aplicación o no de un tratamiento previo de las superficies condicionará su estabilidad futura.

Otra de las alteraciones que pueden dar pie a plantear la sustitución de un mural son sin duda los niveles de
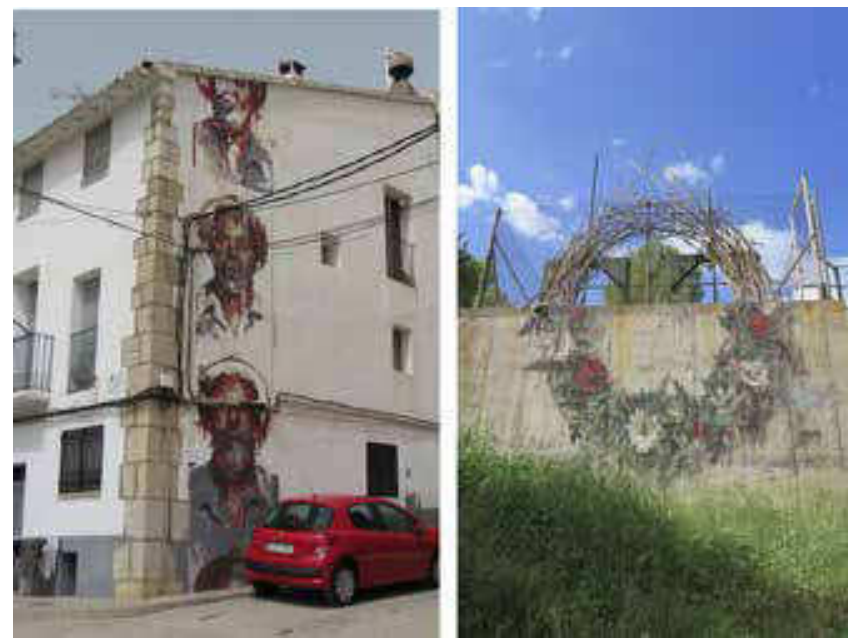

Figura 6. Materiales en la obra de Borondo: rostros y cables en mural y combinación de cañas y pintura (guirnalda). Fotos: Mayte Pastor y Rafa Gascó. decoloración por acción de la luz. En este sentido, las obras del M.I.A.U. combinan productos de mayor o menor resistencia, de los cuales pueden estimarse ciertos períodos de estabilidad.

En cuanto a la estabilidad cromática de los productos de Pinturas Colom $^{\circledR}$, tal y como especifica Francisco Vives director de la empresa ${ }^{9}$, la gama Mayen Color ${ }^{\circledR}$, formulada con pigmentos inorgánicos y una elevada cantidad de resina, podrá mantenerse inalterada durante períodos superiores a cinco años, siempre y cuando los soportes y bases se encuentren en perfecto estado y sean las adecuadas. La formulación con pigmentos inorgánicos (tierras) en las líneas Tinmate ${ }^{\circledR}$ y Tintes Lys ${ }^{\circledR}$ proporcionará una alta durabilidad, mientras que la de los orgánicos será menor en exteriores (sus altas concentraciones pigmentarias son óptimas para interior). Dicha durabilidad se verá mermada si los tonos son rebajados con blanco al disminuir la concentración. Dependiendo de la orientación de la pintura, los colores 67-amarillo, 78-magenta y bermellón podrán presentar algún síntoma de decoloración. De forma orientativa de 1 a 2 años para los tres primeros y de 3 a 4 para el azul ultramar. En el caso de exigir el requisito de máxima durabilidad las pinturas pueden reformularse empleando pigmentos inorgánicos u orgánicos (calidad automoción), lo que incrementa su precio. Sin duda, una información de gran interés para la conservación, que puede trasladarse a los materiales empleados en reintegración cromática.

Las pinturas en aerosol para grafiti MTN $94^{\circledR}$ y Hardcore ${ }^{\circledR}$ presentan una durabilidad cromática en exterior de más de 10 años, si bien algunos tonos de rojo, amarillo, azul, verde, violeta y rosa tendrán una estabilidad menor, siendo baja la de los colores fluorescentes y la de los metalizados (Montana Colors 2016). Miguel Olias, departamento técnico de Montana Colors ${ }^{\circledR}$, señala que aunque en su formulación hay una prevalencia de los pigmentos inorgánicos para garantizar la estabilidad del color, se producirán cambios en las primeras semanas debido al amarilleo de la resina empleada manteniéndose la estabilidad a partir de dichas variaciones ${ }^{10}$. Al igual que Vives, insiste en la importancia del estado de conservación de los muros y recubrimientos, así como del tipo de condiciones ambientales (menor estabilidad en ambientes salinos). En la actualidad la empresa trabaja en la formulación de una línea de alta resistencia para obras de arte urbano planteadas para conservarse.

Aparte, cabrá contar con la reducida durabilidad de los materiales orgánicos (alimentos, vegetales...), así como la de las pinturas ejecutadas con tintas y acuarelas sensibles a la acción de la luz.

A lo anteriormente expuesto hay que añadir una cuestión habitual para la conservación del arte contemporáneo, que obliga a adaptar los criterios 
de conservación e intervención: la propia voluntad artística de que sean o no efímeras según su concepto, más allá de la propia resistencia de los materiales.

Pese a lo anterior, aquello que se planteó como efímero podría dejar de serlo en casos muy concretos. EI M.I.A.U., como proyecto social que es, en el que la máxima es precisamente la convivencia entre vecinos y artistas, abre una reflexión sobre la conservación futura de las obras. ¿Qué ocurrirá con aquellos murales que se han convertido en iconos de este festival?, ¿podrá la decisión popular pedir que una obra se conserve, máxime cuando se ha vivido de una forma intensa junto a los artistas que la crearon, perdiendo su carácter efímero? ¿O incluso, pueden los especialistas y críticos en historia del arte apoyar una petición así? Hay mucho que reflexionar y debatir, sin duda.

López, señala que efectivamente puede darse el caso, aunque depende en parte del artista, a quién se le da siempre la posibilidad de "restaurar" sus obras. Encontramos un claro ejemplo en el mural de Pol Marban, realizado a partir de una fotografía con gente del pueblo, mediante transparencias y aguadas, el cual presenta un importante nivel de decoloración, así como levantamientos y lagunas [Figura 7]. "Este año quería "restaurarse", pero el artista no ha podido venir, por lo que si el año que viene no se interviene, será sustituido por otro"11.

Sin entrar en debates sobre quién debe o no intervenir una obra, esta situación es sin duda muy interesante para la conservación del arte urbano, así como para el establecimiento de criterios específicos de intervención. Planteando desde el ámbito de la conservaciónrestauración la idoneidad de realizar un seguimiento anual del estado de conservación de las obras cuyos valores intrínsecos abren el camino hacia su posible conservación, junto a la aplicación de medidas de conservación preventiva, o a la realización de pequeñas intervenciones consensuadas con los artistas, haciendo

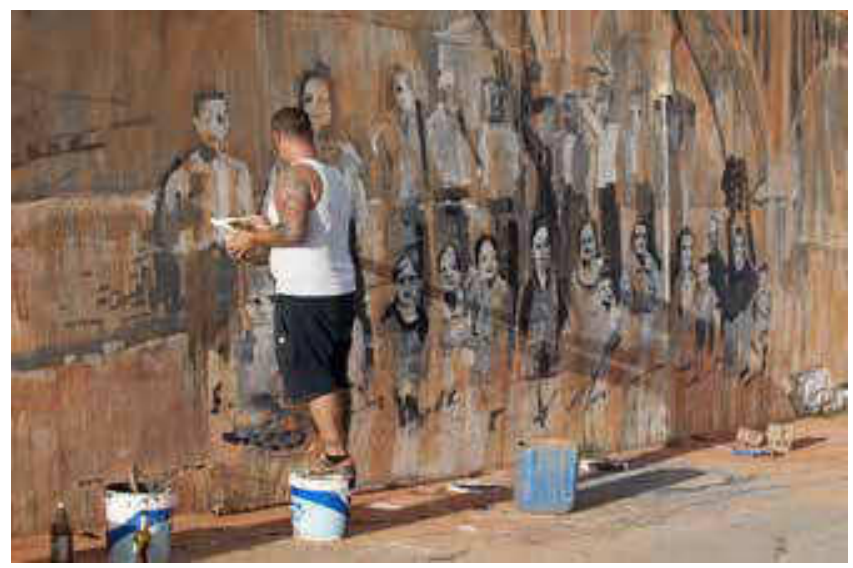

Figura 7. Pol Marban pintando mural. Foto: Rafa Gascó. posible la pervivencia de su imagen, materia y concepto. Nos referimos a la posibilidad que ofrecen algunos tratamientos tales como la aplicación de protectores frente a la acción de los rayos ultravioletas o a la realización de tratamientos puntales de fijación de estratos o incluso de reintegración cromática.

Para concluir, señalar que desde el M.I.A.U. se está realizando una labor de catalogación a través de la creación de un archivo fotográfico, que cuenta tanto con imágenes iniciales, de proceso, como finales, facilitando el estudio, investigación y consulta de las obras de este fantástico y excepcional museo al aire libre.

\section{Notas:}

[1] Colectivo G.U.A.U. (Gestores Universales de Arte Urbano): formado por Hombre López, Pincho, Xèlön, Justin Case, Ruina y Pol Marban, apoyan al festival como directores de artistas. Fuente: Javier López organizador del M.I.A.U, entrevista telefónica y vía WhatsApp agosto-septiembre 2016.

[2]- [4], [6]- [8] y [11] Fuente: entrevista a Javier López.

[5] Las señales de tráfico se realizan con acero y pintura epoxi y los contenedores tipo iglú con poliéster y fibra de vidrio y un recubrimiento exterior de alta resistencia fabricado por Gelcoats.

[9] Mayencolor blanco 205: bióxido de titanio (PW6) y negro humo (PBk7). Fuente: Francisco Vives Colom, responsable de dirección de Pinturas Colom, entrevista telefónica y vía email septiembre 2016.

[10] Fuente: Miguel Olias, departamento técnico de Montana Colors, entrevista telefónica 8/10/16.

\section{Bibliografía}

CHIANTORE, O., RAVA, A. (2005): Conservare I' arte contemporanea. Problemi, metodi, materiali, ricerche, Electa, Milán.

PUGLIESE, M. (2006): Tecnica mista. Materiali e procedimenti nell'arte del XX secolo, Bruno Mondadori, Milán.

SÁNCHEZ PONS, M., SHANK, W. Y FUSTER, L. (2015). Conservation Issues in Modern and Contemporary Murals. Cambridge Scholars Publishing, London.

VV.AA. (2007): Modern Paints Uncovered, GCl, Los Ángeles.

\section{Consultas Online:}

BOSCH, MANOLO. "MIAU hace de Fanzara la capital del arte urbano (II)". No me pierdo ni una. Web No me pierdo ni una. 
15/07/2015. <http://www.nomepierdoniuna.net/miauhace-de-fanzara-la-capital-del-arte-urbano-ii/>. [Consulta: 12/08/2016].

BOSCH, MANOLO. "Artistas y público dicen "sí" al MIAU Fanzara". No me pierdo ni una. Web No me pierdo ni una. 13/07/2016. < http://www.nomepierdoniuna.net/artistas-ypublico-dicen-si-al-miau-fanzara>. [Consulta: 06/09/2016].

GRAS CRUZ, IRENE. Web Irene Gras Cruz, historiadora y crítica del arte. NemO's en MIAU Fanzara. 28/03/2015. "Who is NemO's?" <https://irenegrascruz.com/2015/03/28/nemos-enmiau-fanzara/>. [Consulta: 30/08/2016].

I SUPPORTSTREETART. Web I Suport Street Art. @ 2016 ISSA Best viewed with a nice, cold beer. <http://www.isupportstreetart. com/>. [Consulta: 24/08/2016].

JO53-VALÈNCIA. "Fanzara 2015". 22/07/2015. Arte urbano, pintura mural y graffitis por Valencia. Blog. <http://larteurbano. blogspot.com.es/2015/07/fanzara-2015-1.html>. [Consulta: $30 / 08 / 2016]$.

M.I.A.U. Fanzara. ( ) MIAU Fanzara. Página web M.I.A.U. <http:// miau32.wixsite.com/miaufanzara>. [Consulta: 23/07/2016]; Facebook M.I.A.U. < https://www.facebook.com/pages/ MIAU-Fanzara/272752819594609?fref=ts>, <https://www. facebook.com/272752819594609/photos/a.273683079501 583.1073741828.272752819594609/485821451621077/?ty pe=3\&theater $>$. [Consulta: 12/08/2016] e Insharee M.I.A.U. Fanzara. <http://insharee.com/un/miaufanzara>. [Consulta: 12/08/2016].

MONTANA COLORS. Página web Montana Colors. Montana Colors (c) 2012. <http://www.montanacolors.com>, Fichas técnicas serie MTN 94 y Hardcore: <http://www. montanacolors.com/media/739_79_TDS_MTN\%2094_ SP.pdf>, <http://www.montanacolors.com/media/740_79_ MSDS-MTN\%2094-SPx1.pdf>, <http://www.montanacolors. com/media/715_79_TDS_Hardcore_SP.pdf $>, \quad<$ http:// www.montanacolors.com/media/714_79_MSDS-MTN\%20 HARDCORE-SPx1.pdf>, [Consulta: 12/07/2016 al 20/08/2016].

NITRACELULOSO. Nitrocelulosa Blog. nitraceluloso @gmail. com Ficha obras de Bibbito y Susie Hammer en Fanzara. <http://nitrocelulosa.tumblr.com/post/133411905553/pupobibbito-miau-fanzara-calle-santo >, <http://nitrocelulosa. tumblr.com/post/133475136582/susie-hammer-miaufanzara-traves\%C3\%ADa>. Consultas en general obras Fanzara. [Consulta: 09/08/2016].

PEZ, A. Blog personal. MIAU (Museo Inacabado de Arte Urbano) en Fanzara (Castellón). 30 septiembre 2014. <http://anapez. blogspot.com.es/>. [Consulta: 09/08/2016].

PINTURAS COLOM. Página web Pinturas Colom. OHijo de Guillermo Colom, S.A. <http://www.pinturascolom.com (c) Copyright - Pinturas Colom>, <http://www.pinturascolom. com/contacto/>, Ficha y ficha técnica serie Tinmate: <http:// www.pinturascolom.com/tinmate-serie-a-b/> y <http:// www.pinturascolom.com/fichas-tecnicas/linea-deco/ pintura-mate-decorativa/FICHA-TECNICA-TINMATE-07-07-08. pdf $>$, Ficha y ficha técnica serie Mayen Color: <http://www. pinturascolom.com/mayencolor-liso/> y <http://www. pinturascolom.com/fichas-tecnicas/linea-deco/tratamientofachadas/FICHA-TECNICA-MAYENCOLOR-LISO-19-01-11. pdf> Ficha técnica serie Tintes Lys al agua: <http://www. pinturascolom.com/tintes-lys-al-agua/> y <http://www. pinturascolom.com/fichas-tecnicas/linea-deco/productosauxiliares/FICHA-TECNICA-TINTES-LYS-AL-AGUA-29-04-11. pdf $>$, Ficha técnica serie Acrilico color: <http://www. pinturascolom.com/acrilico-color/> y <http://www. pinturascolom.com/fichas-tecnicas/linea-deco/pinturamate-decorativa/FICHA-TECNICA-ACRILICO-COLOR-10-12-12. pdf>. [Consulta: 12/07/2016 al 20/08/2016].

THESAL, GRUPO MECATHESAL. @ Thesal 2013. “Contenedores de reciclaje". <http://www.thesal.es/contenedores_de_ reciclaje/contenedor_iglu/?active $=2 \&$ contenedor $=3>$. [Consulta: 27/08/2016].

\section{Agradecimientos:}

A los organizadores del M.I.A.U: Javier López y Rafa Gascó, por toda la ayuda prestada, por su infinita paciencia y amabilidad, gracias por vuestras correcciones y fotografías. A Enrique Vives, responsable de Pinturas Colom, por compartir su experiencia y resolver nuestras dudas a nivel técnico. A Miguel Olias, departamento técnico de Montana Colors por atender y despejar nuestras preguntas. A Joan Feliu, profesor de la UJ, por facilitarnos el contacto con el M.I.A.U. Y a Elena Gayo por su ayuda y apoyo.

Mostrar nuestro reconocimiento al proyecto social del M.I.A.U., a los organizadores, vecinos/as, artistas y colaboradores que hacen posible que el arte contemporáneo de calidad siga creciendo como un instrumento de cultura. 


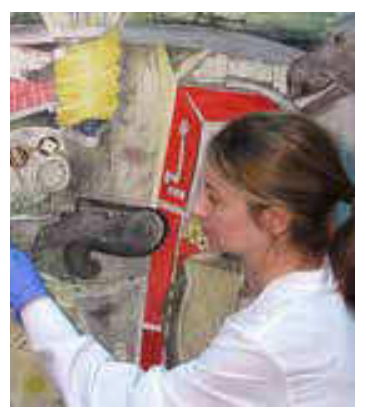

\section{Ma Teresa Pastor Valls}

Castellón de la Plana

maytepastorv@gmail.com

Doctora por la UPV en Conservación y Restauración de Patrimonio Pictórico (Premio extraordinario 2016), Título superior en Conservación y Restauración de Bienes Culturales en la Especialidad de Pintura (ESCRBCC) y Licenciada en Humanidades (UJ).

Ha colaborado en la redacción del Plan Nacional de Conservación de Patrimonio del Siglo XX (IPCE-MCU) como experto externo. Ha colaborado y trabaja como técnico superior en conservación restauración de arte contemporáneo desde 2007 para diversas instituciones y colecciones (Museu d’Art Contemporani Vicente Aguilera Cerni de Vilafamés, Instituto Valenciano de Conservación y Restauración IVC+R, Colección Martínez Guerricabeitia-UV, Fundación Anzo, etc.), actividad que combina en la actualidad con una beca de investigación posdoctoral Andrew Mellon Foundation dentro del Programa Catedral de Santiago, cuya finalidad es la de estudiar la estabilidad y viabilidad de los adhesivos y consolidantes a emplear en el tratamiento de las policromías del Pórtico de la Gloria. 
Conservar este tipo de obras supone acercarse a un campo demasiado heterogéneo como para plantear procedimientos generales, fuera de lo que son metodologías de estudio propias del arte contemporáneo.Esportantonecesarioentenderconqué y cómo pueden estar hechas las obras, algo ineludible para proponer tratamientos tanto conservativos como restaurativos, ya sean consolidaciones, limpiezas, protecciones o planteamientos más agresivos y discutibles como los arranques.

Este texto se centrará exclusivamente en obras pintadas sobre muros y elementos urbanos, consideradas de forma popular como arte urbano. Los materiales pictóricos utilizados han evolucionado en los más de cuarenta años que vienen produciéndose estas obras, cambiando tanto las motivaciones en su elección, como las formulaciones que se emplean en su producción comercial.

\section{Objetivos y metodología}

El arte urbano como objeto de estudio es muy amplio y los materiales y técnicas empleados, aun acotando el estudio en los pictóricos, no lo son menos. La diversidad obliga a una primera aproximación que permita plantear una visión panorámica, asumimos que incompleta, para, sobre ella, plantear futuros estudios específicos.

Por tanto, en esta aproximación, se plantean los siguientes objetivos:

-Identificar las tipologías de pintura más habituales empleadas.

-Establecer una cronología en la evolución comercial de algunos de los productos más comunes.

-Conocer los principales aglutinantes que utilizan estas pinturas.

-Establecer tipologías de superficies pictóricas en relación a los principales aglutinantes de sus composiciones y el medio en el que se presentan. - Identificar vías de estudio necesarias para abordar procesos de conservación específicos para este tipo de obras.

El estudio se fundamentará en: la revisión de textos y publicaciones de expertos en el estudio de la evolución de estas prácticas; la consulta de blogs y páginas web de artistas, así como de entrevistas publicadas por distintos medios; páginas web y publicaciones corporativas de empresas productoras y suministradoras de los productos; estudios de identificación de materiales procedentes de las ciencias forenses, que tratan estas actuaciones como actos vandálicos y del ámbito de la conservación de patrimonio que han comenzado a interesarse en este tipo de obras.

\section{1-Herramientas y técnicas utilizadas: elección y evolu- ción}

Existen numerosos estudios que explican la evolución de la subcultura del grafiti hacia el postgraffiti y arte urbano desde un punto de vista sociológico y artístico, y algunos incluyen aspectos sobre las técnicas y herramientas empleadas, imprescindibles para comprender diferentes orientaciones en cada momento, como los de Castleman (1987), Sthal (2008), Lewishon (2008), Abarca (2010) y Waclaveck (2011), entre otros.

Tanto las herramientas y técnicas utilizadas, como sus usuarios, han cambiado mucho en estas décadas. Algunas comenzaron a usarse en los orígenes, manteniendo una línea evolutiva, y otras han aparecido por el camino ante las reorientaciones de la escritura y la pintura callejera.

Su elección viene determinada por muchos aspectos complementarios entre sí, relacionados tanto con la disponibilidad del material, como con el discurso, el lenguaje estético y la costumbre de quien la emplea, pero también puede vincularse a la propia evolución y transformación progresiva de la práctica, por lo que no se debe desvincular una cosa de la otra.

En los antecedentes y origen del grafiti las ideas de "dejarse ver" y "repetición" son fundamentales, lo que obliga a utilizar herramientas comunes e inmediatas, que permitan dejar la huella del paso por el lugar mediante un grafismo o una incisión. Esta es la motivación fundamental de las primeras firmas o tags, que junto con la ilegalidad de la acción, determina la necesidad de velocidad de ejecución. Los primeros materiales disponibles serán además de tizas y ceras, poco permanentes, la pintura y la brocha, problemática para su transporte.

La popularización de las pinturas en aerosol en los cincuenta y sesenta, al orientar su mercado al ámbito doméstico, proporcionó una herramienta eficaz, que cumplía con todos esos requisitos. Los rotuladores de tinta permanente, en fechas similares, posibilitaron la inmediatez de la firma y su aplicación sobre múltiples superficies. Sin embargo, es la lata de pintura en espray la que se ha convertido en un icono de esta subcultura, influyendo para algunos de forma determinante en la transformación de la propia práctica y por tanto en su evolución como movimiento cultural y artístico (Weide, 2006).

La pintura en aerosol ofrece inmediatez, comodidad, facilidad de transporte, permanencia y adaptación a todo tipo de superficies. Posibilita utilizar colores diferentes de forma rápida y cómoda, con nuevas opciones. Todo esto influye en que las firmas se vayan sofisticando, sus cualidades estéticas adquieren protagonismo, ocupando cada vez más espacio y desarrollando estilos concretos. La repetición no es ya el elemento principal. Aparecen obras mucho más elaboradas o piezas, realizadas sobre vagones, muros y superficies más grandes, que despertarán el 
interés social y crítico, publicándose muchos libros que recopilan sus imágenes contribuyendo a su conocimiento y expansión, como el de Castleman (1982) o el de Chalfant y Prigoff, (1987).

En los años ochenta, la subcultura del grafiti, su atractivo y difusión, hace que pintar en la calle vuelva a resultar interesante y, con y sin permiso, jóvenes de diversos círculos artísticos lo practican con distintos pero confluyentes intereses y finalidades, Keith Haring o Kenny Scharf son ejemplos de ello (Kolossa, 2004). El espray continuará siendo una herramienta útil y simbólica, pero, sobre todo, en obras comisionadas por galeristas e iniciativas privadas, determinadas características que ofrece dejarán de ser imprescindibles. Algunas comienzan a realizarse con brocha y pintura, del ámbito de la construcción y el sector doméstico y decorativo, especialmente cuando se van a cubrir grandes superficies, resultando mucho más cómodas y económicas que las latas de aerosol. Probablemente influyen también los programas como The city of Philadelphia Mural Arts Program, a mediados de esa década, orientado a redirigir a jóvenes con inquietudes artísticas, que se iniciaban en el grafiti y la cultura Hip Hop, hacia obras comisionadas institucionalmente, de grandes dimensiones y con carácter comunitario'. Estos programas, desarrollados en varias ciudades, derivaron en la popularización del mural en la calle a gran escala así como en el uso de otros materiales, como emulsiones acrílicas de más calidad y pinturas al silicato, buscando una perdurabilidad en las obras.

Aún con todo, el espray seguiría siendo una de las herramientas preferidas, tanto por la clandestinidad que permite, como por su estética y simbolismo. Hasta finales de los noventa los aerosoles empleados procedían, del sector doméstico o la automoción, pero con la irrupción en el mercado en 1994 de la empresa española Montana Colors comienza una línea de producción específica de pintura en spray destinada a cubrir los requisitos que los artistas y escritores buscan en el material. Su éxito durante la siguiente década provoca el desarrollo de otras marcas y líneas que facilitan la expansión del movimiento y abren el campo de la creación propiamente artística.

Para entonces la subcultura del grafiti y sus derivaciones se habían expandido de forma global y se había escrito, fotografiado y filmado mucho sobre ella. En cada contexto geográfico y social seguirá una evolución local propia, con notas comunes, pero grandes particularidades, que también ha sido estudiada ampliamente en investigaciones específicas, como en el contexto europeo por Bart Bosmans y Axiel Thiel (Bosmans y Thiel, 1995), en el español por Gabriela Berti, (Berti, 2009) o en el madrileño por Fernando Figueroa y Felipe Gálvez (Figueroa y Gálvez, 2002).

La importancia de las firmas y piezas de los orígenes darán paso también al mensaje icónico a través de la imagen y en esto el uso de la plantilla o stencil será determinante.
Esta técnica permite la repetición, pero también posibilita la ejecución de imágenes potentes, sin autorización, en un tiempo récord. De nuevo el spray facilita la tarea. Estas imágenes cargadas de ironía conectan muy bien con la gente y aunque la técnica ya se realizaba desde los ochenta, figuras como Bleck Le Rat y Bansky contribuirán a la popularización y también a la mediatización de este tipo de prácticas.

Como señala Jaume Gómez, en su percepción como arte han contribuido tanto museos, como instituciones educativas, así como las redes sociales e internet (Gómez, 2014: 26). Desde finales del XX muchos jóvenes artistas en formación conocen estas prácticas en los contextos académicos $y$, con una perspectiva diferente, también deciden salir a pintar al entorno urbano, experimentando tanto con materiales propios del ámbito como con aquellos utilizados durante su formación. Por otra parte, la popularización en los medios mantiene esa conexión con el sector juvenil que revive los primeros pasos de los sesenta varias décadas después y en un contexto diferente, pero experimentando las mismas técnicas con otros materiales.

La fama de ciertas figuras emblemáticas que actúan en la clandestinidad favorece la permisividad hacia este tipo de prácticas, por lo que algunos artistas renuncian incluso a la ejecución veloz, planificando detenidamente la imagen y volviendo a técnicas como la pintura doméstica aplicada con brocha y rodillo. Además los planes de lucha contra el grafiti de algunos ayuntamientos como el de Salamanca ${ }^{2}$ fomentan la proliferación de convocatorias públicas de pinturas murales orientadas a artistas que pintan en la calle sin permiso, en las que los materiales, como sucede en festivales y exhibiciones, son proporcionados por la propia entidad organizadora, con productos de empresas distribuidoras locales.

En origen y puesto que el grafiti es también una forma de socialización, las técnicas se aprendían a través de la propia experimentación y el contacto directo con otros artistas. En la actualidad se organizan talleres y existen hasta recetarios de arte urbano como el publicado por Benke Carlsson y Hop Louie en 2010, traducido al español y reeditado por Gustavo Gili (Benke y Louie, 2013). Las redes sociales también se han convertido en un medio para compartir información y abundan los foros específicos. En definitiva, cada vez resulta más sencillo pintar en la calle y la profusión de imágenes satura al espectador.

La relación con el público resulta mucho más fluida, pero para no pasar desapercibidos han ido surgiendo todo tipo de herramientas y sistemas, que intentan explorar las posibilidades de comunicación en la calle, desde un punto de vista plástico o relacionado incluso con el propio discurso artístico. Cualquier elemento urbano es susceptible de ser utilizado como soporte o como excusa material sobre y con el que trabajar, desde una farola a un jardín. Las técnicas "tradicionales" se van sofisticando apareciendo productos específicamente orientados para 


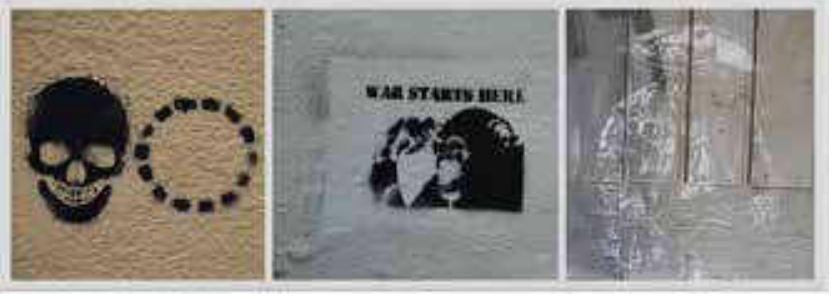

Figura 1. Obras elaboradas con espray y plantilla con diversos niveles de complejidad.

este uso, las plantillas elaboran trabajos verdaderamente complejos, como los de Cawamo e incluso la pintura puede ser propulsada con bombonas, como la krink ${ }^{\circledast}$ applicator de ocho litros, comercializada por la empresa Krink Inc. [Figura1]

Por tanto, las técnicas pictóricas más habituales en la actualidad se basan en el uso del espray o la pintura de brocha, aplicados de forma directa o indirecta a través de plantillas y reservas, sobre soportes diversos, preparados parcialmente en algunos casos y retocadas o combinadas con otras técnicas y materiales en ciertas ocasiones [Figura2].

Además de técnicas que podemos englobar entre las "pictóricas" se utilizan y desarrollan muchas otras que no se van a tratar en este estudio, pero que se podrían agrupar en las siguientes categorías:

-Técnicas sustractivas (como el scratching o el reverse graffiti, entre otras)

-Técnicas apropiativas (como el adbusting, entre otras)

-Técnicas aditivas (como las pegatinas o stickers, carteles e instalaciones, etc...)

\section{2-Principales materiales pictóricos empleados}

A lo largo de estas décadas los materiales disponibles han cambiado y evolucionado. Aún empleando la misma herramienta, el tipo de pintura aplicada puede tener una composición totalmente diferente.

A pesar de que ya se ha realizado alguna intervención sobre obras de arte urbano, como la llevada a cabo sobre una pintura de Haring en un ascensor de la escuela de Bellas Artes de Utrich (Beerkens y Mager, 2005), los recientes arranques realizados con motivo de la exposición Street Art. Banksy \& co. L'arte allo stato urbano (Ciancabilla, 2015) o los procesos que desarrolla el grupo St.a.co, en Grecia ${ }^{3}$, existen pocos estudios específicos centrados en el análisis de la composición de estos materiales, requisito imprescindible para plantear tratamientos compatibles y seguros.

La diversidad de materiales utilizados dificulta enormemente esta tarea, por lo que en este texto se intentará presentar un abanico de aquellos más comunes, agrupados en pinturas en espray, rotuladores comerciales y caseros y pintura doméstica, tratando de establecer tipologías y grupos, atendiendo a los estudios publicados hasta la fecha.

\section{1-Pintura en aerosol o espray}

\subsection{1-Orígenes}

La pintura en aerosol es una de las técnicas que identifican al grafiti y arte urbano. Sin embargo el espray no se refiere a un material concreto, tan sólo a una tecnología de aplicación y a un recipiente que puede contener diferentes tipos de pintura.

Uno de los factores que más impulsaron el desarrollo de esta tecnología y su aplicación en recipientes transportables fue la necesidad de proporcionar insecticidas a los soldados durante
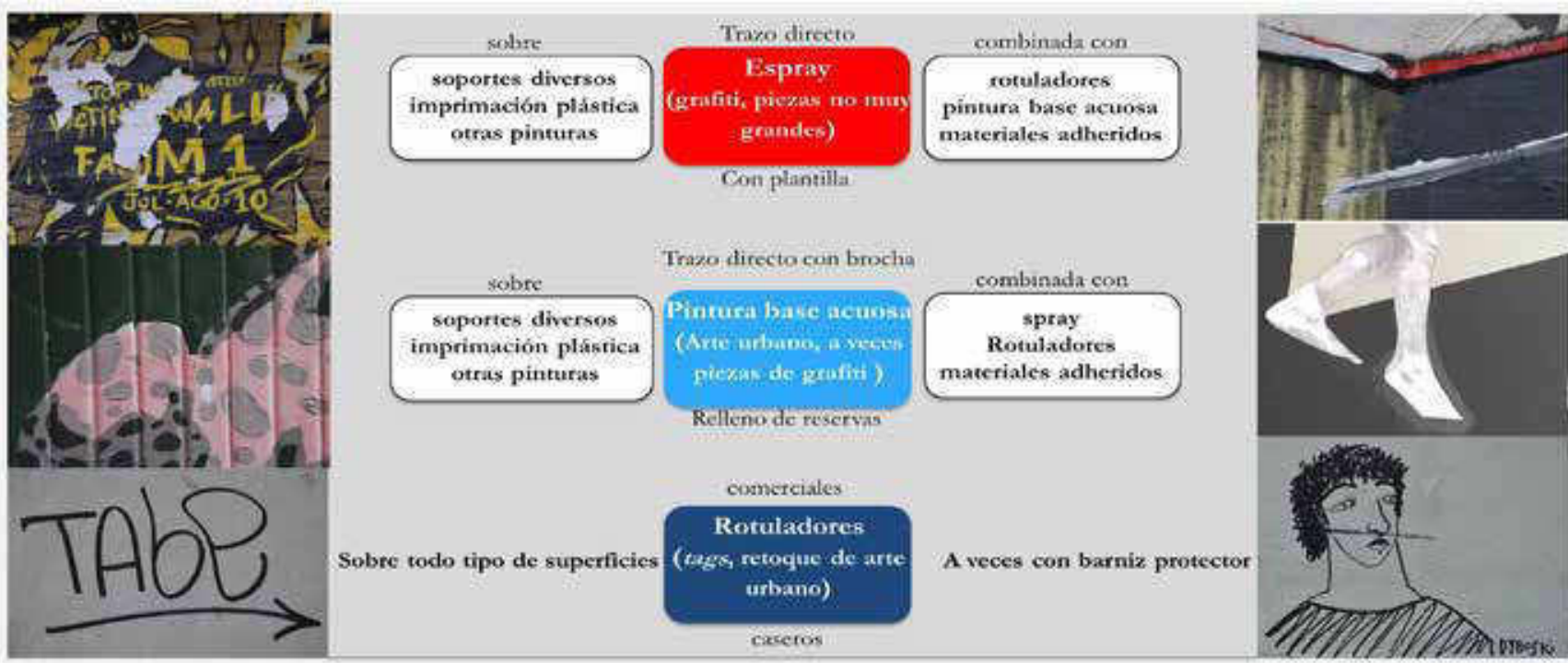

Figura 2. Técnicas pictóricas más comunes en el grafiti y arte urbano. Detalles de obras de Fasim, Lolo, Tag de Tabe, Dafne Tree, Big y Dyboski. 
la Il Guerra Mundial (Shangraw, 1971:11). La válvula patentada por Robert Abplanalp (Abplanalp, 1953) permitió su aplicación para multitud de productos, aunque su uso como recipiente de pintura se debe a Edwar Seymour, fundador de la empresa Seymour ${ }^{\circledast}$ of Sycamour, Inc. en Chicago en $1949^{4}$.

Desde entonces se han desarrollado infinidad de marcas que comercializan pinturas presentadas de este modo, con distintos usos y finalidades, que han sido empleadas por escritores y artistas en distintos momentos.

\subsubsection{Marcas utilizadas}

En los inicios se empleaban esprays de marcas accesibles en el entorno inmediato, la mayor parte de las veces robadas en grandes almacenes y droguerías y será precisamente esta disponibilidad una de las principales influencias en su utilización.

A finales de los setenta y en los ochenta, en pleno apogeo de las guerras de estilo y las piezas más elaboradas, las marcas más utilizadas en el mercado americano eran las que se habían ido experimentando a través de las primeras firmas, comprobando su capacidad cubriente y su resistencia. La accesibilidad de productos como los de Rust-Oleum y Krylon $^{\circledR 5}$, motivó que se utilizaran de forma habitual en América, adquiriendo un protagonismo vigente todavía en la actualidad (Gastman y Neelon, 2011:260). Es fácil ver sus botes en imágenes de esos años recogidos en los libros anteriormente citados. La variedad de productos europeos y americanos que surgieron en los sesenta, setenta y ochenta destinados a recubrimientos protectores, automoción y decoración es enorme y queda patente en algunas publicaciones como la realizada por el colectivo Cap Matches Colors, Two decades of Digging, fruto de un proyecto centrado en la colección, preservación y diseminación de la pintura en espray, especialmente orientado al mercado americano (CMC crew, 2015) y Aerosols, en la que Daniel "Rosko" bajo una óptica similar, presenta un recorrido por las marcas europeas comercializadas, especialmente en Alemania, entre los años 1965 a 1999, y que refleja la gran influencia de algunas como Belton o Sparvar , con su línea específica para grafiti Tuff Colors (Rosko, 2016). En las entrevistas recogidas en ambas publicaciones se puede comprobar también la tendencia de muchos artistas a mezclar diferentes marcas en la creación de una pieza.

En España los materiales también se roban, incluso para revender, tal y como recogen las múltiples entrevistas realizadas por Fernando Figueroa y Felipe Gálvez para documentar los libros Madrid Graffiti 1982-1995 y Firmas, muros y botes (Figueroa y Gálvez, 2002; 2014). En ellos también se incluyen referencias a algunas de las marcas más utilizadas por los españoles: Dupli-Colors ${ }^{\circledast}$, SprayColors o las míticas Novelty, marca ya desaparecida, producida por Weinco S.A (Moreno, 2016), nombradas también en documentales como el de Antoni Sendra sobre el grafiti valenciano (Sendra, 2007). Otras marcas que se citan y que se pueden ver en imágenes de redes sociales en las que comparten fotos de esas décadas, como la página de Facebook Novelty aerosoles, o el grupo Old School Madrid en Flickr ${ }^{6}$, son Altona, Bri-spray, Pictex retoke, CRC, Tamiya Color, Fellez y Mata, Solcolor, Wacolux o Felton Spray. [Figuras 3 y 4 ]

De la división española de esta última, Felton, procedía Jordi Rubio, quien junto con Miquel Galea y los grafiteros Kapi y Moockie revolucionarían la industria internacional de la pintura en aerosol, con la fundación de la empresa Montana Colors S.L. en 1994, reorientando su producción a los requisitos de los grafiteros: productos específicos, resistentes y cubrientes, con una amplia gama de colores, boquillas variadas y adecuadas a los distintos trazos a conseguir, y a un precio mucho más asequible. Esta revolución, venida del mundo de la industria, influirá en la transformación de la práctica ya que las posibilidades estéticas queofrecíanestos productosabríanunasexpectativastotalmente nuevas (Gastman y Neelon, 2011:260). Tal y como relatan en su web corporativa, en 1997 sus productos se distribuían por gran parte de Europa, y en 1999 en Estados Unidos, Canadá, México y Argentina. El éxito alcanzado llevará a que otras muchas empresas comiencen a producir líneas específicas, llegando incluso a tener que litigar por la conservación del nombre con su distribuidora alemana L\&G, fundadora junto con Duplicolor, de Montana Cans, en una maniobra que no hace sino destacar el interés despertado por la gama ofrecida y sus posibilidades de explotación comercial. Este tipo de producto irá asentándose durante los noventa, coexistiendo con otros muchos de los sectores antes mencionados, que continúan utilizándose, incluso en la actualidad.

De las marcas actuales destinadas específicamente al grafiti destacan por su apreciación entre los usuarios, Montana Colors, MontanaTM cans, Belton MolotowTM, Ironlak ${ }^{\oplus}, S_{c r i b o}{ }^{\circledast}$, Clash $^{\circledR}$, FlameTM, Kobra $^{\circledast}$. [Tabla 1]

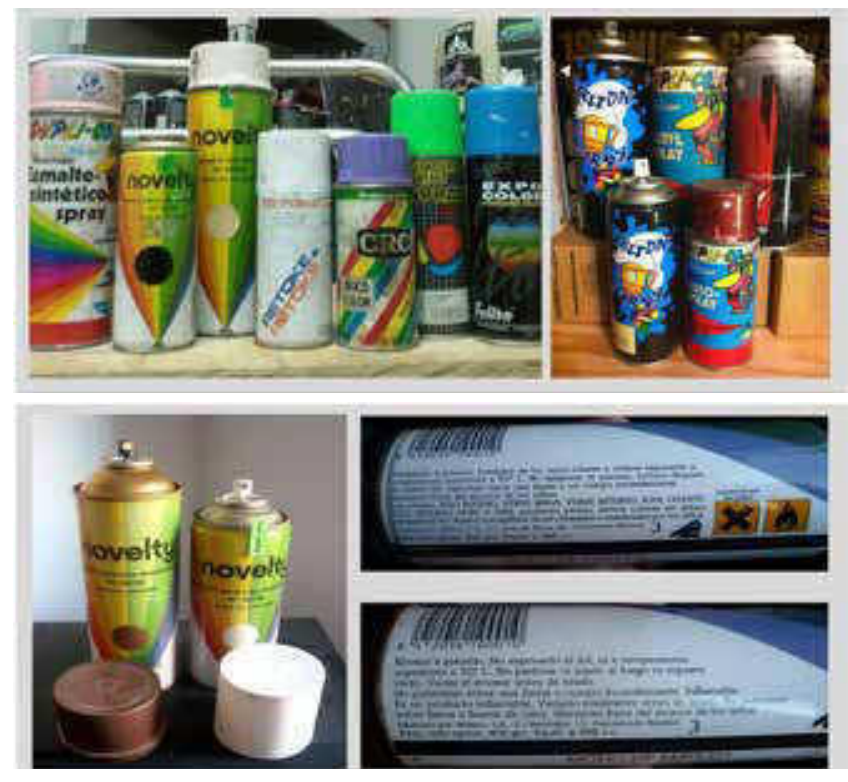

Figura 3 y4. Latas de aerosol de distintas marcas utilizadas por escritores madrileños en los 80 y 90 . Cortesía de Novelty aerosoles Facebook https://www.facebook.com/Novelty-aerosoles. 


\begin{tabular}{|c|c|c|}
\hline $\begin{array}{l}\text { MARCA Y EMPRESA DE } \\
\text { FABRICACIÓN }\end{array}$ & PRINCIPALESLINEAS DE PRODUCTO & $\begin{array}{l}\text { INFORMACIONPROPORCIONADA } \\
\text { ROR EL FABRICANTE }\end{array}$ \\
\hline \multirow[t]{5}{*}{$\begin{array}{l}\text { MONTANA COLORS } \\
\text { Montana Colors SL. España } \\
\text { wwwmontamacolors.com } \\
1994\end{array}$} & $\begin{array}{l}\text { Montana 94 } 189 \text { colores; Allen } 23 \text { colores; Hardcore } \\
109 \text { colores; Krink } 2 \text { colores (blanco y negro); } \\
\text { Megacolors } 12 \text { colores, } 5 \text { peed } 25 \text { colores, TNT } 7 \\
\text { colores }\end{array}$ & $\begin{array}{l}\text { Propelente butano, propano } \\
\text { Ligante: resina alquidica modificada } \\
\text { Dhyyente: mezch aromática } \\
\text { Pigmentos. ver ficha técnica }\end{array}$ \\
\hline & Nitro $2 G$ & $\begin{array}{l}\text { Propelente: GLP C3.C4 } \\
\text { Dilavente: acetato de butio } \\
\text { Pigmentos, ver ficha técnica }\end{array}$ \\
\hline & Nitro 26 Colors 8 colotes & $\begin{array}{l}\text { Diluyente: acetato de etilo } \\
\text { Pigmentos: ver ficha tecnica }\end{array}$ \\
\hline & Mega Plata & $\begin{array}{l}\text { Propelente: butano, propano: } \\
\text { Ligantersesina scnilica } \\
\text { Diluyente: mezcla aromática } \\
\text { Pigmentos: ver ficha tecnica }\end{array}$ \\
\hline & Water-based 52 colores & $\begin{array}{l}\text { Ligante: PU modificado } \\
\text { Dilavente: agua alcohol } \\
\text { Pigmentos, ver ficha técnica }\end{array}$ \\
\hline \multirow{3}{*}{$\begin{array}{c}\text { MONTANA ra CANS } \\
\text { Doplcolor-Vogelsang / L\&G Vertrieb } \\
\text { GmbH } \\
\text { Alemanis (ongen) y China } \\
\text { https//wwwmontana-canscom } \\
2002\end{array}$} & Gold. 215 colores & $\begin{array}{l}\text { Ligante: XC-acnilica } \\
\text { Dilorente mezca de solventes }\end{array}$ \\
\hline & Black (infra 36 colores; tarnegry, sytterehrome) & $\begin{array}{l}\text { Ligante: resina nitrocombinada } \\
\text { xesina nitrocombinada con bitumen en Tar } \\
\text { acrilica en Sy tremolore } \\
\text { Diluyente: mezcla de solventes }\end{array}$ \\
\hline & White $(51$ colores) & $\begin{array}{l}\text { Ligante: resina sintética } \\
\text { Diluyente: mexcha de solventes }\end{array}$ \\
\hline \multirow{4}{*}{$\begin{array}{l}\text { BELTON MOLOTOWrar } \\
\text { Feuersten GmbH } \\
\text { Belton/ Kwasny, Alemania } \\
\text { http// www molotowicom } \\
1999\end{array}$} & 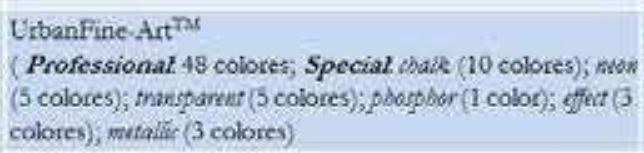 & $\begin{array}{l}\text { Ligante: base acnlica } \\
\text { Diluyente: mezcla de solveutes } \\
\text { Pigmentos:ver ficha técnica }\end{array}$ \\
\hline & 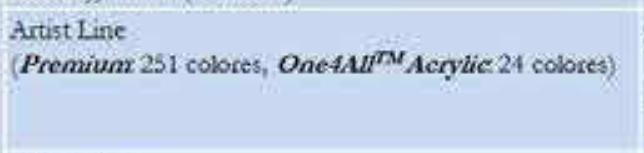 & 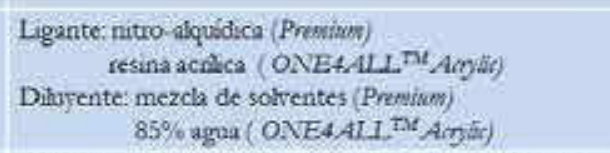 \\
\hline & 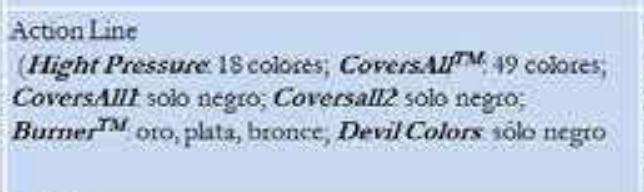 & 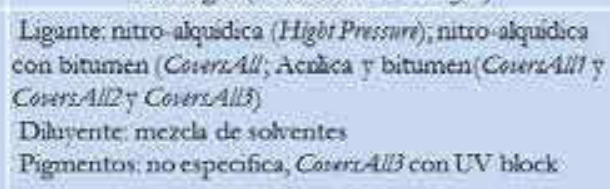 \\
\hline & $\begin{array}{l}\text { Tech Lune } \\
\text { (Phosphor } 3 \text { colotes (verde, natanja y aruf), Pigment } \\
\text { Spray. } 10 \text { colores) }\end{array}$ & \\
\hline \multirow{2}{*}{$\begin{array}{c}\text { IRONLAK } \\
\text { AVT paints LCC } \\
\text { Hasta } 2008 \text { en Australis; ahors en Chirs } \\
\text { https: } / / \text { wwwironlak com } \\
2004\end{array}$} & Ironlak ${ }^{8}\left(137\right.$ colores); Iranlak ${ }^{*}$ Tar Paint (solo negro) & $\begin{array}{l}\text { Ligante: resina acnlica (desde } 2008 \text { ) } \\
\text { Diluyente: mezcla de solventes }\end{array}$ \\
\hline & Sugar $(40$ colores $)$ & $\begin{array}{l}\text { Ligante: resina aculica } \\
\text { Diluyente: agua y accohol }\end{array}$ \\
\hline 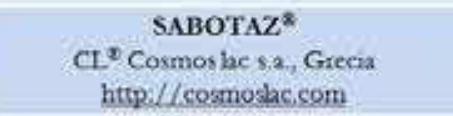 & Siabotaz ${ }^{5}=120$ colores & $\begin{array}{l}\text { Ligante: resina acnica } \\
\text { Diluyente: mezcla de solventes }\end{array}$ \\
\hline $\begin{array}{l}\text { CLASH }^{*} \\
\text { Colorpack, in, Itatia } \\
\frac{\text { www clashpaint com }}{2001}\end{array}$ & $\begin{array}{l}\text { Clash }^{8}-100 \text { coiores; Clash Tyson: } 4 \text { colores (negro, } \\
\text { blanco, tojo y plata) }\end{array}$ & $\begin{array}{l}\text { Ligante: resina acries } \\
\text { Dibuyente; mezcia de solventes }\end{array}$ \\
\hline 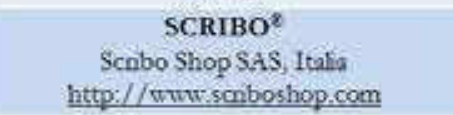 & Scribo 45 colores & $\begin{array}{l}\text { Ligante: resina acnica } \\
\text { Dibuyente; mezch de solventes }\end{array}$ \\
\hline $\begin{array}{l}\text { FLAMETM } \\
\text { Feuerstein GmbH, Alemana } \\
\text { Fabricada en Grecia por Cosmos lac SL } \\
\text { hetp://www flame-paintcom } \\
2011\end{array}$ & $\begin{array}{l}\text { Orange } 48 \text { colores HP } \\
\text { Blue } 104 \text { colores LP }\end{array}$ & $\begin{array}{l}\text { Ijgante: resina acnlica } \\
\text { Diluyente: mezcla de solventes }\end{array}$ \\
\hline $\begin{array}{l}\text { KOBRA* } \\
\text { Spraytec group, Italia } \\
\text { Fabricado por Ital G E T E }\end{array}$ & $\begin{array}{l}\text { Kobrs } 400 \text { HP } 132 \text { colores, Kobn: } 400 \text { Low } 80 \\
\text { colore5; Fluo } 6 \text { colores; Speciat } 3 \text { colores, cobre, plata y } \\
\text { oro }\end{array}$ & $\begin{array}{l}\text { Ligante resina } 100 \% \text { acrilica, Dluyerite mesch de } \\
\text { solventes }\end{array}$ \\
\hline
\end{tabular}

Tabla 1. Marcas actuales más destacadas, destinadas específicamente al grafiti. 
Las grandes firmas americanas Rust-Oleum ${ }^{\circledast}$ y Krylon $^{\circledR}$, sin embargo, nunca han querido ofrecer una gama para el grafiti, precisamente por desvincular su marca y su logo de este tipo de prácticas, y han continuado su línea de producción orientada a los recubrimientos industriales y bricolaje. De hecho Krylon es actualmente criticada por muchos artistas por el cambio experimentado en sus prestaciones (CMC crew, 2016b).

Los productos genuinamente producidos para arte urbano se ofrecen como sistemas de baja o alta presión, en relación a su capacidad/velocidad de cubrición y a su facilidad y control de manejo. Cada marca ofrece varias líneas de producto orientadas a cubrir estas necesidades junto con otros aspectos estéticos. Las claves en el mercado actual son calidad, en cuanto a cubrición y resistencia, precio, posibilidad de control, variedad cromática y en los últimos años ecología y sostenibilidad.

\subsubsection{Naturaleza de sus componentes}

Como toda pintura la que contienen los espray está compuesta por combinaciones de aglutinantes, pigmentos, cargas y aditivos con distintas funciones, presentados en un vehículo adecuado para mantener la mezcla y en este caso con un propelente que posibilita su específica forma de aplicación. Al igual que en otros muchos sectores industriales de pinturas, las formulaciones han evolucionado, ajustando cada vez más la dosificación de sus componentes, con compensaciones específicas en relación al uso para el que son producidas y a cada color en particular.

Las más antiguas eran formuladas con una base de solvente orgánico, propelentes a partir de gases de clorofluorocarbonos, hasta su prohibición en 1989, y en su mayoría con un aglutinante principal de tipo alquídiconitrocelulósico y en algunos casos acrílico. Existen pocos estudios de caracterización de materiales en los que se traten pinturas en espray de los setenta, ochenta y noventa, por lo que continúa siendo un campo por explorar. Encontramos alguna referencia en investigaciones sobre materiales empleados por artistas de renombre, como los realizados sobre los materiales encontrados en el estudio de Bacon, entre los que se incluyeron tres tipos de pintura en espray de diferentes colores, de las marcas Krylon $^{\circledR}$, U-Spray y la francesa peinture aerosol, en las que se identificó para la primera un aglutinante principal de tipo acrílico (metil-metacrilato/butil-metacrilato), para la segunda uno de tipo vinílico y en la tercera resinas alquídicas y nitrocelulósicas (Russell et al, 2012: 199).

Las complejas formulaciones de las marcas para grafiti y arte urbano actuales combinan la presencia de un aglutinante principal, una resina sintética polimérica, otros ligantes secundarios, generalmente otras resinas sintéticas que mejoran algún aspecto de la pintura, cargas y extendedores, pigmentos de diferente composición, aditivos con distintas funciones y el vehículo: diversos solventes orgánicos, agua y alcoholes y como propelentes hidrocarburos derivados del petróleo, como propano, n-butano y éter dimetílico.

La información suministrada por las empresas productoras es muy limitada y genérica. En las marcas más populares se encuentran principalmente dos sistemas: con base solvente y con base acuosa-alcohólica, siendo el primero el más común, ya que hasta la fecha apenas se localizan tres líneas de producto específico del segundo tipo: ONE4ALL ${ }^{\mathrm{TM}}$ Acrylic de Molotow MTN water-based de Montana Colors, introducida en 2014 y la reciente gama de Ironlak Sugar ${ }^{\circledR}$.

En cuanto a sus componentes, atendiendo únicamente a la información literal suministrada en sus últimas fichas técnicas vemos que $C L A S H^{\circledast}, F L A M E T M$, la gama original

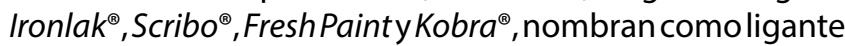
una resina acrílica (sin especificar más y en un medio de disolventes orgánicos y cetónicos variados). en el caso de Montana ${ }^{T M}$ cans en su gama Gold, un aglutinante acríliconitrocelulósico, en la Black una laca "nitrocombinada", mientras en la White una resina "sintética". Por otra parte las gamas de Montana Colors, Alien, 94, Hardcore y TNT identifican como ligante resinas alquídicas modificadas y en el caso de la gama de base acuosa-alcohólica una resina de poliuretano modificada, mientras que las Sugar ${ }^{\circledast}$ de Ironlak refieren un aglutinante acrílico, al igual que la gama Molotow one4all ${ }^{T M}$ acrylic, frente a la gama one 4 al ${ }^{T M}$ original y la High Pressure con aglutinantes nitro-alquídicos (ver Tabla1).

Algunas incorporan pigmentos especialmente resistentes a la acción de la luz, que suelen ser fácilmente identificables en muchas marcas, a través de sus fichas técnicas e incluso bloqueadores de luz UV, como CoversAll 3 de Molotow ${ }^{T M}$.

En algunos de los pocos estudios de caracterización de pinturas en espray realizados hasta la fecha, en el campo de las ciencias forenses (Buzzini y Massonnet, 2004; Ryland, 2010) y más recientemente en ciencias aplicadas a la conservación y restauración del patrimonio (Sanmartin et al, 2014; Germinario et al, 2015) podemos ver que en todos los casos se señala la complejidad de sus formulaciones y la dificultad de caracterización del material, lo que implica la necesidad de combinar diversas técnicas analíticas para lograr resultados efectivos. Estos estudios muestran que se emplean diferentes ligantes, como aglutinantes principales en las composiciones. En concreto Ryland, tras estudiar 71 tipos diferentes de pintura negra en espray, procedentes del mercado americano, concluye en que sobre todo se emplean resinas alquídicas, muchas veces combinadas con otras resinas sintéticas y establece cinco tipos de ligantes principales para la muestra estudiada: lacas acrílicas, esmaltes acrílicos, lacas nitrocelulósicas y esmaltes alquídicos y epoxídicos y como modificadores más comunes estireno, viniltolueno y uretano (Ryland, 2010: 116). El estudio de Giulia Germinario incluye muestras del sector del grafiti, doméstico y de la automoción 
y establece que las 45 muestras estudiadas, pueden agruparse bajo las siguientes tipologías: resinas alquídicas; alquídicas modificadas, la mayoría con nitrocelulosa y con estireno en algunas; resinas acrílicas modificadas con estireno, y las de base estirenada, que en este estudio coinciden con casi todas las pinturas metalizadas. Tanto en las muestras estudiadas de Montana Colors, como en las de Dupli-Colors ${ }^{\circledR}$ se identifican pequeñas diferencias entre los aglutinantes principales y secundarios en función del color estudiado, aún perteneciendo a una misma línea de producto. En concreto en las muestras MTN Hardcore negro y MTN94 negro, turquesa, naranja y azul se detecta resina alquídica modificada con nitrocelulosa y sin modificar en el rojo, amarillo y blanco de MTN94, así como en todas ellos polivinil fenil cetona como aglutinante secundario (Germinario et al, 2015: 931, 932).

La formulación de pinturas en spray eficaces, con base acuosa se ha experimentado en muchos momentos, como muestran las patentes registradas, ya a principios de los años 80, que reflejan los problemas derivados de la formación de espuma con la presión, las dificultades en la formación posterior del film e incluso de la estabilidad en el bote (Suk, 1981). La gama water-based de Montana en su ficha técnica se identifica con una resina de poliuretano y los análisis con Pirólisis-Cromatografía de Gases-Espectrometría de Masas realizados por los técnicos del Instituto de Restauración del Patrimonio revelan la presencia de isocianato, derivados de éste y compuestos nitrogenados propios de una resina de tipo poliuretanoy de un pigmento de tipo azo. Con la introducción de esta línea de productos, así como los one 4 all ${ }^{T M}$ acrylic de Molotow y los Sugar ${ }^{\circledR}$ de Ironlak $^{\circledR}$ es probable que si las prestaciones convencen a los usuarios acaben imponiéndose en la vertiente más artística, por su comodidad para el usuario y su respeto al medio ambiente.

\subsection{Rotuladores o marcadores}

\subsubsection{Orígenes}

Los rotuladores constituyen una de las herramientas básicas vinculadas al grafiti y en concreto a las firmas estilizadas o tags.

A pesar de que existen numerosos antecedentes en relación a patentes de artilugios parecidos a los actuales (Newman, 1910; Passkatch, 1926), se suele identificar su invención con la de 1951 de Rosenthal, que daría pie a la compañía Magic Marker Corporation (Rosenthal, 1951), desbancando a los clásicos modelos de acero inoxidable.

Desde su invención y popularización de los sesenta en adelante ha sido una herramienta fundamental para los escritores por su comodidad, facilidad de transporte y accesibilidad, optando siempre por los modelos indelebles orientados al sector de la rotulación y el marcaje industrial y los permanentes de oficina. Al igual que ocurría con la pintura en espray eran muchas veces sustraídos de los comercios y pronto se ingeniaron artilugios caseros que imitaban los sistemas comerciales. Estas herramientas permitían grafiar el nombre con un trazo continuo, de un ancho considerable y con la posibilidad de generar un estilo propio. Aún hoy este tipo de "rotuladores" son conocidos como mops.

La evolución del sector ofrece en la actualidad una gama de productos que los artistas emplean no sólo para los tags, sino también para el retoque de piezas o para aportar determinados efectos en composiciones más complejas.

\subsubsection{Marcas utilizadas}

Hasta el desarrollo del rotulador, tal y como lo conocemos, solían utilizarse instrumentos de acero inoxidable que utilizaban diferentes acabados en su punta para hacer trazos más o menos anchos, como los drawlet pens que comercializaba Esterbrook. Las primeras marcas que aparecen en el mercado y se popularizan por sus prestaciones son, entre otras, Magic Markers ${ }^{\circledR}$, Dri Mark, Edding ${ }^{\circledR}$, Pentel $^{\circledR}$ y Sharpi ${ }^{\circledast 7}$. Algunas de las más empleadas por los primeros grafiteros serán además de las citadas, el Marko ${ }^{\circledR}$ Permanent, Marks-A-lot ${ }^{\circledast}$, Pilot, Niji ${ }^{\circledR}$, Marvy $^{\circledR}$ y los rellenables Mini-Wide y Ultra Wide ${ }^{T M}$.

Los marcadores caseros se realizaban con todo tipo de recipientes, manipulados para colocar en su punta una esponja o fieltro, como los de los borradores de encerado y se rellenaban con tintas industriales. De esos intentos derivará una de las marcas actuales más conocidas en la actualidad, introducida por el grafitero de los noventa Craig Costello; el éxito que tuvo su tinta casera, confeccionada con papel calcográfico y alcohol, conocida como Krink dio lugar a la fundación de la empresa Krink ${ }^{\circledast}$ Inc., compañía que vende tanto tinta, como rotuladores con diferentes puntas para el mundo del grafiti y recipientes para rellenarlos. Como recogen diversas entrevistas, otras tintas industriales procedían del sector de la rotulación, el calzado y las lacas de bombillas. Una de las más apreciadas por su dificultad de eliminación fue la tinta Inferno, nombre que sigue utilizándose en tiendas especializadas en grafiti y street art. Otras muy utilizadas, especialmente en el sector americano eran Flo-master ink, Marsh ${ }^{\circledast}$ y Garvey Ink (CMC crew, 2016).

Los rotuladores de pintura Posca introdujeron ya en 1983 una gama cromática variada con colores cubrientes, características que han imitado varios años después otras marcas especializadas en grafiti y arte urbano, como Molotow y Montana Colors, entre otras. En la actualidad casi todas las empresas que tienen gamas específicas para grafiti y arte urbano producen también líneas de marcadores. Algunas de las más valoradas, además de las ya mencionadas, son la alemana On The $\operatorname{Run}^{\circledast}$, que comercializa marcadores específicos desde 1997, incorporando distintos modelos, algunos míticos 


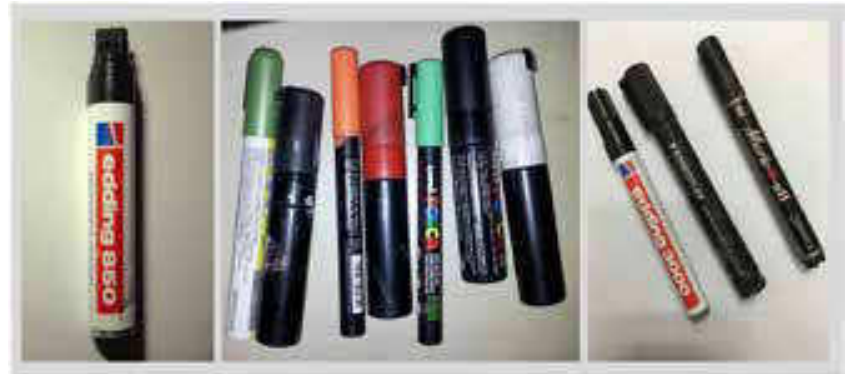

Figura 5. Distintos tipos de rotuladores permanentes empleados para tags y retoque de arte urbano. Cortesía de Novelty aerosoles Facebook https://www.facebook.com/Novelty-aerosoles.

como el Hard to Buff en 1998 o el Flow Pen en el 2000, Grog $^{\circledR}$ y Markwell, empresa americana que introdujo los primeros crayones. Todas ellas ofrecen varios modelos de rotuladores y squeezers, así como tintas y pinturas diversas con las que rellenarlos y puntas intercambiables y renovables. [Figura 5]

\subsubsection{Naturaleza de sus componentes}

La mayoría de rotuladores se basan en el uso de un recipiente que se llena de un líquido, teñido o pigmentado, que, o bien es absorbido por capilaridad hacia la punta, que puede estar hecha con diferentes materiales, con distintos tamaños y acabados, o bien utilizan una válvula dosificadora con una punta realizada también con materiales diversos.

La tecnología que utilizan, así como las formulaciones de la tinta o pintura que contienen han ido modificándose ampliando sus posibilidades de aplicación y orientando sus características hacia el mercado que cada marca ha considerado más conveniente. En los sesenta y setenta el marcaje industrial y de oficina ofrecía rotuladores de tintas permanentes y escasos colores, en disolventes orgánicos, con xileno y tolueno, y el sector escolar y artístico, con tintas borrables, en sistemas al agua poco tóxicos y con una gama de colores más amplia.

Alguna de las tintas míticas empleadas para rellenar los rotuladores caseros, como las Flo-Master contenían plomo, por lo que dejaron de fabricarse.

Estas tintas han ido depurando su composición, eliminando en la medida de lo posible los componentes más tóxicos e incorporando más pigmentos y colorantes. La evolución de los sistemas de aplicación ha permitido incluir pinturas basadas en resinas acrílicas mucho más cubrientes, aunque nuevamente la información suministrada en relación a sus composiciones resulta insuficiente.

Estudios recientes se han interesado en la identificación de los componentes más habituales en una muestra de rotuladores permanentes, identificando cuatro tipos de ligantes principales, en concreto: resinas acrílicas y metacrílicas (modificadas con estireno), generalmente en emulsión acuosa; resinas cetónicas; resinas fenólicas y resinas alquídicas, (Van der Werf et al, 2011: $3486,3487,3488)$. Actualmente se sigue investigando en esta línea con el fin de elaborar una base de datos en relación a estos materiales concretos, que facilite su identificación, pero todavía está en proceso.

En el mercado actual encontramos principalmente dos tipologías de rotuladores orientadas al sector del grafiti:

- los de pintura (con base acuosa de naturaleza acrílica, con base alcohólica y resinas no especificadas y con base solvente, similar a la de las pinturas en espray)

-los de tinta, con base alcohólica o solvente.

La mayoría de ellos son fácilmente eliminables con disolventes cetónicos, por lo que algunas marcas ofrecen barnices protectores que, en algunos casos, además facilitan la compatibilidad con otros productos subyacentes. Los que utilizan pinturas similares a las que contienen los esprays y algunas de las gamas especialmente diseñados para realizar tags suelen contener tintas muy permanentes y penetrantes, con escasos colores, predominando el negro y el rojo. A pesar de la amplia oferta existente algunos prefieren seguir utilizando sistemas caseros y tintas difíciles de eliminar, que penetran más en los soportes porosos e incorporan breas y alquitranes, como se ve en diversos foros en los que comparten recetas ${ }^{8}$.

Con respecto a las pinturas comerciales que se ofrecen para rellenar los dispositivos podemos ver, además de tintas industriales, las mismas tipologías de materiales que cada casa comercial utiliza en los propios rotuladores.

\subsection{Pintura doméstica}

\subsubsection{Orígenes}

Las primeras pinturas que se utilizaron antes de que los sprays ocuparan todo el protagonismo fueron pinturas de tipo industrial, fáciles de conseguir y difíciles de eliminar. La industria de la pintura se ha desarrollado principalmente en el siglo XX al tiempo que la tecnología de producción de las resinas sintéticas.

Los escritores sólo las utilizarán de una forma puntual, sin embargo a partir de los ochenta son muy habituales. Obras míticas de Keith Haring y otros muchos están realizadas con pintura, brocha y rodillo. Todas las que integran la East-Side-Gallery de Berlín, están pintadas de este modo, al igual que muchas de las que realizan artistas actuales de renombre internacional como Blu o Escif. De hecho en la últimas ediciones del festival Poliniza y Poliniza-Dos de la Universitat Politècnica de 
València, queda patente la tendencia de los participantes a decantarse por el uso de pintura de pared, sola o combinada con otras técnicas, como papeles e impresiones digitales adheridas. [Figura 6]

\subsubsection{Marcas utilizadas}

Hablar de marcas en este caso es extenso al tratarse de un sector comercial tan amplio y con un desarrollo tan grande a lo largo de las últimas décadas.

Repasando algunos estudios realizados sobre su evolución (Stavenden 2011; Dresgen 2014) es posible rastrear la aparición de ciertas empresas clave, como Du-Pont o Sherwin-Williams, que irán patentando marcas y firmando licencias de producción o distribución en otros países en fechas muy concretas, lo que ayuda a determinar el momento en el que un artista dispone de un material determinado. Sin embargo estos estudios precisan ser complementados con otros más específicos referidos a otros países, entre ellos España.

Se tiene constancia del uso de pinturas decorativas por alguno de los artistas más influyentes del siglo $\mathrm{XX}$, como Picasso, Bacon o Jackson Pollok, por su disponibilidad, pero también por las cualidades estéticas que ofrecían. Marcas como Carsons, Dulux y Ripolin aparecen en diversos estudios, como los presentados en el simposium celebrado en Marsella "From Can to Canvas: Early uses of house paints by Picasso and his contemporaries in the first half of the 20th century," en 2011, recogidos en dos números especiales del Journal of the American Institute for Conservation en el 2013.

En el arte urbano las pinturas más usadas suelen proceder del ámbito de la pintura de paredes, por su facilidad de adquisición, uso, manejo y baja toxicidad, así como por el rendimiento competitivo que ofrecen. Hay muy pocos estudios que se hayan preocupado de este ámbito y las múltiples entrevistas que se les hace a los artistas pocas veces incluyen el tema de los materiales y las marcas de pintura utilizadas. Lo que sí se puede apreciar es que, en general, emplean las pinturas que les son cercanas y están acostumbrados a manejar, o bien las que les son proporcionadas en el lugar en el que van a realizar la obra, en el caso de exhibiciones y festivales (Sánchez, 2016).

Actualmente al igual que ocurre en otros sectores industriales, las pinturas de construcción y decoración están organizadas bajo grandes holdings que controlan el sector y aglutinan a las diferentes marcas y filiales, como Azko Nobel en Holanda, o Sherwin-Williams en Estados Unidos.

\subsubsection{Naturaleza de sus componentes}

La industria de las pinturas se ha desarrollado a lo largo del siglo $\mathrm{XX}$, al ritmo marcado por la investigación en su química y tecnología. Puesto que importantes artistas convencionales del siglo XX incorporan en sus obras estas pinturas por experimentación, posibilidades plásticas y por supuesto por su accesibilidad, su estudio se está tratando con cierta profundidad en la conservación y restauración de arte contemporáneo. Las primeras pinturas industriales en producirse fueron las pinturas nitrocelulósicas y en pocos años irían incluyéndose los esmaltes basados en pinturas alquídicas, vinílicas y acrílicas, todas ellas con base disolvente, hasta la aparición de los látex sintéticos.

En las décadas de los ochenta y noventa, la industria ya había evolucionado mucho. Las dispersiones acuosas de resinas sintéticas o látex, por sus características, se habían impuesto en la pintura doméstica de pared y era muy fácil encontrarlas en droguerías y grandes almacenes, así

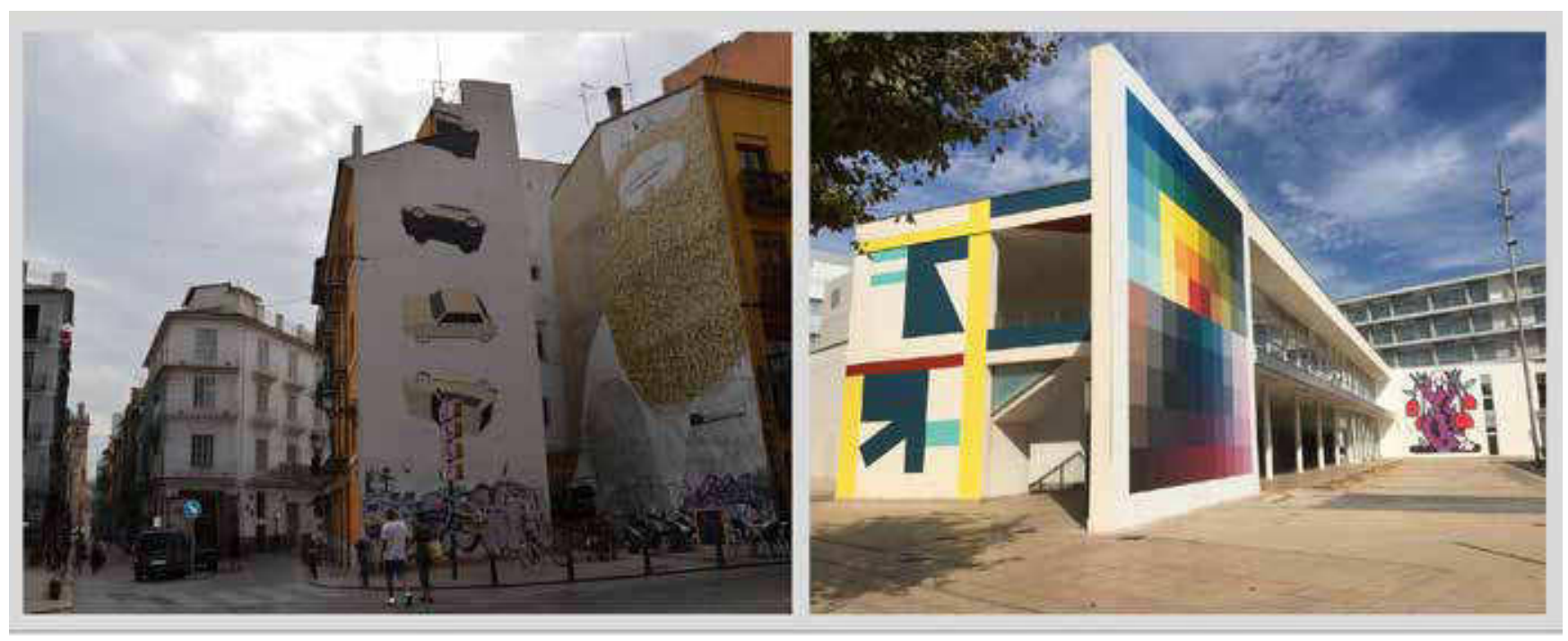

Figura 5. Murales de Escif y Blu en la plaza del Tossal, Valencia. Intervenciones de ElTono, Alberonero y Edjin para Poliniza-Dos XI Trobada d'art urbà, Universitat Politècnica de València. 
como en tiendas específicas de pinturas. Dependiendo de la marca y destino de uso (fondos, acabados, interior o exterior) sus aglutinantes y fórmulas cambiaban, pudiendo encontrar, sobre todo, emulsiones de acetato de polivinilo, emulsiones de estireno-butadieno, copolímeros acrilvinílico y resinas acrílicas para pinturas de exterior, con distintos componentes y proporciones de ingredientes (Learner, 2004). En general son pinturas en las que, sobre una base acuosa se mantienen en suspensión partículas sólidas de diferentes polímeros. Al perder el agua, ya sea por evaporación o por absorción del soporte, y debido a la creciente tensión superficial que se produce al aproximarse las partículas, éstas se fusionan en frío alrededor de las partículas de pigmento, deformándose plásticamente gracias a los agentes coalescentes y compactándolo (Giudice, 2009). Las formulaciones diferentes intentan compensar las composiciones para conseguir unas determinadas características en la película de pintura seca, además de asegurar su estabilidad durante el circuito comercial hasta que son utilizadas.

Estos serán los materiales que con más facilidad podrán encontrarse en el arte urbano realizado con pintura de pared, aunque las formulaciones específicas dependerán del momento concreto de comercialización, la empresa que las produzca o distribuya y la zona geográfica. Por ejemplo en tres pinturas de Keith Haring realizadas en la década de los 80 en Melbourne (1984), París (1987) y Pisa (1989) se identificaron aglutinantes muy diferentes, todos ellos habituales en pinturas sintéticas de emulsión acuosa: vinílicos, acrílicos y alquídicos, en el mural de Collingwood, resinas vinílicas con pequeñas cantidades de $\mathrm{VeoVa}^{T M}$ como plastificante en el Hospital Necker de París, y un copolímero estireno/n butilacrilato en el mural de Tuttomondo en Pisa (La nasa, 2015). La marca de pinturas empleada en este último fue Amphibolin paints de la casa Caparol (Rava et al, 2015). Las tres obras han sido restauradas y cada una se encontraba en un estado diferente, debido no sólo a los materiales empleados, sino también a la interacción entre los distintos estratos, las condiciones ambientales del entorno y a la propia historia de la obra.

Hoy en día continúan utilizándose este tipo de pinturas en dispersión acuosa, tanto para utilizarlos como base, como para emplearlos en la ejecución de la obra, solos o combinados.

Son pinturas parecidas a las acrílicas y vinílicas de tipo artístico pero su formulación está orientada hacia el mercado y uso al que están destinadas, con unos requisitos de calidad y aplicabilidad muy específicos y no necesariamente coincidentes con los artísticos. En general constan de una cantidad mayor de cargas y extendedores, lo que repercute lógicamente en su estabilidad y comportamiento, con pigmentos con distintos grados de resistencia a la luz, así como aditivos que permiten su almacenamiento y distribución en cantidades mayores, pero que, lógicamente, también interfieren en su proceso de envejecimiento y degradación.
A pesar de que estos son los materiales más comunes, no hay que olvidar que los artistas pueden acceder con gran facilidad a multitud de pinturas, tanto del sector artístico como industrial que, en un momento dado y por múltiples circunstancias, pueden resultarles de interés y ser incorporadas en sus creaciones.

\section{Conclusiones}

El conocimiento de los materiales constitutivos de las obras que pretenden ser conservadas es imprescindible. Tal y como se ha demostrado, el arte urbano es mucho más que pintura en espray.

Los materiales pictóricos empleados, tanto en las pinturas en espray, como en los rotuladores y pintura doméstica son muy diversos, por lo que a la hora de documentar estas obras se debería atender a las tipologías mencionadas, intentando incluir no sólo la marca, sino, a ser posible, la gama específica utilizada, con la referencia de color.

Los estudios publicados en relación a la introducción de las pinturas industriales y domésticas en los mercados europeos resultan insuficientes para abordar una posible conservación por lo que sería conveniente emprender líneas concretas en este sentido, al igual que completar la caracterización de pinturas en espray de diversas épocas y marcas comerciales.

También se ha podido comprobar que las entrevistas revisadas, aunque en algunos casos incluyen datos importantes, casi nunca se centran en aspectos relativos a los materiales que utilizan, por lo que se detecta la necesidad de plantear estudios estadísticos en esta línea.

Dada la dificultad para la identificación exacta de los componentes utilizados en las formulaciones modernas de pintura, que precisan del uso de varias técnicas de análisis combinadas y puesto que parte de la información puede obtenerse directamente del fabricante, resulta de especial relevancia, en algunas tipologías de arte urbano, potenciar la documentación de las obras en un momento cercano a su creación, de modo que permita recoger la información relativa a los materiales empleados, contactando incluso con las empresas suministradoras para incorporar los datos precisos para su futura conservación, caso de ser necesaria.

La estabilidad de las pinturas domésticas habituales expuestas al exterior es bastante limitada, ya que está pensada para una duración acorde al mercado de la construcción, en el que los estratos se reponen cada cierto tiempo, como parte de un sistema de mantenimiento, por lo que sería conveniente orientar investigaciones específicas hacia sistemas compatibles de protección. Considerando la controversia actual con respecto a 
la conveniencia de determinadas metodologías de limpieza sobre las pinturas acrílicas sería conveniente plantear los problemas que podrían generarse en estas superficies, muchos menos resistentes a priori y con un porcentaje de cargas y aditivos mayor.

Los problemas técnicos que puedan presentarse pueden llegar a ser muy complejos, pero no por ello irresolubles cuando se cuenta con toda la información posible.

Por todo ello parece necesario estudiar modos de documentación de estas obras, que comiencen en su propio proceso de generación, especialmente en las obras que reconocemos como comisionadas, y así poder establecer, un proceso de conservación preventiva, que pueda facilitar, en el caso de ser necesario, la intervención concreta de protección o incluso de restauración.

\section{Notas}

[1] programa fundado en 1986 por Jane Golden, https://www. muralarts.org [consulta 28-09-15].

[2] El plan de actuación contra las pintadas vandálicas del ayuntamiento de Salamanca incluye en su página 43 un epígrafe denominado: Fomento del grafiti autorizado, accesible en http://www.urbanismo.aytosalamanca.es/es/ archivourbanistico/docs/Plan_actuacion_contra_pintadas_ vandalicas.pdf [consulta 12-07-16].

[3] https://www.facebook.com/staco.street.art.conservators/ [consulta 12-08-16].

[4] http://www.seymourpaint.com/history/ [consulta 17-0716.

[5] Rust Oleum: empresa fundada por Robert Fergusson en 1921 en Nueva Orleans para la producción y comercialización de recubrimientos protectores, en 1932 RUST -OLEUM Paint Co.) En 1959 llega al mercado europeo abriendo una fábrica en Holanda. Actualmente es una filial de RPM Industrial Inc. http://www.rustoleum.com/about-rust-oleum/our-history [consulta 22-05-2015]; Krylon: compañía fundada en 1947 en Filadelfia por Howard E. Kester, bajo el nombre corporativo de Krylon, Inc. para la producción y comercio de protectores en espray de naturaleza acrílica destinados al sector artístico. A principios de la década de los cincuenta reorienta su producción hacia las pinturas de decoración. Actualmente forma parte del grupo Sherwin-Williams, http://www.krylon. com/about/[consulta 22-05-2015].

[6] Facebook Novelty aerosoles, https://www.facebook.com/ Novelty-aerosoles-238824393395/?fref=ts [consulta 22-0616] y Flickr Oldschoolmadrid, https://www.flickr.com/groups/ oldschoolmadrid/members/. [consulta 22-06-16].

[7] Magic Markers Corporation: compañía fundada en 1953,
Estados Unidos, http://www.magicmakersinc.com [consulta 17-06-16]; Drimark Products Inc.: compañía fundada en 1957, Estados Unidos, http://www.drimark.com [consulta 17-0616]; Edding S.L.: compañía fundada en 1960, Holanda http:// www.edding.com [consulta 17-06-16]; Pentel: compañía fundada en 1963, Japón, http://www.pentel.com (acceso 1706-16); Sanford: compañía fundada en 1964, Estados Unidos, https://www.sharpie.com/en-US/about-us. [consulta 17-0616].

[8] BettasGalicia (2011) http://tintasdegraffiticaseras.blogspot. com.es [consulta 25-06-16]

\section{Bibliografía}

ABARCA, J. (2010). El postgraffiti, su escenario y sus raíces: graffiti, punk, skate y contrapublicidad. Tesis doctoral. Madrid: Universidad Complutense de Madrid, Dpto. de Dibujo.

BERTI, G. (2009). Pioneros del Graffiti en España. Valencia: Servicio editorial de la Universitat Politècnica de València.

BEERKENS, L., MAGER, S. (2005): “Keith Haring: art or graffiti. The restoration of Keith Haring's Drawing on elevator (1986) in the Art Academy Utrecht", en Beiträge zur Erhaltung von Kunstund Kulturgut , 2: 114-122.

BLANCH, I. (2015). “East Side Gallery. Proyecto Internacional sobre el muro de Berlín", en Conservation issues in modern and contemporary murals, Sánchez, M., Shark, W., Fuster, L. (editores). Londres: Cambridge Scholars Publishers, 27-39.

BUZZINI, P., MASSONNET, G (2004). "A market study of Green spray paints by Fourier transform infrared (FTIR) and Raman spectroscopy", en Science\&justice, 44: 123-131.

CARLSSON, B., LOUIE, H. (2013): Street Art. Recetario de técnicas y materiales del arte urbano, Gustavo Gili, Barcelona (versión traducida por Darío Giménez de la original Street Art Cookbook: a Guide to Techniques and Materials, Dokument Press, 2010).

CASTLEMAN, Craig. Los Graffiti, Hermann-Blume, Madrid, 1987.

CIANCABILLA, L. (2015). The sight gallery : salvaguardia $e$ conservazione della pittura murale urbana contemporanea a Bologna. Bolonia: Bolonia University Press.

CHALFANT, H., PRIGOFF, J. (1987), Spray Can Art, Londres: Thames\& Hudson.

FIGUEROA, F., GÁLVEZ, F. (2002). Madrid graffiti. Historia del graffiti madrileño 1982-1995. Málaga: Grupo Editorial Megamultimedia.

FIGUEROA, F., GÁLVEZ, F. (2015) Firmas, muros y botes, autoedición. 
GASTMAN, R., NEELON, C. (2011): History of American Graffiti. Nueva York: Harper Collins Publishers.

GANZ, N. (2010): Grafiti. Arte urbano de los cinco continentes. Barcelona: Gustavo Gili.

GIUDICE, C., PEREYRA, A. (2009). Tecnología de pinturas y recubrimientos: componentes, formulación, manufactura y calidad. Buenos Aires: Edutecne.

GÓMEZ, J. (2014). 25 años de graffiti en Valencia: aspectos sociológicos y estéticos, Tesis doctoral, Universidad de Valencia.

LACHLAN MCD. (2006): In Praise of 70K. "Cultural Heritage and Graffiti Style", Continuum, 20: 471-488.

LA NASA, J., ORSINI, S., DEGANO, B., RAVA, A., MODUGNO, F., COLOMBINI, M.P.(2016). "A chemical study of organic materials in three murals by Keith Haring: a comparison of painting tecniques", Microchemical journal, 124: 940-948.

LEARNER, T. (2004). Analisys of Modern Paints. Los Ángeles: Getty Publications.

LEWISOHN, C. (2008). Street Art, The graffiti revolution. Londres: Tate Publishing.

RAVA et Al (2015). "Keith Haring in Pisa: cleaning and protection of an acrylic painting in an outdoor environment" en Conservation issues in modern and contemporary murals. Londres: Cambridge Scholars Publishers, 184-208.

ROSKO, D (2016): Aerosols (oldschool cans). Autoedición

RUSSELL, J., SINGER, B., PERRY, J, BACON, A (2012). “Investigation of the materials found in the studio of Francis Bacon (19091992)", en Studies in Conservation, 57: 195-206.

RYLAND, S. (2010). "Discrimination of Retail Black Spray Paints", en Journal of American Society of Trace Evidence Examiners, 1: 109-126.

SÁNCHEZ, M. (2016). "Arte urbano: selección de materiales y consecuencias" Mural Street Art Conservation, 3: 40-43.

SANMARTÍN, P., CAPPITELLI, F., MITCHELL, R. (2014). "Current methods os graffiti removal: A review", Construction and Building Materials, 71: 363-374.

SHANGRAW, R. (1971:11). Principles of Aerosol Technology. Nueva York: Reinhold.

STANDEVEN, H. (2011). House paints, 1900-1960 History and use. Los Ángeles: Getty Publications.

VAN DER WERF, I., GERMINARIO, G., PALMISANO, F., SABBATINI, L. (2011) "Characterisation of permanent markers by pyrolysis gas chromatography-mass spectrometry", en Analytical and Bioanalalytical Chemistry, 339: 3483-3490.
WACLAVEK, A. (2011) Graffiti and Street Art, Nueva York: Thames \& Hudson.

\section{Consultas Online}

ABPLANALP, R. (1953). Valve mechanism for dispensing gases and liquids under pressure https://www.google.com/patents/ US2631814 (acceso 22-07-16).

CMC crew (2016), entrevista a Crow http://capmatchescolor. $\mathrm{com} / \mathrm{crow} /($ acceso 15-08-16).

CMC crew (2016), entrevista a Luze, http://capmatchescolor. com/luze/(acceso 15-08-16).

MORENO, J. (2016). 22. Novelty, en madridmepriva, https:// madridmepriva.wordpress.com/2016/02/26/22-novelty (acceso 11-06-16)

NEWMAN, L (1910). Marking Pen, https://www.google.com/ patents/US946149 (acceso 22-07-16).

PASSKATCH, B (1926): Fountain Pen Brush http://www.google. ch/patents/US1601596 (acceso 22-07-16).

ROSENTHAL, S. (1951). Felt pack construction of pens US 3050768 A https://www.google.com/patents/US3050768 (acceso 22-07-16).

SENDRA, A (2007). R.E.A. una historia de graffiti a valència, treballarcansa, https://www.youtube.com/ watch?v=aO7mjclbCdQ (acceso 15-4-16).

SCHILLING, J. (2012). Preserving art that was never meant to last, http://www.dw.com/en/preserving-art-that-was-nevermeant-to-last/a-15933463 (acceso 12-07-16).

SUK, A. (1981). Aerosol water-based paint composition US $4265797 \quad$ A, http://www.google.ch/patents/US4265797 (acceso 24-07-16).

WEIDE, R. (2006). "How an object become a subculture", en Objects, Consumption and Desire, http://www.nyu.edu/classes/ bkg/objectsblog/archives/spray.pdf (acceso 20-03-15). 


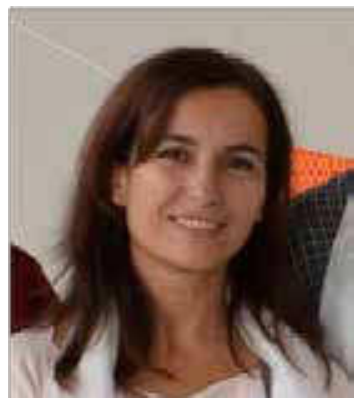

\section{Mercedes Sánchez Pons}

Departamento de Conservación y Restauración de Bienes Culturales de la UPV mersanpo@crbc.upv.es

Doctora por la Universitat Politécnica de Valencia, en el programa de Conservación y Restauración de Bienes Culturales en 2002 y Licenciada en Bellas Artes con la especialidad de Restauración. Desde 2003 es profesora titular del Departamento de Conservación y Restauración de Bienes Culturales de la UPV en los títulos de Grado y Máster. Responsable desde 2006 de la asignatura de máster Conservación y Restauración de Murales Contemporáneos ha dirigido numerosas tesis de grado y máster en relación a este tema.

Forma parte del Grupo de Investigación Taller de análisis e intervención en Pinturas Murales del Instituto de Restauración del Patrimonio de la UPV y pertenece al Micro-Clúster de Investigación (MCI) "Globalización, turismo y patrimonio" en International Campus of Excellence VLC/ CAMPUS.

Ha dirigido y participado en numerosos proyectos de investigación, catalogación e intervención de pinturas murales, nacionales e internacionales, destacando entre los más recientes la restauración de los murales de la iglesia de San Nicolás en Valencia y el Proyecto Europeo Ewaglos: european ilustrated glossary of conservation terms for wall painting and architectural surfaces. Responsable junto a Will Shank y Laura Fuster del congreso internacional Modern and Contemporary Mural Paintings (mcmp2012) es también coeditora y autora del volumen Conservation Issues in Modern and Contemporary Murals (Cambridge Scholars Publishing, 2015).

Desde 2005 forma parte del equipo de Decanato de la Facultad de Bellas Artes de Valencia, como vicedecana de Relaciones con la Empresa, Cátedras de Empresa y en la actualidad con el cargo de Secretaria del centro. 


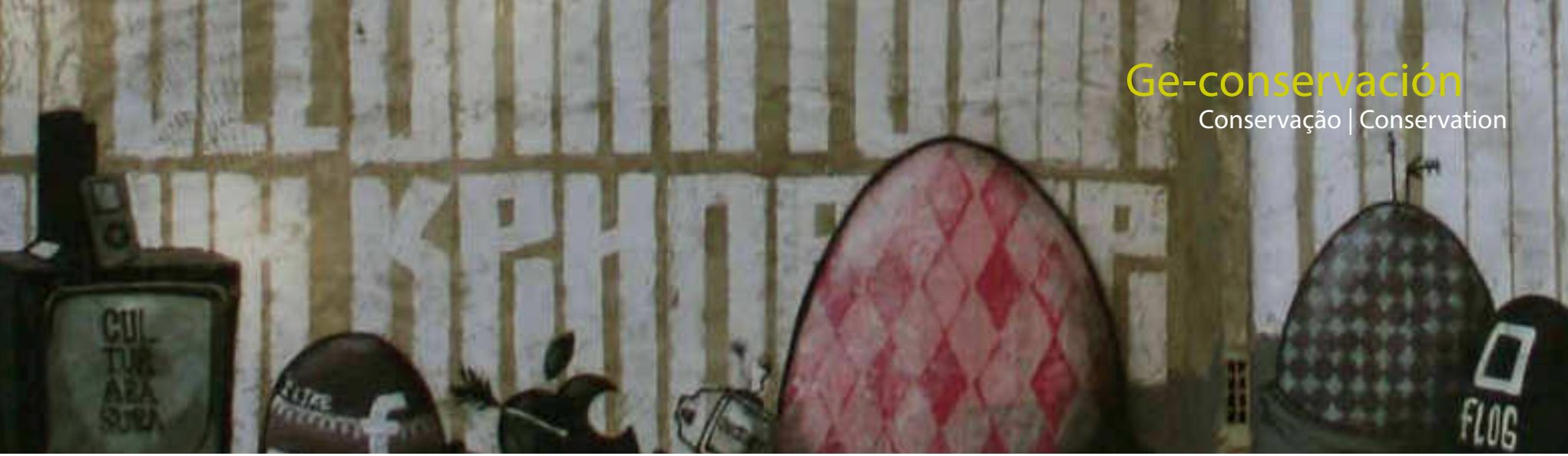

\title{
La conservación del arte urbano. Dilemas éticos y profesionales
}

\author{
Carlota Santabárbara Morera
}

Resumen: La conservación del arte urbano no pasa sólo por la conservación de la imagen y la materia que la soporta, sino también por la conservación de toda una serie de factores ambientales y de contexto que la condicionan para pervivir y evolucionar, en un ambiente urbano. Se plantea una metodología de estudio para la conservación basada en una perspectiva ética.

Palabras clave: restauración, autenticidad, arte urbano, conservación, intencionalidad

\section{The conservation of urban art, ethical and professional dilemmas}

Abstract: The conservation of street art is not only the conservation of the image and the matter which is the support of it. But also the conservation of a whole host of environmental and contextual factors, rather condition to survive and develop, in an urban environment.. The methodology of study showed is based in an ethics perspective.

Key words: restoration, authenticity, street art, conservation, purpose

\section{Introducción. Objetivos y metodología}

La conservación del arte urbano constituye un campo incipiente dentro del ámbito de la conservaciónrestauración. Existen ya algunos ejemplos donde el interés social o institucional ha llevado a la documentación, restauración e incluso al arranque y musealización de algunas obras, promovidas, en la mayoría de los casos, por intereses turísticos y económicos.

El objetivo de este trabajo es plantear preguntas que arrojen luz sobre los límites de lo que es lícito a la hora de intervenir en las manifestaciones artísticas urbanas y con qué criterios éticos. Para ello, es aconsejable partir, en primer lugar, de la comprensión y definición del objeto de estudio.

Se propone analizar el arte urbano como arte actual, popular, que se manifiesta de un modo completamente libre a nivel creativo, tanto desde el punto de vista técnico como material y que se apropia del espacio público utilizándolo como contexto de comunicación e instrumento de expresión. Es necesario revisar el nivel conceptual de las obras para diferenciar claramente cómo afecta, por un lado, a las manifestaciones creadas de forma espontánea, furtiva y libre, y por otro, a las intervenciones que son comisionadas desde el ámbito institucional, ya que el motivo de su génesis determina su razón de ser y por lo tanto, su identidad.

La metodología propuesta traza un estudio en paralelo con otras obras conocidas ya conservadas o restauradas de Arte Contemporáneo, sobre las que se han podido plantear estrategias que permiten un análisis intelectual previo y en las que se observan similitudes conceptuales o materiales similares a algunas de arte urbano. 


\section{Arte furtivo y arte de encargo}

En primer lugar es imprescindible conocer y describir la naturaleza del arte urbano para poder plantear estrategias y metodologías de conservación. Para hacer una descripción de los valores que definen una obra de arte urbano se deben perfilar primeramente sus características más genuinas. En un primer grupo estarían las obras en las que se busca identificar el impulso creativo con su forma de creación, como es el caso de los writers, que son referencia y paradigma de ilegalidad. Como ejemplos de esta manera de actuar se encuentra Kirax, artistas más activistas como Vermibus, que interviene sobre las fotografías publicitarias de las marquesinas, o Banksy, el más mediático, que realiza sus pinturas de manera provocadora en las calles de todo el mundo y siempre con un mensaje político. En estos casos, plantear la conservación de expresiones artísticas urbanas resulta bastante contradictorio, porque se trata de un tipo de intervenciones anónimas, con un trasfondo que invita a la reflexión y a la reacción. Sin embargo, con ellas se ha producido un proceso de transformación social, donde lo que en origen fue un fenómeno denostado y rechazado, por incomprendido y por su carácter ilegal o vandálico, ahora se recibe como una intervención estética que da valor añadido a las ciudades, genera un creciente interés social, cultural y turístico, aportando un atractivo carácter artístico al ámbito urbano. Artistas como ROA, Borondo o Blu viajan por toda Europa dejando testimonio de su creatividad, llenando las calles de murales y generando la expectativa de poder encontrar alguna de sus intervenciones en cualquier lugar recóndito. De este modo, se ha ido generando un atractivo que despierta en la sociedad el deseo y la necesidad de pertenencia y permanencia de obras urbanas. Sin embargo, esa necesidad de posesión y deseo de perpetuarlas se ha producido a posteriori, por un proceso de reconocimiento social, ya que no se crearon con la intención explícita de perdurar en el tiempo. Por lo tanto, el debate que se genera en torno a la conservación o no del graffiti y el arte urbano parte también de un reconocimiento de su valor artístico, en cuanto a objeto de galería.

En segundo lugar, estarían las obras cuyo interés se centra en el concepto mismo de su representación. Restaurar apresuradamente por el mero hecho de conservar una obra, sin analizar los motivos por los que se hace, llevaría a cometer el mismo error que se cometió al restaurar y sustituir la esquina de grasa en caja de cartón de Josep Beuys (Fettecke in Kartonschachtel), y que, al ser adquirida por el Stedelijk Museum de Amsterdam en 1972, se consideró que no sólo se debía conservar, sino también restaurar. Cuando el proceso de deterioro de las grasas animales presentes en la obra provocaron la descomposición de los ácidos grasos y comenzó a desprender un olor a putrefacción muy desagradable, se decidió sustituir por otro material que se asemejara estéticamente, pero con una composición diferente. Entre los materiales elegidos se utilizó mayoritariamente cera de abejas (que era mucho más estable al proceso de degradación) pero la sorpresa del restaurador y del museo fue cuando el propio artista consideró que esa restauración era completamente errónea y la obra había perdido su valor. Según el propio Beuys, la restauración no era una opción viable, puesto que el proceso de deterioro formaba parte de la evolución de la propia obra.

Este ejemplo nos sirve para ilustrar lo que ocurre con tantas obras de arte que son restauradas y conservadas manteniendo su estética aparente, pero olvidando que su importancia radica en otra parte, al igual que puede llegar a ocurrir con el arte urbano, donde la voluntad argumentada del artista debe ser conocida con respecto a las expectativas de conservación y restauración.

En tercer lugar, no sólo abordaremos el caso de las obras de arte urbano espontáneas, sino que también nos atañe, y cada vez más, otro tipo de intervenciones artísticas comisionadas, enmarcadas dentro de un festival o proyecto institucional. Estas intervenciones ofrecen unas posibilidades de conservación quizá más reconocibles, ya que los muros son ofrecidos como soportes artísticos y las obras proceden de encargos. Hoy en día, son muchos los ayuntamientos que organizan festivales de arte urbano convocando a artistas para realizar intervenciones en la calle que mejoran estéticamente las zonas degradadas de las ciudades, como es el Under Pressure de Toronto, el ONO'U Battle en Tahití, o el Nuart en Stavanger, en Noruega. En España, los más conocidos son el Festival Asalto en Zaragoza y Open Walls de Barcelona.

De hecho, cada vez son más difusas las transiciones entre el arte, la arquitectura y la planificación de la ciudad, en cuanto a diseño urbano y sus usos. Y es en esta línea tan sutil donde las políticas de gentrificación manipulan el arte urbano para apropiarse del espacio público y con una apariencia amable y silenciosa llegar a cambiar el aspecto de las ciudades, al propiciar la especulación inmobiliaria.

Sin duda, la expresión artística cambia radicalmente en cuanto a contenido, intención y modus operandi cuando se trata de intervenciones realizadas bajo demanda, y aunque siempre se realizan en el espacio público, sus características al servicio de intereses de terceras personas lo singulariza y diferencia del resto de intervenciones de arte urbano independiente. La periodista especializada en cultura Paloma Fidalgo lo define como "la versión aseada del grafiti" $y$ es que, cada vez más, las instituciones, a través de festivales y convocatorias artísticas, están propiciando la práctica de un "muralismo contemporáneo" políticamente correcto. Se trata de creaciones cuyo origen e intención es notablemente diferente a las manifestaciones conocidas dentro del Postgraffiti, que ahora se instalan como obras decorativas y tal vez con un merchandising excesivo. Por lo tanto, la intención con la que son creadas no solo es legal, sino que se ha institucionalizado $y$, por tanto, es susceptible de ser conservado y restaurado sin que su concepto se vea alterado. 


\section{Los límites de lo efímero}

Ante la posibilidad de conservar o no las manifestaciones artísticas desarrolladas en el ámbito urbano, una de las premisas fundamentales desde la que hay que partir es la de conocer qué es lo que se considera fundamental en ellas. Si su valor radica en la imagen creada, en la experiencia técnica o en la interacción social de un lugar determinado. Para garantizar la permanencia de su autenticidad como manifestación artística habría que conocer, en primer lugar, su identidad creativa, ya que tal vez la intención de conservar y "congelar" una creación se puede contradecir con la razón por la que fue concebida.

En el arte urbano, las intervenciones tienen tendencia a transformarse con el paso del tiempo e, incluso, a ser borradas de un modo natural, tal es el caso, por ejemplo, de las intervenciones que usan el papel, como es el caso de las producciones de Andrea Btoy, que gusta también de elegir soportes en los que se nota el deterioro y así las alteraciones aportan un valor estético en la materia degradada.

En este grupo es interesante la reposición de una obra del artista parisino Xavier Prou, Blek le rat, conocida como La Madonna. Situada en la ciudad alemana de Lepzig, fue creada como efímera, se perdió y posteriormente se recuperó. En 2012 se eliminaron los carteles publicitarios que habían cubierto la imagen durante más de dos décadas, se limpió y fue repintada por el propio artista, protegiéndose con un metacrilato y colocándose una cartela explicando la historia de la obra y cómo estaba dedicada a la que fue su esposa. En este caso, es importante no sólo la restauración y protección, sino también la difusión del valor de una obra que es reconocida y valorada socialmente como tal. Se trata de un ejemplo no sólo de conservación, sino de recuperación de una imagen icónica, a partir de la reproducción con la plantilla original y por el propio artista.

Llegados a este punto, se tendría que plantear el valor de este tipo de obras, no tanto por su autenticidad material, sino por su valor simbólico, que es lo que la hace que sea digna de conservarse y reproducirse. Sin lugar a duda, tal y como preconizaba el filósofo alemán Walter Benjamin, estamos en la era postaurática, en la que la imagen es reproducible y se desprende de su aura de obra única.

En esta misma línea, podemos mencionar cómo en 2015, se realizaron dibujos con pintura plástica sobre el mobiliario urbano de las marquesinas del tranvía en el Festival Asalto de Zaragoza. Sin duda todas estas creaciones fueron concebidas con la certeza de ser efímeras, y se podría decir que de forma performática, procesual, de interacción con el medio, con la comunidad, para dialogar, provocar, contar, o tan sólo impactar en un momento espacio-temporal concreto, a lo que hay que añadir la degradación prematura que sufrieron por estar realizadas sobre cristal. [Figuras 1 y 2 ].

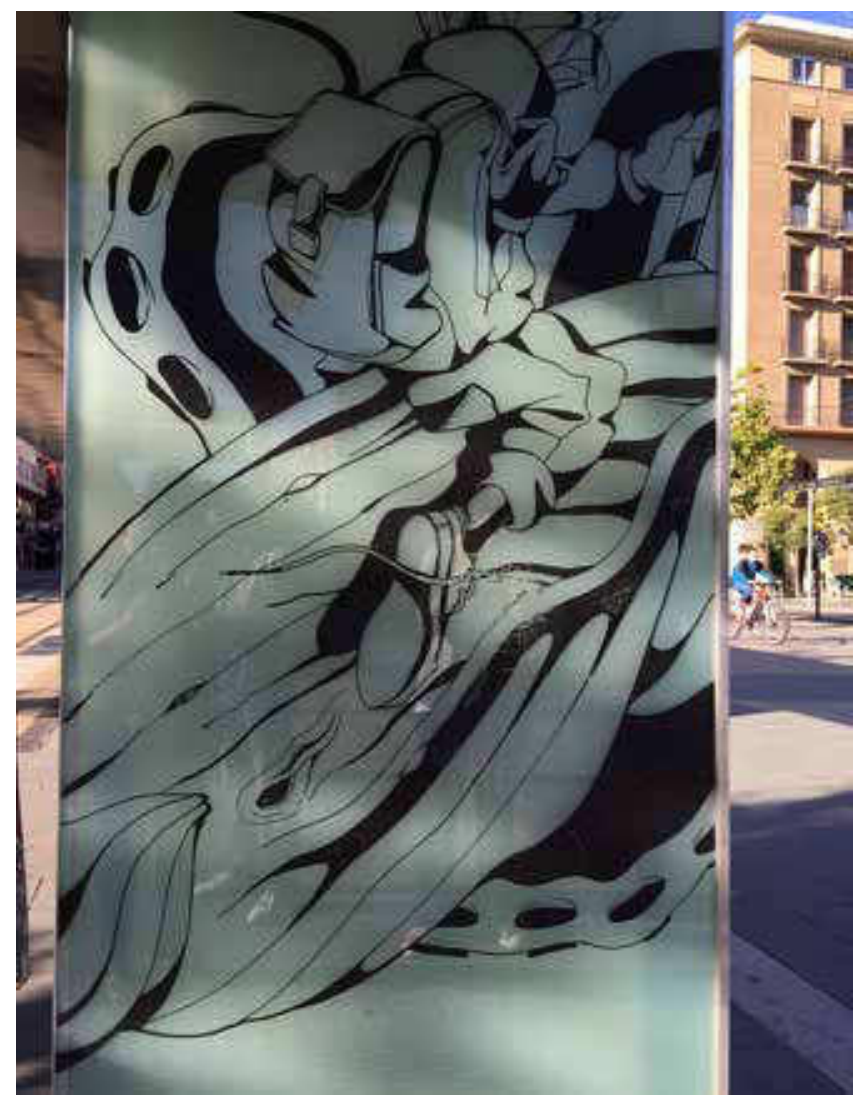

Figura 1. Festival Asalto de Zaragoza. Pintura acrílica negra sobre vidrio. Foto de la autora

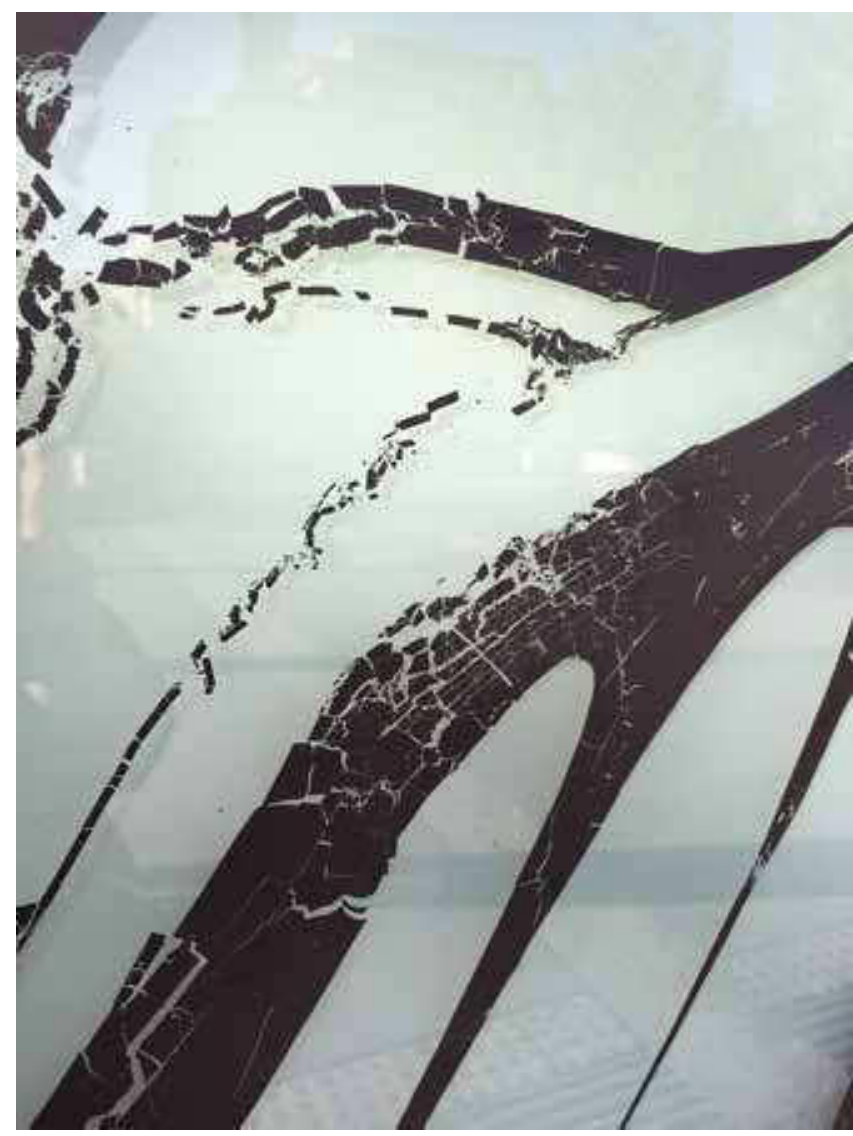

Figura 2. Festival Asalto de Zaragoza. Pintura acrílica negra sobre vidrio. Detalle de degradación. Foto de la autora. 
El concepto de arte efímero, que nace con una voluntad explícita de no ser conservado, existe también en el panorama del arte contemporáneo, donde hay numerosos ejemplos de obras creadas con una intención efímera y cuya conservación o restauración ha llegado a ser motivo de polémica. Tal es el caso de instalaciones de corte conceptual, como es el caso de la obra de Zoe Leonard Strange Fruit (for David), creada en 1993, consistente en una instalación de 302 cáscaras de diferentes frutas que fueron vaciadas. Se trataba de pieles de diferentes frutas que una vez secas, fueron cerradas con zurcidos, decorándolas con botones, cremalleras o suturas de hilo. [Figura 3].

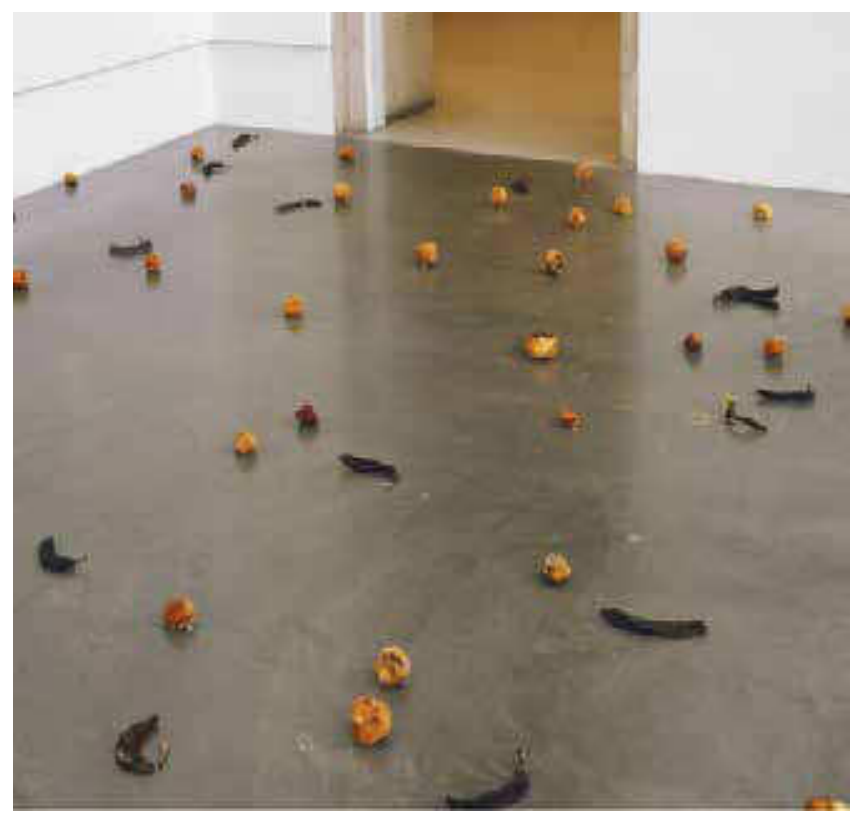

Figura 3. Zoe Leonard. Strange Fruit. Philadelphia Museum of Art. Purchased with funds contributed by the Dietrich Foundation and with the partial gift of the artist and the Paula Cooper Gallery, 1998. http://www.philamuseum.org/collections/ permanent/92277.html

Esta obra tenía una intención explícita al mostrar su degeneración material, dejando que las pieles de fruta se pudrieran hasta que dejaran de existir. Se trata de la representación simbólica del luto después de la muerte de un amigo, reflejando así el tema de la transitoriedad de la vida, como ya se hacía en el barroco con las vanitas. El problema surgió cuando fue adquirida por el Philadelphia Museum of Art, que tenía la intención de conservarla, pero respetando el derecho moral a decidir del autor, hubo que mantener la intención original con la que fue creada y finalmente se dejó autoconsumir hasta desaparecer. Este no deja de ser un ejemplo de cómo el arte contemporáneo va más allá de la mera representación formal, involucrando conceptos semióticos que es necesario conocer y respetar, al igual que ocurre con el arte urbano.

El propio proceso creativo, en la parte que afecta a la técnica elegida, va a definir su expectativa de supervivencia y qué aspecto de la obra va más allá de lo puramente pictórico; tal es el caso de Borondo, que realiza dibujos sustractivos por medio de rayados sobre los cristales de escaparates en desuso, pintados de blanco, creando un efecto de claroscuro muy impactante, pero que claramente están abocados a desaparecer en cuanto el local sea reabierto y los cristales deban lucir transparentes y limpios para un nuevo uso o según el gusto del nuevo propietario. [Figura 4].

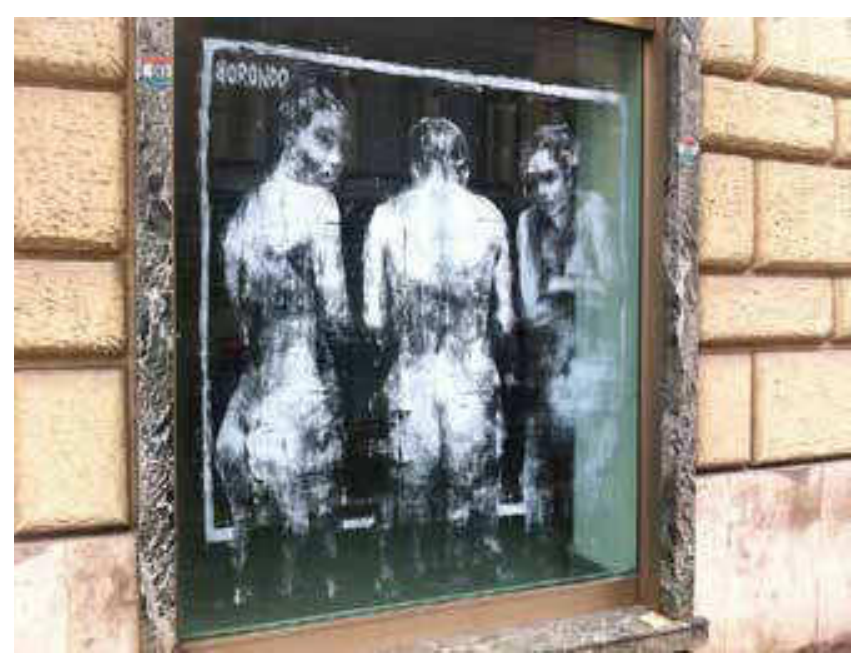

Figura 4. Borondo. en Via Nazionale. Roma. Foto de la autora

Por otro lado, es importante tener en cuenta la voluntad de los artistas por mantener el anonimato y no ser localizados, para consultarles si su obra es efímera o no. La inmediatez de respuesta a un hecho social o el clamor reivindicativo planteado desde un punto de vista político-social, propone una serie de cuestiones por resolver: desde la necesidad de permanencia y conservación, hasta el respeto a un devenir temporal y procesual propio de un arte efímero vinculado a un momento concreto que, a su vez, está inscrito en un contexto socio-cultural determinado y por lo tanto, exento de la posibilidad de ser patrimonializado.

\section{Paralelismo metodológico}

Si nos centramos en la estrategia conservativa, y desde el punto de vista documental, se podría adoptar el método de trabajo planteado por el grupo de investigación de la Foundation for the Conservation of Modern Art de Ámsterdam, que ya en 1993 propuso un modelo para guiar al proceso de decisión que precede a la restauración. ${ }^{1}$ En relación al método mencionado se trata de un esquema que ofrece una discusión preliminar para abordar el camino que llevará al razonamiento y a la toma de decisiones. Este modelo plantea que, en primer lugar, es necesario recopilar toda la información referente a la obra, tal como las noticias técnicas e históricas, así como averiguar el significado y la poética de la intencionalidad artística con la que fue creada, para, a continuación, detallar el estado de conservación y, posteriormente, determinar si la alteración del material 
puede llegar a cambiar el sentido original de la obra. Del mismo modo, en este proceso de investigación, su estado de conservación ha de compararse con el resto de obras de esa misma corriente artística, autor, estilo y mensaje específico, determinando que, sólo si el deterioro es de tal envergadura como para hacer ininteligible el trabajo, se puede programar la intervención.

Desde la perspectiva legal, y teniendo en cuenta el conflicto de intereses presente en las obras de arte urbano, se debe plantear la doble condición observada en estas obras: por un lado, la propiedad intelectual, que es del artista, y por otro, la propiedad de la obra a nivel de pertenencia, que es del propietario de la casa que contiene los muros intervenidos, en el caso de que se trate de una fachada. Ambas propiedades entran en conflicto desde el momento en el que una obra es realizada apropiándose del espacio urbano; el artista conserva el "derecho moral" mientras que el dueño del soporte físico tiene el derecho legal de su propiedad. Aunque la obra deja de pertenecer al artista, desde el momento que la entrega a la colectividad, al espacio urbano, su "derecho moral" impide que se especule con ella, sobre todo si nunca tuvo la intención de comercializarla o de entrar en los canales establecidos del mercado. En este caso, se crearía un conflicto que llevaría a recurrir a la jurisprudencia y analizar casos similares.

Desde el punto de vista ético, el abanico de opciones, así como todas sus variables, ha de ser examinado mediante la identificación de las posibles soluciones técnicas, distinguiendo lo que es factible desde el punto de vista práctico de lo que es adecuado desde el punto de vista ético. Basándose en esta premisa, se debe hacer una elección de compromiso entre las exigencias expresadas, identificando la solución que sea considerada como un mal menor, sin olvidar los problemas prácticos, la unicidad de la obra o los aspectos legales. Por lo tanto, el proyecto de restauración vendría a ser un instrumento de reflexión, que garantizaría la unidad de método y el conocimiento profundo de la obra, y en consecuencia, el restaurador actuaría como un mediador entre la conservación de la parte material de la obra y su parte intelectual.

\section{El margen de los criterios de intervención}

En la conservación de obras en las que intervienen y tienen opinión muchas personas, hay que partir de la certeza de que se pueden dar opciones extremas de conservación, por la diferencia de puntos de vista y objetivos que nada tienen que ver con la restauración, pero en los que ésta se convierte en una opción necesaria justificada fundamentalmente por exposiciones, proyectos comisariados o decisiones del dueño del soporte. Entre las opciones están las intervenciones del artista, los arranques y la musealización.
De la mano del propio artista, se pueden dar situaciones en las que éste quiere realizar una modificación más allá de su conservación, llegando a crear una obra nueva, traspasando los límites de la conservación y alterando el original, el cual habría dejado de existir. Por ello, la decisión debería de tomarse siempre de acuerdo con el propietario del soporte.

También se suele dar, demasiado a menudo en el arte urbano, la posibilidad de decidir el arranque de la pintura del muro para su traslado y conservación en soportes inertes, con el consiguiente cambio de contexto. La obra inmueble se convertiría entonces en mueble y variaría también su tipología. Este hecho, que paraliza la degradación material a la que están expuestas las obras pintadas a la intemperie, distorsiona por completo la propia concepción como arte público y urbano, no sólo en su sentido original, sino especialmente en su relación con el entorno, que resulta alterado en su efecto visual y emocional, así como tantos otros valores que son de gran importancia en la percepción experiencial de la obra urbana.

Es importante por ello tener en cuenta los valores de la obra en su restauración y no al revés, porque si no, se crearía una falsa historia estética, que llevaría a procesos tales como el de la realización de réplicas. Este tipo de actuaciones, aunque hicieran referencia al emplazamiento inicial, podrían desencadenar la musealización de las copias y la pérdida del original.

Es necesario, por tanto, desarrollar una reflexión preliminar a la restauración de una obra de arte urbano, sobre todo en cuanto a las opciones de acción, dado que es el artista el que determina la naturaleza perenne, transitoria o efímera de su obra, los materiales elegidos y cómo usarlos, de acuerdo a unos criterios estéticos específicos. Esta cuestión adquiere cierta complejidad cuando la recopilación de datos técnicos debe hacerse a través de sus herederos, sobre los que recaería el derecho moral del artista tras su fallecimiento, ya que sería un intermediario el que tendría que interpretar la voluntad del artista.

Es interesante observar cómo la percepción de una obra y los valores a conservar varían de una persona a otra, incluso dentro del ámbito profesional e institucional. Por ello, es necesario un programa conjunto de investigación y documentación que permita catalogar las obras y definir los principios generales de las intervenciones, un requisito que se ha desarrollado en el campo de la restauración del arte contemporáneo en la International Network for the Conservation of Contemporary Arte $(I N C C A)^{3}$, en torno a los procesos y protocolos de recopilación de información directa de los artistas y de su entorno, lo que permite la elección de unos criterios de intervención objetivos y universales.

“La restauración de obras de arte contemporáneas es muy diferente a la de las obras llamadas tradicionales, 
pues carece de la tradición de una práctica secular y, por supuesto, de una teorización propia" (Martínez Justicia, 2000: 443), por ello, los retos que se presentan ante la restauración de arte urbano requieren de planteamientos también diferentes.

Hoy en día, el arte se sirve de un tipo de comunicación desigual, ya no se trata de la mera representación formal, sino que va más allá, transmite, comunica, provoca y sobre todo crea experiencias. Por ello, lo importante es averiguar dónde reside la autenticidad de esas manifestaciones para evitar que dejen de tener sentido en el ámbito urbano.

En las teorías conservativas alemanas (Hiltrud Schinzel, 2003), se plantea la recuperación del Kunstwollen (la voluntad artística) expuesta ya por el historiador del arte austrohúngaro Alois Riegl a finales del siglo XIX (18581905), superando la restauración crítica. Del mismo modo la fenomenología del filósofo moravo Edmund Husserl (1859-1938) nos puede acercar más a un planteamiento conservativo basado en la experiencia, la emoción y las sensaciones que nos ofrece el arte urbano, buscando la recuperación de la intencionalidad, rescatando el pensamiento y la voluntad del artista y diferenciando entre lo que es la autenticidad y la originalidad. Debe existir la consciencia de la intención artística como valor fundamental a conservar, por lo que es de vital importancia averiguar por qué y para qué fue creada la obra de arte urbano, para así poder conservarla.

Por lo tanto, podemos afirmar que, si la restauración consiste en preservar la autenticidad del arte, la misión del conservador-restaurador será la de recuperar la intención con la que se creó, la voluntad de producir experiencias y emociones y en definitiva, recuperar el sentido que provocó su creación original. Estas serán las bases en las que se marquen las pautas de la actuación a realizar.

\section{La restauración dinámica o cómo conservar el cambio}

En la concepción occidental de la conservación, existe un gran empeño por la conservación de la materia, pero tal y como afirmaba el filósofo Theodor W. Adorno, el arte es algo más que materia y forma, ya que observó cómo en el arte, al igual que en la música, se necesita de un proceso temporal para su desarrollo, es decir, un carácter social en el que circunscribirse para poder existir. Resulta de gran clarividencia la diferencia que realiza el filósofo Massimo Carboni, desde un punto de vista teórico y filosófico, entre el arte tradicional y el arte contemporáneo y que sería pertinente recuperar aquí para analizar el arte urbano, lo que él Ilama: "la obra de la contingencia, en la que se alude, en el acto mismo de presentarse, a su propia desaparición, a una intencionada e irremediable caducidad." (Carboni, 2014:9)
De este modo, el arte urbano implica una percepción estética colectiva y esa experiencia comunitaria viene vinculada casi siempre a un momento concreto político-social del que no puede ser separado sin correr el peligro de aparecer descontextualizado, y por lo tanto, ser claramente transitorio y efímero. En este sentido y en relación a la Teoría estética de Adorno (Adorno, 1975), Carboni cuestiona cómo "la idea de duración de la obra es modelada sobre su categoría de posesión"(Carboni, 2014.12), es decir, presenta como la creación contemporánea va perdiendo paulatinamente su carácter de objeto y tiende a convertirse en un gesto, una acción o un proceso, por lo que podríamos ponerla en paralelo con la danza o la performance, es decir, un arte sin objeto físico como soporte, lo que nos llevaría a cuestionarnos hasta qué punto se puede conservar una acción. Para el filósofo italiano, la memoria es la metodología correcta y paradójica para respetar su legado estético-cultural y conservarlo para el futuro. En este sentido, cuando el historiador y crítico de arte Cesare Brandi hablaba del máximo respeto al original, hoy en día se debe entender "lo original" o "lo auténtico" ya no como un valor que reside en la materia, sino en la idea creativa, en la expresión artística o en la experiencia sensorial, es decir, en el proyecto o en el concepto artístico en sí mismo.

Por ello, y en relación a la conservación del arte urbano, tal vez lo más adecuado sería admitir que se debe conservar el cambio como una metodología que implique dinamismo en su propia definición. Precisamente, en la Conferencia de Nara, (Japón, 1994) se estableció una teoría que se inclinaba hacia una restauración dinámica, en lugar de una conservación estática, que llegase a congelar el objeto. Sin duda, conservar el cambio es quizá el reto más interesante para los restauradores de arte urbano de hoy en día. Por lo tanto, podemos aseverar que el arte ha evolucionado desde mitad del siglo XX partiendo de una representación material que constaba de un soporte físico y la representación de una imagen, hacia un arte basado en la percepción de un nuevo lenguaje conceptual, donde evidentemente continúa existiendo la materia como soporte de una imagen, pero esta materia evoluciona adquiriendo nuevos significados, sobre todo en el arte urbano, donde los aspectos políticos, sociales y culturales se entremezclan.

\section{Arrancar o conservar "in situ"}

Una vez analizado el objeto de estudio, y su definición, así como los valores que engloba, es obligado hacer las siguientes preguntas: ¿se debe conservar? ¿cómo se debe llevar a cabo ese proceso?

En primer lugar es necesario hacer un análisis cuidadoso a nivel físico, es decir, de los materiales que lo componen, y en segundo lugar averiguar la 
intencionalidad artística para conformar una propuesta conservativa a través de la perspectiva aportada por las distintas profesiones: los conservadores, historiadores y críticos, científicos y artistas, para evaluar sobre todo la necesidad de la intervención y las posibilidades operativas diferentes.

Cabe mencionar que existen ya bastantes ejemplos de arranques de graffitis y de murales urbanos que han sido comercializados con la finalidad de especular con creaciones que no pertenecen a las galerías o casas de subastas, pero que se apropian de ellas para beneficio propio. Es el caso de la subasta de los murales expoliados de Banksy procedentes de diferentes ciudades de Alemania e Inglaterra, obras que se vendieron por más de tres millones de euros sin la autorización ni la consulta al artista. Estas obras fueron expuestas sobre estructuras metálicas en el lujoso hotel ME de Londres, en una muestra llamada: Banksy robado, que precedió a una subasta organizada con fines benéficos. Pero estas exposiciones, con una expectativa claramente mercantilista, no son casos aislados ni nuevos, como el caso ya conocido de la exposición organizada en 1979 en Roma The Fabulous Five: calligraffitti di Frederick Brathwaite e Lee George Quinones, organizada en la Galleria La Medusa. Pero lo que llama más la atención ya no es sólo la incorporación del street art a nivel comercial, sino también la actitud de la institución museística, desde donde se intenta patrimonializar sin justificación alguna un tipo de arte que no debe ser introducido en un espacio museístico, sin un razonamiento previo. Este fue el caso en 1984 de la exposición Arte di frontiera. New York Graffiti, realizada en la Galleria Comunale d'Arte Moderna di Bologna, o Street Art. Banksy \& Co. L'arte allo stato urbano llevada a cabo este mismo 2016, en Bolonia (Italia), en la cual, con la idea de mostrar la evolución del graffiti y arte urbano se exponían piezas de los años setenta y ochenta de Nueva York y proponía una comparativa con Italia. Para esta ocasión se expusieron murales del artista urbano Blu, que habían sido arrancados de sus fachadas y musealizados, aparentemente sin su permiso. Sin duda se trata de la descontextualización de unas obras generadas por y para un ambiente determinado, en las que la imagen permanece, pero desaparece su identidad y su relación con el entorno que la generó.

Estas manifestaciones artísticas deberían permanecer in situ en el lugar donde fueron creadas. No se puede olvidar que el arte urbano, el graffiti y el muralismo comisionado o no, no puede desvincularse de su lugar de creación ya que éste forma parte de su propia definición como lenguaje de comunicación social en un contexto urbano determinado. Además, cabe señalar que la originalidad es un valor que tiene diferentes acepciones según el ámbito de su percepción. Por ejemplo, en el mercado del arte, la originalidad es un valor determinante para otorgar una cotización en su tasación económica, sin embargo para los visitantes de un museo es garantía de experiencias estéticas auténticas. A esto hay que añadir que desde el punto de vista de la conservación-restauración, dentro de su concepción de la originalidad del arte, la originalidad se basa en que un objeto ha sido realizado sin falsificaciones, tanto en el carácter material, como técnico e histórico. En este sentido la conservadora Cornelia Weyer afirma cómo "la existencia de una gran proporción de material original no es sólo el criterio para que una obra de arte sea original" (Weyer, 2010:21). Al hilo de esta argumentación, en el caso del arte urbano, la originalidad de una obra radica en que conserve la característica de su propia definición de "urbano", es decir que permanezca in situ en el lugar para el que fue realizada.

En cuanto a los diferentes intentos de musealización del arte urbano, ya no se valoraría sólo su arranque mural, sino incluso el de su réplica, como es el caso de la realización de calcos. La obra de Keith Haring Todos juntos podemos parar el sida, que realizó en 1989 en el barrio del Raval de Barcelona, es un claro ejemplo de ello. Este mural, realizado sobre un edificio que posteriormente fue demolido, se ha reproducido usando el calco del original, lo que supone una "copia" de una obra de arte urbano que ha perdido su identidad como auténtica, ha dejado de ser autógrafa para pasar a ser realizada por el equipo de restauradores del Museo de Arte Contemporáneo de Barcelona (MACBA), asumiendo, por parte de todas las partes implicadas, que su identidad como obra radica en la imagen misma que es reproducida. En cuanto a la concepción de reproductibilidad, debemos plantear cómo la imagen estética tiene una evidente notoriedad en la sociedad actual y cómo su reflejo puede también estar contemplado en el arte y en su conservación. Aunque, en el arte urbano, se debe entender más allá de la representación formal que es fijada en un muro, una marquesina o el propio asfalto de la ciudad.

El arte urbano desarrolla su propia identidad a partir de diferentes factores que abarcan desde su contexto y localización, hasta el hecho de ser ilegal y furtivo, por lo que el apropiacionismo desde la institución no deja de ser un proceso forzado que genera la momificación de un arte vivo y callejero, para convertirlo en objeto. Estas obras fueron creadas con una fuerza de expresión y comunicación colectiva y social que, dentro de un museo, carece de significado.

\section{Conclusión}

La conservación del arte urbano presenta una dialéctica entre la estructura material y la conceptual, en la que se han de tener en cuenta una gran cantidad de variables. En cuanto a la estructura material, lleva implícito el estado de conservación, en el que hay que incluir los 
cambios sufridos a lo largo del tiempo. Además de su integridad estética, es importante el reconocimiento del significado intangible de la intervención, el mensaje que transmite y su contexto urbano en la convivencia y diálogo con la colectividad, lo que el filósofo alemán Martín Heidegger (1889-1976) llamaba el world de la obra de arte.

Por ello, para respetar la autenticidad de la creación artística, no sólo hay que tener en cuenta la conservación del material como documento histórico, sino también la obra como creación en su concepto más global, abarcando conceptos como la autenticidad, la intencionalidad, el contexto y el mensaje intelectual.

La restauración no puede limitarse a documentar, fotografiar y geolocalizar el arte que emerge en las medianeras de las ciudades, y aunque no se pueda pretender enmarcarlo dentro de lo que se considera bien patrimonial, se deben valorar diferentes vías de conservación de algunas obras relevantes, siempre basadas en una metodología conservativa fundamentada en la ética de la profesión. La decisión de conservar o no el arte urbano dependerá de la voluntad de diferentes agentes: de los artistas, de una comunidad vecinal y de su propietario, entre otros. En definitiva, de las personas que habitan el espacio circundante y a las que pertenece el paisaje visual, las que conviven y las que, durante un periodo de tiempo determinado, se sentirán identificadas con esas manifestaciones artísticas. Por todo ello, el arte urbano ha de permanecer, en la medida que sea valorado socialmente, como creación potencialmente conservable y restaurable, pero siempre en su contexto original, en la calle, que es el medio donde y para el que las obras fueron creadas.

\section{Notas}

[1] Proceso desarrollado sobre la base de un modelo elaborado de Ernst van De Wetering para el arte tradicional, Modern art, who cares?, Ámsterdam, The Foundation for the conservation of modern art and the Netherlands Institute for Cultural Heritage, 1999.

[2] http://www.bez.es/887119047/instituciones-arte-urbanografiti.html [consulta: 20/09/16]

[3] https://www.incca.org [consulta: 20/09/16]

\section{Bibliografía}

BRANDI, C. (1963). Teoria del Restauro, Einaudi, Turín.

CARBONI, M., (2014). "Tutela, conservazione e restauro dell'arte contemporanea: I'orizonte filosofico". En Tra memoria e oblio. Percorsi nella conservazione dell'arte contemporanea, Roma: Lit Edizioni.
DE DIEGO, Jesús. (2000). Graffiti, la palabra y la imagen: un estudio de la expresión en las culturas urbanas en el fin del siglo XX. Barcelona: Los Libros de la Frontera.

FERNÁNDEZ, B. Lorente, J.P. (2009). Arte en el espacio público: barrios artísticos y revitalización urbana. prensas Universitarias Zaragoza. Zaragoza.

FIGUEROA-SAAVEDRA. F. (2006). Graphitfragen. Una mirada reflexiva sobre el graffiti. Madrid: Minotauro Digital D.L.

GARCÍA GAYO, E. (2011). ¿Se debe conservar el arte urbano basado en la premisa de: "piensa, crea, actúa y olvida"? en: Conservación de Arte Contemporáneo, $12^{\circ}$ Jornada. MNCARS. GE-IIC. Madrid.

HERMAN ABEN, K., (1995). "Conservation of Modern Sculpture at the Stedelijk Museum, Amsterdam. En From Marble to chocolate. The conservation of Modern Sculpture. Edited by Jackie Heuman. Tate Gallery Conference. 18-20 september. Achetype Pbulications Ltd. 105-109.

LLAMAS PACHECO, R. (2010). Conservar y restaurar el arte contemporáneo: un campo abierto a la investigación. Valencia: Universitat Politècnica de València D.L.

MARTINEZ JUSTICIA, J.M., (2000). Historia y Teoría de la Conservación y restauración artística, Madrid, Ed. Tecnos.

MERRILL, S. (2014). "Keeping it real?: subcultural graffiti, street art, heritage and authenticity". International Journal of Heritage Studies: 1-21

RUBIA LÓPEZ, EDL. (2013). Arte urbano: grafiti y postgrafiti. Acercamiento a la problemática legal y patrimonial en torno a su conservación. (http://hdl.handle.net/10251/39193) Máster oficial en CYRBBCC. UPV.

SCHINZEL, H., (2003) "La intención artística y las posibilidades de la restauración", en ALTHÖFER, H., Restauración de pintura contemporánea, tendencias, materiales, técnica, Madrid, Editorial Istmo, 45-64.

SUREDA, J., GUASCH, A.M., (1987) La trama de lo moderno, Madrid, Akal/Arte y estética.

TEMKIN A. Stange Fruit. (1999). En “Corzo, M.A, Mortality immortality? Los Angeles: The Getty conservation institute.

WEYER, C., (2010) "Media art and limits of established ethics of restoration", en SCHÄDLER-SAUB, U., WEBER, C., Theory and practice in the conservation of modern and contemporary art: reflections on the roots and the perspectives: proceedings of the international symposium held. 13-14 January 2009 at the University of Applied Sciences and Arts, Faculty Preservation of Cultural Heritage, Hildesheim, Archetype Publications Ltd. Londres. 


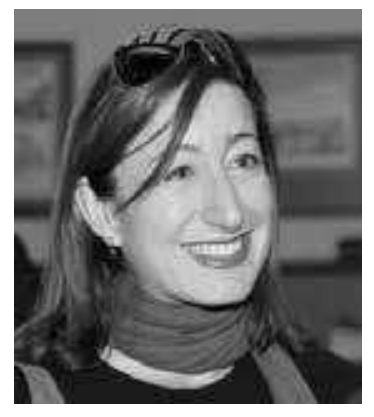

\section{Carlota Santabárbara Morera}

Universidad de Zaragoza

carlotasantabarbara@gmail.com

Doctora en Historia del Arte por la Universidad de Zaragoza y diplomada en conservación y restauración por la Escuela de conservación y restauración de Barcelona. Doctora europea por la Universidad de Zaragoza, con la investigación: “Conservación y restauración del arte contemporáneo. Historia, teoría y crítica". Gestora cultural, graduada por la Universidad Pompeu Fabra de Barcelona.

Colabora como conservadora-restauradora de manera freelance con diferentes instituciones, como el Museo Centro de Arte Reina Sofía de Madrid.

Actualmente es profesora asociada en el Departamento de Historia del Arte de la Universidad de Zaragoza. 


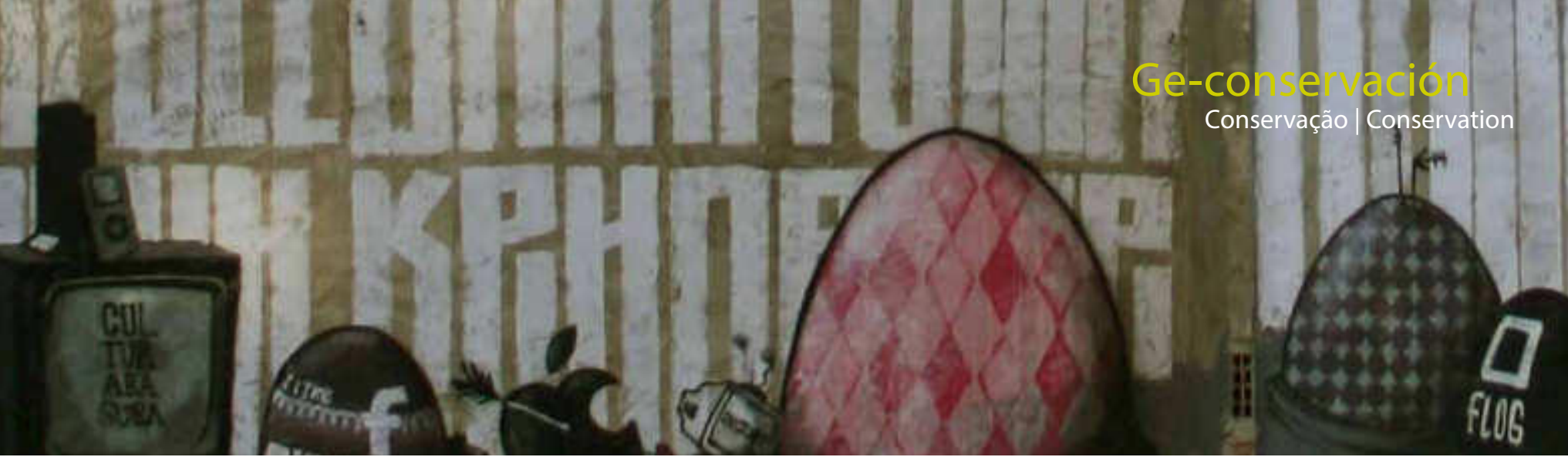

\title{
Propuesta de un modelo de registro para el análisis y documentación de obras de arte urbano
}

\author{
María Isabel Úbeda García
}

\begin{abstract}
Resumen: La presente investigación aporta a la comunidad de conservadores y restauradores, así como a otros especialistas que estudian el arte urbano desde diversos campos de trabajo y perspectiva, una ayuda específica y concreta para la identificación, estudio y análisis de las obras de arte urbano, así como un instrumento útil de clasificación. Se concreta en la propuesta de un modelo de ficha realizada con una metodología específica para documentar el arte urbano. La ficha consta de varios niveles de información: una parte formal y descriptiva (iconográfica, de documentación gráfica-audiovisual) y otra parte para el análisis crítico (iconológico) de la obra y contexto físico, histórico, artístico y social.
\end{abstract}

Palabras clave: documentación, arte urbano, conservación, metodología, análisis, ficha, catalogación, clasificación

\section{Proposal of a model of record for analysis and documentation of art works of street art}

Abstract: This research work aims to contribute to the community studying urban art from various fields of work and perspectives, a specific and concrete help to identify, study and analysis of the works of street art as well as a possible instrument of classification. This aims comes to reality in the proposal of a model record card with a specific methodology to document street art. The record card consists of several levels of depth: a formal and register record card (iconographic, graphic docs, audiovisual documentation) and a critical record card (iconological analysis) of the physical work and its historical, artistic and social context.

Key words: street art, conservation, documentation, methodology, analysis, record card, cataloging, classification

\section{Introducción y justificación}

Una de las cuestiones necesarias dentro del estudio teórico del Arte Urbano ${ }^{1}$ que puede servir para analizar su contexto, sus características y su importancia en el panorama creativo y artístico o comunicativo, es definir y delimitar qué obras se pueden encuadrar dentro de este campo, incluyendo las denominadas manifestaciones estéticas públicas independientes (MEPI) ${ }^{2}$, que por estar en el espacio público son susceptibles de ser robadas o vendidas. Estas obras, necesitan una especial atención por parte de conservadores y restauradores y resto de equipo de profesionales ${ }^{3}$, para su estudio, al estar más expuestas y no tuteladas por ninguna entidad concreta. Aunque se estén dando casos de interés por parte de colectivos, asociaciones vecinales y profesionales de diferentes ámbitos de la cultura, las obras solo se suelen fotografiar con mirada de turista y la mayoría de las veces se pierden, sin llegar a ser documentadas como objetos artísticos.

El primer paso para obtener los registros documentales de las obras para una posterior catalogación, sería tener consciencia del lugar que ocupan dentro de la cultura oficial y qué consideración se les está dando en su entorno natural. 
El campo en el que se mueve el arte urbano bien podría denominarse como experimental, podría decirse que es el de una expresión artística conceptual, crítica y de comunicación directa con un público casual (los viandantes, vecinos y visitantes) y donde casi cualquier definición o clasificación escapa a la ortodoxia. No se pretende, aquí, sentar unas bases inamovibles para clasificar este tipo de intervenciones artísticas, sino aportar un sistema ordenado que permita sacar conclusiones sobre el tipo de obra que se analiza, para rescatar su esencia creativa. Pese a que se trata de una manifestación iniciada en el siglo XX, parece estar aún desubicada y siempre cuestionada, en una balanza que debe decidir entre pasar desapercibida y ser aceptarla como tendencia artística. Aun así, es una expresión viva y accesible que sigue mutando y desarrollándose. Además, en muchas ocasiones, no queda claro con exactitud a qué se refiere el propio término en sí, "arte urbano", ni si los artistas deben ser llamados artistas urbanos, a parte de la complejidad para comprender sus motivaciones y objetivos. El universo urbano comprende también las actuaciones de sus intermediarios, comisarios y promotores artísticos, sus propias acciones (estéticas o conceptuales) y todo aquello que pueda englobarse en un gran contenedor de creatividad popular que se encuentra comprometido en una carrera por ver si llegará a ser considerado como Arte, con mayúsculas, del siglo XXI.

\section{Objetivos y metodología}

\section{Objetivos}

Los cuatro objetivos principales de este estudio son los siguientes:

-1. Promover la clasificación y catalogación, estudio y documentación de las obras de arte urbano a partir de un número amplio de campos y parámetros que ayuden a conservadores y restauradores, así como historiadores del arte y otros agentes implicados, a estudiar estas obras.

- 2. Aportar una herramienta propia de catalogación y análisis pormenorizado para las obras de arte urbano, para definirlas y diferenciar las particularidades técnicas y conceptuales de su ejecución, además de unificar parámetros de documentación y registro; dirigido a cualquier profesional de este ámbito.

- 3. Contribuir, con base científica, a que el arte urbano sea reconocido como expresión artística por sí mismo, y por tanto, que las obras de arte catalogadas como obras de arte urbano sean admitidas dentro de un corpus como "Bien de Interés Común". Estas obras BIComún, como término popular acuñado por la asociación cultural Niquelarte en 2010, se refiere a los bienes aceptados por una comunidad que no se incluyen dentro de lo legislado en la ley de Patrimonio Histórico Artístico, ni a lo descrito para los Bienes de Interés Cultural (BIC). Estos objetos artísticos serían susceptibles de englobarse dentro del patrimonio cultural popular, lo que ayudaría a la declaración de algunas obras de arte urbano como BIComún, y por tanto, permitiría solicitar su protección administrativa para conservarlas (y en su caso restaurarlas) a través de una iniciativa popular y como parte de un legado a generaciones venideras, teniendo en cuenta que su esencia contracultural no resta sino que suma valores.

- 4. Contribuir a definir las distintas tipologías de arte urbano, como fórmula para el conocimiento de su esencia y del proceso creativo.

\section{Metodología}

Para llevar a cabo el estudio e investigación sobre arte urbano es necesario tomar medidas y acciones concretas, igual que para la conservación-restauración. Para que este tipo de manifestaciones artísticas consiga perdurar como legado cultural y que llegue a las siguientes generaciones, es necesario, además, que estos dos núcleos fundamentales, documentación y conservación, compartan un mismo objetivo.

Debido al carácter ilegal de muchas obras, si no se documentan adecuadamente, en poco tiempo se convierten en meros vestigios digitales -fotografías, vídeos, descripciones subjetivas- y reproducciones de merchandising, pero las piezas originales no sobreviven, ni tampoco la documentación objetiva y descriptiva de los materiales utilizados. Por no hablar de la motivación o el proceso creativo seguido por el artista. Aunque es imposible documentar toda la producción artística actual y en ocasiones el soporte será inevitablemente efímero -por su propia idiosincrasia, por casuística o por decisión de sus autores- es evidente que las obras realizadas en la calle representan un medio de expresión que hay que abordar.

De este modo, se propone una metodología desde la perspectiva del conocimiento de las herramientas de descripción usadas hasta ahora por la Historia del Arte, extrapolables y adaptadas para clasificar y desarrollar un análisis crítico de las obra de arte urbano. Este estudio y propuesta se basa en un registro queaporta documentación gráfica, audiovisual, descriptiva y formal. Una ficha, -en realidad un conjunto de fichas- con diferentes campos de interés para la obra y su conocimiento, donde poder aportar una parte crítica que contribuya al análisis de la misma, así como de su contexto físico, histórico, artístico y social. En una fase posterior del estudio, se realizará una entrevista al autor y la gente del entorno de la obra. Durante esa fase, será de especial utilidad un cuestionario para los artistas y el público; así como un registro de aquellas entidades públicas o privadas que se encarguen de organizar actividades donde intervenga el arte urbano.

El modelo de estas herramientas (fichas y entrevista) estará jerarquizado y relacionado según unos campos 
temáticos (metadatos), con un amplio número de subcampos y parámetros organizados de menos a más (detalles), seleccionados bajo unos criterios objetivos y adaptados a las características observadas en las obras de arte urbano.

\section{En busca de una definición}

Existen distintos puntos de partida desde los que analizar estas obras de arte urbano para su clasificación y estudio: por un lado, el estético, por otro lado, su mensaje o su implicación social y finalmente, el contexto o entorno, representado por el barrio o por un concepto espacial más amplio, en el que contemplar valoraciones de grupos organizados como fans de autores, investigadores y periodistas afines a determinados tipos de obras o artistas, que se encuentran entre la comunidad de consumo del arte urbano.

El“arte urbano" es un movimiento artístico y un término que "se utiliza para definir varias corrientes artísticas que son esencialmente diferentes entre sí" una expresión social y reivindicativa que solo puede darse en los espacios públicos comunes y cada vez va siendo más compleja, rica y extensa como para analizarlo desde un solo campo de investigación o perspectiva. Aunque el término postgrafiti se haya superado, es una definición que sitúa bien donde se encuentra el ojo del huracán de su estudio.

Por este motivo, para esta propuesta metodológica, se han investigado herramientas de clasificación y documentación que comprendan el mayor número posible de puntos de vista, para permitir las descripciones de los parámetros más interesantes que marquen su contexto y documentar las obras de arte urbano según su naturaleza, ya sean intervenciones, instalaciones sobre soporte mural o cualquier manifestación independiente, con marcos descriptivos que no opriman su esencia misma.

Esta propuesta metodológica parte, como estudio teórico, desde la Historia del Arte, y tomando al Arte Urbano ${ }^{5}$ como si se tratara de un movimiento artístico y social, como corriente artística o como un periodo ${ }^{6}$ dentro de la Historia del Arte, sin olvidar que el "arte urbano" puede tener unos valores ideológicos de activismo particulares.

\section{Modelo metodológico utilizado}

El presente estudio se encuentra cercano al modelo metodológico del análisis de obras de arte de la Escuela de Warburg, donde estudiosos como Gombrich, Panofsky o Wittkower, entre otros, señalan que la obra de arte es algo más que su forma, y a su vez, hay que analizarla para conocer su significado y simbolismo, de ahí que se realice un estudio analítico de su iconografía e iconología. Esta escuela propone que el Arte nos brinda conocimiento sobre el propio ser humano y su historia, vinculando diversas partes del conocimiento general al conocimiento particular de las obras de arte.

Siguiendo el tipo de análisis que Panofsky propone, con su niveles de lectura y compresión de obras en tres estadios: el formal o temático, el significado (iconografía) y la iconología (su significado en el contexto de la obra, del autor y del estudio), se abordará el estudio y análisis de las obras de arte urbano, sirviendo de referente para la selección de parámetros y su jerarquización.

Por ello, se propone iniciar el análisis de la obra de lo particular a lo general, para llegar finalmente a definir las peculiaridades de la misma.

El estudio propuesto se subdivide en varios campos y niveles, desde los datos sobre morfología (dimensiones del soporte, materiales, herramientas) y lo formal (color, composición, estructura), hasta el contenido estético, de significado artístico o social.

También se añaden otros campos de interés para la investigación, que generalmente no acompañan a una ficha al uso; campos que completan la visión y comprensión global de las necesidades y situación de la obra tales como: exposición o musealización (si se ha dado), interés del autor-es por la conservación-restauración de sus intervenciones, la situación de protección, el estado de conservación y datos técnicos que ayuden -en el caso de necesitarlo- a iniciar un plan de conservación preventiva, o los datos y detalles de restauración si finalmente se necesita o se ha realizado; y otros campos de utilidad, como la financiación (en el caso de una obra de encargo), y un listado de etiquetas digitales con las que se puede buscar y encontrar la obra.

Lo que se espera conseguir con esta amplia selección de campos y parámetros es, en realidad, un estudio lo más profundo y conciso posible, que aporte una valoración, lo más objetiva posible, de la obra y su contexto.

\section{Fases de estudio}

\section{Las fases de estudio se clasifican en cinco:}

- 1. Investigación sobre las metodologías de análisis y crítica del arte, realizando una comparativa de los tipos de catalogación e inventarios empleados en la clasificación de obras de arte contemporáneo, susceptibles de ser usados para el arte urbano.

Tipos de documentación existente y fichas técnicas utilizadas por los agentes de estudio de obras de arte urbano y otro tipo de obras de arte estudiadas para su conservación. Hasta la fecha se cuentan con diversos ejemplos de fichas y entrevistas de profesionales del ámbito histórico, la conservación y la restauración, así 
como de la catalogación de bienes artísticos de museos, instituciones sobre patrimonio o entidades privadas (profesionales autónomos dedicados a la restauración o empresas de subasta o tasación de obras de arte, por ejemplo).

Estudio y búsqueda de las nuevas posibilidades de documentación visual y audiovisual, gráfica y de nuevas tecnologías, como la geolocalización, para obtener un patrón que permita conocer la ubicación de las obras de arte urbano; la captura de imagen tradicional y de última generación tecnológica, como la imagen tomada por drones, captura de alta definición, etc.; información mediante etiquetado como el hashtag, y otros tag.

Estudio de los medios de difusión y divulgación sobre obras de arte y artistas, tanto los medios convencionales como los nuevos tipos de contenidos online -divulgativo científico o de ocio-, redes sociales principalmente, o revistas virtuales, vídeos documentales de los propios artistas o usuarios y seguidores de arte urbano en youtube, vimeo, etc.

\section{- 2. Selección y propuesta de parámetros divididos por} campos. Clasificación y organización de campos de interés según el análisis de la obra a varios niveles: técnico, formal, iconográfico, crítico y contextual (campo iconológico): histórico, artístico y social, económico y político.

- 3. Categorización de marcadores. Varias subfichas dentro de la ficha general, desde el registro de la ficha estándar hasta campos más específicos, que en ocasiones no hará falta concretar. Parámetros seleccionados por niveles y campos con descripciones.

- 4. Exposición y testado. A realizar con los modelos de las fichas para su test de stress o prueba de utilidad en el futuro. En fase de realización aún; para analizar y debatir en el Grupo de Arte Urbano y Conservación ${ }^{7}$

- 5. Conclusiones. Referentes tanto al modelo de registro final que se presenta (las fichas, o ficha global) como a observaciones generales del estudio sobre la realización del registro en sí.

\section{Arte urbano y las dificultades de acotación}

Ante la gran amplitud de manifestaciones artísticas englobadas en el arte urbano ${ }^{8}$, supone un reto describir qué es una obra de arte urbano. Actualmente hay una fuerte corriente muralista que nada tiene que ver con los orígenes del arte callejero, que asume su lenguaje pero está más cercano a lo meramente decorativo y pretende embellecer las calles o entornos ruinosos; por no hablar de las obras realizadas con fines utilitarios o mercantiles. En otras ocasiones, aunque mantienen su fuerza expresiva y combativa, hay obras que se desarrollan bajo fórmulas de festivales, convocatorias o jornadas, por lo que dejan de estar en un marco ilegal (algo que originariamente las caracterizaba). Por otro lado, el factor de localización y selección de espacios tampoco es determinante, pues, a día de hoy, no sólo se encuentran obras en rincones oscuros o de difícil y prohibido acceso, sino en calles principales, fachadas emblemáticas o interiores -como naves industriales o edificios abandonados o antiguas iglesias desacralizadas-. En cuanto al factor "lugar", la urbe (la ciudad, barrios y zonas deprimidas) también ha cambiado como elemento de conquista, puesto que encontramos pueblos pequeños o el mismo campo, que han sido tomados como contexto de los distintos lenguajes del arte urbano.

Por todo ello, se ha optado por buscar parámetros y campos lo más diversos posibles donde clasificar o catalogar las obras en sí, para saber si pueden ser denominadas como obras de arte urbano, y a qué tipo de expresión nos enfrentamos.

\section{La importancia de la terminología a la hora de docu- mentar}

El vocabulario o la terminología de uso, tanto en la práctica como en la teoría de esta forma de expresión artística, es también una de las "dificultades" añadidas al estudio del corpus de obras de arte urbano, pues está en pleno proceso de desarrollo y definición, aunque, cada vez hay más un consenso en determinados términos, en parte gracias a investigadores ${ }^{9}$ que estudian este tipo de manifestaciones artísticas, pero sobre todo gracias a la información que se va a añadiendo a través de las redes sociales y el reconocimiento social de los artistas, que ofrecen cada vez más entrevistas.

Encontramos que, según las corrientes estilísticas, el tipo de intervenciones o los lugares de procedencia de los autores, se utiliza un determinado tipo de vocabulario o terminología diferente, incluso, al referirse a las técnicas similares, por ejemplo. Los encargados de difundir el arte urbano también suelen utilizar diferentes términos $y$, en las redes sociales, prima la imagen por encima de la información del contenido. Por ello, a la hora de investigar y documentar se debe proceder con cautela, para poder describir correctamente las técnicas de ejecución.

Según la procedencia de los artistas (del grafiti, del postgrafiti o del arte convencional, con estudios artísticos académicos) se definen las obras de una manera u otra. Grafiteros y demás, tienen un registro de vocablos muy extenso a la hora de hablar sobre sus obras, sus procesos de factura y las técnicas empleadas, sin embargo entre los artistas más académicos que trabajan en las calles, el vocabulario suele ser otro. En cualquier caso, hay una gran riqueza de expresiones y términos que podemos y debemos recabar, registrar y utilizar en la realización de la ficha. 


\section{Documentar para conservar}

Al comienzo del estudio y en la fase de selección de parámetros, se plantean los tipos de clasificación posibles para un número determinado de elementos definidos, organizando los temas mediante un organigrama de tipo árbol. Se establece una amplia cantidad de campos, con unos parámetros objetivos evaluables, donde albergar información concreta, como la valoración artística y científica, evitando los datos subjetivos de opinión.

Es conveniente señalar que el estudio parte de los criterios de selección de campos y parámetros empleados en la catalogación y documentación convencional empleados en otros campos del conocimiento, como la Historia del Arte y de la Conservación, transformándolos según las necesidades del arte urbano.

Como ejemplos en uso, se han analizado diferentes tipos de fichas técnicas y descriptivas sobre arte convencional, y referimos aquí algunas de las que más nos han interesado, como la ficha técnica estándar de las obras del Museo del Prado, el de la Tate Britain en su modalidad online ${ }^{10}$, ambas con enlaces a otras referencias mediante hashtag. Estas fichas tienen una interesante estructura interna con enlaces a otras obras del autor, datos básicos de la obra seleccionada, y, lo más interesante, enlaces a parámetros temáticos, según la iconografía y temática de la obra (remitiendo a obras de otros autores por afinidad), también a modo de hashtag, para la consulta de público general. También se ha tomado la referencia del catálogo de enseres de Museo Cerralbo (versión online) e inventario de obras catalogadas, porque se ocupa de objetos, no solo de pintura, y comparte tipología de ficha con el resto de museos estatales ${ }^{11}$. Además, se considera oportuno mencionar que tras los campos básicos y habituales es posible crear enlaces a otros parámetros, como el "contexto cultural" o "estilo".

En cuanto a los ejemplos estudiados dentro del campo de la conservación-restauración, se han analizado varias propuestas ${ }^{12}$ donde se propone el estado de conservación de la obra como parte fundamental de la ficha técnica, tras los datos generales y estudio técnico y material. También se ha analizado el modelo de ficha básico que proponen Rosa Gasol y Rosa Senserrich al alumnado de la Facultad de Bellas Artes de Barcelona para el estudio y primer contacto con los murales: "Examen, diagnosi i documentació. Documentació i identificació de la pintura mural al carrer". En este caso, parece interesante manejar también un tipo de ficha más concreto, pues se limitan al "mural al carrer", primando la tipología de obra sobre otros campos, aunque, no obstante, el resto de datos técnicos al uso siguen apareciendo. Tras la parte de datos formales, aparecen los campos más técnicos y específicos para los restauradores y conservadores de este tipo de piezas: como "descripción de materiales y técnicas de aplicación" o "estado de conservación y degradación" con sus subcampos. También aporta bastante a nuestro estudio el modelo de ficha que se utiliza en algunos talleres de restauración, para documentar trabajos de restauración arqueológica, donde los gráficos y el "estado del terreno" o "factores de deterioro" (con los agentes de deterioro divididos en "agentes biológicos" y "factores geomorfológicos") son fundamentales.

Además, se han extraído elementos de las formas de catalogación de las bases de datos online, como Tesauro, cuyos parámetros son muy extensos, aunque contienen metadatos y campos muy concretos para la catalogación digital actual, o DOMUS, el sistema integrado de documentación y gestión museográfica desarrollado por el Ministerio de Cultura, una aplicación informática para el catálogo y gestión de los fondos museográficos y documentales de los museos españoles, nacido a partir del informe "Normalización Documental de Museos: elementos para una aplicación informática de gestión museográfica" (Ministerio de Cultura, 1996). Se han analizado, a su vez, las recomendaciones para documentar la imagen en los catálogos del Instituto Andaluz de Patrimonio Histórico porque aportan interés a nivel documental, en cuanto a la amplia tipología de formas de captura de imagen y sus posibilidades para el arte urbano. $Y$ por último, se han extraído elementos interesantes del Inventario de Intervención y Conservación del Archivo IAPH con su Catálogo de obras restauradas ${ }^{13}$.

Cuando la ficha pertenece a una serie de obras, catálogo o colección concreta, lleva siempre un número de registro o un código, que en Arte Urbano puede sustituirse por los parámetros de geolocalización, sus coordenadas. Las obras de los museos se refieren a colecciones y tipologías del propio museo, pero en el caso del modelo de registro de obra de arte urbano que aquí se propone, aunque también está pensado para formar parte de inventarios u otros compendios más generales, se puede utilizar de forma particular en estudios individualizados.

Por otro lado, la documentación gráfica siempre está presente, y sigue siendo la fotografía el medio más útil. Cuando la ficha se refiere a la conservaciónrestauración, este campo de documentación se amplía significativamente. Unas veces, como mera información o muestra del estado de la obra, y otras, como datos concernientes al proceso de intervención.

\section{Los criterios de selección de campos}

La selección de campos se ha basado en criterios objetivos, sobre la obra, objeto o producción artística, la autoría y la localización. Cuestiones o criterios valorativos más subjetivos, se reservan a los campos del final.

El orden y jerarquización de parámetros dentro de los campos es el que ofrece más complejidad, pues cada obra tiene sus circunstancias particulares y puede suceder 
que, en ocasiones, prime la ubicación sobre la técnica, o la autoría sobre la propia obra (caso en que interese conservar y estudiar una pieza por el origen o el autor, no porque la pieza en sí tenga un valor estético o artístico notable). Este modelo se propone para facilitar el análisis y para poder catalogar las obras, de manera que también se tiene en cuenta la posibilidad de jerarquización o descripción de parámetros particulares no contemplados hasta el momento, ofreciendo una cierta flexibilidad, según las circunstancias de la obra.

Los criterios propuestos son los siguientes:

\section{Criterios objetivos: datos técnicos y formales. La autoría ${ }^{14}$}

Aquí se incluyen los datos generales, como realización, técnica, fecha, nombre autor, título, dimensiones, ubicación, temática; es decir, una descripción formal que incluiría la tipología y una descripción objetiva, sin lugar a interpretaciones. También aparecen los temas legales (propiedad, derechos, etc.).

\section{Criterios en base a la observación artística. Iconografía}

Apartado en el que se incluyen parámetros más subjetivos y de valoración, como la estética o estilo, intención del autor o de la obra, contexto artístico, social, etc. Pero por otro lado, también incluiremos parámetros o campos referidos a la valoración crítica del arte, y parámetros útiles para la difusión de la obra, medios de comunicación, redes sociales, etc.

\section{Criterios en base a la conservación, estado de la pieza o conjunto}

En este campo se incluye la evaluación del estado de conservación de la obra. Estos datos son susceptibles de irse ampliando con documentación gráfica sobre sus procesos de degradación. Se incluye documentación si existe, como algún plan de conservación, dossier, etc.

\section{Criterios en base a la restauración}

Si se ha llegado a esta fase, se ampliará la ficha técnica con los datos y campos necesarios según el criterio del equipo de restauración que deberá contemplar en primer lugar el examen y valoración de su estado de conservación.

\section{Criterios en base a la valoración externa}

Se puede ampliar el informe incluyendo toda la información publicada en los medios de comunicación, según la repercusión de la obra. Por otro lado, se propone incluir en este apartado si existe una valoración económica de la misma, así como las circunstancias que han acompañado este hecho.

\section{Criterios en base a la valoración personal}

Según el tipo de obra estudiada, se puede dar el caso de que la opinión del profesional que realiza la ficha esté enfrentada con la de otros profesionales. En este caso, se debe dejar claro que se exponen valoraciones y criterios personales y se debe justificar adecuadamente.

7. Criterios en base a la valoración extraída de la opinión o datos vertidos por el artista en las entrevistas y/o el entorno de la obra

La entrevista es una de las herramientas complementarias más interesantes que puede ayudar a la comprensión de algunos datos fundamentales para poder valorar la necesidad de conservación-restauración de una obra. La importancia de poseer información de primera mano (artista, organización) no es fácilmente sustituible. Si se poseen entrevistas, aunque no las haya realizado el mismo profesional, se aportarán como documento de especial importancia.

\section{Modelo de registro: conjunto de fichas propuesto}

En la siguiente tabla (Tablas 1-7), se desarrolla el modelo de registro propuesto. Se muestra en formato de tabla para organizar mejor los campos y parámetros seleccionados, aquí expuestos. En algunos espacios explicamos parte de lo que se pretende describir en cada apartado.

\section{Modelo de registro propuesto [Tablas 1, 2, 3, 4, 5, 6, 7]}

Especificaciones sobre campos o parámetros empleados en la Tabla:

*1 Se pondrá el nombre real del autor. Pero este dato no se hará público (en publicaciones o cesión de datos a terceros) en el caso de que el autor prefiera el anonimato -y esto será respetado-, o en caso de que pueda peligrar la integridad de la obra por algún motivo relacionado.

*2 Se hará público si es adecuado para la obra; si se pone en riesgo, no se hará público. Tampoco si hay riesgo de multa para la autoría o responsables.

*3 Puede darse el caso de que, aun estando ante una obra de arte urbano -por emplear técnicas, procesos y procedimientos, estético o incluso temática y mensajes propios del arte urbano-, por su iniciativa y realización privada, en espacio privado, pierda su carácter de obra independiente pública, que es parte de la esencia del Street art. 


\begin{tabular}{|c|c|}
\hline \multicolumn{2}{|c|}{ REGISTRO PARA ANALISIS, DOCUMENTACIÓN Y CATALOGACIÓN DE OARAS OT ARTE URTANO } \\
\hline \multicolumn{2}{|c|}{ 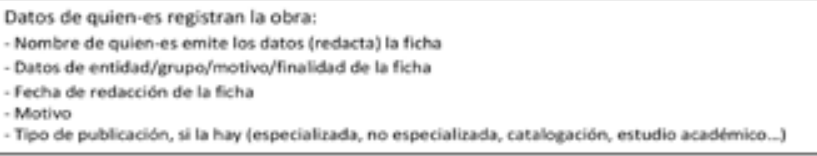 } \\
\hline \multicolumn{2}{|c|}{ LFICHA TECNICA estándar (resumen) de la obra } \\
\hline \multicolumn{2}{|c|}{$\begin{array}{l}\text { 1. Titulo de la obra } \\
\text { 2. Autoria } \\
\text { 3. Tipología de obra: técnica, soporte (estilo o estética) } \\
\text { 4. Localización } \\
\text { 5. Fecha de realización } \\
\text { 6. Situación legal de la pieza (origen y actualidad) } \\
\text { 7. Estado general de la pieza (protegida o no, conservada o no, restaurada o no...) } \\
\text { 8. Cambio en su situación juridica } \\
\text { 9. Importancia de la pieza (formal, técnica, emocional, social, grupal o general...) } \\
\text { 10. Doxumentación previa y su procedencia (documemada antes/no documentada } \\
\text { previamente) }\end{array}$} \\
\hline \multicolumn{2}{|c|}{ "HICEA TECNICA Y FORMAL } \\
\hline \multicolumn{2}{|c|}{ (campos de dotas descriptivos formales tetenicos e iconogrdficas) } \\
\hline 1. TITULO DE LA MEEZA & [Si lo tiene o si se le conoce con algún nombre] \\
\hline \multicolumn{2}{|l|}{ 2. FECMA de REALIZACIÓN } \\
\hline 3. AUTORIA *1 & $\begin{array}{l}\text { Datos biograficos básicos. [Fecha nacimiento } \\
\text { autor/es, tipo de obra que trabaja; } \\
\text { documentación básica: web o algùn enlace } \\
\text { donde podamos ver otras obras o entrevista...] }\end{array}$ \\
\hline 3A. TIPO OE AUTORIA & $\begin{array}{l}\text { 1) INOIMDUAL/COLECTIVO } \\
\text { 2) NOMBRE ARTISTICO O FIRMA } \\
\text { 3) NOMBRE REAL (si Se Sabe) } \\
\text { 4) DESCONOCIOA }\end{array}$ \\
\hline $\begin{array}{l}\text { 38. AESPONSABLE/S DEL } \\
\text { MANTENIMIENTO DE LA OERA. } \\
\text { 1/SI } \\
\text { 2) NO } \\
\text { 3)QUIEN/-ES }\end{array}$ & $\begin{array}{l}\text { (Los responsables de la pieza no tienen por qué } \\
\text { ser los autores. Estos pueden desinteresarse o } \\
\text { desvincularse por completo de las obras } \\
\text { responsables legales (o de la conservación, } \\
\text { etc.) implicados en la realización de la misma, } \\
\text { alguien que privadamente ha pedido que se } \\
\text { realice una obra en su propledad, o muro, en }\end{array}$ \\
\hline & $\begin{array}{l}\text { casos de un festival, o de alguna convocatoria } \\
\text { pública de institución, un museo o galeria, etc.] }\end{array}$ \\
\hline $\begin{array}{l}\text { 4. LOCALZZACION, SOPORTE Y DESCRIPCIONN } \\
\text { DE LA OERA }(\cdot 2) \text { : }\end{array}$ & $\begin{array}{l}\text { (Según la singularidad de la pieza, puede ser } \\
\text { más importante la localización y radique ahi su } \\
\text { fuerza comunicativa o social, y otras veces, } \\
\text { puede ser en si, como pleza artistica, o por la } \\
\text { singularidad del soporte, de dificil acceso y } \\
\text { producción, por ejemplo.] }\end{array}$ \\
\hline $\begin{array}{l}\text { 4A. DESCRIPCIÓN GENERAL DE } \\
\text { CONUNTO: SOPORTE- LUGAAR } \\
\text { TECNICA }\end{array}$ & $\begin{array}{l}\text { "Por ejemplo: "Obra mural (acrilica) sobre } \\
\text { medianera en edificio antiguo de protección } \\
\text { oficial de los antos } 50^{\circ} \text {. } \\
\text { o "Conjunto de stencil en pawimento, techos y } \\
\text { paredes (vanos u otras partes del edificio) en } \\
\text { antigua fabrica azucarera del principios de sigjo } \\
\text { XX". }\end{array}$ \\
\hline
\end{tabular}

48) LOCAUZACION

48a. DIRECCIÓN:
Calle o via y número.
Población y CP. Pals.
40b. GEOLOCAUIZACIÓN
O COORDENADAS OE
POSICIÓN (si se tienen)

Captura de imagen, coordenadas de mapa de ubicación; imágenes tomadas con la ayuda crones, para obtener una perspectiva del contexto del lugar, o imagen más adecuada y información útil sobre el estado de la pieza. incion uni sobre el estado de la pleza, asicrion obras cercanas, y el habbitat de la pieza).]

4BC. DESCRIPCIÓN

1) Entorno Urbano o Rura

DETALLADA DEL LUGARY 2) Exterior o Interior

LA LOCALZZACIÓN:

2) Exterior o Interior

- Se debe ser lo miss exacto posible en la descripción.

Si es calle, avenida, patio, ruinas, plaza, carretera, etc.

-Si es junto a una rona industrial, o vias de tren, puentes, solares, pasos a nivel, garajes, etc.

4C. SOPORTE

\begin{tabular}{l|l}
$\begin{array}{l}\text { 4Ca. TIPO DE SOPORTE: } \\
\text { ESTÁAICO O MOVIL }\end{array}$ & $\begin{array}{l}\text { Tipos de soporte: } \\
\text { 1) Mobiliario urbano-publico estático (exterior): } \\
\text { como farolas, marquesinas, kioscos, semáforos, } \\
\text { señales de tráfico, pavimentos (suelos, aceras): }\end{array}$
\end{tabular}

\begin{tabular}{|c|c|}
\hline & 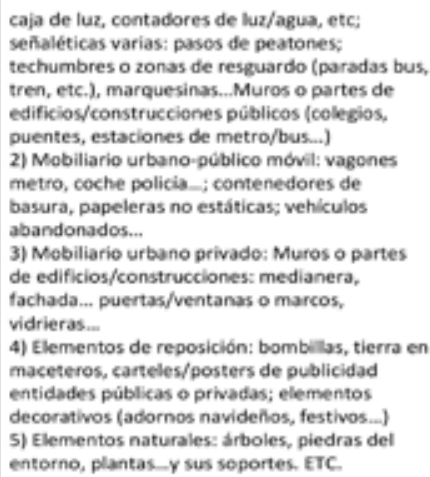 \\
\hline $\begin{array}{l}\text { 4CB. MATERIAL O } \\
\text { MATERIALES DEL/LOS } \\
\text { SOPORTES }\end{array}$ & $\begin{array}{l}\text { Materiales: metal, ladrillo, mamposteria, } \\
\text { hormigón, vidrio, madera... } \\
\text {-Si se puede especificar más, se hara. }\end{array}$ \\
\hline
\end{tabular}

40. DESCRIPCIÓN DE LA OBRA EN OETALLE

\begin{tabular}{|c|c|}
\hline $\begin{array}{l}\text { 4Da. DESCRIPCIÓN } \\
\text { TECNICANARTISTICA }\end{array}$ & $\begin{array}{l}\text { 1) Técnica artistica o creativa: pintura, } \\
\text { taladrado, poster, pegatina... } \\
\text { 2) Materiales (aerosol, dleo, acrilicos, témpera, } \\
\text { papel...) } \\
\text { 3) Dimensiones } \\
\text { 4) Proceso creativo } \\
\text { 5) Tipologia de arte urbano donde se puede } \\
\text { adscribir: stencil, mural, poch, croche... } \\
\text { (Nombres técnicos anglos o en espahol, } \\
\text { francés...) }\end{array}$ \\
\hline $\begin{array}{l}\text { 4Db. DESCRIPCION } \\
\text { ICONOGRASICA: } \\
\text { Forma/contenido }\end{array}$ & $\begin{array}{l}\text { 1) Descripción formal (formas, composicion, } \\
\text { color...) } \\
\text { 2)Temática: lo que representa (historia, } \\
\text { narración, si la hay) } \\
\text { 3) Iconografia; descripxión de los elementos } \\
\text { artisticos (contenido simbollico, etc.) } \\
\text { 4) Estilo y/o estética } \\
\text { 5) Dimensión creativa: si proviene de idea } \\
\text { original, copla o referencia de obra existente }\end{array}$ \\
\hline
\end{tabular}

(campos de criterios más subjetivas o valorotivos)

\begin{tabular}{|c|c|}
\hline AE. ICONOLOGIA & $\begin{array}{l}\text { La obra dentro del Contexto de creación } \\
\text { artistica y comunicación, histórico y social. }\end{array}$ \\
\hline & $\begin{array}{l}\text { 1) Valores creativos y técnicos artísticos } \\
\text { respecto a su contexto artistico concreto } \\
\text { (corrientes estéticas imperante/momento } \\
\text { concreto-fechas). } \\
\text { 2) Valores social (significado de la obra y/o su } \\
\text { autoría o lugar por su momento concreto) } \\
\text { 3) Valoración dentro del Arte urbano (en su } \\
\text { enlace con póblico, mensajes, contexto } \\
\text { histórico-social...): Por ejemplo, es diferente } \\
\text { valoración la que necesita una obra en el } \\
\text { contexto de la reivindicación en el } 15 \mathrm{M} \text {, si } \\
\text { habla de ello, o no. }\end{array}$ \\
\hline $\begin{array}{l}\text { 45. CONTEXTO SOCIAL } \\
\text { Tipo de entorno social donde se } \\
\text { ubica la obra a registrar/analizar }\end{array}$ & $\begin{array}{l}\text { 1) Contexto social } \\
\text { 2) Contexto económico } \\
\text { 3) Contexto historico y artistico (si hay } \\
\text { escultura pública, o es un barrio de un casco } \\
\text { historico o antiguo_.) } \\
\text { 4) Posibles intereses de la zona (especulativos, } \\
\text { derribo, remodelación, estable...) }\end{array}$ \\
\hline \multicolumn{2}{|c|}{ 5. VINCULACIÓN LEGML Y ORIGEN (PROPIEDAD, ETC.) } \\
\hline $\begin{array}{l}\text { SA. ORaGEN Legal }(* 3) \\
\text { (De donde parte la iniciativa de la } \\
\text { obra] }\end{array}$ & $\begin{array}{l}\text { 1) Oficial - encargo privado } \\
\text { 2) Oficial - encargo público: dentro de una } \\
\text { convocatoria pública, en un marco de legalidad } \\
\text { o institucional (festivales, concursos...) } \\
\text { 3) independiente }\end{array}$ \\
\hline $\begin{array}{l}\text { 58. SITUACIÓN ILEGAL/ALEGAL O } \\
\text { LEGAL DE LA OBRA } \\
\text { [SEgün su ubicatión] }\end{array}$ & $\begin{array}{l}\text { [Puede coincidir con el origen de la obra } \\
\text { (campo 38), o no: porque aunque un festival } \\
\text { haga una comocatoria, por ejemplo, y se } \\
\text { realice la obra en su marco, despubs, el soporte } \\
\text { y la obra quedan desligadas de toda } \\
\text { responsabilidad y puede entrar (o volver) a } \\
\text { situación ilegal, cuando nacio "de forma legar } \\
\text { u oficialmente.] }\end{array}$ \\
\hline $\begin{array}{l}\text { SC. EXPOSICIONO } \\
\text { MUSEALIZACION } \\
\text { [El estado de la pieza para ello] }\end{array}$ & $\begin{array}{l}\text { *Si ha estado en alguno de estos procesos, } \\
\text { detallar los agentes culturales intervinientes: } \\
\text { colectivos, asociaciones, fundaciones, fondos } \\
\text { museisticos, galerias. }\end{array}$ \\
\hline 5Ca. En caso de ser obra & $\begin{array}{l}\text { 1) Nombre de evento } \\
\text { 2) Detalles del evento (programa de actividad) }\end{array}$ \\
\hline
\end{tabular}

Tablas 3 y 4 .

Tablas 1 y 2. 


\begin{tabular}{|c|c|}
\hline $\begin{array}{l}\text { por encargo o en festival } \\
\text { (o para una exposición...) }\end{array}$ & $\begin{array}{l}\text { 3) Contrato (pago, disposiciones, derechos } \\
\text { sobre la obra y su reproduccion) } \\
\text { 4) Financiación (entidad o patrocinio y cuantia } \\
\text { presupuestada para la producción) } \\
\text { 5) situación de derechos de imagen: tipos de } \\
\text { licencia bajo la que se postula la obra } \\
\text { (copyright, copyleft...) } \\
\text { 6) Tasación (especulativa/real, sil se da el caso) }\end{array}$ \\
\hline \multicolumn{2}{|c|}{ (compos can dotos documentoles) } \\
\hline \multicolumn{2}{|c|}{ 6. DOCUMENTACION GRAFICA (descriptiva-técrica, o de medios de mans, ditusion, etc) } \\
\hline 6A. FOTOGRAFIAS (importante) & $\begin{array}{l}\text { [Foto general y de detalle; con datos de la } \\
\text { imagen y autoria, permisos y licencias] }\end{array}$ \\
\hline $\begin{array}{l}\text { 68. AUDiovisuAL (cualquiler } \\
\text { soporte } \mathrm{y} \text { formato, analógico o } \\
\text { digital) }\end{array}$ & $\begin{array}{l}\text { Nipo de soporte/producción: } \\
\text { - -Video (productión particular) } \\
\text { - Recreación virtual } \\
\text { - QfCode... } \\
\text {-Cine, cortometraje, spot publicitario, } \\
\text { videoclip... (groducción gran escala), etc. }\end{array}$ \\
\hline 7. DOCUMENTACIÓN BIBLOGRAFCA & $\begin{array}{l}\text {-Resehada en libros, articulos de prensa } \\
\text { general o especializados; difusión o } \\
\text { divulgación. } \\
\text {-Online o en papel. }\end{array}$ \\
\hline $\begin{array}{l}\text { 8. DOCUMENTACION APARECIOA EN } \\
\text { MEOLOS OE COMUNECACION DE MASAS O } \\
\text { REDES SOCLALES (generales o partieulares) }\end{array}$ & $\begin{array}{l}\text { Sobre la imagen o noticia de la obra, } \\
\text { referencias de difusión o dimulgación en } \\
\text { reportaje, noticia, estudio, imvestigación } \\
\text { cientifica o en: } \\
\text { 1) Internet: Web, blog personales, redes como } \\
\text { Vimeo, Youtube, focebook, instagram, Tbr, } \\
\text { twitter, Fikr, etc. } \\
\text { 2) Tr (archivos en analogico o digital) } \\
\text { 3) Radio (archivos analogicos o podcost) }\end{array}$ \\
\hline \multicolumn{2}{|c|}{$\begin{array}{l}\text { 9. USTADO OE TAGS O MASHTAG IDENTIFICADORES } \\
\text { (Para relocionar temas u obras entre s.-) }\end{array}$} \\
\hline \multicolumn{2}{|c|}{ II. FICHA DEL ESTADO DE CONSERVACION } \\
\hline 10. ESTADO DE CONSERVACIÓN & $\begin{array}{l}\text { 1) Bueno } \\
\text { 2) En estado de deterioro (con necesidades de } \\
\text { conservacion) } \\
\text { 3) Ya deteriorado (con necesidades de plan de } \\
\text { restauracion) }\end{array}$ \\
\hline $\begin{array}{l}\text { 11. DISCRIPCION DEL ISTADOO DE } \\
\text { CONSERVACION }\end{array}$ & $\begin{array}{l}\text { Cualquier expediente, informe, valoración } \\
\text { técnica existente o de interés. }\end{array}$ \\
\hline 12. PLAN dE CONSERVACOÓN O PROTOCOLO & Cualquier expediente, informe, valoración \\
\hline ACONSEAADO & técnica existente $o$ de interés. \\
\hline $\begin{array}{l}\text { 13. DOCUMENTACIÓN ADIUNTA DE } \\
\text { CONSERVACIÓN }\end{array}$ & $\begin{array}{l}\text { Cualquier expediente, informe, valoración } \\
\text { técnica existente o de interés.. }\end{array}$ \\
\hline $\begin{array}{l}\text { 14. DOCUMENTACION GRAFICAY } \\
\text { AUDIOVISUAL } \\
\text { (tipos de documentación) }\end{array}$ & $\begin{array}{l}\text { 1) Imagen panorámica de rango dinámico } \\
\text { amplio. } \\
\text { 2) Imagen hiperespetral. } \\
\text { 3) videografis estereoscópica (30) o inmersiva } \\
\text { 4) Documentación geometrica } \\
\text { 5) Documentación gráfica de alta resolución } \\
\text { 6) Audiovisual } \\
\text { 7) Reconstrucción virtual }\end{array}$ \\
\hline $\begin{array}{l}\text { 15. DOCUMENTACIÓN EN CASO DE ESTASR } \\
\text { SIENDO CONSERVADA LA PIEZA YA }\end{array}$ & $\begin{array}{l}\text { Cualquiler dossier, de descripción técnica o } \\
\text { memoria de actuaciones llevadas a cabo }\end{array}$ \\
\hline \multicolumn{2}{|c|}{ IV. FICHA SOBRE INTERES DEL AUTOR-ES EN LA CONSERVACION DE SU OBRA } \\
\hline $\begin{array}{l}\text { 16. ¿SE CUENTA CON EL DESEO DEL AUTOR- } \\
\text { ES DE PRESERVAR SU OBRA? }\end{array}$ & SI/NO \\
\hline 16A. En caso de que si & $\begin{array}{l}\text { 1) El mismo se encargará de lo conservación o } \\
\text { repinte, reposición de piezas, etc. } \\
\text { 2) Se encarga el, pero con ayuda o } \\
\text { asesoramiento necesarios } \\
\text { 3) Lo deja en manos de profesionales bajo su } \\
\text { supervisión } \\
\text { 4) Lo deja en manos de profesionales } \\
\text { totalmente } \\
\text { 5) No le interesa saber nada del tema, aunque } \\
\text { no le importa que se conserve/restaure }\end{array}$ \\
\hline 168. En caso de que no & $\begin{array}{l}\text {-Preguntar los motivos al autor-a/s } \\
\text {-Detallar los motivos lo máximo posible } \\
\text { - Si se cuenta con material de archivo de la } \\
\text { opinión, añadir como documentación }\end{array}$ \\
\hline \multicolumn{2}{|c|}{ v. HCLA DATOS Básicos en cavo de Proceso de restauRAción } \\
\hline 17. EQUIPO PROFESIONAL ENCARGADO & $\begin{array}{l}\text { Detallar profesional o equipo de peofesionales; } \\
\text { Breve CV de ellos; entidad encargada, etc. }\end{array}$ \\
\hline $\begin{array}{l}\text { 18. ESTADO DEL PROCESO DE } \\
\text { RESTAURACION }\end{array}$ & $\begin{array}{l}\text { Breve descripción de la situación: exponer en } \\
\text { qué grado o fase de restauración se encuentra } \\
\text { la obra: } \\
\text { 1) Iniciado: evaluación o establecimiento de } \\
\text { protocolo de actuación } \\
\text { 2) En estado de restauración }\end{array}$ \\
\hline 19. PLAN DE RESTAURACIÓN O PROTOCOLO & Medidas tecnicas a tomar \\
\hline
\end{tabular}

Tablas 5 y 6.

\begin{tabular}{|c|c|}
\hline ACONSEMADO & \\
\hline $\begin{array}{l}\text { 20. DOCUMENTACION AOBUNTA, TECNICA, } \\
\text { DE MESTAURACION }\end{array}$ & $\begin{array}{l}\text { Cualquier expediente, informe, valoracion } \\
\text { técnica existente o de interes... }\end{array}$ \\
\hline $\begin{array}{l}\text { 21. PLANIFACACIÓN DEL PROCESO DE } \\
\text { RESTAUURACION (SI SE DA EL CASO) }\end{array}$ & $\begin{array}{l}\text { Especificación de materiales, tetricas, } \\
\text { procesos. }\end{array}$ \\
\hline $\begin{array}{l}\text { 22. FECHA DE FINALZZACION DEL PROCESO } \\
\text { DE RESTAURACION }\end{array}$ & Aplacamientos, prórogas, etc., si se diera. \\
\hline \multicolumn{2}{|c|}{ V. FCHA DE SITUACION DE PROTECCION DE LA OBRA DE ARTE URBANO (tras restauración) } \\
\hline $\begin{array}{l}\text { 23. SITUACION DE LA OBRA AL FINAL DE LA } \\
\text { RESTAUARACION. }\end{array}$ & Medidas de conservación tras la restauración. \\
\hline \multicolumn{2}{|l|}{$\begin{array}{l}\text { 24. SITUACIÓN DE LA OBRA RESPECTO A } \\
\text { PATRIMONOO ARTISTICO (DICOMUN) }\end{array}$} \\
\hline \multicolumn{2}{|l|}{ 25. BIBUOGRAFIA SOBRE rL CASO } \\
\hline \multicolumn{2}{|c|}{ VII. fINANACIACión para la conservación (si se da el caso) } \\
\hline $\begin{array}{l}\text { 26. ENTDAADES FINAONCIADORAS Y DETALLES } \\
\text { SOBRE FINANCACIÓN }\end{array}$ & $\begin{array}{l}\text { 1) Cuantia o presupuestos } \\
\text { 2) Motivaciones (si se sabe) } \\
\text { 3) Plan de conservación } \\
\text { 4) Finslidades concretas (exhibición, fondos, } \\
\text { catślogo...) }\end{array}$ \\
\hline \multicolumn{2}{|c|}{ 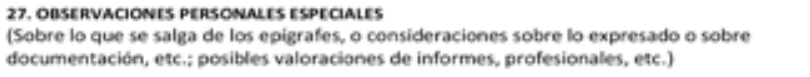 } \\
\hline
\end{tabular}

Tabla 7.

\section{Conclusiones}

La propuesta de registro para la realización de una ficha técnica, formal y crítica, con un amplio número de campos donde exponer toda la información y documentación concreta, forma parte de un posicionamiento, abierto a la reflexión, sobre los criterios que deben ser aplicados en el Arte Urbano, desde el punto de vista de la conservación.

Para ello, se han tenido en cuenta distintos niveles de interés y se han registrado desde los datos más básicos hasta los que implican la comprensión global del tema, como el contexto, su relación con lo representado, la composición, el estado de conservación material y los procesos de conservaciónrestauración.

El arte urbano tiene la suficiente entidad como para que sus obras sean catalogables, debiéndose de estudiar previamente, de forma analítica, crítica e histórica, desde diversos campos del conocimiento.

Aunque este estudio es una propuesta inicial, quiere ser una aproximación abierta, que permita seguir trabajando en esta línea.

El modelo de registro propuesto parte de parámetros seleccionados según las necesidades que presentan las obras de arte urbano, y debe ser testado por una mayoría de profesionales relacionados con el arte urbano, expertos en diversas materias entre las que se incluye la de la conservación-restauración.

De forma trasversal a este estudio, se observa la necesidad de crear un glosario de términos de uso en el arte urbano, en varios idiomas. Así como un diccionario o glosario de técnicas específicas de arte urbano. 


\section{Notas}

[1] Arte Urbano, Street Art. Se refiere a la parte artística gráfica en general, ya que analizar sus diferencias no es el objetivo de este estudio (grafiti, postgrafiti y otras manifestaciones estéticas independientes) realizadas en espacio público; ilegales o no, incluidas las obras realizadas al amparo de festivales, con libertad de temática sin censuras previas ni motivaciones especulativas y comerciales, desarrolladas en el espacio público.

[2] MEPI: Manifestaciones estéticas públicas independientes. Según Luis Martín, en su texto La conservación de manifestaciones estéticas, públicas e independientes, el concepto significa: "intervenciones realizadas en el espacio urbano. Nacen por iniciativa propia, sin apoyo de la institución ni fines comerciales. (Op. referenciada en Bibliografía)

[3] Por equipo de profesionales nos referimos a todos los actores que intervienen en la petición de conservación de una pieza u obra arte urbano: artistas o autores, historiadores del arte, gestores culturales (de instituciones públicas o asociaciones), críticos, difusores y otros agentes que puedan intervenir.

[4] Término explicado por Javier Abarca en su tesis doctoral: ABARCA SANCHÍS, F. J. (2010). El postgraffiti, su escenario y sus raíces: graffiti, punk, skate y contrapublicidad. Tesis doctoral. Facultad de BBAA. Universidad Complutense de Madrid. Madrid. Pág. 25.

[5] Tomando el ejemplo del investigador Fernando Figueroa Saavedra, que escribe Grafiti (con mayúscula) cuando se refiere al movimiento cultural (no sólo a la técnica), tal como explica en su libro El grafiti de firma (pág. 6), aquí escribimos Arte Urbano (en mayúsculas) al referirnos al movimiento artístico y cultural que engloba los distintos estilos, estéticas, técnicas y lenguajes, así como vías culturales y sociales. (Op. referenciada en Bibliografía).

[6] Nos sentimos cercanos a lo que el historiador y crítico de arte, Rafael Schacter refiere en uno de sus artículos y aportaciones a la teoría del arte urbano, y es que el Arte Urbano es un período más dentro de la Historia del Arte, como lo es el Manierismo, o el Barroco, etc. (ver referencia a este artículo en la Bibliografía).

[7] Grupo de arte urbano y conservación, vinculado al GEIIC, desde 2015.

[8] Una definición válida de arte urbano, según la autora, podría ser: arte realizado en espacios públicos, tanto con dimensión expresiva y de comunicación directa con un público no seleccionado, como de dimensión estética con sus propios códigos, lenguajes, técnicas y procesos.

[9] Fernando Figueroa Saavedra, Felipe Gálvez, Gabriela Berti y Javier Abarca, investigando en el panorama del grafiti en el territorio español, y otros estudiosos del street art y el grafiti, a nivel internacional.

[10] http://bit.ly/1oddZ5j Ejemplo de ficha de una obra de arte de la Colección del Prado en su web oficial; y ejemplo de una ficha en la Tate Britain de Londres: http://bit.ly/2dJxLCh.
[11] http://ceres.mcu.es/pages/Main Enlace a los museos (sus fichas completas de colección) estatales españoles. http://bit. ly/2dmpm7Y Catálogo General del Museo Cerralbo (acceso online).

[12] https://riunet.upv.es/handle/10251/49221 Ester López Rodríguez: "Propuesta de conservación documental de murales urbanos en el barrio del Carmen de Valencia"Trabajo doctoral.

[13] http://bit.ly/2dhPvZy Archivo del IAPH.

[14] Autoría, o autor, autores, autora, ya que el término artista tiene unas connotaciones más excluyentes o más definitorias sobre la actitud, conocimientos o interés en el arte.

\section{Bibliografía}

ABARCA SANCHÍS, F. J. (2010). El postgraffiti, su escenario y sus raíces: graffiti, punk, skate y contrapublicidad. Tesis doctoral. Facultad de BBAA. Universidad Complutense de Madrid. Madrid. [ http://eprints.ucm.es/11419/]

ARGÁN, G.C. (2010). Lo artístico y lo estético. Ed. Casimiro libros. Madrid.

BANKSY (2005). Wall and Piece. Random House, London.

BAUER, H.(1980). Historia del arte. Introducción crítica a la historia del arte. Taurus, Madrid.

BOZAL, V. (1996). Historia de las ideas estéticas y de las teorías artísticas contemporáneas, 2 vols. Visor, Madrid.

CARLSSON, B. y LOUIE, H. (2013). Street art. Recetario de técnicas y materiales del arte urbano. Ed. Gustavo Gili, Barcelona.

CALABRESE, O. (1987). El lenguaje del arte, Paidós, Barcelona.

CRUZ FERNÁNDEZ, P y HERNÁNDEZ NAVARRO, M.A. (eds.). (2005). La práctica de la crítica: el artista y el escritor críticos de arte. Asociación Murciana de Críticos de Arte. Murcia.

DE DIEGO, E (2015). Artes visuales en occidente desde la segunda mitad del siglo XX. Madrid: Cátedra.

FIGUEROA SAAVEDRA, FERNANDO (2014). El grafiti de firma. Minobitia textos. Madrid.

GAYA NUÑO, J.A. (1975). Historia de la crítica de arte en España, Iberoamericana, Madrid.

GOMBRICH, E. (1992). Lo que nos cuentan las imágenes. Ed. Debate, Madrid.

GUASCH, AM. (2000). El arte último del sigloXX. Del posminimalismo a lo multicultural. Alianza Forma. Madrid.

HAUSER, Arnold. (1975). Teorías del Arte. Ed. Guadarrama, Madrid, 
HAUSER, A. (1975). Historia social de la literatura y el arte, 3 vols, Guadarrama, Madrid.

HUNTER, GARRY (2012). Street Art. From around the world. London. Ed. Arcturus.

MARÍAS, F. (1996). Teoría del arte, Historia 16, Madrid.

MARTÍNFERNÁNDEZ, L. (2014). La conservación de manifestaciones estéticas,públicas e independientes. Trabajo Fin de Máster Universitario en Conservación del Patrimonio Cultural, Facultad de BBAA. Universidad Complutense de Madrid.

PANOFSKY, ERWIN. (1992). Estudios sobre iconología. Alianza Universidad, Alianza Editorial.

PANOFSKY, ERWIN. (1977). Idea. Contribución a la historia de la teoría del arte. Ediciones Cátedra, Madrid.

PANOFSKY, ERWIN. (1991). El significado de las artes visuales. Alianza editorial. Madrid.

PLINIO (1987). Textos de Historia del Arte, Visor, Madrid.

RAMÍREZ, J.A. (1996). Cómo escribir sobre arte y arquitectura, Ed. Serbal, Barcelona.

RIEMSCHNEIDER, B. y GROSENICK, U. (Ed.). (2001). Arte de hoy. Ed. Taschen. Köln.

RIPA, C. (1987). Iconología, Tomo 1. Ed. Akal. Madrid.

RUSSI, P. (2016). Grafitis. Trazos de imaginación y espacios de encuentro. Editorial UOC. Barcelona.

SENO Ethel; MCCORMICK, Carlo; SCHILLER, Marc; SCHILLER Sara; PASTERNAK, Anne; SERRA, J y Banksy (2010). Trespass: historia del arte urbano no oficial. TASCHEN BENEDIKT. London.

VASARI, G. (1957). Vidas de artistas ilustres, 5 vols, Iberia, Barcelona,.

VENTURI, L. (2004). Historia de la crítica de arte. Colecc. Debolsillo. Ed. Random House Mondadori. Barcelona.

VAL CUBERO. A. (2010). Una aproximación metodológica en el análisis de las obras de arte. (Tesis doctoral) Departamento de Periodismo y Comunicación Audiovisual. Universidad Carlos III. Madrid.

VVAA (2014). Escenas del graffiti en Granada. (Ramón Pérez Sendra Ed.). Editan: Ciengramos y TRN Laboratorio artístico transfronterizo.

VVAA (2016).“Propuesta de evaluación cultural de Bienes Muebles de Patrimonio religioso". Revista digital GE-Conservación, Madrid. p. 45-57.

WINCKELMANN, J. (1987). Reflexiones sobre la imitación del arte griego en la pintura y en la escultura. Edit. Aguilar. Madrid.
WOLFFLIN, H. (1924). Conceptos fundamentales en la historia del arte, Calpe, Madrid.

\section{Vínculos web}

ABARCA, J. Urbanario. http://www.urbanario.es "El papel de los medios en el desarrollo del arte urbano".04-04-2011. Versión corregida del artículo del mismo título publicado en la revista de la AACA, no 12, septiembre de 2010. Madrid. [consulta: 21/09/16].

ASALTO PRODUCCIONES. Festival Asalto. http://www. festivalasalto.com [consulta 21/09/16].

BANKSY (2012). Exit through the gift shop. Película. Filmin. Plataforma de cine online. https://www.filmin.es/pelicula/exitthrough-the-gift-shop [consulta: 25/09/16].

BOA MISTURA: "La vida es un estado mental. Lodz, Polonia”. 2016. http://www.boamistura.com [consulta: 30/09/16].

CABRERA CHELIN, SEBASTIÁN y JIMÉNEZ MORALES, YOSELIN (2012): Arte Urbano como recurso publicitario en la ciudad de Santo Domingo, periodo 2010-2012. Escuela de Publicidad. Decanato de Artes y Comunicación. Universidad Apec Unapec. Santo Domingo, República Dominicana. Tesis-Arte-Urbano. http://es.scribd.com/doc/58915577/ [consulta: 21/09/16].

CAPEÁNS, Juan: “Qué es la Nueva Agenda Urbana?". 06/10/2016. http://ecosistemaurbano.org [consulta: 07/10/16].

DELAMADRID, G.Escritoen la pared. http://www.escritoenlapared. com/ Consulta general sobre artistas e imágenes de obras y sus referencias. [consulta: 21/09/16].

DE LA MADRID, G. Prieto, D. (2016.) Madrid Street Art Project: "Creación artística en la calle". http://madridstreetartproject.com. [consulta: 21/09/16].

ELTONO.COM: “Pintura generativa y participativa, Cité Brûlard (las "408") Besançon, Francia". 03/2016. http://www.eltono.com/es/ murals/les-408/ [consulta: 21/09/16].

FARAQUEL: “Obras interactivas de arte urbano en algunas calles en Italia" 10 /08/2013 http://bit.ly/2dvTnoK. [consulta: 20/09/16].

GAU (Galeria de Arte Urbana) Revista virtual: vol 04. -versión portugués- https://issuu.com/galeriadearteurbana/docs/gau_ vol4_pt [consulta: 21/09/16].

GENUS BONONIAE. (2016). "Extracto de conversación del restaurador de la exposición Street Art - Banksy \& Co. Arte allo stato urbano, Bologna". Audiovisual. Youtube, Marzo-2016. https://www.youtube.com/watch?v=09o-JDk5-yA [consulta: 25/09/16].

GRAFFITI.ORG. Art Crimes. The Writing on the Wall: "Glosario de términos sobre Graffiti". http://bit.ly/2esb5L5 [consulta: 25/09/16]. 
IPCE Instituto del Patrimonio Cultural de España: Patrimonio inmaterial/enlaces. http://ipce.mcu.es/conservacion/planesnacionales/ inmaterial.html [consulta: 21/09/16].

LA MIRADA DIFUSA: "Artistas urbanos. Filthy-luker". Agosto, 2016. http://www.lamiradadifusa.com/ [consulta: 21/09/16]

METRÓPOLIS: "Arte Urbano". Audiovisual, en RTVE web. http://bit. ly/2etONFV [consulta: 24/09/16].

MULAFEST.COM: (sobre Arte urbano en entorno social y cultural). http://mulafest.com [consulta: 20/09/16].

NIQUELARTE.ORG: “BIComún: Identidad, Memoria Colectiva y Bienes Comunes". 04/08/2014. http://bit.ly/2etAlH2 [consulta: 21/09/16].

NIQUELARTE.ORG: "Qué es BIComun". http://bit.ly/2ehOEsh [consulta: 25/09/16].

PLAZA, D. (realizador y guión). “Arte urbano”. Vídeos sobre Arte y sociedad. Recursos educativos. UNED. https://canal.uned.es/mmobj/ index/id/12408 [consulta: 21/09/16].
PRIETO, Diana: “Arte Urbano: Respuestas Abiertas a Preguntas Cerradas", 2016. http://bit.ly/2dvZERv [consulta: 21/09/16].

RECUERO, R. : "Entrevista a Laura Mema". 06/09/, 2016. (modelos de entrevistas). http://www.plataformadeartecontemporaneo.com/pac/category/entrevista/ [consulta: 20/09/16].

SCHACTER, R.: "Street art is a period period or the emergence of intermural art". Hiperallergic.com. 31/06/16. http://bit. ly/2a62fjD [consulta: 25/09/16].

SLOWLY, Anita. Streetart Addicted: "Sr. Mu: O la imperiosa necesidad de contar-nos". ( modelos de entrevista). 25/06/2015. http://streetartaddicted.blogspot.com.es/ [consulta: 21/09/16].

UNESCO.ORG: "¿Qué es el patrimonio cultural inmaterial?". http://bit.ly/1mQD3zp [consulta: 15/9/16].

WRITERSMADRID: “DARE, to be different" 26/05/16 http:// www.writersmadrid.es/blog-writers/page/2 [consulta: 21/09/16].

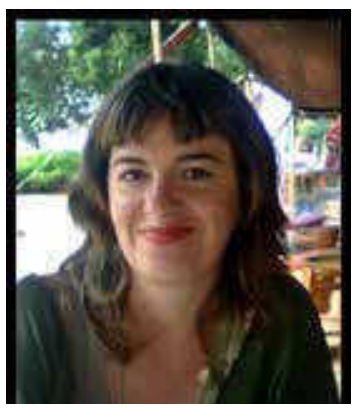

\section{María Isabel Úbeda García}

maribel.ubeda@gmail.com; www.maribelubeda.org

@mariveh (twitter e instagram)

Licenciada en Historia del Arte y suficiencia investigadora en 2000, especialidad en Historia del Arte Moderno y Contemporáneo. Certificado de Aptitud Pedagógica en Ciencias Sociales. Técnico de Grado Superior en Fotografía artística. Miembro de la Asociación murciana de críticos de arte (AMUCA) y de AECA (Asociación Española de Críticos de Arte).

Ha trabajado en diferentes ámbitos de la enseñanza reglada y no reglada: Música e Historia del Arte, habilidades sociales, radio y teatro; en gestión cultural, con asesoramiento a artistas visuales, comisariado y edición de textos sobre arte, como: AMUCA, catálogos de exposición Salón de la Crítica, Murcia; ALBIAC -Bienal de arte. Almería-, y A la deriva. Asociación cultural: Libros A la deriva. Ha ejercido la crítica de arte para la Galería Acanto y AMUCA. También realiza fotografías, maquetación, diseños y dibujos para diversas webs, merchandasing (Universidad de Murcia), cartelería y difusión en diferentes soportes y medios, así como edición audiovisual y contenidos culturales en línea (streaming, blogs, redes sociales). Actualmente compagina su actividad freelance en gestión cultural con el estudio y experimentación del arte y nuevas tecnologías en "pymientoproject", hacklab Almería. Es community manager de varias cuentas de artistas y galerías, realiza una importante actividad de divulgación en el Blog cultural que gestiona.

Investigadora independiente, forma parte del grupo de Arte Urbano del Grupo Español del International Institute for Conservation of historic and artistic works (GE-IIC), desde febrero de 2015. 

durante su aventura por artistas urbanos conocidos como Cope2, FUTURA, OBEY, Seen, Smith y T-kid 170. La elección de estos personajes reales no es algo dejado al azar, ya que cada uno enseña a Trane una habilidad que, por sus destrezas, les han sido adjudicadas a estos artistas: habilidad para marcar el sistema de metro, pintar murales, el empleo de adhesivos, bombardear vagones, sigilo...

Este juego ha generado mucha polémica, ya que fue censurado en Australia y en Inglaterra por la Asociación Anti-Graffiti. Marc Echō, en una entrevista en el periódico neoyorkino Metro, dijo que este conflicto no es debido solo a la visión criminalizada que se tiene sobre el grafiti, sino además a una desconexión generacional con las tecnologías ${ }^{2}$.

La relevancia de Marc Echō's: contents under pressure reside en que este juego ha sido concebido como el primer simulador de grafiti y hace referencia a una serie de artistas urbanos que otorgan a este título un grado importante de complicidad con este tipo de creaciones, además de ser uno de los primeros proyectos que se acercaron al arte urbano, y funciona a modo de documento de algunas técnicas empleadas así como de algunos de sus artistas más reseñados. Tanto es así que Jota Mayúscula, doblador de voz de Trane, afirma que lo que le llevó a aceptar la participación en el juego fue el respeto con el que trabajaron hacia la cultura del grafiti y el Hip Hop, además de reflejar la escena del arte urbano correspondiéndose a un cien por ciento de la realidad ${ }^{3}$.

\section{WiiSpray: aerosol cableado, pintura digital}

Como resultado del proyecto Information places de 2007, los estudiantes Martin Lihs y Frank Matuse, pertenecientes al Media Department de la Bauhaus University Weimar, crearon un dispositivo que, unido al mando de la consola de Nintendo Wii, permite la posibilidad de usar un objeto visualmente parecido a un aerosol, ofreciendo además una función similar de manera digital.

Junto a este hardware o dispositivo, se ha elaborado un programa o software que funciona a modo de paleta virtual, de tal forma que se pueden elegir entre diversos colores, permitiendo mezclarlos para crear numerosos tonos personalizados. A esta libertad cromática se le añade la posibilidad de poder elegir el tipo de aerosol que el jugador necesita en cada momento para calibrar a su gusto el tipo de trazo que realiza, así como el tipo de boquilla que se precisa para cada efecto. Tal es el empeño de alcanzar el realismo que, entre las opciones que ofrece WiiSpray, se pueden emplear plantillas personalizadas.

La idea más interesante de este proyecto es la posibilidad de poder realizar unos primeros acercamientos al arte urbano y poder usarlo como una herramienta de experimentación y de toma de contacto con los materiales que se emplean habitualmente en estas creaciones. Además, sirve como una ayuda en el estudio previo a la realización de una obra por parte de los artistas, para así poder visualizar qué resultados obtendrían.

\section{GRAFITE VIRTUAL: de la calle a los eventos sociales}

Actualmente, la sociedad ha ido aceptando con el paso del tiempo la cultura del arte urbano, ya que, como dice Aldo Iván Gómez en su artículo, El Graffiti como fuente de inspiración en la industria dela moda, afirma: "Lafilosofía delos primeros años del graffiti ha ido cambiando paulatinamente debido a la inmersión de este como un producto de moda. En un principio se busca la discreción, donde se debía de realizar bajo el anonimato. Ahora las marcas están al pendiente de cuál es el graffitero más sobresaliente del momento para poder realizar colaboraciones con estos. Se dieron cuenta de que el graffiti vende ${ }^{\prime \prime 4}$. Es decir, estas expresiones artísticas cada vez están ganando más aceptación, llegando a calar incluso en grandes marcas como es el caso del previamente entrevistado artista taiwanés Ano, que colaboró con Nike y Adidas en varios eventos ${ }^{5}$.

Un buen ejemplo de la aceptación y del interés de las grandes marcas por el arte urbano, en concreto en su versión digital, es Grafite Virtual. En la promoción de este simulador ya se advierte que la idea de sus creadores, de origen brasileño, procede por el interés del grafiti de su país, ya que afirman que ese estilo es uno de los más reconocidos del mundo. Usando este pensamiento casi a modo de premisa, sus creadores ofrecen una funcionalidad muy similar al citado WiiSpray, pero en su defecto, Grafite Virtual está enfocado más a su uso en eventos sociales que a un juego para el hogar, como sería el caso del proyecto para Nintendo.

Este simulador ofrece una gran cantidad de colores, formatos, opciones e incluso accesorios para su utilización, aunque - y aun presumiendo de su novedad a nivel nacional y mundial-el dispositivo con el que se realizan las creaciones también es similar al formato de WiiSpray, imitando a un aerosol; pero en este caso funciona con unas latas originales adaptadas con sensores y tecnología de infrarrojos. Como resultado, Grafite Virtual es una herramienta visualmente muy atractiva que ha sabido mostrar que el arte urbano tiene potencial a la hora de presentar a una empresa o a un producto como un elemento muy llamativo e interactivo. Son muchas las marcas y empresas que han contado con los servicios de esta herramienta para promocionarse, entre ellos Google, Facebook, SAP, Natura, Yahoo, Coca-cola, Chanel o Mercedes-Benz . [figura 1].

La relevancia de este sistema es que hace ver que el arte urbano tiene un gran impacto social, ya que es una actividad rápida y fresca, tan dinámica como la tecnología y el videojuego, permitiendo todo ello dar libertad a la creatividad, como en los casos de los escaparates de Chanel o la feria de Mercedes Benz, en los que los transeúntes se convierten en artistas improvisados y, como con los materiales reales, pueden dejar una huella personalizada de esta acción. 


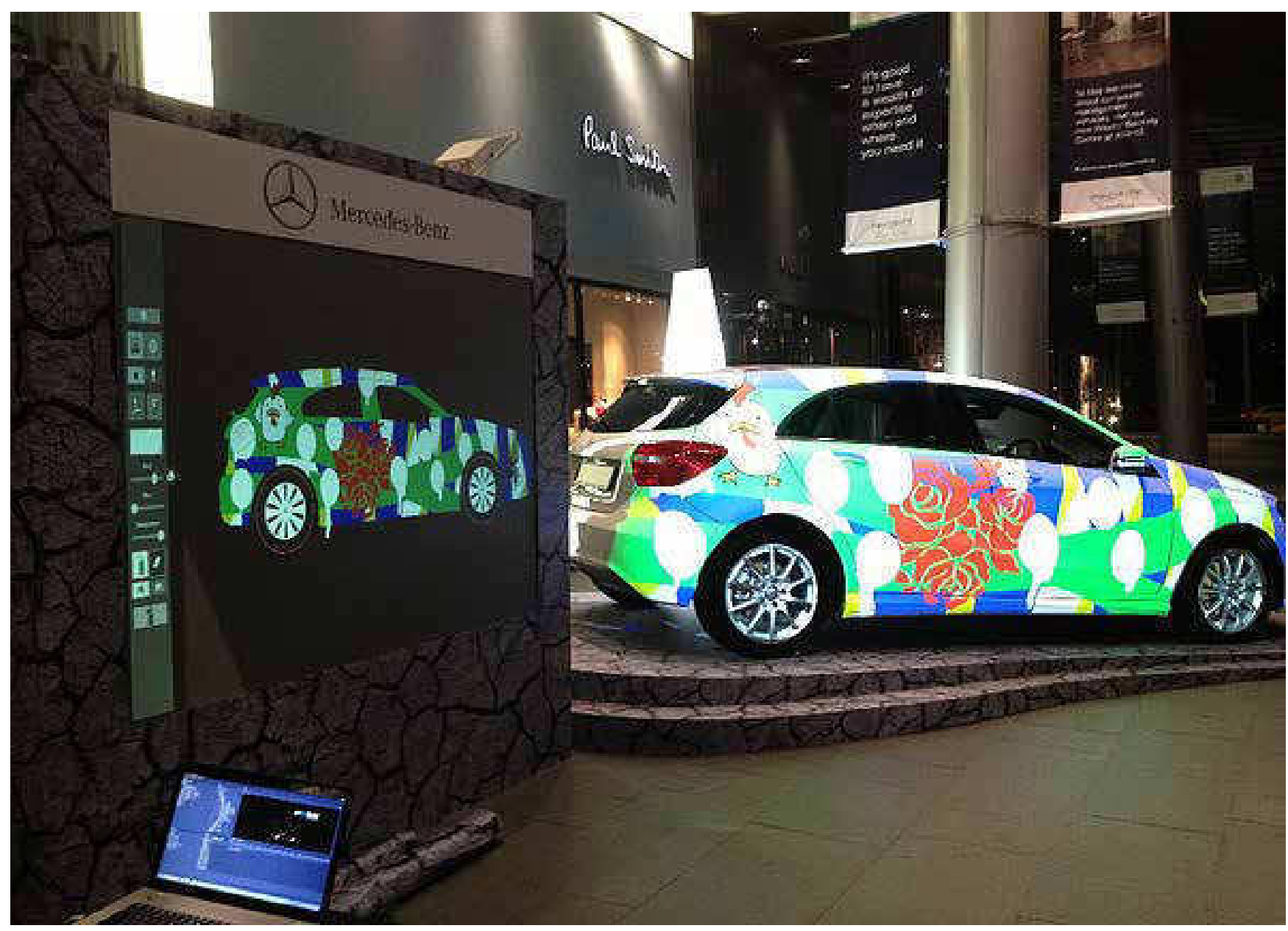

Figura 1.-Exposición de Mercedes Benz usando Grafite Virtual. Contenido perteneciente a: http://www.grafitevirtual.com.br/grafitedigital

\section{Kingspray graffiti simulator: La experiencia en realidad virtual}

Gracias a la evolución tecnológica, el nuevo punto de mira de los videojuegos se centra en la realidad virtual. Esta herramienta se ha aplicado a distintos géneros dentro de los videojuegos, como ya se ha adelantado previamente; $y$, con este ejemplo, se puede ver que ha llegado a aproximarse al arte urbano.

Este simulador ofrece unas características similares a las citadas en los ejemplos de Grafite virtual o WiiSpray, pero su novedad está en que ha sido pensado y desarrollado para las gafas de realidad virtual, unos periféricos que sirven para dar sensación de inmersión en un escenario imaginario.

En este caso, la acción se desarrolla en un entorno urbano en el cual se puede elegir la zona sobre la que se quiere realizar la intervención. Kingspray graffiti simulator es un juego que ha querido llevar el realismo de la experiencia al máximo, ya que entre las configuraciones puedes elegir qué hora del día quieres que sea y, entre otros efectos, si aplicas mucha cantidad de producto se puede dar un efecto dropping muy realista.
Todo esto muestra cómo el arte urbano es de gran interés para el mundo del videojuego y los simuladores, ya que proporciona experimentación de una acción "ilegal" dentro de un entorno idealizado y, además, se podrán conservar las obras y compartirlas gracias a las funciones relacionadas con las redes sociales. [Figura 2].

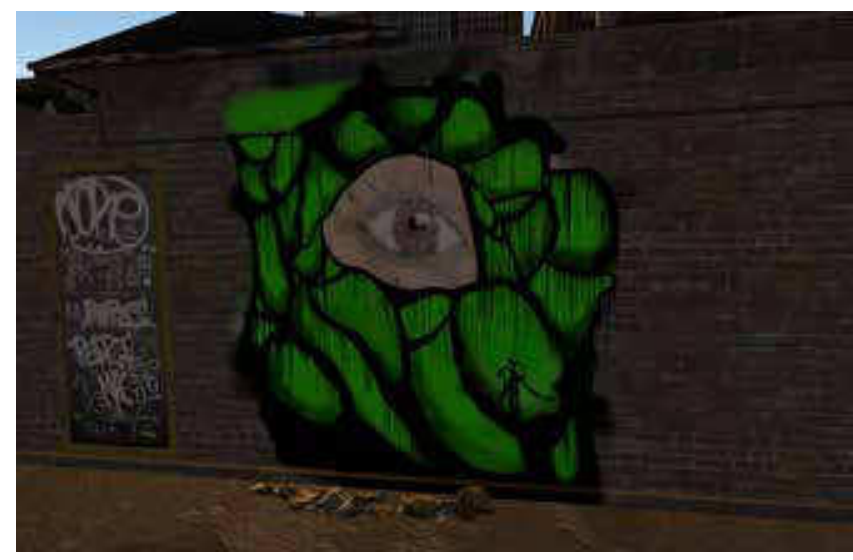

Figura 2.- Proyecto realizado con Kingspray graffiti simulator. Contenido perteneciente a: http://graffitisimulator.com/ kingspray-35/ 


\section{Augmented reality creator: Generador en App}

Además de juegos y simuladores, como los anteriormente citados, podemos encontrar en otras plataformas diversos recursos igualmente interesantes, siendo en este caso para teléfonos de nueva generación o smartphones: Augmented reality creator.

Diseñada para el sistema operativo iOS, Augmented reality creator combina un editor de realidad virtual con redes sociales, aunque, como en el arte urbano, ofrecen la posibilidad de publicar en la librería de la propia aplicación con total anonimato. Es reseñable que juega con la perspectiva, en tiempo real, en el emplazamiento en el que se encuentre el jugador, quien es ayudado al realizar el grafiti por un personaje animado llamado Max Morrison, al cual se puede personalizar. La aplicación, como novedad, ofrece la posibilidad de crear arte urbano en cualquier parte y momento, usando como soporte lo que quiera en ese momento el jugador.

Augmented reality creator, además, en su página web, va acompañado de unas palabras de su creador donde deja clara su percepción del arte urbano:

"El grafiti de spray no es aceptado socialmente, pero no te preocupes por ser cogido con un bote de aerosol (virtual) en las manos- Max Morrison se llevará la culpa. Max es el tipo adecuado para el trabajo; es un marginado, no es extremadamente bien aceptado en una vida diaria medida por los estándares tradicionales de una vida exitosa. Él se siente orgulloso de sí mismo en ser libre y extremadamente intransigente. A él no le importa. Si piensa o siente que hay algo que decir, lo dirá. No solo lo dirá, lo grafiteará, y cuanto más atractivo el soporte, mejor. El edificio del parlamento, una sala de ópera, un colegio, detrás de una chica guapa, si la superficie se ciñe a su propósito, es rociado con el spray. Su propósito en vida es dibujar grafitis en todos los edificios famosos en el mundo. Los usuarios tienen que ser animados a ser como Max y grafitear lo que sea que tengan en mente en ese momento, ser creativos, divertidos, y controvertidos [...]. No hay límite para la creatividad de los usuarios, elaborando mensajes potentes con un excelente potencial viral." ${ }^{\prime 6}$.

De estas palabras podemos extraer como la percepción de su creador es la de un arte urbano muy reivindicativo que bombardea la ciudad con mensajes polémicos. Por ello, el interés de esta aplicación reside en la idea con la que fue concebida: un lugar donde compartir pensamientos, donde poder expresarse libremente sin censura. En definitiva, quiere mimetizar la libertad creativa del arte urbano, dando cabida a todas las opiniones y guardando todas esas intervenciones ficticias en una misma aplicación.

\section{Pokémon Go y la geolocalización del arte urbano}

En julio de este año se estrenó el conocido juego para plataformas móviles Pokémon Go, el cual experimenta con la realidad inmersiva para poder capturar las criaturas creadas por la compañía Game Freak.

El objetivo se resume en ser el mejor entrenador de pokémon, y para ello, hay que obtener materiales en unos lugares llamados "pokeparadas" para poder capturar y fortalecer a las criaturas. Estas zonas denominadas así, son emplazamientos de interés general vinculados al entramado urbanístico (estatuas, tiendas, edificios...). Es justo en este punto en el que el arte urbano se convierte en una herramienta muy importante para Pokémon Go. Al entrar en contacto con el juego, destaca que muchos de los puntos de interés están relacionados con grafitis. Esto deja un tema abierto: la obra como punto de encuentro de los jugadores y el conocimiento del entorno. Por un lado, Pokémon Go ha vinculado estos puntos de encuentro a las "pokeparadas", lugar donde es habitual observar a personas congregadas en torno a esa zona, geolocalizado que cerca existe un grafiti. Esto, además

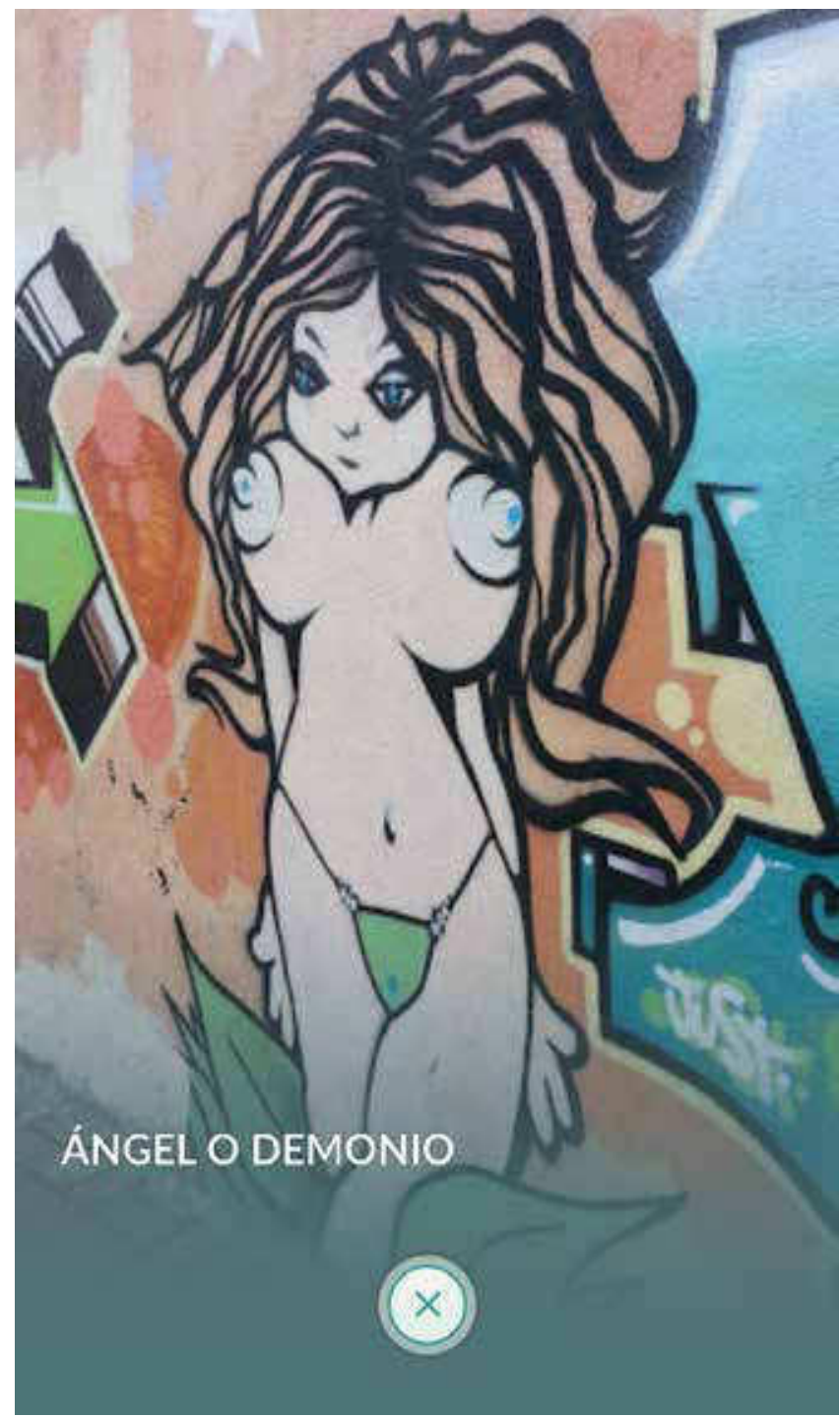

Figura 3.- Intervención denominada "Ángel o Demonio". Captura realizada por: María del Mar Vázquez 
de acrecentar la socialización, crea un conocimiento del propio entorno y de intervenciones que, quizás, de otra forma habrían pasado desapercibidas. Por otro lado, no habría que pasar por alto que esta predilección hacia el arte urbano funciona en cierto modo como una forma de documentación. Observando la imagen propuesta por la aplicación podemos acudir posteriormente a su ubicación y proceder a evaluar sus cambios. Este asunto es especialmente interesante en este campo de la conservación, ya que facilita la documentación. El caso más concreto es el de una intervención llamada en Pokémon Go "Angel o Demonio". Este grafiti, ubicado en el barrio de Vallecas, ha sido empleado como punto de interés de una "pokeparada". Transcurrido el tiempo, ese grafiti fue eliminado, pero en el juego se mantiene su presencia. [Figura 3].

Lachlan MacDowall en su artículo For lovers of graffiti, Pokémon Go is old hat ${ }^{7}$ comenta que esta idea de Pokémon Go no es nueva, ya que la gente, con anterioridad a este juego, procedían a capturar imágenes antes de que desapareciera la obra de artistas reconocidos como Banksy. Como él mismo apunta, es reseñable que este juego pone en alza a obras más y menos conocidas como puntos de interés con una recompensa para el jugador, además de la propia de poder transitar la ciudad y conocer su arte urbano.

\section{Conclusiones}

Tras estos ejemplos citados en el presente texto, cabría destacar que solo son una pequeña porción de todos los juegos que se podrían analizar, ya que hay otros ejemplos existentes; pero casi todos en la misma línea de los que aquí se han recogido y analizado.

Como se ha podido observar en este artículo, no solo se ha llevado el arte urbano al videojuego, tanto como objetivos a cumplir de la narrativa, como escenarios, etc., sino que ha llegado al ámbito tecnológico del hardware para convertirse en una herramienta que se encuentra entre el ocio y el diseño gráfico.

Algunos juegos y simuladores se presentan como alternativas experimentales muy útiles para preparativos previos a las intervenciones $y$, además, sirven como un elemento didáctico para acercar la cultura del arte urbano. Así mismo, otros juegos crean unos ambientes que sumergen al jugador en un contexto adaptado a la realidad, donde pueden meterse en la situación y en el rol de los artistas urbanos.

Por todo ello, habría que analizar todos estos simuladores como una herramienta útil desde el punto de vista creativo; pero, además habría que estudiar la posibilidad de que sirvan como ayuda a la documentación de estas obras, como es el caso de Pokémon Go en su geolocalización.
De otra forma, todo este artículo, junto a las investigaciones realizadas anteriormente, deja entrever aún más la importancia de la relación del arte urbano con la tecnología $y$, en este caso en concreto, con el videojuego. Por un lado, no se ha podido obviar que muchos artistas se han inspirado en los códigos visuales y personajes como autoproclama o muestra de su influencia por los videojuegos. Por otro, los propios desarrolladores de videojuegos para múltiples plataformas se han valido del arte urbano como un recurso visual y narrativo que, en la mayoría de los casos, es el eje vertebrador de toda la acción, mostrando un cierto grado de estudio centrado en la cultura urbana y, de forma generalizada, la visión criminalizada de este tipo de creaciones como es el caso de Jet Set Radio.

Considerando esto anterior, habría que sopesar la posibilidad de realizar un acercamiento pormenorizado a la iconografía subyacente en el arte urbano en torno a los videojuegos para analizar la relevancia discursiva que pudieran tener tanto para el artista como para el espectador y el entorno en el que se encuentra. Además, y en paralelo a este estudio sobre este interés del arte urbano por el mundo del juego, sería interesante contar con información en tanto a las opiniones de los artistas sobre los múltiples simuladores citados, para conocer hasta qué punto el mundo tecnológico se ha volcado en los intereses de los artistas y saber qué esperan de esta, cada vez más latente, vinculación entre arte y videojuego.

\section{Referencias:}

[1] ROJAS, M., "El boom de las gafas de realidad virtual en 2016", en GadgetoWeb. http://www.gadgetoweb.com/elboom-de-las-gafas-de-realidad-virtual-en-2016/[Consulta: 8/5/2016]

[2] NOQUEDANMASNICK, "Marc Ecko achaca la polémica de su juego a las diferencias intergeneracionales", en MeriStation (22-2-2006). http://www.meristation.com/noticias/marcecko-achaca-la-polemica-de-su-juego-a-las-diferenciasintergeneracionales/1637128 [Consulta: 12/10/2016]

[3] GRANDíO, P., "DJ Jota Mayúscula doblará al protagonista de Getting Up", en Vandal (13-7-2005). http://www.vandal.net/ noticia/17452/dj-jotamayuscula-doblara-al-protagonista-degetting-up/ [Consulta: 12/10/2016]

[4] GÓMEZ VILLAFAÑA, A. I., "El graffiti como fuente de inspiración para la industria de la moda", en Moda en el diseño (27-5-2015). http://modaeneldiseno.blogspot.com.es/2015/05/el-graffiticomo-fuente-de-inspiracion.html [Consulta: 1/8/2016]

[5] VÁZQUEZ DE LA FUENTE, M., "Vinculados a Ano", en Mural Street Art Conservation, № 3, pág. 52. https://issuu. com/observatoriodearteurbano/docs/mural_3 [Consulta: 4/8/2016] 
[6] AUGMENTED REALITY TRENDS, "Max Morrison- Augmented Reality Graffiti Creator". Traducido de Augmented Reality Trends (3-11-2014). http://www.augmentedrealitytrends.com/ ar-app/max-morrison.html [Consulta: 4/8/2016]

[7] MACDOWALL, L., "For lovers of graffiti, Pokemon Go is old hat", en The Conversation (19-7-2016). https://theconversation. com/for-lovers-of-graffiti-pokemon-go-is-old-hat-62683 [Consulta: 19/09/2016]

\section{Bibliografía:}

VÁZQUEZ DE LA FUENTE, M. (2016): Vinculados a Ano. Mural Street Art Conservation. Revista especializada digital del Observatorio de Arte Urbano №2. (pp. 52)

\section{Vínculos Web:}

AUGMENTED REALITY TRENDS, Max Morrison- Augmented Reality Graffiti Creator (3-11-2014). http://www. augmentedrealitytrends.com/ar-app/max-morrison.html (4-82016)
GÓMEZ VILLAFAÑA, A.I. El graffiti como fuente de inspiración para la industria de la moda. Moda en el diseño (27-5-2015). http://modaeneldiseno.blogspot.com.es/2015/05/el-graffiticomo-fuente-de-inspiracion.html (1-8-2016)

GRANDÍO, P., DJ Jota Mayúscula doblará al protagonista de Getting Up. Vandal (13-7-2005). http://www.vandal.net/ noticia/17452/dj-jotamayuscula-doblara-al-protagonista-degetting-up/ (12-10-2016)

MACDOWALL, L., For lovers of graffiti, Pokemon Go is old hat. The Conversation (19-7-2016). https://theconversation.com/forlovers- of-graffiti- pokemon-go- is-old- hat-62683 (19-9-2016)

NOQUEDANMASNICK., Marc Ecko achaca la polémica de su juego a las diferencias intergeneracionales. Meristation. (22-2-2006). http://www.meristation.com/noticias/marcecko-achaca-la-polemica-de-su-juego-a-las-diferenciasintergeneracionales/1637128 (12-10-2016)

ROJAS, M., El boom de las gafas de realidad virtual en 2016. Gadgetoweb. http://www.gadgetoweb.com/el-boom-de-lasgafas-de-realidad-virtual-en-2016/ (8-5-2016)

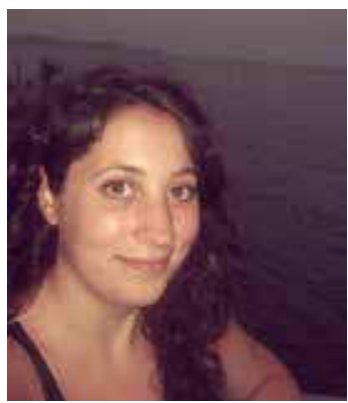

\section{María del Mar Vázquez de la Fuente}

Historiadora del arte

marimarvz@gmail.com

Graduada en Historia del Arte por la UAM (Universidad Autónoma de Madrid). Técnico en Radiografiado de Obras de Arte. 

6. Los artistas buscan la posteridad física, aunque asuman su carácter efímero.

7. Busca medios diferentes de llegar al público de forma universal y gratuita.

8. Las obras de Arte Urbanoilegal yalegal son reconocidas como "Manifestaciones Independientes". El presente documento se referirá a las intervenciones de encargo y convocatorias públicas denominadas como "Muralismo Contemporáneo", si se trata de obras sobre soporte mural, e "Intervenciones Contemporáneas" en el caso de ser obras diferentes a las murales. De esta manera, la conservación de ambas manifestaciones artísticas se realizará partiendo de puntos de vista diferentes.

9. El Muralismo contemporáneo y las Intervenciones Contemporáneas nacen de la necesidad de profesionalización del movimiento.

\section{Está desprotegido de una tutela de conservación.}

ElArteUrbano(manifestacionesindependientes, muralismo contemporáneo e intervenciones contemporáneas) está conformado de elementos culturales alterables, independientes, artísticos, documentales, ambientales, históricos, científicos, sociales o espirituales particulares, adquiere un carácter significativo que debe considerarse y transmitirse a generaciones futuras.

A pesar de no haber precedentes que consideren alguna obra de Arte Urbano como patrimonio susceptible de ser conservado y restaurado, se propone que sean tenidas en cuenta como Bienes Culturales Comunes (BIComun)': identidad y memoria colectiva, con la pretensión de englobar estas manifestaciones artísticas que no menciona la Ley de Patrimonio Histórico Español (Ley 16/1985, de 25 de junio).

\section{Implicados}

El presente código no define únicamente las pautas del Conservador-Restaurador, sino que vincula a todos los profesionales que interactúen para favorecer su estudio, divulgación, educación, conservación y restauración de Arte Urbano: historiadores del arte, artistas, gestores patrimoniales, arquitectos, sociólogos, antropólogos, críticos, filósofos, así como cualquier profesional que no se identifique en los anteriores grupos y cuya práctica disciplinar cumpla los objetivos planteados en este código.

El trabajo ha de ser interdisciplinar y transversal, contando con la colaboración de los diferentes ámbitos profesionales para garantizar la correcta conservación ética de las Intervenciones Contemporáneas ubicadas en el espacio público.

Cada uno de los agentes de la comunidad artística reconocerá el valor del trabajo del resto y hará evidente ese apoyo ante el sector y la sociedad.
6. The artists seek physical posterity, although they assume ephemerality.

7. It seeks different universal and cost-free ways to reach the public.

8. Illegal works of Street Art are recognized as "Independent expressions." This document will refer to commissioned creative interventions as "Contemporary Muralism", if executed on a wall, and "Contemporary Artistic Creations" in the case of works that differ from murals. Thus, conservation of both types of artistic expressions shall be based on different points of view.

9. Contemporary Muralism and Contemporary Artistic Creations stem from the need for the professionalization of the movement.

\section{It is not protected by conservation guardianship.}

Street Art (independent expressions, contemporary mural painting and contemporary creations) consists of changeable, independent, artistic, documentary, environmental, historic, scientific, social or spiritual cultural elements, which acquire a significant character to be considered and passed on to future generations.

Although there are no precedents of considering a work of urban art as qualified heritage to be preserved and restored, it is proposed that they be taken into account as Cultural Heritage (BIComun)': Identity, Collective Memory and Common Heritage, with the aim of encompassing these artistic creations that are not mentioned in the Spanish Historical Heritage Act (Law 16/ of 25 June 1985).

\section{Those Who Would Be Involved}

This code not only defines the guidelines of the conservator, but it also encourages all professionals to interact in order to further their study, dissemination, education, conservation and restoration of street art: art historians, artists, cultural affairs managers, architects, sociologists, anthropologists, critics, philosophers, and other professionals who are not identified in the above groups and whose disciplinary practice meets the objectives outlined in this code.

The work must be interdisciplinary and cross-referenced, with the collaboration of different professional fields, in order to ensure a proper conservation ethic of Contemporary Artistic Creations located in public space.

Each of the agents of the artistic community will recognize the value of work of the others, and each will make evident their support of the sector and of society. 
Los profesionales implicados tendrán como referencia y deberán respetar el código ético de la propia disciplina. Este código pretende ser una guía orientativa sin sustituir a ninguno de los que cada grupo profesional haya podido redactar o prepare en el futuro.

\section{Procedimiento}

Este código ha sido creado por el grupo de trabajo de Arte Urbano del GE-IIC, conformado por un heterogéneo equipo de profesionales dedicados al estudio y conservación de patrimonio histórico artístico, que se hará cargo, hasta su disolución, de facilitar el conocimiento, seguimiento, aplicación y revisión del mismo.

La creación del código deontológico es, en su propia definición, un proceso en el que la casuística pone en evidencia la necesidad de acotación de las intervenciones que afectan al Arte Urbano.

\section{Valores y principios de actuación}

\section{Principios generales para la aplicación del Código}

-Artículo 1: El presente código ético de conservaciónrestauración incorpora los principios, obligaciones y comportamientos que cada ámbito profesional relacionado con el Arte Urbano debe esforzarse en seguir en la práctica de la propia profesión.

-Artículo 2: El desarrollo de la actividad de los profesionales implicados es de interés público y se debe practicar en cumplimiento de todas las leyes pertinentes y acuerdos nacionales e internacionales, particularmente en los que se refieren a propiedad robada, entendiendo expresamente el derecho moral de los artistas sobre las intervenciones, o de aquellas personas en las que ellos deleguen. ${ }^{2}$

-Artículo 3: El Conservador-Restaurador y todos los profesionales implicados adquieren, trabajando en contacto directo con el Arte Urbano, una responsabilidad con la sociedad a la que pertenecen dichas intervenciones artísticas (vecindario y propietarios de los lugares intervenidos) y con el artista.

El Conservador-Restaurador deberá respetar y defender su ética profesional así como argumentar las intervenciones que estarán basadas en el respeto a la obra y a la intención del artista.

El Conservador-Restaurador tiene derecho en todas las circunstancias a rechazar cualquier petición que crea contraria a los términos o a la finalidad de la obra y de los hechos culturales que contienen. Toda actividad profesional estará guiada por el respeto hacia la significación histórica, estética y social de las obras de arte, valorándose su aportación a la formación estética y
The involved professionals will reference and must respect the code of ethics of the discipline itself. This code is intended as a guide without replacing any such code that each professional group might been able to write or prepare in the future.

\section{How To Proceed}

This code has been created by the working group Urban Art GE-IIC, consisting of a diverse team of professionals dedicated to the study and conservation of artistic heritage, which will take charge, until its dissolution, of facilitating its understanding, monitoring, implementation and revision.

The development of the code of practice is, by its own definition, a process in which sophistry highlights the need for precise observation of creations of street art.

\section{Values and Principles}

\section{General Principles for the Implementation of the Code}

- Article 1:The present ethical code of conservation incorporates the principles, obligations and behavior which every professional field related to Street Art must strive to follow in the practice of the profession.

- Article 2: The development of the activity of the involved professionals is in the public interest and must be practiced in compliance with all relevant laws and national and international agreements, particularly those relating to stolen property, specifically understanding the moral right of artists in creative work, or those which they supervise. ${ }^{2}$

- Article 3: The Conservator, and all involved professionals, acquire through working in direct contact with Street Art, a responsibility to the society to which such artistic creations belong (neighborhoods and owners of the appropriated sites) and the artist.

The Conservator must uphold professional ethics and defend the stance that conservation interventions will be based on respect for the work and for the artist's intent.

The Conservator is entitled in all circumstances to refuse any request that may be created contrary to the terms or the purpose of the work and cultural facts contained therein. All professional activity will be guided by respect for the social historical significance, aesthetics and art, valuing their aesthetic and civic contributions. The professionals 
cívica. Los profesionales aquí representados asumimos nuestra responsabilidad en el legado patrimonial para las generaciones venideras, sean elementos avalados por la cultura oficial o no, y siempre que su forma de expresión artística no constituya un ataque a la dignidad e integridad física y moral de las personas.

-Artículo 4: Las propuestas de conservación-restauración de Arte Urbano pueden ser solicitadas por cualquier persona o colectivo y deben contar en primer lugar con la aprobación del artista, con los profesionales, la comunidad, la propiedad o el organismo del que dependa la ubicación de la obra.

-Artículo 5: Las actuaciones de conservación sobre Murales Contemporáneos deben ser iniciadas por los organizadores de la convocatoria que dio lugar a la existencia de la obra, o por un colectivo bajo propuesta razonada.

-Artículo 6: Ante cualquier intervención de conservación - restauración de una obra el artista ha de ser consultado en primera instancia, respetándose sus derechos ${ }^{2}$ ante la posibilidad incontrolada de explotación de sus obras.

-Artículo 7: Las intervenciones realizadas por artistas en sus propias obras ya finalizadas, se denominarán "repintes", y no intervenciones de conservación-restauración, ya que estas requieren del estudio y establecimiento de unos criterios de intervención objetivos concretos. Pero, en el caso de intervenciones realizadas por artistas en colaboración con conservadores-restauradores, sí podrán ser identificadas como tales. En estos casos, la labor del conservador-restaurador se limitará al examen de las posibilidades de conservación-restauración de la obra dentro de sus competencias y criterio profesional, sin ser su labor o intención crear un adoctrinamiento que pueda variar la idea del artista.

-Artículo 8: Se respetará la importancia estética, histórica y espiritual, así como la integridad física de la obra de Arte Urbano confiada al cuidado de los profesionales implicados.

-Artículo 9: Las obras intervenidas y conservadas tendrán un reconocimiento patrimonial y social dentro de su contexto como obras BIComún y se trabajará para su propuesta y aceptación oficial como Bien de Interés Cultural (BIC). Éstas representarán las obras elegidas por los ciudadanos como patrimonio representativo de su época.

-Artículo 10: Los profesionales implicados deberán fomentar la formación artística, la investigación y el estudio permanente con miras a la interpretación de las obras de arte, a su mejor conservación y gestión. Debe existir un compromiso para la mejora de la formación de los ciudadanos en el conocimiento del patrimonio cultural, con una visión más amplia en la que se puedan valorar expresiones populares que no sean susceptibles de ser protegidas por la actual Ley de Patrimonio. represented here assume our responsibility in the heritage for generations to come, whether or not there are elements endorsed by the official cultural, and provided their form of artistic expression does not constitute an attack on the dignity and physical and moral integrity of persons.

- Article 4: Proposals for conservation of Street Art can be requested by any person or group and must first have the approval of the artist, as well as practitioners, community property or agency associated with the location of the work of art.

- Article 5: Murals conservation actions on Contemporary Murals must be initiated by the organizers of the request that led to the existence of the work, or under a collective reasoned proposal.

- Article 6: Before any intervention conservation intervention on a work of art, the artist must be consulted first, respect to their rights vis-a-vis the possibility of uncontrolled exploitation of their works.

- Article 7: Interventions by artists on their own already-completed works will be called "repainting," not conservation intervention, since these latter require the study and establishment of specific goals of intervention criteria. But in the case of interventions by artists in collaboration with conservators, then they can be identified as such. In these cases, the work of the conservator is limited to the consideration of the possibilities of conservation and restoration of the work within their competence and professional judgment, without being their own work or intending to introduce elements that might change the idea of the artist.

- Article 8: The aesthetic, historic and spiritual importance must be respected, as well as the physical integrity of the work of Street Art entrusted to the care of the professionals involved.

- Article 9: The works that have been preserved will have cultural and social recognition within their context as Cultural Heritage ("BIComún") works, and we will work for their proposal and official acceptance as a Cultural Heritage Landmarks ("BIC"). These represent the works chosen by citizens as representative of their era.

- Article 10: The professionals involved should encourage artistic training, research and ongoing study with a view to the interpretation of works of art, as well as better conservation and management. There must be a commitment to improving the training of citizens in the knowledge of cultural heritage, with a broader vision in which they can assess popular expressions that are not likely to be protected by the current Heritage Act. 
-Artículo 11: Los profesionales deben trabajar al mejor nivel con independencia de cualquier opinión respecto al valor comercial de la obra BIComún. Aunque las circunstancias puedan limitar el alcance de la acción de restauración, se debe mantener el respeto al Código propuesto.

-Artículo 12: Se valorarán todos los aspectos de la conservación preventiva antes de llevar a cabo una actuación directa sobre la obra de Arte Urbano y se limitará el tratamiento solamente a lo que sea estrictamente necesario para su comprensión material y estética.

-Artículo 13: Se preferirá el uso de productos, materiales y procedimientos que, según el nivel actual de conocimiento, no dañen la obra, el ambiente o a las personas. Las intervenciones y materiales introducidos deben respetar las obras sin modificar el aspecto, acabado o concepto de las mismas, garantizando su estabilidad, compatibilidad respecto a la obra y su autor/es, así como garantizar la retratabilidad.

-Artículo 14: El tratamiento de conservaciónrestauración de Arte Urbano se debe documentar mediante un registro escrito e ilustrado del examen de diagnóstico, de cualquier intervención de restauración y de toda información relevante. El informe debe también incluir los nombres de todos los que han realizado el trabajo, incluidos sus contactos. Se debe presentar una copia del informe, que siempre se mantendrá accesible, a los responsables legales de la obra y de la restauración. En este documento se debe especificar cualquier requisito posterior para el mantenimiento, exhibición o acceso a la propiedad cultural.

-Artículo 15: Cada uno de los profesionales implicados debe emprender solamente trabajos para los que sea competente. El Conservador-Restaurador no debe ni comenzar ni continuar un tratamiento que no sea beneficioso para el BIComún.

-Artículo 16: Los profesionales deben esforzarse en enriquecer sus conocimientos y habilidades con el objetivo constante de mejorar la calidad de su trabajo profesional, fomentando la investigación y creando nuevas técnicas que agilicen las intervenciones.

-Artículo 17: Cuando sea necesario o apropiado, el Conservador-Restaurador colaborará con otros profesionales y participará con ellos en un intercambio completo de la información. Un modelo ideal de intervención es aquel que cuenta con la aprobación del artista, de los especialistas y de la comunidad, trabajando juntos para la conservación-restauración de la obra.

-Artículo 18: En cualquier emergencia en la queel BIComún esté en peligro inmediato, el Conservador-Restaurador - con independencia de su campo de especialización proporcionará toda la ayuda posible, ofreciendo varias
- Article 11: Professionals must work at the highest level regardless of any opinion on the commercial value of the work designated as Cultural Heritage ("BIComún"). Although circumstances may limit the scope of the restoration action, one must maintain respect for the proposed Code.

- Article 12: All aspects of preventive conservation will be evaluated before intervening on a work of Street Art, and treatment is limited only to that which is strictly necessary for the understanding of materials and aesthetics.

- Article 13: The use of products, materials and procedures that, according to current knowledge, do not harm the environment or people will be preferred. Interventions and materials introduced must respect the work without changing its appearance, finish or concept, ensuring stability, compatibility regarding the work and its author(s) and ensure the possibility of further treatment.

- Article 14: The conservation-restoration treatment of Street Art must be documented by a written and illustrated diagnostic examination, with any restorative intervention described along with all relevant information. The report should also include the names of those who have performed the work, including their contact information. One must submit a copy of the report, which will always remain accessible, to those legally responsible for the work and for its conservation. This document must specify any further requirement for maintenance, display or access to cultural property.

- Article 15: Each of the professionals involved should undertake work only for which it is competent. The Conservator must neither begin nor continue a treatment that is not beneficial to the Cultural Property ("BIComún").

- Article 16: Professionals must strive to enrich their knowledge and skills with the constant aim of improving the quality of their professional work, promoting research and creating new techniques to increase the efficiency of treatments.

- Article 17: Where necessary or appropriate, the Conservator shall collaborate with other professionals and shall participate with them in a full exchange of information. An ideal model of intervention is one that has the approval of the artist, specialists and the community working together for conservation of the work.

- Article 18: In any emergency where the Cultural Property ("BIComún") is in immediate danger, the Conservator--regardless of his/her field of expertise-will provide all possible help, offering several 
alternativas para la acción que se le propone.

Las intervenciones de urgencia no deben aportar mayores alteraciones a las obras, por lo que, antes de que sean llevadas a cabo, deberán tenerse en cuenta los aspectos negativos que pueden aportar, evaluando si su puesta en marcha es realmente necesaria.

-Artículo 19: El Conservador-Restaurador no retirará ningún material de la obra de Arte Urbano a menos que sea imprescindible para su preservación o que interfiera sustancialmente con su valor histórico y/o estético.

En el caso que se realice cualquier tipo de sustitución o se opte por retirar definitivamente un material original, estos deberán ser conservados siempre que sea posible, y el procedimiento empleado se documentará completamente en el registro de la intervención.

-Artículo 20: Cuando el uso social del BlComún sea incompatible con su preservación, el Conservador-Restaurador solicitará el asesoramiento del artista, del propietario y/o del guardián legal, para la fabricación de una reproducción del objeto como solución intermedia apropiada. El ConservadorRestaurador recomendará procedimientos apropiados de reproducción para no dañar al original.

-Artículo 21: El público o la comunidad puede no tener los criterios suficientes para tomar decisiones de intervención conservativas o de restauración, pero su opinión nunca dejará de ser importante; por ello, se debe aportar la información relevante necesaria que ayude a la toma de una decisión final, presentando aspectos positivos y negativos del proceso de conservación- restauración.

-Artículo 22: Es aconsejable que la conservación de obras de Arte Urbano se programe y siga un periodo de revisión pautado.

-Artículo 23: El Conservador-Restaurador podrá asesorar a los artistas o comitentes, si éstos lo requieren, sobre las buenas prácticas de preparación y ejecución del soporte mural o de los materiales que se emplearán en la intervención para facilitar una mejor conservación y durabilidad de la obra.

\section{Obligaciones y respecto del autor, propietario o guar- dián legal}

-Artículo 24: Se informará al autor y al propietario legal de la obra sobre cualquier acción requerida y se deberán especificar los medios más apropiados para un cuidado continuado.

Es aconsejable que se establezca un diálogo con el responsable del soporte (edificio, pared...) respecto a: la ubicación de la obra; la conveniencia de participación de -la comunidad para la conservación de la obra y su futuro; -la toma de decisiones compartidas con la comunidad. alternatives for the action that is proposed.

Emergency interventions should not make major alterations to works, so, before they are carried out, one should take into account the negative aspects and to assess whether its implementation is really necessary.

- Article 19: The Conservator shall not remove any material from the work of Street Art unless it is essential for its preservation or if it substantially interferes with its historical and/or aesthetic value.

Should one make any replacement or opt for the definitive removal of any original material, it should be preserved whenever possible, and the procedure should be fully documented in the report.

- Article 20: When the social use of the cultural property ("BIComún") is incompatible with its preservation, the Conservator should seek the advice of the artist, owner and/or legal guardian, regarding the manufacture of a reproduction of the object as an appropriate compromise. The Conservator shall recommend proper reproduction procedures in order to avoid damaging the original.

- Article 21: The public or community may not have sufficient criteria to make decisions regarding preservation intervention, but its opinion will never cease to be important; therefore, it must provide the relevant information necessary to help to make a final decision, presenting both positive and negative aspects of conservation-restoration processes.

- Article 22: It is advisable that the conservation of works of Street Art program and follow a period of scheduled review.

- Article 23: The Conservator can advise artists or principals, if they so require, on good practices of preparation and execution of wall supports or materials to be used in their artistic creation in order to facilitate better maintenance and durability.

\section{Obligations and Respect for the Author, Owner, or Guardian}

- Article 24: The author and the legal owner of the work shall be informed about any required action and shall specify the most appropriate means of continued care.

It is advisable to have a dialogue with the agent responsible for the mural support (the building, the wall ...) regarding the establishment of the following: The location of the work; The appropriateness of community participation in the conservation work and in its future;- Shared decision-making with the community. 
-Artículo 25: Para los casos en los que el artista hubiera proyectado la desaparición de su obra y ésta se convirtiera en un emblema para la comunidad, los pasos a seguir para transformarla en una obra BIComún deben pasar por obtener el consentimiento de su autor y el del dueño del muro o de su guardián legal. Se deben proponer cauces de entendimiento y de diálogo para establecer un protocolo de conservación que cuente con acciones alternativas, si la obra lo precisa, tales como la fabricación de reproducciones, calco, u otras que carácter similar.

-Artículo 26: No se apoyarán aquellos casos objeto de especulación urbana residencial en los que el Arte Urbano haya sido utilizado para la gentrificación. Tampoco se apoyará el comercio ilícito a través de arranques de murales del espacio para el que fueron creados, sin autorización de su autor. En caso contrario, estos hechos se reconocerán como un expolio cultural y un fraude moral, ya que se vulneran los derechos de propiedad intelectual. Se debe trabajar activamente para evitarlo. Deberá recogerse toda la información posible antes de iniciar cualquier trabajo de conservación.

-Artículo 27: Cualquier proyecto expositivo o de cualquier naturaleza que implique unos tratamientos de conservación y/o restauración que no cumpla con estos requisitos, aunque la obra vaya a perderse irremediablemente, debe desestimarse y limitarse a la exposición documental.

\section{Notas}

[1] Término acuñado por la asociación Cultural Niquelarte en 2010 ( http://www.niquelarte.org/ )

]2] Éstos quedan recogidos en el Real Decreto Legislativo 1/1996, de 12 de abril, por el que se aprueba el texto refundido de la Ley de Propiedad Intelectual, de modo que toda intervención garantice la integridad física, material y conceptual de sus obras.
- Article 25: In the cases in which the artist had intended for the disappearance of his/her work and in which it had become an icon for the community, steps to transform it into a Cultural Heritage work("BIComún") must be followed in order to obtain the consent of its author and the owner of the wall or its legal guardian. They should propose avenues of understanding and dialogue in order to establish a conservation protocol that offers alternative actions, if the work requires it, such as making reproductions, tracing, or other responses of a similar nature

- Article 26: Cases subject to residential urban speculation through specific works of urban art that can be an instrument for gentrification, or illegal trade through start-ups or other means of separation of the work space will not be supported, where it was created/exposed to the art market with profit motives, recognizing these facts as a cultural spoliation and moral fraud on a work that can be the subject of intellectual property rights, which cannot be privatized or commercialized without permission; on the contrary, one must work actively to prevent it. When the legal ownership, support and artistic work, is in doubt, one should check all available sources of information before any work begins.

- Article 27: Any proposed project or a conservation treatment of any nature that does not meet these requirements, although the work may be irretrievably lost, must be rejected and limited instead to documentation.

\section{Notes}

[1] A term coined by Niquelarte Cultural Association in 2010 (http://www.niquelarte.org/) (10/15/2016)

[2] These are contained in Royal Legislative Decree 1/1996 of 12 April, approving the revised text of the Copyright Act, so that any intervention ensures that the physical, material and conceptual integrity of the work is approved.

\section{Miembros del grupo de trabajo:}

Amor García, Rita Lucía. Giner Cordero, Ester. García Gayo, Elena. Gasol Fargas, Rosa. Luque Rodrigo, Laura. Mata Delgado, Ana Lizeth. Parada Martín, Maria Jesús. Sánchez Pons, Mercedes. Santabárbara, Carlota. Senserrich Espuñes, Rosa. Pastor Vals, Teresa. Úbeda García, María Isabel. Vázquez de la Fuente, María del Mar. Traducción al inglés de Will Shank. 

3. organizadores de eventos

4. profesionales relacionados con la conservación de patrimonio histórico artístico

Documentación de campo:

1.-Descripción de las obras, sin emitir juicios de valor

2.-Observación con mirada de turista y tag emocional

3.-Documentación aportada por la organización de eventos

4.-Documentación aportada por artistas

5.-Entrevistas a:

5.1 -artistas

5.2 -público

5.3 -expertos

5.4 -organizadores de eventos de Arte Urbano

5.5-profesionales del ámbito de patrimonio histórico artístico

\section{Descripción de la metodología y toma de datos}

Hasta el momento se han llevado a cabo actuaciones en el $X$ Asalto de Zaragoza, Open Walls 2015 de Barcelona, la 17a Jornada de Conservación de arte contemporáneo, 2016, del GEIIC en el MNCARS de Madrid y Vincularte, encuentro abierto sobre Arte Urbano, 2016, en la Casa Encendida de Madrid. Posteriormente se extendió también, en junio de 2016, a los alumnos y colaboradores del Dipartimento Ambiente Costruzioni e Design de la Scuola Universitaria Professionale della Svizzera Italiana de Lugano, como colaboración a la investigación a través de una de las investigadoras del grupo de trabajo.

Se identifica a los colaboradores voluntarios entre profesionales y estudiante relacionados con el patrimonio histórico artístico, seguidores de arte urbano, escépticos sobre el arte urbano (aquellas personas que tienen reservas en cuanto a la aceptación del arte urbano) y artistas plásticos.

Las votaciones mediante pegatinas de colores sobre fotos de murales muy conocidos se realizan opcionalmente a la entrada o salida de la convocatoria. Se colocan en las paredes del espacio de las jornadas. La encuesta se ofrece a los asistentes al llegar, antes de la presentación de diversos temas relacionados con el Arte Urbano y en los que se menciona la posibilidad de su conservación unida a sus particularidades; se recoge al salir.

Las opciones que se plantean en los pósters sobre los murales son: lo conservaría, me agrada, no me gusta, y lo borraría. En algunos casos el público ha añadido uno más: no intervendría.

Además, se propone escribir un tag emocional a modo de interpretación eimplicación sentimental con la representación, que puede servir para un análisis comparativo con el proceso creativo y el proyecto artístico.

En los eventos se facilita la participación del público, unas veces mediante preguntas generales a las que se responde con cartulinas de colores o cediendo la palabra. Algunas de las convocatorias han sido retransmitidas por streaming y otras grabadas en vídeo.

\section{Análisis de las respuestas}

Se pretende que los resultados ayuden a conocer la disposición de los distintos colectivos participantes y complementen otras propuestas para aclarar la relación de las obras con el entorno y el público.

Para facilitar el análisis de los datos recogidos se proponen las siguientes preguntas:

1.-¿Llega el público a entender el discurso que presentan los artistas?

2.-¿Se buscan respuestas en cuanto a la relación de las obras con el entorno o se reciben como obras de arte de la calle sin un contexto y ubicación concreta?

3. ¿ ¿ Es respetada la libertad de acción de los artistas?

4.-¿Cuál es el medio de difusión más popular del Arte Urbano?

5.-¿Cuál es el grado de relación que el espectador percibe entre Arte Urbano y Graffiti? (análisis según los grupos participantes identificados)

6.-¿Cuál podría ser la implicación en la conservación de cada grupo identificado?

7.-¿Qué intensidad por la salvaguarda del Arte Urbano ofrece cada grupo identificado?

8.-¿En qué entorno se podría encontrar una mayor colaboración futura?

En la propuesta de votación con pegatinas se han propuesto murales relacionados con la ciudad o la convocatoria de Arte Urbano en la que se participa.

En ámbitos más generales en los que se esperaba la asistencia de público de toda España se optó por intervenciones muy conocidas de toda España e, incluso, del resto de Europa.

\section{Análisis de las votaciones sobre murales.}

La presentación de imágenes pretende, por una parte, ayudar a la comprensión de las preguntas de la encuesta y facilitar la relación del grupo con el público ofreciendo una fórmula de participación lo más visual y atractiva posible. Por otra parte, facilitar la toma de decisiones sobre un bien público en cuanto a la posibilidad de conservación.

Finalmente, los resultados totales y parciales formarán parte de los diferentes estudios que los miembros del grupo de trabajo decidan aportar y de los documentos que el grupo de trabajo estime oportuno.

\section{Tiempo de la investigación.}

La propuesta ha sido desarrollada en año y medio y corresponde al primer ciclo de trabajo del grupo de Arte Urbano del GEIIC. Desde Febrero de 2015 hasta Junio de 2016. 


\section{ENCUESTA}

aquí su pegatina de color

verde: si es profesionales o estudiante relacionado con el patrimonio azul: seguidor de arte urbano,

, rojo: artísta plástico

\section{TEST PARA EL PÚBLICO (círculo en la respuesta que proceda)}

1. ¿Se plantea lo que el artista ha querido decir en una obra de arte urbano? sí / no

2. ¿Qué le importa más, lo que le transmite o la intención que el artista haya podido tener?

$1-2$

3. ¿Mira el entorno de la obra buscando claves para interpretar el tema? sí / no

4. ¿Le gustaría que la fachada de su casa fuese destinada a soporte de una obra? si / no / depende sólo de si me gusta la obra.

5. ¿Cree que es necesario destinar espacios en la ciudad para la expresión artística libre? sí / no

6. En qué medio cree que es más frecuente encontrar manifestaciones artísticas urbanas: 1.convocatorias y festivales, 2.publicaciones, 3.internet, 4.paseando? $1-2-3-4$

7. ¿Cree que hay diferencias entre graffiti y arte urbano, o es todo lo mismo? diferente / lo mismo / en parte/ no sé

8. ¿Defendería la conservación de una obra de arte urbano, que le guste, para que no se eliminase?

$$
\text { sí / no }
$$

9. El Arte Urbano es Arte o vandalismo?

10. ¿Qué finalidad percibe en estas manifestaciones? 1. expresión de ideas 2. transgresión

3. dialogo visual 4. vandalismo 5 . ocio

1- 2 - 3- 4 


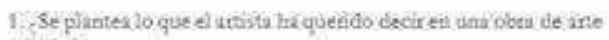
untino

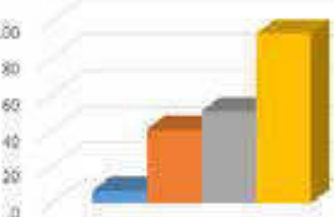

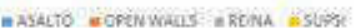

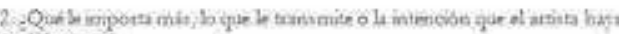
padido benet

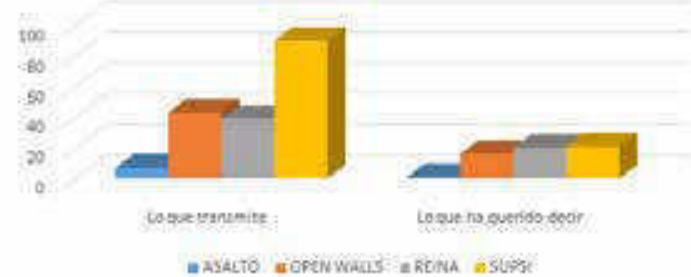

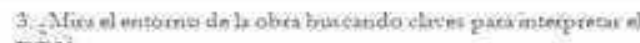
temas

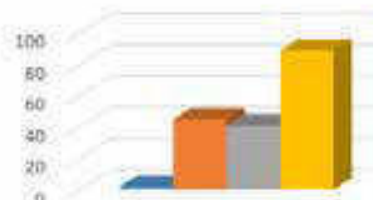

- ASALTO mOPEN WALLS MREIKA IS SUESI

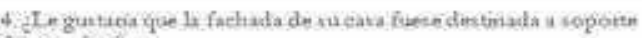
devon pobet

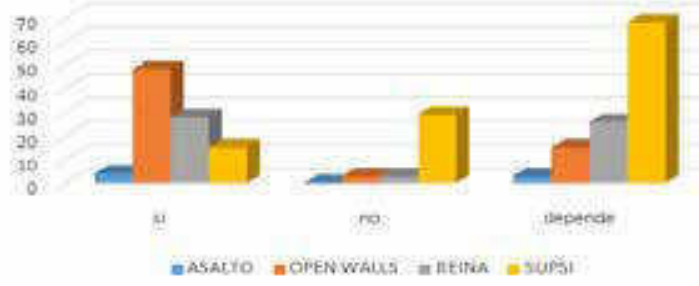

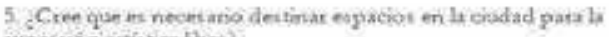
expresion artistica libre?

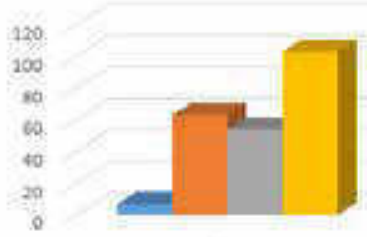

a

gasacio momen walus a metria gesupsi
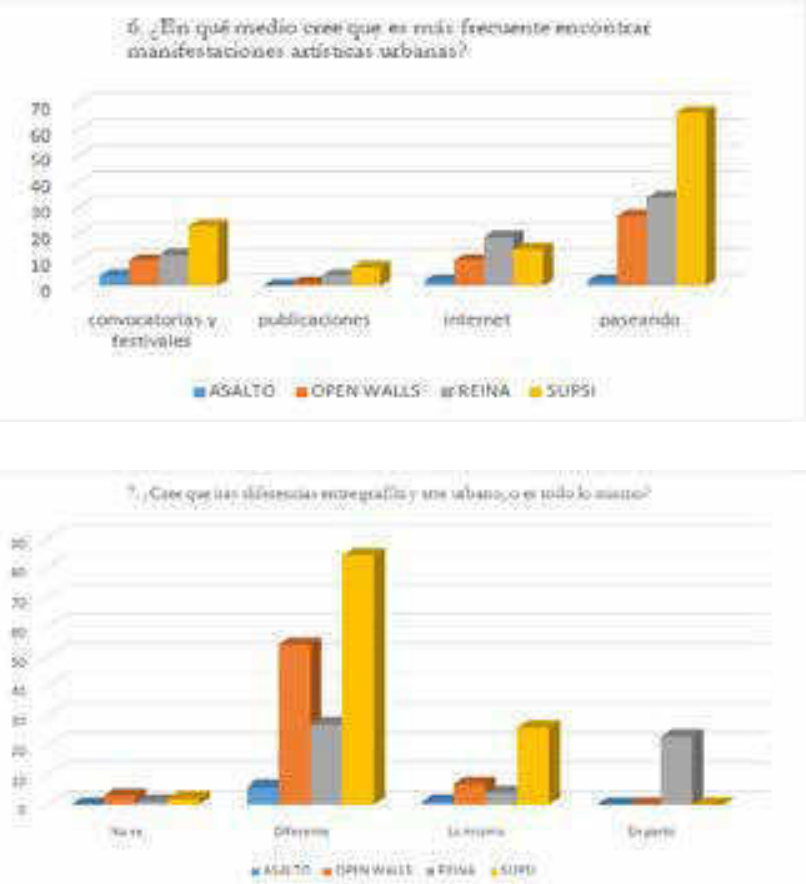

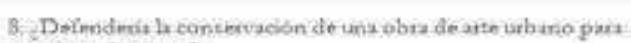
que no se elinimase?

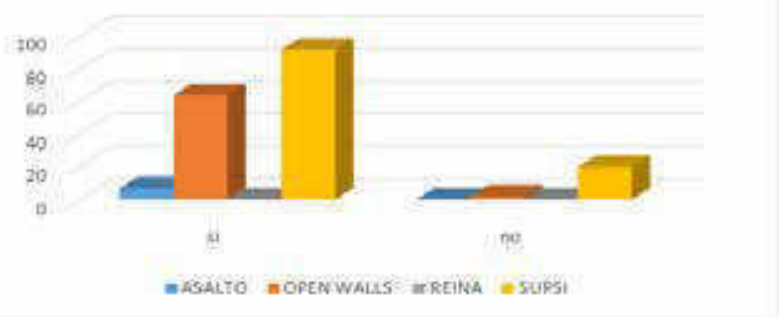

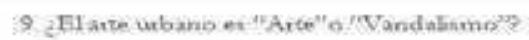

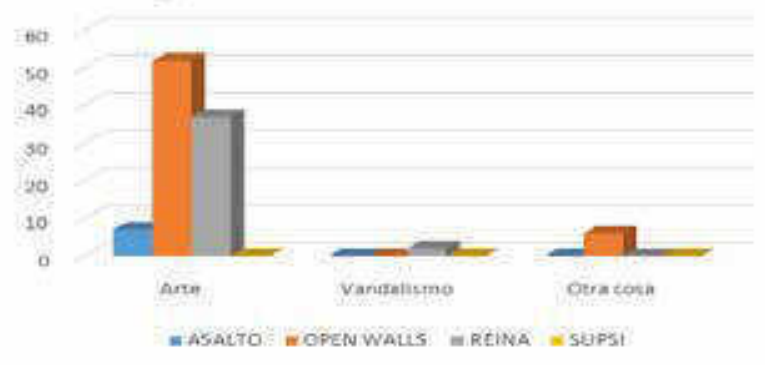

10. 4 Que finalidad perdibie en ettan manifetacionst?

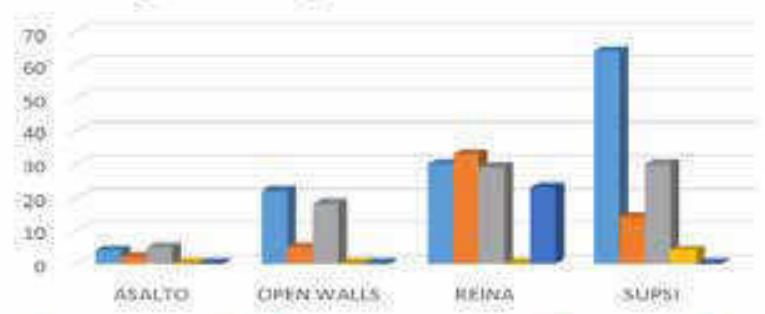

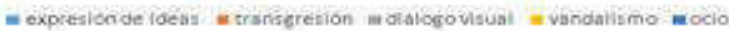




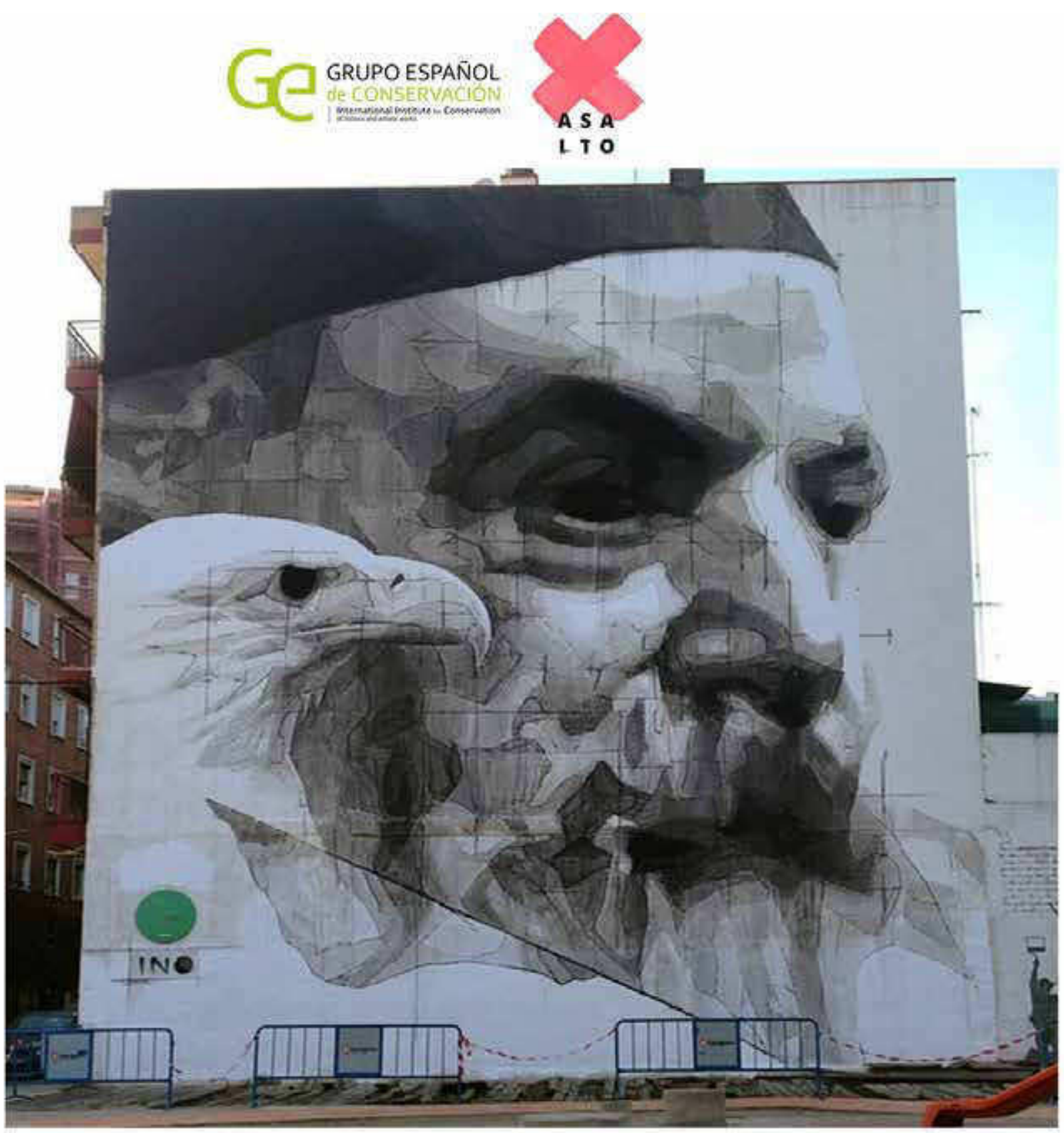

\section{opina con colores}

lo conservaría meagrada no megusta lo borraría

escribe un tag emocional palabras que te sugiera:

Poster Din A 0. Votación con pegatinas de colores

Mural de INO, IX Asalto de Zaragoza. 2014.

Foto del Observatorio de Arte Urbano 


\section{AGRADECIMIENTOS}

Gracias a los miembros del grupo que han participado en lo que les ha sido posible, que ha sido mucho: Silvia Álvarez, Vanessa Magalí, Luis Martín, Victoria Quirosa y Alicia Urda. A los que lo han hecho de forma puntual enviando sus opiniones a través de los artículos que se han ido publicando en la revista del Observatorio de Arte Urbano, MURAL Street Art Conservation no 1, 2 y 3: Miguel Carmona Astilleros, Rocío Domínguez, Belén García, Pedro Soares, Victoria Ríos y Santiago Villajos. A nuestra última y valiosa incorporación Virginia Santamarina y a nuestro traductor especializado y compañero Will Shank.

Agradecemos las atenciones recibidas por parte del equipo de gestión del Festival Asalto de Zaragoza, por permitir la presencia del grupo en su primera convocatoria pública en 2015: Sergio Beltrán, Luis García Alemán, Alfredo Martínez e Isabel Tris.

A los gestores de Open Walls de Barcelona: Xavier Ballaz Bogunyà, Cristian Diamante Aguilar y Ana Manaia, por invitarnos a participar en 2015. A Rosa Marina Ruiz Formento, Marta Vilà Rabella e Isabel Ayala Díaz, por su ayuda desinteresada y especializada. A Javier Abarca Sanchís, por contar con nosotros en Open Walls 2016.

A La Casa Encendida de Madrid, que albergó el I Encuentro abierto de Arte Urbano: Monica Carroquino y Pedro Rubio. Los artistas que participaron: Gonzalo Borondo, Pablo Ferreiro Medeiros, del colectivo Boa Mistura. Andrea Michaelson, Btoy, y a Vermibus por hacer tan fácil nuestro trabajo. A Madrid Street Art Project, por la profesionalidad de sus visitas guiadas: Guillermo de la Madrid y Diana Prieto.

Nuestra gratitud a Gabriela Berti y a Fernando Figueroa Saavedra, por su ayuda, colaboración, comprensión y paciencia infinitas.

Gracias a Jorge García Gómez-Tejedor, coordinador de los grupos de trabajo del GEIIC, por facilitar nuestras reuniones y a la Junta directiva del GEIIC por permitir la creación del grupo de trabajo de Arte Urbano y esta publicación. 


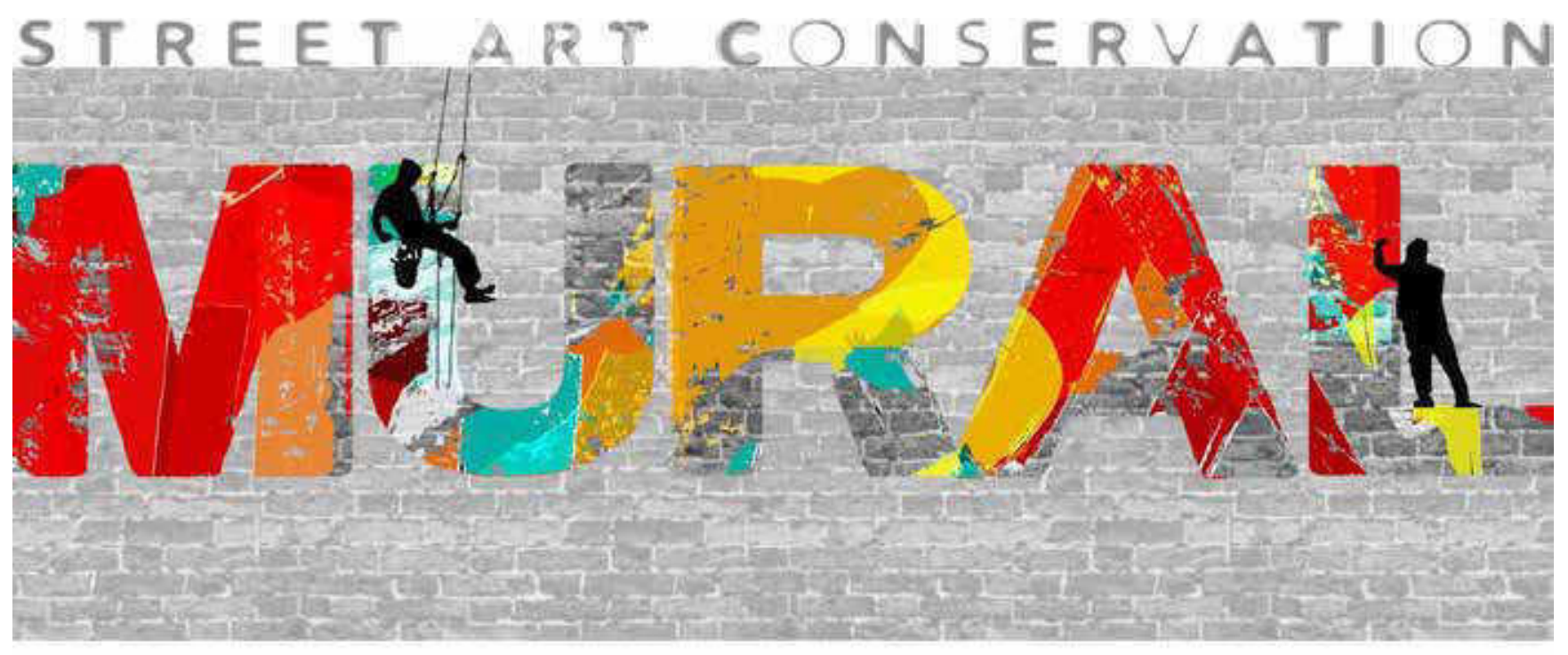

\section{OBSERVATORIO DE ARTE URBANO}

https://issuu.com/observatoriodearteurbano/docs/mural__1

MURAL Street Art Conservation n¹

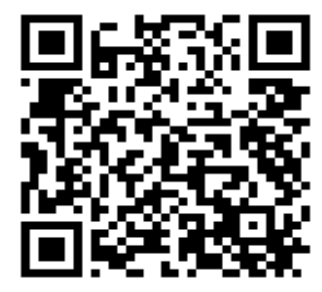

https://issuu.com/observatoriodearteurbano/docs/mural__2

MURAL Street Art Conservation n²

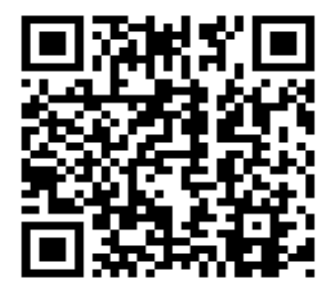

https://issuu.com/observatoriodearteurbano/docs/mural_3

MURAL Street Art Conservation n॰3

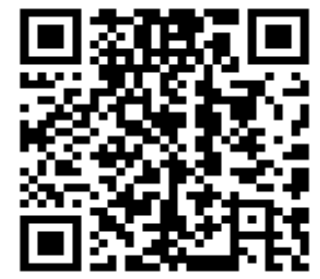


www.revista@ge-iic.com

Edición digital del GEIIC 